CIVIL ENGINEERING STUDIES

Illinois Center for Transportation Series No. 20-006

UILU-ENG-2020-2006

ISSN: 0197-9191

\title{
Data Trends and Variability in Quality Control for Performance and Pay for Performance Specifications: Statistical Analysis
}

\author{
Prepared by \\ Imad L. Al-Qadi \\ José J. Rivera-Perez \\ Watheq Sayeh \\ Javier J. García Mainieri \\ Hadi Meidani \\ University of Illinois at Urbana-Champaign \\ Hasan Ozer \\ Arizona State University \\ John Huang \\ Interra Inc. \\ Adam Hand \\ University of Nevada, Reno \\ Research Report No. FHWA-ICT-20-005 \\ The first of two volumes of the findings of \\ ICT PROJECT R27-189
}

Evaluation of Data Trends and Variability in the Quality for Performance (QCP) and Pay for Performance (PFP) Programs

https://doi.org/10.36501/0197-9191/20-006

Illinois Center for Transportation

June 2020 

TECHNICAL REPORT DOCUMENTATION PAGE

\section{Report No.}

FHWA-ICT-20-005
2. Government Accession No.

$\mathrm{N} / \mathrm{A}$

\section{Title and Subtitle}

Data Trends and Variability in Quality Control for Performance and Pay for

Performance Specifications: Statistical Analysis

\section{Authors}

Imad L. Al-Qadi (https://orcid.org/0000-0002-5824-103X), José J. Rivera-Perez (https://orcid.org/0000-0001-6180-9602), Hasan Ozer (https://orcid.org/00000003-1526-6840), Watheq Sayeh, Javier J. García Mainieri (https://orcid.org/00000002-8302-474X), Hadi Meidani (https://orcid.org/0000-0003-4651-2696), John Huang, Adam Hand (https://orcid.org/0000-0002-5041-7491)

\section{Performing Organization Name and Address}

Illinois Center for Transportation

Department of Civil and Environmental Engineering

University of Illinois at Urbana-Champaign

205 North Mathews Avenue, MC-250

Urbana, IL 61801

\section{Sponsoring Agency Name and Address}

Illinois Department of Transportation (SPR)

Bureau of Research

126 East Ash Street

Springfield, IL 62704

\section{Supplementary Notes}

Conducted in cooperation with the U.S. Department of Transportation, Federal Highway Administration. A complementary report to this project is available: Case Studies Using Quality Control for Performance and Pay for Performance Specifications: Field Observations.

\section{Abstract}

Quality assurance programs for hot-mix asphalt (HMA) have evolved from method specifications to quality assurance specifications that distribute responsibilities and risks between contractors and owners. The Illinois Department of Transportation (IDOT) developed two acceptance specifications, quality control for performance (QCP) and pay for performance (PFP), integrating contractor pay incentives and/or disincentives associated with air voids (AV), voids in mineral aggregate (VMA), and in-place density limits. A major factor that could compromise contractors' pay in both specifications is the variability of test results due to mix production, construction, sampling, and/or inherent testing variability. Therefore, the objective of this project was to understand the distribution and variability of the test results observed under QCP and PFP specifications, as well as the potential causes of variability. The assessment approach included statistical analysis of the test results obtained for the 20152017 construction seasons and on-site field observations of 11 projects visited during the 2018 construction season. The pay factors of the 2015-2017 construction seasons showed contractors earned pay incentives under the PFP specification but received disincentives under QCP and PFP specifications. Contractors appeared to have more experience working with QCP projects than PFP projects. The statistical analysis identified that more than $80 \%$ of the test results between the contractor and the district were not significantly different. In those cases, it is likely that issues with mix production or construction were the reasons that led to a disincentive. However, there are possible testing issues that need to be addressed by the district and contractor such as reheating consistency and test weight control. Density was a major factor driving contractor disincentives in both specifications, followed by AV. Finally, the site visit identified mix production and construction issues that can lead to possible causes of pay disincentives, including mix switching, dust control, and aggregate contamination.

\section{Key Words}

Asphalt Plants, Asphalt Mixtures, Hot-Mix Asphalt, Quality Control, Statistical Quality Control, Quality Assurance

\section{Distribution Statement}

No restrictions. This document is available through the National Technical Information Service, Springfield, VA 22161.

19. Security Classif. (of this report)

Unclassified

Form DOT F 1700.7 (8-72)
20. Security Classif. (of this page) Unclassified
21. No. of Pages $87+$ appendices
22. Price $\mathrm{N} / \mathrm{A}$ 



\section{ACKNOWLEDGMENT, DISCLAIMER, MANUFACTURERS' NAMES}

This publication is based on the results of "ICT-R27-189: Evaluation of Data Trends and Variability in Quality Control for Performance (QCP) and Pay for Performance (PFP) Specifications." ICT-R27-189 was conducted in cooperation with the Illinois Center for Transportation; the Illinois Department of Transportation; and the U.S. Department of Transportation, Federal Highway Administration.

Members of the Technical Review Panel (TRP) were the following:

- Jim Trepanier, TRP Chair, Illinois Department of Transportation

- Bill Pine, Heritage Research Group

- Dennis Bachman, Federal Highway Administration

- Kevin Burke, Illinois Asphalt Pavement Association

- Dennis Dvorak, Federal Highway Administration

- Amy Harms, Illinois Department of Transportation

- Greg Heckel, Illinois Department of Transportation

- Brian Hill, Illinois Department of Transportation

- George Houston, Illinois Department of Transportation

- John Huang, Interra Inc.

- Jeff Kern, Open Road Paving

- Brian Pfeifer, Illinois Department of Transportation

- Pouya Teymourpour, Rock Road Companies, Inc.

- Laura Shanley, Illinois Department of Transportation

- Ryan Sheley, Illinois Department of Transportation

- Tom Zehr, Illinois Department of Transportation

The contents of this report reflect the view of the authors, who are responsible for the facts and the accuracy of the data presented herein. The contents do not necessarily reflect the official views or policies of the Illinois Center for Transportation, the Illinois Department of Transportation, or the Federal Highway Administration. This report does not constitute a standard, specification, or regulation.

The authors would like to extend their appreciation to David Lippert and Seunggu Kang for their assistance with the research project. Thanks are also extended to ICT project management staff: Kristi Anderson, Audrey Donoho, McCall Macomber, and Brian Lorbiecki. 


\section{EXECUTIVE SUMMARY}

Quality assurance (QA) programs for hot-mix asphalt (HMA) have evolved from method specifications to QA specifications that distribute responsibilities and risks between contractors and owners to ensure that the final product meets acceptable criteria. The Illinois Department of Transportation (IDOT) developed two acceptance specifications, quality control for performance (QCP) and pay for performance (PFP), integrating contractor pay incentives and/or disincentives associated with air void $(\mathrm{AV})$, voids in mineral aggregate (VMA), and in-place density limits.

The main difference between QCP and PFP is the calculation of pay adjustments. QCP is a stepped payment system where fixed pay disincentives increase by various intervals. PFP is a percent within limit (PWL) specification used for the national highway system, state route roadways, and full-depth asphalt pavement projects with a minimum mix quantity of 8,000 tons (IDOT, 2018a). QCP and PFP exclusions exist such as sidestreets, short turn lanes, short-term temporary pavements, and other exclusions defined by IDOT. These sections of asphalt pavements default to the existing QC/QA method of acceptance. All sublot test results are used to estimate the percentage of the lot that is within the limits. QCP, on the other hand, is for smaller mainline HMA projects, where mixture quantities range between 1,200 and 8,000 tons at the time of bidding. Mix samples and density cores are collected from the jobsite under both specifications to measure AV, VMA, and density.

A major factor that could compromise contractors' pay in both specifications is the variability of test results due to mix production, construction, sampling, and/or inherent testing variability. Therefore, the objective of this project was to understand the distribution and variability of the test results included in QCP and PFP specifications, as well as the potential causes of variability.

A multiprobe data analysis program was performed on the test results of QCP and PFP projects constructed between 2015 to 2017. Five data sets were compiled from Districts 1, 2, 5, 6, 8, and 9 for this study: pay factors, mix sublot results, PFP dispute results, IDOT Uniformity Study results (round robin), and jobsite visit data. The data analysis included hypothesis testing to compare test results from districts and contractors, including mean, distribution, and variance using the Mann-Whitney (mean comparison), Shapiro-Wilk (distribution), and Levene's F (variance) tests.

Jobsites in selected districts and respective contractor facilities were visited to collect information that was used to understand the causes of variability. Each jobsite visit included three activities: interviewing district and contractor personnel on testing procedures and data analysis; monitoring sampling, blending, and splitting during mix production at district laboratories, plants, and jobsites; and analyzing data and test results to identify possible causes of variability that could lead to pay incentives/disincentives. Details are presented in Al-Qadi et al. (2020).

The pay factors (PFs) of the 2015-2017 construction seasons showed that contractors generally earned higher payment disincentives under the PFP specification than QCP. However, contrary to QCP, PFP allows pay incentives to the HMA pay. These incentives were given to $54 \%$ of the HMA tons placed under the PFP specification (PF > 100). Contractors often had more experience working with QCP projects than PFP, as more QCP projects were awarded than PFP projects. Hence, the pay per 
HMA ton has increased with time for the QCP specification. Any disincentive discussed in this report does not include any summary or cost estimate for mixtures that were subject to removal and replacement. Per PFP and QCP specifications, for any mixture result subject to removal and replacement, the pay results are replaced with the new results upon completion.

The statistical analysis of the test results showed that district and contractor results were not significantly different statewide for $82 \%$ of density, $88 \%$ of VMA, and $91 \%$ of AV comparisons. As a result, when contractor and district results are insignificantly different, the chance of the contractor being unfairly penalized or the district accepting nonconforming material is reduced. This suggests that IDOT's quality management program (QMP) for HMA effectively identifies mix production and/or construction issues. Multiple factors drove pay disincentives in both specifications. In PFP, standard deviations impact the calculation of the pay factor. Density was a major factor driving the reduction in pay under both specifications, followed by AV. IDOT recently increased minimum HMA layer thickness for 9.5FG binder mixes from 0.75 to 1.25 in to ensure three times the nominal maximum aggregate size (NMAS) requirements are achieved. This change will help contractors increase density without changing compactive effort. Exclusions specific to scabbing areas will also reduce density variability and failing results.

Density was the parameter that showed the largest percentage of cases with a significant difference between district and contractor test results, followed by VMA and then AV. While density issues were related to mix production and compaction, VMA and AV issues were related to mix design, gyratory compactor calibration and operation, reheating procedures, and specimen preparation. Mix and density disputes typically were in favor of the contractor for AV and VMA, who selected the disputed lot. The jobsite visits revealed that inconsistencies in aggregate gradations and material variability were found in projects that reflected pay disincentives for contractors.

The site visits allowed the researchers to observe some of the root causes that could lead to disincentives. For production/construction, contractors that had a significant number of mix switches during a production day were more vulnerable to having issues with AV and VMA results. Second, mid-construction season changes in the aggregate supplier source could affect the mix AV and VMA, resulting in disincentives. Plants without proper dust control could also have off-target $\mathrm{G}_{\mathrm{mb}}$ results. For testing issues, the differences in the reheating procedure, gyratory compactor model, technician running the test, or calibrations may cause differences between contractor and district results.

IDOT has taken steps to improve quality management specifications. On June 28, 2017, IDOT modified the PFP composite pay factor (CPF) pay equation (IDOT, 2018c), which included a $2 \%$ increase in AV, VMA, and density PFs. The pay for the 2015-2017 seasons was recalculated using the new formula to understand the possible impact in future PFP pay. The results indicated that if the new formula had been implemented during the project period, the percentage of the total tonnage with the pay incentive amount (PF > 100) would have increased from $54 \%$ to $76 \%$. Pay factor incentives/disincentives in QCP and PFP specifications were caused by several factors that require collaborative effort by IDOT and contractors to be addressed. However, the QMP's requirements are achievable, appear to be fair, and are appropriate for the kinds of projects for which each specification is used. 


\section{TABLE OF CONTENTS}

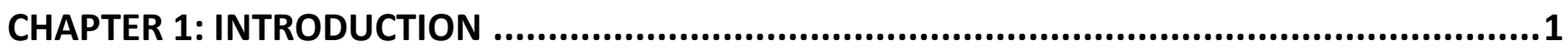

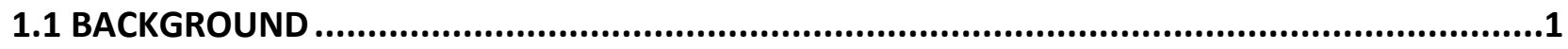

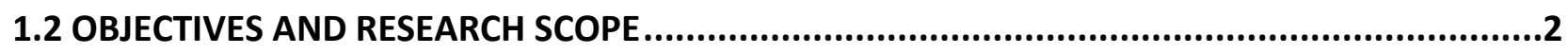

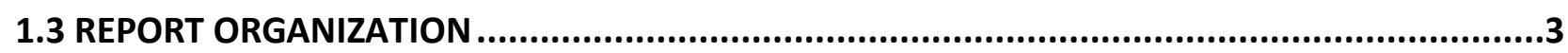

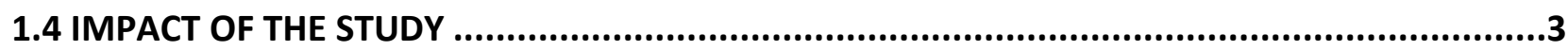

CHAPTER 2: CURRENT STATE OF KNOWLEDGE ON QUALITY ASSURANCE PROGRAMS AND

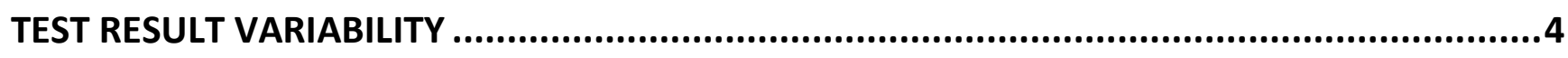

2.1 USE AND DEVELOPMENT OF QA PROGRAMS IN THE US WITH EMPHASIS ON ILLINOIS ..............4

2.2 ILLINOIS QUALITY MANAGEMENT PROGRAM (QMP)........................................................7

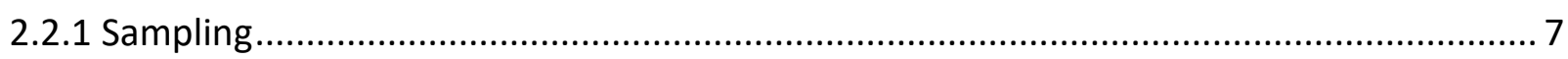

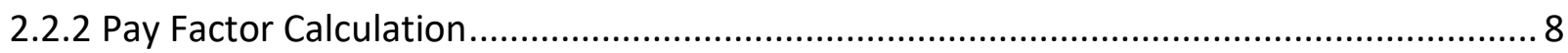

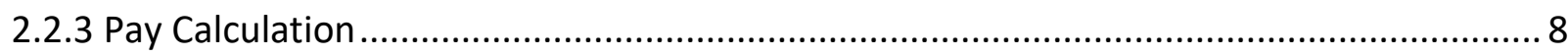

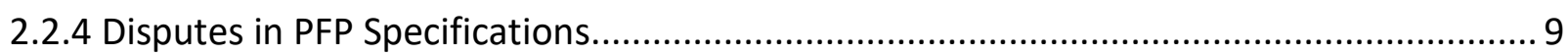

2.3 REPORTED DIFFERENCES IN AGENCY AND CONTRACTOR HMA TEST RESULTS ....................10

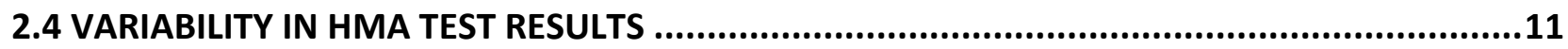

2.4.1 Comparing the Volumetric and Mechanical Properties of Laboratory and Field Specimens of Asphalt Concrete .......................................................................................... 11

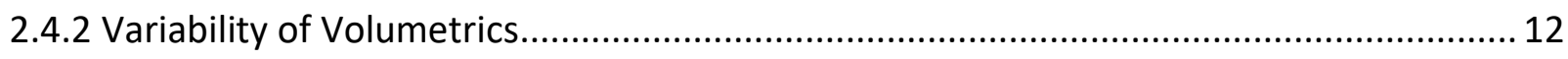

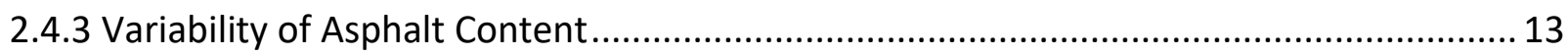

2.4.4 Quality Levels of Pay Parameter's Mean and Variability ................................................ 13

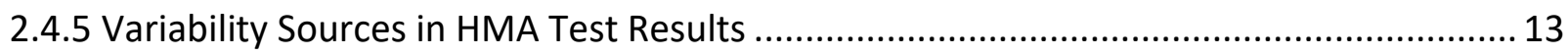

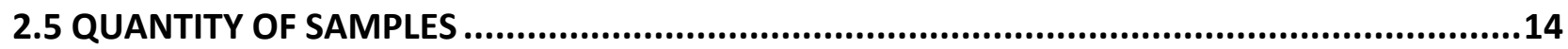

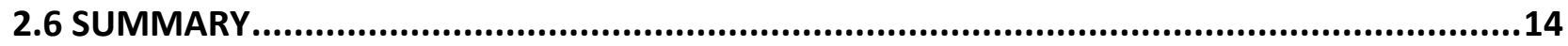

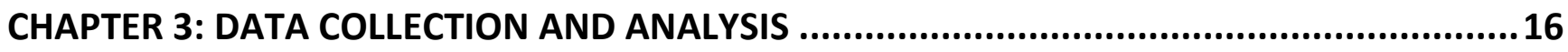

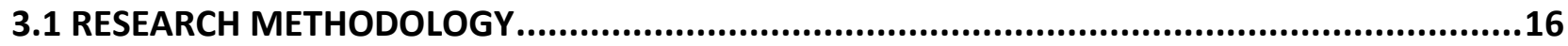

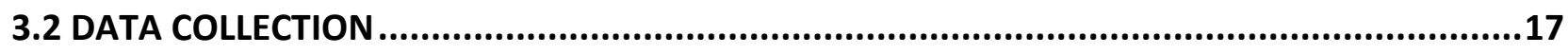

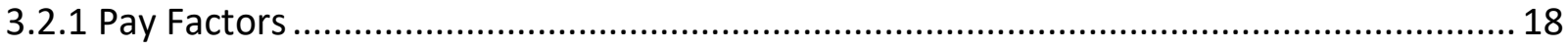

3.2.2 Quality Assurance and Quality Control Sublot Test Results ............................................ 19

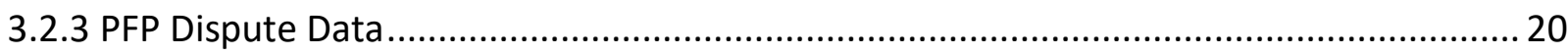


3.2.4 IDOT Volumetric Uniformity Study Results (Round Robin) ........................................ 21

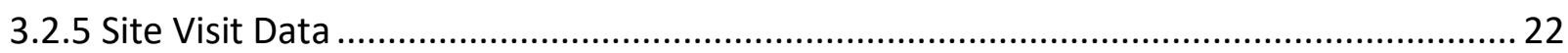

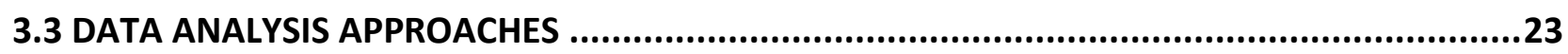

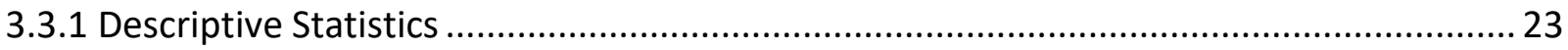

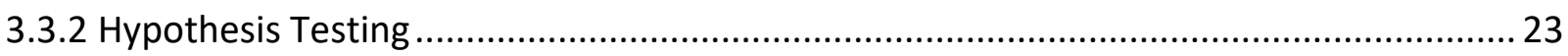

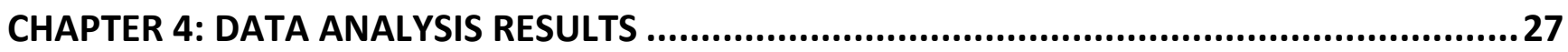

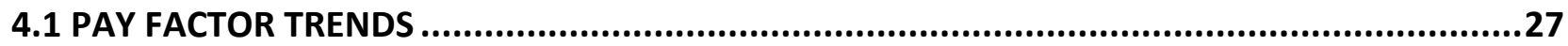

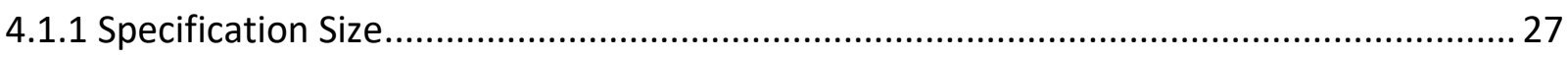

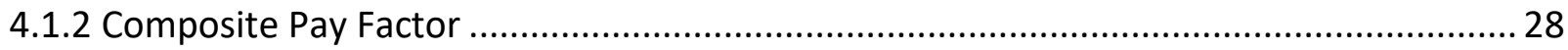

4.1.3 Air Voids, Voids in Mineral Aggregates, and Density Pay Factors ............................... 30

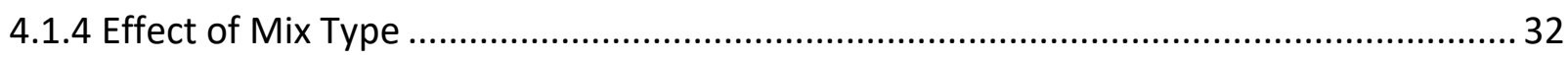

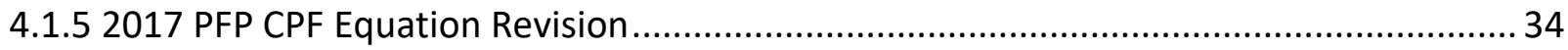

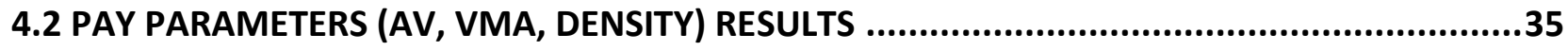

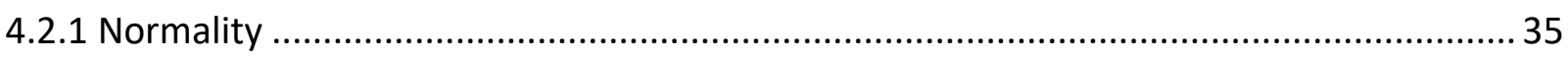

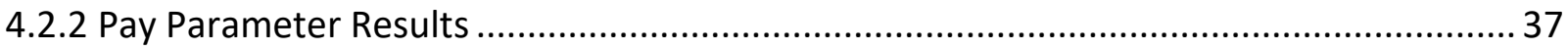

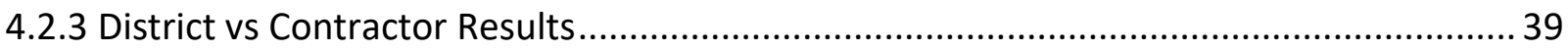

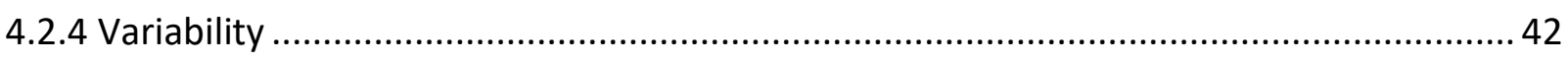

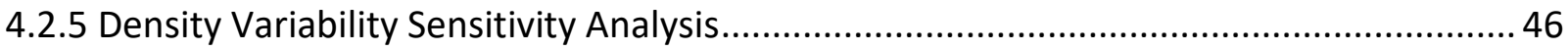

4.3 AGGREGATE GRADATION AND ASPHALT CEMENT CONTENT EVALUATION ......................48

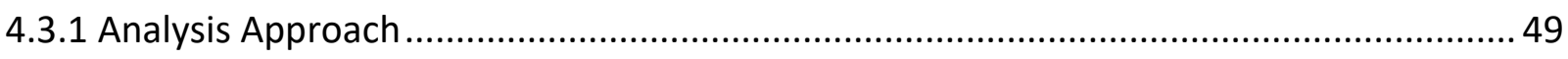

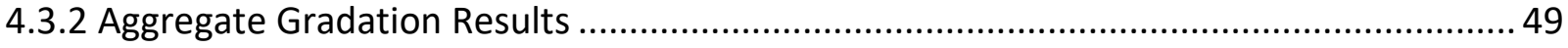

4.4 VOLUMETRIC TESTS (GMB AND GMM) RESULTS EVALUATION .........................................53

4.4.1 Distribution and Average Comparison................................................................. 54

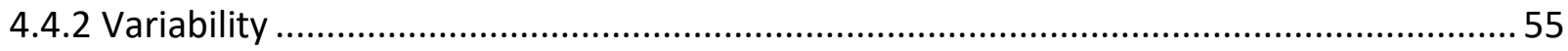

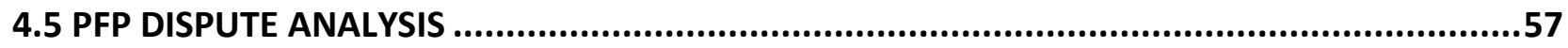

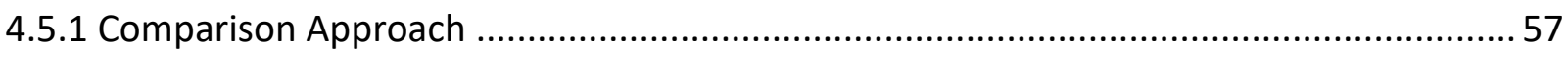

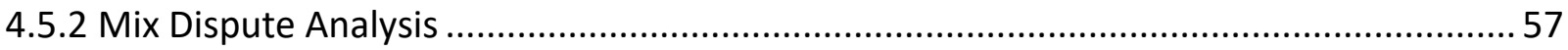

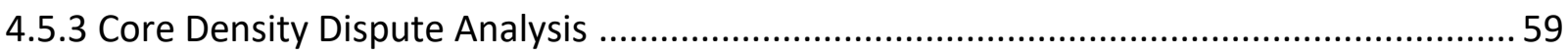

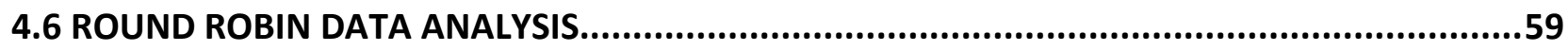

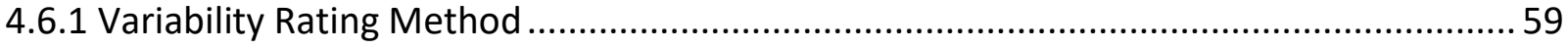

4.6.2 Z-Score Evaluation of District and Contractor Laboratories .................................... 60 


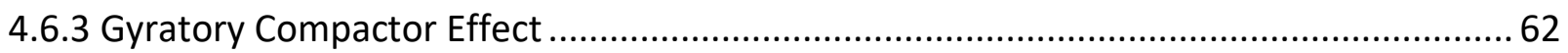

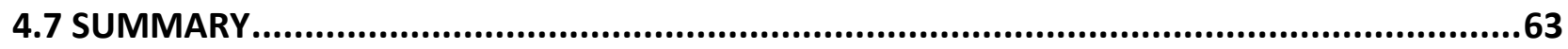

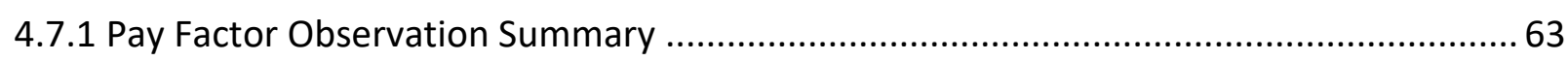

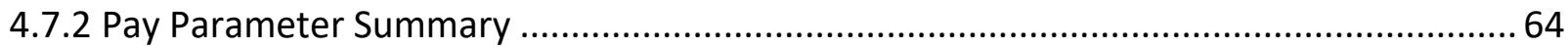

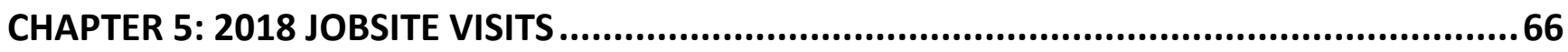

5.1 INTRODUCTION ................................................................................................................66

5.2 SITE SELECTION............................................................................................66

5.3 SITE VISIT DESCRIPTION AND ANALYSIS PROCEDURE................................................67

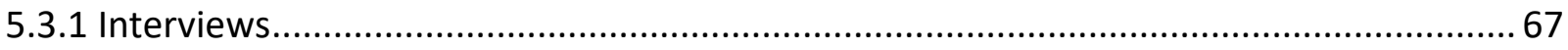

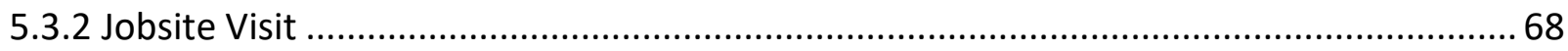

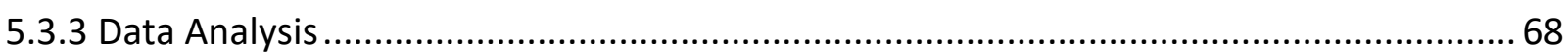

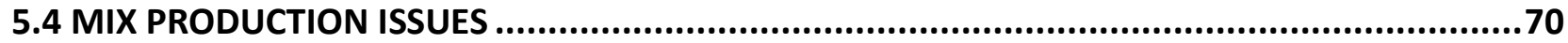

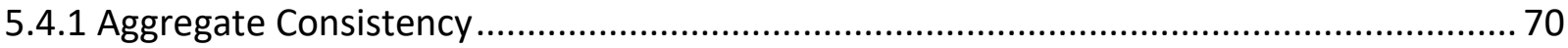

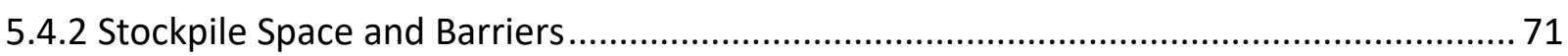

5.4.3 Stockpile Contribution to Total Design .................................................................... 73

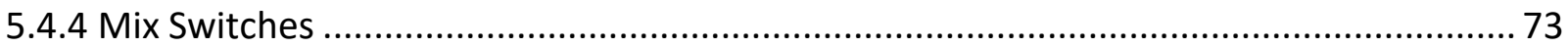

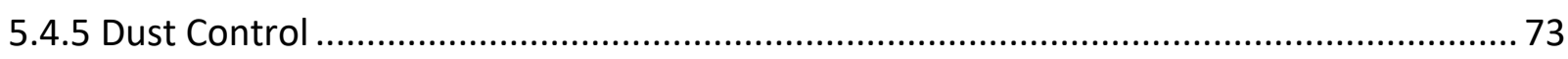

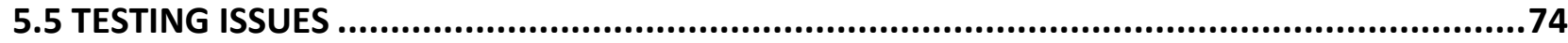

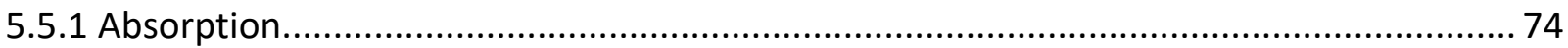

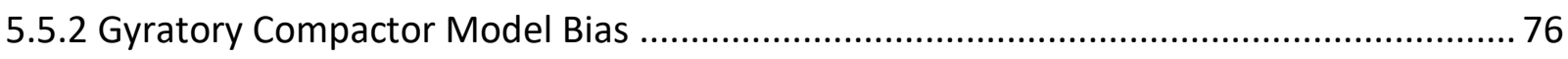

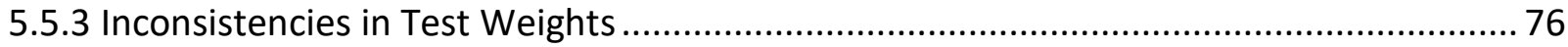

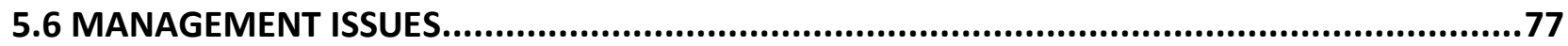

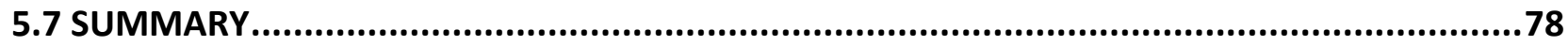

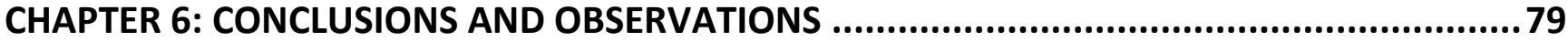

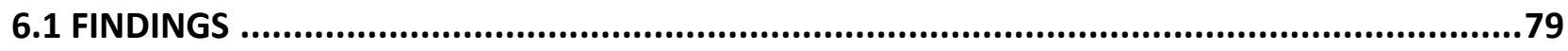

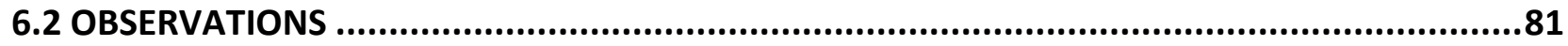

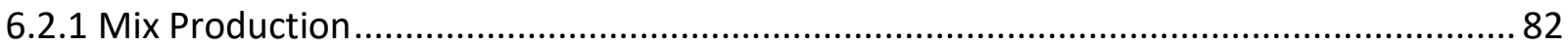

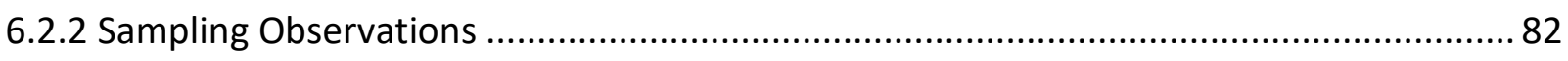

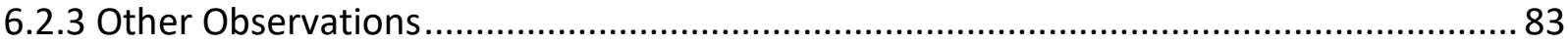

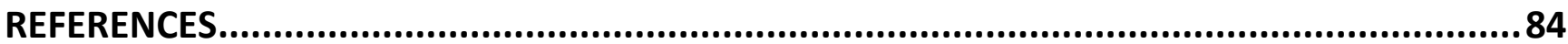




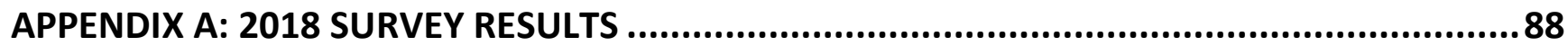

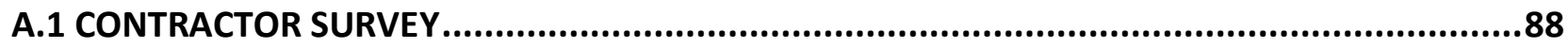

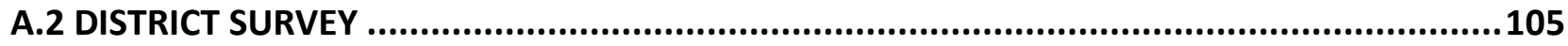

APPENDIX B: EARLY DEVELOPMENT OF QA PROGRAMS IN THE US ............................111

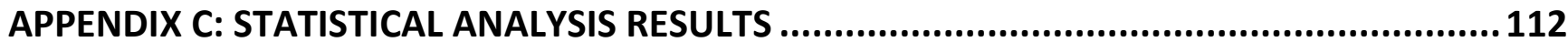

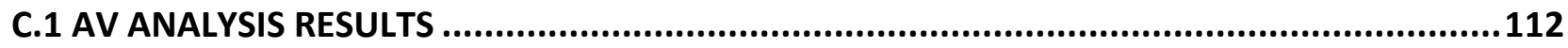

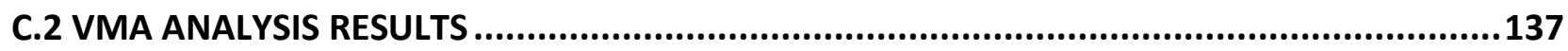

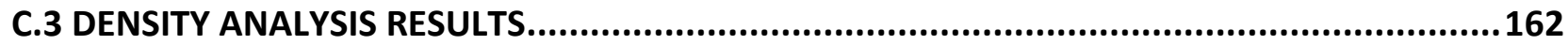

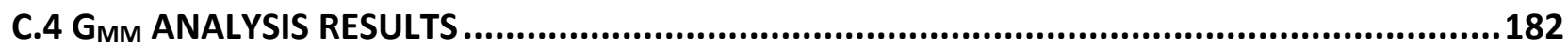

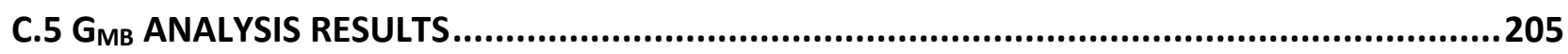

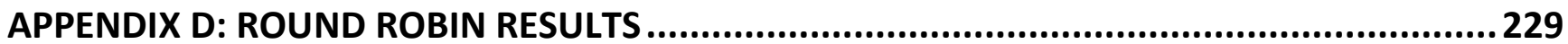

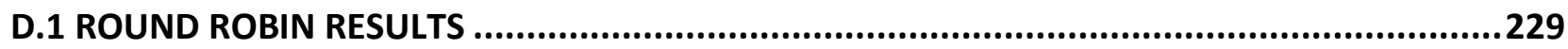




\section{LIST OF FIGURES}

Figure 2.1. Concept of (a) PWL and (b) step system (Buttlar and Manik, 2007)............................... 6

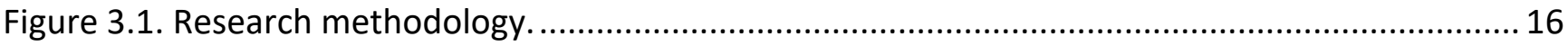

Figure 3.2. IDOT districts included in the project's scope and respective district office locations. ...... 18

Figure 3.3. Total number of pay factors collected from each district. .............................................. 19

Figure 3.4. Sublot test results received for (a) QCP and (b) PFP projects. ........................................ 20

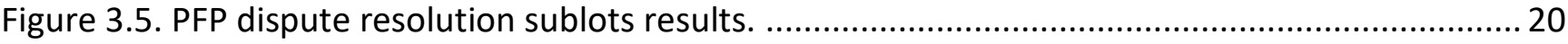

Figure 3.6. IDOT volumetric uniformity study (round robin) results............................................ 21

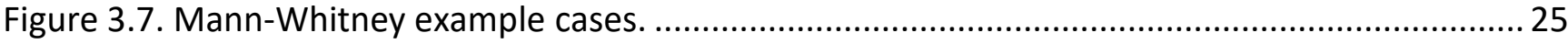

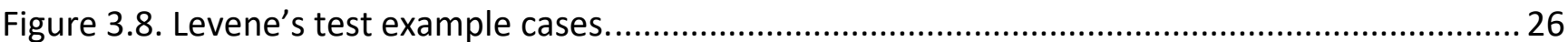

Figure 4.1. District HMA production size for (a) QCP and (b) PFP specifications from 2015 to $2017 . . .28$

Figure 4.2. Cases recorded per contractor by IDOT's QCP and PFP specifications from 2015 to 2017

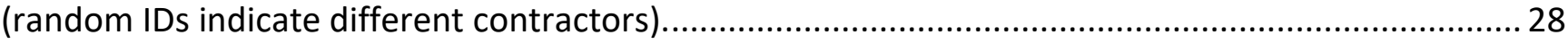

Figure 4.3. Distribution of CPF for IDOT's (a) QCP and (b) PFP specifications from 2015 to 2017....... 29

Figure 4.4. Distribution of pay factors for IDOT's (a) QCP and (b) PFP specifications from 2015 to 2017.

Figure 4.5. Pay factors per district for IDOT's (a) QCP and (b) PFP specifications from 2015 to 2017. . 30

Figure 4.6. Pay factors per pay parameter for IDOT's (a) QCP and (b) PFP specifications from 2015-2017.

Figure 4.7. Disincentivized sublots were classified by failing the upper or lower limit of either the QCP or PFP specification.

Figure 4.8. Pay factors per AC layer type for IDOT's (a) QCP and (b) PFP specifications from 2015-2017. . 32

Figure 4.9. Pay factors per pay parameter for SC, BC, and LB mixes for IDOT's QCP and PFP specifications from 2015 to 2017

Figure 4.10. Density pay factors per course type for IDOT's (a) QCP and (b) PFP specifications from 2015 to 2017.

Figure 4.11. Distribution of CPF and pay parameters for PFP specifications from 2015 to 2017 recalculated with 2017 pay factor equation: (a) statewide, (b) district, (c) yearly, and (d) per pay parameter.

Figure 4.12. Shapiro-Wilk normality test results for (a) AV, (b) VMA, and (c) density. 
Figure 4.13. Example of a SC N90 9.5 NMAS density cases for (a) non-normally distributed $(p<0.05)$

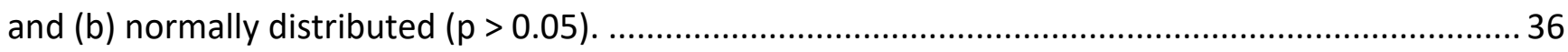

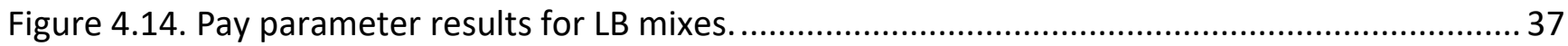

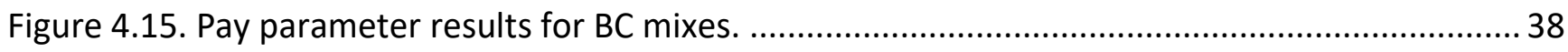

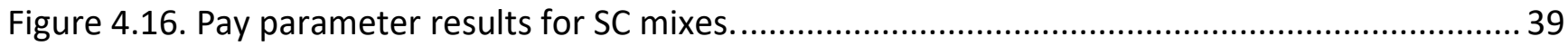

Figure 4.17. Mann-Whitney results for QCP and PFP mix contract cases.................................... 40

Figure 4.18. Magnitude of the differences between contractor and district results by district........... 41

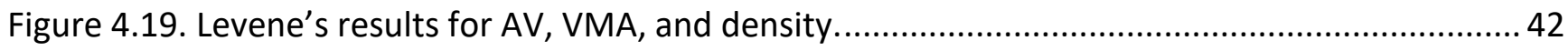

Figure 4.20. Standard deviations in AV, VMA, and density for LB mixes. ........................................ 43

Figure 4.21. Standard deviations in AV, VMA, and density for BC mixes...................................... 44

Figure 4.22. Standard deviations in AV, VMA and density for SC mixes....................................... 45

Figure 4.23. Standard deviations of AV (\%) per district and contractor. ........................................ 45

Figure 4.24. Standard deviations VMA (\%) per district and contractor. .......................................... 46

Figure 4.25. Standard deviations of density (\%) per district and contractor. ................................... 46

Figure 4.26. (a) SC and (b) BC density pay factors distribution for various standard deviation values. 47 Figure 4.27. Density pay factor average change against density standard deviation......................... 48

Figure 4.28. Aggregate gradation issues identified for cases with and without pay disincentives. ...... 50

Figure 4.29. Distribution of aggregate gradation standard deviations per sieve size for LB mixes....... 51

Figure 4.30. Distribution of aggregate gradation standard deviations per sieve size for BC mixes. ..... 52

Figure 4.31. Distribution of aggregate gradation standard deviations per sieve size for SC mixes.......53

Figure 4.32. $\mathrm{G}_{\mathrm{mb}}$ and $\mathrm{G}_{\mathrm{mm}}$ differences between contractor and district results. .............................55

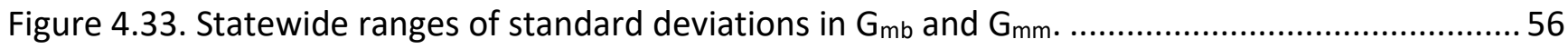

Figure 4.34. Ranges of standard deviations in $\mathrm{G}_{\mathrm{mb}}$ and $\mathrm{G}_{\mathrm{mm}}$ per district. ...................................56

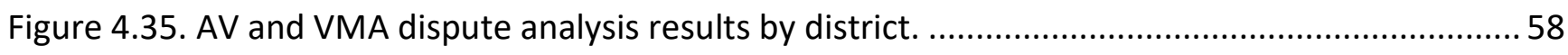

Figure 4.36. $\mathrm{G}_{\mathrm{mb}}$ and $\mathrm{G}_{\mathrm{mm}}$ dispute analysis result by district................................................... 58

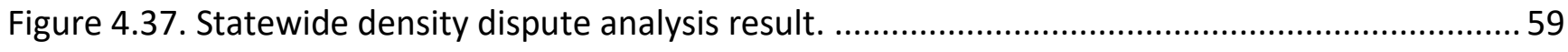

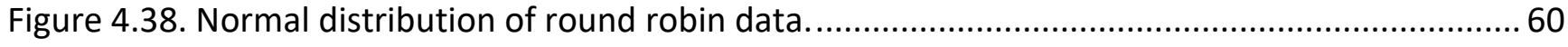

Figure 4.39. $\mathrm{G}_{\mathrm{mb}}$ standard deviations per district. (Each color represents a different round robin year.) 61

Figure 4.40. $\mathrm{G}_{\mathrm{mm}} \mathrm{Z}$-scores for district laboratories. 61

Figure 4.41. $\mathrm{G}_{\mathrm{mb}} \mathrm{Z}$-scores for district laboratories. 62 
Figure 4.42. Gyratory compactor evaluation results: (a) Z-scores, (b) average result, (c) standard

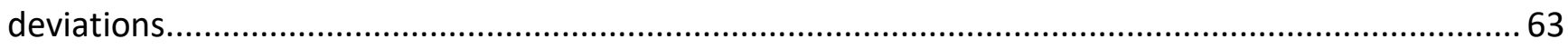

Figure 5.1. 2015-2017 pay factors of contractors visited during the 2018 site visits.

Figure 5.2. Example of a PFP jobsite visit mix sublot results for (a) AV, (b) VMA, (c) $G_{m m}$, and (d) $G_{m b}$ (LL and UL refers to lower and upper limit, respectively).........................................................69

Figure 5.3. District 9 QCP jobsite visit mix sublot results for (a) $A V$, (b) VMA, (c) $G_{m m}$, and (d) $G_{m b} \ldots 71$

Figure 5.4. Stockpile handling in a plant illustrating space constraint. ......................................... 72

Figure 5.5. Gradation results for (a) sublots 4 and 8 and (b) HMA production from datalogger......... 72

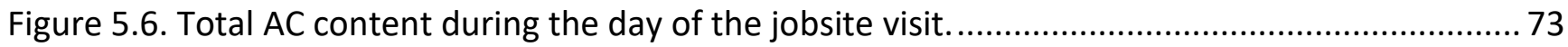

Figure 5.7. Aggregate gradation results and datalogger for virgin AC percentage and dust removal rate.. 74

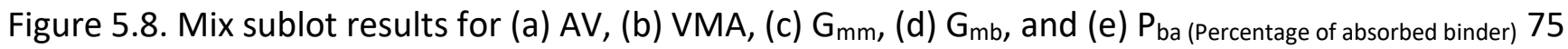

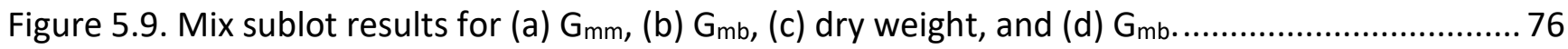

Figure 5.10. Inconsistent test weights-example of (a) dry $G_{m b}$ weight vs $N_{d}$ height, (b) $G_{m b}$ vs $N_{d}$

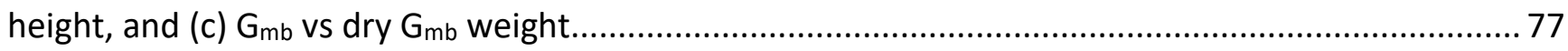

Figure A.1. Districts that had business with the contractors that were surveyed............................ 88

Figure A.2. Number of personnel assigned exclusively for quality control tasks.............................. 88

Figure A.3. Minimum level of training required for technicians. ................................................. 89

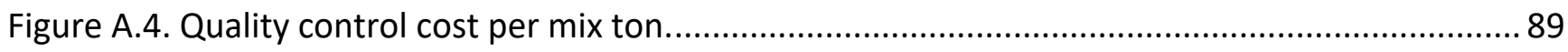

Figure A.5. Parameter driving pay loss.

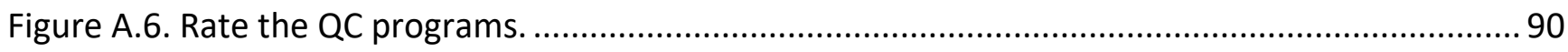

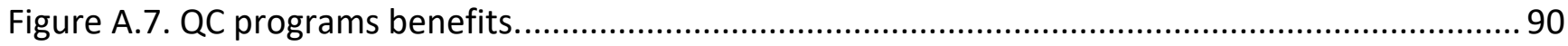

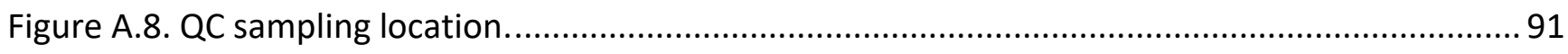

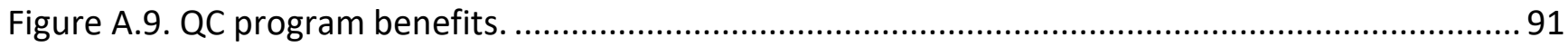

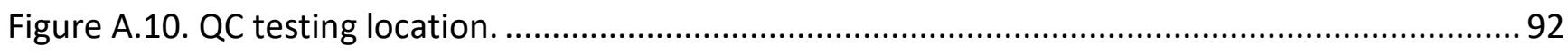

Figure A.11. Does the company have the same person running all samples on a project? ................. 92

Figure A.12. How often are the molds inspected with a bore gauge? ............................................ 92

Figure A.13. What equipment is used to determine AC content? ................................................. 93

Figure A.14. How often is the lift test performed on the ignition oven? ........................................ 93

Figure A.15. What is your typical offset between your lab and the district lab for? .........................93

Figure A.16. For those mixes that seem to have more variability, is the variability related to one or

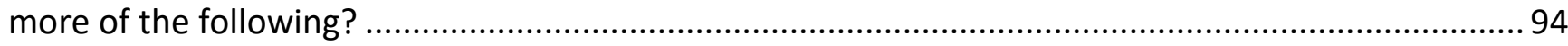


Figure A.17. For contractors working with multiple department district labs, do you notice a difference in the following tests results between labs for pay samples?

Figure A.18. Please rate from 1 to 5 , where 1 is not acceptable and 5 is acceptable: PFP specification, QCP specification, communication with IDOT, timeliness or turnaround time of the results by IDOT.95

Figure A.19. What type of RAP stockpiles do you have? (Check all that apply.) .95

Figure A.20. Rank the source of variability at the plant (1 is least and 5 is greatest); RAS was not used by all producers. 95

Figure A.21. How often is the aggregate stockpile moisture test conducted? 96

Figure A.22. Plant manufacturer. 96

Figure A.23. Plant year. 96

Figure A.24. Do you switch mixes while producing for PFP/QCP projects? 97

Figure A.25. Rank the following criteria for cause of error (or pay disincentive). 97

Figure A.26. Are the QC managers directives ever overruled by others (project superintendent, chief estimator, etc.)? .98

Figure A.27. Rank the following nine sources of error that typically lead to failure to meet PFP/QCP volumetric requirements ( 1 is least and 9 is greatest). 98

Figure A.28. Rank the following ten sources of error to meet PFP/QCP in-place density requirements ( 1 is least and 10 is greatest). .99

Figure A.29. Parameter driving pay loss. 105

Figure A.30. Rate the QC programs. 106

Figure A.31. Total number of personnel assigned to QC testing. 106

Figure A.32. What is the minimum level of training required for a technician performing volumetric testing? 107

Figure A.33. How often is the lift test performed on the ignition oven? 107

Figure A.34. How are volumetric parameters $\left(G_{m m}, G_{m b}, V M A\right.$, etc.) calculated? 108 


\section{LIST OF TABLES}

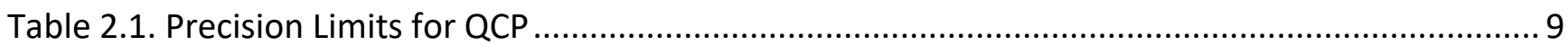

Table 2.2. Precision Limits for PFP Dispute Resolution Method Nos. 1 and 2 ................................. 9

Table 2.3. HMA Property Levels of Variability (NCHRP, 2016) ...................................................... 11

Table 2.4. Volumetric Tolerance Recommendations (NCHRP, 2016) . ........................................... 12

Table 2.5. Summary of Material Properties by Quality Level (Hall and Williams, 2002) .................... 13

Table 2.6. Summary of Variability Sources in HMA Testing* ........................................................... 14

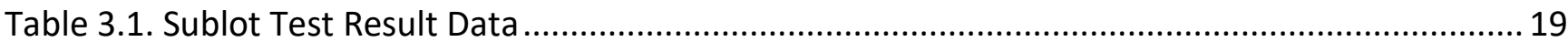

Table 3.2. Test Conducted in IDOT Uniformity Studies ................................................................ 21

Table 4.1. Average Density Pay Factor for Various Mixes ................................................................... 47

Table 4.2. Sieve Sizes Used to Evaluate Aggregate Gradation on the Bailey Method........................... 49

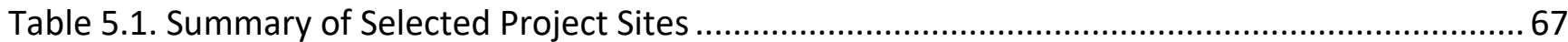

Table 5.2. Summary of Observed Issues at Project Sites ............................................................. 78

Table 6.1. Percentage of Cases with Significantly Different Test Results in Which Pay Was Equal or

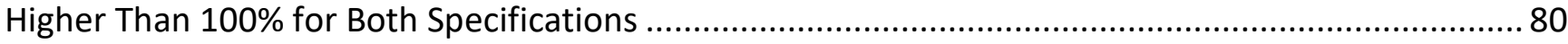

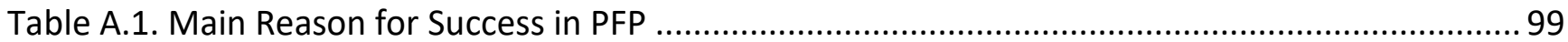

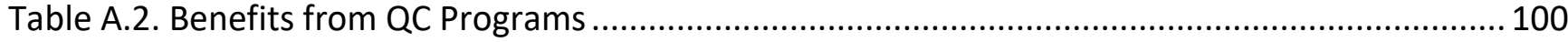

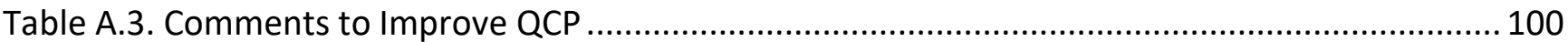

Table A.4. How Is the Decision Made on What Gyratory Compactor to Use for What Materials/Projects?

Table A.5. Information for Your HMA Ovens. 101

Table A.6. Are There Specific Mixes (Mix Type, Nominal Maximum Aggregate Size (NMAS), Binder Grade, Recycle Content, etc.) That Tend to Show More Variability in Test Results Than Others? 102

Table A.7. In the Order of Importance (First Is the Most Important), What Are the Top Three Improvements You Suggest to the Department Specifications to Enhance Payout and Reduce Penalties?

Table A.8. What Test(s) Do You Perform Quality Control Testing on Aggregate Stockpiles and How Do You Use That Information?

Table A.9. Please Explain If You Requite Aggregate Suppliers to Comply with Tighter Aggregate Specifications than the Department? 
Table A.10. If Multiple Ignition Ovens Are Used in Your Lab, How Do You Decide Which Ignition Oven

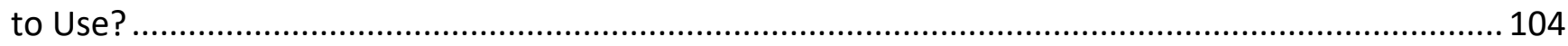

Table A.11. Do You Switch Mixes While Producing for PFP/QCP Projects? ..................................... 104

Table A.12. Please Answer the Following Question Regarding Shutdowns................................... 104

Table A.13. Provide the Following Information for Gyratory Compactors .................................... 108

Table A.14. If Multiple Gyratory Compactors Are Used, How Is the Decision Made on What Gyratory

Compactor to Use for What Materials/Projects? ............................................................................ 109

Table A.15. Is a Review Process Used for Checking Test Results before Determining Pay? ............... 110

Table A.16. Information for Your HMA Ovens...................................................................... 110

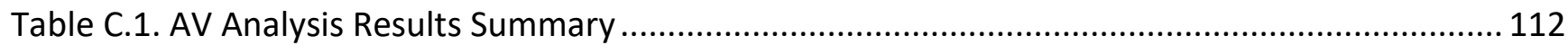

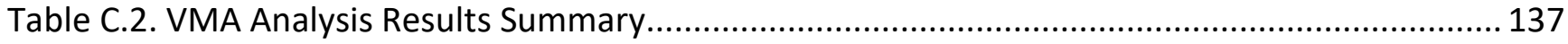

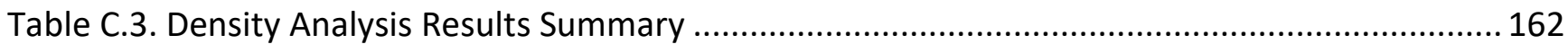

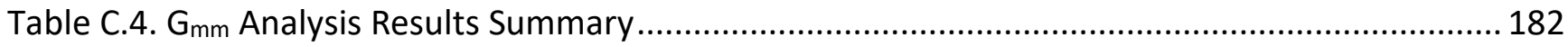

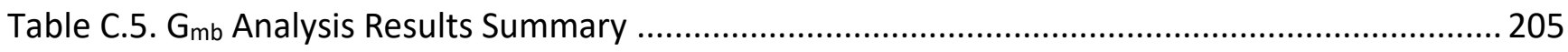

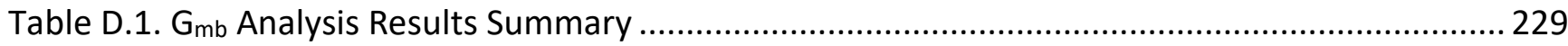





\section{CHAPTER 1: INTRODUCTION}

\subsection{BACKGROUND}

Quality assurance (QA) is the process of ensuring the quality of a product will satisfy given requirements. In this report, all planned and systematic actions that provide confidence that hot-mix asphalt (HMA) will perform satisfactorily in service are referred to as "QA program." Quality control (QC) is the process with which a contractor monitors, assesses, and adjusts their production or placement processes to ensure that the final product will meet the specified level of quality. Quality control is specified by the agency and includes sampling, testing, inspection, and corrective action (where required) for contractors to maintain continuous control of a production or placement process (TRB, 2018). Most successful contractors accomplish more than the minimum specified by the department.

By the early 2010s, HMA QA specifications had evolved to be related to performance and were statistically based in Illinois and elsewhere in the United States. The Illinois Department of Transportation (IDOT) developed two specifications for the state's QA program, quality control for performance (QCP) and pay for performance (PFP), to meet the intent of the Code of Federal Regulations and Federal Highway Administration (FHWA) Technical Advisory recommendations (IDOT, 2010). This also helped IDOT to better control the quality of constructed pavements, ensure performance, and overcome previous limitations.

The current PFP specification was implemented for interstate and full-depth asphalt pavement projects having a minimum HMA quantity of 8,000 tons per mix (IDOT, 2018a). PFP may be used for smaller projects in which a more accurate measure of quality is desired. On the other hand, the QCP specification is used for relatively smaller HMA projects (mixture quantities ranging between 1,200 and 8,000 tons) along with certain shoulder applications and for leveling binder mixtures (IDOT, 2018b). Note that leveling binders are no longer part of IDOT's HMA specifications because of adjustments in minimum lift thickness.

The ultimate goal of QCP and PFP specifications is to reward contractor ingenuity and improve the quality of the HMA end product. Pay factors are a key component of QCP and PFP specifications, defining the incentive or disincentive percentage that a contractor may receive based on the quality provided. Pay factors are determined based on the agency's test results following QA procedures that involve statistical analysis of test results randomly obtained during and after construction. In Illinois, IDOT is the agency in charge of state-maintained public roadways. IDOT has nine districts that bear acceptance responsibilities.

The QA program requires agency testing of plant-produced loose mix sampled at the jobsite for laboratory-compacted air voids (AV), voids in mineral aggregate (VMA), asphalt content, gradation, and dust/AC ratio. It also includes agency-testing field density from cores obtained according to specific IDOT procedures. Air voids, VMA, and core density are referred to as pay parameters (IDOT, 2018a, 2018b). 
Minimum QC-testing requirements are also defined in the QCP and PFP specifications. Contractors are required to test for mixture aggregate gradation, binder content $\left(\mathrm{P}_{\mathrm{b}}\right)$, maximum theoretical specific gravity $\left(G_{m m}\right)$, bulk specific gravity $\left(G_{m b}\right)$, as well as field density and dust/asphalt content (AC) ratio in QCP and PFP. Mixture aggregate gradation and $\mathrm{P}_{\mathrm{b}}$ are only for process control. They are reflected in the VMA; however, both results are not used directly by the agency in the pay calculation. Both are referred to as non-pay parameters. Testing frequencies vary for QCP and PFP specifications. Jobsite sampling locations are randomly determined in both specifications.

IDOT's QCP and PFP specifications have been successfully used for HMA projects since their inception. Both specifications use pay adjustments solely based on test results of the aforementioned parameters obtained at the district laboratories. At a minimum, contractors are required to perform testing to control production quality according to the QC schedule defined by QCP and PFP specifications.

Selection of the appropriate tests and parameters related to pavement performance is key to the success of current QA specifications. However, inherent variability exists in test results, and this can have an impact on pay factors. Therefore, understanding the distribution and variability of the test results is critical for evaluating the initial quality of constructed pavements. Test parameter variability is attributable to four factors. The total variability of test results is composed of sampling, testing, material, and construction variability (Stroup-Gardiner et al., 1994). The components and total variability can vary among HMA types.

Sometimes differences or bias between the results obtained by two different parties exists, for example between an IDOT district and a contractor's lab. Hence, it is necessary to evaluate test results obtained from projects under QCP and PFP specifications and perform a statistical analysis. The statictical analysis presented allows for an understanding of the test parameter variability and its impact on specifications and pay factors.

\subsection{OBJECTIVES AND RESEARCH SCOPE}

The objective of this project is to understand the distribution and variability of the test results included in the QCP and PFP specifications, as well as the potential causes of variability. The study is intended to address practical concerns and questions regarding QCP and PFP specifications and evaluate the trends observed when comparing IDOT district and contactor test results. A multiprobe assessment of data obtained from a large pool of projects constructed under the QCP and PFP specifications was conducted. The assessment approach included statistical methods and on-site field observations.

To achieve these goals, data analysis was conducted to evaluate the distribution of test results and variability. The scope of the data analysis included hypothesis testing to compare test results from districts and contractors. These results included mean, distribution, and variance using the MannWhitney (mean comparison), Shapiro-Wilk (distribution), and Levene's F (variance) tests. Jobsites in selected districts and respective contractor facilities were visited to collect information that was used to understand the causes of variability. Finally, recommendations were developed to reduce variability created during sampling, testing, material production, and construction processes. 


\subsection{REPORT ORGANIZATION}

The outcome of the data analysis procedures and the evaluation of the jobsite visits are presented in this report. In addition, a list of recommended actions to reduce the sources of variability, provide consistent results between laboratories, and improve HMA quality is presented. The report's chapters are organized as follows:

Chapter 2: A literature review of the development of PFP specifications used in Illinois is presented. Data variability concerns and sources identified in the literature for QA agency and contractor testing are discussed.

Chapter 3: The planned research methodology for assessing QCP and PFP specifications is presented. Additionally, data collected and used in the study is described.

Chapter 4: The evaluation of the distribution of test results and variability, using various statistical approaches, is discussed.

Chapter 5: Observations from several construction project visits during the 2018 construction season and observations from interviews with district engineers and contractors are summarized. The data analysis and results from the jobsite visits are presented.

Chapter 6: The conclusions and observations of this study are summarized.

\subsection{IMPACT OF THE STUDY}

The results from this study provide discussion on the causes of variability patterns existing in the data collected on projects constructed under IDOT's QCP and PFP specifications. This is expected to lead to better control of variability in the future. The study provides a list of observations to improve quality and consistency of QCP and PFP test results. Upon implementation of the proposed observations, it is expected that comparison between contractor and district test results will reduce potential disputes between IDOT and contractors in the acceptance process. 


\section{CHAPTER 2: CURRENT STATE OF KNOWLEDGE ON QUALITY ASSURANCE PROGRAMS AND TEST RESULT VARIABILITY}

This chapter summarizes and discusses IDOT's QA program for HMA. The use and development of QA programs in the United States and Illinois are first discussed to understand the origin and purpose of the current program. Then, the review focuses on studies that evaluated the differences in agency and contractor test results within QA programs. Finally, the expected variability of HMA testing and possible causes are discussed relevant to this study.

\subsection{USE AND DEVELOPMENT OF QA PROGRAMS IN THE US WITH EMPHASIS ON ILLINOIS}

Since the 1960s, Department of Transportation (DOT) QA programs have had to adhere to Title 23 of the Code of Federal Regulations, Part 637 (23 CFR 637) and be approved by FHWA (2007). As per the CFR, each state highway authority (SHA) shall develop a quality assurance program that will assure that the materials and workmanship incorporated into each federal-aid highway construction project on the national highway system are in conformity with the requirements of the approved plans and specifications, including approved changes. The program must meet the criteria in Sec. 637.207 and be approved by FHWA. FHWA conducts stewardship reviews to assess DOT QA program practices and procedures, as well as ascertain the status of DOT implementation of this QA regulation. More recently, FHWA has been evaluating the effectiveness (health) of QA programs to ensure DOTs receive high-quality materials and "minimize the potential for abuse" (FHWA, 2008). Reviews and evaluations are discussed later in this chapter.

Before 1990, IDOT designed HMA and controlled its production at plants by having proportioning technicians stationed at each plant. In the early 1990s, IDOT developed a quality management program (QMP) referred to as "QC/QA." It was used to gradually involve contractors and the industry to design and control HMA production. By the end the decade, IDOT began to evaluate changes to QC/QA and their implications to get specifications that evaluate the quality of the HMA end product and not the construction (Patel et al. 1997). Context and events that led to similar changes on other QA programs nationwide are sumarized in Appendix B.

In 1993, Indiana implemented the Superior Performing Asphalt Pavement (SuperPave) HMA design method, with no QA procedure, initially. The National Cooperative Highway Research Program (1998) included a QA plan of field production, placement, and compaction to ensure that as-placed HMA conformed with the method and to assist the industry with implementation of SuperPave. SuperPave mixes had to be compliant with certain tolerances before and during construction. Presently, many states have established and used their own mix tolerances.

As of 1995, the 23 CFR 637 regulation allowed the use of contractor-performed sampling and testing in acceptance decisions and established a systematic approach for QA and validation of contractor test results when used (FHWA, 2007). Effective use of contractor-performed test results in acceptance is an ongoing area of research, e.g., NCHRP Project 10-58(2) and more recently NCHRP Project 10-100 (NCHRP, 2017). IDOT's previous QMP (QC/QA) used contractor test results in the acceptance decision of HMA. 
In 2005, the most-used atributes for QC of HMA included aggregate gradation, binder content $\left(P_{b}\right)$, AV and HMA field density, and VMA (NCHRP, 2005). The most commonly used acceptance criteria included density, $\mathrm{P}_{\mathrm{b}}$, and ride quality, followed by aggregate gradation and AV. QA calculations to assess quality of HMA and placement were mainly completed using percent within limit (PWL), ranges, or averages. Based on the quality of construction, agencies used pay factor adjustments to encourage quality improvements. Nine states used a disincentive (pay factor reduction for poor quality), and 32 states used both incentives (pay factor increment for specified quality with low variability) and disincentives.

In highway construction projects, materials and construction quality characteristics are important factors for the long-term performance of a finished work. Monismith et al. (2004) and Deacon et al. (2001) reported the effects of various HMA characteristics on pavement performance and promoted choosing quality characteristics that relate to or describe performance for QA. Among IDOT's goals in 2013 was moving to a system that included the use of high-speed profilometers to measure the International Roughness Index (IRI) (IDOT, 2013) on roadways with speed limits of $50 \mathrm{mph}$ and greater.

Performance-related specifications focus primarily on quality characteristics that have been found to correlate with fundamental engineering properties that may be used to predict performance. Performance-based specifications describe directly the levels of fundamental engineering properties. This kind of specification has not yet found application in transportation construction (TRB, 2018). FHWA outlined specific policies and programmatic framework in the Moving Ahead for Progress in the $21^{\text {st }}$ Century (MAP-21) act in 2012 (Federal Motor Carrier Safety Administration, 2019). It recommends streamlined policies and specifications that consider performance for surface transportation programs, including pavements. Currently IDOT's HMA QA program, and most QA programs in the United States, include pay parameters that are related to performance.

Performance models can be used to estimate the impact of material properties on pavement service life. Thus, acceptance test results combined with appropriate risk analysis can be used to calculate rational pay factors. These concepts are known and development was encouraged by the research community (NCHRP, 1995). NCHRP (2011) provided a tool that performs pay adjustment factors and payment computations by comparing the as-built pavement performance with that of the asdesigned pavement. This approach has not yet been pursued by state agencies, and FHWA has not moved forward with this concept for material quality acceptance decisions.

IDOT developed a QA specification based on PWL and performance-related parameters through collaboration with the Illinois Center for Transportation (ICT). HMA construction projects were constructed and monitored. A tool that mapped the relationship between quality characteristics, engineering properties, and measured distresses (rutting, cracking, moisture damage, etc.) was developed (Buttlar and Harrell, 1998). The resulting QA specification was used for demonstration projects in the 2000s as part of the ICT-R27-23 performance-related specifications research project (Buttlar and Manik, 2007).

By 2019, 34 state agencies used PWL for HMA acceptance (FHWA, 2014). PWL, which is a continuous system, uses the mean and standard deviation to estimate the amount of material within 
specification limits. The concept of PWL is shown in Figure 2.1 (a). Uncertainties that may occur during production and placement can be incorporated in specification limits of PWL. This was a major improvement from the traditional QA programs that used the pass/fail criterion for acceptance. Alternatively, stepped systems have been used. A pay factor is assigned for each sublot obtained. If the sublot is within the specification limits, then it receives $100 \%$ pay. If not, the pay factor depends on how far results from the sublot were from the lower and upper requirements, as seen in Figure 2.1 (b). Using a pay factor system based on a single test is unusual for HMA acceptance. It can be considered acceptable for certain sizes and types of projects.

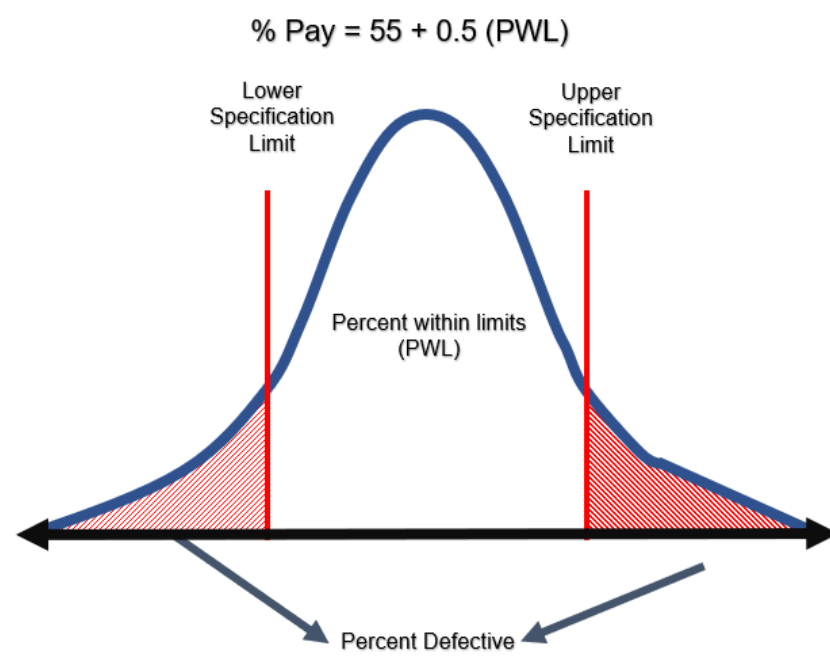

(a)

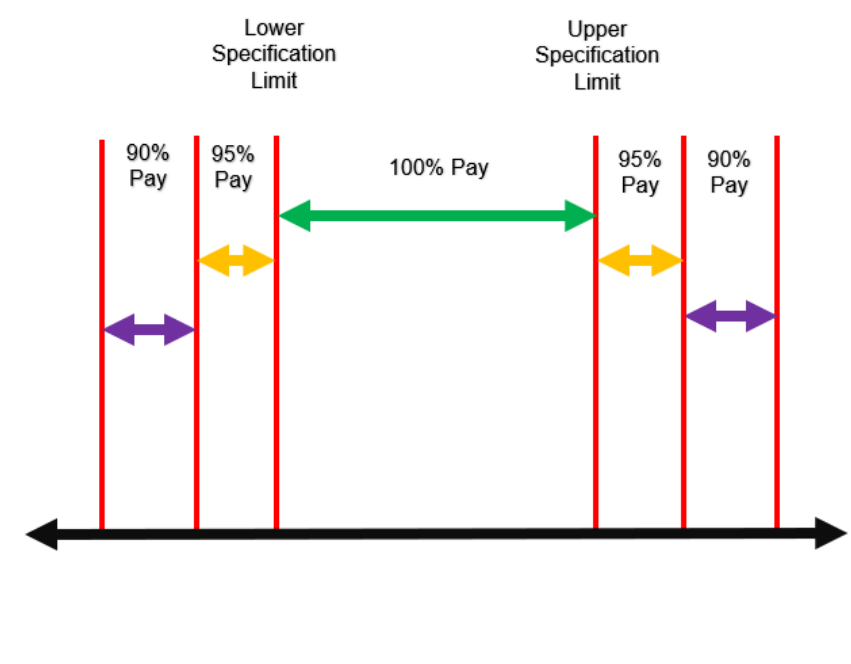

(b)

Figure 2.1. Concept of (a) PWL and (b) step system (Buttlar and Manik, 2007).

FHWA assessed the effectiveness of DOT QA programs in 2008, 2010, 2012, and 2014 (FHWA, 2014). The assessment was designed to reflect the strength of each QA program and its ability to minimize the possibility of waste, fraud, and abuse. There was significant improvement by all state agencies compared to previous reviews. The areas in which more agencies improved were in controlling the location of random sampling, material-testing dispute-resolution processes, electronical management of test results used in the acceptance process, and agency technician proficiency verification. There were some areas in which agencies needed to improve. Among them were the statistical method for acceptance if the agency is using contractor test results and independent assurance (IA) programs.

FHWA (2008) classified Illinois among the top-five states with a demonstrated weakness in its QA program in the ability to measure quality or have a weakness that could lead to contractor abuse and fraud. The low effective score reported by FHWA encouraged IDOT to make changes to its HMA QA procedures. IDOT created the PFP specification based on the specification used in the research project ICT-R27-23 (Buttlar and Manik, 2007). Pay adjustments based on agency test results (following Michigan's lead) were added along with jobsite sampling with sample security measures (Trepanier, personal communication, August 2019). 
In 2010, IDOT began transitioning projects to the PFP specification. At the time, IDOT's resources were insufficient to fully comply with federal regulations and FHWA's recommendations. A combination of planned engineering technician and civil engineering hires in conjunction with consultant agreements were executed. IDOT's goal was to use PFP for all projects over 4,000 tons by 2014. After adopting PFP, the department would implement a system for projects less than 4,000 tons (IDOT, 2010). The QCP specification was implemented by IDOT first in 2012. It was intended for projects where a minimum of eight tests is not possible or projects in which the nature of construction site conditions make it difficult to achieve uniform production, e.g., thin overlays on existing pavements with poor condition, poor base conditions, non-uniform production operation, etc. IDOT's objective was to complete the transition to QCP specification on projects that qualified by 2014 (IDOT, 2013).

\subsection{ILLINOIS QUALITY MANAGEMENT PROGRAM (QMP)}

IDOT's current QA program implements QCP and PFP specifications. IDOT's former QA specification, $\mathrm{QC/QA}$, is being phased out, but is still used for smaller and miscellaneous mix applications. Its use will continue to be limited. It was not part of this study's scope.

For PFP, a PWL specification is used for US, state route, and national highway system roadways such as interstate, freeway, and expressway resurfacings, as well as full-depth asphalt pavement projects with a minimum HMA quantity of 8,000 tons per mix (IDOT, 2018a). QCP and PFP exclusions exist such as sidestreets, short turn lanes, short-term temporary pavements, and other exclusions defined by IDOT. These sections of asphalt pavements default to the QC/QA method of acceptance. PFP can also be used for smaller projects, where a more accurate measure of quality is desired, provided the sublot size is reduced to maintain eight or more sublots. On the other hand, QCP is for smaller mainline HMA projects, where mixture quantities range between 1,200 and 8,000 tons. It has also been implemented for narrow shoulder applications and leveling binder mixes (IDOT, 2018b).

As of July 26, 2019, IDOT changed nomenclature (eliminating the term "leveling binder") and increased the minimum compacted lift thickness requirements such that mixtures are not placed at less than three times the nominal maximum aggregate size (NMAS). As a result, all lower lifts of HMA are named binder mixtures (IDOT, 2019). Therefore, QCP and PFP can be implemented for QA of mixes used for levelling purposes. Therefore, both can now be implemented for off-interstate applications. For the data presented in this report (2015-2017), this change had not yet been implemented. In addition, all other QCP and PFP changes made by IDOT in 2019 are not reflected in the data presented in this report.

\subsubsection{Sampling}

The pay parameters for both QCP and PFP specifications include field VMA, AV, and in-place density. Step-based pay disincentives exist for the dust/AC ratio and, in the case of PFP, unconfined edge density that is out of tolerance. Aggregate gradation, binder content, and VMA, which are affected by mix segregation, are measured by the contractor as part of their process control but are not directly used as pay parameters. Although such information is obtained by districts too, it is not reported at this time. 
HMA sampling in Illinois is completed by the contractor:

- Mix samples are usually obtained in the field behind the paver from the mat after placement and prior to compaction.

- Mix samples are randomly obtained from every sublot (typically 1,000 tons), with QCP requiring a minimum of one sublot sample per project and PFP requiring 10 sublots per lot.

- Density is obtained by drilling cores in the road surface once the HMA has been compacted and cooled.

- Cores are obtained from a random location in every density interval (typically $0.2 \mathrm{mi}$ for lift thicknesses of 3 in or less, and 0.1 mi for lift thicknesses greater than 3 in or wide paving).

In QCP, the average of five consecutive density intervals is taken as the agency's density sublot results.

- In PFP, each density interval is considered a density sublot and 30 density intervals consists of a density lot. Random samples are obtained from the jobsite for mix samples and field cores. The mix samples are split for the contractor (QC) and agency (QA) testing. A third sample is obtained for a third-party dispute resolution in the case of PFP.

Sampling techniques used by contractors are discussed in Chapter 5.

\subsubsection{Pay Factor Calculation}

A major difference between QCP and PFP is the calculation of the pay parameters. QCP is a stepped system whereas PFP is a PWL system (see Figure 2.1). PFP pay factors are computed per Equation (2.1):

$$
\text { Pay Factor }=55+0.5(\mathrm{PWL})
$$

where pay factor (PF) is defined and calculated for each pay parameter. The pay factors range from $90 \%$ to $100 \%$ for QCP projects and from $55 \%$ to $105 \%$ for PFP projects.

Equation (2.1) used to be Pay Factor $=53+0.5(P W L)$ and the maximum pay factor for QCP was $103 \%$ before June 2017 (IDOT, 2018c). For the data presented on this report (2015-2017), this change had not yet been implemented.

In addition, for density calculation, PFP uses a single density measurement, while QCP uses an average of five density measurements.

\subsubsection{Pay Calculation}

For both specifications, the pay factors of each parameter are combined into one composite pay factor (CPF) for final pay using Equation (2.2):

$$
\mathrm{CPF}=0.30_{(\mathrm{PF} \mathrm{AV})}+0.30_{(\mathrm{PF} \mathrm{VMA})}+0.40(\mathrm{PF} \text { Density })
$$


where, PF AV is the pay factor for AV, PF VMA is the pay factor for VMA, and PF density is the pay factor for density, all are expressed as percentages. The composite pay factor is then used to compute the final pay of the project, as shown in Equation (2.3):

$$
\text { Final Pay }=\text { Mixture Unit Price * Quantity * CPF }
$$

Under the PFP specification, contractors can earn pay incentives when the CPF is greater than $100 \%$. Under the QCP specification, pay factors of each pay parameter are truncated to $100 \%$ prior to calculating the CPF.

In the QCP specification, if the difference between QC and QA contractor and agency test results are outside the precision limits shown in Table 2.1, sublots are retested by agency personnel. If the retested sublot results are outside precision limits or have a pay factor less than $100 \%$, all sublots in a lot are tested by IDOT.

Table 2.1. Precision Limits for QCP

\begin{tabular}{|l|c|}
\hline Test Parameter & Precision Limits \\
\hline $\mathrm{G}_{\mathrm{mb}}$ & 0.030 \\
\hline $\mathrm{Gmm}_{\mathrm{mm}}$ & 0.026 \\
\hline $\mathrm{VMA}$ & $1.0 \%$ \\
\hline
\end{tabular}

\subsubsection{Disputes in PFP Specifications}

PFP projects allow contractors to dispute district (QA) sublot results when the difference between the results exceeds the precision limits shown in Table 2.1. All sublots are tested in PFP. The contractor must request the sublot to be disputed. Thus, not all sublots that exceed the precision limits are disputed.

Currently, two methods are used for dispute resolution (IDOT, 2018a). The first method allows the contractor to dispute the pay parameter result such as AV, VMA, dust/AC ratio, or core density when the results are outside the limits of precision, as shown in Table 2.1. The Central Bureau of Materials (CBM) laboratory would then proceed to test the third sample of the disputed sublot and replace the district test results with the CBM test results. In 2018, IDOT began a second method that allows the contractor to dispute only an individual test, such as $G_{m m}, G_{m b}$, or $P_{b}$, that exceeds the precision limits shown in Table 2.2. This method applies only to contractors who participate and comply with the "AASHTO re:source Proficiency Sample" program. In this study, data collection occurred before 2018; therefore, all disputed sublots were tested according to the first method.

Table 2.2. Precision Limits for PFP Dispute Resolution Method Nos. 1 and 2

\begin{tabular}{|l|c|l|c|}
\hline \multicolumn{2}{|c|}{ Method No. 1 } & \multicolumn{2}{c|}{ Method No. 2 } \\
\hline Test Parameter & Precision Limits & Test Parameter & Precision Limits \\
\hline Air Voids (AV) & $1.0 \%$ & $\mathrm{G}_{\mathrm{mm}}$ & 0.008 \\
\hline VMA & $1.0 \%$ & $\mathrm{G}_{\mathrm{mb}}$ & 0.012 \\
\hline Dust/Asphalt Binder & 0.2 & Asphalt Binder & 0.2 \\
\hline Core Density & $1.0 \%$ & & \\
\hline
\end{tabular}




\subsection{REPORTED DIFFERENCES IN AGENCY AND CONTRACTOR HMA TEST RESULTS}

Disagreements between contractor (QC) and agency (QA) testing have been reported (Benson, 1999). Parker and Hossain (2002) used the F-test to run a comparative assessment between contractor and Alabama DOT (AIDOT) test results. $\mathrm{P}_{\mathrm{b}}, \mathrm{AV}$, and density data from projects constructed from 1997 to 2000 presented statistically significant differences, with a few exceptions. During that time, AIDOT was only beginning to implement SuperPave mixes; thus, it is understandable that issues of this type were found.

Turochy et al. (2006) used F- and t-tests and found statistically significant differences between agency QA and contractor QC for aggregate gradation and $\mathrm{P}_{\mathrm{b}}$ of mixes placed in Georgia during the 2003 construction season. This occurred in less than $10 \%$ of the projects when analyzing the means. Additionally, $10 \%$ to $13 \%$ of the projects had statistically significant differences in variance.

Conversely, Hall and Williams (2002) indicated that test data from six projects throughout Arkansas, such as $\mathrm{P}_{\mathrm{b}}, \mathrm{AV}, \mathrm{VMA}$, and density, reported by three different operators (contractor, Arkansas DOT, and a third party) were statistically similar. (It is not stated whether the operators used the same equipment.) Similarly, Mahboub et al. (2008) reported no significant difference between testing by contractors and Kentucky Transportation Cabinet (KYTC) data. However, the contractor-reported standard deviations were sometimes smaller than those reported by KYTC. For their acceptance procedure, KYTC performs tests on the contractor's equipment or on the department's equipment. Data was not distinguished in the report.

LaVassar et al. (2009) analyzed pay parameters from four state departments of transportation, including Texas and Washington. HMA pay parameters were assumed to be normally distributed and various statistical tests were performed, including F- and t-tests, to compare QC and QA variances and mean values. For the data from Texas, the study reported statistically significant differences for $60 \%$ of the mixes for in-place $\mathrm{AV}$, and $40 \%$ in density and asphalt content measurements. For the data from Washington, the study reported statistically significant differences for $20 \%$ of the mixes for $\mathrm{P}_{\mathrm{b}}$.

Mohammad et al. (2013) performed a single-factor ANOVA on AV, $\mathrm{P}_{\mathrm{b}}, \mathrm{VMA}$, voids filled with asphalt (VFA), and density test data from projects in Florida and Kansas. In Florida, no significant difference occurred in at least $90 \%$ of the cases. Kansas, however, had $20 \%$ of its mixes showing significant differences in variances for state and contractor measurements. When t-tests were performed, $14 \%$ of the mixes showed differences in AV measurements while $48 \%$ showed differences in density measurements. The authors, as part of a NCHRP (2016) phase I study, noted that, in general, variability in the contractor measurements were less than that of the agency, and third-party test results had the highest variability.

The aforementioned research studies identify and describe differences between agency and contractor test results of samples of the same HMA batch or specified mat. Understanding where the differences between contractor and district results originate, however, remains a necessity to improve those programs and are not clearly identified. Test variability and bias are repeatedly noted. Finally, the sample pool of QA and QC testing results comparison are usually small, with fewer than 30 data points. Regardless, researchers have used parametric tests, assuming populations of the 
compared samples are normally distributed. Of the mentioned studies, only Hall and Williams (2002) validated this typical assumption in their study. The assumption has been validated for HMA properties mentioned in other studies, e.g., Chakroborty et al. (2010) and Aguiar-Moya and Prozzi (2011).

\subsection{VARIABILITY IN HMA TEST RESULTS}

Apart from material and construction variability, HMA test results yield variability caused by testing (equipment, operator, method) and sampling. Identifying variability sources and understanding its magnitude of importance are required when differences between contractor and agency test results are evaluated. Hand and Epps (2000) performed Monte Carlo simulations to evaluate the effect of precision limits on optimum asphalt binder selection. The study reported that testing variability within the precision required by AASHTO standards could translate to differences of $0.7 \%$ to $1.4 \%$ in the selected optimum $\mathrm{P}_{\mathrm{b}}$.

\subsubsection{Comparing the Volumetric and Mechanical Properties of Laboratory and Field Specimens of Asphalt Concrete}

NCHRP (2016) explained how construction processes and handling may influence the magnitudes of the differences within and among three specimen types: plant-mixed and field-compacted (PF), plantmixed and laboratory-compacted (PL), and laboratory-mixed and laboratory-compacted (LL). The report quantified the levels of variability in the measurements of volumetric properties and aggregate gradation of dense-graded HMA based on test data from agencies and contractors of 13 states (Table 2.3).

Table 2.3. HMA Property Levels of Variability (NCHRP, 2016)

\begin{tabular}{|c|c|c|c|}
\hline \multicolumn{5}{|c|}{ Volumetric Properties } \\
\hline Property & Sample Type & Standard Deviation Range & Average Standard Deviation \\
\hline $\mathrm{P}_{\mathrm{b}}$ & $\mathrm{PL}$ & $0.17-0.29$ & 0.20 \\
\hline $\mathrm{AV}$ & $\mathrm{PL}$ & $0.33-0.99$ & 0.62 \\
\hline $\mathrm{VMA}$ & $\mathrm{PL}$ & $0.38-0.64$ & 0.54 \\
\hline $\mathrm{VFA}$ & $\mathrm{PL}$ & $3.40-4.92$ & 4.03 \\
\hline \multirow{2}{*}{$\mathrm{G}_{\mathrm{mb}}$} & $\mathrm{PL}$ & $0.008-0.018$ & 0.015 \\
\cline { 2 - 4 } & $\mathrm{PF}$ & $0.008-0.033$ & 0.019 \\
\hline$G_{\mathrm{mm}}$ & $\mathrm{PL}$ & $0.005-0.012$ & 0.011 \\
\hline Density & $\mathrm{PF}$ & $0.74-1.49$ & 1.11 \\
\hline
\end{tabular}

Table 2.4 presents the tolerance values developed in that study. The tolerance values encompass mixtures from around the country. The proposed tolerances are 1.96 times the standard deviation of the differences found among specimens. The report recommends that states review their current tolerances with respect to these values. The tolerances used in Illinois were found to be less than the reported values. 
Table 2.4. Volumetric Tolerance Recommendations (NCHRP, 2016).

\begin{tabular}{|c|c|c|c|c|}
\hline Property & \multicolumn{3}{|c|}{ Comparison } & Tolerance Recommendation ( \pm ) \\
\hline $\mathrm{AV}(\%)$ & \multirow{3}{*}{ Design (LL) } & - & \multirow{3}{*}{ Production (PL) } & 0.8 \\
\hline VMA (\%) & & - & & 1.2 \\
\hline VFA (\%) & & - & & 5.4 \\
\hline \multirow{3}{*}{$\mathrm{P}_{\mathrm{b}}(\%)^{*}$} & Design (LL) & - & Production (PL) & \multirow{3}{*}{0.2} \\
\hline & Design (LL) & - & Construction (PF) & \\
\hline & Production (PL) & - & Construction (PF) & \\
\hline \multirow{3}{*}{$\mathrm{G}_{\mathrm{mm}}$} & Design (LL) & - & Production (PL) & 0.02 \\
\hline & Design (LL) & - & Construction (PF) & 0.013 \\
\hline & Production (PL) & - & Construction (PF) & 0.018 \\
\hline \multirow{3}{*}{$\mathrm{G}_{\mathrm{sb}}$} & Design (LL) & - & Production (PL) & 0.014 \\
\hline & Design (LL) & - & Construction (PF) & 0.019 \\
\hline & Production (PL) & - & Construction (PF) & 0.017 \\
\hline \multirow{3}{*}{ Aggregate Passing $0.075 \mathrm{~mm}$ Sieve } & Design (LL) & - & Production (PL) & 0.5 \\
\hline & Design (LL) & - & Construction (PF) & 0.7 \\
\hline & Production (PL) & - & Construction (PF) & 0.5 \\
\hline
\end{tabular}

*Note the tolerance reported for $\mathrm{P}_{\mathrm{b}}$ was developed by solvent extraction. The standard deviation of the solvent extraction results is lower than the ignition method. Consequently, the tolerance for ignition would be slightly higher.

\subsubsection{Variability of Volumetrics}

The $G_{m b}$ and $G_{m m}$ tests are usually the main source of variability of the other volumetric results, including AV, VMA, and density (Hand and Epps, 2000). $G_{s b}$ has also been found to be a factor in causing variability (NCHRP, 2016). This depends on whether the state allows the value to change. Testing method, equipment, and sampling are sources of variability affecting test results and are discussed hereafter.

Crouch et al. (2002) evaluated the precision and accuracy of four methods to determine AV of compacted HMA: CoreLok, parafilm, SSD (method used in Illinois), and dimensional analysis (AASHTO T269 [volume method]). All methods were found to be capable of producing high-precision results; the precision of the SSD method was the highest. However, AV values based on $\mathrm{G}_{\mathrm{mb}}$ obtained by this method were always the lowest. The authors demonstrated that results obtained using this method do not change if a sample has a different percentage of internal voids. Because of this limitation, they ruled out the use of the SSD method for HMA. Although the authors did not recommend a method, the study showed the CoreLok method was the most accurate test for $90 \%$ of the samples.

The assumption of equivalency of properly calibrated SuperPave gyratory compactors has historically been called into question. Buchanan and Brown (2001) and Mahoney and Stephens (2003) were two examples. Internal-angle measurements and calibrations were introduced and specified by many states and AASHTO to correct this. FHWA (2010) drew attention to the physical condition of compaction equipment. Its cleanliness, excessive wear in molds (inside diameter in the area of the mold wall subject to compaction, i.e., 1 to 5 in from the bottom), how sampling can affect test results, and how these sources of variability should be corrected.

In 2013, segregation was considered a continuing problem for IDOT's HMA construction projects (IDOT, 2013). Coarse-graded HMA may increase the potential for segregation during sampling and subsequent sample handling/preparation (FHWA, 2010). HMA with segregation causes AV to vary by 
$0-4 \%, 2-6 \%$, and $>6 \%$ for low, medium, and severe segregation, respectively. The three main causes of segregation are related to aggregate gradation, temperature, and asphalt content. Aggregate gradation segregation is the most common because of aggregate stockpiling and handling (NCHRP, 2000). Segregation may cause sampling variability. FHWA (2013) suggests sampling of loose HMA should be done strictly from behind the paver where the final "in-place" properties are evaluated.

\subsubsection{Variability of Asphalt Content}

In Illinois, $\mathrm{P}_{\mathrm{b}}$ is usually determined using the ignition oven method or reflux extractors. Less frequently, it is determined with centrifuge extractors. Recently, automated extractors have been used by Districts 1, 3, and 4. Contractors and independent labs in Illinois have also begun to use automated extractors.

Sholar et al. (2002) used an approach to encompass the variability associated with the following sampling locations and other variables: (a) differences in HMA within the truck bed, (b) collection of samples from the truck, (c) splitting of the HMA mixture into samples for testing, (d) differences in ignition oven equipment, and (e) operator. Six SuperPave mixtures and three open-graded friction courses of different NMAS were used for the experiments. The results of the study indicate that the allowable difference between two test results for asphalt binder content should be no greater than $0.32 \%$ within a laboratory and $0.44 \%$ between laboratories.

\subsubsection{Quality Levels of Pay Parameter's Mean and Variability}

Hall and Williams (2002) reported an approach to establish the variability for HMA construction in Arkansas. As shown in Table 2.5, the data were grouped into high-, medium- and low-quality levels. The values provided by NCHRP (2016) in Table 2.4 would be considered of medium quality for density, whereas $\mathrm{P}_{b}, \mathrm{AV}$, and VMA values would be considered high quality.

Table 2.5. Summary of Material Properties by Quality Level (Hall and Williams, 2002)

\begin{tabular}{|c|c|c|c|c|c|c|}
\hline \multirow{2}{*}{ Property } & \multicolumn{4}{|c|}{ Quality Level } \\
\cline { 2 - 7 } & \multicolumn{2}{|c|}{ High } & \multicolumn{2}{c|}{ Medium } & \multicolumn{2}{c|}{ Low } \\
\cline { 2 - 7 } & Mean & $\begin{array}{c}\text { Standard } \\
\text { Deviation }\end{array}$ & Mean & $\begin{array}{c}\text { Standard } \\
\text { Deviation }\end{array}$ & Mean & $\begin{array}{c}\text { Standard } \\
\text { Deviation }\end{array}$ \\
\hline $\mathrm{P}_{\mathrm{b}}(\%)^{*}$ & 0.06 & 0.184 & 0.21 & 0.251 & 0.33 & 0.413 \\
\hline $\mathrm{AV}(\%)$ & 3.58 & 0.649 & 3.09 & 0.768 & 5.02 & 2.097 \\
\hline $\mathrm{VMA}(\%)$ & 14.92 & 0.346 & 14.32 & 0.589 & 14.94 & 1.136 \\
\hline Density $\left(\% \mathrm{G}_{\mathrm{mm}}\right)$ & 92.57 & 0.79 & 91.82 & 0.959 & 90.43 & 1.313 \\
\hline
\end{tabular}

*expressed as percent difference from design $\mathrm{P}_{\mathrm{b}}$

\subsubsection{Variability Sources in HMA Test Results}

Table 2.6 presents the most important factors identified affecting HMA test results. Specifications or test methods should explicitly address each of these items, providing clear requirements if an agency wishes to reduce variability among test results obtained by multiple laboratories. 
Table 2.6. Summary of Variability Sources in HMA Testing*

\begin{tabular}{|c|c|}
\hline Category & Variability Source \\
\hline Production & $\begin{array}{l}\text { - } \quad \text { Baghouse fines variation } \\
\text { - } \quad \text { Silo storage time of asphalt } \\
\text { - } \quad \text { Plant type and settings } \\
\text { - } \quad \text { Segregation } \\
\text { - } \text { Aggregate absorption (field vs lab) } \\
\text { - } \text { Aggregate moisture } \\
\text { - } \quad \text { Aggregate degradation } \\
\text { - } \quad \text { Aggregate } \mathrm{G}_{\mathrm{sb}}\end{array}$ \\
\hline Construction & $\begin{array}{l}\text { - Segregation control } \\
\text { - Use of material transfer device } \\
\text { - Competency of contractor } \\
\text { - Construction equipment }\end{array}$ \\
\hline Testing & $\begin{array}{l}\text { - } \text { Reheating procedure } \\
\text { - Sampling location } \\
\text { - Sampling method } \\
\text { - Splitting method } \\
\text { - Sample type } \\
\text { - SuperPave gyratory compactor's cleanliness, physical condition, } \\
\text { - } \text { and wearing of molds } \\
\text { - Equipment calibration or lack of } \\
\text { - Equipment maintenance }\end{array}$ \\
\hline
\end{tabular}

*This table includes the sources of variability listed in NCHRP (2016).

\subsection{QUANTITY OF SAMPLES}

IDOT's current QCP and PFP specifications and latest updates are in line with FHWA's (2019) recommendations regarding density. The most common frequency of density testing (identified by FHWA as best practices) was every 250 to 500 tons. IDOT's QCP and PFP require density core tests every density interval of typically less than 250 tons (and as small as approximately 120 tons). The number of test results considered for pay calculations of IDOT's current QA program is appropriate.

\subsection{SUMMARY}

The main ideas discussed in this chapter are summarized below:

- Three decades ago, design and process control responsibilities of HMA construction shifted from agencies to contractors. The importance of statistically based pay calculation and performance-related parameters became evident in the 2000s. In the early 2010s IDOT's QA transitioned to QCP and PFP specifications to fully comply with federal regulations (23 CFR 637) and FHWA's recommendations. 
- The specifications implemented in IDOT's QMP are described in section 2.2: Illinois Quality Management Program. The QMP relies on QCP for mixtures in the $1,200-8,000$ ton range and PFP for mixtures greater than 8,000 tons. The main difference between QCP and PFP is the pay calculation and density calculation approach. The PFP specification incorporates the PWL method, whereas QCP uses a stepped procedure to determine pay factors.

- IDOT's QCP and PFP specifications are appropriate when compared to the previously referenced documents for the type of projects for which each is used.

- Since SuperPave mix-design specifications were completed and implemented nationally, differences in agency and contractor results have been found. The root causes were not clearly identified. Sampling and test result variability and bias, however, cause a significant portion of these differences. Variability in test results has repeatedly been found to be greater for agencies than for contractors, perhaps because of the number of samples. A detailed list of possible causes and variabilities is listed in the chapter.

- Reducing test variability would control apparent differences between agency and contractor test results and help distinguish bias from expected variability. The variability of the $G_{m b}$ and $G_{m m}$ tests are usually the main driver of variability in the volumetric results.

- To comply with FHWA's recommendations and reduce potential variability, IDOT requires the contractor to sample loose HMA from behind the paver with a standardized random sampling procedure. 


\section{CHAPTER 3: DATA COLLECTION AND ANALYSIS}

A data analysis program was developed per the objectives of the study. The scope of the data analysis program includes descriptive statistics, hypothesis testing, data visualization, and correlations. This chapter introduces the research methodology followed by data sets compiled from the Illinois Department of Transportation (IDOT) and contractors in Illinois. Finally, the statistical tests used for the data analysis are described.

\subsection{RESEARCH METHODOLOGY}

The research methodology consists of the following parts: (1) pay factor analysis, (2) pay parameter statistical analysis, (3) volumetric results analysis, (4) mix composition analysis, (5) round robin evaluation, and (6) data analyses from site visits. Assessing data variability was performed in accordance with the flowchart illustrated in Figure 3.1.

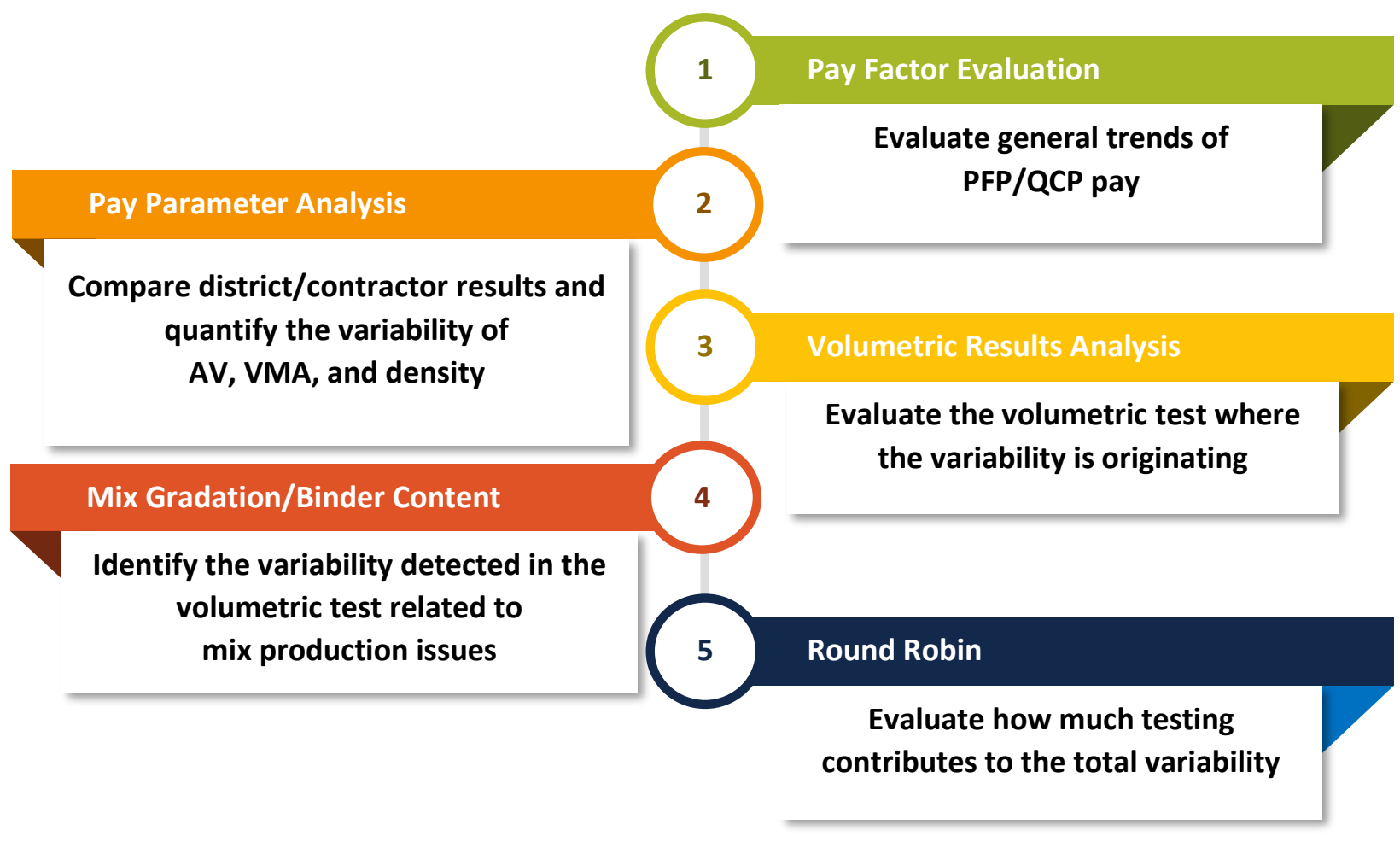

Figure 3.1. Research methodology.

The first part of the analysis observed the pay factor trends to compare variation in data trends as a function of key factors that may contribute to variability in QCP and PFP projects. First, the pay factors were grouped per district and year to check uniformity between districts and changes over time, respectively. In addition, each pay factor parameter (AV, VMA, and density) trend was analyzed individually to evaluate the effect of each parameter on payment. Finally, the pay factors were grouped and analyzed according to mix type groups. 
The second and third parts of the evaluation consisted of conducting descriptive statistics and hypothesis tests on QCP and PFP sublot results. Again, the analysis focused on the pay parameters (AV, VMA, and density). The analysis used descriptive statistics and hypothesis testing to quantify the magnitude of the variability in the test results and to identify any significant difference between the results reported by the contractor and district. In the case of a significant difference existing, the magnitude of the difference was reported. Afterwards, statistical analysis was conducted on $\mathrm{G}_{\mathrm{mm}}$ and $G_{m b}$ results, from which the AV and VMA were computed. $G_{m m}$ was also used to compute core density. Finally, test results related to mix composition, aggregate gradation, dust, and asphalt binder content were analyzed considering the variability observed in the $G_{m b}$ and $G_{m m}$ tests to identify mix production issues.

The fourth part of the analysis focused on the evaluation of the variability due to testing using data from IDOT Volumetric Uniformity Study results, also known as round robin studies. The uniformity studies consist of the test results for $\mathrm{G}_{\mathrm{mm}}$ and $\mathrm{G}_{\mathrm{mb}}$ obtained from a group of 40 laboratories for five consecutive years. Each laboratory received the same mix sampled by IDOT Central Bureau of Materials (CBM). As a result, it was assumed that differences in test results and variability were related to testing procedure, operator, and/or equipment. Sampling-related variability was eliminated.

The last part of the analysis focused on the evaluation of data compiled from the jobsite visits. Jobsite shadowing visits were conducted on 11 construction projects during the 2018 construction season to monitor sampling, blending, splitting, and testing during production and construction. The collected information was analyzed to determine potential root causes of pay disincentives and variabilities, if they existed. This would assist in developing recommendations regarding mix production, construction, and testing provided in the report.

\subsection{DATA COLLECTION}

Five data sets were compiled for this study: pay factors, mix sublot results, PFP dispute results, IDOT Uniformity Study results (round robin), and jobsite visit data. The data collected corresponds to the projects constructed under the QCP and PFP specifications in Districts 1, 2, 5, 6, 8, and 9, as shown in Figure 3.2. Only the 2015, 2016, and 2017 construction seasons were included in the scope of the data collection. For the 2018 jobsite shadowing visits, additional data that included individual mix test results, plant datalogger, and temperature records were collected.

A total of 710 mix contract combinations were identified for the districts and construction years within the scope of the project. A mix contract case is a unique combination of a specific contract and mix. For example, if a contract has more than one mix (i.e., surface mix and a leveling binder), then each mix was analyzed separately and referred to as a mix contract case. As a result, data from the same mix but used in different construction contracts were not grouped together for the analysis. The report uses the term "cases" to refer to each mix contract combination. 


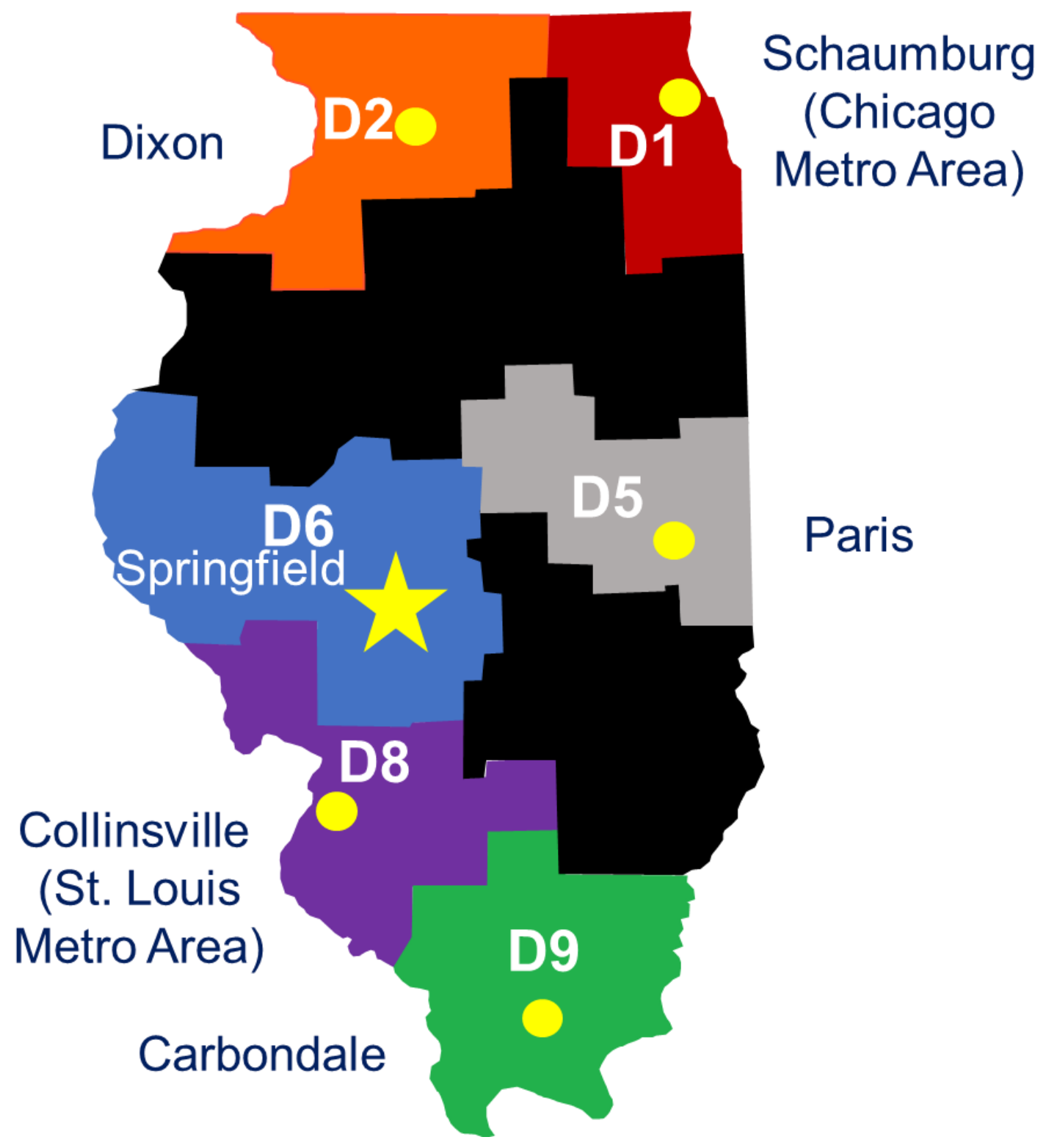

Figure 3.2. IDOT districts included in the project's scope and respective district office locations.

\subsubsection{Pay Factors}

The pay factors correspond to the percentage pay adjustment for AV, VMA, and density received based on the quality assurance (QA) test results. The AV, VMA, and density pay factors are computed using a step-based system for QCP projects and percent within limits (PWL) for PFP projects according to "PFP Quality Level Analysis, Appendix E.1" and "QCP Pay Calculation, Appendix E.6"(IDOT, 2017).

The pay factors were collected from each individual district's file records and compiled into a database. A total of 710 pay factors were collected for the 2015-2018 construction seasons. Figure 3.3 shows a breakdown of the 710 pay factors per district and quality management program. District 1 has a substantially larger number of cases than the rest of the districts because it covers the Chicago metropolitan area, where many state projects are located. 


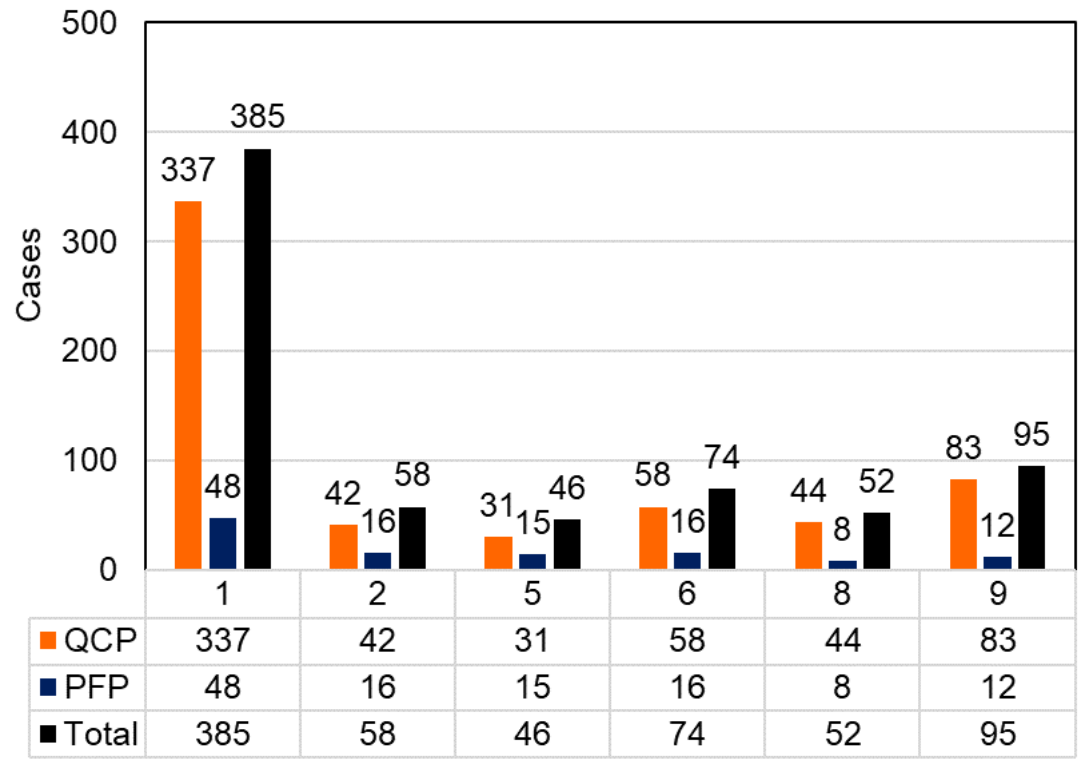

Figure 3.3. Total number of pay factors collected from each district.

\subsubsection{Quality Assurance and Quality Control Sublot Test Results}

The QA and QC sublot results for QCP and PFP projects were collected. The results correspond to the plant-produced materials sampled at the jobsite in accordance with the "PFP and QCP Hot-Mix Asphalt Random Jobsite Sampling, Appendix E.4" (IDOT BDE, 2017). Other contractor QC results were not included but were an important part of the QC process. The density results originated from the cores obtained in accordance with the "PFP and QCP Random Density Procedure, Appendix E.3" (IDOT, 2018c). The mix and density sublot results were used to calculate the pay factors described in section 3.2.1: Pay Factors. Table 3.1 describes the data collected from the sublot test results with respect to the pertinent Illinois modified AASHTO specifications.

Table 3.1. Sublot Test Result Data

\begin{tabular}{|l|c|}
\hline Data Type & IL Modified AASHTO Specification \\
\hline Gradation & T 30 \\
\hline Binder Content & T 308 \& T 164 \\
\hline Bulk Specific Gravity $\left(G_{\mathrm{mb}}\right)$ & T 166 \\
\hline Maximum Specific Gravity $\left(\mathrm{G}_{\mathrm{mm}}\right)$ & T 209 \\
\hline Air Voids & M 323 \\
\hline Field VMA & M 323 \\
\hline Dust/AC Ratio & $\begin{array}{c}\text { Calculation from gradation and binder content test results. } \\
\text { Defined in IDOT Art. 1030.04 }\end{array}$ \\
\hline Density & T 166 \\
\hline
\end{tabular}

The sublot test results were obtained from the IDOT MISTIC database and Excel and PDF spreadsheets provided by the districts. QC and QA tests were conducted for all cases in the 20152017 period. However, not all results were digitally accessible for the research team; some data were 
stored in paperwork. Figure 3.4 shows a breakdown of the cases: digitally accessible for both $Q C$ and QA ("Both Reported"), not digitally accessible for QA ("No QA Results"), or QC ("No QC Results")." In summary, for a total of 595 QCP cases, 506 digitally reported the results from QC and QA. For PFP, from a total of 115 cases, 93 digitally reported the QC and QA results.
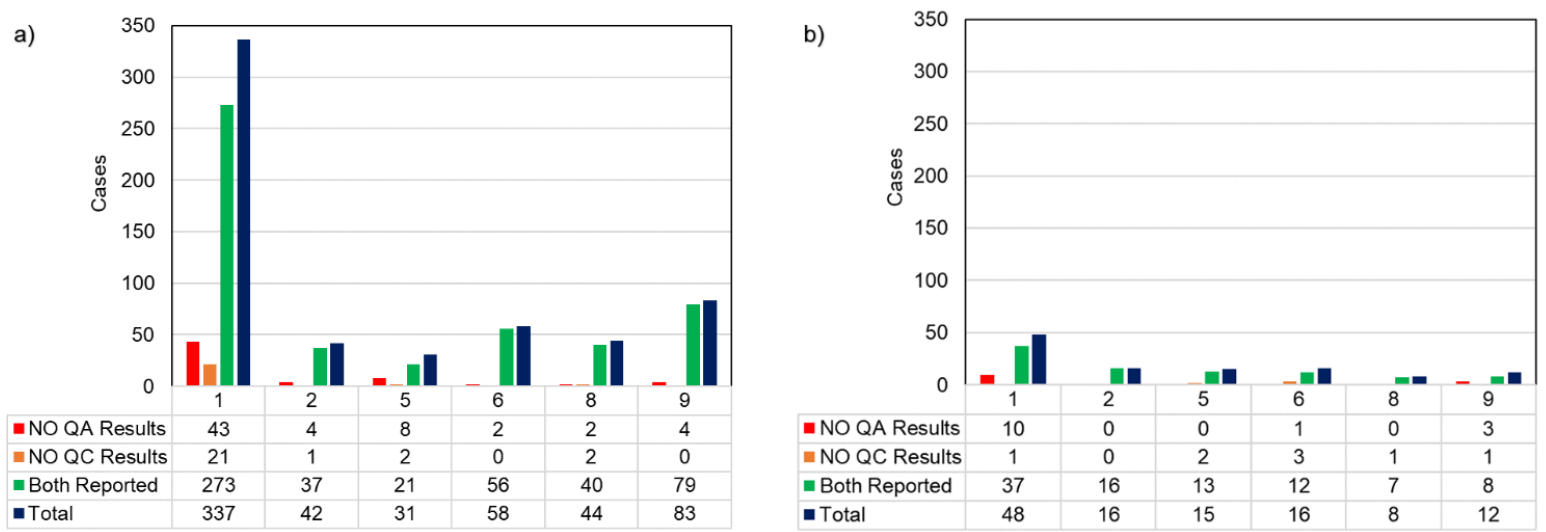

Figure 3.4. Sublot test results received for (a) QCP and (b) PFP projects.

\subsubsection{PFP Dispute Data}

The sublot results for PFP dispute resolution were collected from CBM records. A total of 149 disputed sublot results were received for the years and districts within the scope of the project. The sublot breakdown per dispute type (mix or density), year, and district is shown in Figure 3.5. From the figure, the majority of the disputed sublots were in Districts 1,2 , and 6 , with $63 \%, 19 \%$, and $12 \%$ of the reported sublots, respectively. Mix disputes (AV, VMA, dust/AC ratio) constitute $70 \%$ of the total number of disputes while density disputes are $30 \%$. Finally, there has been a reduction in the number of sublots disputed over the last three years, except for District 1. In 2016, District 1 reported one density sublot disputed.

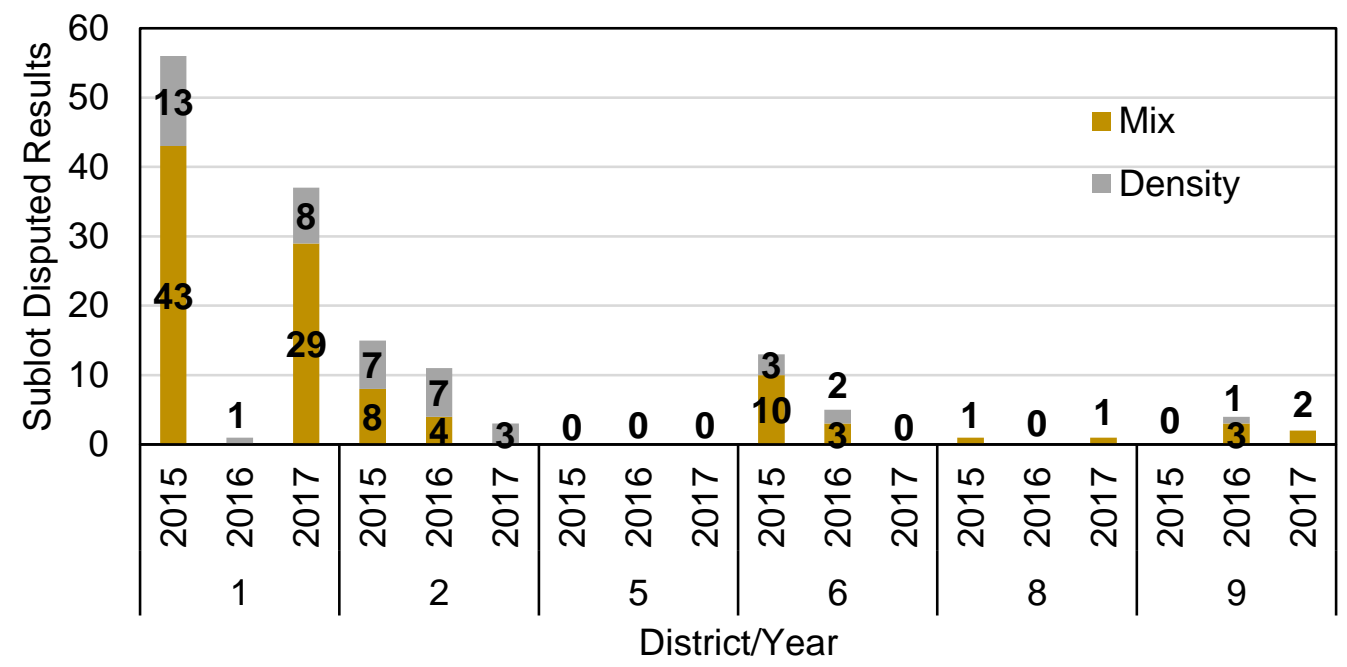

Figure 3.5. PFP dispute resolution sublots results. 


\subsubsection{IDOT Volumetric Uniformity Study Results (Round Robin)}

The results from IDOT round robin studies for the years 2015 to 2019 were received. The uniformity study is an annual interlaboratory testing program to assess laboratory performance in terms of the volumetric testing within IDOT districts and participating laboratories. The statewide round robin testing program is administered by the CBM. A similar program was also separately held in District 1. The data from both round robin programs were obtained and compiled for data analysis. Each year, the CBM selected one plant-sampled batch of HMA surface mixture. The 40 participating laboratories were supplied with one sample. Each laboratory reheated the mixture and conducted the tests described in Table 3.2 according to the applicable Illinois modified AASHTO specifications and the IDOT Manual of Test Procedures (MoTP) requirements (IDOT, 2018c).

Table 3.2. Test Conducted in IDOT Uniformity Studies

\begin{tabular}{|l|c|}
\hline Test Conducted & IL Modified AASHTO Specification \\
\hline Mix Gradation & T 30-13 \\
\hline Binder Content & T 308-10 \\
\hline Bulk Specific Gravity $\left(G_{\mathrm{mb}}\right)$ & T 166-13 \\
\hline Maximum Specific Gravity $\left(\mathrm{G}_{\mathrm{mm}}\right)$ & T 209-12 \\
\hline Moisture-induced Damage & T 283-07 \\
\hline
\end{tabular}

A total of 161 results from the IDOT volumetric uniformity study were received for the years 20152019 for Districts 1, 2, 5, 6, 8, and 9, for both state and private labs. The results breakdown per laboratory, year, and district are shown in Figure 3.6. The figure illustrates the received results for each round robin conducted during the years 2015-2019.

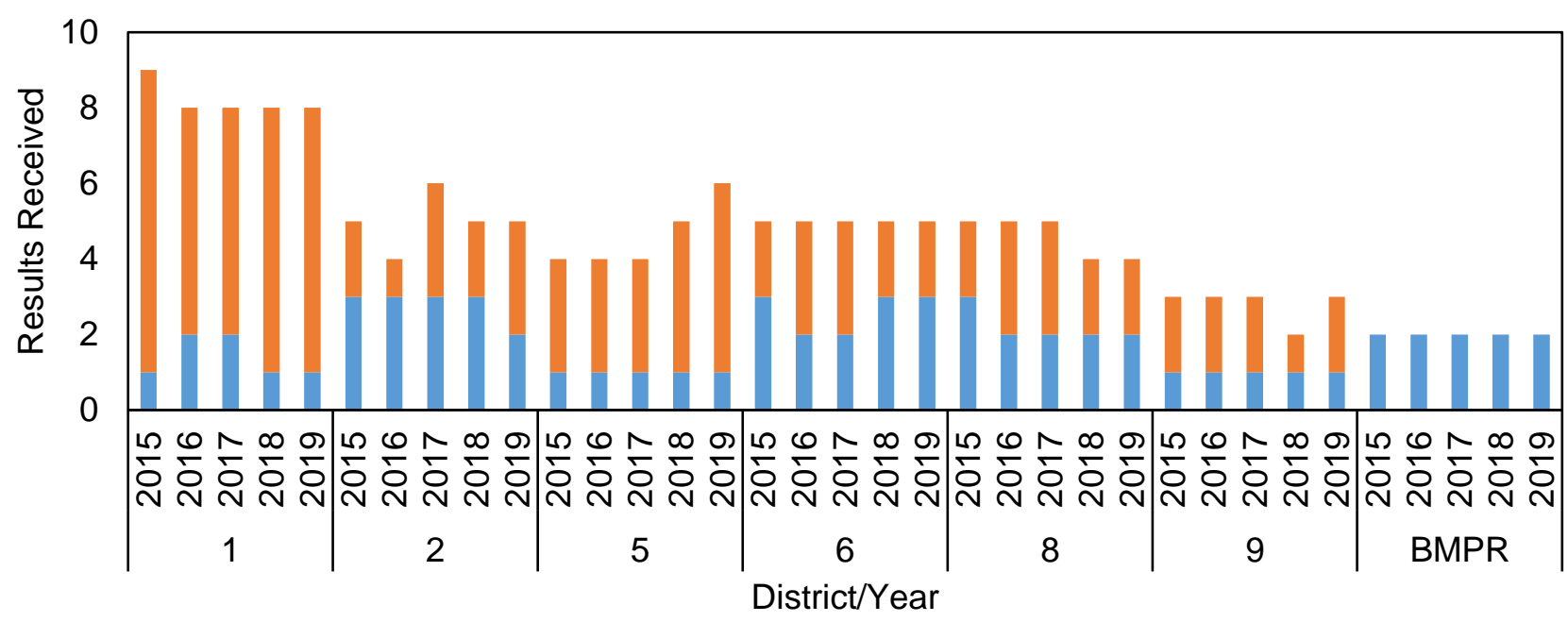

- IDOT District/CBM IIndpendent/Contractor

Figure 3.6. IDOT volumetric uniformity study (round robin) results. 


\subsubsection{Site Visit Data}

During the 2018 construction season, 11 construction projects were visited to understand the root causes of deviation, variability, and loss of pay. The visits were conducted at the jobsite, plant, contractor lab, and district lab. The QMP sublot test results, pay factors, and dispute results (if any) were collected. In addition, the mix design, QC/QA packages files (individual test weight), datalogger, and temperature records were collected.

The mix design information was collected to compare the test results to the target values. From the mix design sheets, the following items were considered:

- Aggregate blend

- Design aggregate gradation and AC content

- Dust/AC ratio

- $\mathrm{N}$-design, $\mathrm{G}_{\mathrm{mm}}$ vs $\mathrm{AC}$ content, and $\mathrm{G}_{\mathrm{mb}} \mathrm{vs} A \mathrm{AC}$ content curves

- Optimum design data (AC content, $G_{m b}, G_{m m}, A V, V M A$ )

The IDOT QC/QA package program contains standardized IDOT MS Excel files that complete the calculations used to obtain the mix sublot test results. These files contain the following information for each of the two replicates used:

- Bulk Specific Gravity $\left(G_{m b}\right)$, per Illinois modified AASHTO T 166, sample weight for submerged and saturated surface dry conditions (SSD).

- Maximum Specific Gravity $\left(G_{m m}\right)$, per Illinois modified AASHTO T 209, sample and pycnometer weights at submerged and dry conditions.

- Mix Aggregate Gradation, per Illinois modified AASHTO T 30, raw weights and ignition oven calibration factors.

- Calculations for the AV, VMA, and dust/AC ratios.

The datalogger is the HMA plant computer record that stores the amount of material that entered the drum during the day of production. The plant computer system stores the cumulative weight (in tons) added for each aggregate, binder, and additive. Then, approximately every $6 \mathrm{~min}$, the computer system produces a printout that displays the cumulative tonnage. The datalogger allows for the calculation of the following information for the production day:

- Production speed

- Number of mixes produced/times mix design was changed

- Asphalt binder content

- Percentage of each aggregate stockpile

- Moisture content

- Recycled binder content

- Dust content 
In addition to the datalogger, the plant temperature charts and/or record were collected to observe the binder and mix temperature fluctuation through the production day.

\subsection{DATA ANALYSIS APPROACHES}

This section discusses the statistical tests used to compare and analyze district and contractor results: descriptive statistics, Mann-Whitney, Shapiro-Wilk, and Levene's test.

\subsubsection{Descriptive Statistics}

Three descriptive statistics parameters were used during the evaluation: mean, standard deviation, and coefficient of variation. Mean is a measure of central tendency. The population mean can be defined as the summation of the values of all random variables divided by their count. The exact population mean is a constant and a characteristic of the population that cannot realistically be obtained because all values of the population are not measured. Therefore, an unbiased estimate of the sample mean is given by the average of the samples defined in Equation (3.1).

$$
\bar{x}=\frac{\sum_{i=1}^{n} x_{i}}{n}
$$

where $\bar{x}$ is sample average and $n$ is sample size.

Standard deviation is a measure used to quantify data dispersion and variation. The standard deviation is the square root of the variance. As in the case of the mean, the standard deviation can also be a population standard deviation or a sample standard deviation. The best estimate of the population standard deviation is the sample standard deviation, defined in Equation (3.2):

$$
s=\sqrt{\frac{\sum_{i=1}^{n}\left(x_{i}-\bar{x}\right)^{2}}{n}}
$$

where $\mathrm{s}$ is sample standard deviation and $x_{i}$ is the value of $\mathrm{i}^{\text {th }}$ observation (sample).

Finally, the coefficient of variation is used as a standardized way to show variability. The coefficient of variation (COV), which is used in some parts of the report, is the standard deviation divided by the mean. It is usually used to normalize the spread of the data by the expected value of the data (the mean) as shown in Equation (3.3):

$$
\operatorname{COV}=\frac{s}{\bar{x}}
$$

\subsubsection{Hypothesis Testing}

Hypothesis testing was used to compare the sublot results from the QA (districts) and QC (contractors). Hypothesis tests evaluate the significance of the differences between the two parties' results or the chance at a prespecified level of significance. Non-parametric tests were used to analyze the data consistently because part of the case analysis did not satisfy parametric test 
assumptions. Unlike parametric tests, non-parametric tests do not require a (normal) distribution of the given data.

\subsubsection{Shapiro-Wilk Test}

The Shapiro-Wilk test (1965) is a test of whether a population with a given sample is normally distributed. This test is needed for two reasons. First, the PFP quality management specification assumes a normal distribution of the population samples. It fits a normal distribution to the given sample results to find the percent within limit (PWL) based on which pay factor is calculated. The second reason is to check whether parametric testing of the equality of the mean can be conducted (for both QCP and PFP), which has normality as a prerequisite. The test is qualitatively based on sorting the property test result by value, giving it a weight, and dividing it by the total deviation from the sample mean. The significance level $(\alpha)$ was taken as 0.05 . The null $\left(H_{0}\right)$ and alternative $\left(H_{a}\right)$ hypotheses of the test are as follows:

- $H_{0}$ : The sample belongs to a normal distribution.

- $H_{a}$ : The sample does not belong to a normal distribution.

The statistic used in this test is shown in Equation (3.4):

$$
W=\frac{\sum_{i=1}^{n}\left(a_{i} x_{(i)}\right)^{2}}{\sum_{i=1}^{n}\left(x_{i}-\bar{x}\right)^{2}}
$$

where, $W$ is Shapiro-Wilk statistic; $a_{i}$ is tabulated weights; $x_{(i)}$ is $i^{\text {th }}$ ordered random observations; $\bar{x}$ is mix contract property mean; and $x_{i}$ is $\mathrm{i}^{\text {th }}$ random observation.

For each Shapiro-Wilk test statistic, there is a corresponding p-value. A p-value is the probability of getting a false positive, or the probability of rejecting the null hypothesis (saying the data is not normally distributed) when it should not be rejected. Based on this p-value, the normality of the test is judged. If the $p$-value corresponding to the test statistic is smaller than the prespecified $\alpha$, then the distribution is said to be non-normal. Otherwise, it is said to be normal.

\subsubsection{Mann-Whitney Test}

The Mann-Whitney U-test is used to check whether two samples belong to similar distributions. The test is qualitatively based on dividing the test results to intervals, finding the rank of each interval between the two sides, and taking the smaller $U$ statistic (Equation 3.5) between the two sides. The null and alternative hypotheses can be stated as follows:

- $H_{0}$ : The two samples come from populations with the same distribution.

- $H_{a}$ : The two samples come from populations with different distributions.

The statistic used in this test is shown in Equation (3.5):

$$
U=n_{1} n_{2}+\frac{n_{2}\left(n_{2}+1\right)}{2}-\sum_{i=n_{1}+1}^{n_{2}} R_{i}
$$


where, $U$ is Mann-Whitney test statistic; $n_{1}$ is number of sublots in the first side's sample; $n_{2}$ is number of sublots in the second side's sample; and $R_{i}$ is rank of the interval based on the number of sublots.

For each $U$ statistic, there is a corresponding $p$-value. If this $p$-value is lower than $\alpha$, which was taken as 0.05 , then the averages of the two samples are said to be significantly different (Mann and Whitney, 1947). Figure 3.7 shows two samples, one with the same distribution (a) and one with different distributions (b).

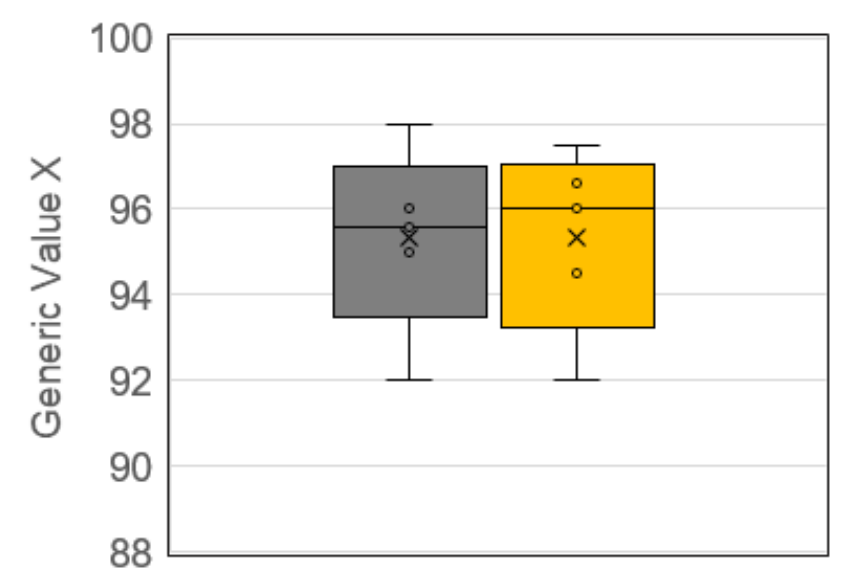

Not Significantly Different $(p>0.05)$

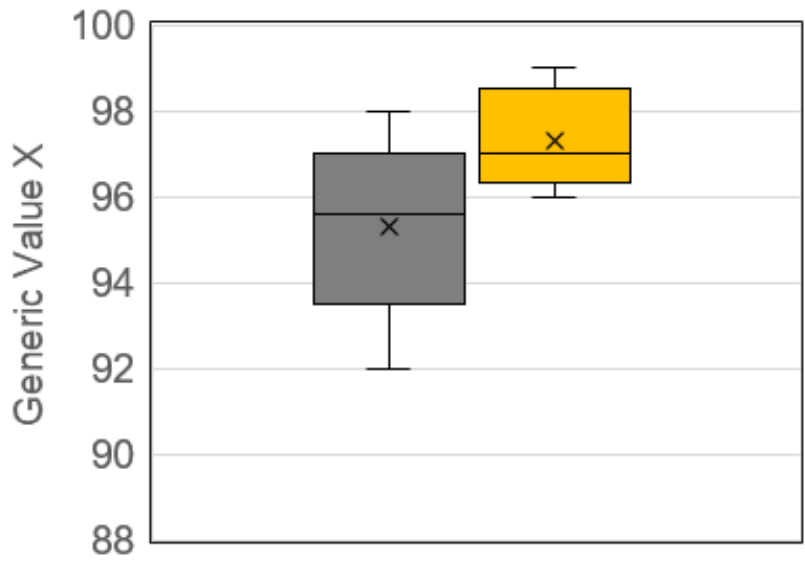

Significantly Different Case $(p<0.05)$

$\square$ District $\square$ Contractor

Figure 3.7. Mann-Whitney example cases.

\subsubsection{Levene's Test}

Levene's test is used to check the equality of the variances of two populations given samples from these distributions. The two goals of using this test are to evaluate if the two parties (the contractor and the agency) have the same precision for the test results and to know whether parametric testing of the mean, which requires the equality of variances, works. The null $\left(\mathrm{H}_{0}\right)$ and alternative $\left(\mathrm{H}_{\mathrm{a}}\right)$ hypotheses are as follows:

- $H_{0}$ : The two samples with the same variability.

- $H_{a}$ : The two samples with different variability.

The statistic used in this test is shown in Equation (3.6):

$$
W=\frac{N-k}{k-1} * \frac{\sum_{i=1}^{k} N_{i}\left(Z_{i .}-Z_{. .}\right)}{\sum_{i=1}^{k} \sum_{j=1}^{N_{i}} N_{i}\left(Z_{i j}-Z_{i .}\right)}
$$

where,

$W$ : Levene's test statistic; 
$k$ : The count of different groups from which the samples come;

$N_{i}$ : The count of cases in the $\mathrm{i}^{\text {th }}$ group;

$N$ : The total count of cases in all groups;

$Z_{i j}$ : The absolute difference between $Y_{\mathrm{ij}}$ and the mean or the median of group $\mathrm{i}$;

$Y_{i j}$ : The level of the $\mathrm{j}^{\text {th }}$ variable in the $\mathrm{i}^{\text {th }}$ group;

$Z_{i .}:$ The mean of $Z_{\mathrm{ij}}$ for group $\mathrm{i}$; and

$Z_{. .}:$The mean of all $Z_{\mathrm{ij}}$.

The groups compared in this project are district and contractor. There is a p-value corresponding to the calculated Levene's statistic. If this $p$-value is lower than the prespecified $\alpha$ (taken as 0.05 ), then the standard deviations are said to be significantly different. Otherwise, the standard deviations are said to be equal. Figure 3.8 shows two samples, a case with the same variability (a) and a case with different variability (b).
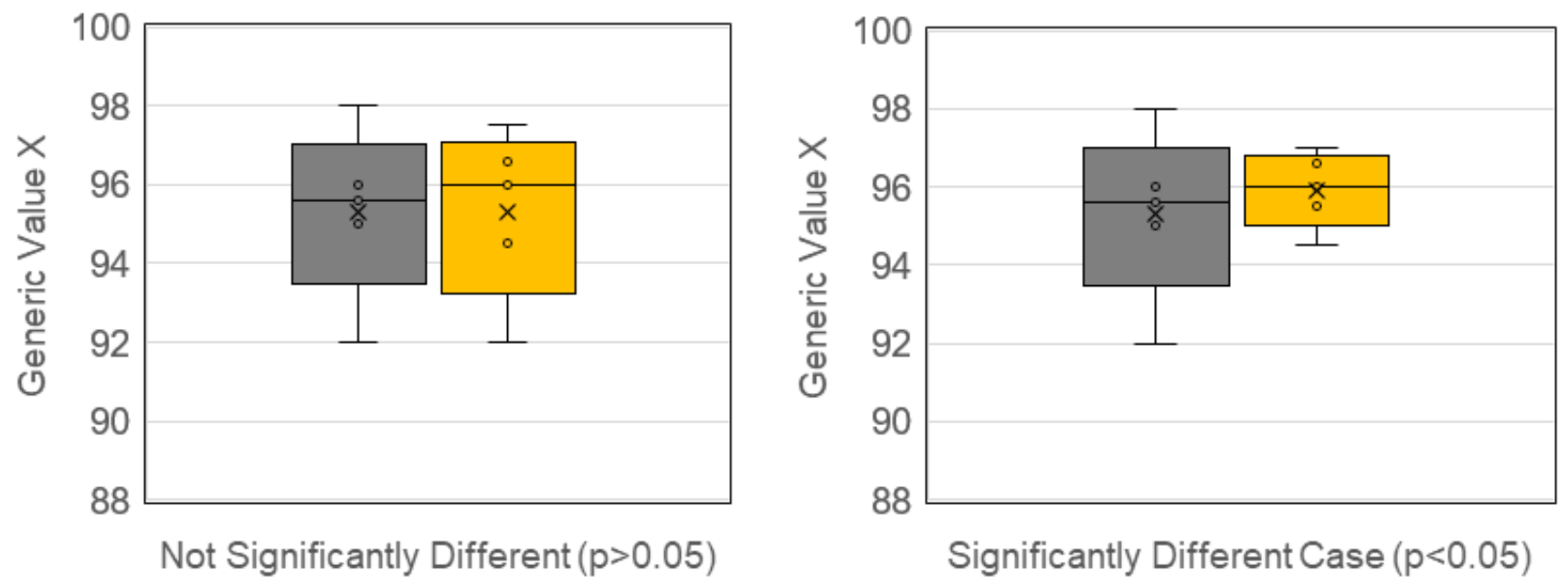

$\square$ District $\square$ Contractor

(a)

(b)

Figure 3.8. Levene's test example cases. 


\section{CHAPTER 4: DATA ANALYSIS RESULTS}

This chapter presents a summary and a discussion of collected data from the districts and statistical analysis results. Pay factor trends are presented to identify which pay factors generated pay incentives and disincentives for the QCP and PFP specifications. Mix sublot volumetric test results and core densities are discussed. Data results were analyzed to identify differences between district and contractor test results. To identify potential mix production issues, aggregate gradations were evaluated. CBM results of PFP disputed sublots were compared to better understand the source of variation. To identify potential issues with laboratory testing, IDOT round robin test results were evaluated.

\subsection{PAY FACTOR TRENDS}

General trends in QCP and PFP specifications were evaluated in the pay factor analysis. The total tonnage is presented to provide distribution of pay factors with respect to specification type and size in various districts for different production seasons. The composite pay factor (CPF) was evaluated to identify differences between the QCP and PFP specifications and among district's pay performance. The pay factors for AV, VMA, and density are grouped per specification and mix type.

\subsubsection{Specification Size}

A total of 595 mix contract cases were recorded between 2015 and 2017 in the QCP specification while 115 were received for the PFP specification. These cases accumulated to 3,255,000 tons and 2,690,000 tons of HMA produced for QCP and PFP, respectively. Hence, QCP and PFP specifications have comparable total produced HMA tonnage sizes from 2015 to 2017. This represents an average of 5,470 tons per QCP mixture and 23,391 tons per PFP mixture. This is expected because QCP is meant for less than 8,000 tons, whereas PFP is meant for more than 8,000 tons.

The total tonnage for both specifications is presented per district in Figure 4.1. District 1, which covers Chicago's metro area with a total of 1,657 mi of state highways (IDOT, 2018c), had the highest production. Districts 2, 9, and 6 followed, with a similar share of tonnage that ranged between $13 \%$ to $20 \%$. District 2 covers the Quad Cities metro area, I-88, I-80, and I-74, with a total of 671 mi of state highways (IDOT, 2018c). District 9 covers I-57 and I-24, with a total of 532 mi of state highways (IDOT, 2018c). District 6 covers Springfield, with a total of $830 \mathrm{mi}$ (IDOT, 2018c). Districts 5 and 8 had the smallest amount of total HMA production. Finally, Districts 5 and 8 have a total of 548 and $774 \mathrm{mi}$ of state highways, respectively (IDOT, 2018c).

Figure 4.2 shows the number of mix contract cases per contractor. Forty-two contractors produced mixes using QCP while 22 produced mixes with PFP. Sixteen contractors had contracts in District 1 , seven in District 2, three in District 5, five in District 6, eight in District 8, and three in District 9. Contractors have more experience working with QCP projects than PFP projects. Out of the 22 contractors working with PFP cases, 11 had fewer than five PFP cases during the last three years, because there are fewer PFP projects available for bidding. This results in contractors who are less experienced in designing, producing, and constructing mixes under PFP requirements, including the statistical principles used to evaluate their mixes when calculating the pay factor. There are 
contractors that achieve at least $100 \%$ pay for most of the executed contracts while other contractors achieve the opposite. Both cases were observed in all districts.

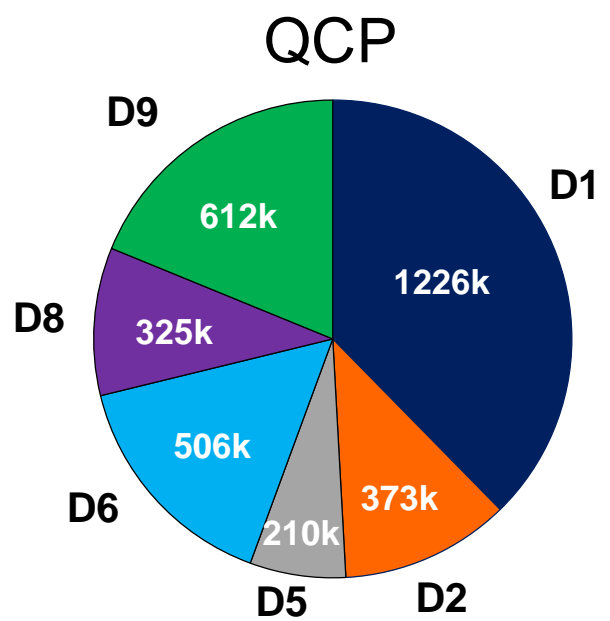

(a)

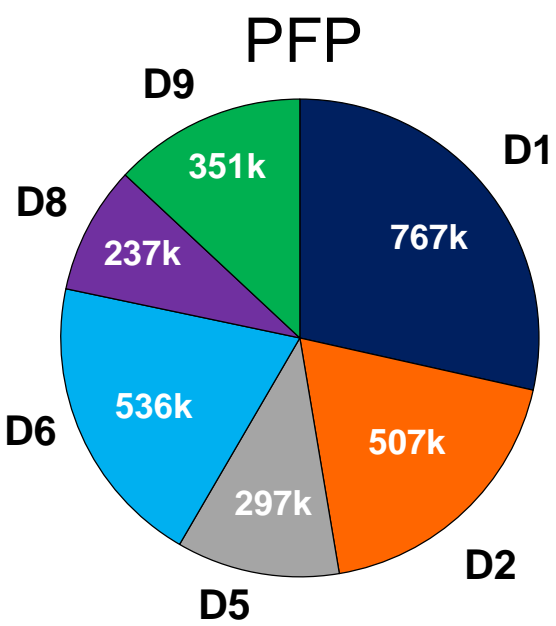

(b)

Figure 4.1. District HMA production size for (a) QCP and (b) PFP specifications from 2015 to 2017.

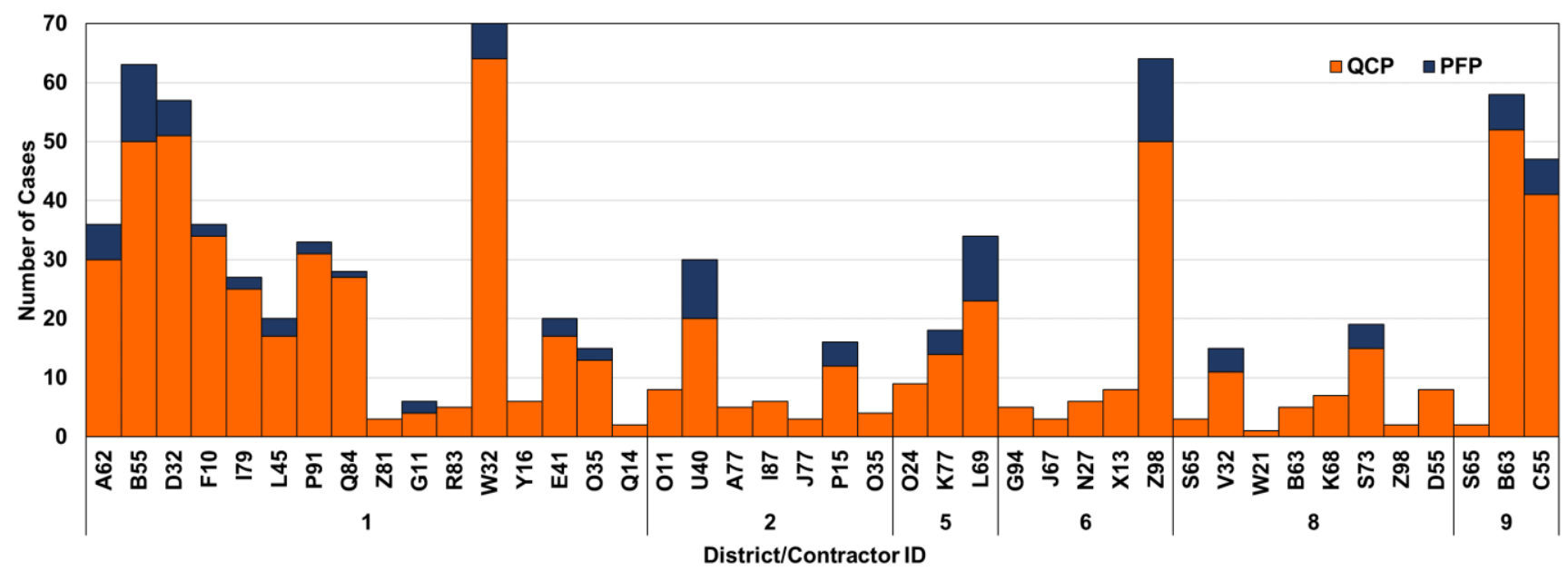

Figure 4.2. Cases recorded per contractor by IDOT's QCP and PFP specifications from 2015 to 2017 (random IDs indicate different contractors).

\subsubsection{Composite Pay Factor}

Figure 4.3 presents the CPF for both QCP and PFP specifications from 2015 to 2017. For QCP, only $45 \%$ of the total tonnage received full pay. Most of the pay disincentives led to a total combined pay factor of $97.5 \%$ to $99.9 \%$ for $46 \%$ of the tonnage (close to full pay). Only $9 \%$ of the projects had a total combined factor pay lower than $97.4 \%$. For PFP, $54 \%$ of the tonnage received a bonus while $44 \%$ of the tonnage resulted in pay disincentives. On the other hand, only $4 \%$ of PFP production had a total pay lower than $90 \%$. Hence, it appears that QCP projects have less probability of receiving a high pay disincentive, which is expected because QCP has a maximum disincentive of $10 \%$. Conversely, for PFP projects, a contractor has more odds of receiving a pay disincentive, for which they are compensated 
by having a chance to get a pay incentive that is not available in QCP. In general, PFP is a stricter specification than QCP because PFP considers variability in the pay calculation. For example, if sublot results are within the upper and lower limits for $100 \%$ pay in QCP, they achieve $100 \%$ pay. However, in PFP, even if the test results are within the lower and upper limits, the pay factor depends on the variability of the results. This is because contractor pay is calculated based on the t-distribution that was fit to the results of the sublot. In QCP, the pay is computed based only on the sublot results.

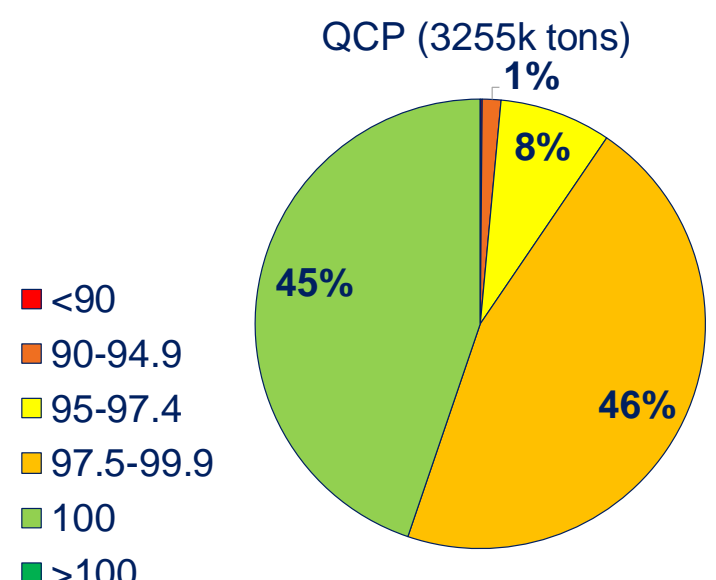

(a)

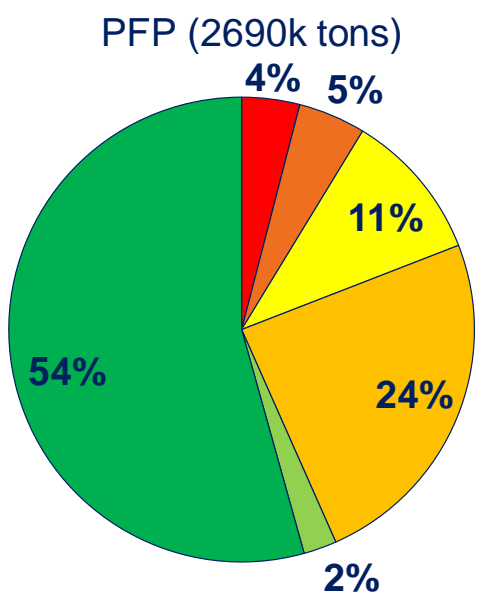

(b)

Figure 4.3. Distribution of CPF for IDOT's (a) QCP and (b) PFP specifications from 2015 to 2017.

To understand yearly variations in each specification's total pay, the CPF is presented per year and per specification in Figure 4.4. For QCP, the production receiving full pay has increased from $34.1 \%$ in 2015 to 61\% in 2017, indicating that contractors have improved their performance in the QCP specification during that time. For PFP, the percentage of the tonnage that received a pay incentive or full pay decreased from $65.9 \%$ to $45.1 \%$. This could be related to the greater number of QCP projects and contractors' growing experience working under this specification. Note that no changes were made to QCP or PFP pay factor calculations for the studied data over this time period.

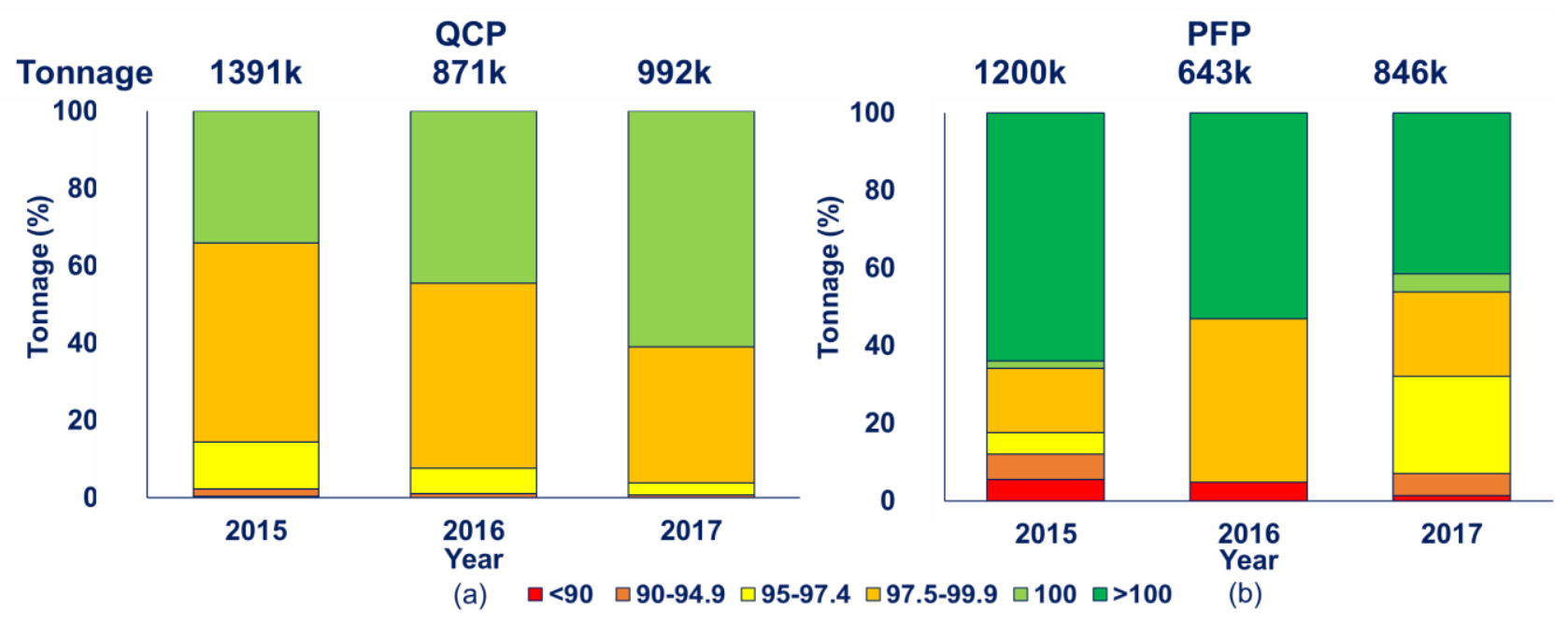

Figure 4.4. Distribution of pay factors for IDOT's (a) QCP and (b) PFP specifications from 2015 to 2017. 
Districts 5 and 6 have higher pay performance than the rest of the districts in both QCP and PFP specifications (Figure 4.5). The production in these districts received full pay or a pay incentive between $70 \%$ to $100 \%$ of the total tonnage. On the other hand, District 2 had the most pay disincentives in QCP. Only 17.3\% of the total tonnage received full pay. For PFP, Districts 1 and 9 received the most pay disincentives in the specification. Less than $40 \%$ of their projects achieved full pay or a bonus.

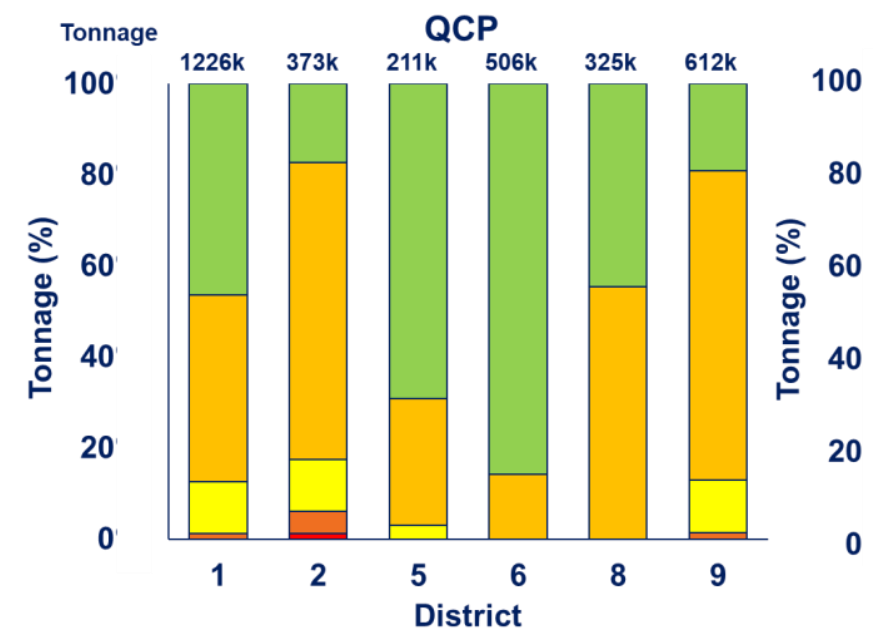

(a) $\square<90 \quad \square 90-94.9 \square 95-97.4 \square 97.5-99.9 \square 100 \square>100$

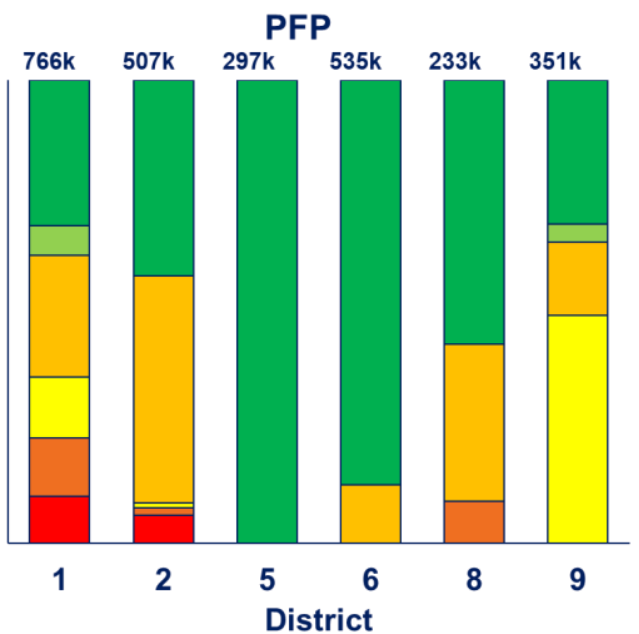

(b)

Figure 4.5. Pay factors per district for IDOT's (a) QCP and (b) PFP specifications from 2015 to 2017.

\subsubsection{Air Voids, Voids in Mineral Aggregates, and Density Pay Factors}

As discussed in Chapter 2, the CPF is based on AV, VMA, and density pay factors, some of which influence pay reduction more than others. Figure 4.6 presents the total tonnage for the QCP and PFP specifications and the corresponding $A V, V M A$, and density pay factors. For the QCP specification, the influence of $A V, V M A$, and density was similar. Based on AV, VMA, and density, $67.8 \%$ to $72 \%$ of the tonnage produced received full pay. However, for the PFP specification, density has the lowest average pay factor. Less than $44 \%$ of the PFP production received at least $100 \%$ payment for density, followed by AV and VMA.

Note that there are projects that received less than $100 \%$ pay in AV and full pay in VMA. This could be attributed to the fact that $A V$ has more variability than VMA. The testing variability of $G_{m b}$ and $G_{m m}$ could affect AV while only the $G_{m b}$ test affects VMA (as well as the binder content, which is used to compute the percentage of stone). Another possible reason for these changes is a mix switch; aggregate gradation might be controlled during production but not the binder content (as discussed in section 5.4.4: Mix Switches). As a result, the VMA (an indicator of the aggregate structure) meets the requirements, while the $\mathrm{AV}$, which is affected by binder content, may not. The absorption of the aggregates could also have differed because of reheating conditions.

The sublot test results used to calculate the pay factors in Figure 4.6 were evaluated to observe if the penalties were due to a failure in achieving the lower limit (LL) or upper limit (UL) of the QCP and PFP specification for $100 \%$ pay. Figure 4.7 presents the results for QCP and PFP cases. The limits used for 
QCP are lower limits to achieve $90 \%$ pay for the respective volumetric. For PFP, there is only one upper limit and one lower limit for each volumetric parameter and the results are shown taking these limits into account. Figure 4.7 shows similar trends between QCP and PFP.

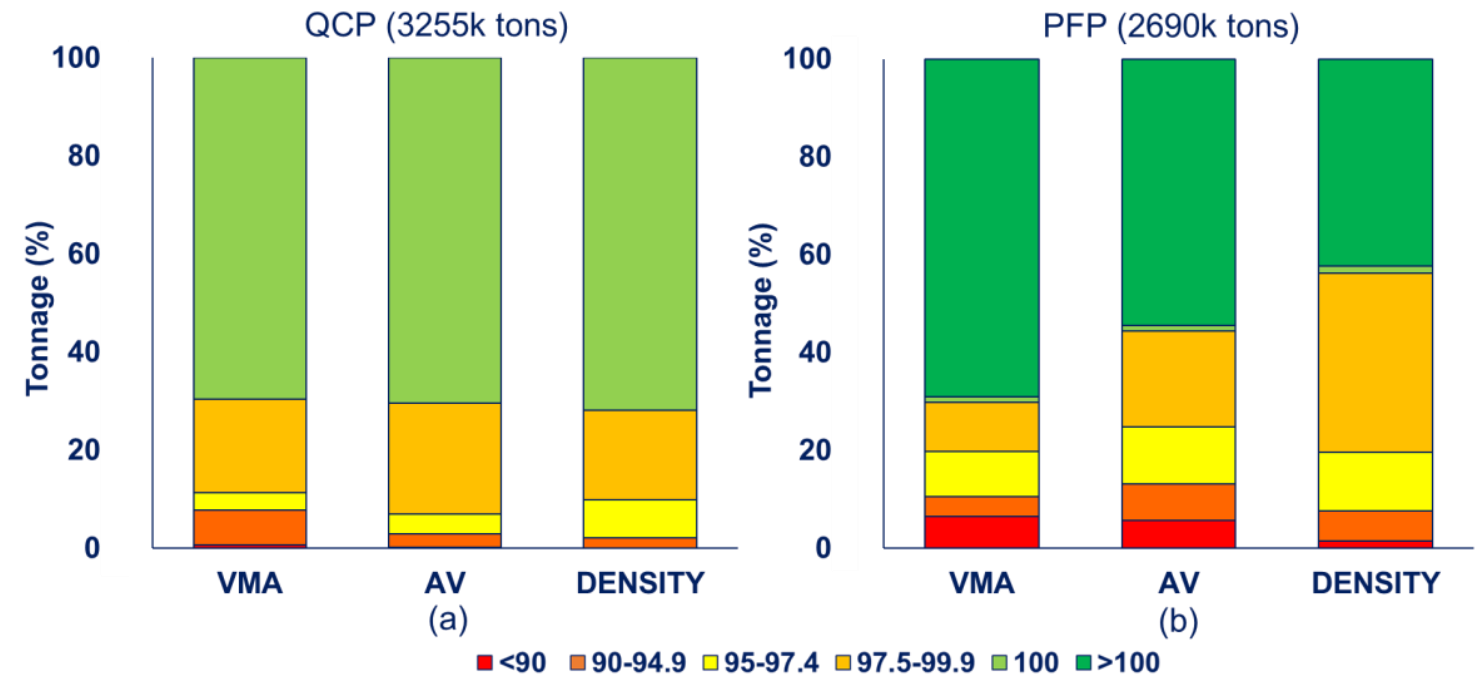

Figure 4.6. Pay factors per pay parameter for IDOT's (a) QCP and (b) PFP specifications from 2015-2017.

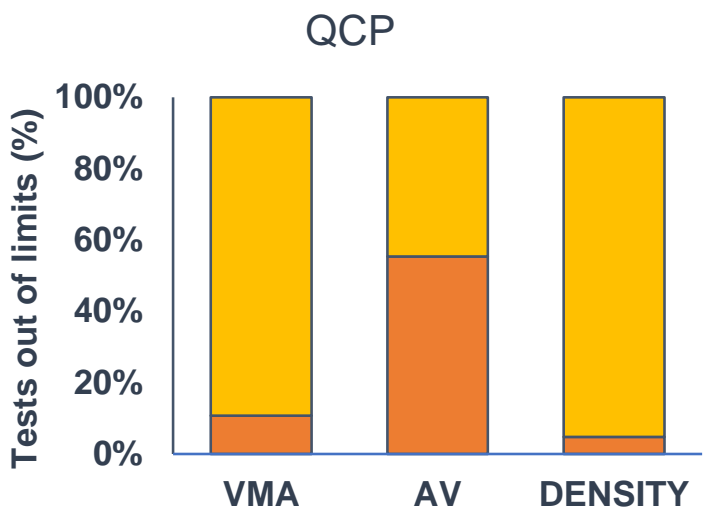

(a) $\square$ UL $\square$ LL

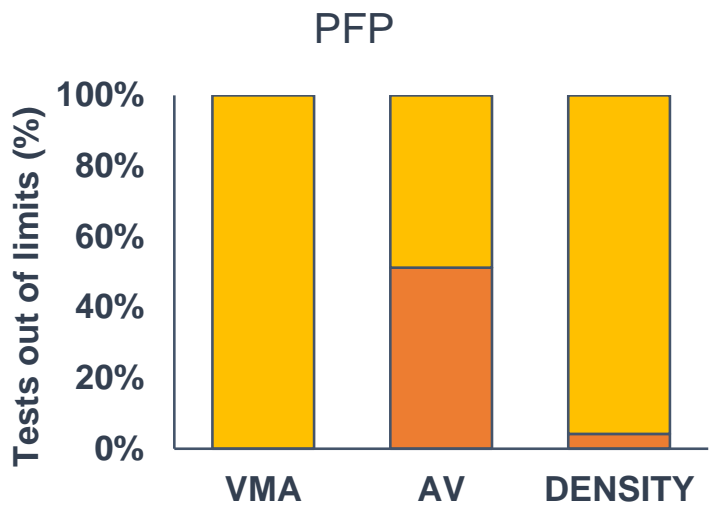

(b) $\square$ UL $\square$ LL

Figure 4.7. Disincentivized sublots were classified by failing the upper or lower limit of either the QCP or PFP specification.

Tests out of limits for AV were evenly distributed, which is expected for random deviations induced by variability. Tests out of limits for VMA tended to be under the lower limit, i.e., the disincentives on the VMA PF were usually due to producing under the specified VMA. This would be expected because increasing the VMA for fixed aggregate sources and gradations, without altering AV significantly, requires adding more asphalt binder, which is the most expensive component of HMA. Tests out of limits for density tended to be under the lower limit, i.e., the disincentives were associated with not achieving HMA within-limits density (assuming all tests were accurate). This could be related to fieldencountered difficulties and/or mix production. 
For all considered mix-contract cases, $15.6 \%$ of the cases had a density disincentive (density PF $<100$ ) only. This suggests the disincentive is related to the construction phase. Of the cases that had a density disincentive, $52.7 \%$ also had an AV or VMA disincentive (AV PF $<100$ or VMA PF < 100). In these cases, a density disincentive could potentially had been caused by a mix production issue.

\subsubsection{Effect of Mix Type}

The CPF (described in section 2.2: Illinois Quality Management Program (QMP) for both QCP and PFP specifications is grouped by mix type in Figure 4.8. IDOT has three main mix categories: leveling binder (LB), binder course (BC), and surface course (SC). LBs are typically fine-graded mixes used in resurfacing projects to level milled surfaces before a SC is applied. The BC is a structural layer. The SC is the wearing layer that mainly provides the needed friction and skid resistance. Figure 4.8 shows that LB was the most-penalized mix (31.5\% received full pay) in the QCP specification, while $47.65 \%$ of the SC received at least $100 \%$ pay. The performance of SC mixes in QCP and PFP was comparable. SC mixes received full pay in $49 \%$ of the cases in QCP while $47.65 \%$ in PFP received at least $100 \%$ pay for SC mixes. BC pay performance in PFP was better than that in QCP: $70.6 \%$ received at least $100 \%$ pay in PFP and $43 \%$ received full pay in QCP.

Figure 4.9 shows the AV, VMA, and density pay factors per mix type. As expected, LB density had the highest impact because of difficulties in achieving density in thin LB layers that have a low NMAS/thickness ratio. In addition, LB is laid as the first lift after milling (on irregular surface). For example, approximately $68 \%$ of the LB $4.75 \mathrm{~mm}$ mix tonnage received a density PF of $100 \%$ compared to $35 \%$ of the tonnage of the LB $9.5 \mathrm{~mm}$ mix. For BC and SC constructed in QCP, the three pay factors had a similar effect on the total pay. However, density was the driving factor in the pay loss in PFP. In $\mathrm{BC}$, it was the main reason for pay loss and the second in SC; AV was the main factor in the SC layer.

AV is more penalized than VMA in the PFP specification because of the former's higher variance. Variance influences the pay factor because of the PWL calculation. Figure 4.10 presents the density pay factor per NMAS for the three mix types. IDOT uses four NMAS in the mixes: $4.75 \mathrm{~mm}, 9.5 \mathrm{~mm}$, $12.5 \mathrm{~mm}$, and $19 \mathrm{~mm}$.
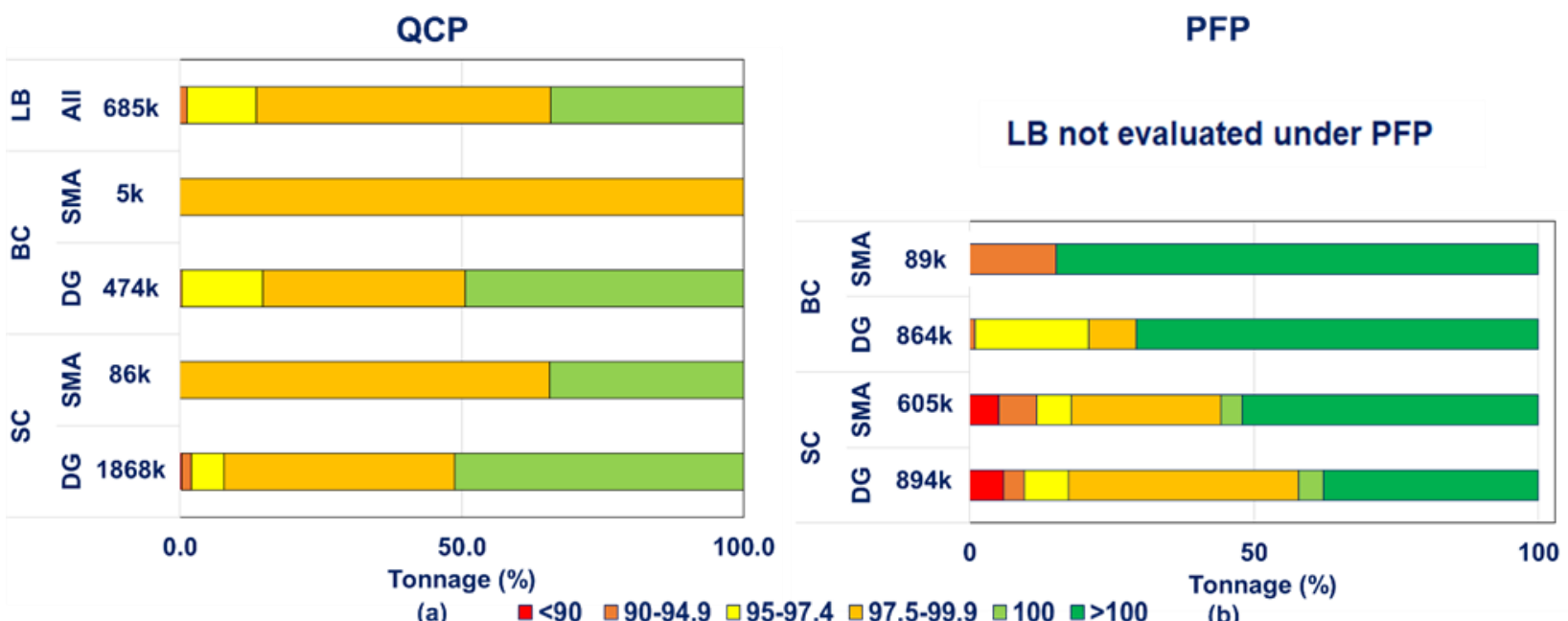

(a) $\quad \square<90 \quad \square 90-94.9 \square 95-97.4 \square 97.5-99.9 \square 100 \square>100$

(b)

Figure 4.8. Pay factors per AC layer type for IDOT's (a) QCP and (b) PFP specifications from 2015-2017. 


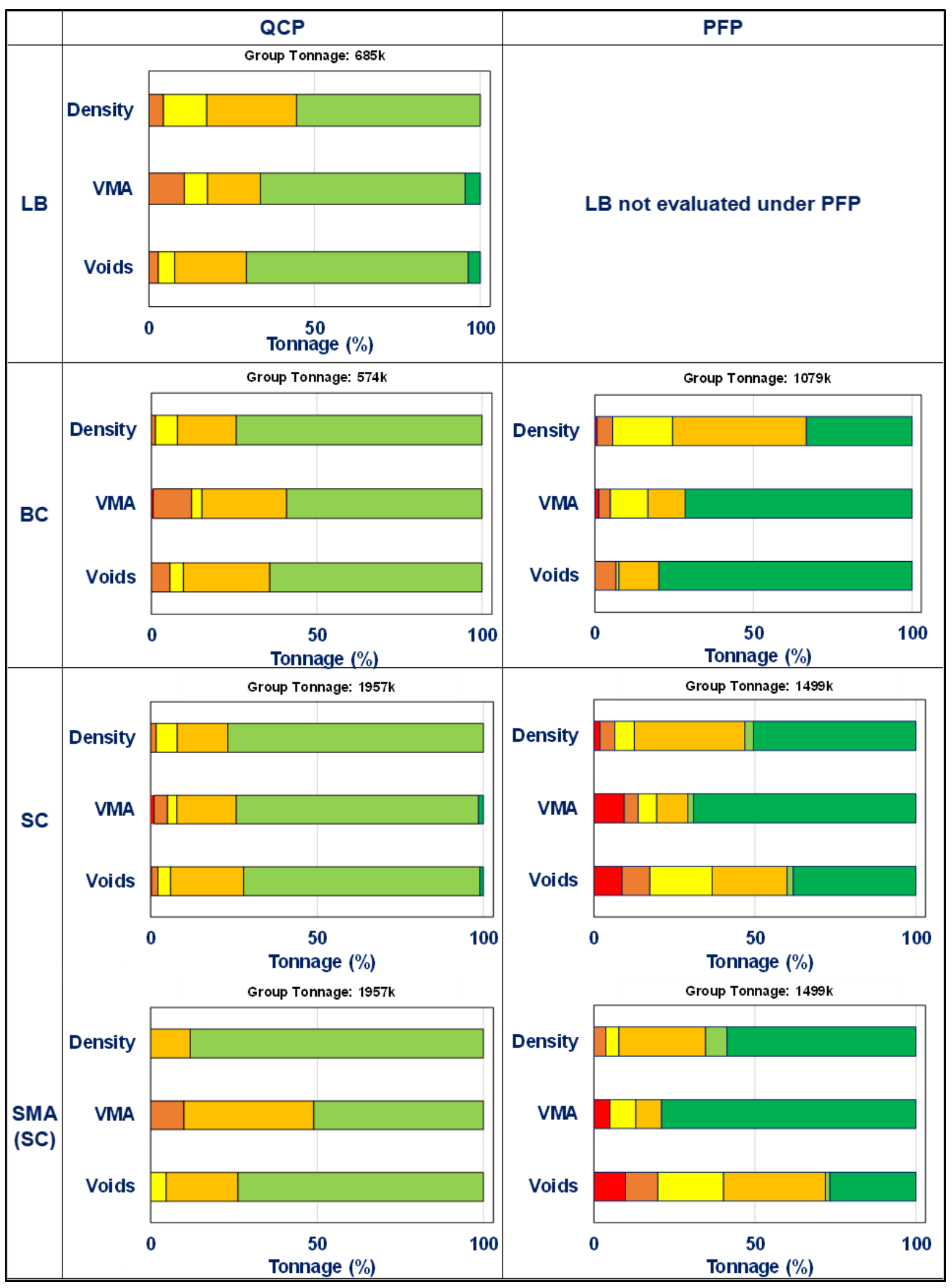

Figure 4.9. Pay factors per pay parameter for SC, BC, and LB mixes for IDOT'S QCP and PFP specifications from 2015 to 2017. 


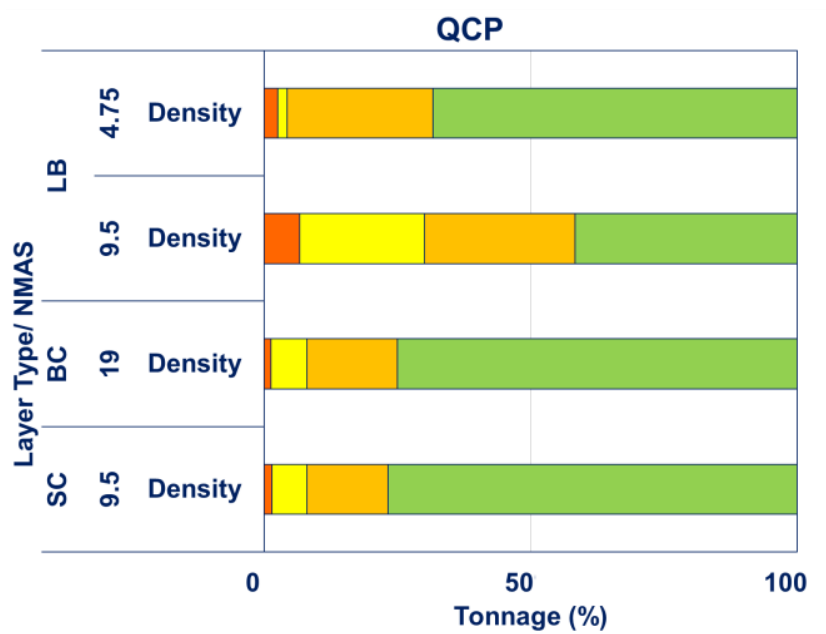

(a) $\square<90 \quad \square 90-94.9 \square 95-97.4 \square 97.5-99.9 \square 100 \square>100$

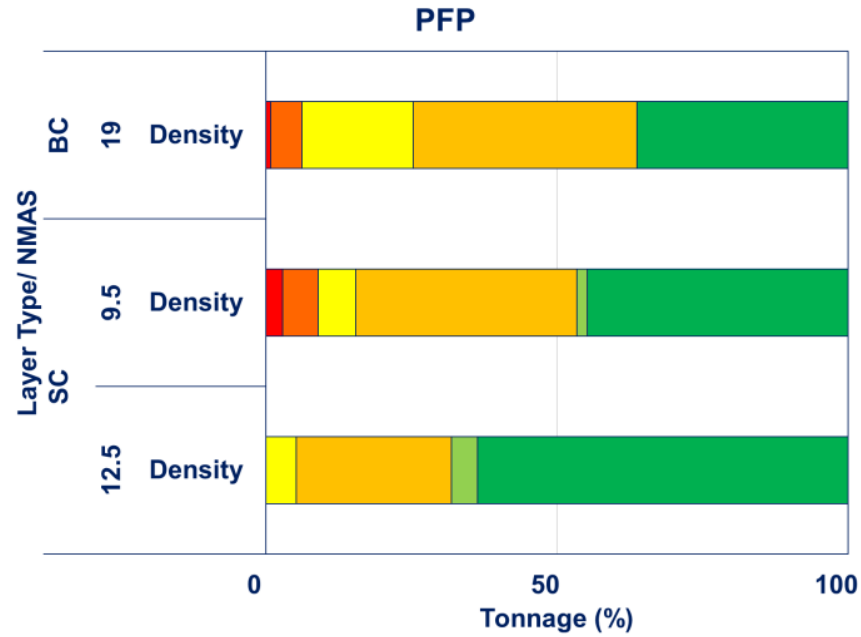

(b)

Figure 4.10. Density pay factors per course type for IDOT's (a) QCP and (b) PFP specifications from 2015 to 2017.

\subsubsection{PFP CPF Equation Revision}

On June 28, 2017, IDOT modified the PFP CPF pay equation (IDOT, 2018c) to the current one (Equation 2.1). The previous equation was the following:

$$
\text { Pay Factor }=53+0.5(P W L)
$$

where Pay Factor (PF) is defined and calculated for each pay parameter. The change between Equation 2.1 and 4.1 was a $2 \%$ increase in the $\mathrm{AV}, \mathrm{VMA}$, and density pay factors. The change was considered to increase the pay of contractors to make the specification more achievable to get at least $100 \%$ pay.

The pay factors for all the contracts analyzed in this study were calculated using Equation 4.1. Analysis was performed using Equation 2.1 to estimate the impact of the specification change. Hence, the pay factors obtained from 2015-2017 were adjusted according to the new specification and recalculated using Equation 2.1 (2018c).

Figure 4.11 shows the distribution of the pay factors recalculated using Equation 2.1. Overall, the pay incentive amount (PF > 100) increases from 54\% to 76\% (Figure 4.11 [a]). In Figure 4.11 (b) the increment would have most impacted the pay of contractors in Districts 1, 2, and 9, which were the most impacted by the pay disincentives. In addition, the density pay, which was most impacted by the PFP specification, would benefit the most (Figure 4.11 [d]) if the change would have been implemented in 2015. In summary, a fixed increment of $2 \%$ for each pay factor roughly translated to an overall increase in the total pay of each mix contract. 


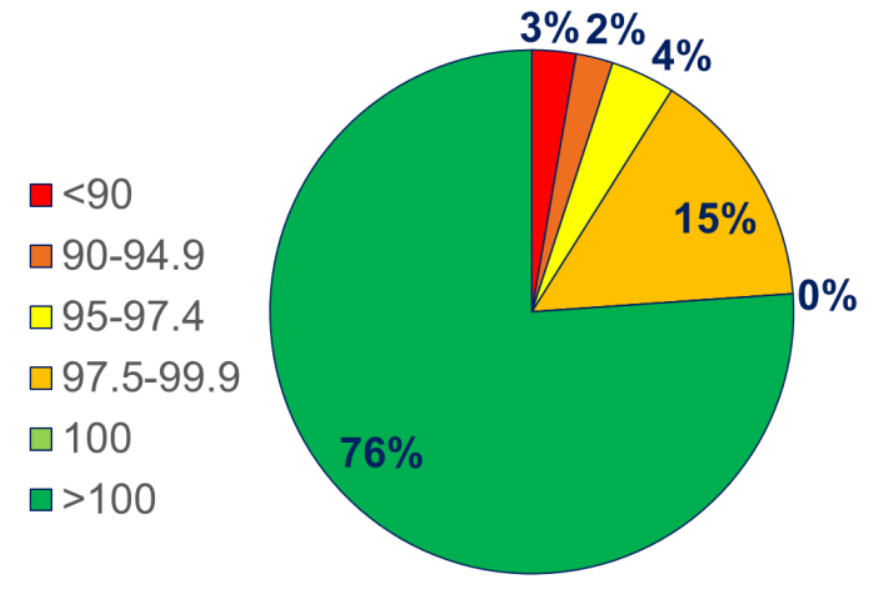

(a)

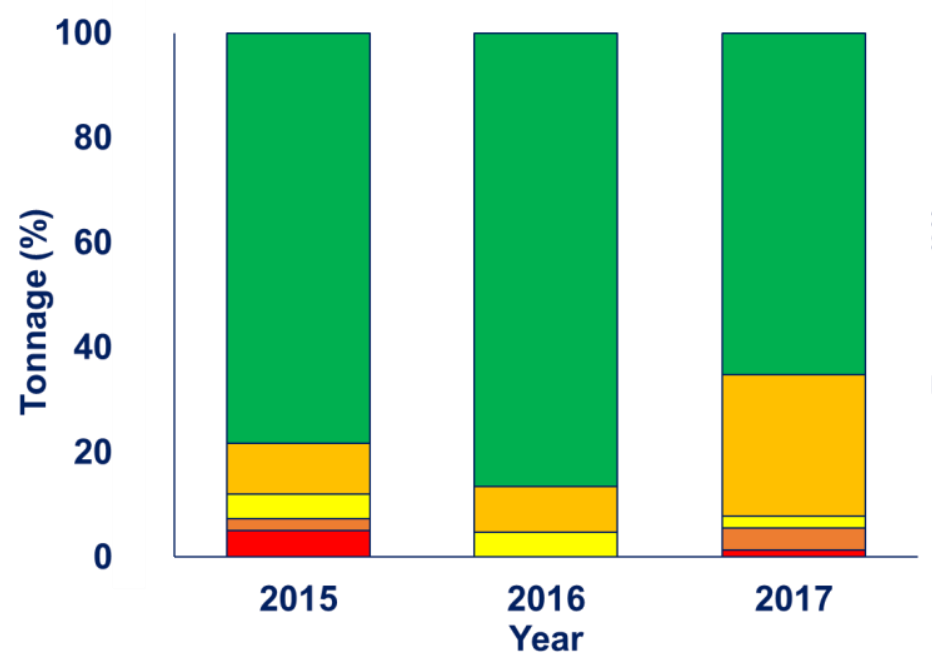

(c)

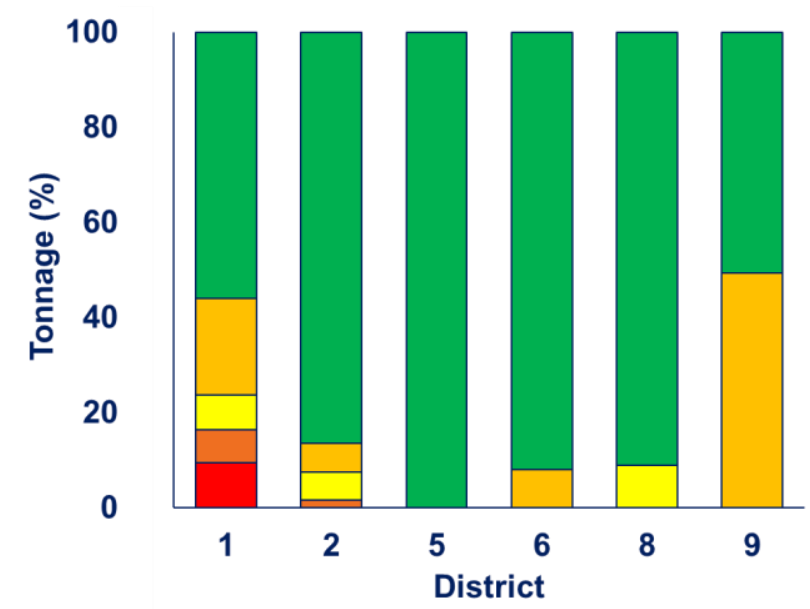

(b)

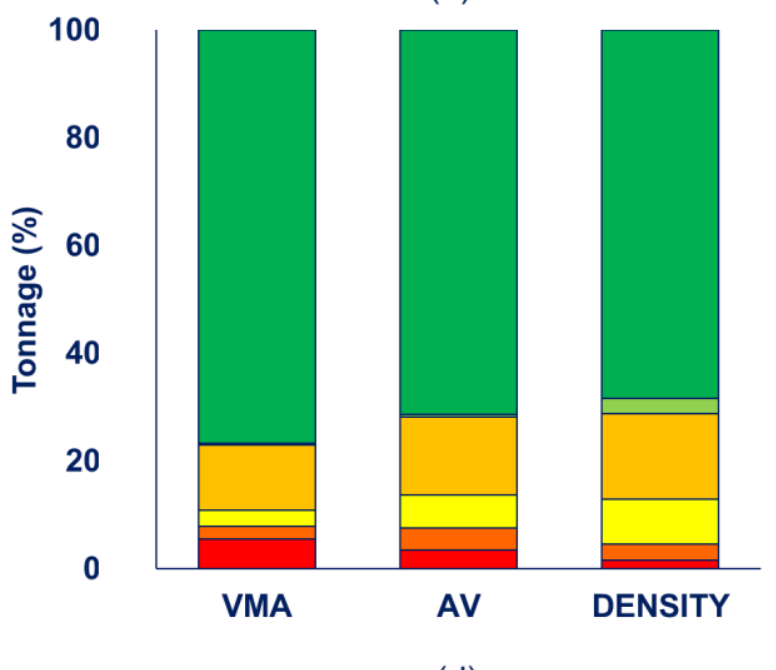

(d)

Figure 4.11. Distribution of CPF and pay parameters for PFP specifications from 2015 to 2017 recalculated with 2017 pay factor equation: (a) statewide, (b) district, (c) yearly, and (d) per pay parameter.

\subsection{PAY PARAMETERS (AV, VMA, DENSITY) RESULTS}

This section presents the results of statistical testing including Shapiro-Wilk, Mann-Whitney, and Levene's tests for pay parameters. The mix pay parameters are AV, VMA, and density, which are directly used to calculate the pay factors. The differences in the mean and standard deviation between the contractor and district mix test results are presented.

\subsubsection{Normality}

Prior to performing any statistical tests, the Shapiro-Wilk test was used for a normality check to select appropriate hypothesis testing: parametric or non-parametric (Figure 4.12). If the p-value of the test is greater than 0.05 , then the sample's population is normally distributed. This is an assumption used by the PFP specification. From 590 cases, 9\% (PFP, district data) to 18\% (PFP, contractor data) of the 
cases have p-values lower than 0.05 for AV. However, 13\% (PFP, district data) to $21 \%$ (PFP, contractor data) of VMA have $p$-values lower than 0.05 . Hence, most cases appear to follow a normal distribution for AV and VMA, as previously stated by Hall and Williams (2002). Note that the cases with a few sublot replicates failed the Shapiro-Wilk test.

For density, 560 cases were tested; $23 \%$ to $29 \%$ of the cases have p-values lower than 0.05 in QCP, which are slightly greater than the AV and VMA p-values. However, for PFP, $56 \%$ to $57 \%$ of district and contractor results do not follow the normal distribution. Density in PFP failed the normality assumption regardless of the sample size. Figure 4.13 (a) and (b) illustrates two samples that fail and pass the Shapiro-Wilk test, respectively. The case that fails the Shapiro-Wilk test shows skewness: the tail in the test result distribution extends longer to a lower density value. On the other hand, the passing case shows both tails are evenly distributed. Because a large number of Shapiro-Wilk test results suggest sample populations are not normally distributed, a non-parametric test was selected to compare the tests from districts and contractors.

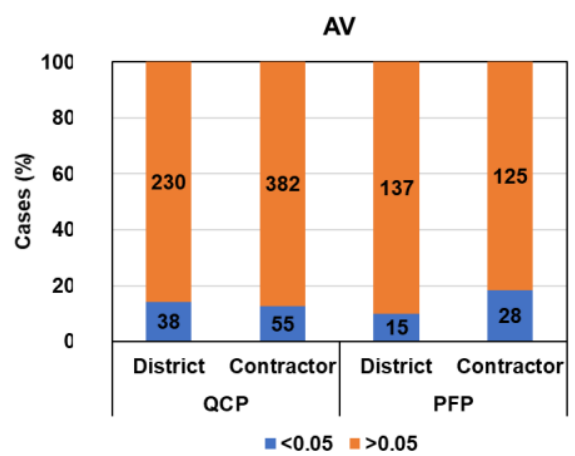

(a)

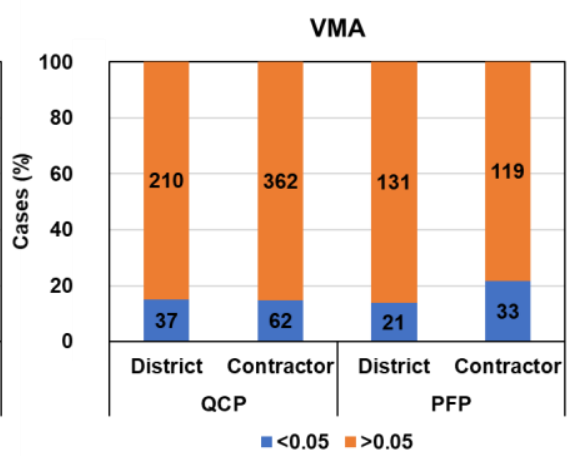

(b)

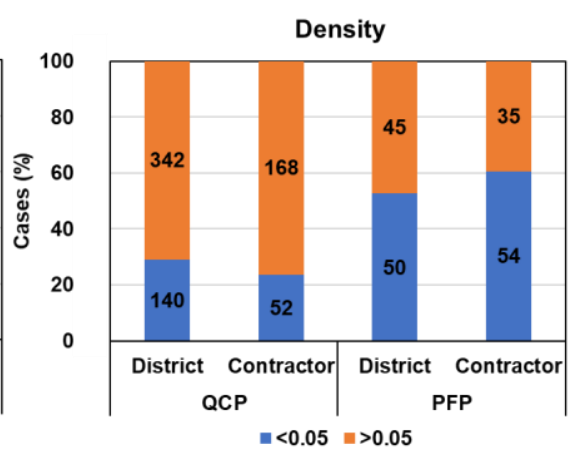

(c)

Figure 4.12. Shapiro-Wilk normality test results for (a) AV, (b) VMA, and (c) density.

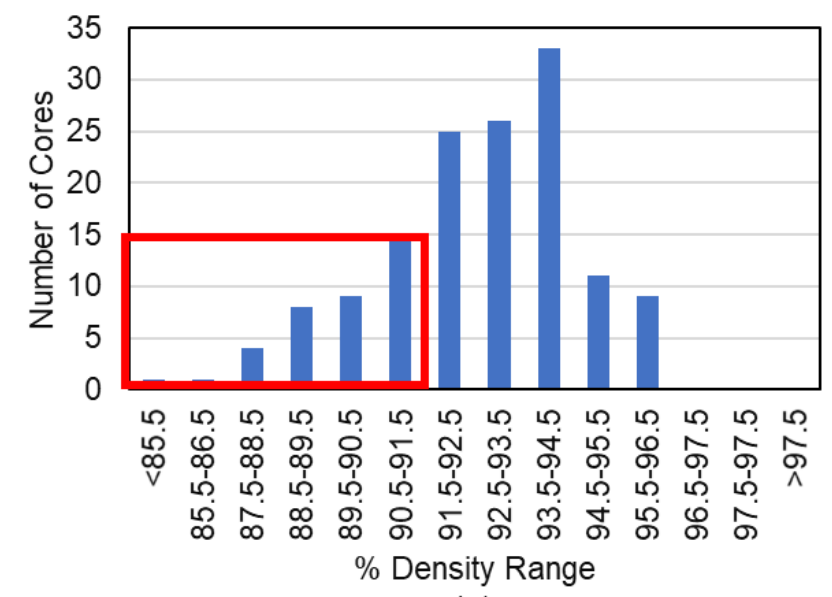

(a)

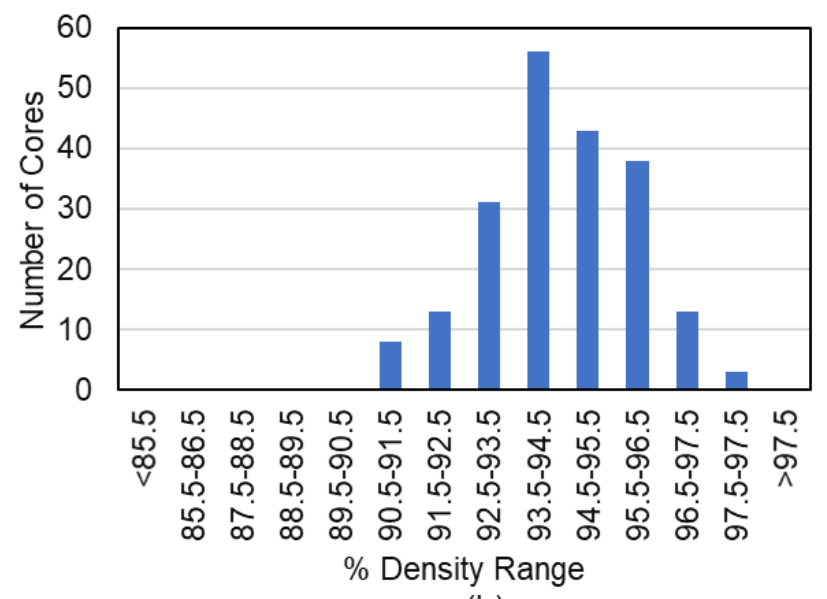

(b)

Figure 4.13. Example of a SC N90 9.5 NMAS density cases for (a) non-normally distributed $(p<0.05)$ and (b) normally distributed $(p>0.05)$. 


\subsubsection{Pay Parameter Results}

The statewide distribution of the pay parameter results per sublot are presented for $\mathrm{LB}, \mathrm{BC}$, and $\mathrm{SC}$ mixes in Figures 4.14, 4.15, and 4.16, respectively, for QCP and PFP specifications. The results for each mix type are presented per NMAS. In Illinois, LB is designed using $9.5 \mathrm{~mm}$ or $4.75 \mathrm{~mm}$ NMAS, BC uses $19 \mathrm{~mm}$ or $12.5 \mathrm{~mm}$ (for SMA), while SC uses $9.5 \mathrm{~mm}$ or $12.5 \mathrm{~mm}$ (for SMA). For LB mixes, Figure 4.14 (a) presents the minimum design $\mathrm{VMA}$, design $\mathrm{AV}$, and the total number of sublots per mix type used to calculate the distribution of $A V, V M A$, and density. Figure 4.14 (b) shows the AV results for each of the two NMASs. Figure 4.14 (c) presents the deviation from the minimum VMA per Equation (4.2). The pay disincentive is based on the deviation from the minimum VMA. Finally, the density results are shown in Figure 4.14 (d). Similarly, other layers are presented in the corresponding figures.

$$
\text { Deviation from Min VMA }=V M A_{\text {sublot }}-V M A_{M i n}
$$

where $V M A_{\text {design }}$ is the design VMA, $V M A_{\text {sublot }}$ is the sublot VMA, and $V M A_{M i n}$ is the minimum design VMA.

\begin{tabular}{|c|c|c|}
\hline Type & LB & LB \\
\hline NMAS & $9.5 \mathrm{FG}$ & 4.75 \\
\hline Target AV & 4.0 & $4.0(3.5$ in D1) \\
\hline Min VMA & 15.0 & 18.5 \\
\hline Mix Sub-Lots & 442 & 877 \\
\hline Density Sub-Lots & 1783 & 9084 \\
\hline
\end{tabular}

(a)

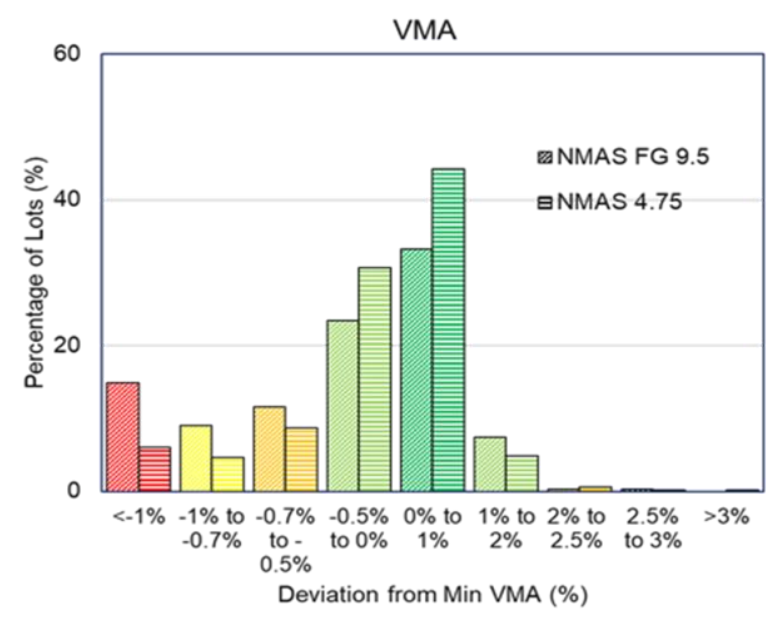

(c)

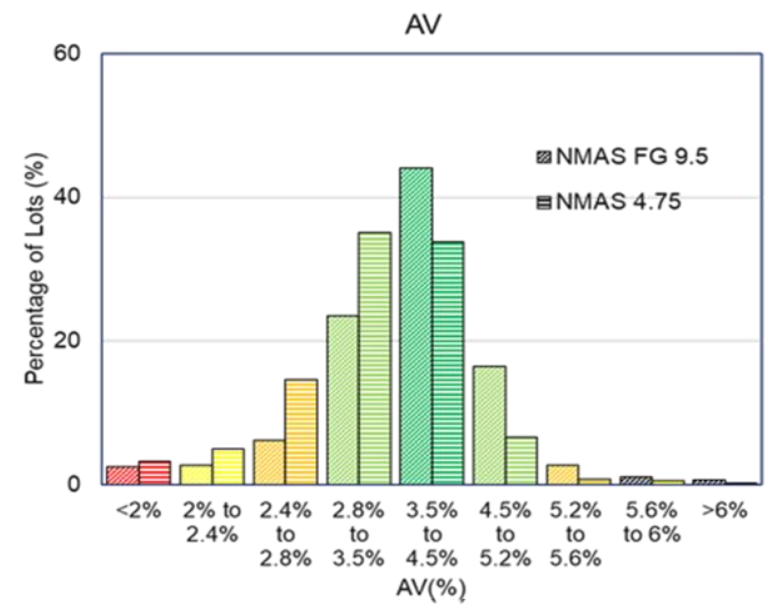

(b)

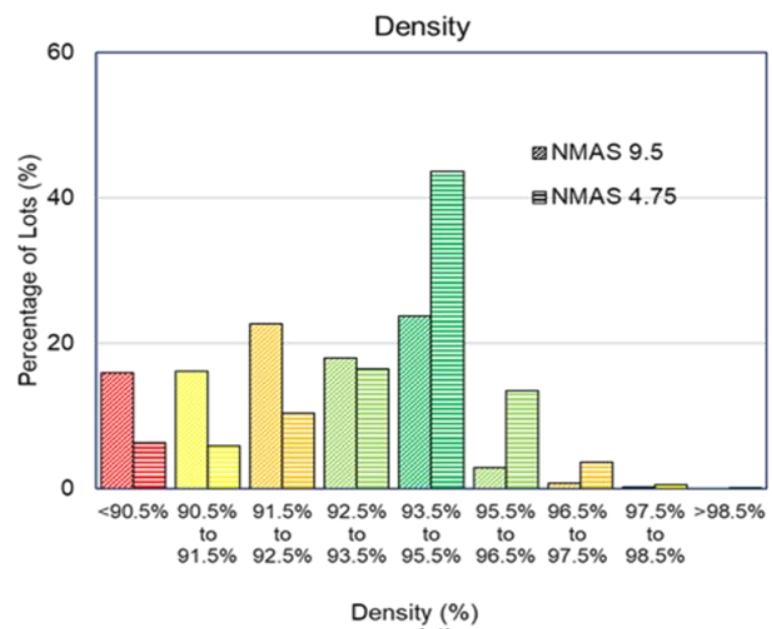

(d)

Figure 4.14. Pay parameter results for LB mixes. 
From Figure 4.14, AV results in the fewest pay disincentives (less than 5\%). Approximately $11.3 \%$ of the LB 9.5 mm FG NMAS sublots were lower than 2.8\%, and $22.9 \%$ of the LB $4.75 \mathrm{~mm}$ NMAS sublots were lower than $2.8 \%$. The rest of the sublots were within $2.8 \%$ to $5.2 \%$ AV. The LB $9.5 \mathrm{~mm}$ FG mixes failed VMA more than $4.75 \mathrm{~mm}$ NMAS mixes. Of the LB $9.5 \mathrm{~mm}$ sublots, $35.4 \%$ had VMA at least $0.5 \%$ lower than the minimum design VMA, while $19 \%$ for the LB $4.75 \mathrm{~mm}$. Finally, density is the main reason for LB pay disincentives, especially $9.5 \mathrm{~mm}$ mixes, possibly due to being laid at less than three times NMAS. Hence, $4.75 \mathrm{~mm}$ mixes appear to be more appropriate considering lift to NMAS ratio.

\begin{tabular}{|c|c|c|}
\hline Type & BC & BC \\
\hline NMAS & 19.0 & 12.5 SMA \\
\hline Target AV & 4.0 & $4.0(3.5$ in D1) \\
\hline Min VMA & 13.5 & 16.0 \\
\hline Mix Sub-Lots & 3469 & 134 \\
\hline Density Sub-Lots & 16921 & 993 \\
\hline
\end{tabular}

(a)

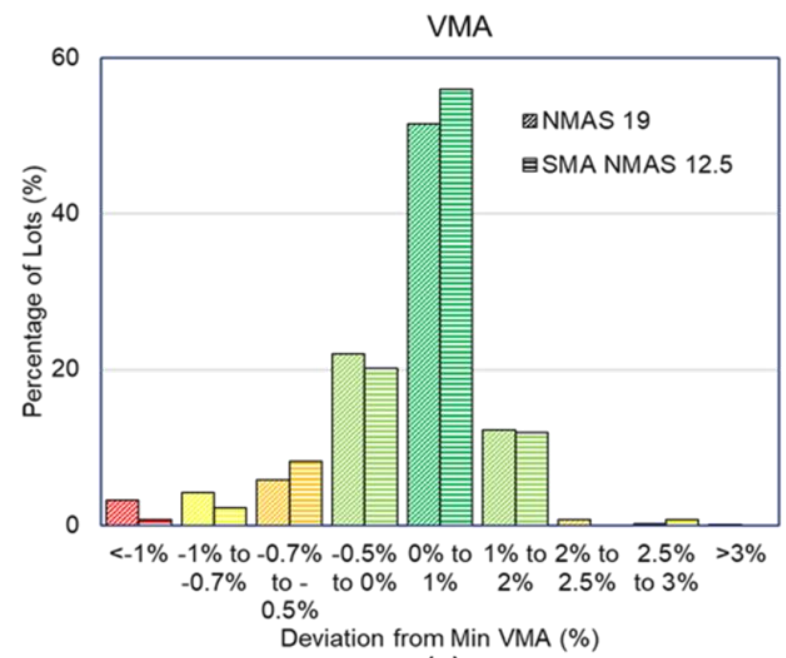

(c)

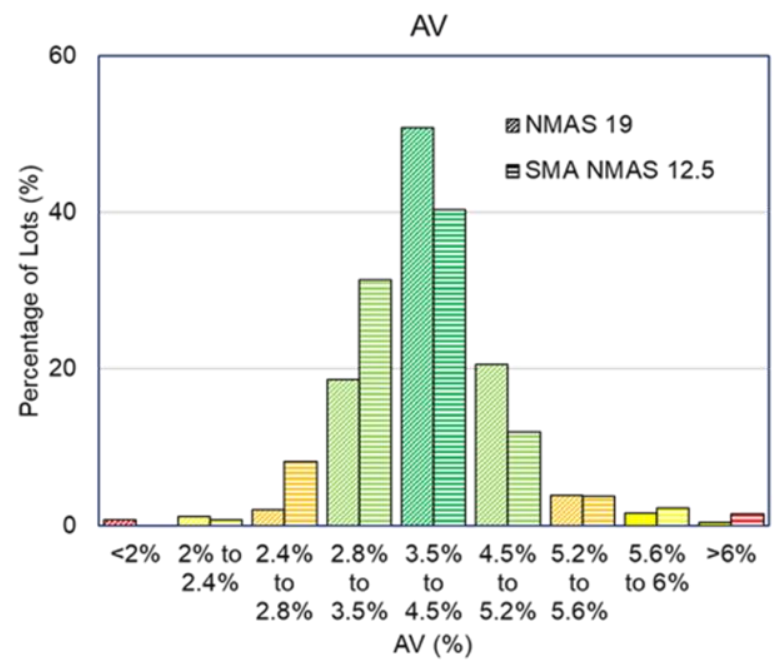

(b)

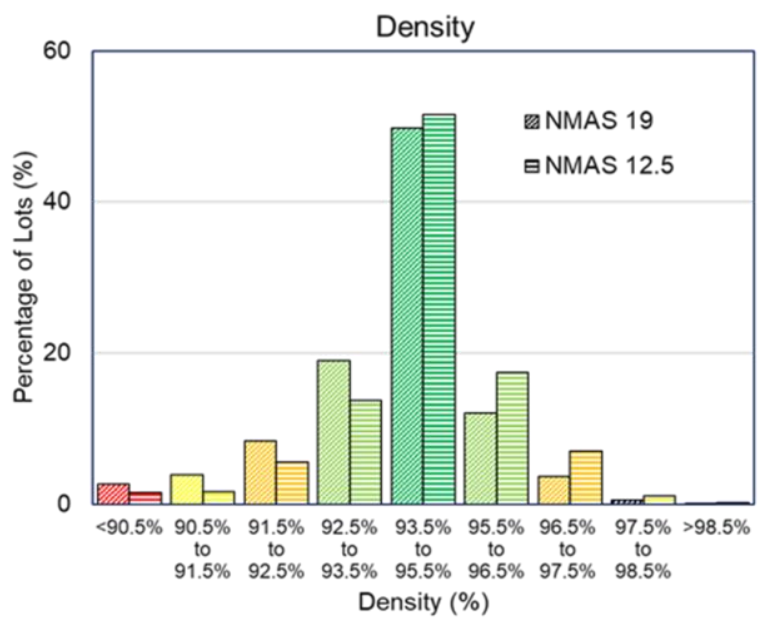

(d)

Figure 4.15. Pay parameter results for $\mathrm{BC}$ mixes.

Figure 4.15 shows the results for $B C$ mixes. The AV results show that both $B C$ mixes (19.0 and 12.5 SMA) have similar chances of AV pay disincentives. VMA pay disincentives were a result of lower VMA values, irrespective of the NMAS. Of the BC $19.0 \mathrm{~mm}$ NMAS sublots, $14.9 \%$ had densities lower than $92.5 \%$ compared to $8.9 \%$ for the BC SMA $12.5 \mathrm{~mm}$ NMAS sublots. These values were slightly less for $\mathrm{BC} 19 \mathrm{~mm}$. 


\begin{tabular}{|c|c|c|c|}
\hline Type & SC & SC & SC \\
\hline NMAS & 12.5 SMA & 9.5 & 9.5 SMA \\
\hline Target AV & $4.0(3.5$ D1) & 4.0 & 3.5 \\
\hline Min VMA & $17.0(16.0$ D1) & 15.0 & 17.0 \\
\hline Mix Sub-Lots & 1284 & 6092 & 182 \\
\hline Density Sub-Lots & 8389 & 36317 & 1803 \\
\hline
\end{tabular}

(a)

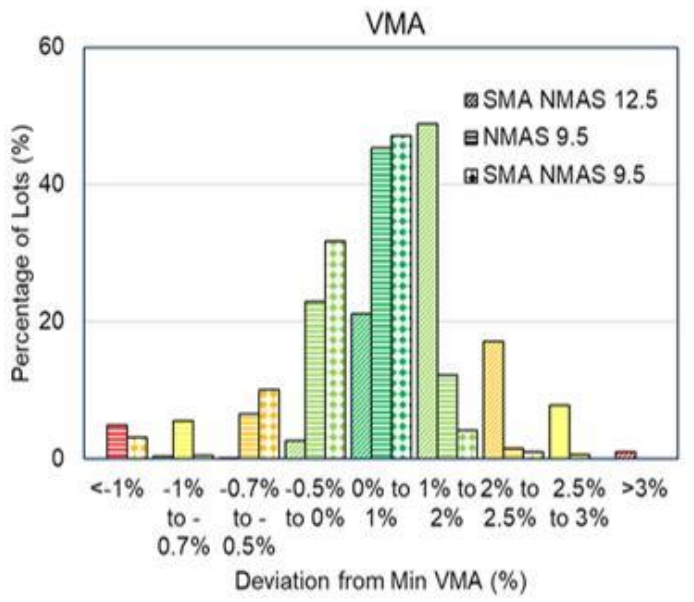

(c)

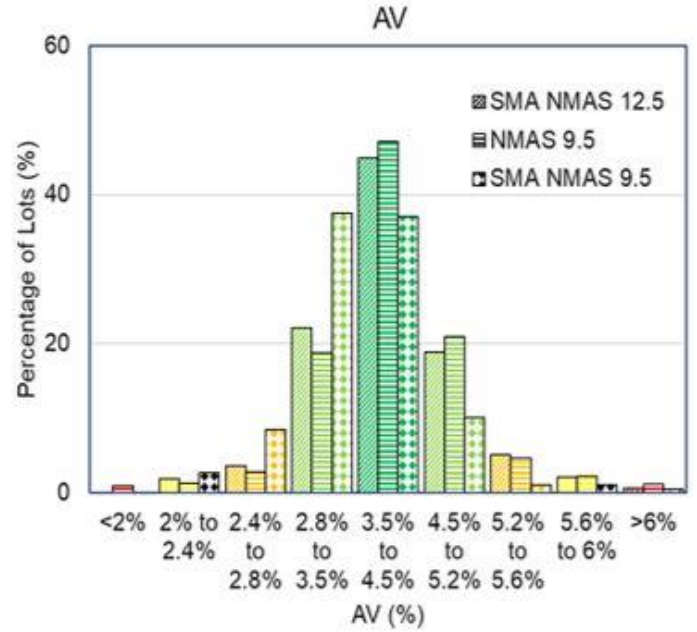

(b)

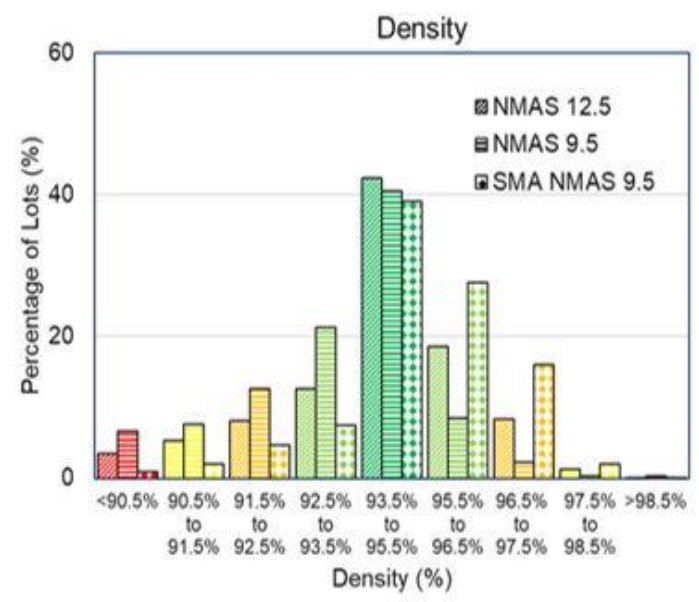

(d)

Figure 4.16. Pay parameter results for SC mixes.

For SC mixes, AV results show that both SC mixes ( 9.5 and $12.5 \mathrm{~mm}$ ) have similar chances of pay disincentives (Figure 4.16). Of the SC $9.5 \mathrm{~mm}$ mixes, 16.7\% have VMA $0.5 \%$ or lower than the minimum design VMA compared to $1 \%$ for the $12.5 \mathrm{~mm}$ SMA. For density, $13.4 \%$ of the $12.5 \mathrm{~mm}$ mixes have low densities compared to the $9 \%$ that have high densities. The lower density increases for the $9.5 \mathrm{~mm}$ mixes (25.8\%).

\subsubsection{District vs Contractor Results}

The differences between district and contractor results could be indicative of offsets, sampling/blending, and/or high variability that could be caused by sample collection, reheating, and testing procedures. Statistical analysis was performed on district and contractor test results. Figure 4.17 illustrates the Mann-Whitney sublot results for AV, VMA, and density per district for both QCP and PFP specifications. If the p-value is lower than 0.05 , then there is a significant difference between district and contractor results. At a statewide level, the district and contractor results were not significantly different for $91 \%$ of $\mathrm{AV}, 88 \%$ of $\mathrm{VMA}$, and $82 \%$ of density results. 
The significantly different cases in AV ranged from as low as 4\% (District 5) to 20\% (District 6). On the other hand, the results ranged from $8 \%$ (District 1) to 25\% (District 6) for VMA. Note that the highest percentage of significant differences for AV and VMA were in District 6, which had the best pay performance. Figure 4.17 (d) shows the results of the Mann-Whitney test for the density cores. District 2 had the lowest variation, while Districts 8 and 9 showed the highest variation. Note that the latter districts had smaller sample sizes that could be attributed to the higher variation.

For the significantly different cases that received full pay, contractor results had sublots outside of the QCP and PFP upper limits, while district results were within the limits. For cases that were significantly different and had a pay disincentive, district results were outside the limits (density and VMA results were mostly low and AV results were either low or high), while contractor results were not.

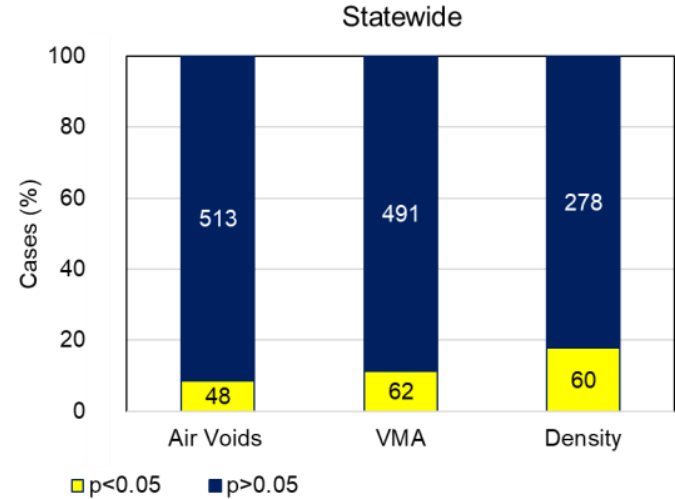

(a)

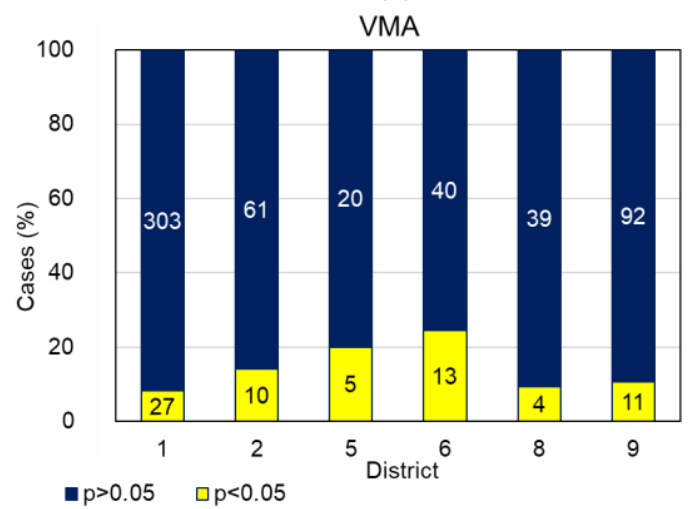

(c)

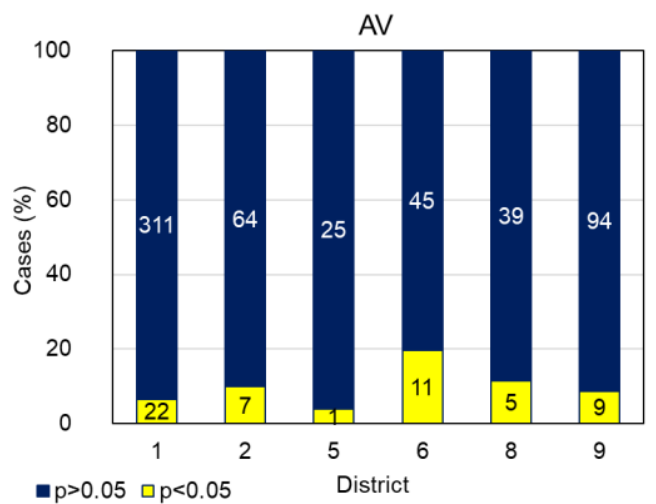

(b)

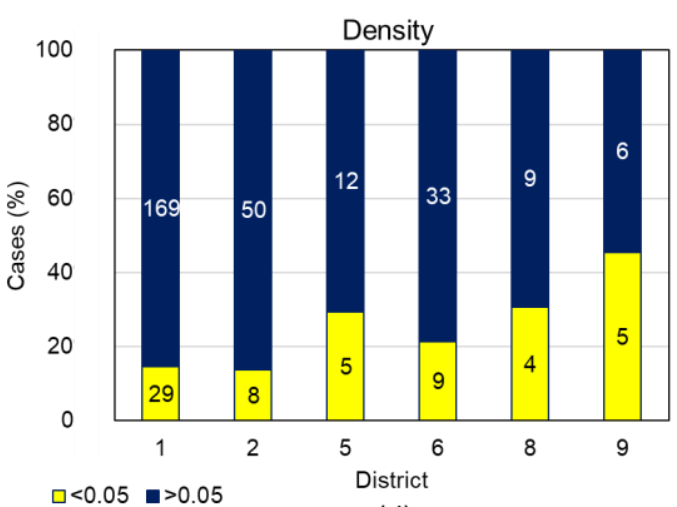

(d)

Figure 4.17. Mann-Whitney results for QCP and PFP mix contract cases.

Figure 4.18 presents the magnitude of the differences between contractor and district results. The calculation is based on Equation (4.3). A positive difference indicates the district's average result is greater than that of the contractor's.

$$
D=\text { Pay Parameter }_{D}-\text { Pay }_{\text {Parameter }_{C}}
$$

where, $D$ is difference in the parameter; Pay Parameter $_{D}$ is average of parameter district sublot results; and Pay Parameter Pav $_{C}$ average of parameter contractor sublot results. 
Figure 4.18 (a) shows the statewide results for AV, VMA, and density. For AV, the chance is the same that district results are either higher or lower than contractor test results. For VMA, district results were more likely to be lower than contractor results. For density, which is the parameter that had the most significant differences, there was a higher chance for district results to be lower than contractor results.

Figure 4.18 (b) shows the AV differences per district. District 1 and 2 results have the same chance of being either higher or lower than the contractor test results. However, AV results in Districts 5 and 6 appeared to be higher than those of the contractor. District 6 had the best pay performance but also the highest rate of significantly different results, and district AV values were higher than those by the contractor. These were indications of bias in AV and VMA test results of District 6 . Contractor average results were biased to be higher than Districts 8 and 9 results.

In general, when there were differences between district and contractor results, district VMA was lower than contractor results, except in District 8 (see Figure 4.18 [c]), where VMA pay factor was significantly better than AV pay factor. Also, contractors have higher density average results than districts, Figure 4.18 (d). Consistency in submerged period and submerged surface dry (SSD) was desirable.

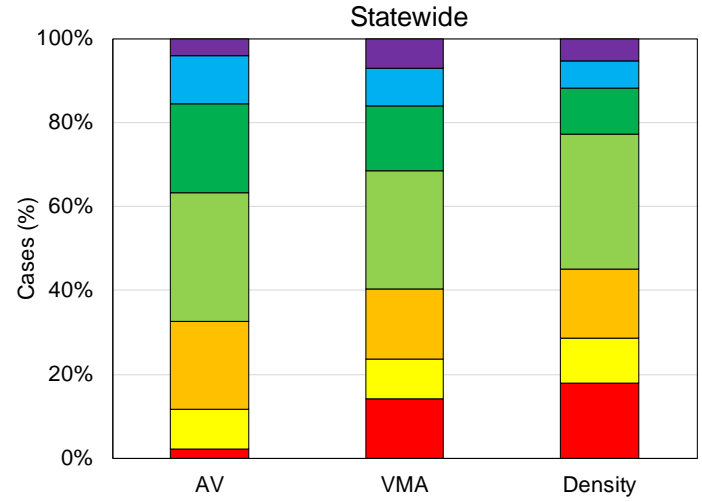

(a)

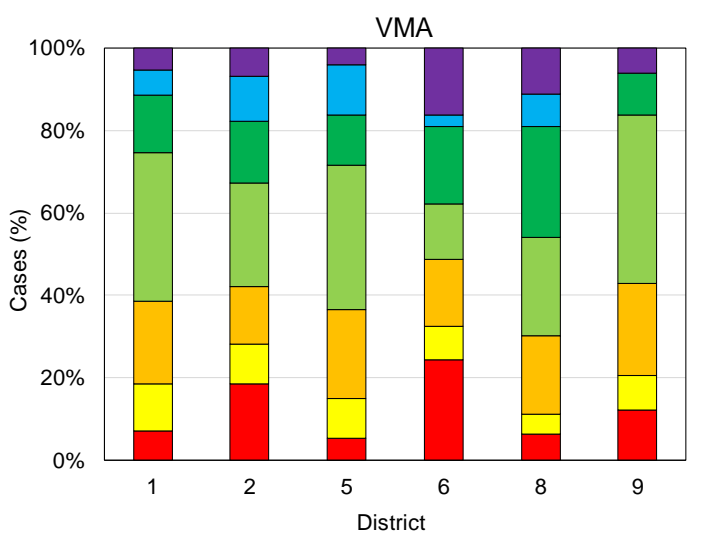

(c)

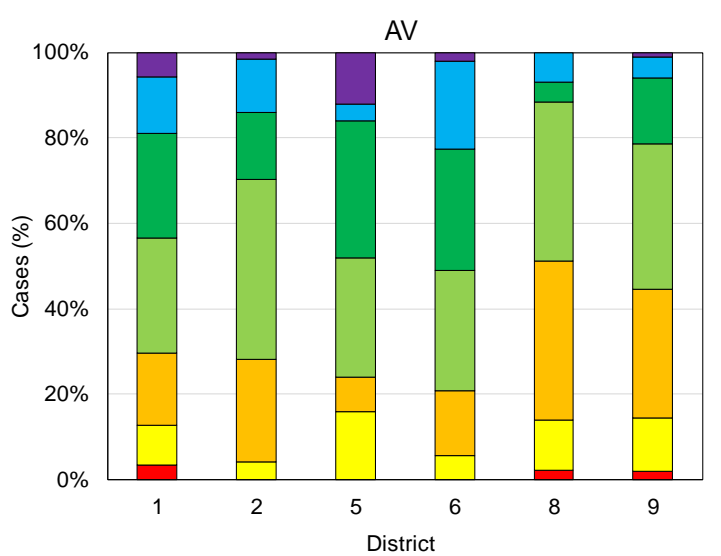

(b)

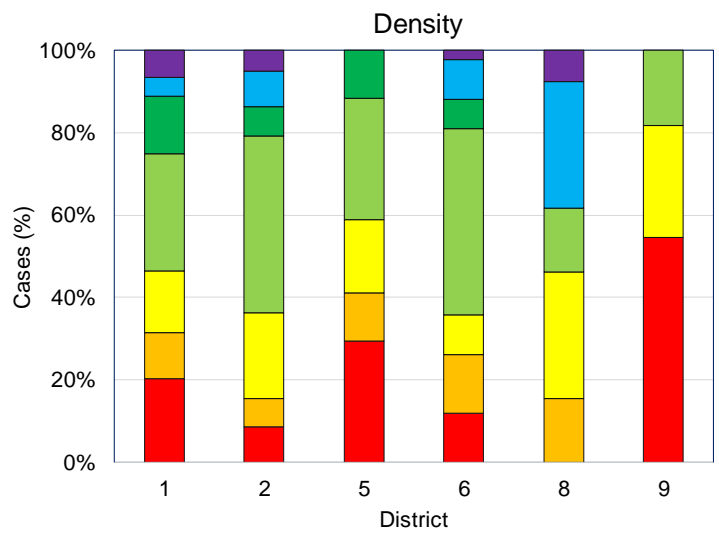

(d)

$\square<=-1 \square-1$ to $-0.6 \square-0.6$ to $-0.2 \square-0.2$ to $0.2 \square 0.2$ to $0.6 \square 0.6$ to $1 \square>1$

Figure 4.18. Magnitude of the differences between contractor and district results by district. 


\subsubsection{Variability}

The variability in the data may result from testing as well as mixture characteristics and production. Levene's test was conducted to check the significant difference in variance of contractor and district results. If the variance is similar, then the source is most likely due to changes in mix production or construction. On the other hand, if there is difference in the variance, this could be attributed to sample splitting and/or testing. Figure 4.19 shows Levene's test results for VMA, AV, and density. The results were similar to that of the Mann-Whitney test results. At a statewide level, contractor and district results were not significantly different for $91 \%$ of $A V, 89 \%$ of $V M A$, and $82 \%$ of density results. In general, Levene's test results show an agreement between district and contractor data variances. As a result, the variabilities in the variances of contractors and those of districts are comparable. This may suggest that mix production is the main factor causing high variabilities between sublots, and, hence, affecting the same tests conducted by the two independent parties. Laboratory test variability exists but is not the main cause for the variances found in the analyzed data. Suggestions have been provided to minimize such variabilities in Chapter 6 .

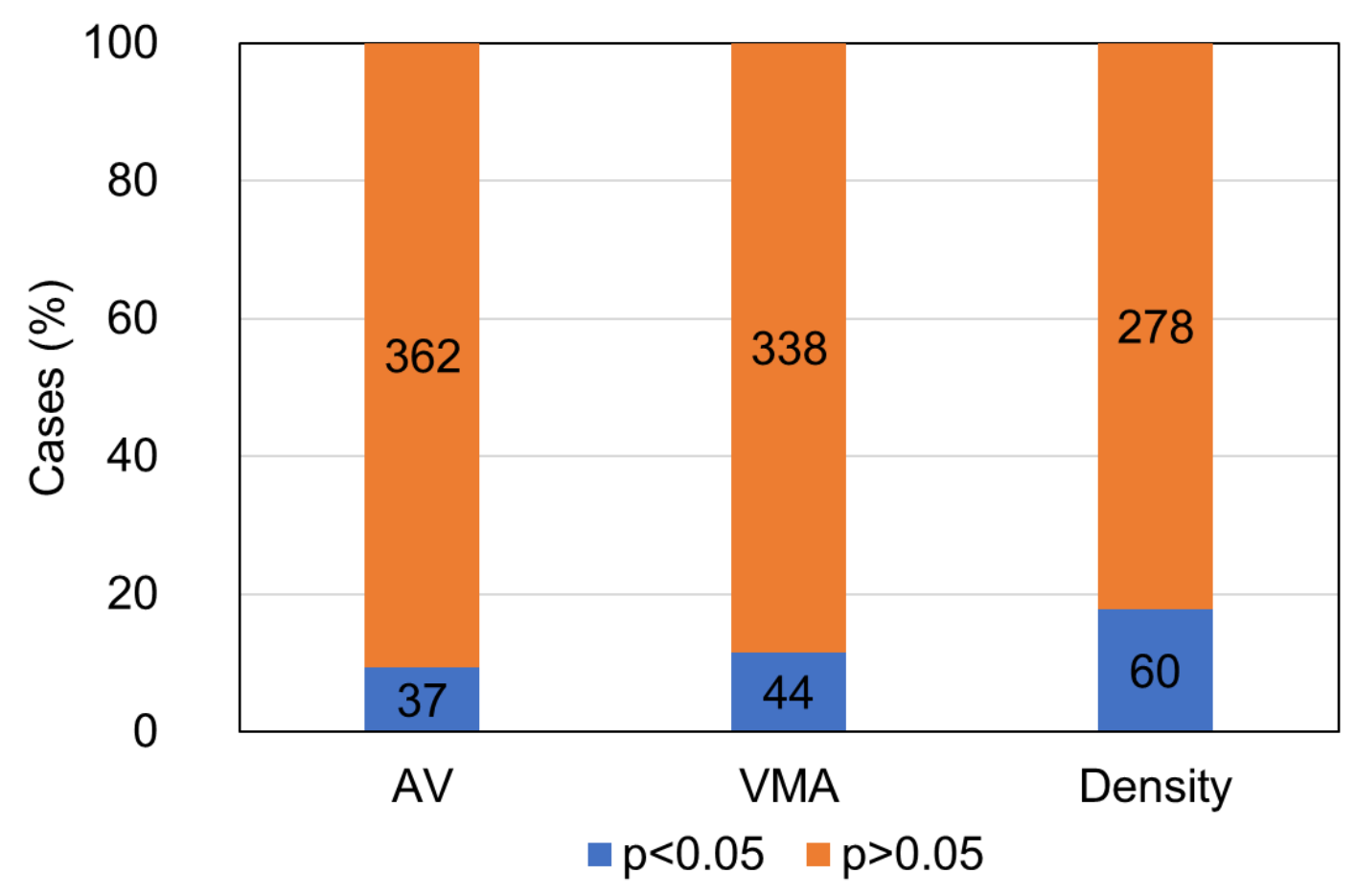

Figure 4.19. Levene's results for AV, VMA, and density.

For LB mixes, the AV results show that $4.75 \mathrm{~mm}$ mixes had lower AV standard deviation than $9.5 \mathrm{~mm}$ NMAS (Figure 4.20). More than $60 \%$ of the $4.75 \mathrm{~mm}$ NMAS cases had AV standard deviations between $0 \%$ to $0.2 \%$ while less than $40 \%$ of the 9.5 NMAS mm had a standard deviation in the same range. Figure 4.20 (c) shows the standard deviation for VMA. The distribution for the 4.75 and 9.5 mm NMAS was similar. Figure 4.20 (d) shows the standard deviation results for density. Density is the most variable parameter for all the mixes. The distribution of the $4.75 \mathrm{~mm}$ NMAS standard deviations is centered around $1.6 \%$ to $2 \%$ while $9.5 \mathrm{~mm}$ mixes are around $0.8 \%$ to $1.2 \%$. 
For BC $12.5 \mathrm{~mm}$ SMA and $19 \mathrm{~mm}$ mix (Figure 4.21), density was the most variable of the evaluated parameters, with approximately $80 \%$ having a standard deviation of $0.8 \%$ to $2 \%$. AV was the second most variable parameter, followed by VMA.

\begin{tabular}{|c|c|c|}
\hline Type & LB & LB \\
\hline NMAS & 9.5 & 4.75 \\
\hline Target AV & 4.0 & $4.0(3.5$ in D1) \\
\hline Min VMA & 15.0 & 18.5 \\
\hline Mix Cases & 31 & 108 \\
\hline Density Cases & 39 & 105 \\
\hline
\end{tabular}

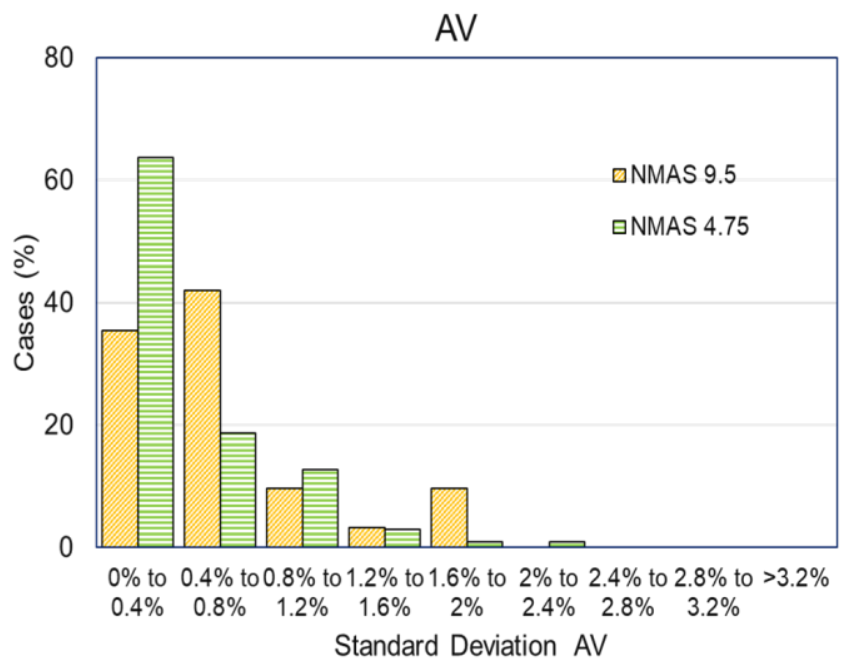

(a)

(b)

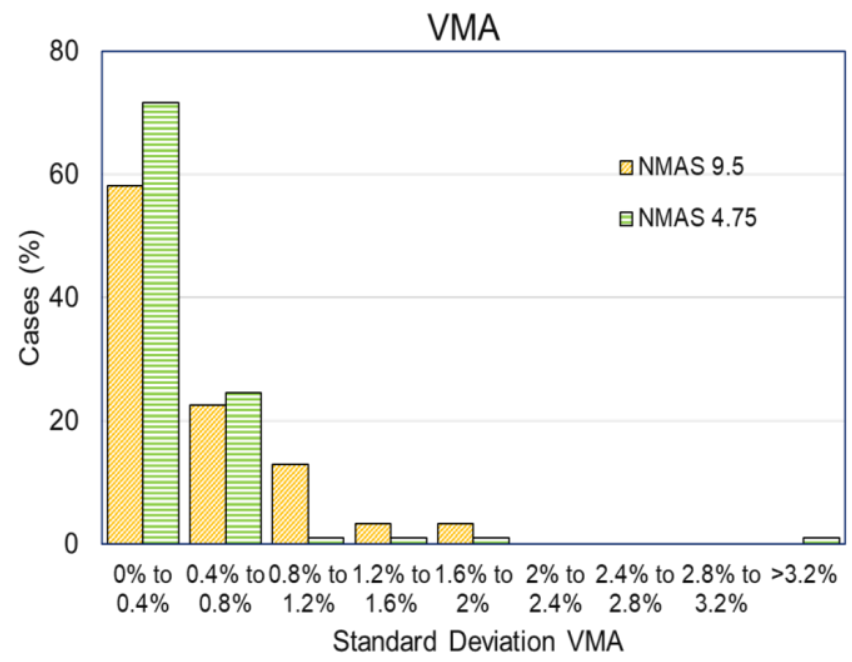

(c)

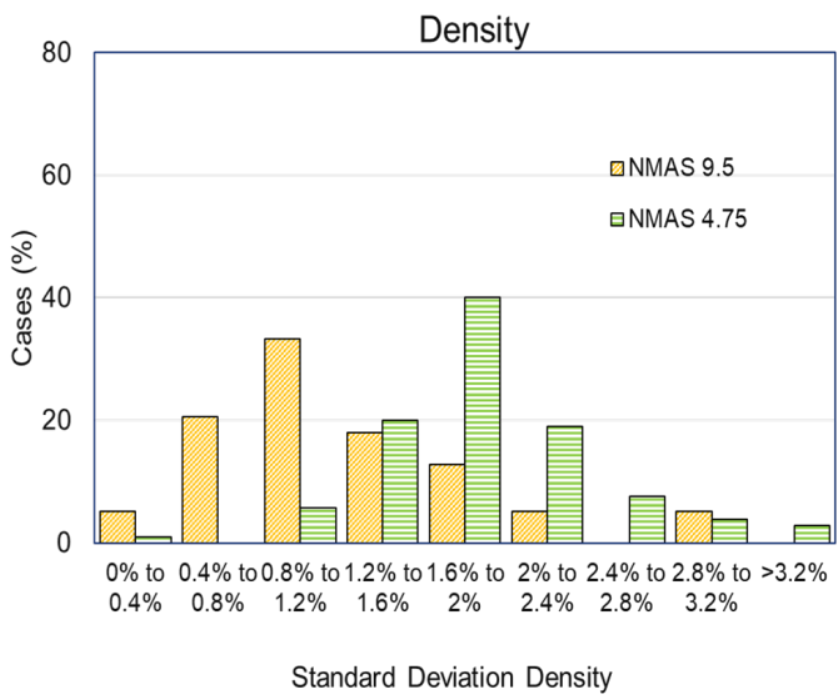

(d)

Figure 4.20. Standard deviations in AV, VMA, and density for LB mixes.

Figure 4.22 shows the results for $12.5 \mathrm{~mm} \mathrm{SMA}$ and $9.5 \mathrm{~mm} \mathrm{SC}$ mixes. The trend was similar to $\mathrm{BC}$ and SC mixes. Density showed the highest variances among the three parameters, with $90 \%$ having a standard deviation of $0.8 \%$ to $2.4 \%$ for both mixes. However, the $12.5 \mathrm{~mm}$ SMA showed slightly less standard deviation than the $9.5 \mathrm{~mm}$ mix, 65\% and 53\%, respectively, with a standard deviation lower than $1.6 \%$. AV showed less variability in the $9.5 \mathrm{~mm}$ mix than the $12.5 \mathrm{~mm}$ SMA. VMA is the least variable. In general, the $9.5 \mathrm{~mm}$ mix appears less variable for AV and VMA and more variable for density than the $12.5 \mathrm{~mm}$ SMA. 


\begin{tabular}{|c|c|c|}
\hline Type & BC & BC \\
\hline NMAS & 19.0 & 12.5 SMA \\
\hline Target AV & 4.0 & $4.0(3.5$ in D1) \\
\hline Min VMA & 13.5 & 16.0 \\
\hline Mix Cases & 99 & 3 \\
\hline Density Cases & 95 & 3 \\
\hline
\end{tabular}

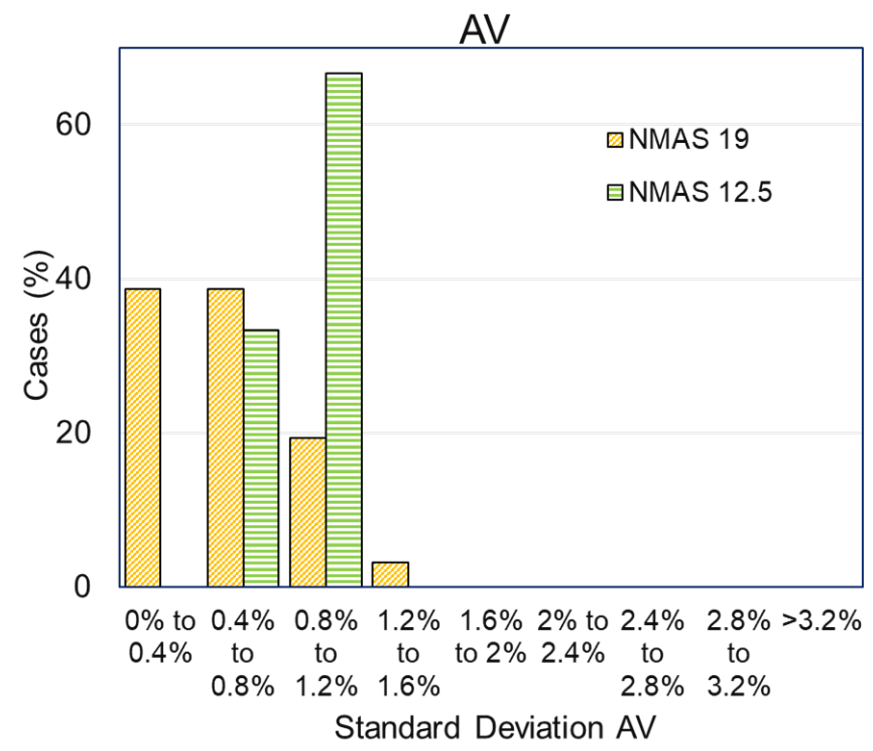

(a)

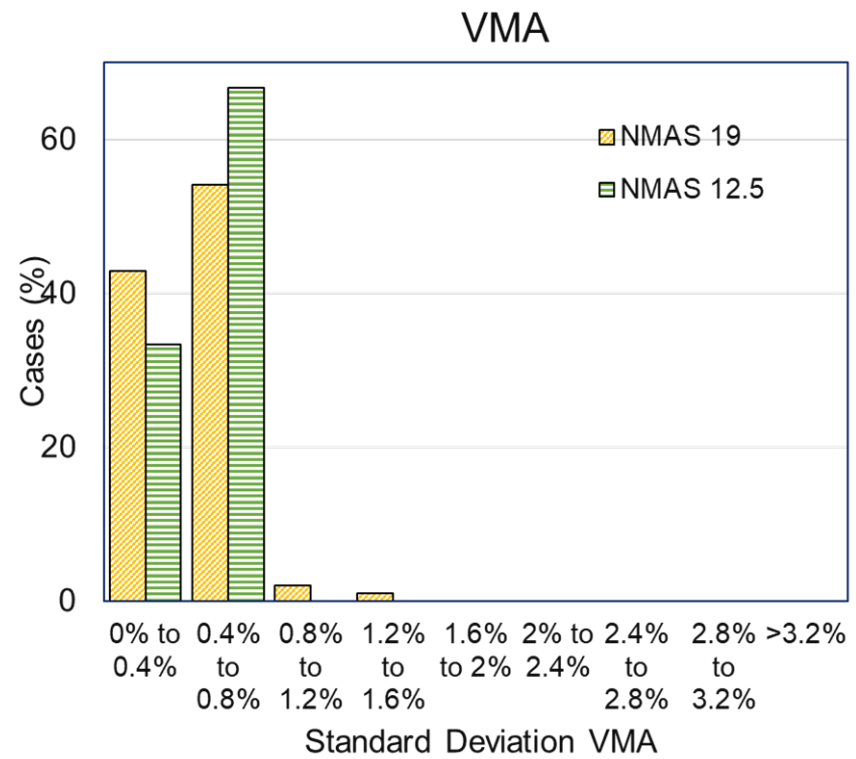

(c) (b)

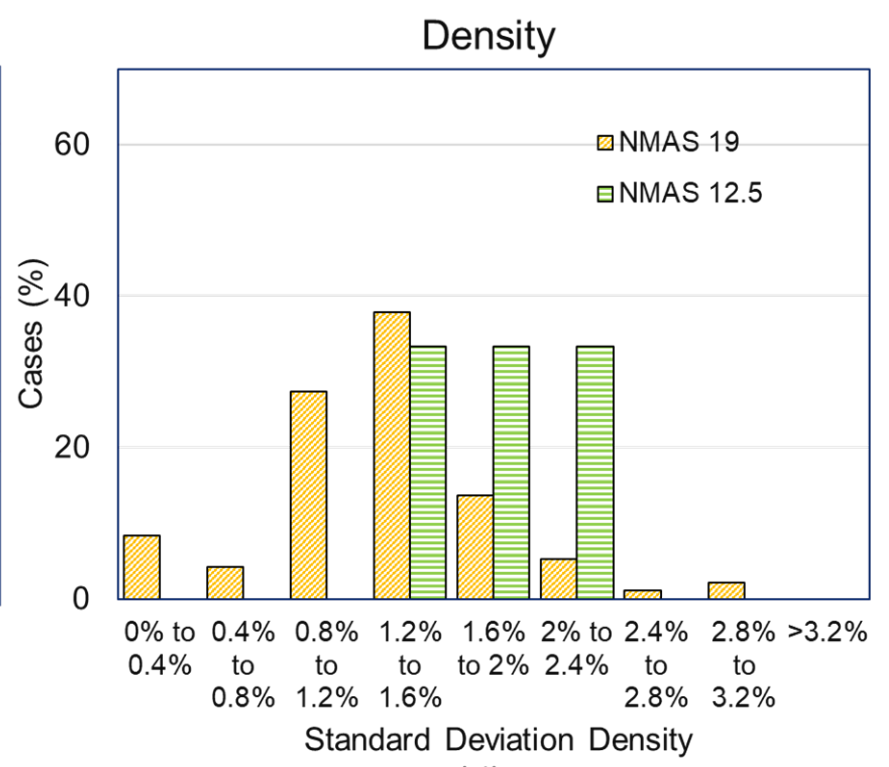

(d)

Figure 4.21. Standard deviations in AV, VMA, and density for BC mixes.

Districts had higher standard deviations than contractors for AV (Figure 4.23). Similarly, for VMA (Figure 4.24), Districts 8 and 9 had the largest share of cases, with a standard deviation exceeding $0.6 \%$ (56\% and $44 \%$, respectively). District 5 had smaller AV and VMA standard deviations, which contributed to the pay performance success. For density (Figure 4.25), district standard deviations were generally higher than the contractor's. Districts 1, 5, and 6 were higher; Districts 2 and 9 were comparable; while District 8 had higher contractor standard deviation. 


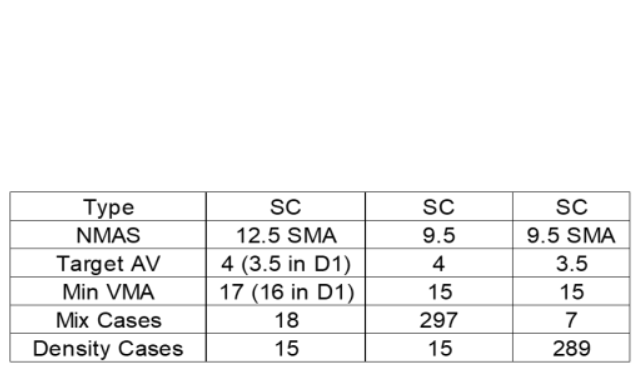

(a)

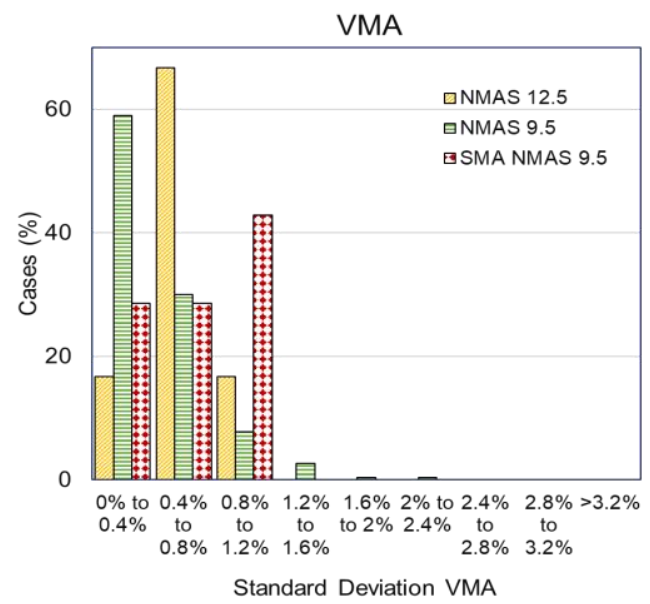

(c)

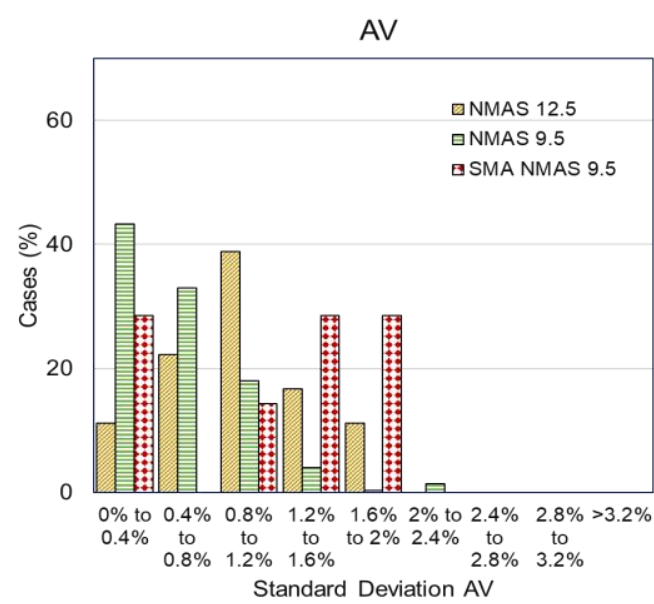

(b)

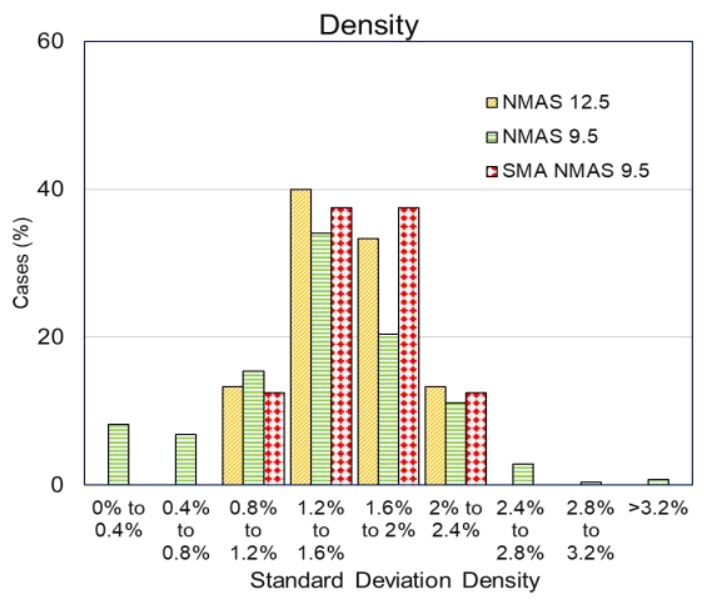

(d)

Figure 4.22. Standard deviations in AV, VMA and density for SC mixes.

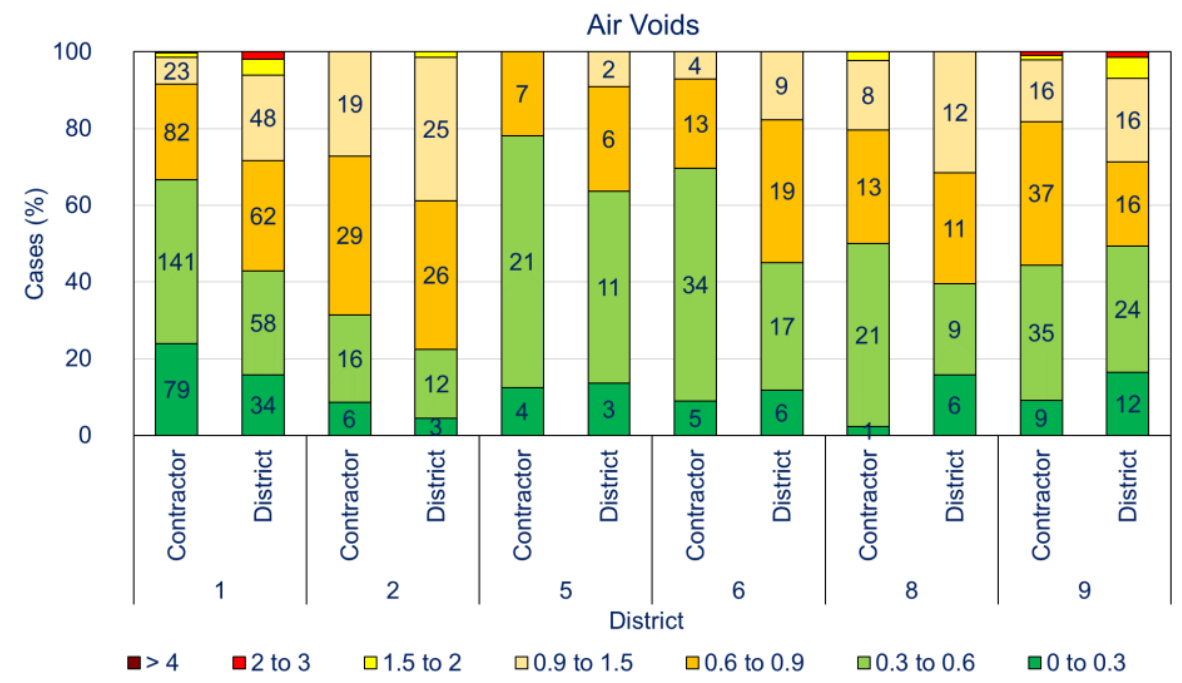

Figure 4.23. Standard deviations of AV (\%) per district and contractor. 


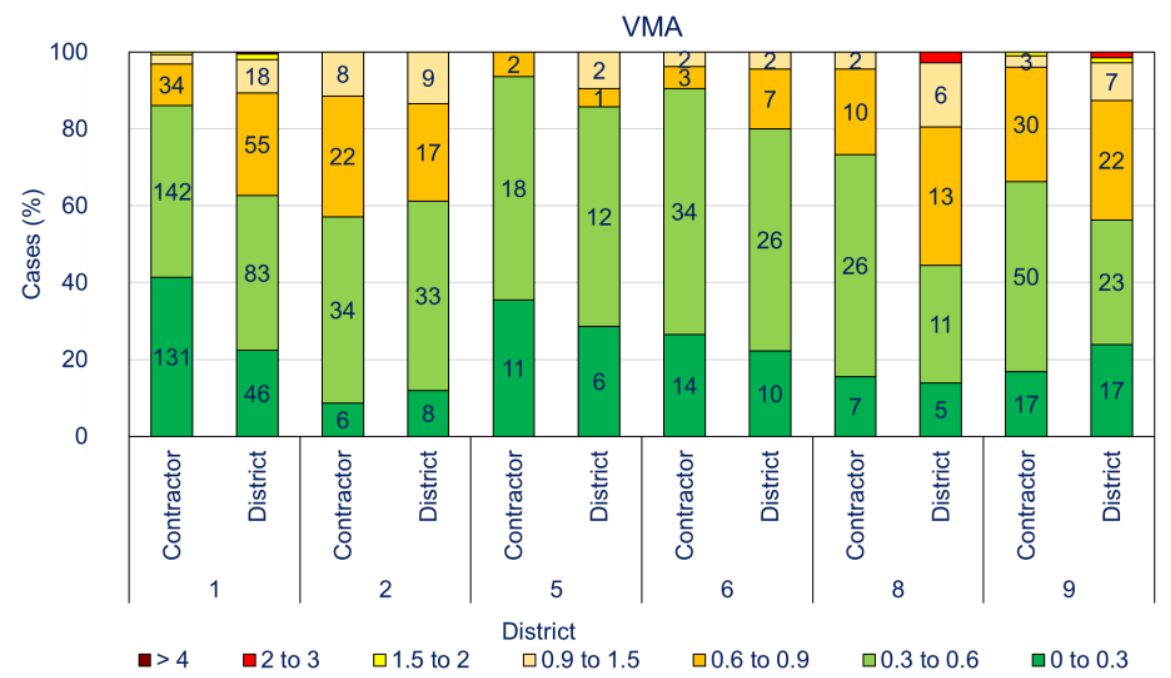

Figure 4.24. Standard deviations VMA (\%) per district and contractor.

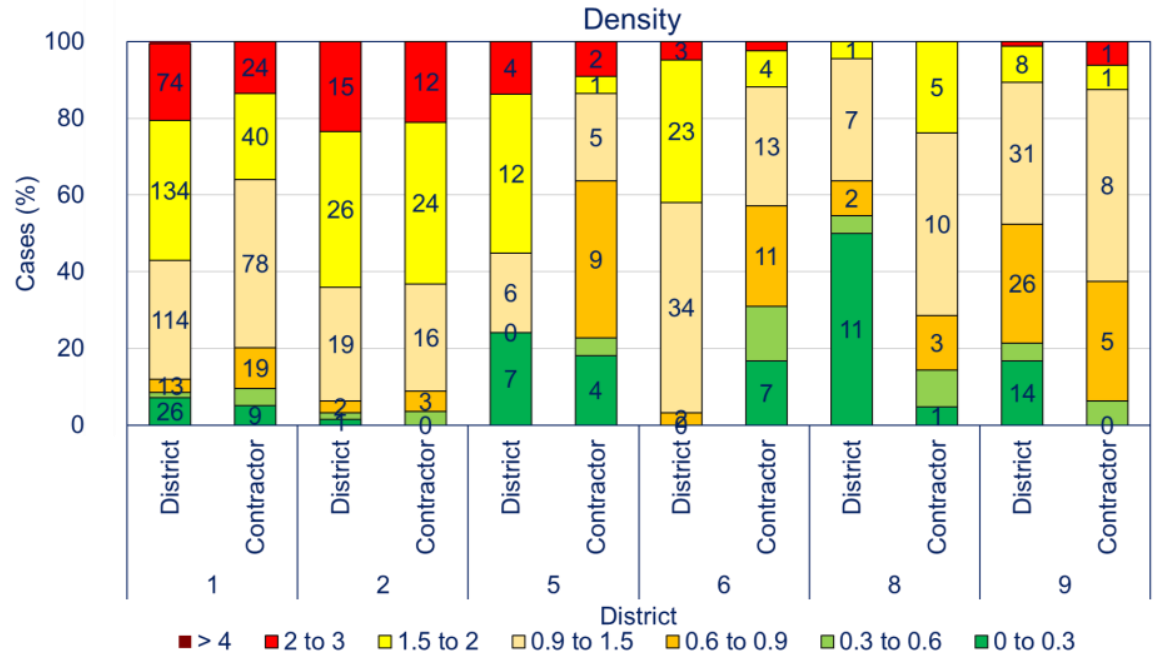

Figure 4.25. Standard deviations of density (\%) per district and contractor.

\subsubsection{Density Variability Sensitivity Analysis}

In the PFP specification, contractors are not only evaluated for meeting the specification ranges but also for variability. In the pay factor calculation process, a distribution is fitted to the data, and high variability leads to the tails being outside the pay limits, inducing pay disincentives. For these reasons, it is crucial to understand how variability affects pay factors in the PFP specification and to quantify the financial impact of having higher variability on the pay factor.

Density is the most variable pay parameter. This causes more pay disincentives in PFP compared to QCP because of PFP's evaluation of variability in the pay calculation. Before simulating different standard deviation levels and their impact on pay factors, it is important to check the pay factor data 
distribution. Table 4.1 presents levels of density values and corresponding standard deviation categories with their respective pay factors. A total of 77 mix contract cases were used.

Table 4.1. Average Density Pay Factor for Various Mixes

\begin{tabular}{|c|c|c|c|}
\hline $\begin{array}{l}\text { Mix } \\
\text { Type }\end{array}$ & $\begin{array}{l}\text { Density } \\
\text { (\%) }\end{array}$ & $\begin{array}{c}\text { Density Standard } \\
\text { Deviation (\%) }\end{array}$ & $\begin{array}{c}\text { Average Density Pay } \\
\text { Factor }\end{array}$ \\
\hline \multirow{9}{*}{ SC } & \multirow{3}{*}{$\begin{array}{c}91.5- \\
93.0\end{array}$} & $0-1$ & $\mathrm{~N} / \mathrm{A}$ \\
\hline & & $1-2$ & 98.42 \\
\hline & & $>2$ & 91.29 \\
\hline & \multirow{3}{*}{$\begin{array}{c}93.0- \\
94.5\end{array}$} & $0-1$ & $\mathrm{~N} / \mathrm{A}$ \\
\hline & & $1-2$ & 98.71 \\
\hline & & $>2$ & 97.55 \\
\hline & \multirow{3}{*}{$\begin{array}{l}94.5- \\
96.0\end{array}$} & $0-1$ & 100.73 \\
\hline & & $1-2$ & 100.39 \\
\hline & & $>2$ & $\mathrm{~N} / \mathrm{A}$ \\
\hline \multirow{9}{*}{$\mathrm{BC}$} & \multirow{3}{*}{$\begin{array}{l}91.5- \\
93.0\end{array}$} & $0-1$ & 98.00 \\
\hline & & $1-2$ & $84.00 *$ \\
\hline & & $>2$ & 96.80 \\
\hline & \multirow{3}{*}{$\begin{array}{c}93.0- \\
94.5\end{array}$} & $0-1$ & 102.30 \\
\hline & & $1-2$ & 98.92 \\
\hline & & $>2$ & $96.45^{*}$ \\
\hline & \multirow{3}{*}{$\begin{array}{c}94.5- \\
96.0\end{array}$} & $0-1$ & $\mathrm{~N} / \mathrm{A}$ \\
\hline & & $1-2$ & 100.47 \\
\hline & & $>2$ & $\mathrm{~N} / \mathrm{A}$ \\
\hline
\end{tabular}

*Data are based on 77 cases divided into 18 categories. Hence, outcome interpretation is limited.

In general, the higher the density variability, the lower the pay factor. To quantify this, different scenarios of standard deviation were simulated to evaluate the impact on pay factor. Standard deviation varied from low (0.5) to high (2) with an increment of 0.5 ; the mean density values remained constant. Seventy-seven mix contract cases were used: 64 SC and 15 BC. Figure 4.26 shows the density pay distribution by standard deviation. The category " $\mathrm{s}$ " refers to the pay distribution calculated using the standard deviation values from the actual collected data from districts.

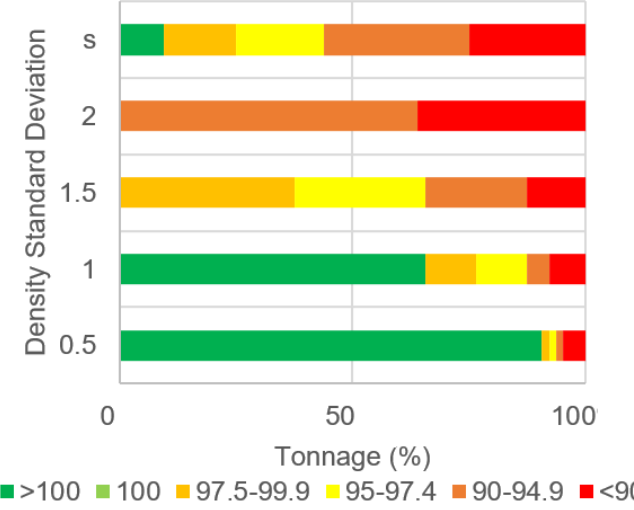

(a)

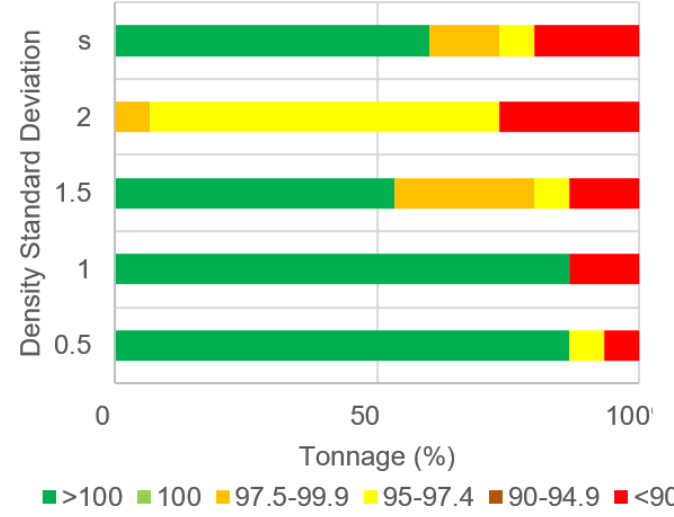

(b)

Figure 4.26. (a) SC and (b) BC density pay factors distribution for various standard deviation values. 
The standard deviation has a high impact on pay distribution in the PFP specification (both for BC and SC). The higher the standard deviation, the more notable the shift to lower pay factors. To quantify this impact, Figure 4.27 shows the pay factor average change as a function of standard deviation. This shows that uniformity of density results is important. To illustrate this, the average tonnage of a PFP project is approximately 23,000 tons and the average bid price is approximately $\$ 86 /$ ton. However, this average does not consider cost inflation. Therefore, Consumer Price Index (CPI) data from the Bureau of Labor Statistics was used for base year 2019. A year's CPI change was taken as the difference between the average of CPI change of June and July of the base year 2019. The CPI of the year 2019 was not available at the time this report was published. The inflation of one USD in 2015 was found to be $7.5 \%$. The inflation rates of 2016 and 2017 were found to be $6.5 \%$ and 5\%, respectively. The value average price per ton of a PFP project was found to be around \$92 in 2019. Achieving a density standard deviation of 1 leads to an average increase in pay factor of around $4.5 \%$ compared to the actual pay factor. This amounts to an average monetary value as calculated in Equation (4.4):

$$
M V=0.4 * C * P * T
$$

where, $M V$ is monetary value corresponding to the change in pay factor (2019 USD); $C$ is change in Pay Factor; $P$ is price per ton (2019 USD/ton); and $T$ is tonnage (ton).

Substituting $C$ as $0.045, P$ at 92 of 2019 USD/ton, and $T$ at 23,000 ton, the value of MV is roughly US\$38,000 (\$1.7/ton) in 2019. If a standard deviation of 0.5 is used, then the total pay difference would be US\$59,000 in 2019. The average standard deviation of density for PFP projects used in the analysis is around 1.67. Although there are many factors affecting field compaction and thus density, better quality control and lowering density variability as much as possible leads to the aforementioned financial benefits.

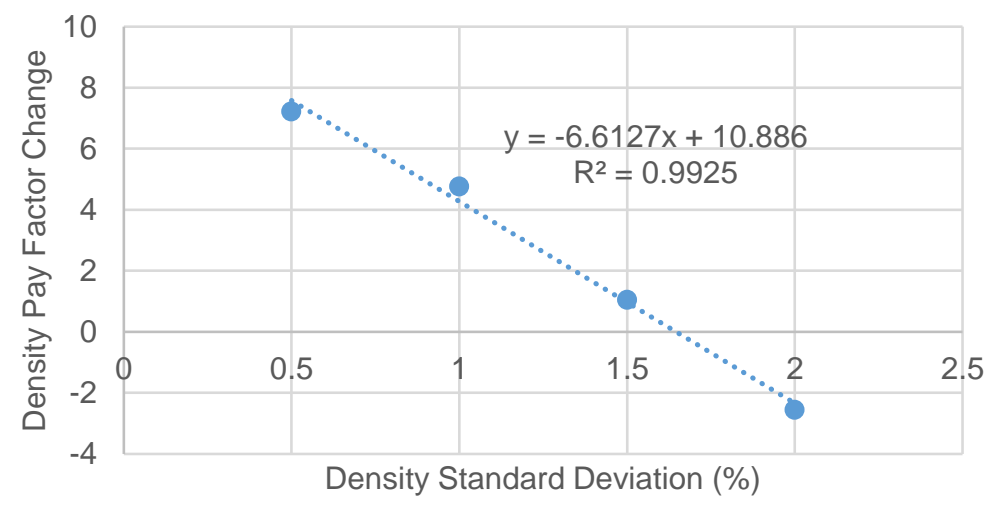

Figure 4.27. Density pay factor average change against density standard deviation.

\subsection{AGGREGATE GRADATION AND ASPHALT CEMENT CONTENT EVALUATION}

As indicated earlier, most contractor and district results ( $91 \%$ of $A V, 88 \%$ of $\mathrm{VMA}$, and $82 \%$ of density results) are not significantly different. As a result, when there is a pay disincentive related to AV and 
VMA and both the contractor and district test results indicate significantly similar results, it is probably because of an issue with the mix production. To confirm the claim is true, other supporting data related to production should be evaluated such as the extracted aggregate gradation and dust/AC content to identify a possible mix issue.

\subsubsection{Analysis Approach}

IDOT is required to report AC content for each mix sublot, which includes running a washed aggregate gradation. However, mix aggregate gradations are not a pay parameter. Twelve sieve sizes are reported: 1.5 in, 1 in, 3/4 in, 1/2 in, 3/8 in, \#4, \#8, \#16, \#30,\#50, \#100, and \#200. IDOT obtains the aggregate gradation from an exclusive HMA sample, utilizing ignition oven, centrifuge, or reflux. (Note that several districts and contractors currently use automated extraction devices.) The ignition oven is the most widely used method in Illinois for separating binder from the aggregates in HMA samples.

Bailey method control sieves were used to analyze the aggregate gradation because the impact of each sieve size is different depending on the NMAS (TRB, 2002). For example, the amount of material passing sieve \#8 has a greater impact on a $9.5 \mathrm{~mm}$ mix than on a $19 \mathrm{~mm}$ mix. The Bailey method identifies four control sieves that are used to characterize the behavior of the aggregate gradation. The primary control sieve (PCS) defines the threshold between coarse fraction and fine fraction of the blend. The half sieve (HS) is used to break the coarse fraction into two parts. The secondary control sieve (SCS) and tertiary control sieve (TCS) divide the fine fraction of the blend in a similar way as the PCS with the total blend (TRB, 2002).

Table 4.2. Sieve Sizes Used to Evaluate Aggregate Gradation on the Bailey Method

\begin{tabular}{|c|c|c|c|c|}
\hline NMAS* & $19 \mathrm{~mm}\left(3 / 4^{\prime \prime}\right)$ & $12.5 \mathrm{~mm}\left(1 / 2^{\prime \prime}\right)$ & $9.5 \mathrm{~mm} \mathrm{(3/8^{ \prime \prime } )}$ & $4.75 \mathrm{~mm}(\# 4)$ \\
\hline HS & $3 / 8^{\prime \prime}$ & $1 / 4^{\prime \prime}$ & $\# 4$ & $\# 8$ \\
\hline PCS & $\# 4$ & $\# 8$ & $\# 8$ & $\# 16$ \\
\hline SCS & $\# 16$ & $\# 30$ & $\# 30$ & $\# 50$ \\
\hline TCS & $\# 50$ & $\# 100$ & $\# 100$ & $\# 200$ \\
\hline
\end{tabular}

* half sieve (HS), primary control sieve (PCS), secondary control sieve (SCS), and tertiary control sieve (TCS)

For each mix contract case, the sublots that fail to meet either the AV or VMA requirements were identified for evaluation. Bailey method critical sieves were used for the evaluation: HS, PCS, SCS, and TCS (Table 4.2). In addition, the NMAS and the dust/AC ratio were considered in the evaluation. Then, the amount passing in each sieve was compared to IDOT aggregate gradation limits, as reported in the Standard Specification for Road and Bridge Construction (IDOT, 2016), to identify any deviation from the required limits. Contractors are required to design HMA within the limits specified in the standard specifications.

\subsubsection{Aggregate Gradation Results}

The aggregate gradations for 690 cases were analyzed (Figure 4.28). From Figure 4.28 (a) and (b), 27\% and $6 \%$ of $\mathrm{AV}$ and VMA pay disincentive cases, respectively, did not show noticeable differences in the aggregate gradation or AC content results when compared to design values. On the other hand, when the mixes were not penalized with a pay reduction (disincentive) for AV and VMA, $82 \%$ and 
$73 \%$, respectively, of the cases did not show irregularity in the aggregate gradation or AC content results (Figure 4.28 [c] and [d]). Cases that have a pay disincentive either in AV or VMA were likely to have corresponding issues with aggregate gradation results. Multiple reasons, such as aggregate variability, mix control, segregation when sampling, or others, could have caused aggregate gradation of a mix not to meet the specifications. The gradation results eventually affect AV and VMA results. Five major issues were identified: PCS LL, SCS LL, TCS UL, dust/AC ratio, and NMAS; LL and UL refer to lower and upper limits, respectively.

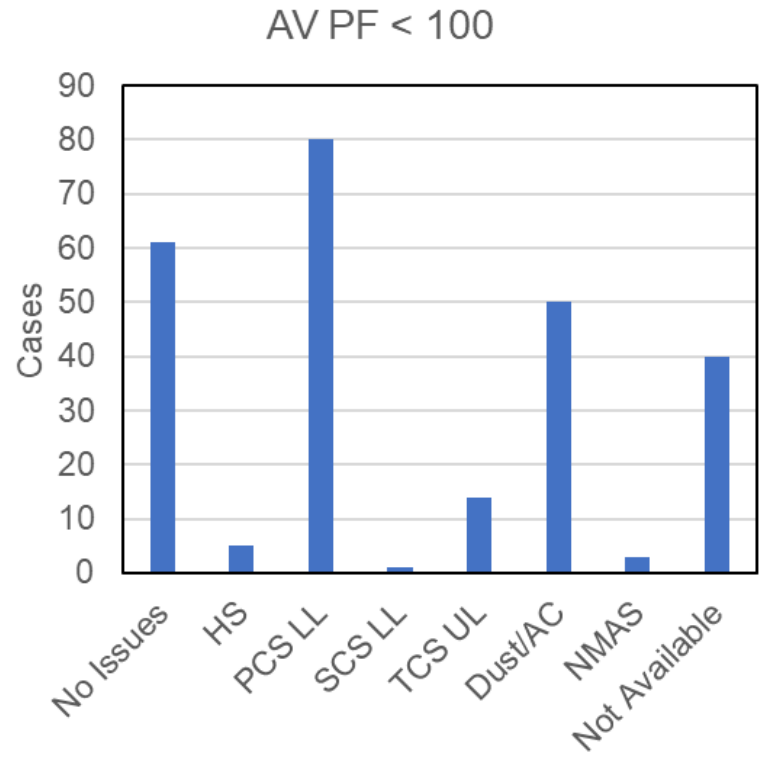

Gradation/AC Issues

(a)

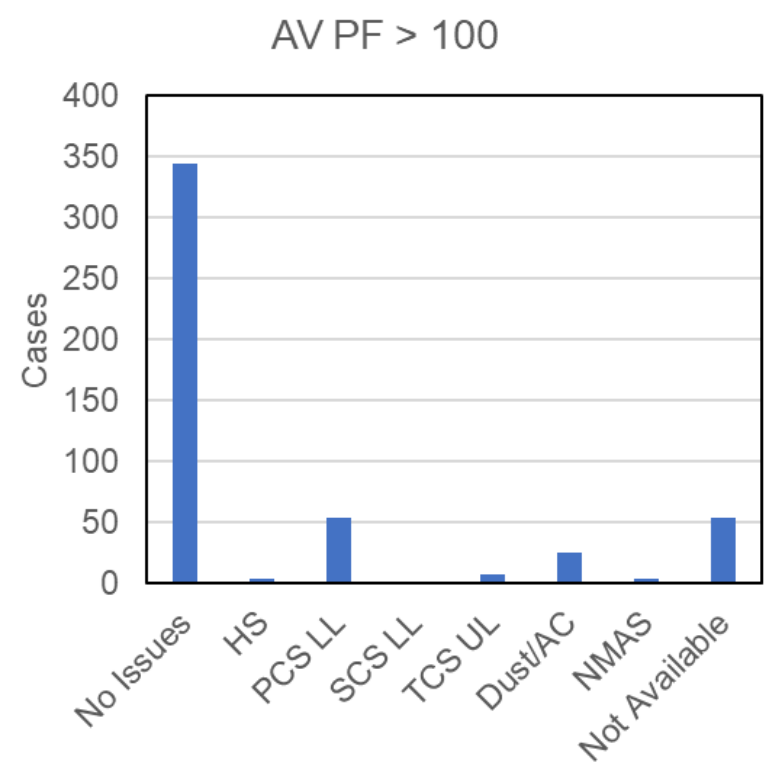

Gradation/AC Issues

(c)

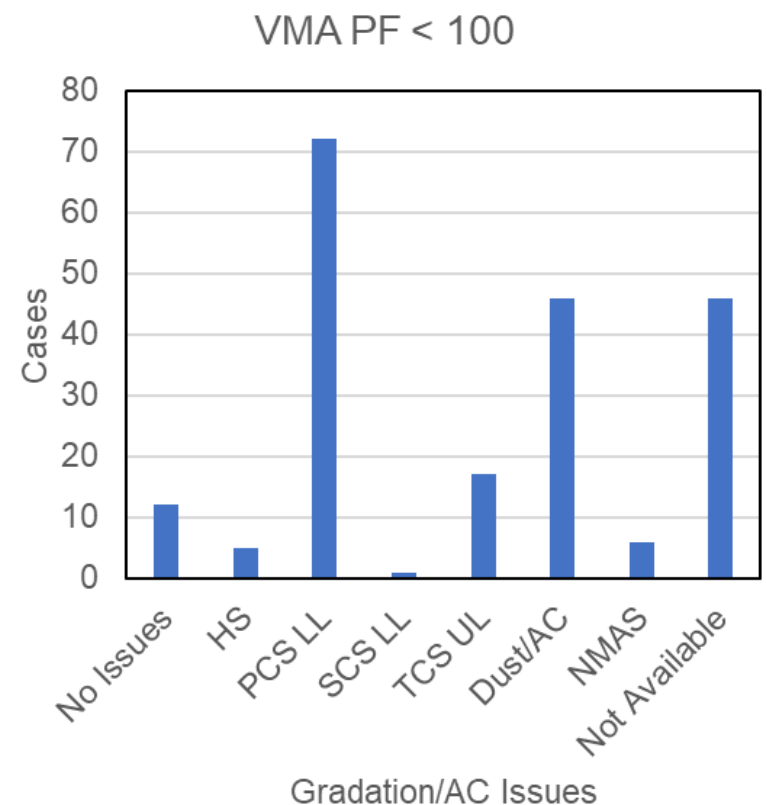

(b)

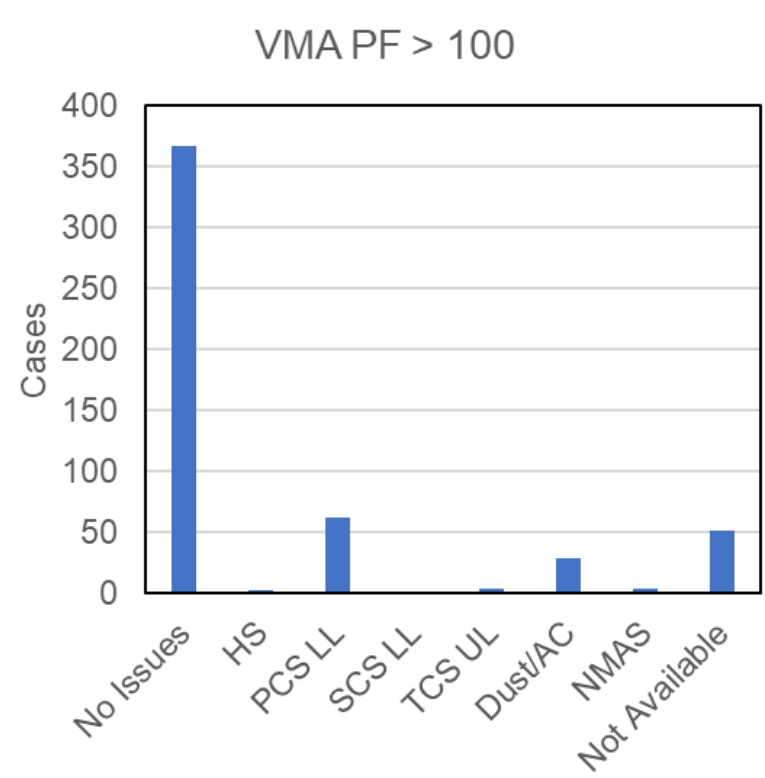

Gradation/AC Issues

(d)

Figure 4.28. Aggregate gradation issues identified for cases with and without pay disincentives. 
To describe the aggregate sizes that caused issues with aggregate production, the standard deviation and coefficient of variation (COV) of all the gradation results per mix contract case was computed for each required sieve size used. The standard deviation of each mix contract case was grouped for LB (Figure 4.29), BC (Figure 4.30), and SC mixes (Figure 4.31) to create boxplots that show the distribution between the 690 cases that were analyzed. For all mix types, coarser aggregates were more susceptible to higher variability, which led to the issues in aggregate gradations discussed. In LB mixes sieves \#4, \#8, \#16, and \#30 showed the highest standard deviation. Also, 9.5 NMAS LB mixes had higher standard deviation for these sieves than 4.75 LB NMAS. For BC mixes, sieves 1/2", 3/8", and \#4 (which corresponded to the coarse aggregate fraction) showed the largest amount of variability. Similarly, 3/8" and \#4 also showed the highest variance in SC mixes. The COV analysis typically showed that the smaller the sieve size, the more susceptible to higher COV for most mix types (Figures 4.29-4.31). Finally, between all mix types, LB 4.75 mixes showed the least amount of aggregate gradation variance.

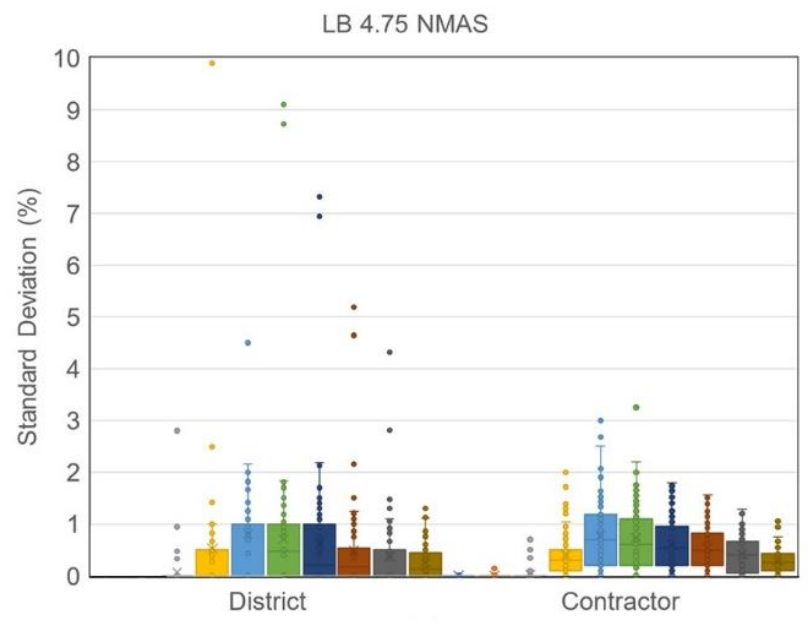

(a)

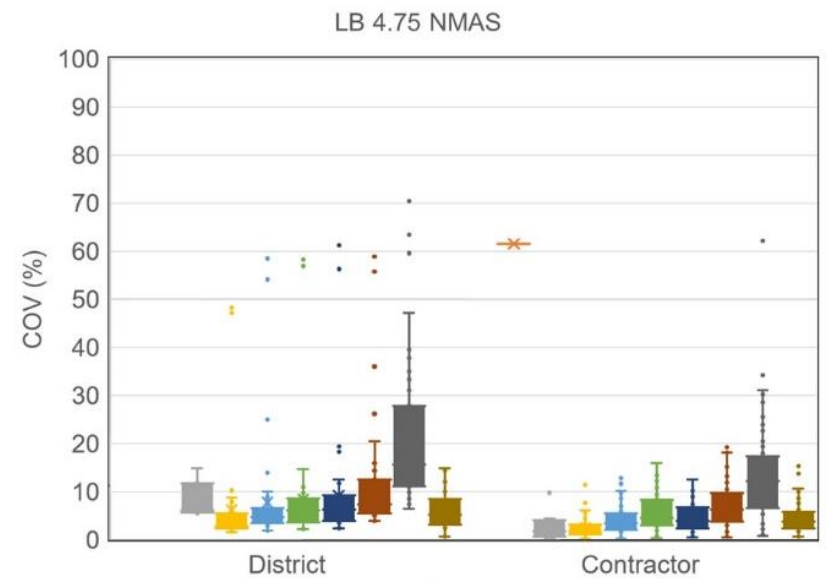

(c)

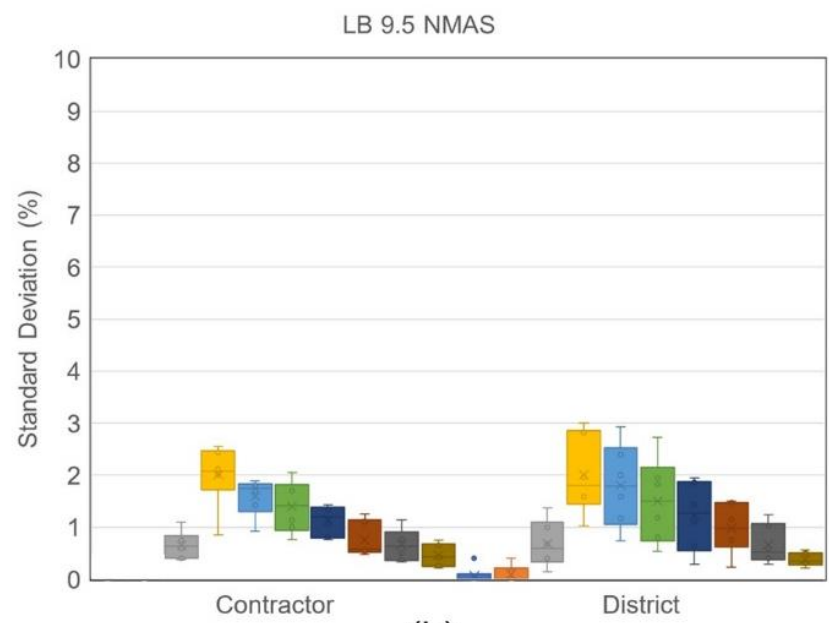

(b)

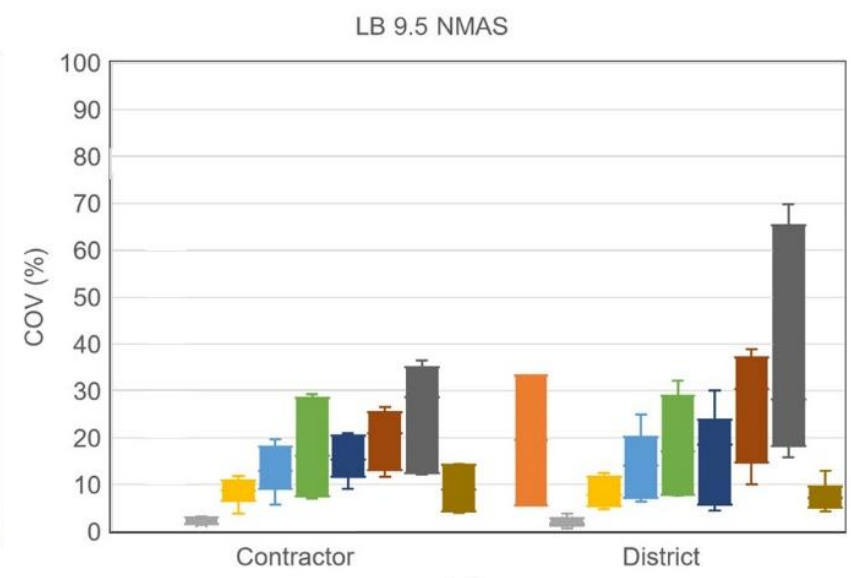

(d)

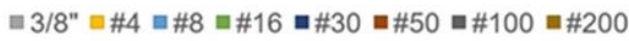

Figure 4.29. Distribution of aggregate gradation standard deviations per sieve size for LB mixes. 


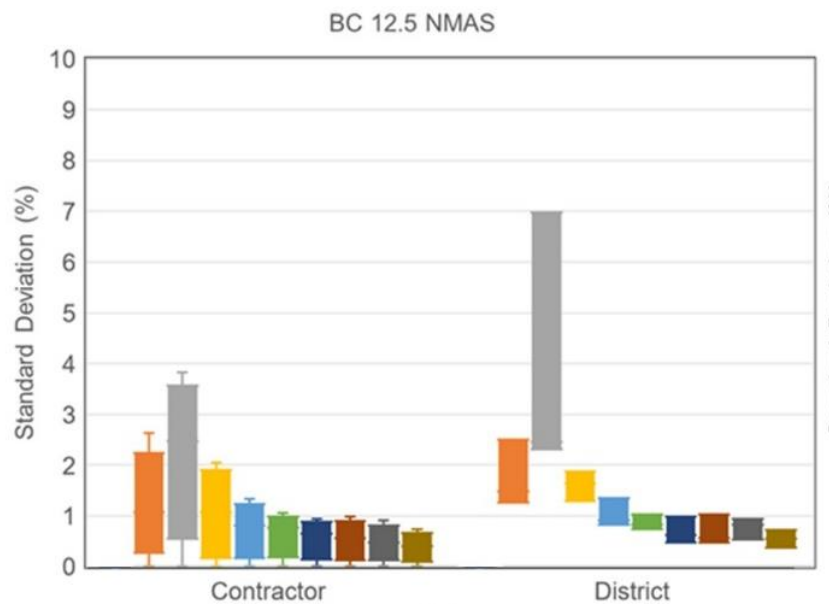

(a)

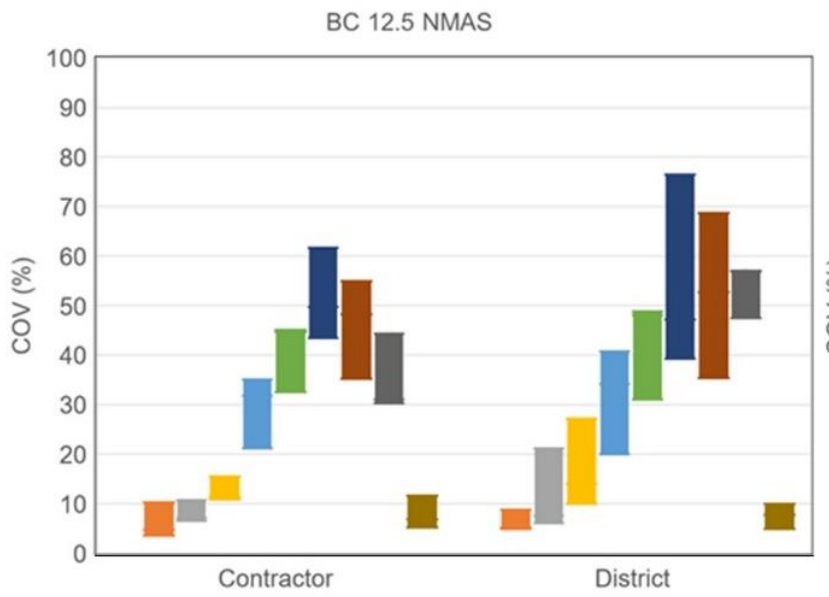

(c)

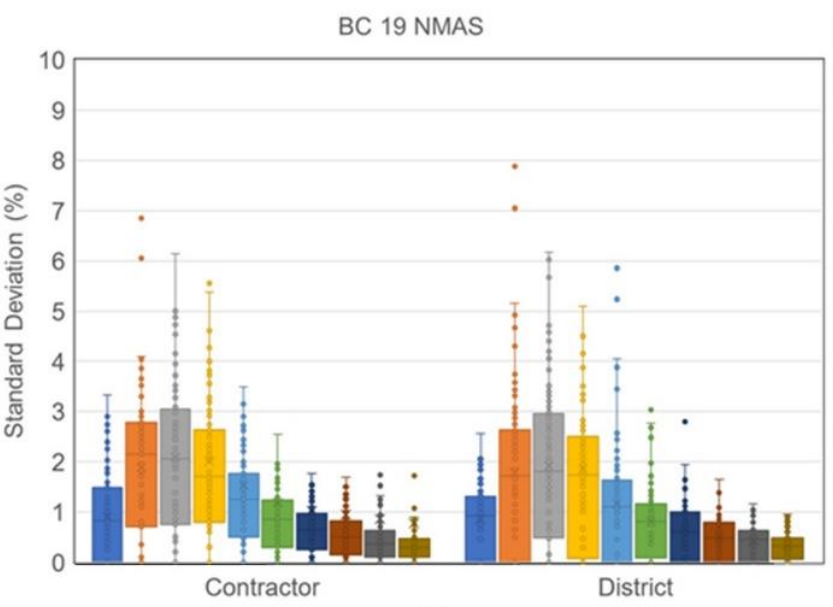

(b)

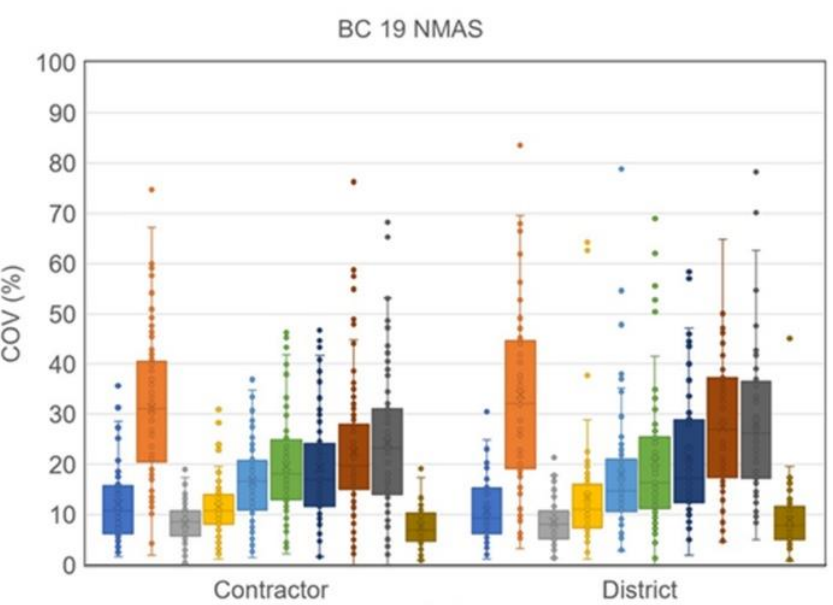

(d)

=3/4" =1/2" =3/8" =\#4 =\#8 =\#16 =\#30 =\#50 =\#100 =\#200

Figure 4.30. Distribution of aggregate gradation standard deviations per sieve size for BC mixes. 


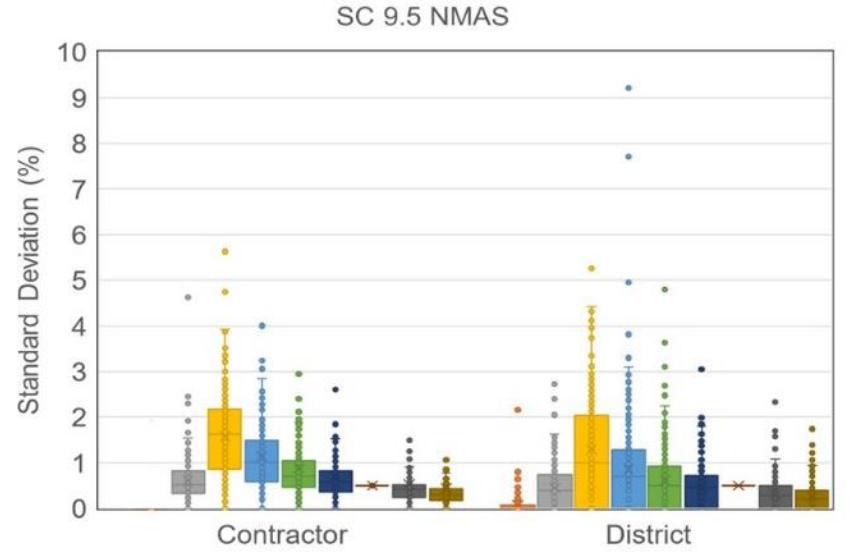

(a)

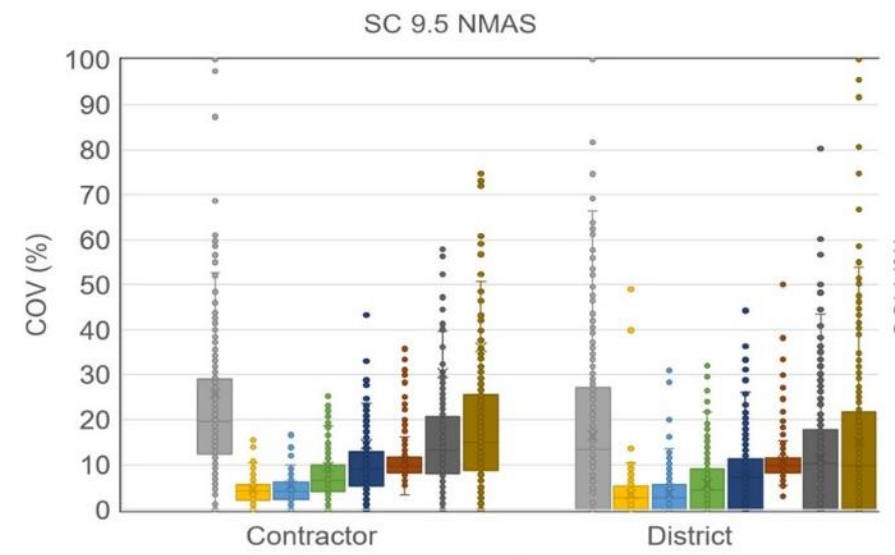

(c)

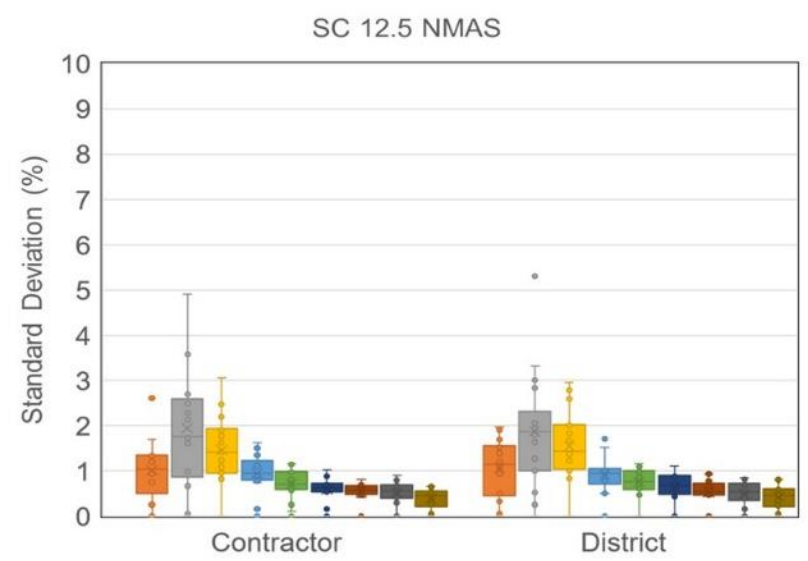

(b)

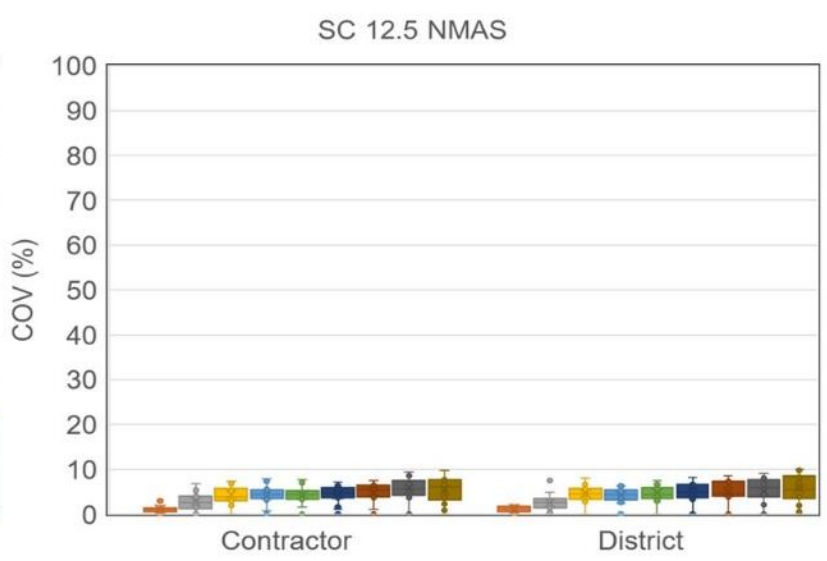

(d)

$=1 / 2 "=3 / 8 "=\# 4=\# 8=\# 16=\# 30=\# 50=\# 100=\# 200$

Figure 4.31. Distribution of aggregate gradation standard deviations per sieve size for SC mixes.

\subsection{VOLUMETRIC TESTS ( $\mathrm{G}_{\mathrm{MB}}$ AND $\mathrm{G}_{\mathrm{MM}}$ ) RESULTS EVALUATION}

Most contractor and district results ( $91 \%$ of $\mathrm{AV}, 88 \%$ of VMA, and $82 \%$ of density results) were not significantly different. However, the Mann-Whitney test results did not account for the effects of testing because cases with significant differences between contractor and district results were detected. As a result, the major source of testing differences between contractor and district results was investigated.

Despite not being pay parameters (i.e., not being used to calculate pay factors), it is important to analyze theoretical maximum specific gravity of the mixture $\left(G_{\mathrm{mm}}\right)$ and bulk specific gravity of the mixture $\left(G_{m b}\right)$ data, as they can shed light on the variability and bias in AV and VMA. This section presents the results of statistical testing, including Shapiro-Wilk, Mann-Whitney, and Levene's tests for $\mathrm{G}_{\mathrm{mm}}$ and $\mathrm{G}_{\mathrm{mb}}$. 


\subsubsection{Distribution and Average Comparison}

Figure 4.32 (a) and (c) shows the differences in the two parameters ( $G_{m m}$ and gyratory $\left.G_{m b}\right)$ between the districts and the contractors calculated using Equation (4.3).

\section{D = Volumetric Result D $_{D}-$ Volumetric Result}

where, $D$ is difference in the volumetric result; Voumetric Result $_{D}$ is average of $\mathrm{G}_{\mathrm{mb}}$ or $\mathrm{G}_{\mathrm{mm}}$ district sublot results; and Volumetric Result R $_{\text {is average of }} \mathrm{G}_{\mathrm{mb}}$ or $\mathrm{G}_{\mathrm{mm}}$ of the contractor sublot results.

The difference in $\mathrm{G}_{\mathrm{mm}}$ of less than $( \pm 0.010)$ in the average sublot results between districts and contractors is $76 \%$. On the other hand, $G_{m b}$ has only $62 \%$ of the cases with differences of less than \pm 0.01 . The greater differences for $G_{m b}$ may be attributed to the following sources: testing variability, reheating, compaction, sample soaking, gyratory compactive effort, and SSD weight, as opposed to only reheating and sample soaking in the case of $\mathrm{G}_{\mathrm{mm}}$. The AASHTO acceptable range for the $\mathrm{G}_{\mathrm{mb}}$ tests of two results (d2s) is 0.017 . The percentage of the cases exceeding the acceptable limits for the $\mathrm{G}_{\mathrm{mb}}$ is $15 \%$. As a result, this may indicate that a bias between the testing parties exists because of the differences in sample handling between contractors and districts.

Figure 4.32 (b) and (d) divides differences between the average $G_{m b}$ and $G_{m m}$ results per district. District $G_{m m}$ results were more comparable to the contractor results than those of $G_{m b}$. When the difference between contractor and district results for $\mathrm{G}_{\mathrm{mm}}$ is relatively high, district results are greater than those from the contractor. This could be affected by the variation in reheating procedure and time, which would affect the adsorbed binder. The longer the heating time, the higher the $\mathrm{G}_{\mathrm{mm}}$. Soaking time in the water bath is regulated by IDOT specifications.

Some districts were more likely to have $G_{m b}$ results higher than the contractor results, such as Districts 5, 8, and 9. On the other hand, Districts 1, 2, and 6 tended to have a similar proportion of the $\mathrm{G}_{\mathrm{mb}}$ results either higher or lower than the contractor results. These differences can also be a function of the fixed offsets that contractors and districts have. Contractors often keep track of the offsets between their results and the districts' results. These offsets allow the contractors to estimate where the results of the districts will probably lead. Data from Districts 5, 8, and 9 showed larger offsets of $\mathrm{G}_{\mathrm{mb}}$ values; district results were higher than the contractor values.

Figure 4.32 shows District 5 results are more likely to be higher than contractor results for both $\mathrm{G}_{\mathrm{mm}}$ and $G_{m b}$. There were more cases that had a difference of 0.005 (district being higher than the contractor) or higher than there were cases with - 0.005 difference (contractor being higher) or lower. This was noticed for both $G_{m m}$ and $G_{m b}$. This difference in $A V$ is more manifested than in VMA. VMA was only affected by $G_{m b}$ (as well as $A C$ content) but in $A V$ both the $G_{m b}$ and $G_{m m}$ contributes to the variability of this parameter. In summary, $G_{m b}$ is more critical, at this point, than $G_{m m}$ because the reported difference is greater for the former. 


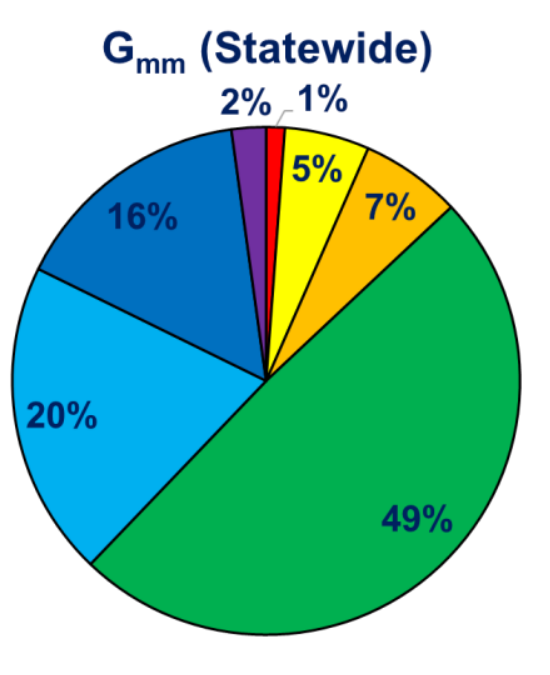

(a)

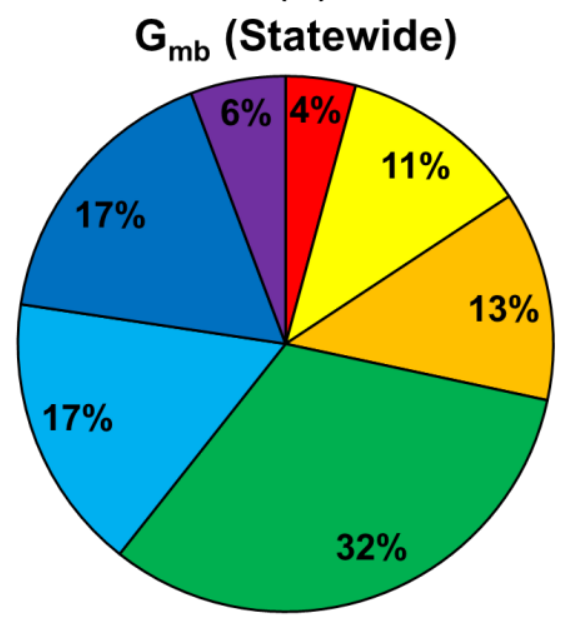

(c)

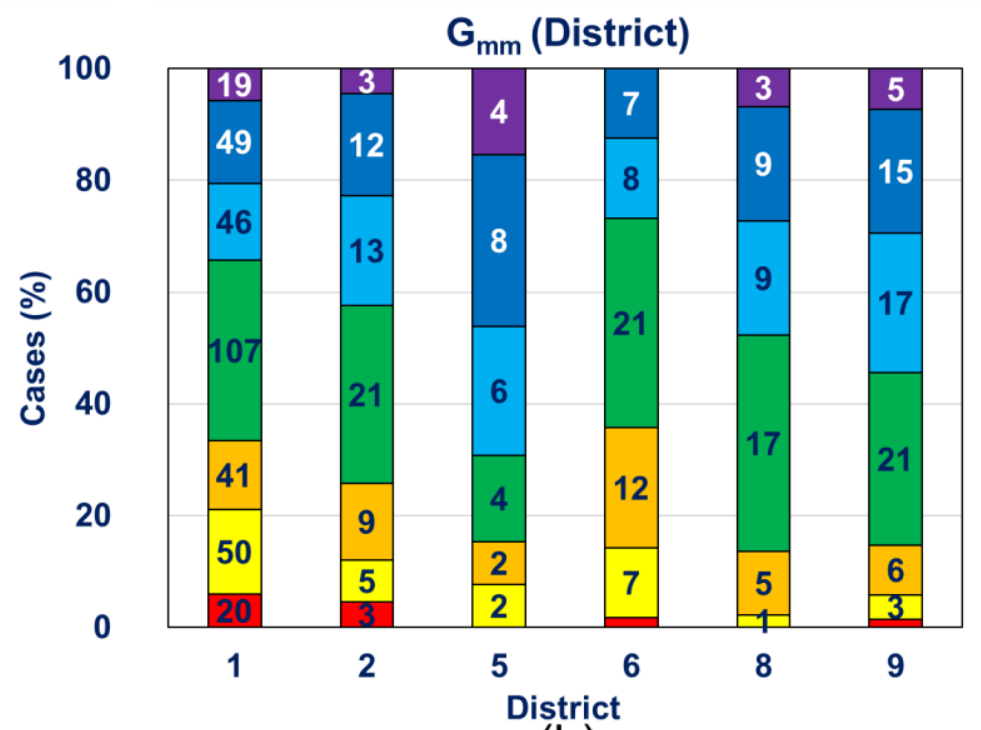

(b)

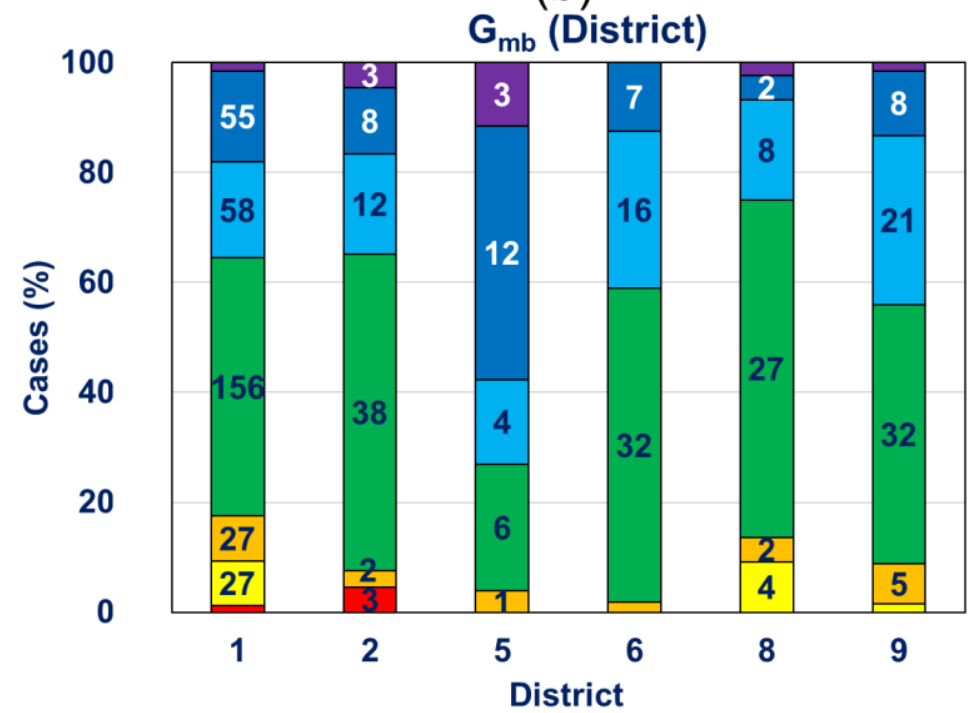

(d)

$\square<=-0.02 \square-0.02$ to $-0.01 \quad \square-0.01$ to $-0.005 \square-0.005$ to $0.005 \square 0.005$ to $0.01 \quad \square 0.01$ to $0.02 \quad \square>=0.02$

Figure 4.32. $G_{m b}$ and $G_{m m}$ differences between contractor and district results.

\subsubsection{Variability}

$\mathrm{G}_{\mathrm{mm}}$ presents less variability than $\mathrm{G}_{\mathrm{mb}} ; 81 \%$ of the total cases have standard deviation values lower than 0.005 , while $\mathrm{G}_{\mathrm{mb}}$ has $44 \%$ of values lower than 0.005 (Figure 4.33). Figure 4.34 presents the $\mathrm{G}_{\mathrm{mb}}$ and $\mathrm{G}_{\mathrm{mm}}$ standard deviations per contractor and district. In general, for the $\mathrm{G}_{\mathrm{mb}}$ test, district results have slightly lower or similar standard deviations to contractor results. In the case of $G_{m m}$, the standard deviations for contractor and district results were similar and varied less than $G_{m b}$. 


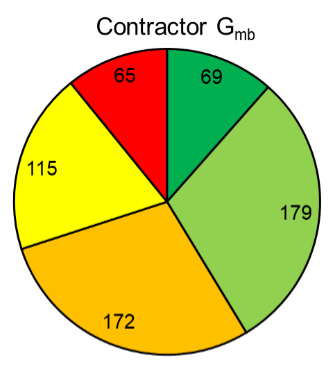

(a)

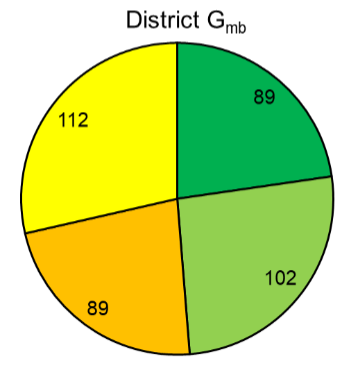

(c)

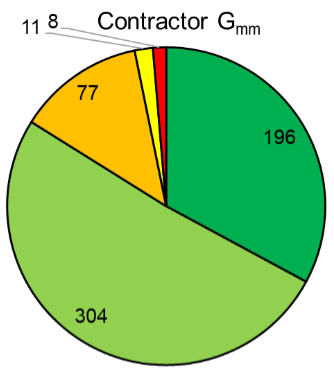

(b)

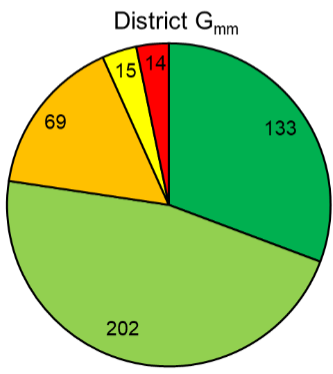

(d)

$\square 0$ to $0.005 \square 0.005$ to $0.01 \quad \square 0.01$ to $0.015 \quad \square 0.015$ to $0.02 \quad \square>0.02$

Figure 4.33. Statewide ranges of standard deviations in $\mathbf{G}_{\mathrm{mb}}$ and $\mathbf{G}_{\mathbf{m m}}$.

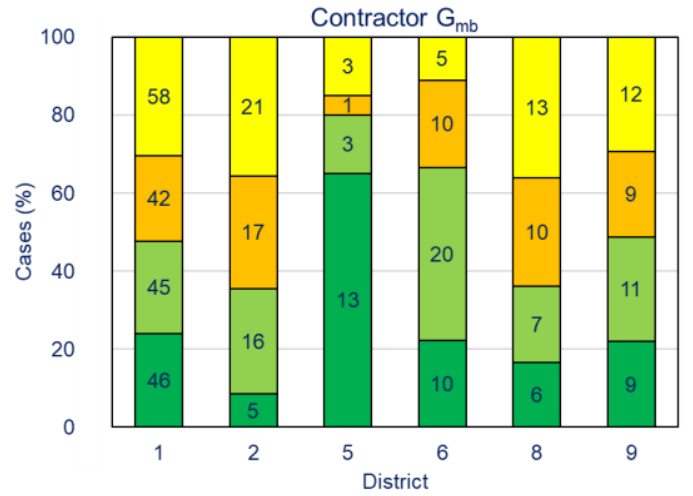

(a)

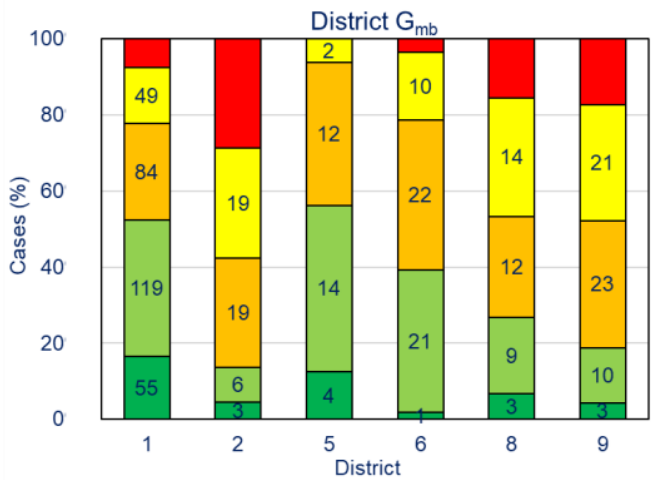

(c)

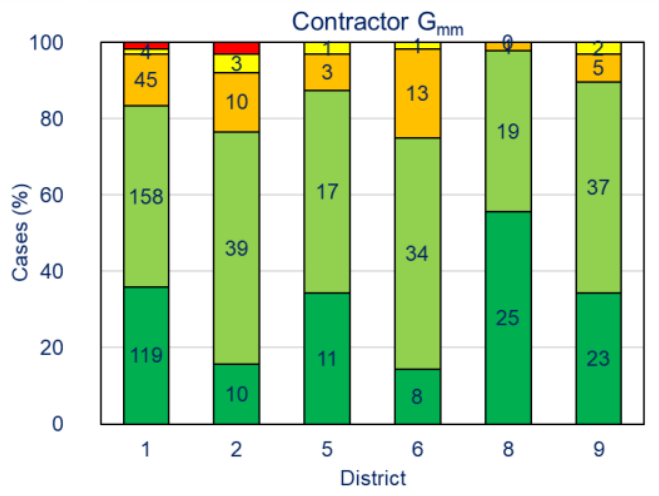

(b)

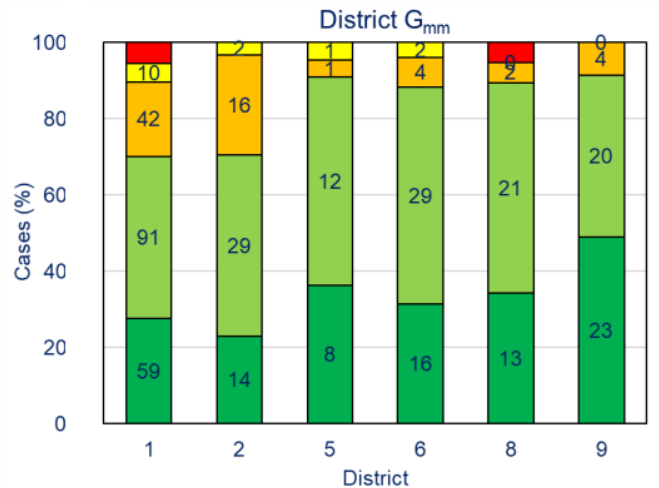

(d)

$\square 0$ to $0.005 \quad \square 0.005$ to $0.01 \quad \square 0.01$ to $0.015 \quad \square 0.015$ to $0.02 \quad \square>0.02$

Figure 4.34. Ranges of standard deviations in $\mathbf{G}_{\mathrm{mb}}$ and $\mathbf{G}_{\mathrm{mm}}$ per district. 


\subsection{PFP DISPUTE ANALYSIS}

The sublot results for the PFP dispute resolution collected from CBM records were analyzed. In PFP, contractors can dispute district sublot results if the difference exceeds the precision limits or if the result is outside the acceptable limits. The dispute of district and contractor results is conducted by the CBM. Contractors select the sublot(s) to be disputed and are required to pay for dispute testing if the dispute favors the district. Therefore, contractors do not dispute all results that are eligible for dispute because winning the dispute would either decrease pay or favor the district. In this study, all sublot results were grouped to allow an overall perspective on how each district and contractor compares with the central laboratory.

\subsubsection{Comparison Approach}

The analysis requires a one-to-one comparison to determine which of the contractor and district test results is closer to the CBM test result. The difference between CBM and the contractor $\left(\triangle C C_{m i x_{i}}\right)$ or the district $\left(\triangle C D_{\text {mix }_{i}}\right)$ results were computed using Equations (4.5) and (4.6).

$$
\begin{aligned}
& \Delta C C_{\text {mix }_{i}}=\text { Mix Property } \text { CBM }_{i}-\text { Mix Property } \text { contractor }_{i} \\
& \Delta C D_{\text {mix }_{i}}=\text { Mix Property }_{C B M_{i}}-\text { Mix }_{\text {Property }} \text { district }_{i}
\end{aligned}
$$

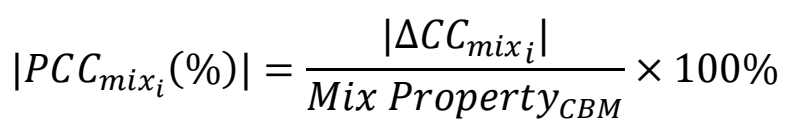

$$
\begin{aligned}
& \left|P C D_{\text {mix }_{i}}(\%)\right|=\frac{\left|\Delta C D_{\text {mix }_{i}}\right|}{\text { Mix } \text { Propert }_{C B M}} \times 100 \%
\end{aligned}
$$

where:

- $\left(\triangle C C_{\text {mix }_{i}}\right.$ ): difference between CBM and contractor mix property (AV, VMA, $\mathrm{G}_{\mathrm{mb}}, \mathrm{G}_{\mathrm{mm}}$, and density) result;

- $\left(\triangle C D_{\text {mix }_{i}}\right.$ ): difference between CBM and district mix property (AV, VMA, $\mathrm{G}_{\mathrm{mb}}, \mathrm{G}_{\mathrm{mm}}$, and density) result;

- $\left(P C C_{m i x_{i}}\right)$ : difference between CBM and contractor normalized in percentage to the mix property magnitude; and

- $\left(P C D_{\text {mix }_{i}}\right)$ : difference between CBM and contractor normalized in percentage to the mix property magnitude.

For the one-to-one comparison between $\left|P C C_{\text {mix }_{i}}\right|$ and $\left|P C D_{\text {mix }_{i}}\right|$, the smaller of the two indicates its proximity to the CBM test results, Equations (4.7) and (4.8). The mix properties evaluated were AV, VMA, $G_{m b}, G_{m m}$, and density.

\subsubsection{Mix Dispute Analysis}

The results of dispute analysis for the mix pay parameters (AV and VMA) are presented in Figure 4.35. The blue (contractor) and orange (district) bars represent CBM's result proximity to contractor and 
district results, respectively. The gray (neither) bar refers to the number of tested samples when the absolute percent difference between the CBM results and contractor/district results is the same. Statewide, in more than $63 \%$ of the cases, the CBM results were closer to the contractor results for AV and VMA. Contractors typically were closer to the CBM test results in $60 \%$ to $70 \%$ of the cases for AV. For VMA, contractors were closer to the CBM test results in $60 \%$ to $70 \%$ of the cases in Districts 1 , 2 , and 6. Only District 9 had comparable percent ratios for contractor and district. In general, District 5 had no dispute for any mix property.

The contractor and CBM AV and VMA test results were comparable because the $\mathrm{G}_{\mathrm{mb}}$ values were more comparable than $\mathrm{G}_{\mathrm{mm}}$. Figure 4.36 shows the results of the $\mathrm{G}_{\mathrm{mb}}$ and $\mathrm{G}_{\mathrm{mm}}$ tests. Contractors typically are closer to CBM's test results in $60 \%$ to $70 \%$ of the cases for $\mathrm{G}_{\mathrm{mb}}$ (similar rates as seen for $A V$ and $V M A)$. For the case of $G_{m m}$, contractors were closer to CBM's test results in Districts 1, 8, and 9. In District 2 and 6, district test results were closer to CBM's.

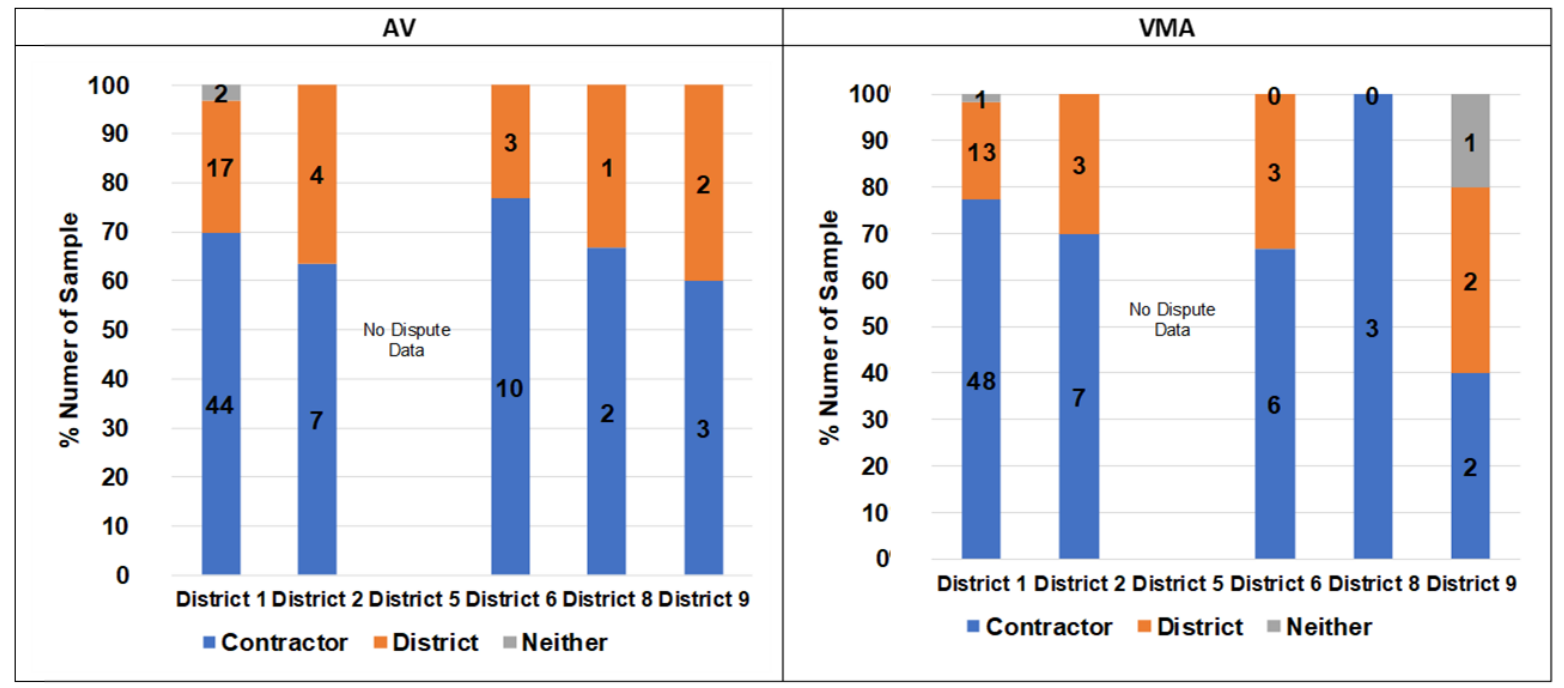

Figure 4.35. AV and VMA dispute analysis results by district.

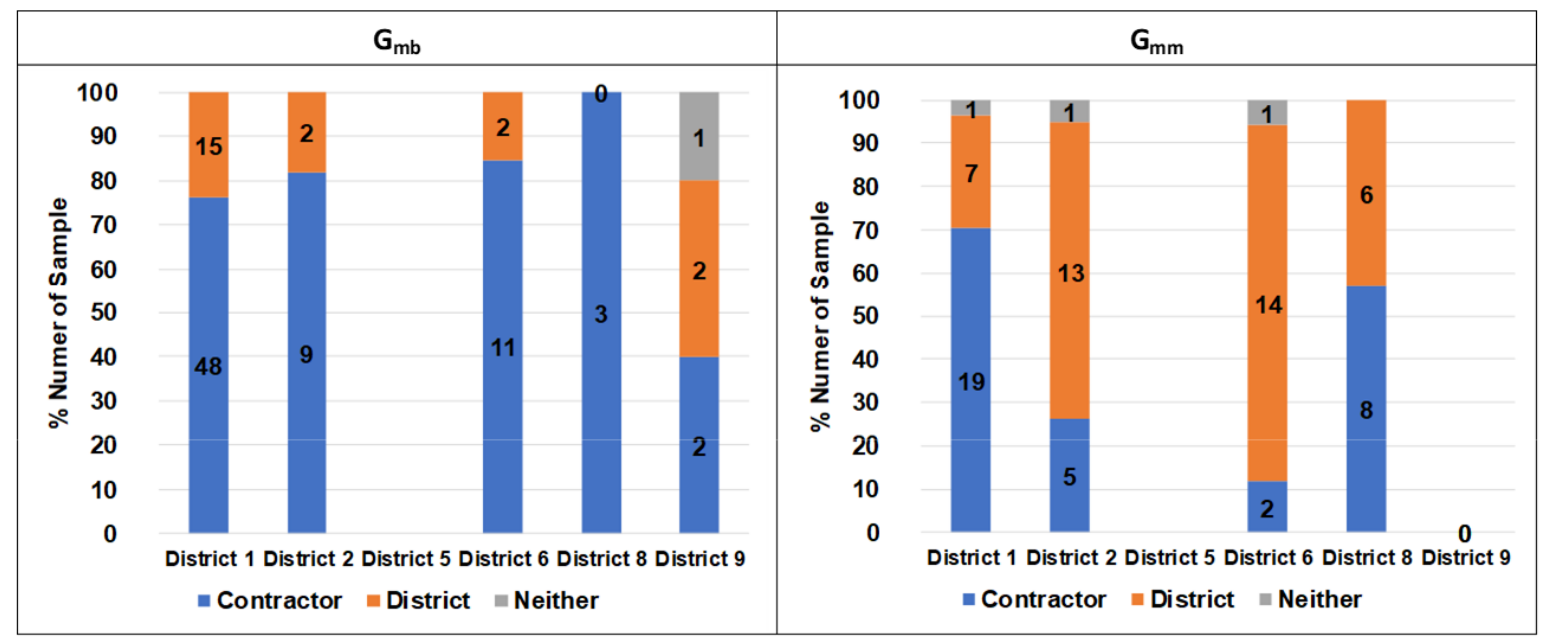

Figure 4.36. $G_{m b}$ and $G_{m m}$ dispute analysis result by district. 


\subsubsection{Core Density Dispute Analysis}

According to the core density comparison shown in Figure 4.37 (a), $57.7 \%$ and $41.7 \%$ of the sublots indicate the proximity of $\mathrm{CBM}$ test results to contractor and district results, respectively. The remaining $0.6 \%$ indicates that $\left|P C C_{\text {density }}\right|$ and $\left|P C D_{\text {density }}\right|$ are the same. The results are presented per district in Figure 4.37 (b). Blue (contractor) and orange (district) bars indicate the proximity of CBM results to contractor and district results, respectively. The gray (neither) bar indicates that the absolute percent difference between CBM results and contractor/district results was the same. Districts 5 and 6 (and District 1 to a lesser degree) results favored the contractor more than the district. Of the District 2 results, $60 \%$ of the samples were similar to CBM's. District 8 was close to a 50-50 comparison with CBM. The top three disputed PFP mixes were SMA SC N80 12.5 F REC, HMA SC N70 D REC, and SMA SC N80 9.5 REC. While the top three density disputed PFP mixes were HMA BC N90 19.0R, HMA SC N90 D REC, and HMA SC N70 D REC.

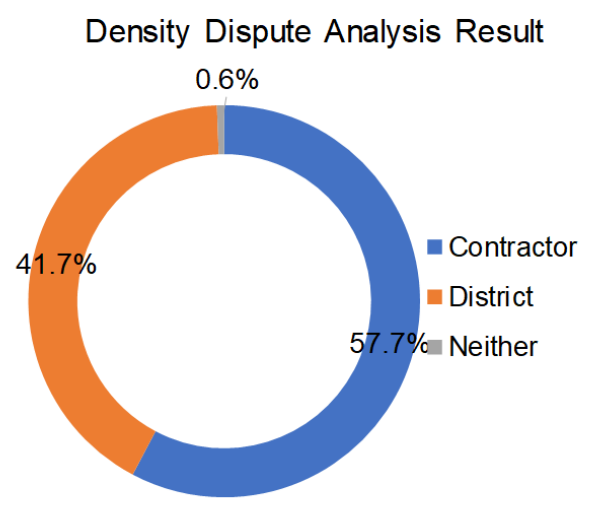

(a)

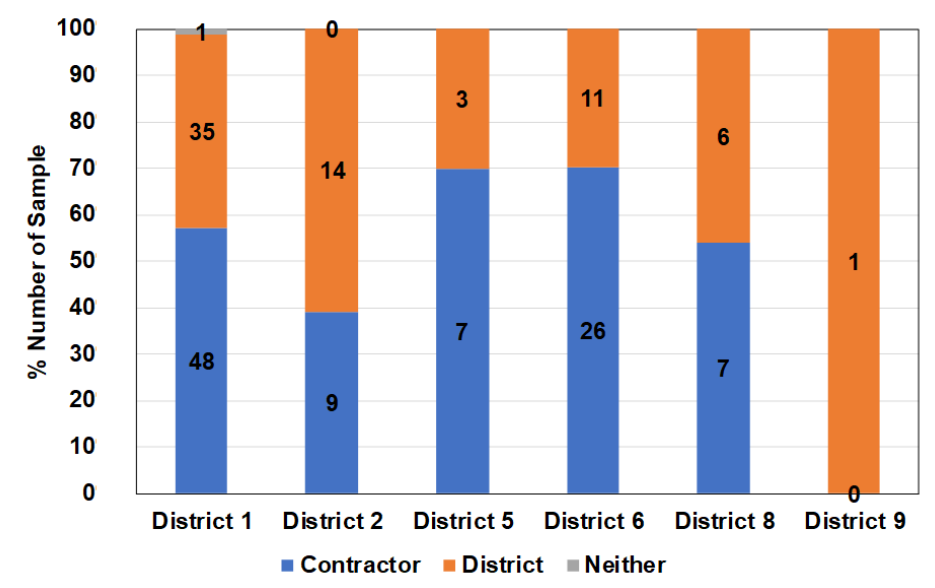

(b)

Figure 4.37. Statewide density dispute analysis result.

\subsection{ROUND ROBIN DATA ANALYSIS}

Round robin neutralizes construction- and production-associated variability and concentrates only on testing issues. During each yearly round robin test, a plant-produced mix is sampled and sent to selected district and contractor laboratories. The laboratory-conducted $\mathrm{G}_{\mathrm{mm}}$ and $\mathrm{G}_{\mathrm{mb}}$ tests for the samples follow IDOT specifications. Therefore, under ideal situations, all test laboratories should report the same values. Differences may be attributed to equipment, operator factors, and/or potentially testing a non-representative sample. Data from the 2015 to 2018 round robins were collected.

\subsubsection{Variability Rating Method}

The round robin results were analyzed based on the average of the results. Outliers were removed to prevent inaccurate data from affecting the evaluation. The average and standard deviation for each data set were computed and used to determine Z-scores. The Z-score measures how far the results of a laboratory were from the mean. Round robin data were assumed to be normal. Consequently, Z- 
scores were calculated using Equation (4.9). To illustrate the Z-score, Figure 4.38 shows the normal distribution probability density function.

$$
Z_{i}=\frac{\overline{x_{l}}-\bar{x}}{s}
$$

where, $Z_{i}$ is Z-score in lab $\mathrm{i} ; \bar{x}_{l}$ is average of the two tests conducted at lab $\mathrm{i} ; \bar{x}$ is average of all tests conducted statewide in that specific year; and $s$ is standard deviation calculated based on all tests statewide.

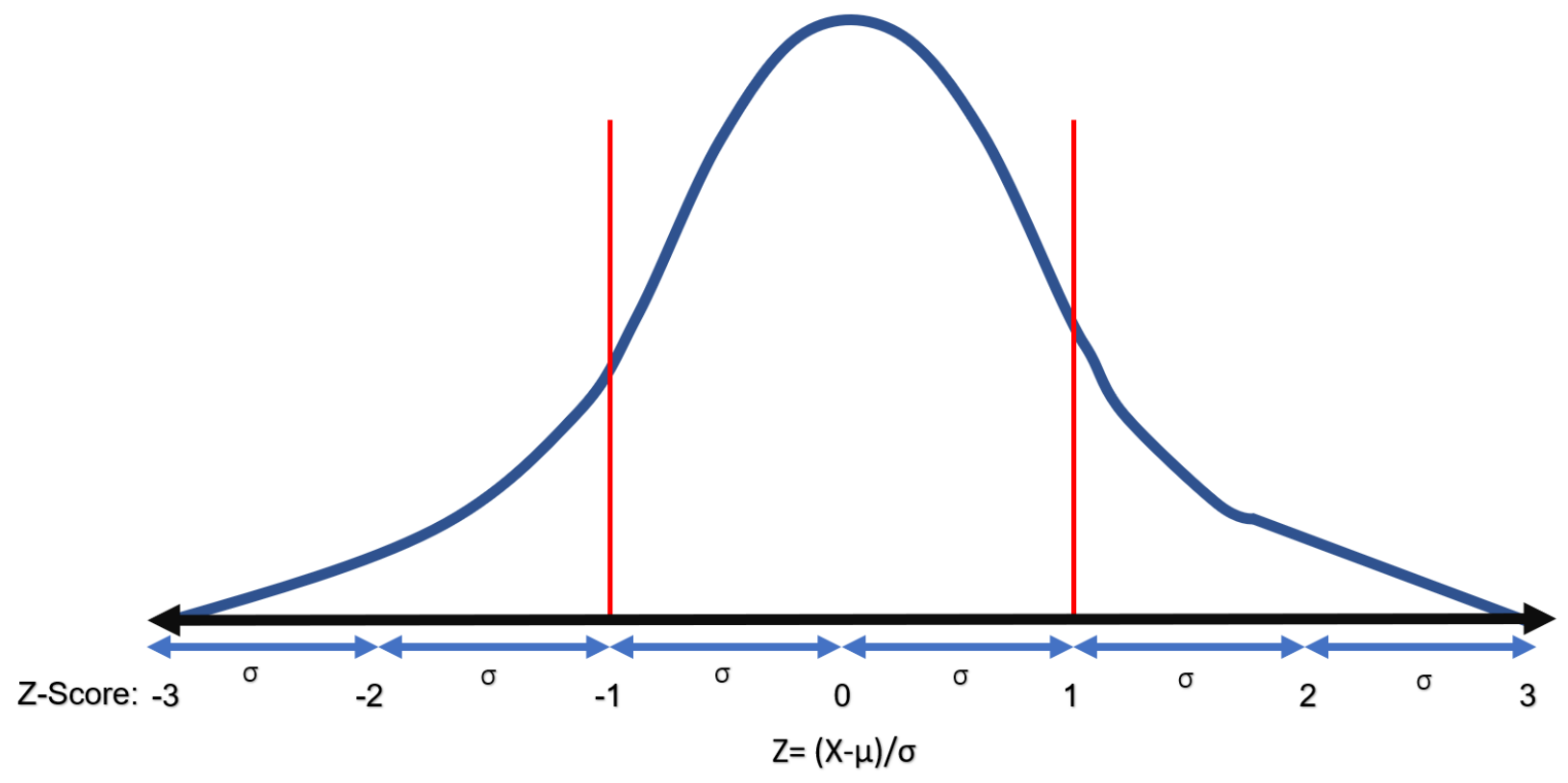

Figure 4.38. Normal distribution of round robin data.

\subsubsection{Z-Score Evaluation of District and Contractor Laboratories}

The Z-score analyzed for both $G_{m b}$ and $G_{m m}$. $G_{m m}$ standard deviations did not exceed 0.005 for all districts, while $\mathrm{G}_{\mathrm{mb}}$ standard deviations varied per district, as shown in Figures 4.39 and 4.40. The following were observed:

- $\mathrm{G}_{\mathrm{mm}}$ : All district laboratories were close to the average $\mathrm{G}_{\mathrm{mm}}$ result. However, because of the low standard deviation, the Z-score varied, and the district results were either higher or lower than the average $\mathrm{G}_{\mathrm{mm}}$ and no bias was observed.

- $\mathrm{G}_{\mathrm{mb}}$ : For District 1, the district laboratory was consistently lower than the round robin means, and the contractor results were around the mean (Figure 4.41). District 2 laboratory results were kept within 0.5 of the standard deviation. District 5 was the second-closest laboratory to the mean. In the first three years, District 6 consistently had lower $\mathrm{G}_{\mathrm{mb}}$ results from the mean. The laboratory in District 8 was the closest to the state mean in the five years analyzed. The contractors of the district were equally spread or either higher or lower than the district result. $G_{m b}$ round robin results show that District 9 results were consistently higher than the mean. 


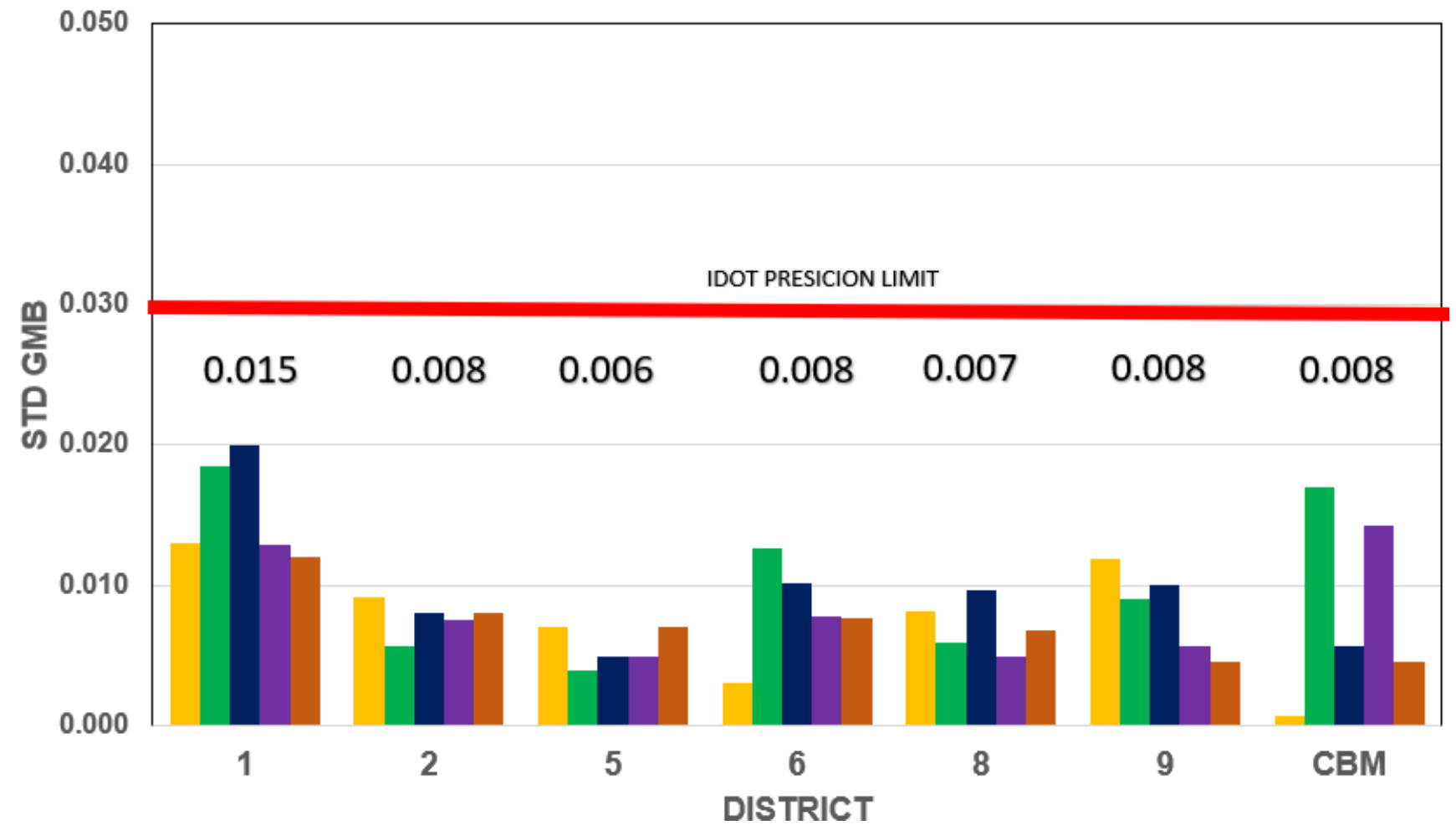

Figure 4.39. $\mathrm{G}_{\mathrm{mb}}$ Standard deviations per district. (Each color represents a different round robin year.)

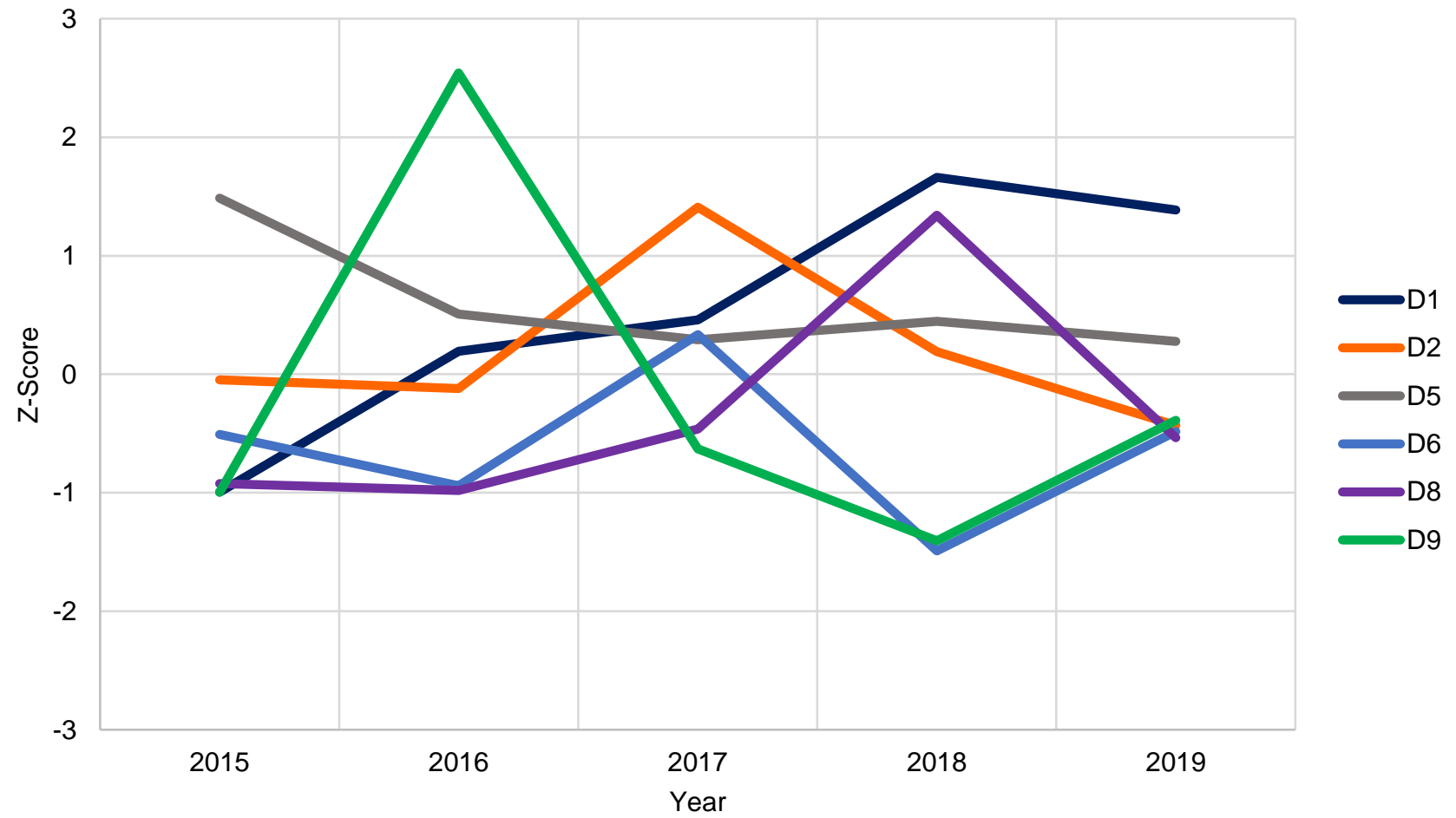

Figure 4.40. $\mathrm{G}_{\mathrm{mm}} \mathrm{Z}$-scores for district laboratories. 


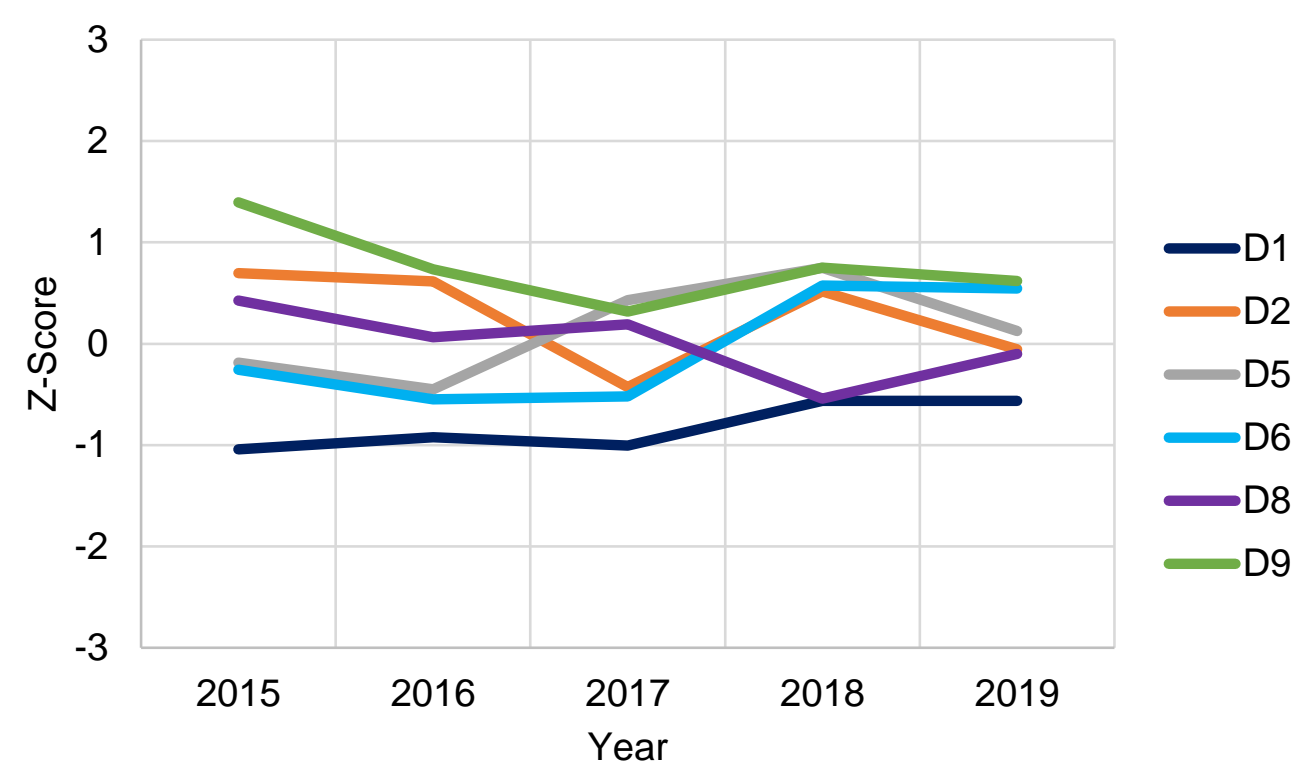

Figure 4.41. $\mathrm{G}_{\mathrm{mb}} \mathrm{Z}$-scores for district laboratories.

\subsubsection{Gyratory Compactor Effect}

$\mathrm{G}_{\mathrm{mb}}$ test results were grouped separately by gyratory compactor to see if the type of gyratory compactor notably influences the results, Figure 4.42. For the gyratory compactor type, the Z-scores were within \pm 0.5 standard deviation, except for the IPC Servopac 2500 (used only by one round robin participant), which produced $G_{m b}$ results lower than the average, Figure 4.42 (b). Hence, equipment calibration and operation and sample handling, rather than the brand, may be responsible for the bias. Figure 4.42 (c) shows the standard deviation for gyratory compactors per year.

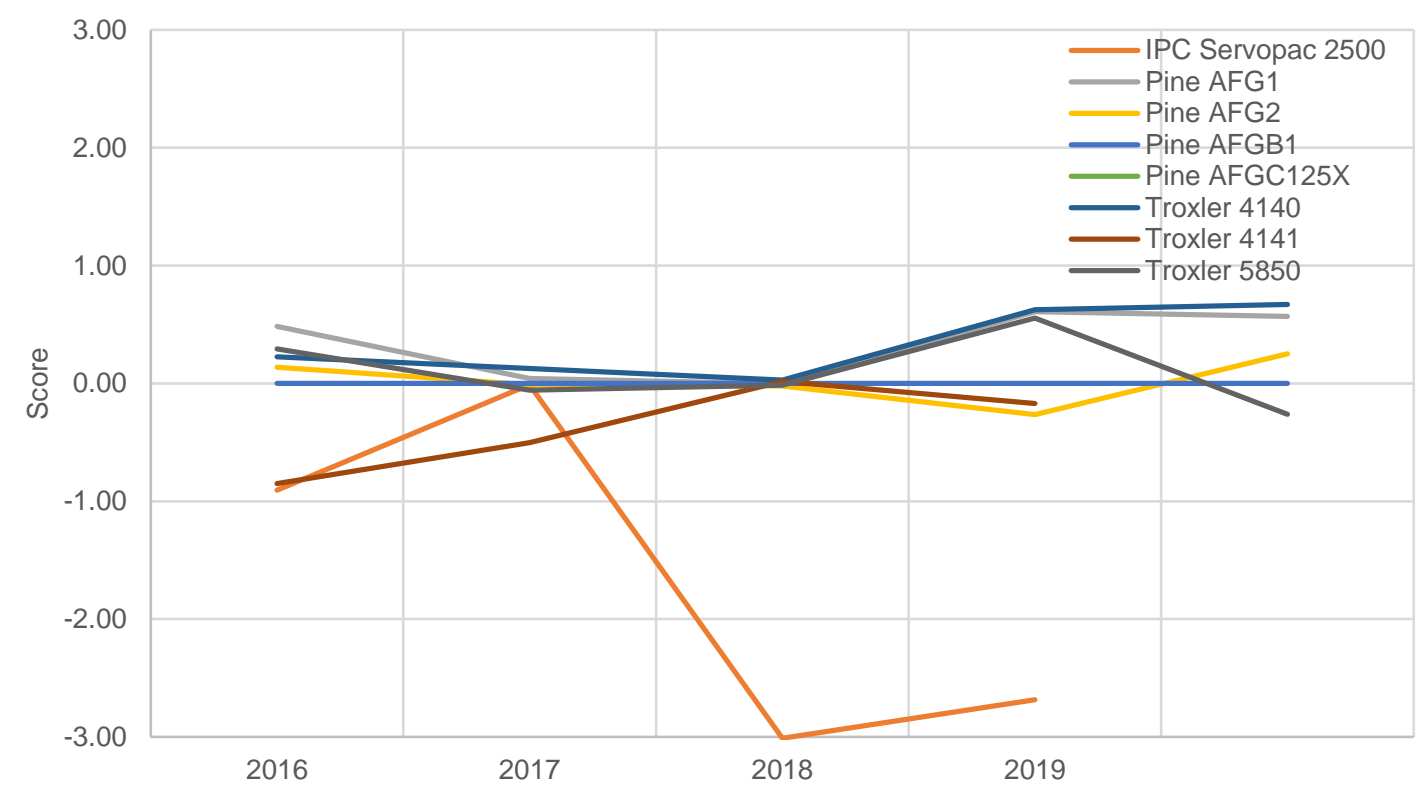

(a) 


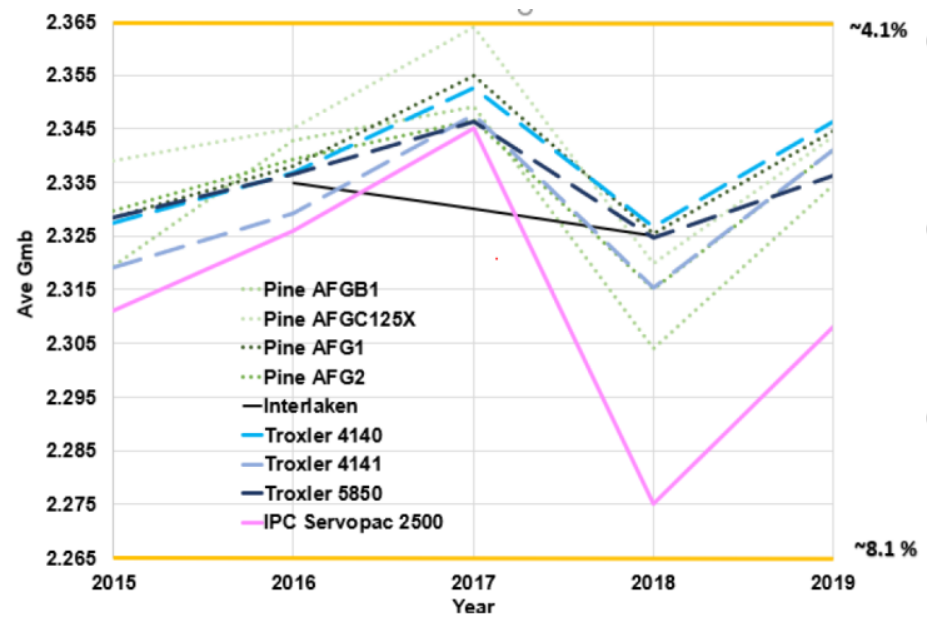

(b)

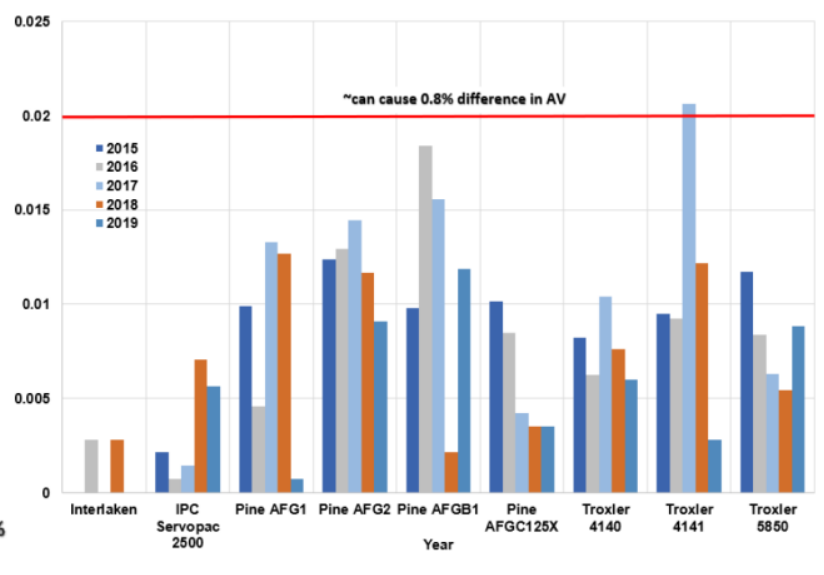

(c)

Figure 4.42. Gyratory compactor evaluation results: (a) Z-scores, (b) average result, (c) standard deviations.

\subsection{SUMMARY}

Statistical analysis showed that contractor and district results were not significantly different for most cases evaluated. In cases where contractor and district results were not significantly different, but a pay disincentive was assigned, aggregate gradation and/or asphalt content may affect the produced mix because of production and/or aggregate source variability. Twenty to thirty percent of cases had a significant difference in test results, suggesting potential testing issues. The main observations from the data analysis are the following:

\subsubsection{Pay Factor Observation Summary}

- The QCP specification is used more frequently than PFP by the number of cases; however, the total mix tonnage produced is slightly lower than PFP.

- Contractors have more experience working with QCP projects as compared to PFP projects. Of the 22 contractors working with PFP cases, 11 had fewer than five cases during the last three years. It is suggested to educate contractors about the PWL calculations used in the PFP specification.

- PFP has reported consistently higher pay disincentives than QCP. This is due to PFP's more stringent PWL approach than the step-based system used by QCP. However, it is possible to make a pay incentive in PFP as opposed to QCP. Over the three years evaluated in this study, contractors have increased their pay in QCP. The pay is typically between 97.5 to 100. PFP pay performance has not increased over the last three years.

- Projects in Districts 5 and 6 received higher pay than the rest of the districts in both PFP and QCP specifications. In QCP, District 2 had the most pay disincentives. In PFP, Districts 1 and 9 received the most pay disincentives in PFP specifications. 
- Contractor pay varies within the same district. Some contractors received full pay while others received pay disincentives.

- In the QCP specification, the performance of the contractors for individual pay factors (density, AV, and VMA) was similar. However, in the PFP specification, density was the most influential factor driving the pay disincentive. This might be because PFP is a more stringent program and considers variability, especially in density.

- Leveling binder was found to be the most penalized in QCP; while in PFP, it was the SC mix. Note, however, that no LB cases were studied for PFP.

- In QCP, density was the major factor contributing to the LB pay disincentives, while the three pay factors ( $A V, V M A$, and density) had a similar influence in the total pay for $B C$ and SC.

- In PFP, density was a major factor driving pay disincentives for BC and SC. As expected, AV had higher pay disincentives than VMA because AV was more variable.

\subsubsection{Pay Parameter Summary}

- Most of the AV and VMA cases seemed to follow a normal distribution. Cases with fewer sublot replicates failed the Shapiro-Wilk test. However, for density, the distribution fails to be normal. This was more pronounced for both smaller and larger numbers of replicates.

- $4.75 \mathrm{~mm}$ mixes resulted in better pay because VMA and density were easier to achieve than the $9.5 \mathrm{~mm}$ level binder mixes that were placed at a thickness less than the recommended three times NMAS. For SC and BC, NMAS did not play a significant distinction between the results.

- In general, the results failing VMA and density were usually lower, while AV could be lower or higher.

- Production issues with AV and VMA could have been reflected as disincentives associated with all three pay factors (AV, VMA, and density).

- At a statewide level, the results of contractors and districts were not significantly different for $91 \%$ of $A V, 88 \%$ of VMA, and $82 \%$ of density results. Density was the parameter that showed the largest percentage of significant differences, followed by VMA and AV.

- Note that significant differences were seen in cases that obtained full pay and those that received a pay disincentive. For the significantly different cases that received full pay, contractor results had sublots outside of the QCP and PFP upper limits, while district results were within the limits. On the other hand, in cases that were significantly different and have a pay disincentive, the district results were outside the limits and the contractor results were not. Note that contractors keep track of the offsets between their results and those of the districts, which could influence the observed difference in the data. However, these offsets are per each contractor and district combination.

- When there are differences between district and the contractor results:

- AV: District results could be higher or lower than contractor results. 
○ VMA: District results are lower than contractor results.

○ Density: District results are lower than contractor results.

- District 6 results for AV and VMA are close to the contractor values or higher than the contractor. If the district overestimates the results consistently, mixes within the limits still obtain full pay. Sampling, splitting, and testing observed in District 6 were consistent and acceptable.

- District 5 test result variability in AV and VMA are lower than the rest of the districts, which contributed to better pay performance. District $5 \mathrm{VMA}$ values have more significant differences between contractor and district results.

- As expected, AV standard deviation values are higher than those of VMA. In PFP, variability impacts pay calculation in the PWL specification.

- The cases that resulted in a pay disincentive either in AV or VMA were also likely to have issues with the aggregate gradation results.

- $\mathrm{G}_{\mathrm{mm}}$ is a test in which the contractor and the district achieved more comparable results than in the $G_{m b}$ test.

- PFP mix disputes typically are in favor of the contractor for AV and VMA, while PFP density disputes were close to a 58-42 ratio in favor of the contractor. However, the contractors select which sublot(s) to dispute.

- From IDOT round robin results, inconsistent results between districts and contractors could be related to equipment calibration, operation, and/or non-representative samples. 


\section{CHAPTER 5: 2018 JOBSITE VISITS}

\subsection{INTRODUCTION}

During the 2018 construction season, 11 contracts were studied by the ICT research team to assess the possible causes of data variability and bias. Each contract study comprised of three parts: interviewing district and contractor personnel on testing procedures and data analysis; monitoring sampling, blending, and splitting during mix production and construction at district laboratories, plants, and the jobsites; and analyzing data and test results to identify possible causes of pay incentives/disincentives and differences between contractor and district test results.

This chapter describes the procedure used to select and evaluate each contract; the outcome of each evaluation is available in a second report (Al-Qadi et al., 2020). Issues observed during production, construction, and testing were identified and described.

\subsection{SITE SELECTION}

Location and contractor pay factors were the main criteria for selecting the visited contractors. A minimum of one project per district was identified, except for District 1 . Five projects in District 1 were selected because the district has approximately $38 \%$ of the total contractors. For the pay factor, the QCP and PFP pay success rate (100\% pay or more) was considered. Figure 5.1 shows the 20152017 pay factor distribution for the visited contractors. The goal was to choose contractors that consistently achieve full pay and who struggle to achieve full pay, representing different pay performance realities. For example, in QCP, four contractors achieved $100 \%$ pay for $75 \%$ or more of the total produced tonnage; five contractors achieved $100 \%$ pay for approximately $50 \%$ of their produced tonnage; two contractors achieved $100 \%$ pay for $25 \%$ of the total tonnage or less; and the contractors to be visited were chosen accordingly. A similar selection approach was used with PFP.

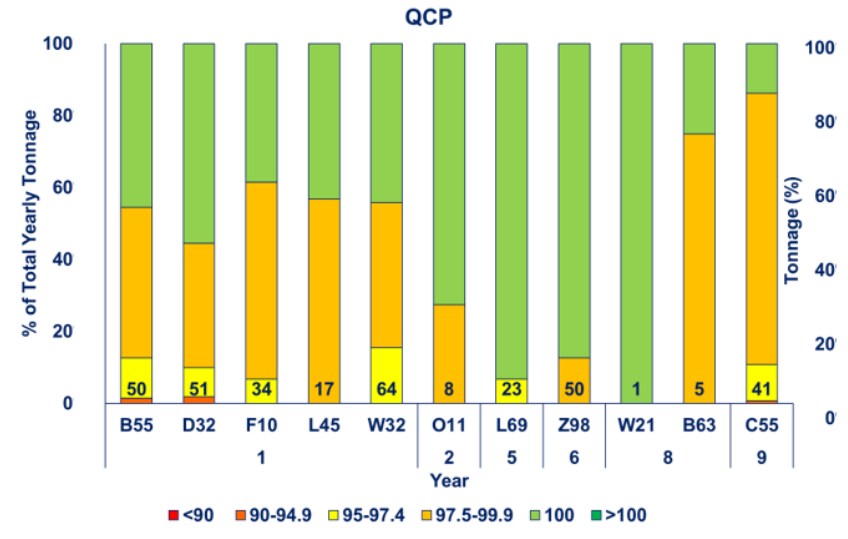

(a)

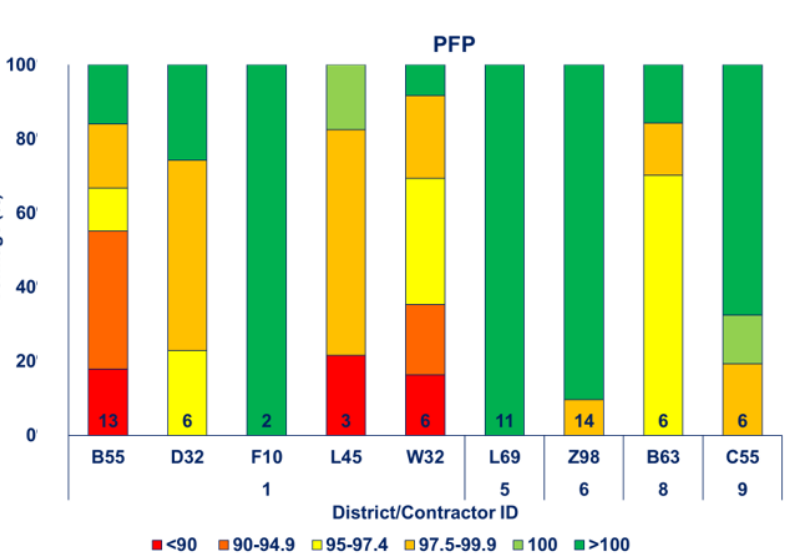

(b)

Figure 5.1. 2015-2017 pay factors of contractors visited during the 2018 site visits.

After choosing the contractors, a contract was selected to cover possible combinations of road type, pay specification, and mix type. A summary of the contract studied on each site visit is shown in Table 
5.1. The project selection includes three roadway types: interstate, state routes, and avenues. Five contracts were QCP and six were PFP. For the mix type, six mixes were SC, two BC, two LB, and one SMA.

Table 5.1. Summary of Selected Project Sites

\begin{tabular}{|c|c|c|c|c|c|}
\hline Site Visit No. & District & No. of Lanes & Road Type & Specification & Mix Type \\
\hline 1 & 1 & 4 & Minor Arterial & PFP & SC N70 D REC \\
\hline 2 & 1 & 4 & Other Principal Arterial & PFP & SMA N80 9.5 REC \\
\hline 3 & 1 & 2 & Other Principal Arterial & QCP & SC N70 D REC \\
\hline 4 & 1 & 4 & Other Principal Arterial & PFP & SC N70 E 9.5 REC \\
\hline 5 & 1 & 2 & Minor Arterial & PFP & SC N70 E \\
\hline 6 & 2 & 4 & Interstate & PFP & BC N90 19.0R \\
\hline 7 & 5 & 4 & Other Principal Arterial & QCP & SC N90 D REC \\
\hline 8 & 6 & 4 & Interstate & PFP & BC N90 19.0R \\
\hline 9 & 8 & 2 & Other Principal Arterial & QCP & LB N70 REC \\
\hline 10 & 8 & 2 & Other Principal Arterial & QCP & SC N70 E \\
\hline 11 & 9 & 2 & Other Principal Arterial & QCP & LB N90 FG REC \\
\hline
\end{tabular}

\subsection{SITE VISIT DESCRIPTION AND ANALYSIS PROCEDURE}

As stated previously, each contract study comprised of three parts: interviews, site visits, and data analysis. The interviews and site visits were conducted during the 2018 construction season (JuneOctober). The district and contractor interviews were conducted on the same day during the jobsite visit for all districts, except District 1. In District 1, the interviews were completed on a different day than the site visit. District interviews were performed at district HMA laboratories. The data analysis was conducted once the pay was determined; data were made available in winter 2018-2019.

\subsubsection{Interviews}

The interviews with contractor and district personnel identified any deviations from standard procedures that may have caused data variability or testing bias. The first part of the interview discussed the views and concerns related to QCP and PFP specifications. The mix design procedure was discussed to identify any differences for QCP or PFP projects. The interview focused on discussing mix production to understand the effect of mix switches, hot stops, or any other deviation. In addition, the contractor or district engineer discussed techniques observed or implemented that help achieve better mix production and consistent test results between QC and QA. Finally, suggestions on improving the current QA program were collected.

After the interview was concluded, district and contractor HMA laboratories were visited. The team observed cleaning procedures and conditions of equipment used for reheating, blending, and compaction. The equipment included ignition oven, gyratory compactor, oven, splitter, pycnometer, and water bath. There are multiple methods to perform aggregate extractions in Illinois, including: reflux, centrifuge, ignition oven, and automated extractor. During the site visits only the ignition oven and auto extractors were used. The procedure to obtain and handle samples from QCP and PFP projects used by the visited contractor was observed, including storage, reheating, and re-blending. 


\subsubsection{Jobsite Visit}

The jobsite visits started at the contractor asphalt plant. The team observed the plant, stockpiles, and tower control conditions. From the plant, the following details were observed:

- Manufacturer

- Plant type and condition

- Years in operation

- AC pump type
- Dust control

- Silo capacity and storage times

- Operator's experience

- Loading of trucks

Afterwards, the stockpiles were observed for the base material type, entry/exit points, and barriers between stockpiles. Finally, the team visited the control tower to observe the panel and talk with the plant operator about procedures to control the mix, hot stops, and mix switches. Hot stops occur when HMA production is paused during the production day. Finally, the datalogger of the day the site was visited was requested to evaluate the final production of the mix.

After the plant production was visited, the team drove the haul truck route to the jobsite to record the time and observe the type of trucks used to haul the mix. Then, the pavement construction was observed, focusing on the following:

- Weather condition

- Dumping procedure

- Paver model
- MTD model

- Placing procedure

- Roller equipment

Finally, at least one mix sampling and density coring was observed in all visited jobsites. During the sampling, the following was observed:

- Mix sampling method

- Number of times the sample was split and re-blended
- Coring equipment

- Storage and sample security

After the visit was concluded, test results, sample weights, and additional data, listed under section 5.3.3: Data Analysis, were requested from contractors and districts via email for analysis.

\subsubsection{Data Analysis}

Data were requested from the contractor or district for each visit, including: pay summary report, mix design, mix and density sublot test reports, QC/QA package data, and datalogger.

The first part of the analysis was performed to identify the pay factors for AV, VMA, and density, as well as any deduction from the pay summary report because of the dust/AC ratio. The pay factors show the source of pay disincentives. In addition, the pay factors were compared to contractors' historical data on pay disincentives. The mix design was then reviewed for the following aspects:

- Number of stockpiles

- Type of aggregate

- Percent of mix used from each stockpile
- Design blend compared to specification limits

- Design VMA compared to specification minimum 
The second part of the analysis consisted of evaluating the mix sublot results. The contractor and district AV and VMA results were paired per sublot, as shown in Figure 5.2 (a) and (b), to identify any significant differences between the two results. A potential mix production problem could be indicated if the contractor and district results were not significantly different but the AV, VMA, and density did not meet the limits. However, if a significant difference is noted, then this could be an indication of a potential testing issue.

The district and contractor $G_{m m}$ and $G_{m b}$ results were paired and plotted per sublot to compare differences. The dispute precision limits and round robin offsets observed in both laboratories during the site visits were also plotted. Because $G_{m m}$ and $G_{m b}$ depend on $A C$ content, the comparison was done against the mix design $G_{m b}$ and $G_{m m}$ versus the $A C$ content curve instead of a specific target value, as shown in Figure 5.2 (c) and (d). Production may vary from designs when different targets were needed to produce acceptable material, as reflected in the adjusted job mix formula (AJMF). Otherwise, when $G_{m m}$ and $G_{m b}$ results deviate from the mix design curve, this could be related to differences in material, lab mix design versus plant mix production (aggregate gradations, material variability), and/or testing issues (inconsistent sample weights, gyratory compaction, and/or temperature). Therefore, aggregate gradation, sample weight, gyratory compactor height, and datalogger data were evaluated.

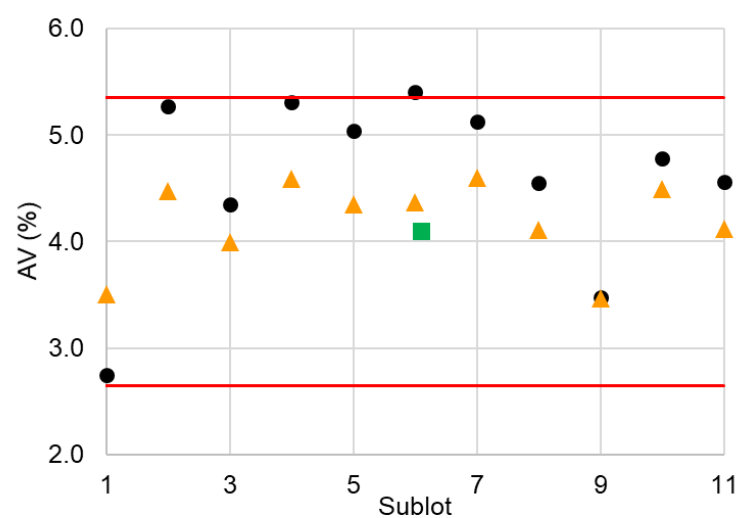

(a)

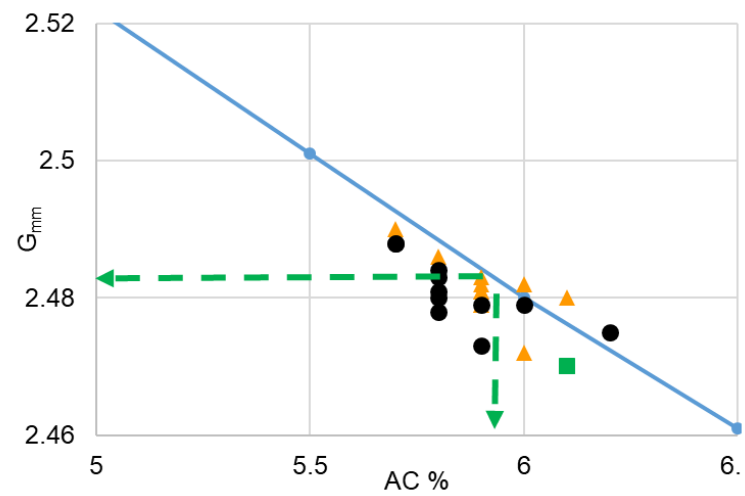

(c)

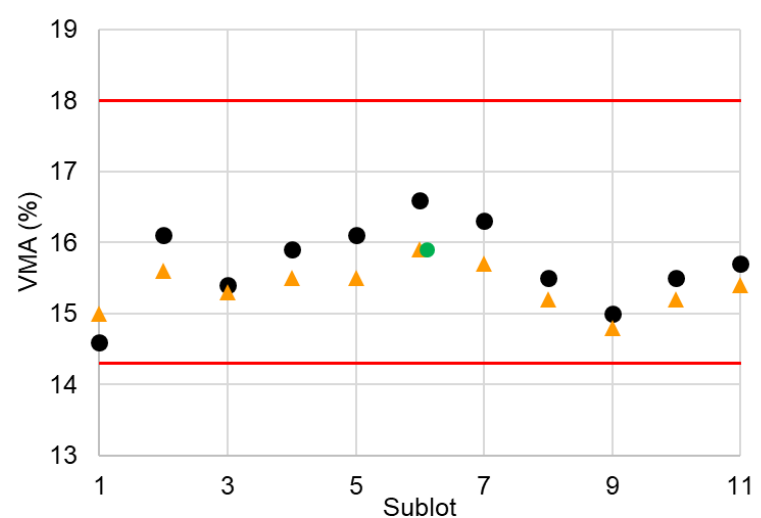

(b)

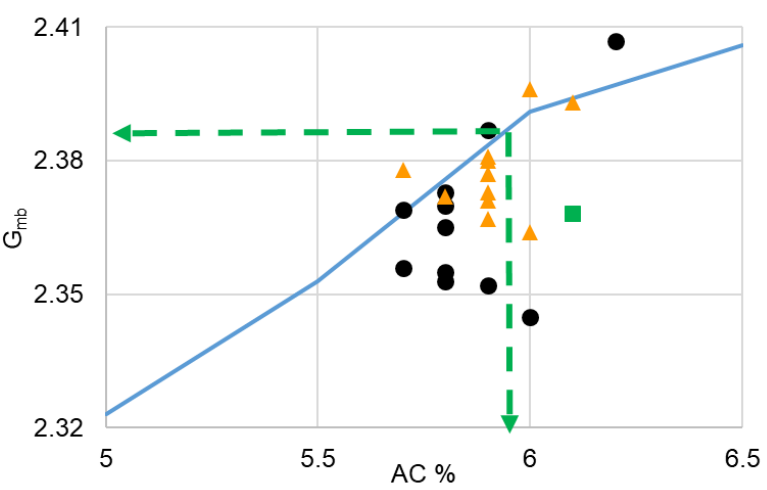

(d)

- District 4 Contractor $\because \mathrm{CBM} — \mathrm{LL} \longrightarrow \mathrm{UL} \triangleleft--$ Target $\rightarrow$ Mix Design

Figure 5.2. Example of a PFP jobsite visit mix sublot results for (a) $A V$, (b) VMA, (c) $G_{m m}$, and (d) $G_{m b}$ (LL and UL refers to lower and upper limit, respectively). 
The recovered aggregate gradation results and $A C$ content were compared to those from the plant datalogger. The datalogger was analyzed to identify variations in production speed, dust control, and AC content. Also, the datalogger showed mix switches, hot stops, or other operational activities during mix production. Aggregate gradation results were compared against the mix design and IDOT aggregate gradation requirements. When $G_{m b}$ values deviated from the design and AJMF, this may be a result of differences in laboratory production and plant production (mixing, aging, storage, etc.), potential segregation, management of baghouse fines, or elevated material variability.

The $G_{m m}$ and $G_{m b}$ sample weights and $G_{m b}$ specimen heights were checked for consistency. The difference in split test weights was compared to IDOT requirements. IDOT requires that the difference between each split test specimen not exceed $10 \%$ for $G_{m m}$ samples and $1 \%$ for $G_{m b}$ replicates. The specimen height between the samples was also compared. If the materials are identical, then the same heights should be obtained if splitting and compaction are consistent. For example, if two test specimens have different heights but the same weight, then compaction temperature may be a cause. This assumes the aggregate gradations are identical. As NMAS increases with coarse-graded mixtures, some difference could be due to aggregate gradation differences.

\subsection{PRODUCTION ISSUES}

\subsubsection{Aggregate Consistency}

Because aggregate is the primary component in HMA, changes in consistency may impact the contractor's ability to meet HMA requirements. Changes in aggregate production or high material variability are two common issues that affect the contractor's ability to meet a mix requirement. During the contractor interviews, it was indicated that for certain aggregate suppliers, the stockpile properties may change from one shipment to another, resulting in high variability. One of these scenarios was observed during the jobsite visit in District 9.

The District 9 jobsite visit was to a two-lane pavement resurfacing project. A leveling binder N90, 9.5 FG, was placed over a milled surface. The mix was evaluated using the QCP specification, resulting in pay factors of $101.5 \%$ for $\mathrm{AV}, 95 \%$ for $\mathrm{VMA}$, and $97.5 \%$ for density. The AV and VMA test results are shown in Figure 5.3 (a) and (b). The results from the contractor and the district show that the VMA dropped from the design value of 15.7 to 14.6 . The AV fluctuated between $3.5 \%$ to $4.4 \%$. Figure 5.3 (c) and (d) shows $G_{m m}$ and $G_{m b}$ versus $A C$ content. The results of the $G_{m b}$ deviated from the design.

The researchers did not receive the datalogger to evaluate the mix production. However, the contractor indicated that the drop in VMA was a result of aggregate supply. The quarry that supplies the contractor shifted into a new ledge, and the $\mathrm{G}_{\mathrm{sb}}$ values needed to be updated. As a result, all mix designs were affected. When the contractor noticed the changes, it was too late to adjust the mix for the project. However, the mix designs were adjusted for the remainder of the year. This could be avoided with regular $\mathrm{G}_{\mathrm{sb}}$ checks and corresponding volumetric designs. 


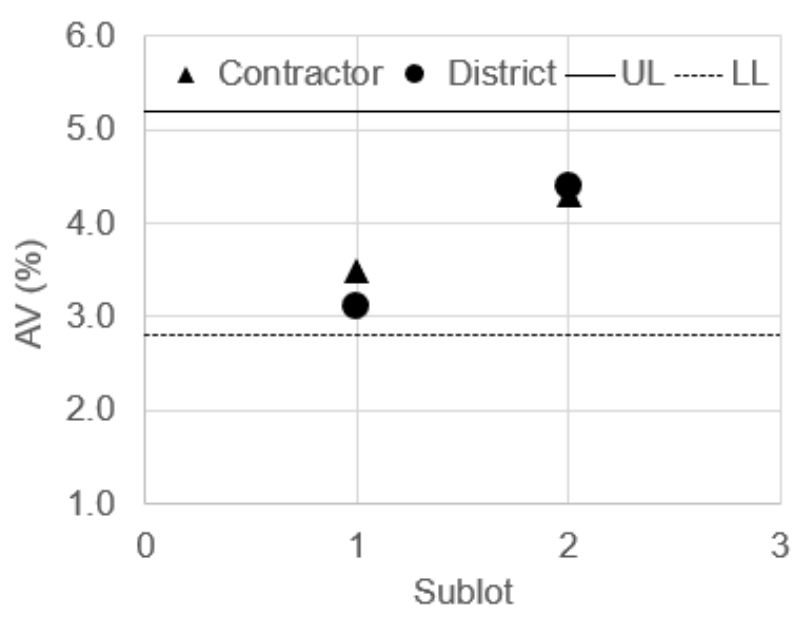

(a)

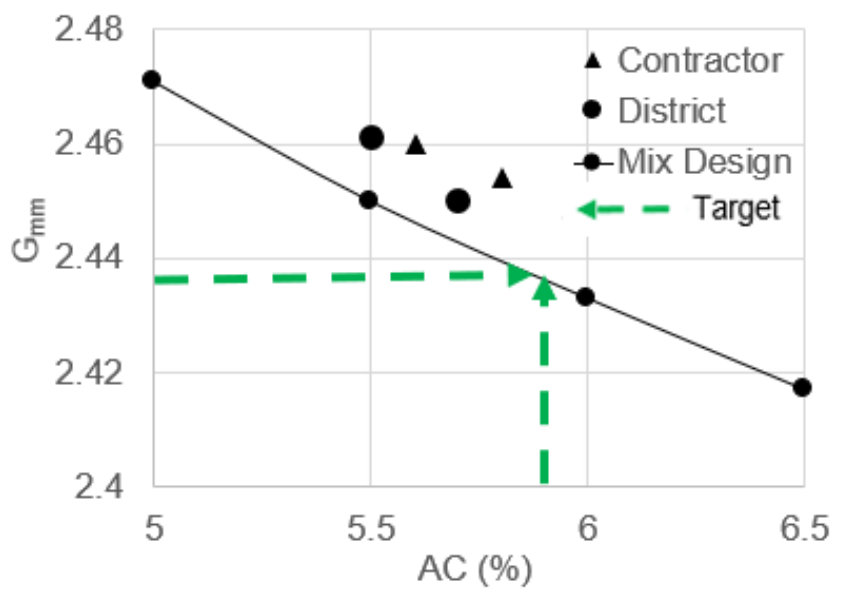

(c)

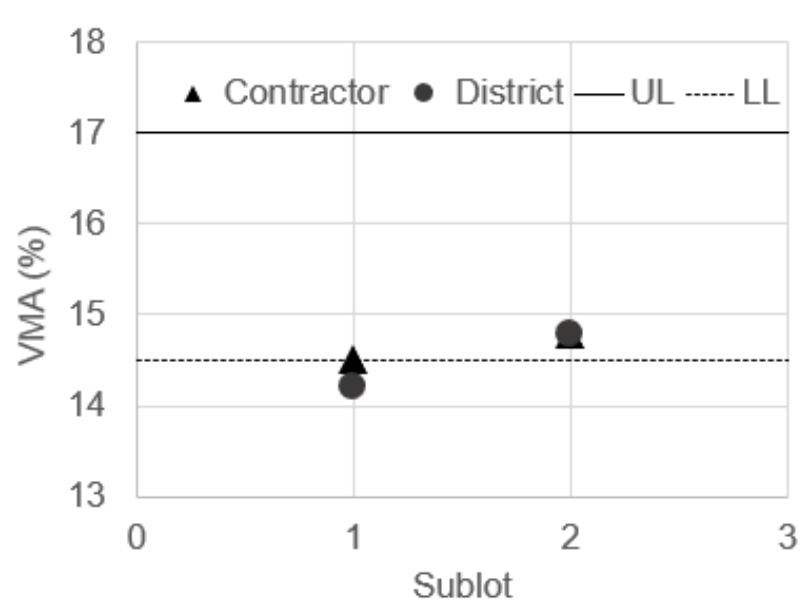

(b)

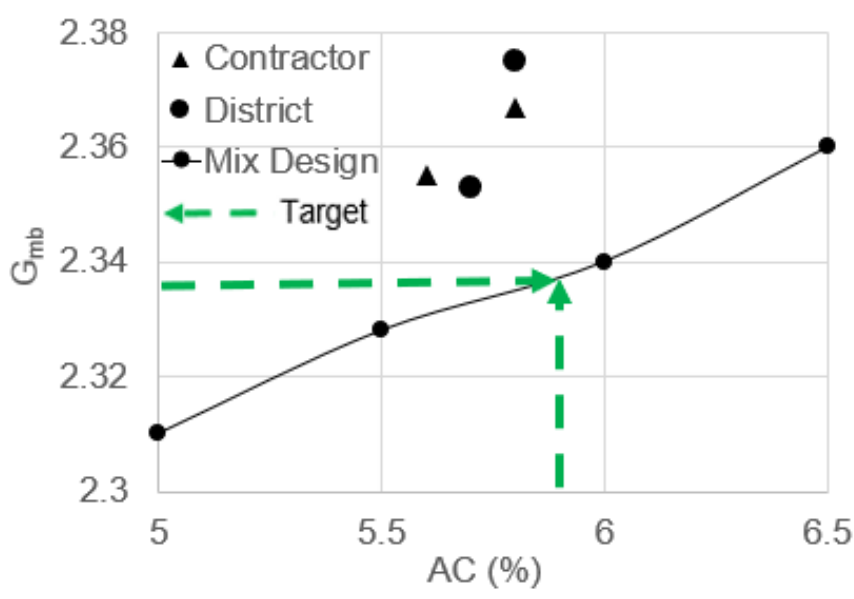

(d)

Figure 5.3. District 9 QCP jobsite visit mix sublot results for (a) AV, (b) VMA, (c) $G_{m m}$, and (d) $G_{m b}$.

\subsubsection{Stockpile Space and Barriers}

Space is limited for aggregate stockpiles at certain plants in District 1. Figure 5.4 illustrates this concept and shows a plant not located in Illinois, while not disclosing the contractor's identity. If aggregate stockpiles are placed next to each other with no barrier between them, blending of the aggregates can occur at the interface of the stockpiles, which may impact mix quality. When there is one side for aggregate entry/exit for the stockpiles, newly arrived material is loaded to feeders. Therefore, any change in the aggregate properties gets immediately reflected in the mix production because of limited time to check aggregate gradation or $\mathrm{G}_{\mathrm{sb}}$ values. Hence, loading aggregate to the feeder from multiple sides of the stockpile and full stockpile separation are important to maintain mix quality if inconsistency exists in the aggregate supply. Additionally, height of the stockpiles may cause segregation. 


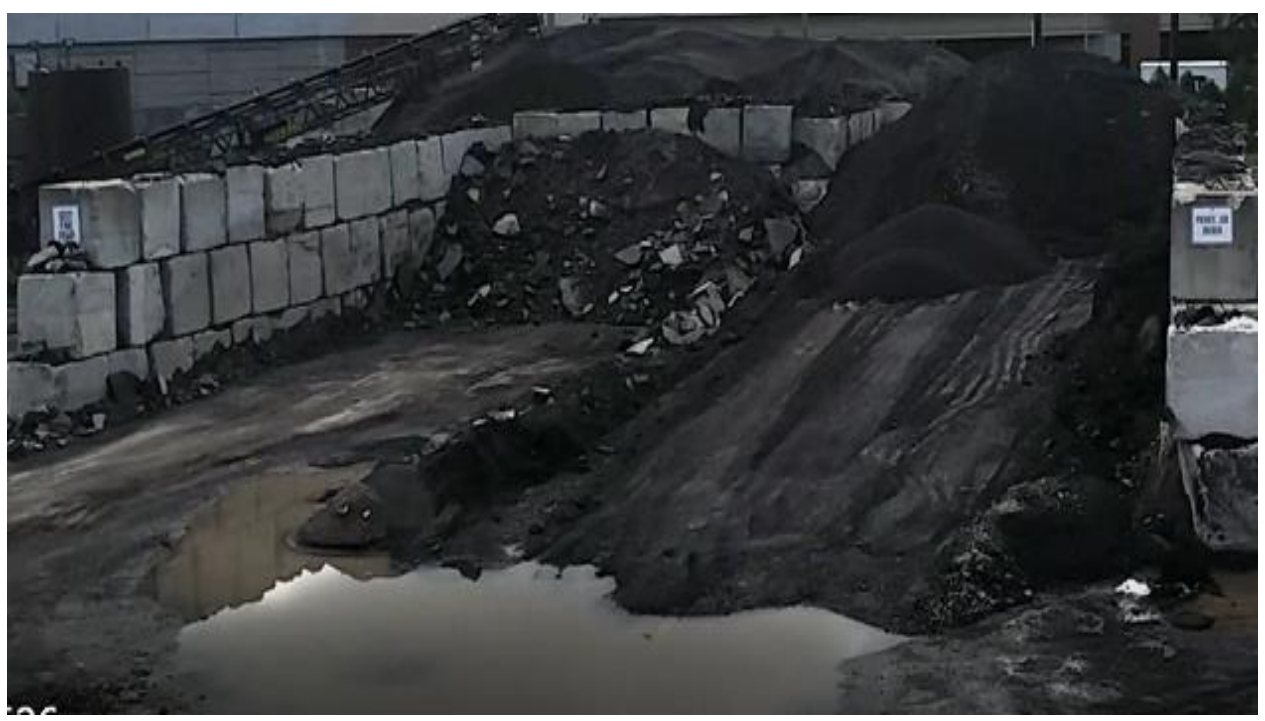

Figure 5.4. Stockpile handling in a plant illustrating space constraint.

Issues in aggregate stockpile are usually reflected in the mix blend gradation. At site visit no. 3, in District 1, the amount of material passing the \#4 and \#16 sieves was up to $6 \%$ higher than the target in the first five sublots. In the last two sublots, the material passing the \#4 sieve was lower than the target by $7 \%$. Figure 5.5 (a) shows an example of the two aggregate gradations from the adjusted mix formula (AMF) for sublots 4 and 8 . Sublot 8 illustrates the cases with aggregate gradation higher than the target, and sublot 4 indicates the opposite. The possibility of mix control issues was dismissed because the datalogger for the two days of production did not reflect any significant difference in production. Figure 5.5 (b) shows the datalogger output. The portion of the production destined for the visited IDOT project is highlighted in green. Mix switches were limited, and the contractor kept a consistent production. Finally, the issues with aggregate variability eventually resulted in $\mathrm{G}_{\mathrm{mb}}$ results deviating from the design, which were reflected in the AV and VMA pay factors.

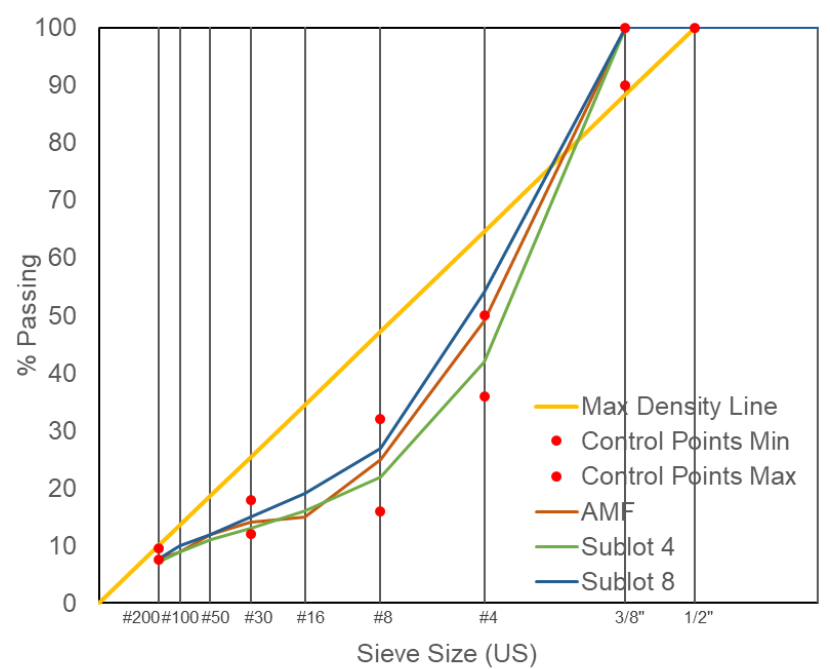

(a)

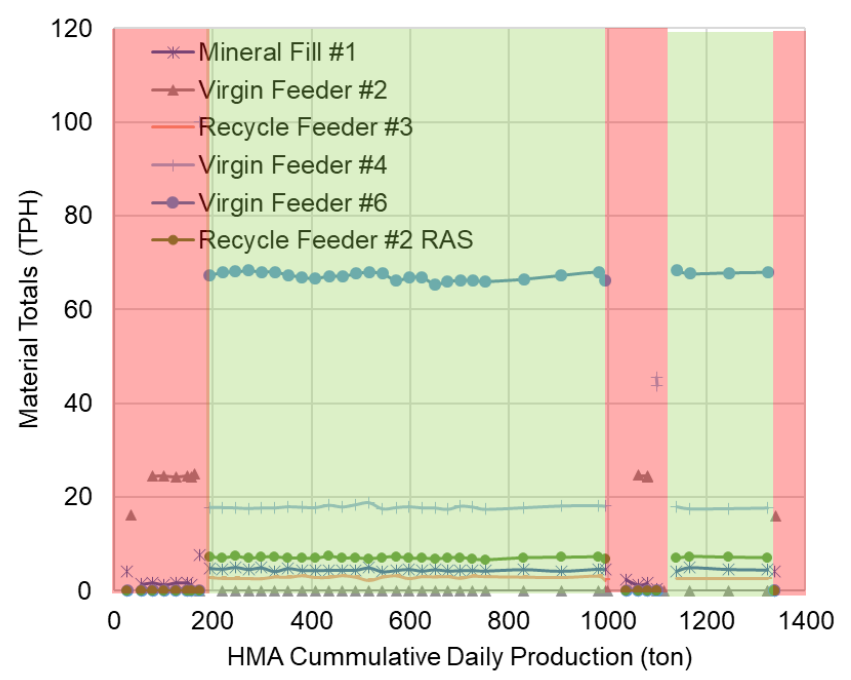

(b)

Figure 5.5. Gradation results for (a) sublots 4 and 8 and (b) HMA production from datalogger. 


\subsubsection{Stockpile Contribution to Total Design}

Mix designs that rely on few stockpiles are more susceptible to aggregate gradation variability. In the mix design described in section 5.4.1: Aggregate Consistency, $71 \%$ of the mix blend comes from a single stockpile identified as crushed dolomite (CM16). As a result, the mix design was susceptible to variability of this individual stockpile. The impact of variability may be reduced by dividing single aggregates that contribute more than $30 \%$ between multiple cold feeds instead of a single cold feed.

\subsubsection{Mix Switches}

Contractors commonly produce multiple mix designs in the same day. As a result, the plant needs to switch properly between different designs. When mix switches are made, a plant needs to respond quickly or a small amount of mix produced during transitions may be wasted.

Figure 5.6 shows AC content during the production day of site visit no. 4, as reported by the plant datalogger. The plant was not able to keep the AC content stable; it fluctuated between $5.7 \%$ to $7.2 \%$ for three different mixes, with a range of target value being $0.8 \%$. The actual range of AC percent for the individual mix design collectively was $0.0-0.6 \%$, and the average within a mix design was a range of $0.3 \%$. The issues were with bias between target and actual, as well as transition control. In this case, the main cause of pay disincentives was the mix production inconsistency. Hence, better mix control and plant operation are needed.

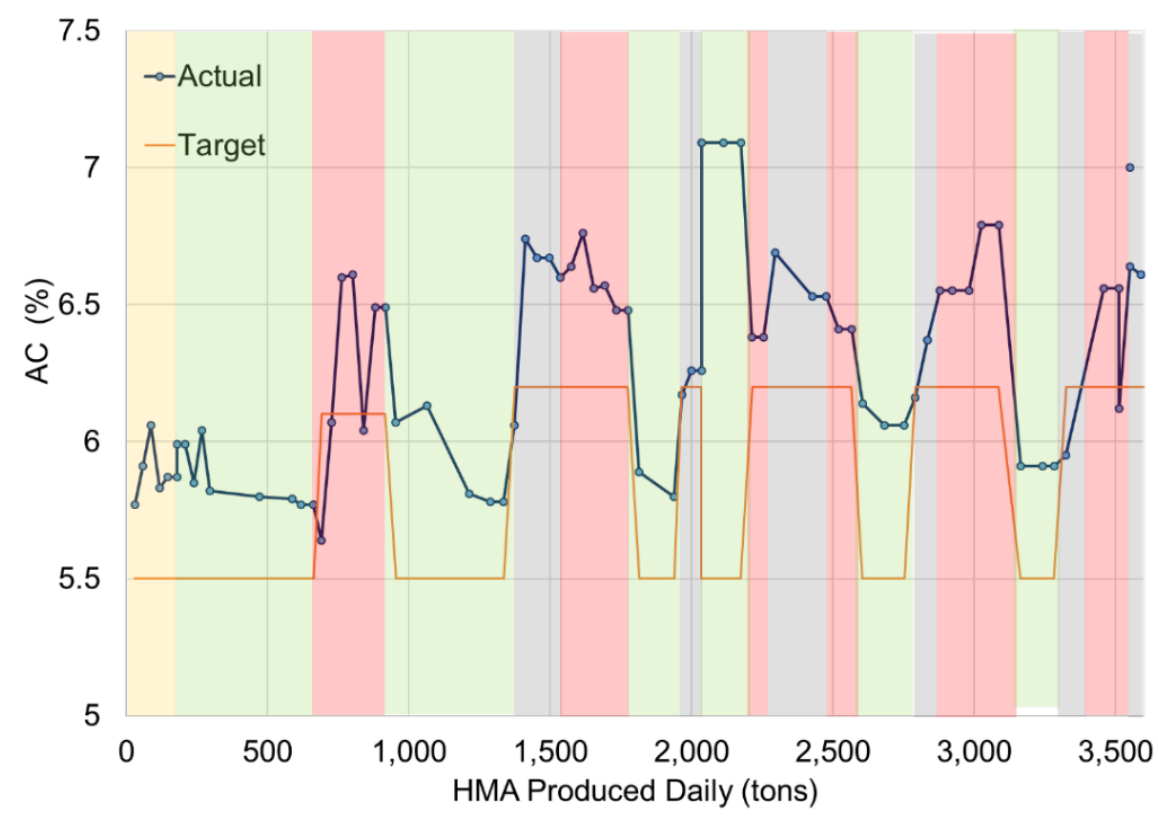

Figure 5.6. Total AC content during the day of the jobsite visit.

\subsubsection{Dust Control}

During the downstate site visits (Districts 6, 8,9), it was common to encounter HMA plants without positive dust control, which resulted in pay disincentives. Dust affects $G_{m b}$ test results, which is reflected in $\mathrm{AV}$ and $\mathrm{VMA}$ results. Although $\mathrm{AV}, \mathrm{VMA}$, and density received $100 \%$ in $\mathrm{QCP}$, a pay 
disincentive was assigned on dust/AC. Note that if a PWL specification is used, then a pay disincentive on $A V$ and VMA would be assigned because the tail of the distribution exceeds the limits.

The datalogger of the jobsite visit day was evaluated to understand the issues with mix production. An example of dust removed from the mix and AC content are shown in Figure 5.7 (b), indicating variations in dust removal while AC content remained the same. The plant had issues keeping consistent dust control. The datalogger of the next day of production was requested. It reflected the same variation, which may suggest an operational issue. As a result, the main cause of pay disincentives in this contract was attributed to dust control. The plant was not able to keep a consistent dust removal rate and, at the same time, did not have positive dust control. The aggregate gradation was slightly off from the target, which impacted AV and VMA.

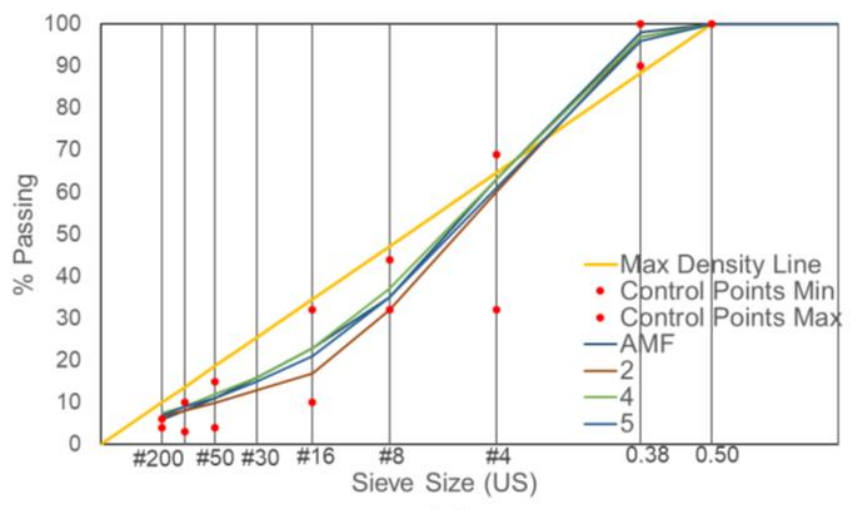

(a)

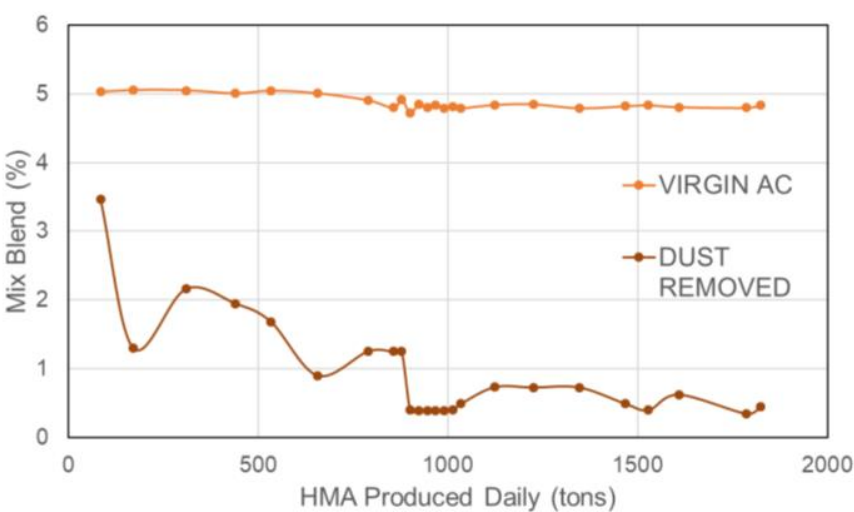

(b)

Figure 5.7. Aggregate gradation results and datalogger for virgin AC percentage and dust removal rate.

\subsection{TESTING ISSUES}

\subsubsection{Absorption}

Absorption was an observed factor that led to consistent one-directional bias in the $\mathrm{G}_{\mathrm{mm}}$ and possibly $\mathrm{G}_{\mathrm{mb}}$ results when comparing district and contractor results. This issue was observed in the District 2 site visit. The visit was to an 8.67-mi interstate pavement resurfacing project. A 2.25-in polymerized N90 IL-19.0 HMA BC was placed over a continuously reinforced concrete pavement. The PFP specification was used to evaluate 29,000 tons of BC. The minimum design VMA was $13.5 \%$ and the production limits were from $-0.7 \%$ to $+3.0 \%$ from the minimum design requirement; $\mathrm{AV}$ at $4 \% \pm$ $1.35 \%$, and density at $92.2 \%$ to $97.5 \%$. The mix pay was $101.2 \%$ for $A V, 100.3 \%$ for VMA, and $97.7 \%$ for density, with a composite pay factor of $99.7 \%$.

The results show an offset between contractor and district AV and VMA results, Figure $5.8(\mathrm{a})$ and (b), resulting from differences in both $\mathrm{G}_{\mathrm{mm}}$ and $\mathrm{G}_{\mathrm{mb}}$ test results. On average, the paired $\mathrm{G}_{\mathrm{mm}}$ results between the contractor and district were off by 0.009 between the 31 sublots tested. The difference exceeded the precision limits of 0.008 . When paired, the average $G_{m b}$ results were off by 0.023 , which also exceeded the precision limits of 0.017. Reheating drove the differences in $\mathrm{G}_{\mathrm{mm}}$. In the case of $\mathrm{G}_{\mathrm{mb}}$, additional issues, such as the gyratory equipment, can also affect the differences between 
district and contractor results. However, reheating cannot be discarded to affect $\mathrm{G}_{\mathrm{mb}}$ because the bias in both tests was in the same direction. This could be related to a systematic difference in reheating procedure, because AV and VMA data is biased. District samples absorbed on average $0.7 \%$ more binder than contractor samples, which resulted in higher specific gravities than contractor results. Hence, a uniform reheating procedure must be adopted.

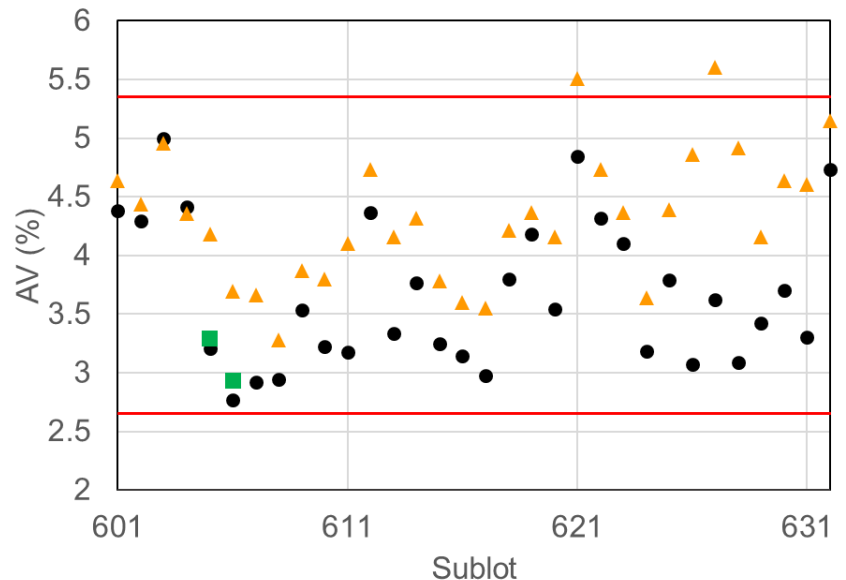

(a)

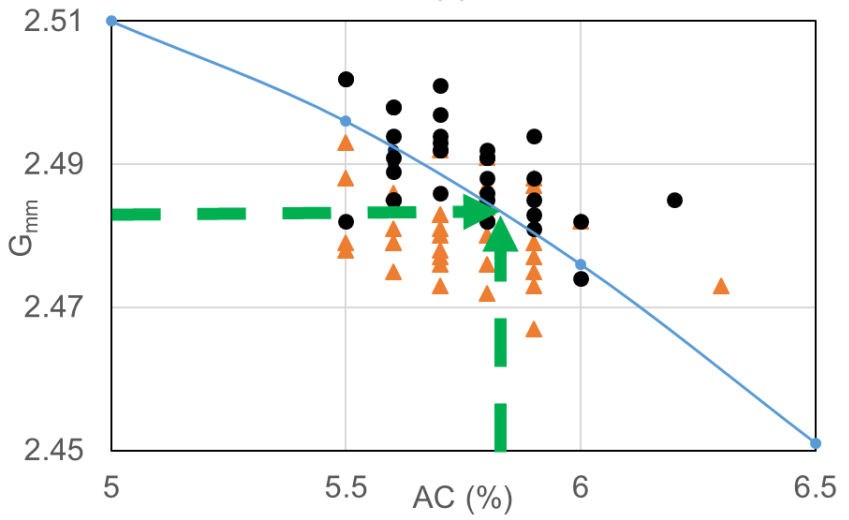

(c)

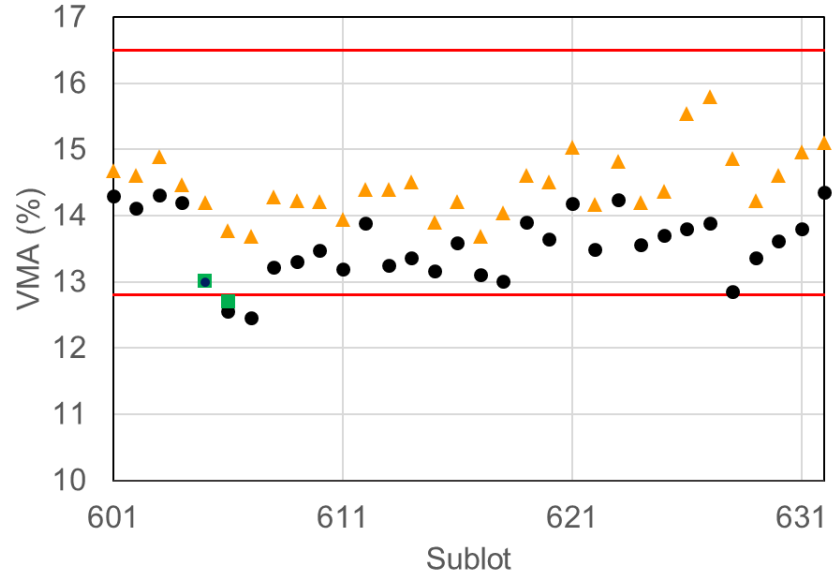

(b)

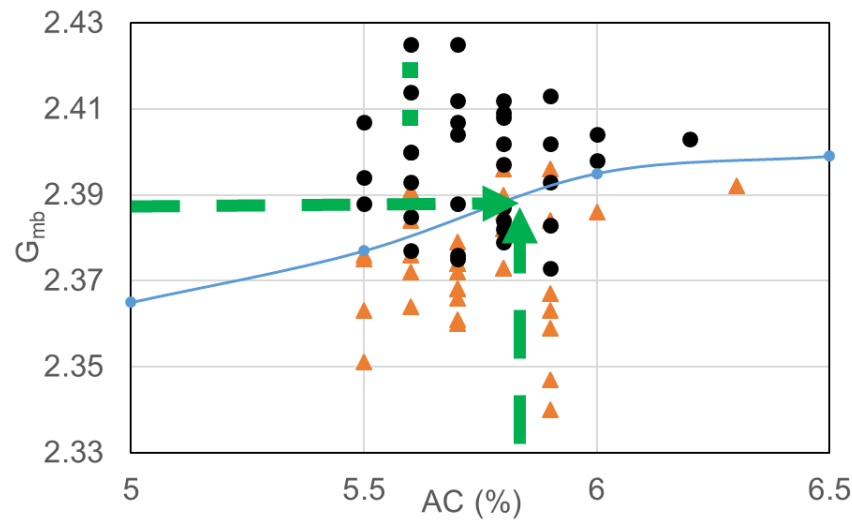

(d)

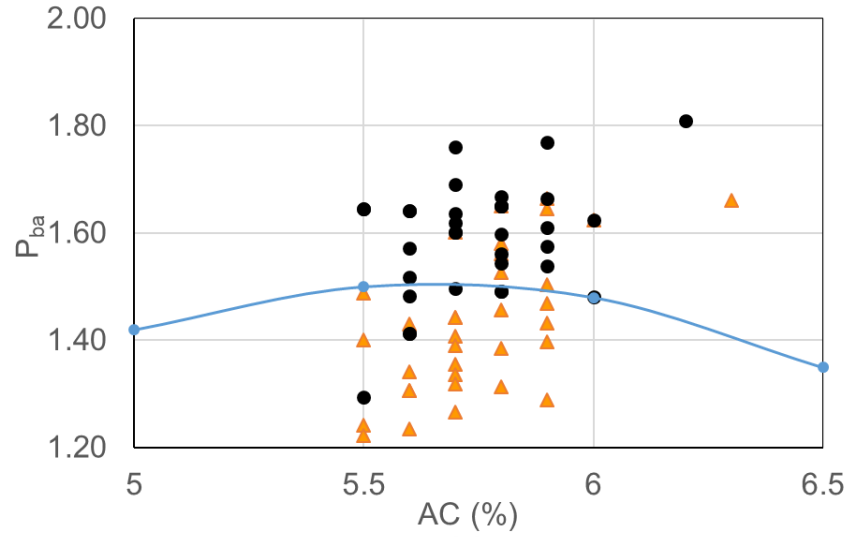

(e)

- District $\triangle$ Contractor $=\mathrm{CBM}-\mathrm{LL} \longrightarrow \mathrm{UL} \triangleleft--$ Target $\rightarrow-$ Mix Design

Figure 5.8. Mix sublot results for (a) $A V$, (b) VMA, (c) $G_{m m}$, (d) $G_{m b}$, and (e) $P_{b a}$ (Percentage of absorbed binder) 


\subsubsection{Gyratory Compactor Model Bias}

A common concern reported by the contractors is the inherent test result variability among different gyratory compactors. A possible bias was observed in one of the District 1 site visits. There were consistent differences in the results of $\mathrm{AV}$ and VMA between the district and contractor, which were attributed to the consistent differences only in the gyratory $G_{m b}$ test results (Figure 5.9).

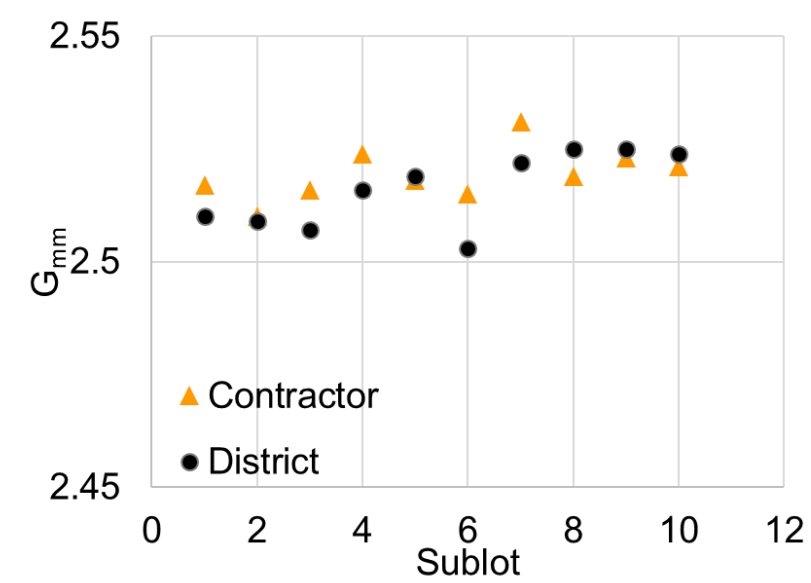

(a)

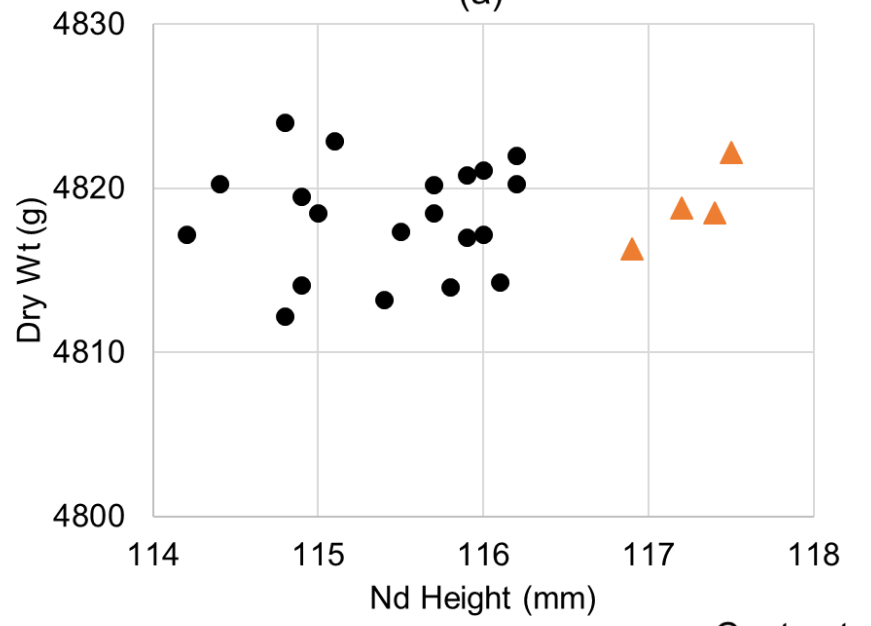

(c)

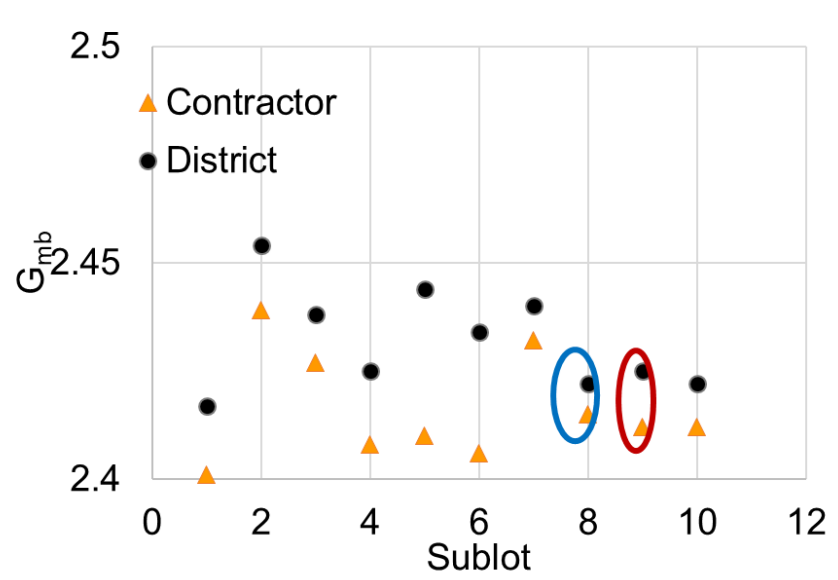

(b)

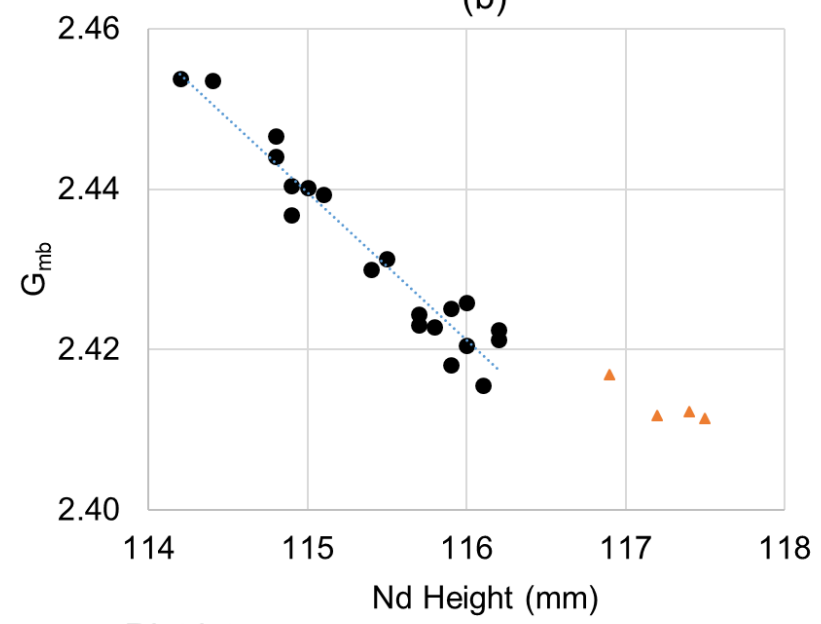

(d)

Figure 5.9. Mix sublot results for (a) $G_{m m},(b) G_{m b}$, (c) dry weight, and (d) $G_{m b}$.

\subsubsection{Inconsistencies in Test Weights}

Inconsistencies in the test weight and/or compaction temperature were observed, which could affect the height of the test specimens. If the gyratory compactors are operating properly, temperature may cause two samples with the same weight to be compacted to different heights. In a visit, a difference of $80 \mathrm{~g}$ between specimens with the same height was observed. This difference resulted in a spread of 0.022 in the $G_{m b}$ (Figure 5.10); this could be related to temperature. A constant weight should be used by both the district and the contractor for gyratory specimens. 


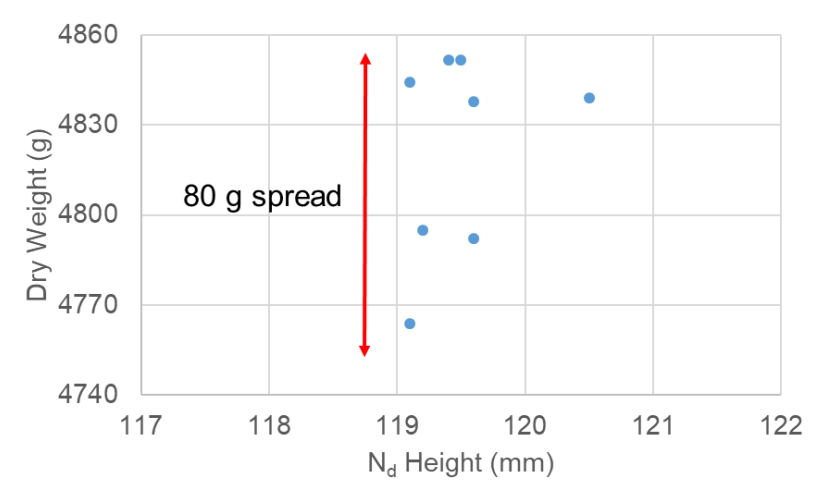

(a)

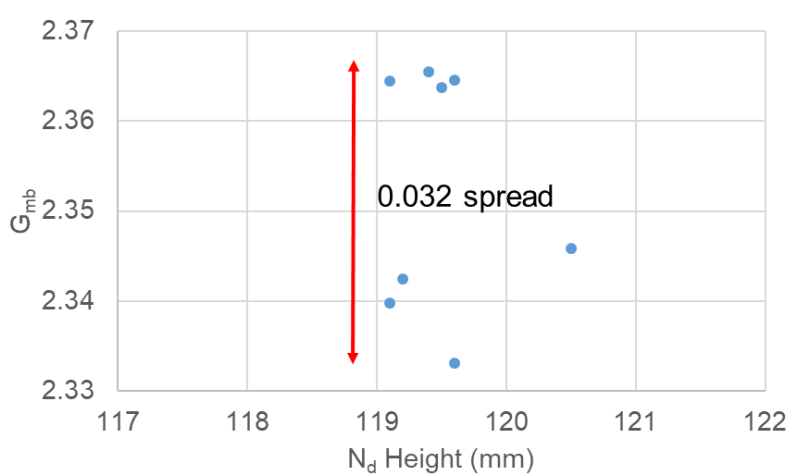

(b)

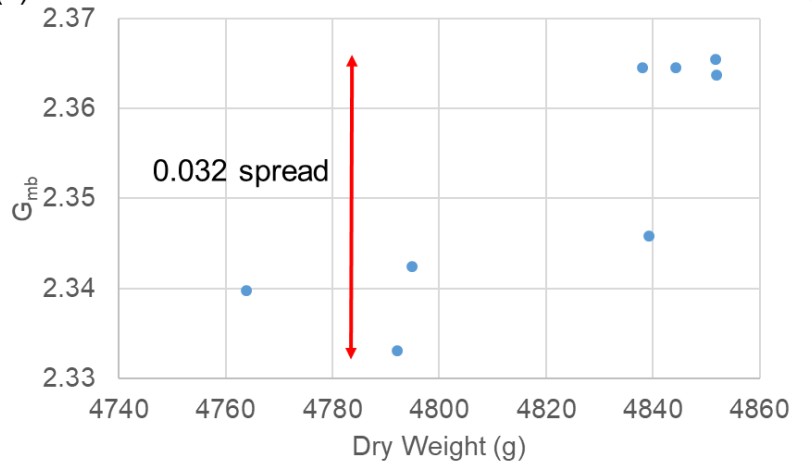

(c)

Figure 5.10. Inconsistent test weights-example of (a) dry $\mathbf{G}_{\mathrm{mb}}$ weight vs $\mathbf{N}_{d}$ height, (b) $G_{m b}$ vs $N_{d}$ height, and (c) $G_{m b}$ vs dry $G_{m b}$ weight

\subsection{MANAGEMENT ISSUES}

During the site visits, the research team observed three issues related to the management of the construction from the district personnel that may compromise the work of the contractor: absence of an experienced engineer supervisor in the field, insufficient time provided to contractors for sampling, and contractors' and districts' inability to resolve in situ difficulties in a fast manner (e.g., broken material transfer device MTD).

The first and second issue occurred during a site visit where the resident engineer (RE) was supervising more than one job at a time. When the research team arrived, the RE was not at the visited site and an assistant was supervising the job. Typically, the RE informs the production tonnage where the sample will be once the truck that contains it has arrived at the site. This practice prevents any special treatment to the material that will be sampled. It also allows enough time for the contractor's quality control personnel to prepare the equipment for sampling and splitting. During the site visit, the assistant in charge was not aware of the practice and notified the sampling tonnage when the truck containing the sample was already feeding the paver. As a result, there was not enough time to prepare, which stopped the paving operation.

The third issue occurred during a site visit where a N80 9.5 NMAS SMA surface layer was placed. The MTD broke down during the site visit. The district and contractor personnel were not sure if the specifications allowed the contractor to place the 9.5 SMA mix without using an MTD. The confusion 
caused an hour and a half delay with approximately eight trucks waiting on the lane with mix. The conflict was resolved when both parties agreed that the specifications allowed the mix to be placed without the MTD.

\subsection{SUMMARY}

Table 5.2 shows a summary of the issues observed at project sites. A detailed explanation per project site is reported in a second report (Al-Qadi et al., 2020). In summary, most pay disincentives observed were a direct result of issues with mix production. However, testing issues also caused contractordistrict disputes.

Table 5.2. Summary of Observed Issues at Project Sites

\begin{tabular}{|c|c|c|c|c|c|c|c|c|c|c|c|}
\hline $\begin{array}{c}\text { Site Visit } \\
\text { No. }\end{array}$ & District & Program & $\mathrm{AV}$ & VMA & Density & CPF & Sampling Technique & Reblending & Testing & Mix & Density \\
\hline 1 & 1 & PFP & 98 & 90 & 101.7 & 97.1 & Shoveling at Mat & Yes & 5.5 .2 & 5.4 .4 & \\
\hline 2 & 1 & PFP & 94.5 & 101 & 104.4 & 100.4 & Shoveling at Mat & No & 5.5 .4 & 5.4 .3 & \\
\hline 3 & 1 & PFP & 98 & 105 & 101.1 & 101.3 & Shoveling at Mat & Yes & & 5.4 .1 & \\
\hline 4 & 1 & PFP & 84.5 & 103 & 95.5 & 94.5 & Shoveling at Mat & Yes & & 5.4 .4 & High Variabiltiy ${ }^{2}$ \\
\hline 5 & 1 & QCP & 100 & 100 & 100 & 100.0 & Shoveling at Mat & Yes & & & \\
\hline 6 & 2 & PFP & 101.2 & 100.5 & 97.9 & 99.7 & Bottom Compartment MTD & Yes & 5.5 .1 & Binder Content ${ }^{1}$ & High Variabiltiy ${ }^{2}$ \\
\hline 7 & 5 & QCP & 100 & 100 & 100 & 100.0 & Plates at Mat & Yes & & & \\
\hline 8 & 6 & PFP & 104.8 & 104.8 & 103.5 & 104.3 & Quarter Master at MTD & Yes & 5.5 .1 & 5.4 .1 & \\
\hline 9 & 8 & QCP & 95 & 96.7 & 100 & 97.5 & Auger (Levelign Binder) & Yes & & 5.4 .5 & \\
\hline 10 & 8 & QCP & 100 & 100 & 100 & 100.0 & Plates at Mat & Yes & & & \\
\hline 11 & 9 & QCP & 101.5 & 95 & 97.5 & 98.0 & Plates at Mat & Yes & & 5.4 .1 & Roller Issues ${ }^{3}$ \\
\hline
\end{tabular}

${ }^{1}$ Binder Content: Binder content not on the target.

2 High Variability: Density results varied all over the allowed range.

3 Roller Issues: Contractor did not provide the required roller.

${ }^{4}$ The numbers under Testing, Mix, and Density indicate the sections of the chapters that describe the issues observed. 


\section{CHAPTER 6: CONCLUSIONS AND OBSERVATIONS}

The purpose of this study is to identify causes of variability as well as to ensure that specifications are fair and achievable and risks are well balanced between contractors and owners. To achieve this, a multiprobe assessment of a large QCP and PFP data pool was performed. The main objective was to understand the distribution and variability of test results. The outcome of the study was intended to address the difference between contractor and district results to identify potential causes and to identify issues affecting mix production, construction, and testing quality. Finally, several observations are offered to improve mix consistency and quality.

The assessment consisted of two major parts for both QCP and PFP projects: data analysis and site visits. The first part involved an analysis of test results from QCP and PFP construction projects between 2015 to 2017. The test results evaluated included AV, VMA, core density, $G_{m b}, G_{m m}$, mix aggregate gradation, and binder content. Descriptive statistics and hypothesis tests were used to compare test results from districts and contractors, including mean, distribution, and variance using Mann-Whitney (mean comparison), Shapiro-Wilk (distribution), and Levene's (variance) tests. In addition, average and standard deviation results per mix contract case were evaluated.

The second part of the analysis involved 11 project site visits to identify possible root causes of data variability and bias. The site visits allowed the research team to monitor the construction process in the field and to evaluate related test results. Hence, issues could be identified during the site visits. As part of the site visits, district and contractor personnel were interviewed, and industry concerns related to testing procedures and production were reported. In general, plants, labs, and jobsites were visited to observe sampling, blending, splitting, and testing during mix production and construction. Finally, test results were analyzed to identify possible root causes of pay disincentives and differences between contractor and district test results, if any. Details on the site visits and corresponding data analysis are presented in Al-Qadi et al. (2020).

\subsection{FINDINGS}

The findings of the study are listed below:

1. Proper quality control protocols and achieving uniformity have a tangible monetary impact on final pay factors for contractors. If a contractor producing a density variance (square of standard deviation) of 2.79 could reduce it to 1 , the contractor would have been paid approximately $\$ 38,000$ (2019 USD) more than what they were paid on an average project.

2. Approximately, $82 \%, 88 \%$, and $91 \%$ of core density, VMA, and $\mathrm{AV}$, respectively, were statistically similar when comparing contractor and district test results. Mix production and construction issues, in addition to sampling and blending in accordance with IDOT MoTP (2018c), were considered the main cause of contractors' pay loss. Better control of these parameters during production is an opportunity for contractors to correct these issues and increase their pay and the quality of asphalt provided. Hence, the QMP is appropriate to identify mix production and/or construction issues. 
3. When statistically different test results are encountered, the mean, distribution, and variance of a sample by either the contractor or district may not be representative of the population. In such cases, there is potential for uncertainties in payment: for the district to have paid in full (or with a pay incentive) for low-quality material or for the contractor to have been paid with a pay disincentive for high-quality material (known as $\alpha$ risk). Monetary losses or risks associated with these uncertainties were not quantified in this report. However, it is possible to demonstrate that there is no bias in pay when there is potential for uncertainties in payment (see Table 6.1).

Table 6.1. Percentage of Cases with Significantly Different Test Results in Which Pay Was Equal or Higher Than $\mathbf{1 0 0 \%}$ for Both Specifications

\begin{tabular}{|c|c|c|c|c|c|c|c|}
\hline \multicolumn{2}{|c|}{ Percentage of Cases } & \multicolumn{3}{c|}{ QCP } & \multicolumn{3}{c|}{ PFP } \\
\hline $\begin{array}{c}\text { Average Comparison } \\
\text { (Mann Whitney) }\end{array}$ & Pay Factor & AV & VMA & Density & AV & VMA & Density \\
\hline \multirow{2}{*}{$\begin{array}{c}\text { Not Significantly } \\
\text { Different }\end{array}$} & PF $<100$ & 26.7 & 25.5 & 41.4 & 41.7 & 24.2 & 50.6 \\
\cline { 2 - 8 } & PF $\geq 100$ & 66.9 & 66.6 & 39.2 & 39.6 & 48.4 & 34.5 \\
\hline \multirow{2}{*}{ Significantly Different } & PF $<100$ & 3.4 & 3.1 & 5.5 & 9.4 & 9.5 & 8.0 \\
\cline { 2 - 8 } & PF $\geq 100$ & 3.0 & 4.8 & 13.8 & 9.4 & 17.9 & 6.9 \\
\hline \multicolumn{2}{|c|}{ Total } & 100 & 100 & 100 & 100 & 100 & 100 \\
\hline
\end{tabular}

4. When statistical differences in the parties' test results were identified, testing variability must be questioned. The main contributor to differences in AV and VMA results were the $\mathrm{G}_{\mathrm{mb}}$ test results. The difference was usually caused by sampling, splitting, specimen preparation, reheating temperature, gyratory compaction effort, and/or test procedure adherence. A 0.015 difference in $G_{m b}$ between the contractor and district is considered a significant variation; the AASHTO precision limit is 0.017 and QCP precision limit is 0.030 .

5. Core density variability was the main cause of reduction in pay, followed by AV and VMA, respectively. Air voids fail (PF $<100$ ) because of both upper and lower limits, while core density and VMA fail mainly because of the lower limit.

6. Mix compaction control and condition of the underlying pavement were found to be important factors causing disincentives. Data show that mixes typically constructed over a milled surface had higher density variability. It is expected that the increased minimum lift thickness requirement would reduce the variability and disincentive pay adjustments.

7. The high $\mathrm{AV}$ variability was due to mix production issues (e.g., AC content and dust control), and testing (e.g., variability of $\mathrm{G}_{\mathrm{mb}}$ and $\mathrm{G}_{\mathrm{mm}}$ tests). Suggestions to reduce variability are offered under recommendations.

8. Coarse aggregate gradation variability or segregation during sampling and paving affected AV and VMA and, hence, mix pay factors. Relatively high standard deviations were observed in aggregate gradation regardless of the mix NMAS.

9. Testing turn-around time (between sample delivery and receiving test results) should be limited. In 2018, District 1 was able to achieve a two-day testing turn-around time. 
10. In general, contractors are more experienced with the QCP specification compared to the PFP specification. The QCP projects obtaining full pay increased between 2015-2017, while PFP decreased. This could be attributed to the lack of experience with PFP contracts.

11. It was also noted that contractors design and produce HMA too close to minimum targets. This eventually translates to pay loss.

In addition to the findings of the study, an acknowledgement of IDOT's efforts to increase incentives for contractors and make their QMP more achievable is relevant. These efforts include the following:

- IDOT changed the CPF equation for PFP, resulting in an increase in pay of $2 \%$. If this change would have been applied for the analyzed period, then $76 \%$ of produced HMA tons would have been paid with a pay incentive (in comparison to the actual 54\%). This change is expected to increase pay for contractors working on future projects under the PFP specification. Note that values in Table 6.1 would be higher if this change would have been considered.

- IDOT adjusted lift thickness for all lifts (including levelling lifts), which was increased recently to at least three times the NMAS. This should help address the concern with density pay disincentives by avoiding low compactability scenarios and is expected to reduce those pay disincentives in the future. However, variability may also be affected by base structural capacity.

In conclusion:

- Pay disincentives in QCP and PFP specifications are caused by several factors that require collaborative efforts by districts and contractors to be addressed.

- Per the findings (2, 3, and 4), QCP and PFP specifications appear to be fair and are appropriate (when compared to the reference documents) for the kinds of projects for which each is used.

- Fifty-four percent of the HMA tons, controlled by the PFP specification, were paid with an incentive (PF > 100). The pay per HMA ton has increased with time for the QCP specification. Hence, the QMP's requirements are achievable.

Considering the statistical analysis results and field observations, several observations are offered.

\subsection{OBSERVATIONS}

It is suggested that IDOT and industry consider the identified risks and make changes to improve mix consistency and quality. The following observations and suggestions are related to mix production and construction, sources of pay factor pay incentives/disincentives, sampling, and testing, among others. 


\subsubsection{Mix Production}

- Mix switches during production: Limit the number of mix switches during production. The more mix switches per day, the greater the material variability and the more challenging to control AC content.

- Dust control: The specification should clearly identify that a baghouse return system meters the fines to a specific percentage value.

- Stockpile handling: Utilize proper stockpile construction and recommended stockpile loadout procedures from IDOT quality management training courses (Aggregate Technician and HMA Level II).

- Cold feed control: A single mix aggregate that contributes $30 \%$ or more to the design aggregate blend should be divided into more than one cold feed.

- Stockpile barriers: Plants should use barriers between aggregate stockpiles in accordance with IDOT Standard Specifications Section 1102.01(2).

\subsubsection{Sampling Observations}

- Sampling location: To limit segregation potential, sampling location should be identified in accordance with the following (e.g., behind a paver for most mixes and at an auger for 4.75 NMAS):

\subsubsection{Uniformity in Sampling, Blending, Storage, and Preparation}

- To fulfill requirements by all parties, specifications must be met. HMA Level I practice for sampling, blending, and splitting will help as well as using consistent reheating practices to improve uniformity.

- Reheating protocol: To improve consistency, it is suggested that district and contractor personnel follow the reheating protocol in the IDOT MoTP (2018c) for QCP and PFP.

\subsubsection{2 $G_{m b}$ and $G_{m m}$ Testing Observations}

- $\mathrm{G}_{\mathrm{sb}}$ : It is recommended that the VMA calculation be completed with the yearly updated $\mathrm{G}_{\mathrm{sb}}$ of the aggregates used for production in accordance with the IDOT MoTP Appendix B.9. Tracking $\mathrm{G}_{\mathrm{sb}}$ is recommended as a $\mathrm{QC}$ activity to allow the monitoring of incoming aggregate and test protocols of AC content, RAP, and production issues.

- Gyratory bias monitoring: It is recommended to extend the internal district round robins to all contractors and districts every year. It is suggested to conduct them early in the construction season to allow contractors to detect differences in their test results due to gyratory compactor results and adjust accordingly, given that procedure, maintenance, and calibration are well-documented. Both parties may agree to consider AASHTO re:source inspection or accreditation as a requirement.

- Test weights: MoTP should be updated to require $\mathrm{G}_{\mathrm{mb}}$ test sample weight consistency is within 10 grams for dense graded and 15 grams for SMA. 


\subsubsection{Other Observations}

- Aggregate gradation variability from the supplier may significantly impact pay factors. Therefore, contractors should understand which aggregate sources exhibit a high degree of variability and communicate concerns to the supplier to improve consistency. In addition, IDOT should review AGCS to determine any improvements from the aggregate supplier.

- Mix design VMA target: Contractors should be aware that designing close to the minimum design VMA will increase the chances of receiving disincentives. The plant-produced VMA was observed to be lower than the design value. A production of $0.5 \%$ VMA above the minimum design value is suggested.

- Importance of production control: Production issues have the potential to cause significant disincentives in the CPF.

- PFP training: To help contractors optimize their pay factors, their knowledge in the PFP specification must be enhanced through workforce training. This includes training courses and developing documentations to identify production issues they should address based on the procedures used to evaluate the site visits.

- Data storage and monitoring: IDOT collects a significant amount of mix production and construction data. Currently, only final sublot average volumetric results and aggregate gradation are stored at the central database. The rest of the data, e.g., individual replicate results and raw test weights, are stored separately by districts. Improvement of the central database to include all information available is recommended through the new IDOT Construction and Materials Management system.

- Department staff: Resident engineers/technicians should comply with the IDOT Quality Management Training Program requirements, as stipulated by FHWA requirements. Acceptance testing should be completed by the same experienced and approved technician for each project. If changes are made to technicians and/or equipment, the contractor should be notified as soon as possible.

- Further investigation of the causes of the poor quality (low payment) observed in specific districts should be performed. Statistical analysis may be considered.

- IDOT's newly recruited personnel should always be under the supervision of experienced personnel to avoid sampling issues with location and time.

- Based on field visits, it would be beneficial for all testing labs to closely adhere to the "Best Practices for PFP and QCP Implementation" document in the IDOT's MOTP (2018c). 


\section{REFERENCES}

Al-Qadi, I. L., Rivera-Perez, J. J., Sayeh, W., García Mainieri, J. J., Meidani, H., Ozer, H., Huang, J., \& Hand, A. (2020). Case Studies Using Quality Control for Performance and Pay for Performance Specifications: Field Observations. Report No. FHWA-ICT-20-006. Illinois Center for Transportation, Rantoul, IL. https://doi.org/10.36501/0197-9191/20-007

Aguiar-Moya, J. P., \& Prozzi, J. A. (2011). Effect of Field Variability of Design Inputs on the MEPDG. Transportation Research Board 90th Annual Meeting, Washington, DC. https://trid.trb.org/view/1091815

Aschenbrener, T., Brown, E. R., Tran, N., \& Blankenship, P. B. (2018). The FHWA's Demonstration Project for Enhanced Durability of Asphalt Pavements through Increased In-Place Pavement Density. Transportation Research Record, 2672(26), 57-67. https://doi.org/10.1177/0361198118767419

Benson, P. E. (1999). Performance Review of a Quality Control/Quality Assurance Specification for Asphalt Concrete. Transportation Research Record, 1654(1), 88-94. https://doi.org/10.3141/1654-10

Buchanan, M. S., Shane Buchanan, M., \& Ray Brown, M.S. (2001). Effect of Superpave Gyratory Compactor Type on Compacted Hot-Mix Asphalt Density. Transportation Research Record, 1761(1), 50-60. https://doi.org/10.3141/1761-07

Buttlar, W., \& Harrell, M. (1998). Development of End-Result and Performance-Related Specifications for Asphalt Pavement Construction in Illinois. Crossroads 2000 Proceedings, p.195-202, Ames, lowa https://trid.trb.org/view/507748

Buttlar, W., \& Manik, A. (2007) Evaluation of Risk in End-Result Specifications for Asphalt Pavement Construction. Research Report FHWA-ICT-07-013. Illinois Center for Transportation, University of Illinois at Urbana-Champaign. http://hdl.handle.net/2142/45992

Chakroborty, P., Das, A., \& Pijush, G. (2010). Determining Reliability of an Asphalt Mix Design: Case of 15 Marshall Method. ASCE Journal of Transportation Engineering, 136(1), 31-37. https://doi.org/10.1061/(ASCE)0733-947X(2010)136:1(31)

Deacon, J. A., Monismith, C. L., Harvey, J. H., \& Popescu, L. (2001). Pay Factors for Asphalt-Concrete Construction: Effect of Construction Quality on Agency Costs, Technical Memorandum TM-UCBPRC-2001-1, University of California Pavement Research Center, Berkeley, California. http://www.ucprc.ucdavis.edu/PDF/TM01-01.pdf

Federal Highway Administration. (2015). Quality Assurance Assessment Report-2014. Office of Pavement Technology. Washington, DC.

Federal Highway Administration. (2013). Quality Assurance Stewardship Review Summary Report for Fiscal Years 2009 through 2012. Office of Pavement Technology. Washington, DC. https://www.fhwa.dot.gov/pavement/materials/stewardship2013.pdf

Federal Highway Administration. (2011). Independent Assurance Tech Brief. Report No. FHWA-HIF-12001. Office of Pavement Technology. Washington, DC. 


\section{https://www.fhwa.dot.gov/pavement/materials/hif12001.pdf}

Federal Highway Administration. (2010). SuperPave Gyratory Compactors Tech Brief. Report No.

FHWA-HIF-11-032. Office of Pavement Technology. Washington, DC.

https://www.fhwa.dot.gov/pavement/materials/pubs/hif11032/hif11032.pdf

Federal Highway Administration. (2008). National Advanced Quality Assurance Systems Assessment Report. Office of Pavement Technology. Washington, DC.

Federal Highway Administration. (2007). Quality Assurance in Materials and Construction. Final Report, Office of Professional and Corporate Development Program Improvement Team, National Review Program, Washington, DC. https://www.fhwa.dot.gov/construction/cqit/qamc0607/

Federal Highway Administration. (1995). Quality Assurance Procedures for Construction. Report No.23 CFR Part 637B, Federal Register, Washington, DC. https://www.fhwa.dot.gov/legsregs/directives/fapg/cfr0637b.htm

Federal Motor Carrier Safety Administration (FMCSA). (2019). MAP-21-Moving Ahead for Progress in the 21st Century Act. Retrieved from https://www.fmcsa.dot.gov/mission/policy/map-21-movingahead-progress-21st-century-act

Fugro Consultants and Arizona State University. (2011). A Performance-Related Specifiaction of HotMix Asphalt. Report 704, Project 9-22, National Cooperative Highway Research Program, Washington, DC. http://www.trb.org/Publications/Blurbs/166347.aspx

Hall, K. D., \& Williams, K. D. (2002). Establishing Variability for Hot-Mix Asphalt Construction in Arkansas. Transportation Research Record, 1813(1), 172-180. https://doi.org/10.3141/1813-21

Hand, A. J., \& Epps, A. L. (2000). Effects of Test Variability on Mixture Volumetrics and Mix Design Verification. Journal of the Association of Asphalt Paving Technologies, 69, 635-674 https://trid.trb.org/view/675410

Highway Research Board. (1962). Special Report 61B: AASHO Road Test, Report 2-Materials and Construction, Publication 951, National Academy of Sciences-National Research Council, Washington, DC.

Illinois Department of Transportation (IDOT). (2019). Internal Memorandum 80416: Special Provision for Hot-Mix Asphalt-Binder and Surface Course. Springfield, Illinois http://idot.illinois.gov/Assets Luploads/files/Doing-Business/Specialty-Lists/Highways/Design-\&-Environment/BDE-SpecialProvisions/80416\%20HMA\%20Binder\%20and\%20Surface\%20Course.pdf

Illinois Department of Transportation (IDOT). (2018a). Internal Memorandum 80347: Special Provision for Pay for Performance Using Percent within Limits-Jobsite Sampling. Springfield, Illinois.

Illinois Department of Transportation (IDOT). (2018b). Internal Memorandum 80383: Special Provision for Pay for Hot Mix Asphalt-Quality Control for Performance. Springfield, Illinois.

Illinois Department of Transportation (IDOT). (2018c). Manual of Test Procedures for Materials. Springfield, Illinois http://idot.illinois.gov/Assets/uploads/files/Doing-Business/Manuals-Guides\&-Handbooks/Highways/Materials/Manual\%20of\%20Test\%20Procedures\%20for\%20Materials \%20December\%202018.pdf 
Illinois Department of Transportation (IDOT). (2013). Internal Memorandum: Revised Goals for Quality Assurance Procedures. Springfield, Illinois.

Illinois Department of Transportation (IDOT). (2010). Internal Memorandum: Needed Improvements to Quality Assurance Procedures. Springfield, Illinois.

LaVassar, C. J., Mahoney, J. P., \& Willoughby, K. A. (2009). Statistical Assessment of Quality Assurance Quality Control Data for Hot Mix Asphalt, Research Report No. WA-RD 686.1. Washington State Transportation Center, Seattle, Washington. https://www.wsdot.wa.gov/research/reports /fullreports/686.1.pdf

Mahboub, K. C., Goodrum, P. M., Glasgow, A. Enlow, J., Hendrix, N., \& Uddin, M. (2008). QC/QA: Evalutaion of Effectiveness in Kentucky. Research Report KTC-08-19/SPR347-07-1F. Kentucky Transportation Center, Lexington, Kentucky. https://uknowledge.uky.edu/ktc researchreports $180 /$

Mohammad, L. N., Elseifi, M. A., Cooper III, S. B., \& Raghavendra, A. (2013). Levels of Variability in Volumetric and Mechanical Properties of Asphalt Mixtures. Journal of Materials in Civil Engineering. https://ascelibrary.org/doi/pdf/10.1061/\%28ASCE\%29MT.1943-5533.0000545

Mohaney, J., \& Stephens, J. E. (2003). Connecticut Superpave Gyratory Round Robin-2003 Final Report. Connecticut Transportation Institute, University of Connecticut. http://www.caplab .uconn.edu/pdfs/Final\%20Report\%204-18-03.pdf

Monismith, C. L., Popescu, L., \& Harvey, J. (2004). Performance-Based Pay Factors for Asphalt Concrete Construction: Comparison with a Currently Used Experience-Based Approach. Electronic Journal of the Association of Asphalt Paving Technologists, 73, 147-194.

National Cooperative Highway Research Program (NCHRP). (2017). Procedures and Guidelines for Validating Contractor Test Data. Retrieved from https://apps.trb.org/cmsfeed/TRBNetProjectDisplay.asp?ProjectID=4192

National Cooperative Highway Research Program (NCHRP). (2016). Report 818: Comparing the Volumetric and Mechanical Properties of Laboratory and Field Specimens of Asphalt Concrete. Washington, DC. https://doi.org/10.17226/23475

National Cooperative Highway Research Program (NCHRP). (2011).A Performance-Related Specification for Hot-Mixed Asphalt, Transportation Research Board, Vo. 704. Washington, DC. https://doi.org/10.17226/22835

National Cooperative Highway Research Program (NCHRP). (2005). State Construction Quality Assurance Programs. Synthesis 346, Project 20-5, Transportation Research Board, Washington, DC. https://doi.org/10.17226/23310

National Cooperative Highway Research Program (NCHRP). (2000).Segregation in Hot-Mix Asphalt Pavements. Transportation Research Board, Vol. 441._Washington, DC. http://onlinepubs.trb.org/onlinepubs/nchrp/nchrp rpt 441.pdf

National Cooperative Highway Research Program (NCHRP). (1998). Quality Control and Acceptance of Superpave-Designed Hot Mix Asphalt. Transportation Research Board, Vol. 409. Washington, DC. http://onlinepubs.trb.org/onlinepubs/nchrp/nchrp rpt 409.pdf 
National Cooperative Highway Research Program (NCHRP). (1995). Performance-Related Specifications for Highway Construction and Rehabilitation. NCHRP Synthesis 212, Transportation Research Board, Washington, DC. http://onlinepubs.trb.org/Onlinepubs/nchrp/nchrp syn 212 . pdf

National Cooperative Highway Research Program (NCHRP). (1979). Quality Assurance. NCHRP Synthesis 65, Transportation Research Board, Washington, DC. http://www.trb.org /Publications/Blurbs/154526.aspx

National Cooperative Highway Research Program (NCHRP). (1976). Statistically Oriented End-Result Specifications. NCHRP Synthesis 38, Transportation Research Board, Washington, DC. http://www.trb.org/Publications/Blurbs/154548.aspx

National Research Council (US). Highway Research Board, \& American Association of State Highway Officials. (1962). The AASHO Road Test: Report 2, Materials and Construction (Special Report, 61b). National Academy of Sciences-National Research Council. Washington, DC.

Patel, A., Thompson, M., Harm, E., \& Sheftick, W. (1997). Developing QC/QA Specifications for Hot Mix Asphalt Concrete in Illinois. Transportation Research Record, 1575(1), 66-74. https://doi.org/10.3141/1575-10

Parker, F., Jr., \& M. S. Hossain. (2002). Statistics for Superpave Hot-Mix Asphalt Construction Quality Control/Quality Assurance Data. Transportation Research Record: Journal of the Transportation Research Board, 1813, 151-156. https://trid.trb.org/view/731945

Parker, F., \& Turochy R. E. (2007). Using the Results of Contractor-Performed Tests in Quality Assurance: Contractor's Final Report. National Academies of Sciences, Engineering, and Medicine Washington, DC. https://doi.org/10.17226/23134

Sholar, G. A., Page, G. C., \& Musselman, J. A. (2002). Precision Statements for Ignition Oven for Use with Plant-Produced Mixtures. Transportation Research Record, 1813(1), 142-150. https://doi.org/10.3141/1813-17

Stroup-Gardiner, M., Newcomb, D., \& Savage, D. (1994). Defining Specification Limits with Respect to Testing Variability. Association of Asphalt Paving Technologists. Vol 63. https://trid.trb.org/view/1168549

Transportation Research Board (TRB). (2018). Glossary of Transportation Construction Quality Assurance Terms. Seventh Edition. Transportation Research Circular. No. E-C235, Washington, DC. http://www.trb.org/Main/Blurbs/178085.aspx

Transportation Research Board (TRB). (2002). Bailey Method for Gradation Selection in Hot-Mix Asphalt Mixture Design. Transportation Research Circular. No. E-C044, Washington, DC. http://onlinepubs.trb.org/onlinepubs/circulars/ec044.pdf

Turochy, R. E., Willis, J. R., \& Parker, F. (2006). Quality Assurance of Hot-Mix Asphalt: Comparison of Contractor Quality Control and Georgia Department of Transportation Data.Transportation Research Record, 1946(1), 47-54.https://doi.org/10.1177/0361198106194600106 


\section{APPENDIX A: 2018 SURVEY RESULTS}

\section{A.1 CONTRACTOR SURVEY}

During spring 2018, a survey was sent to IDOT contractors to gather their opinions about QCP and PFP. Twenty-four responses were received. The responders typically conducted business with more than one of the IDOT districts. Figure A.1 shows the districts with which these contractors did business.

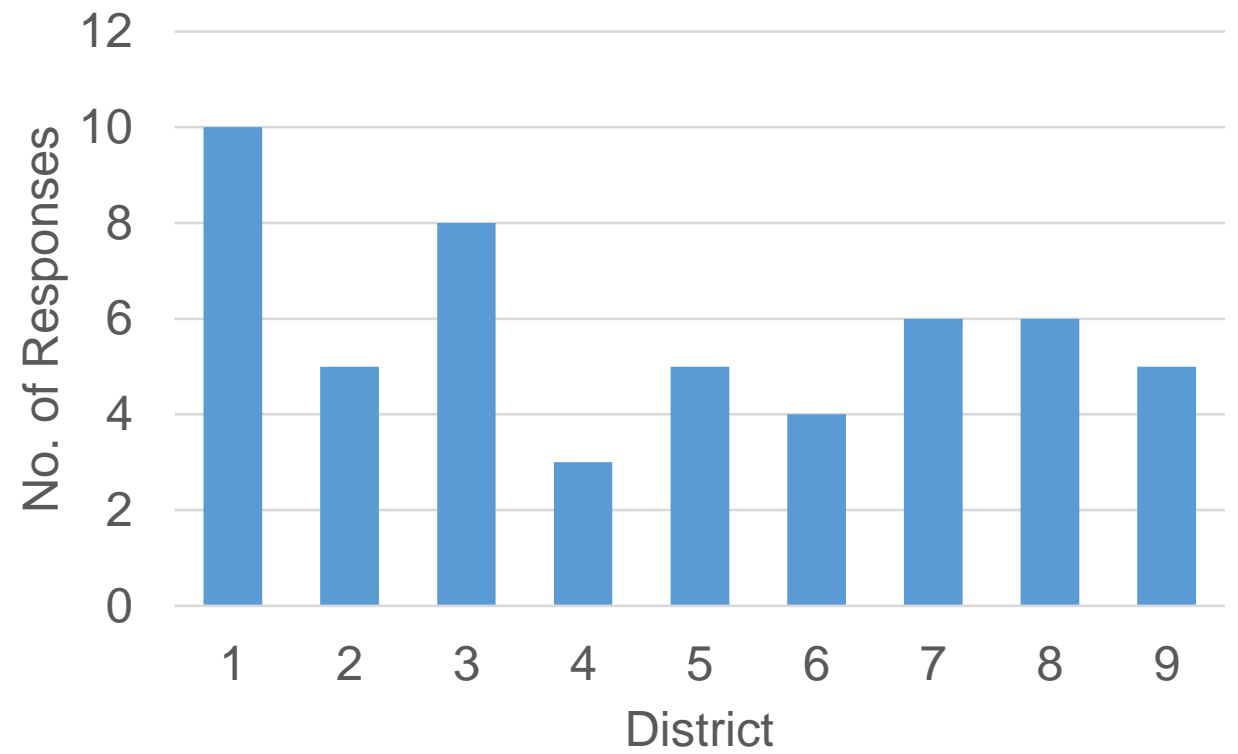

Figure A.1. Districts that had business with the contractors that were surveyed.

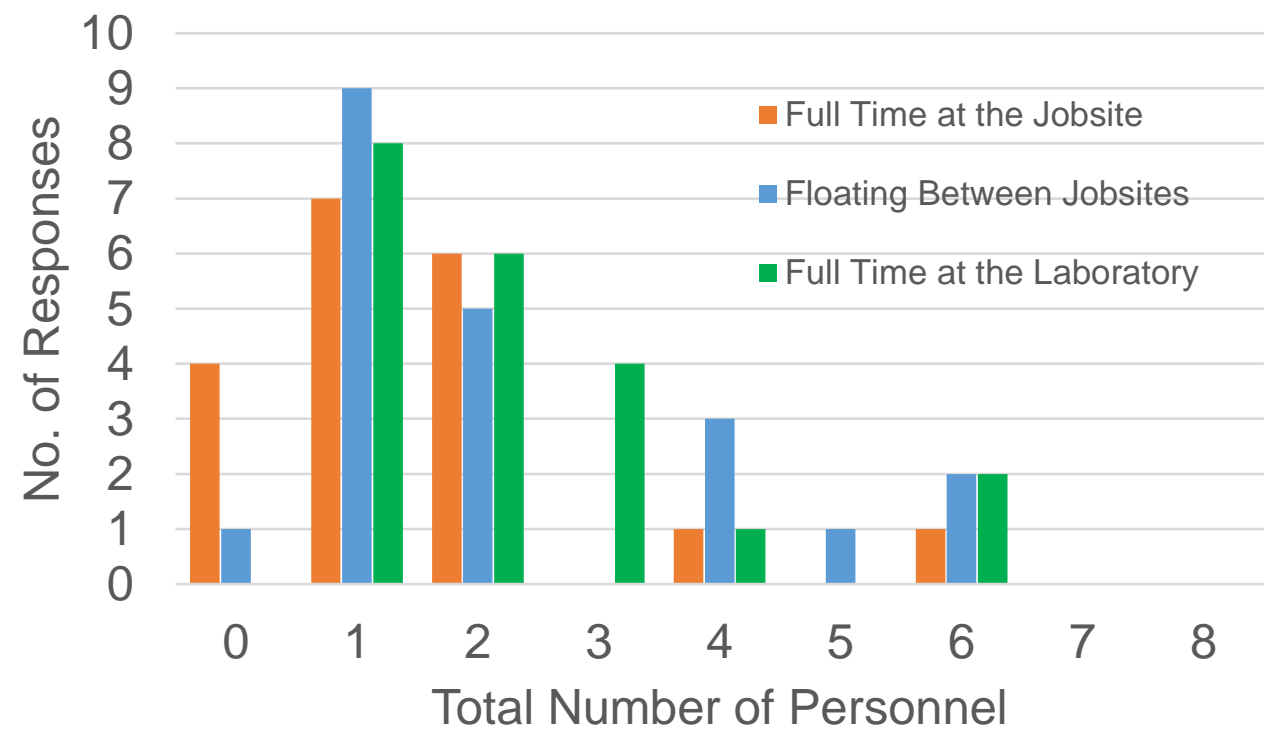

Figure A.2. Number of personnel assigned exclusively for quality control tasks. 


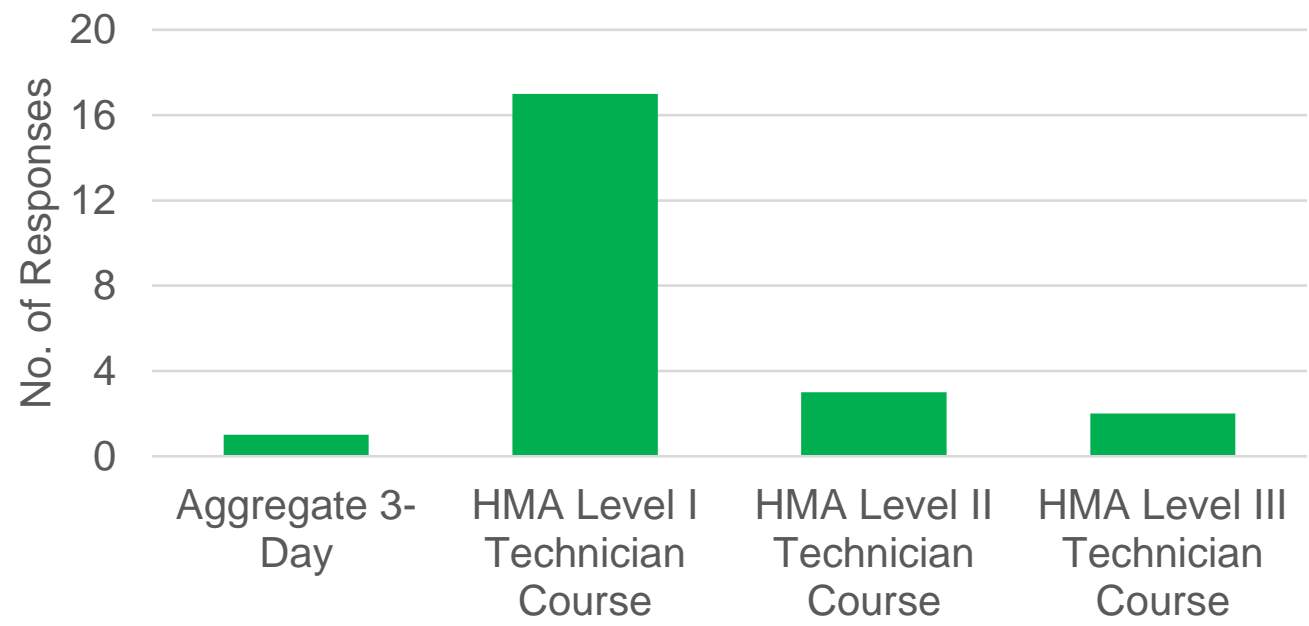

Figure A.3. Minimum level of training required for technicians.

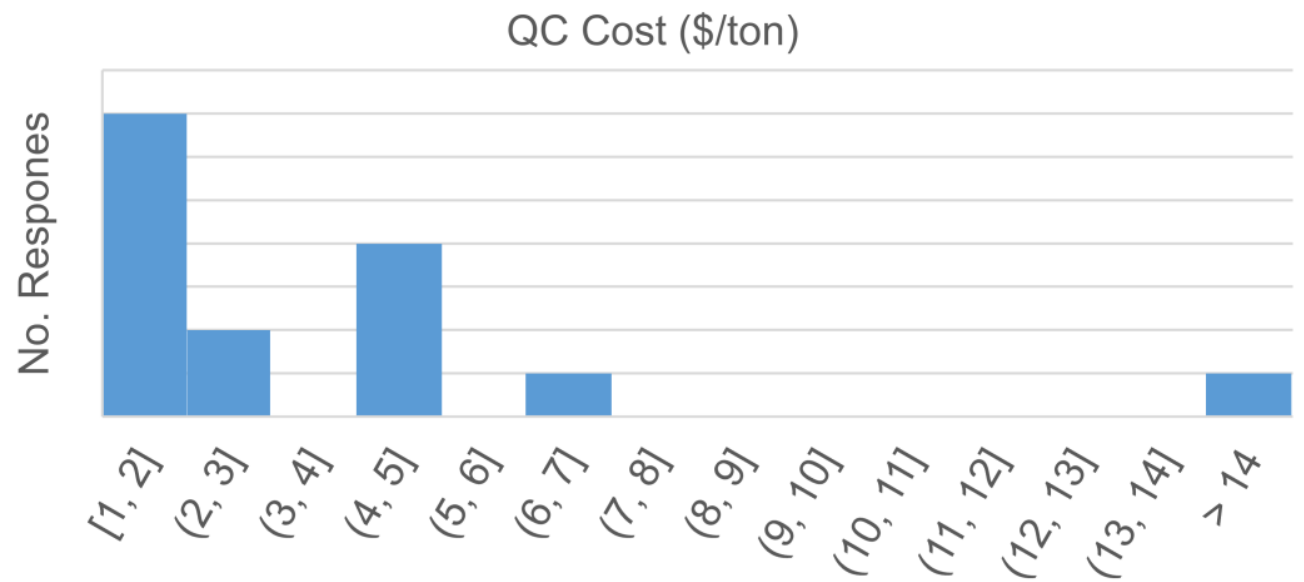

Cost $(\$)$

Figure A.4. Quality control cost per mix ton.

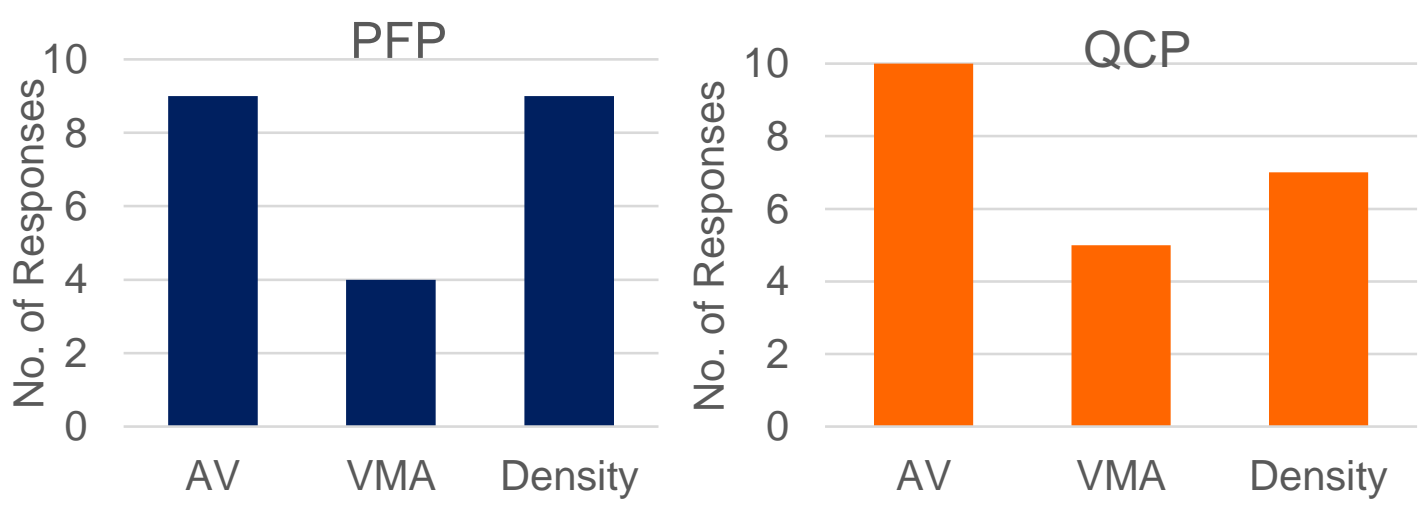

Figure A.5. Parameter driving pay loss. 


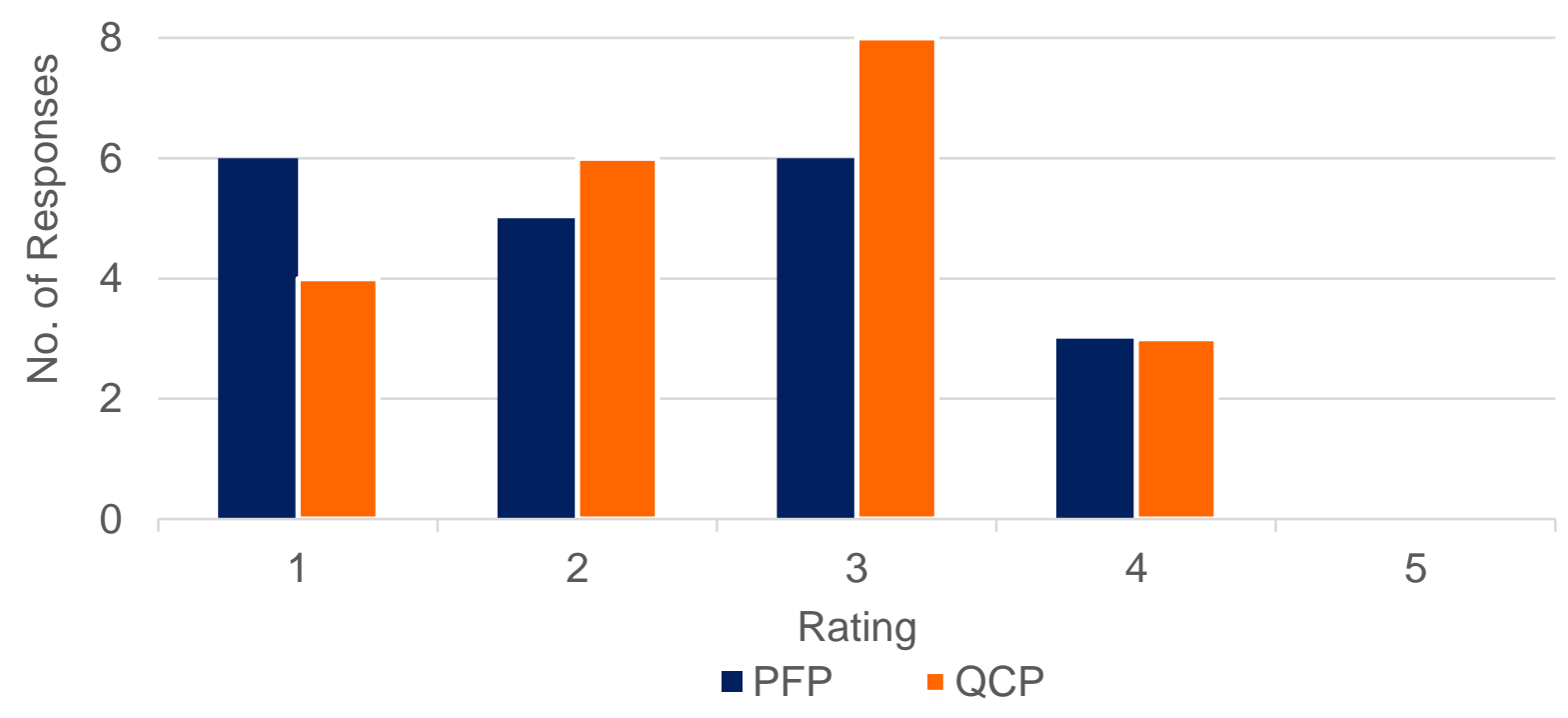

Figure A.6. Rate the QC programs.

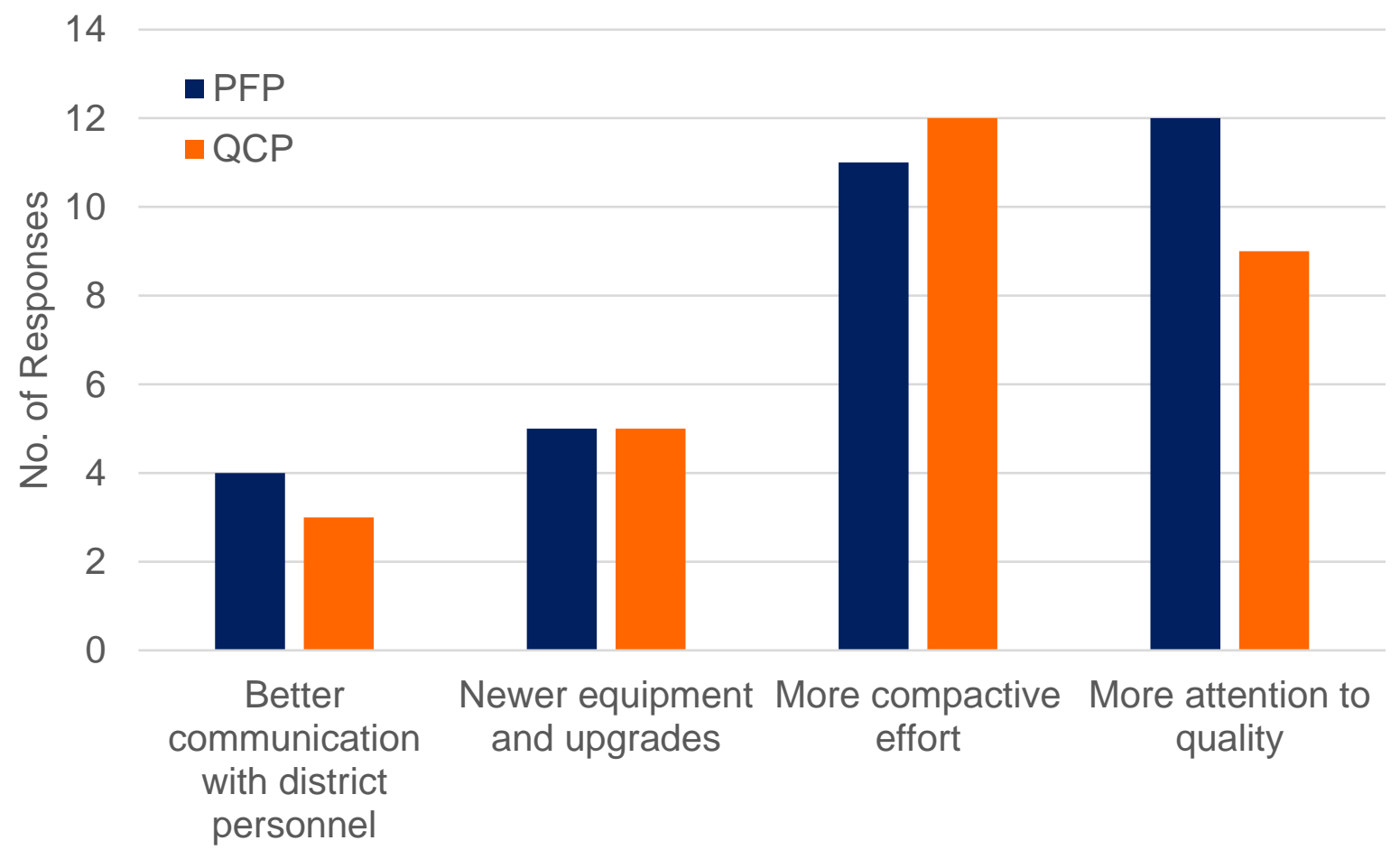

Figure A.7. QC programs benefits. 


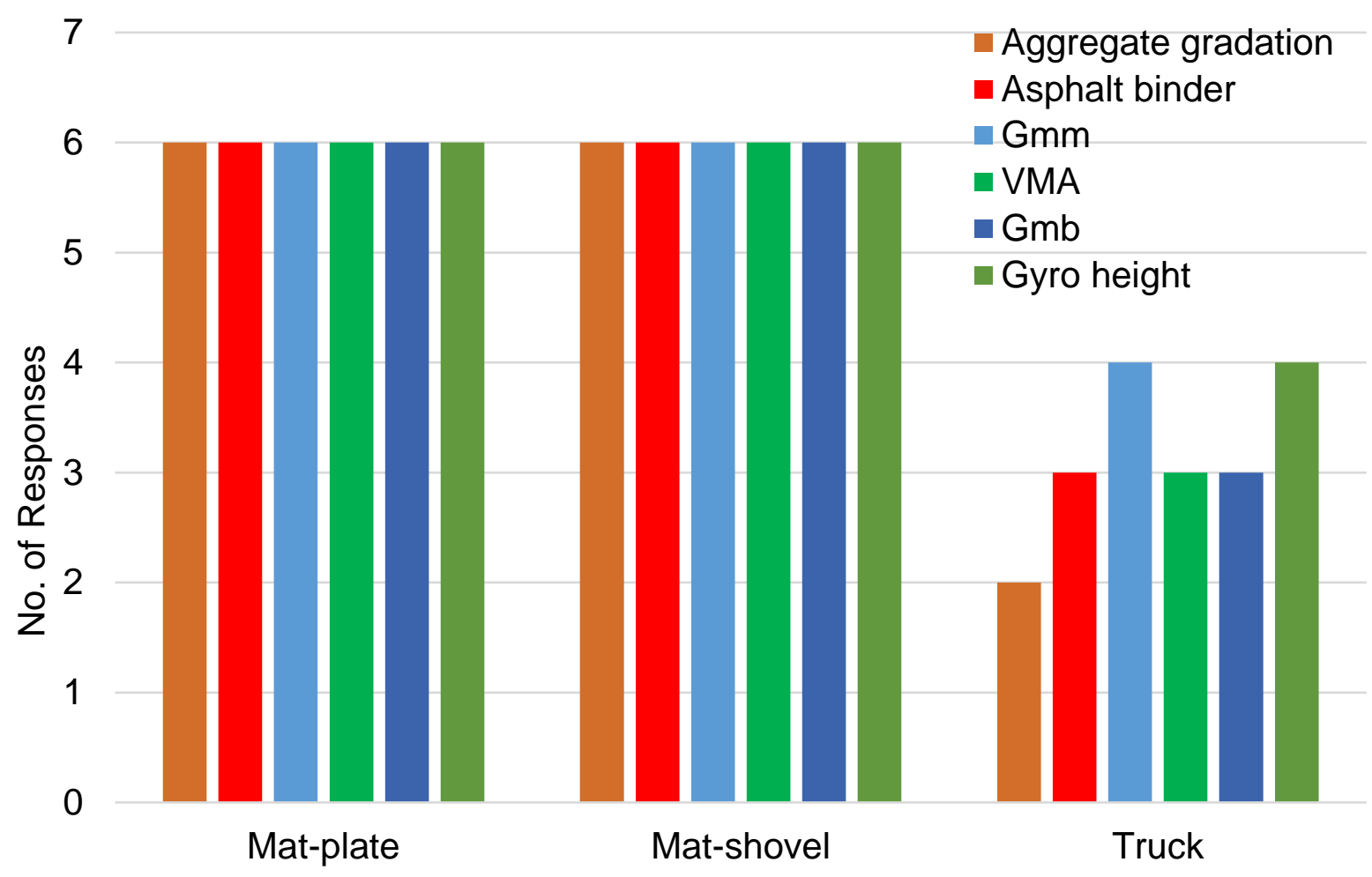

Figure A.8. QC sampling location.

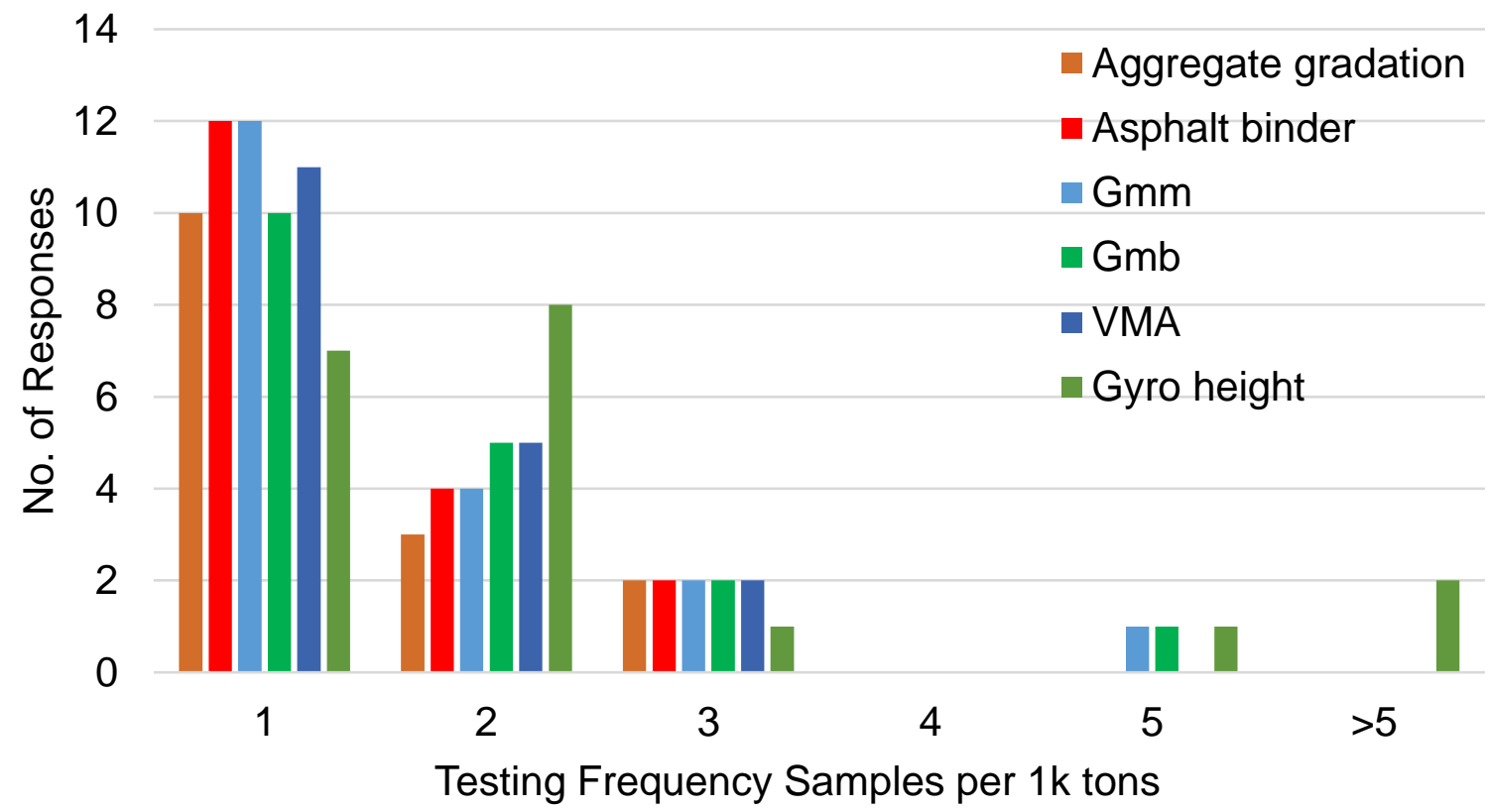

Figure A.9. QC program benefits. 


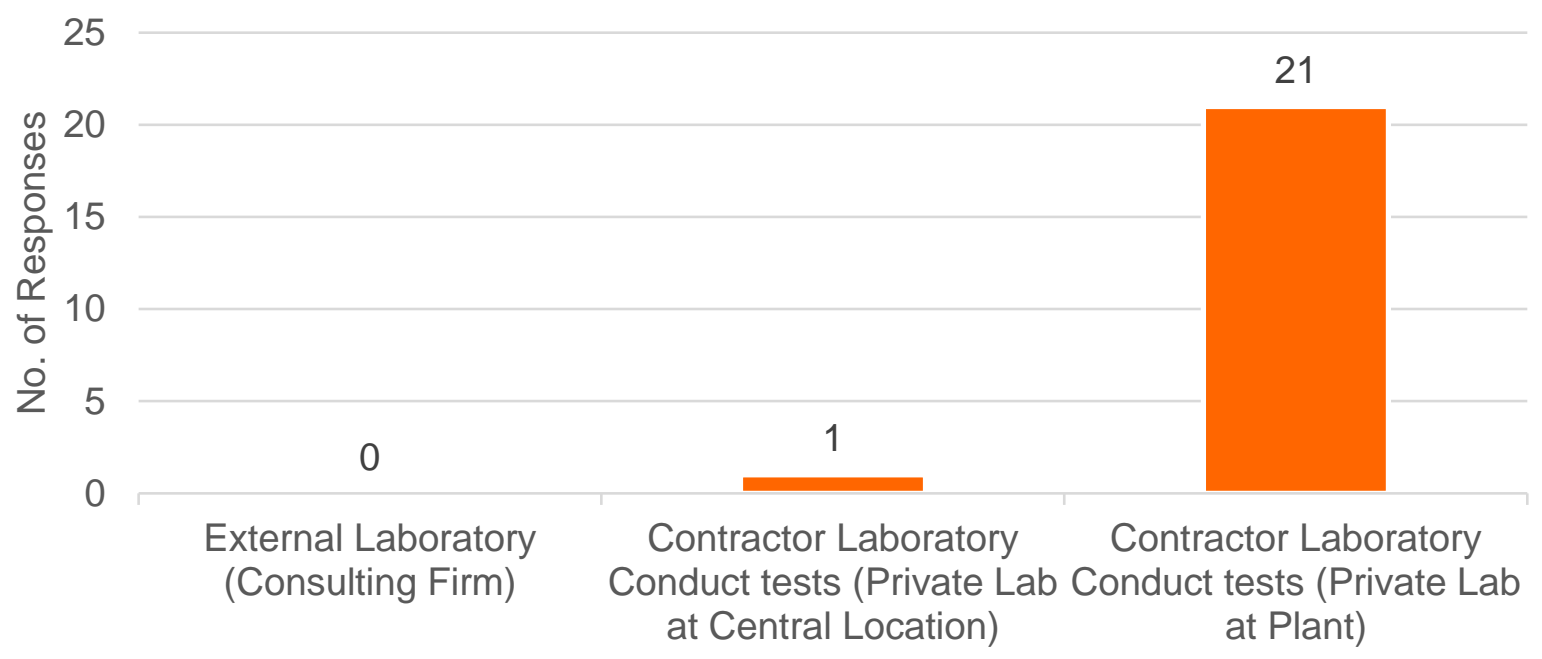

Figure A.10. QC testing location.

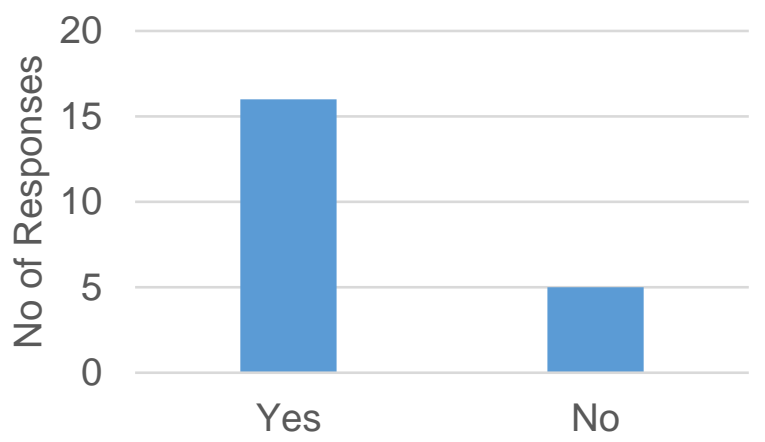

Figure A.11. Does the company have the same person running all samples on a project?

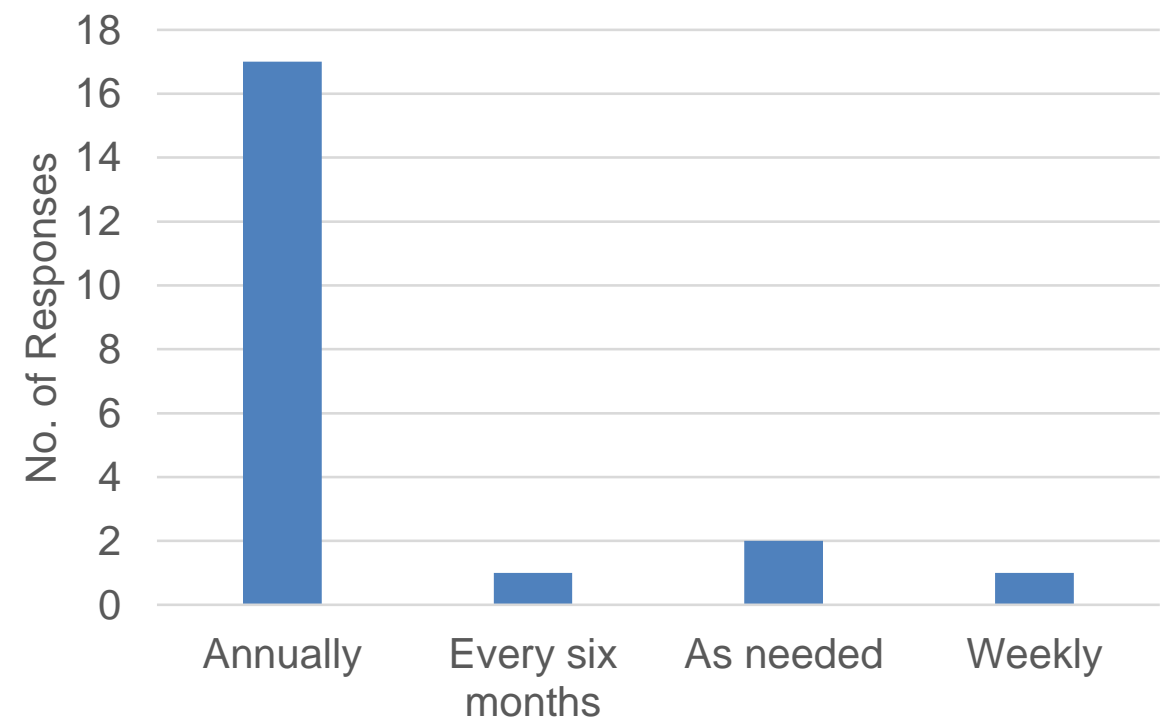

Figure A.12. How often are the molds inspected with a bore gauge? 


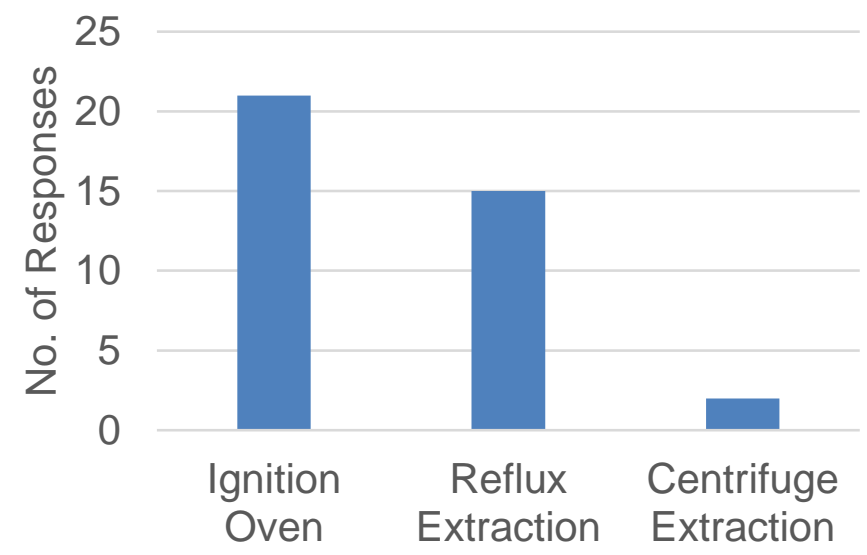

Figure A.13. What equipment is used to determine AC content?

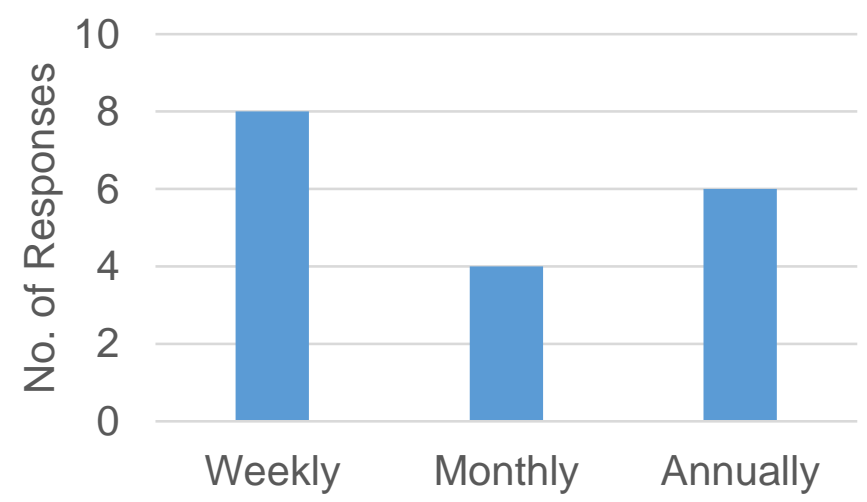

Figure A.14. How often is the lift test performed on the ignition oven?

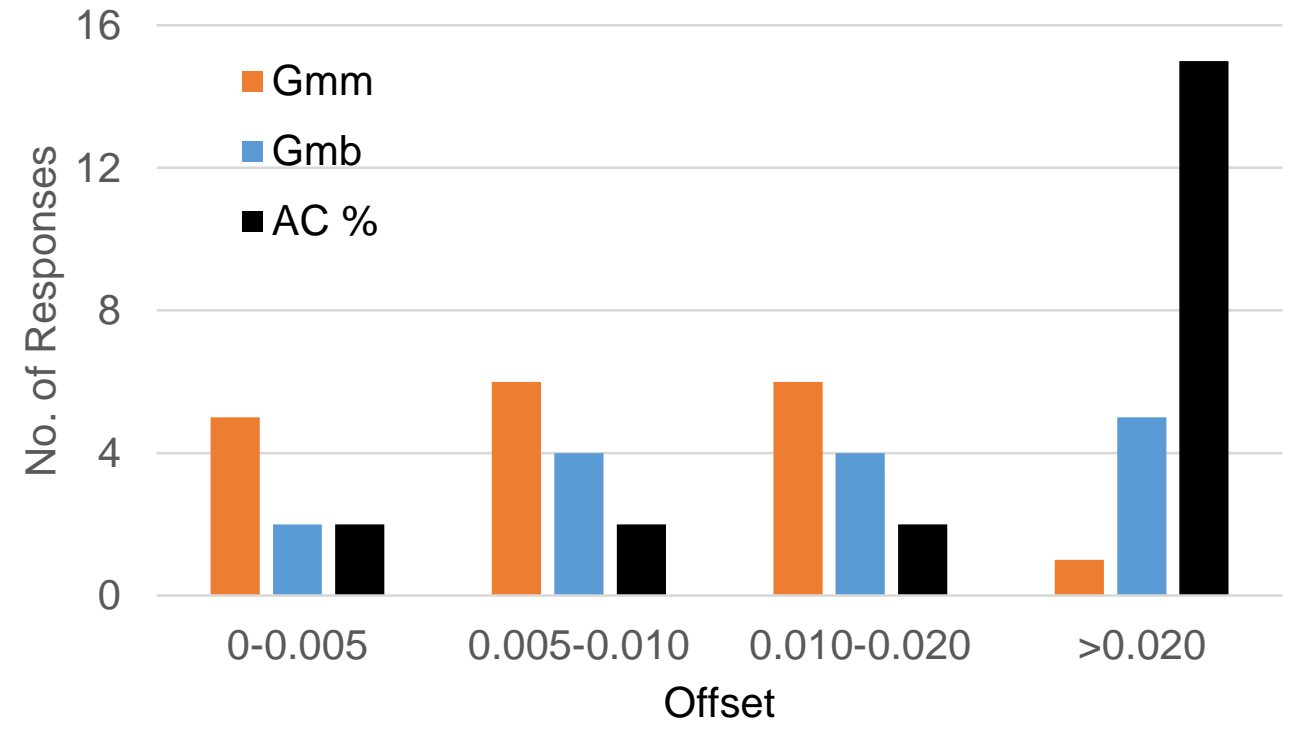

Figure A.15. What is your typical offset between your lab and the district lab for? 


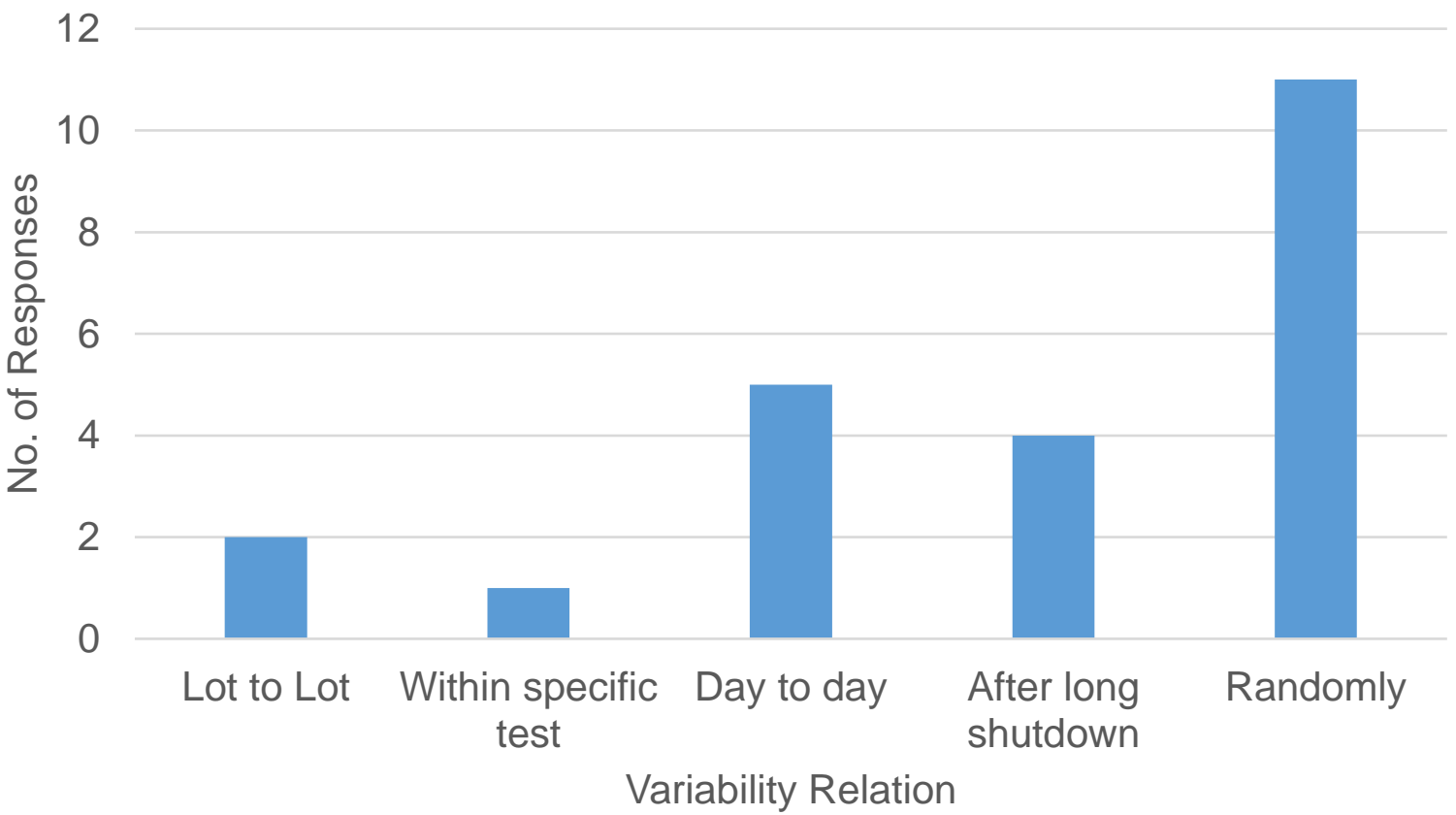

Figure A.16. For those mixes that seem to have more variability, is the variability related to one or more of the following?

10

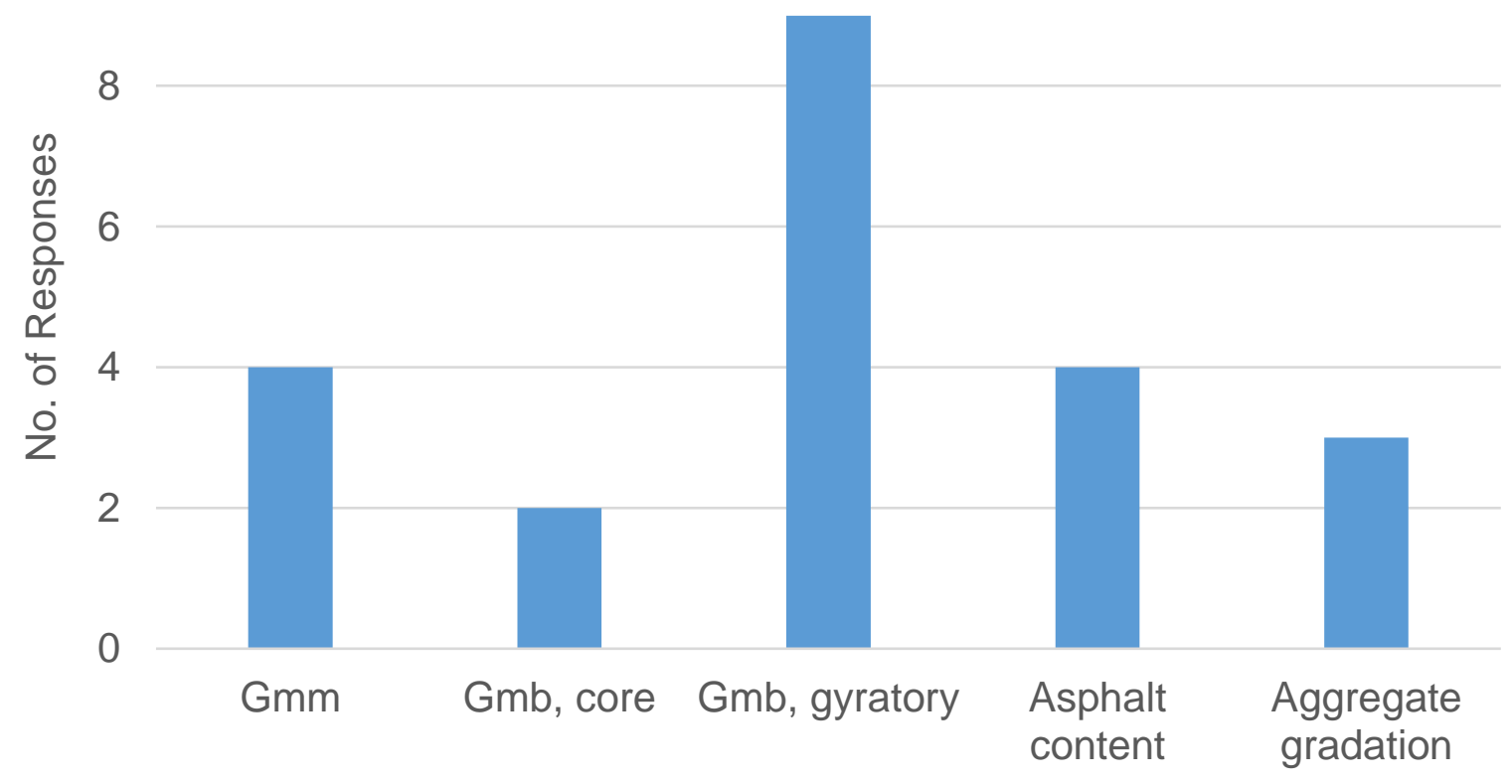

Figure A.17. For contractors working with multiple department district labs, do you notice a difference in the following tests results between labs for pay samples? 


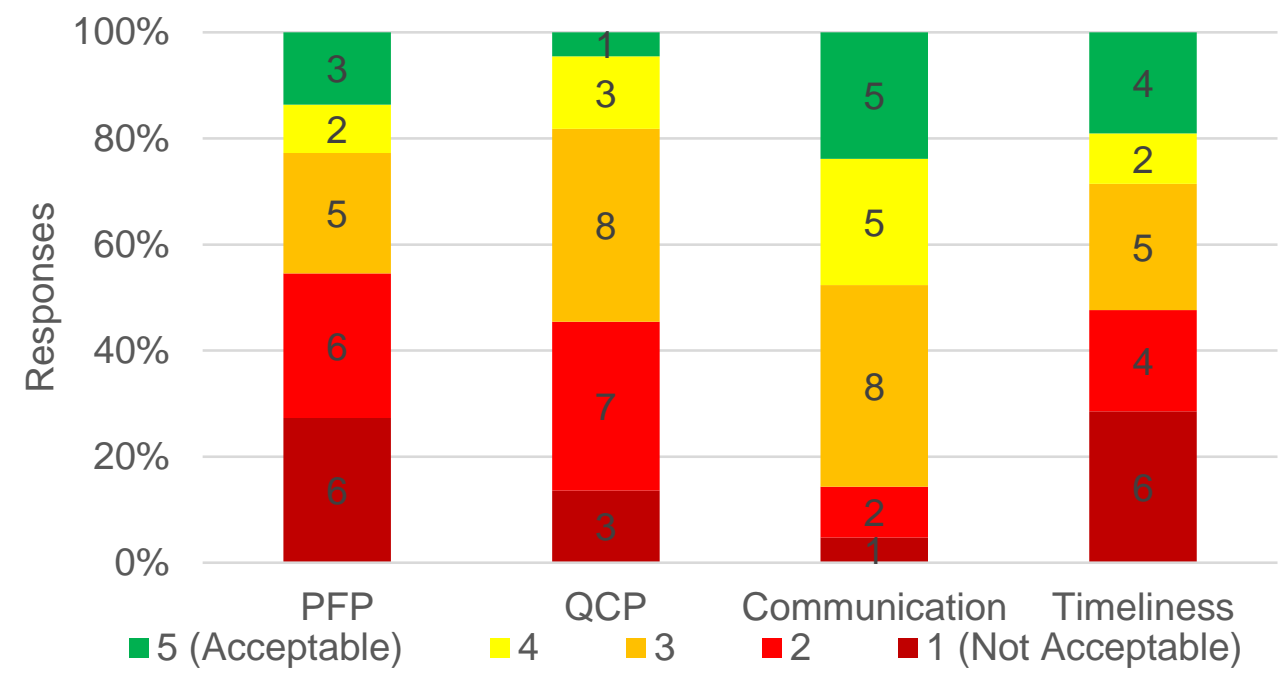

Figure A.18. Please rate from 1 to 5 , where 1 is not acceptable and 5 is acceptable: PFP specification, QCP specification, communication with IDOT, timeliness or turnaround time of the results by IDOT.

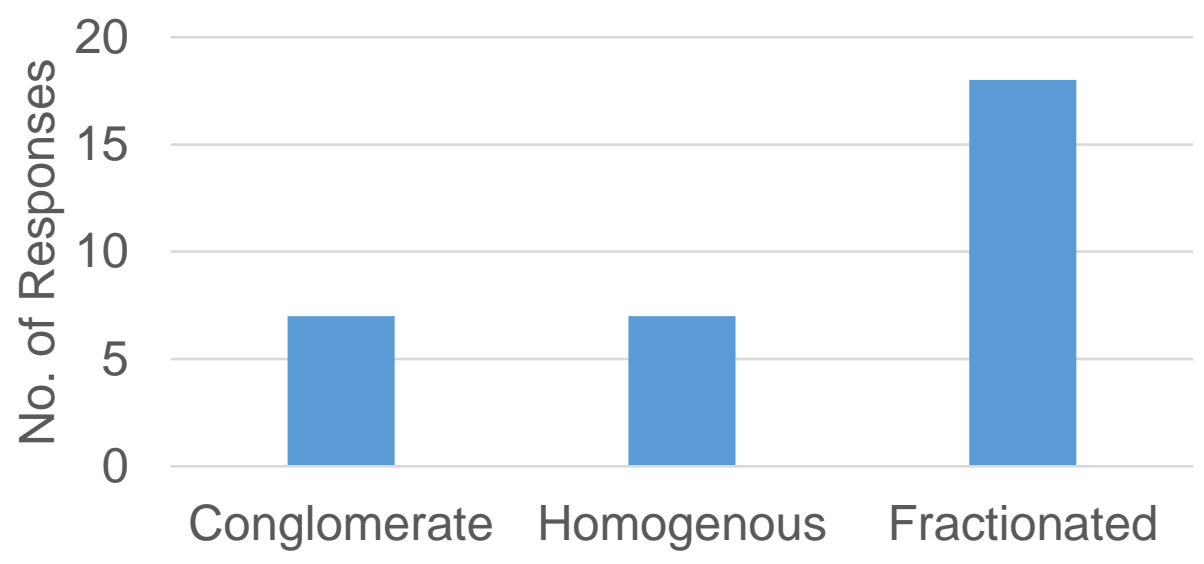

Figure A.19. What type of RAP stockpiles do you have? (Check all that apply.)

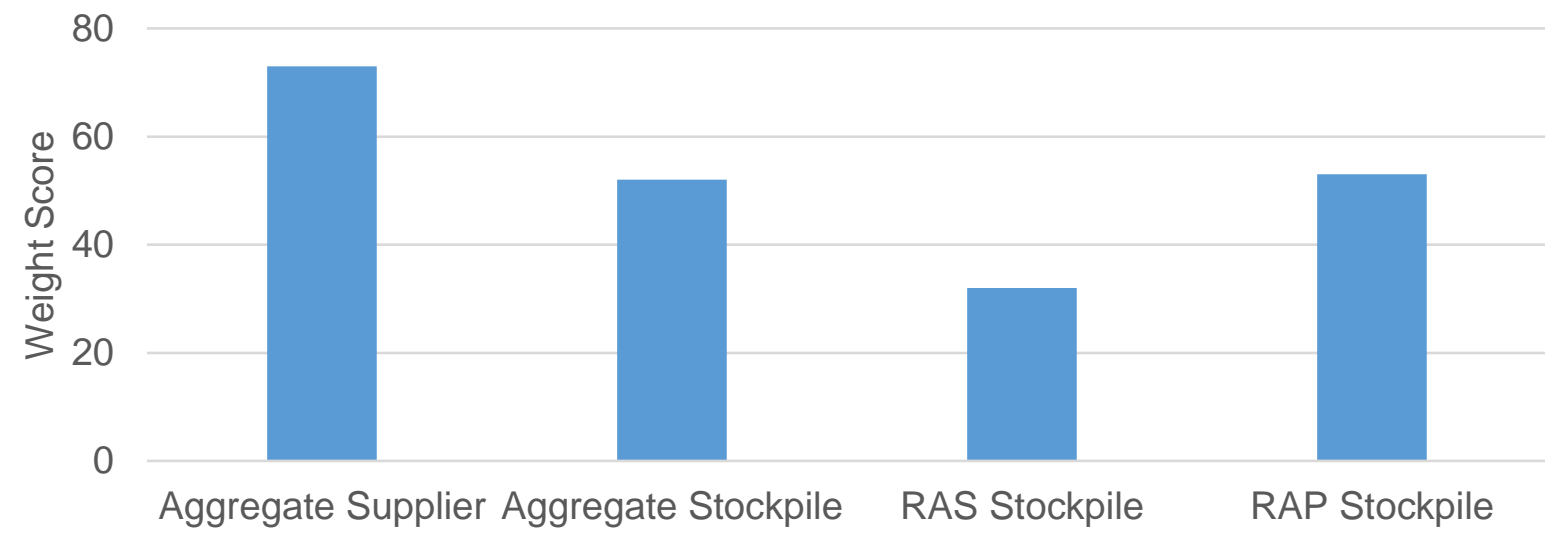

Figure A.20. Rank the source of variability at the plant (1 is least and 5 is greatest); RAS was not used by all producers. 


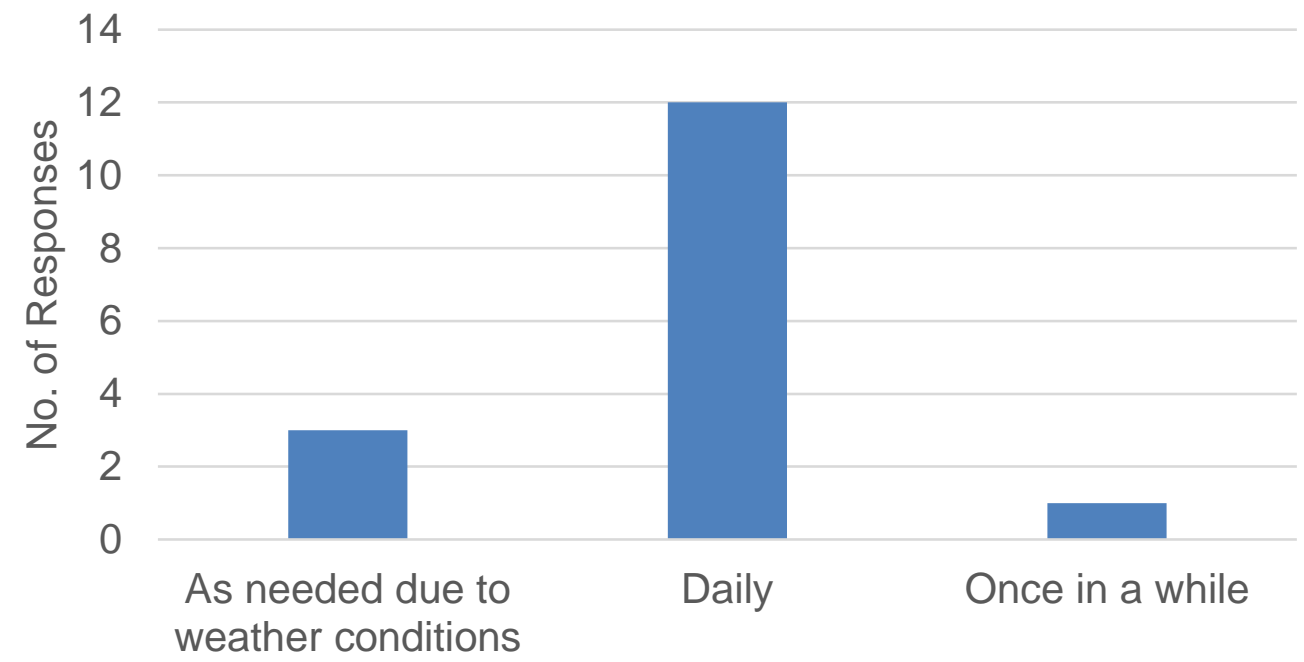

Figure A.21. How often is the aggregate stockpile moisture test conducted?

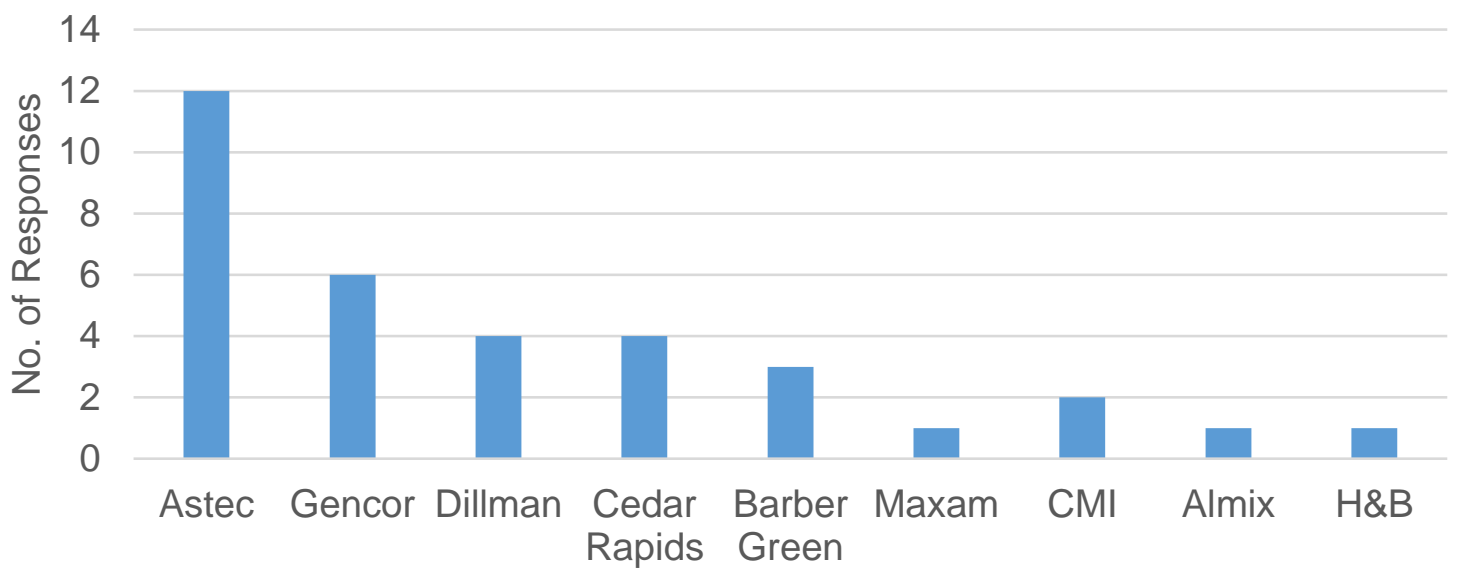

Figure A.22. Plant manufacturer.

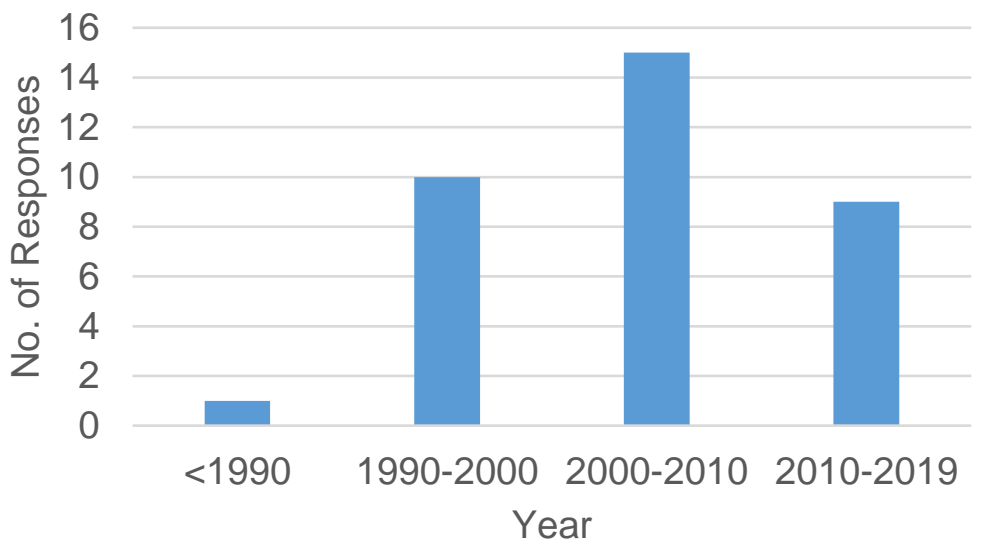

Figure A.23. Plant year. 


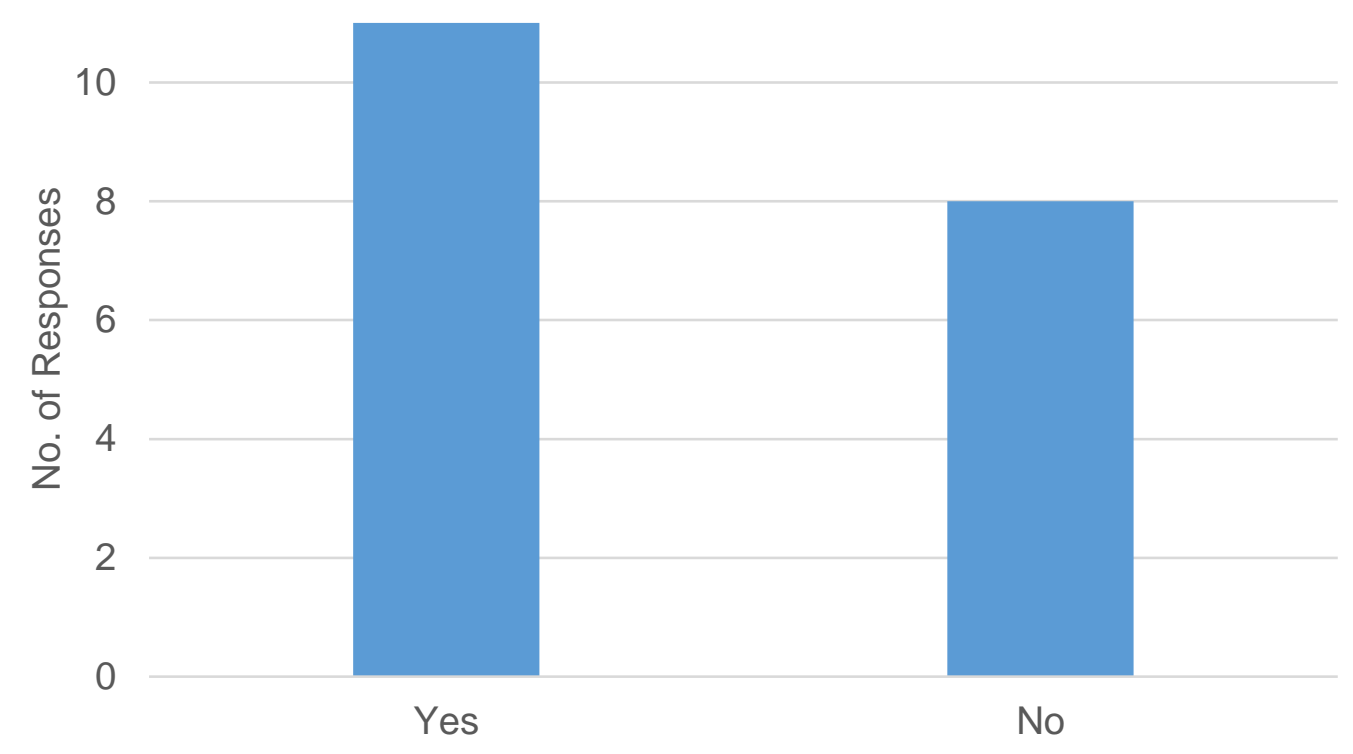

Figure A.24. Do you switch mixes while producing for PFP/QCP projects?

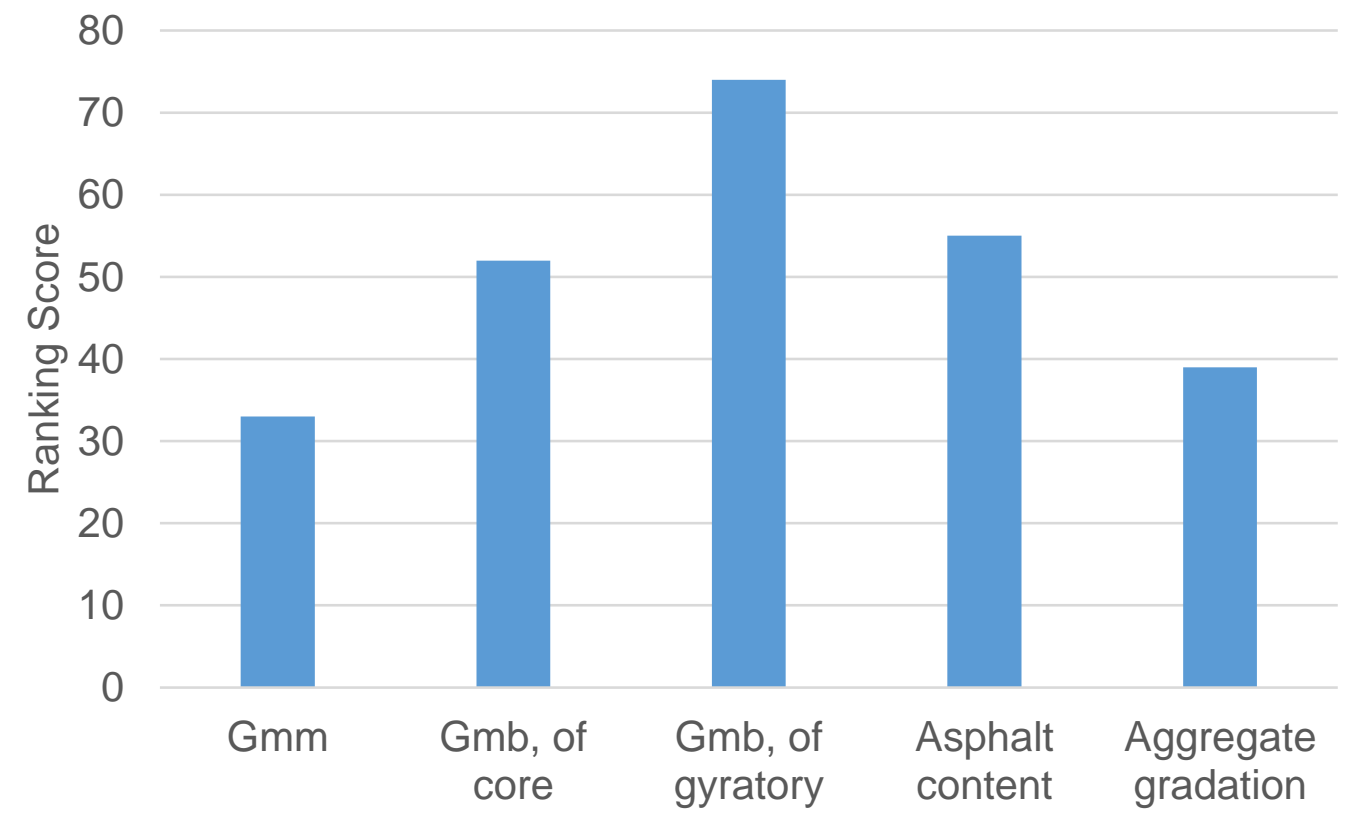

Figure A.25. Rank the following criteria for cause of error (or pay disincentive). 


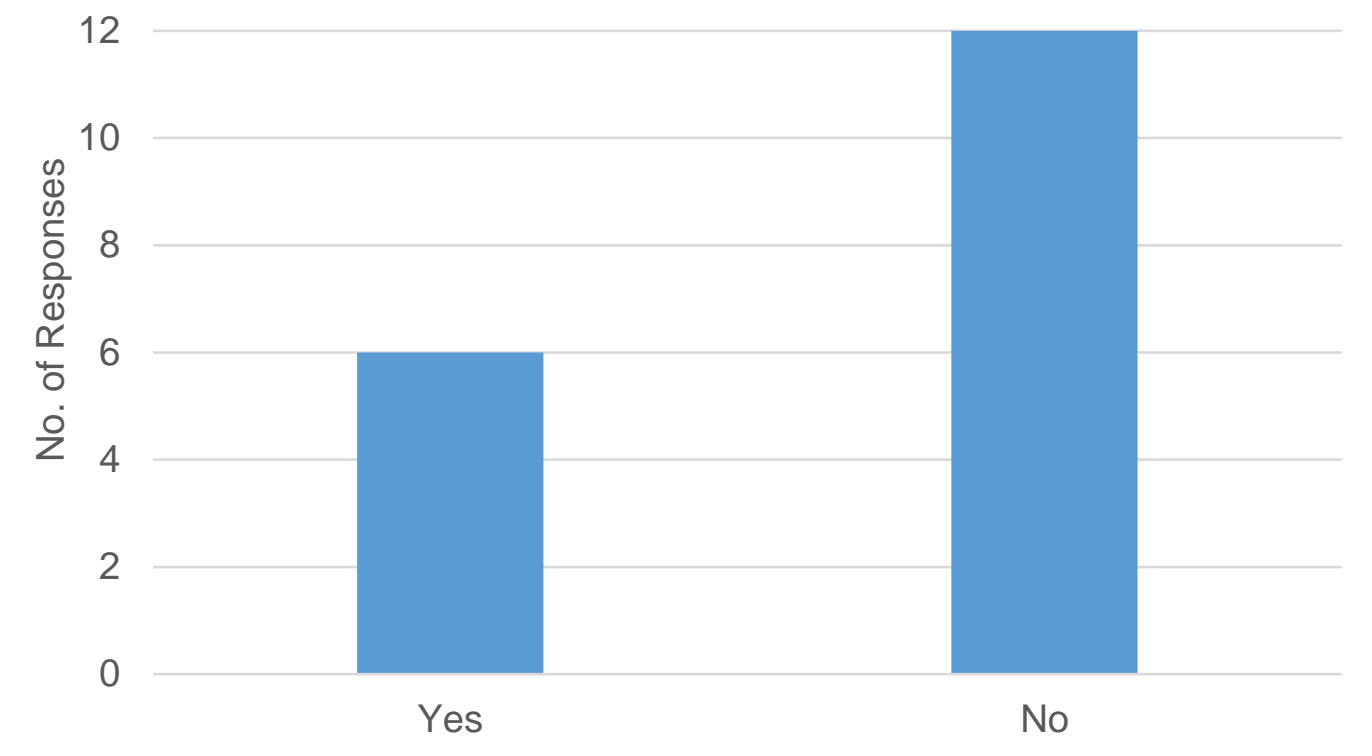

Figure A.26. Are the QC managers directives ever overruled by others (project superintendent, chief estimator, etc.)?

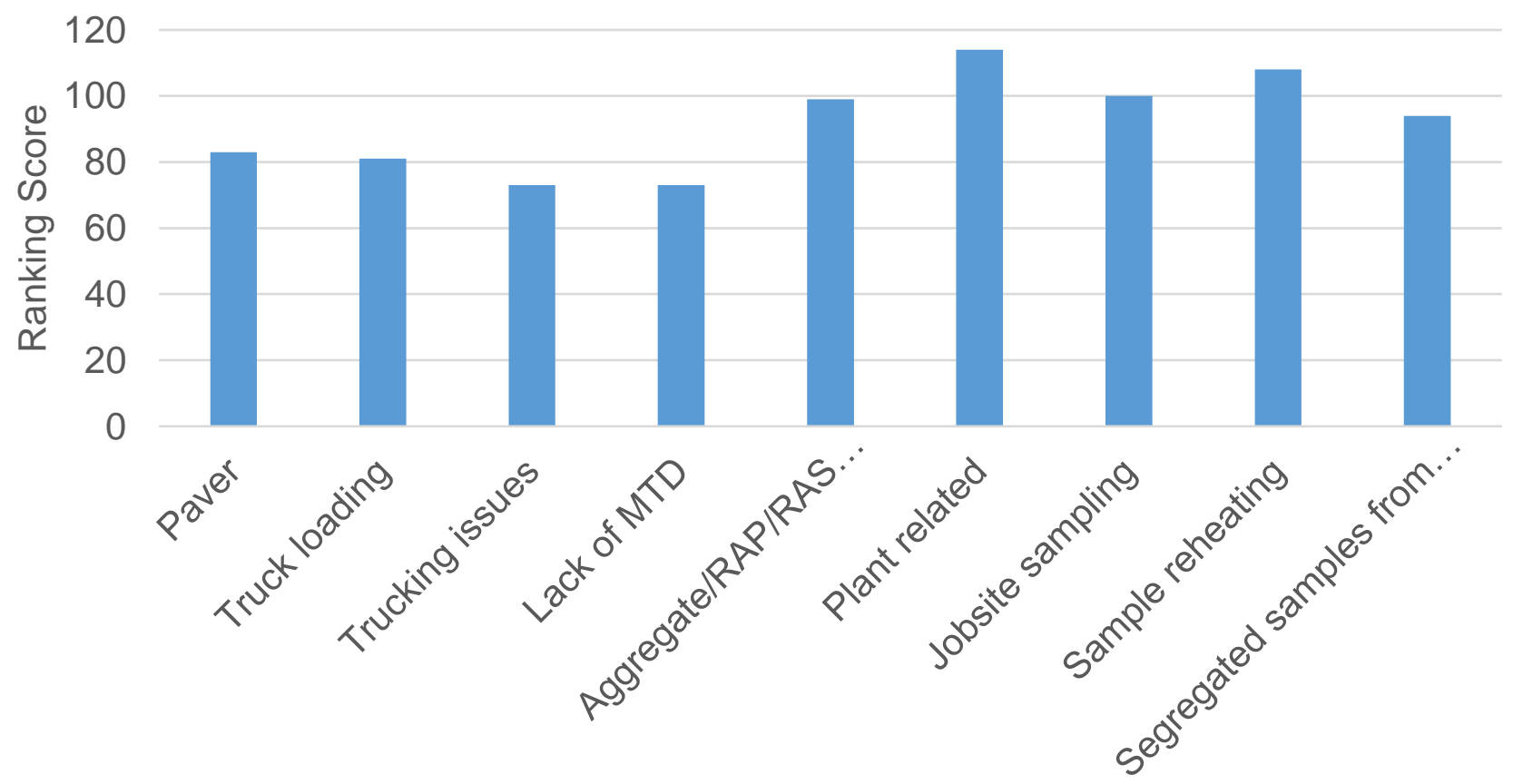

Figure A.27. Rank the following nine sources of error that typically lead to failure to meet PFP/QCP volumetric requirements (1 is least and 9 is greatest). 


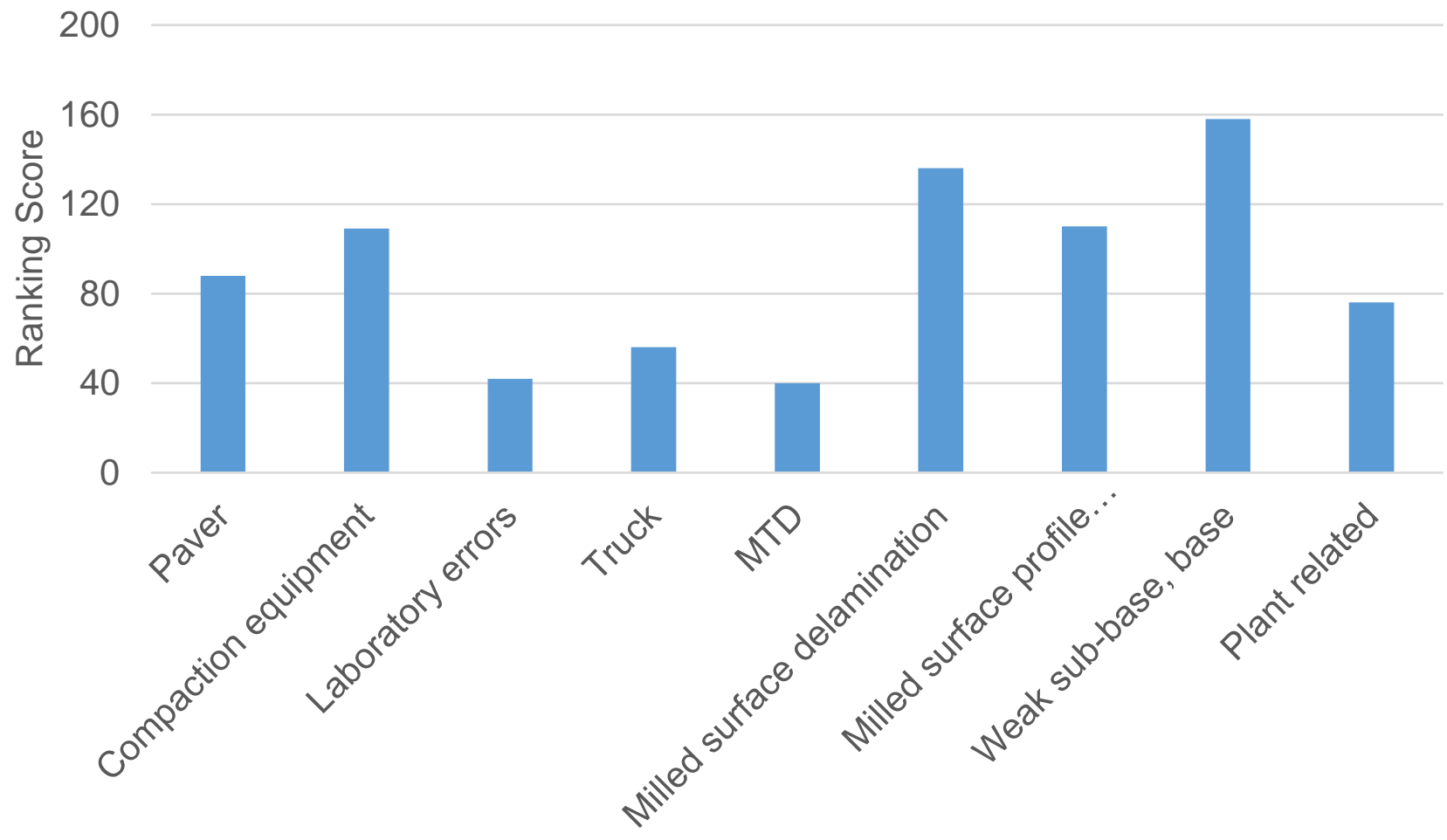

Figure A.28. Rank the following ten sources of error to meet PFP/QCP in-place density
requirements ( 1 is least and 10 is greatest).

Table A.1. Main Reason for Success in PFP

\section{Responses}

We treat PFP/QCP testing the same as every other mix that we run. With focus on having accurate and consistent results that we can make good decisions on to control the mix. But there is also a lot of luck involved with IDOT getting good test results also.

Extra testing on all factors, continual testing above and beyond required frequency. We receive test results from IDOT next day. This is extremely important!

Team Work \& Communication.

Because it was a PFP project there was an opportunity for a bonus. Timely adjustments to mix and density. Was proactive instead of reactive.

Communication between everyone involved. Including but not limited to, aggregate suppliers, loader operators, plant crew, paving crew, QC staff and management.

Good QC in the lab and the field

Consistency of mix.

Was able to play the correct windage with IDOT samples and had no flyer that time.

24 hour turn around time on results 
Table A.2. Benefits from QC Programs

Responses:

Is all I have is frustration!

I think everyone in our company makes sure that they are doing whatever it takes to ensure we are placing the best product we can on the roads.

None. More compactive effort is applied but many times it is too much and we are reducing the life of the mat. It has cost all contractors monetarily. It is tough in a competitive market to receive $.90 / .97 \%$ on the $\$ 1.00$ bid.

PFP has made quicker responses to mix issues a necessity.

More testing takes place only to find out I can't apply any windage to D1 because they are all over the place with their numbers.

None. IDOT is not receiving any better of a product than the QC program gave them

More compactive effort detrimental to pavement. More attention to quality more attention to detail.

\section{Table A.3. Comments to Improve QCP}

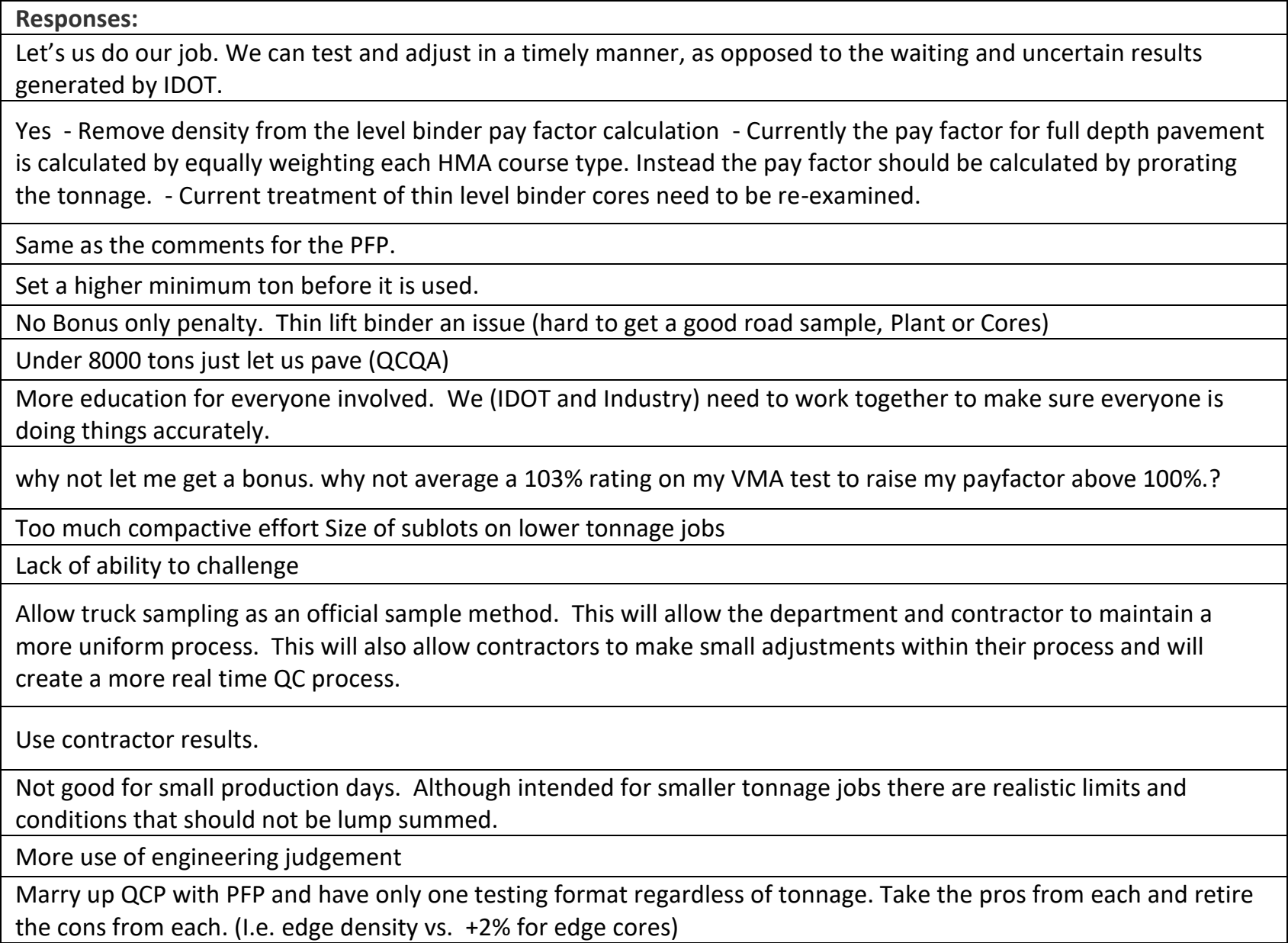


Table A.4. How Is the Decision Made on What Gyratory Compactor to Use for What Materials/Projects?

\begin{tabular}{|l|}
\hline Responses \\
\hline We only have one in each lab. \\
\hline Randomly to serve as a check and balance \\
\hline Based on which District we are running the mix for. All the labs are different on their bulks. \\
\hline Same one is always used. The extra is a backup. \\
\hline Match IDOT \\
\hline Location (gyratory at each plant site) \\
\hline
\end{tabular}

Table A.5. Information for Your HMA Ovens

\begin{tabular}{|c|c|c|}
\hline $\begin{array}{l}\text { Please identify the manufacturer, model, and size of the oven } \\
\text { used to heat HMA samples. }\end{array}$ & $\begin{array}{l}\text { Does your lab use } \\
\text { temperature alarms for } \\
\text { ovens? }\end{array}$ & $\begin{array}{l}\text { How often is the oven } \\
\text { temperature checked? }\end{array}$ \\
\hline Thermolyne NCAT & Yes & Weekly \\
\hline DesPatch, LAC2-18-6, 18CF & Yes & Every three months \\
\hline Despatch LBB1-69A 6.9cuft & No & As needed \\
\hline $\begin{array}{l}\text { Humboldt; H-30160.2F; } 7.2 \text { cu. ft. / Humboldt; H-30145; } 7.8 \text { cu. } \\
\text { ft. }\end{array}$ & No & Daily \\
\hline Blue $\mathrm{M}$ & Yes & Annually \\
\hline Blue M SPX & Yes & Daily \\
\hline Despatch LAC Series 6.6 cubic feet & Yes & As needed \\
\hline Despatch & Yes & Annually \\
\hline Despatch, LAC1-67 (6.7 cubic feet) & Yes & Daily \\
\hline 1680 VWR its big. & No & Annually \\
\hline Despatch LBB2-12-1 12 Cubic Ft & Yes & Daily \\
\hline $\begin{array}{l}\text { Blue M/DC-246-F-PM Blue M/DC-246-F-HP Hot Pack/TruTemp } \\
212061\end{array}$ & Yes & As needed \\
\hline blue $\mathrm{m} 336$ size 336 & Yes & Daily \\
\hline Grieve Ovens & Yes & Daily \\
\hline Despatch LBB2-18-2 Same as D1 Lab & No & Annually \\
\hline Despatch forced Air LC18 & Yes & Daily \\
\hline 2 each Deptach LAC, $3 \mathrm{cu} \mathrm{ft}$ & Yes & Every month \\
\hline Despatch, Protocol Plus, 22CF & Yes & Daily \\
\hline Blue M DC-246-F-ST350 & Yes & Every three months \\
\hline Quincy Labs 31-350 10.6 cuft. & No & Every three months \\
\hline
\end{tabular}


Table A.6. Are There Specific Mixes (Mix Type, Nominal Maximum Aggregate Size (NMAS), Binder Grade, Recycle Content, etc.) That Tend to Show More Variability in Test Results Than Others?

\begin{tabular}{|l|}
\hline Responses \\
\hline D mixes. \\
\hline IL $4.75 \mathrm{~mm}$ mix have more variability \\
\hline To a minor extent mixes utilizing recycled materials present an issue \\
\hline Any mix with steel slag \\
\hline We tend to have more variability in mixes that use Dolomite (CM16 and FM20). \\
\hline $\begin{array}{l}\text { N70 Surface for me, Voids = IDOT came in } 2 \% \text { higher on test strip (mine was actually below spec), 1\% on Lot 1, 0\% on } \\
\text { lot 2...... }\end{array}$ \\
\hline IL19.0, IL9.5 D Mix aggregate segregation/ high absorptions \\
\hline 19.0 mm mixes have been the hardest to get a good comparison \\
\hline Depends on the day. Sometimes $4.75 \mathrm{~mm}, 9.5 \mathrm{~mm}$, or $19.0 \mathrm{~mm}$ \\
\hline Binder mixes \\
\hline 9.5 surface \\
\hline
\end{tabular}

Table A.7. In the Order of Importance (First Is the Most Important), What Are the Top Three Improvements You Suggest to the Department Specifications to Enhance Payout and Reduce Penalties?

\begin{tabular}{|c|c|c|}
\hline \multicolumn{3}{|c|}{ Responses: } \\
\hline 1 (most important) & 2 & 3 \\
\hline \multicolumn{3}{|l|}{$\begin{array}{l}\text { Timely turnaround of results so I can } \\
\text { adjust in a timely manner }\end{array}$} \\
\hline Use consultant labs & $\begin{array}{l}\text { Quick turn around on sample } \\
\text { results }\end{array}$ & delete unconfined joint spec \\
\hline $\begin{array}{l}\text { Use contractor lab results for pay } \\
\text { calculations }\end{array}$ & $\begin{array}{l}\text { For QCP, allow } 105 \% \text { pay factor for } \\
\text { each component to carry through } \\
\text { to final pay calculation }\end{array}$ & $\begin{array}{l}\text { Remove level binder density from the } \\
\text { QCP program }\end{array}$ \\
\hline $\begin{array}{l}\text { Testing: use common sense, if } \\
\text { something looks wrong it generally is. } \\
\text { Then they should rerun tests. }\end{array}$ & $\begin{array}{l}\text { Test in our labs. Contractor } \\
\text { provided gyratory. }\end{array}$ & $\begin{array}{l}\text { Control reheating the material which } \\
\text { effects our } \mathrm{G}_{\mathrm{mm}} \text {. }\end{array}$ \\
\hline $\begin{array}{l}\text { PFP should be pass/fail not statistical } \\
\text { analysis }\end{array}$ & $\begin{array}{l}\text { Better IDOT turnaround time on } \\
\text { samples }\end{array}$ & $\begin{array}{l}\text { IDOT districts should determine any } \\
\text { credits not Central Bureau }\end{array}$ \\
\hline No thin lift cores & Edge cores on two lanes & $\begin{array}{l}\text { loosen up spec for pay for projects } \\
\text { which have low tonnage days. }\end{array}$ \\
\hline Eliminate QCP & $\begin{array}{l}\text { Dist } 2 \text { need to follow } 8000 \text { ton spec } \\
\text { for PFP }\end{array}$ & $\begin{array}{l}\text { Correct } 1 \text { flyer in a sublot, maybe } \\
\text { average the other } 9\end{array}$ \\
\hline $\begin{array}{l}\text { Do not use QCP / PFP where it is not } \\
\text { appropriate }\end{array}$ & $\begin{array}{l}\text { Verify that everyone is doing things } \\
\text { the same }\end{array}$ & $\begin{array}{l}\text { Provide some best practices seminars } \\
\text { for PFP / QCP }\end{array}$ \\
\hline $\begin{array}{l}\text { Adjusting sublot tonnage on lower } \\
\text { tonnage QCP }\end{array}$ & Less reliance on density & Less coring \\
\hline Loosen tolerances & Guarantee $100 \%$ Payment & \\
\hline $\begin{array}{l}\text { Work together instead of against one } \\
\text { another }\end{array}$ & $\begin{array}{l}\text { Test samples in the contractor's lab } \\
\text { witnessed by trained IDOT } \\
\text { inspectors for prof of testing } \\
\text { procedure compliance }\end{array}$ & $\begin{array}{l}\text { Provide results within a timely } \\
\text { manner so that the customer can get } \\
\text { what is required within the } \\
\text { specifications }\end{array}$ \\
\hline
\end{tabular}




\begin{tabular}{|l|l|l|}
\hline \multicolumn{1}{|c|}{1 (most important) } & \multicolumn{1}{|c|}{2} & \multicolumn{1}{|c|}{3} \\
\hline loosen statistical limits & & Proper assignment of QCP/PFP \\
\hline Use of supporting information & Dispute samples (QCP) & 3rd party dispute sampling \\
\hline 24 hour turnaround & $\begin{array}{l}\text { increase QCP tonnage <20,000, PFP } \\
>20,000\end{array}$ & $\begin{array}{l}\text { Rewrite edge density spec, 6" from } \\
\text { edge }+2 \% \text { added to final density } \\
\text { must be }>90 \%\end{array}$ \\
\hline $\begin{array}{l}\text { Marry QCP/PFP, alter penalties to only } \\
\text { affect tonnages pay factors on the } \\
\text { specific paving days/tonnages for which } \\
\text { penalties occurred }\end{array}$ &
\end{tabular}

Table A.8. What Test(s) Do You Perform Quality Control Testing on Aggregate Stockpiles and How Do You Use That Information?

\begin{tabular}{|l|}
\hline \multicolumn{1}{|c|}{ Responses } \\
\hline Gradation results to adjust blend, control mix. \\
\hline Bulk gravity and Moistures \\
\hline Follow the AGCS program, grad checks to ensure that we are within our targets of the mix design parameters \\
\hline Bailey Method to understand how stockpile variability impacts VMA and Voids. \\
\hline $\begin{array}{l}\text { Incoming aggregates are tested as well as stockpile samples. Let's us know if we're getting good materials in from the } \\
\text { quarries which is not always the case. }\end{array}$ \\
\hline Occasionally specific gravity \\
\hline
\end{tabular}

\section{Table A.9. Please Explain If You Requite Aggregate Suppliers to Comply with Tighter Aggregate Specifications than the Department?}

\begin{tabular}{|c|}
\hline Responses \\
\hline $\begin{array}{l}\text { We ask suppliers to try and supply material within half of the tolerance then normal spec. Most of the time we do get } \\
\text { materials with in those ranges }\end{array}$ \\
\hline At our request in order to better control the quality of the mix during production \\
\hline We try too. But most will only do what IDOT requires them to do. \\
\hline If they only meet AGCS standards our PFP/QCP pay will suffer. We give them tighter master bands especially on dust. \\
\hline $\begin{array}{l}\text { In receiving aggregates from a supplier, we request that they are within tolerance of what gradation percent's we } \\
\text { design with. }\end{array}$ \\
\hline $\begin{array}{l}\text { We look at the average and standard deviations that suppliers have shown us in the past and expect them to remain } \\
\text { consistent. This is done with communication. Unfortunately, IDOT specifications are not tight enough to produce } \\
\text { HMA consistent enough for PFP and QCP. }\end{array}$ \\
\hline we require it, but they don't always. \\
\hline We try to keep targets within $4 \%$ and have very good communications with most of our suppliers \\
\hline
\end{tabular}




\section{Table A.10. If Multiple Ignition Ovens Are Used in Your Lab, How Do You Decide Which Ignition Oven to Use?}

\begin{tabular}{|l|}
\hline Responses: \\
\hline We calibrate each mix to both ovens. \\
\hline For PFP / QCP, we often use two ovens and use the average results. \\
\hline Calibrate per mix \\
\hline Only one machine at each site. \\
\hline
\end{tabular}

Table A.11. Do You Switch Mixes While Producing for PFP/QCP Projects?

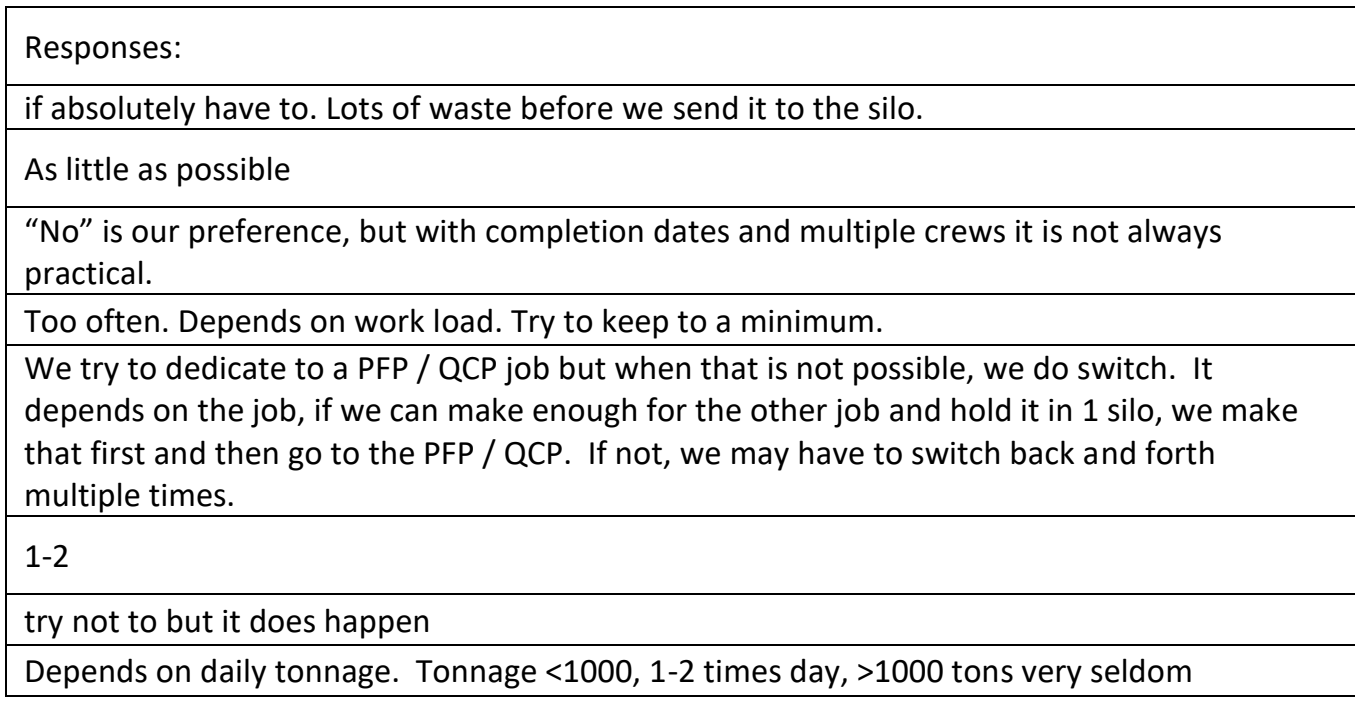

Table A.12. Please Answer the Following Question Regarding Shutdowns.

\begin{tabular}{|c|c|c|}
\hline $\begin{array}{l}\text { How often do you need to } \\
\text { shut down during daily } \\
\text { production? }\end{array}$ & $\begin{array}{l}\text { What are the top three causes for the } \\
\text { shutdowns? }\end{array}$ & $\begin{array}{c}\text { How much } \\
\text { material do you } \\
\text { waste on each } \\
\text { start-up? (tons) }\end{array}$ \\
\hline 2-4 times & Waiting on trucks & $6-8$ \\
\hline once or twice a day & $\begin{array}{l}\text { plants running faster than paving, } \\
\text { reduce over curing on mix }\end{array}$ & $20-30$ \\
\hline not often & Full silo, breakdown, weather & 15 \\
\hline $\begin{array}{l}\text { Only when the silo's are full } \\
\text { or the when the required } \\
\text { amount of mix is made. }\end{array}$ & Silo full; Plant problems; Weather & 3 \\
\hline $\begin{array}{c}\text { Depends on production } \\
\text { schedule }\end{array}$ & Job production, end of day, weather & 5 \\
\hline Varies & Too far ahead of paving crew; weather & $10-15$ \\
\hline 2 & $\begin{array}{c}\text { End of day, trucking isssues, production } \\
\text { issues (plant equipment) }\end{array}$ & $5-10$ \\
\hline minimal & crew moving/full silo/no trucks & $20-30$ \\
\hline 2 & $\begin{array}{l}\text { Issues with the paving crew, making sure } \\
\text { RAP chutes are not plugging up }\end{array}$ & 25 \\
\hline
\end{tabular}




\begin{tabular}{|c|c|c|}
\hline $\begin{array}{l}\text { How often do you need to } \\
\text { shut down during daily } \\
\text { production? }\end{array}$ & $\begin{array}{l}\text { What are the top three causes for the } \\
\text { shutdowns? }\end{array}$ & $\begin{array}{l}\text { How much } \\
\text { material do you } \\
\text { waste on each } \\
\text { start-up? (tons) }\end{array}$ \\
\hline $1-2$ & mix changes & 3 \\
\hline $\begin{array}{l}\text { hopefully not ever, but } \\
\text { occasionally }\end{array}$ & field breakdowns of equipment & 20 \\
\hline 2 & Plant issues/road issues/material issues & 10 \\
\hline $\begin{array}{c}\text { Depends on TPH paving and } \\
\text { traffic }\end{array}$ & $\begin{array}{c}\text { 1. Maintain a constant inventory } 2 . \\
\text { Haul time and jobsite issues/trucking } 3 . \\
\text { Weather }\end{array}$ & 30 \\
\hline not much & break down & 5 \\
\hline occasionally & out of trucks, holding, & 1 \\
\hline 0 to 1 & mix balance, breakdown, weather & 3 \\
\hline $1-3$ at most & $\begin{array}{l}\text { inaccuracy on tonnage orderd by crew, } \\
\text { aggregate change, weather concerns }\end{array}$ & 20 \\
\hline Aim to not shut down & $\begin{array}{l}\text { field breakdown, bad estimate of } \\
\text { material, plant too far ahead of field }\end{array}$ & 15 \\
\hline
\end{tabular}

\section{A.2 DISTRICT SURVEY}

During spring 2018, a survey was sent to IDOT districts to gather opinions about PFP and QCP quality control programs. One response per district was received.
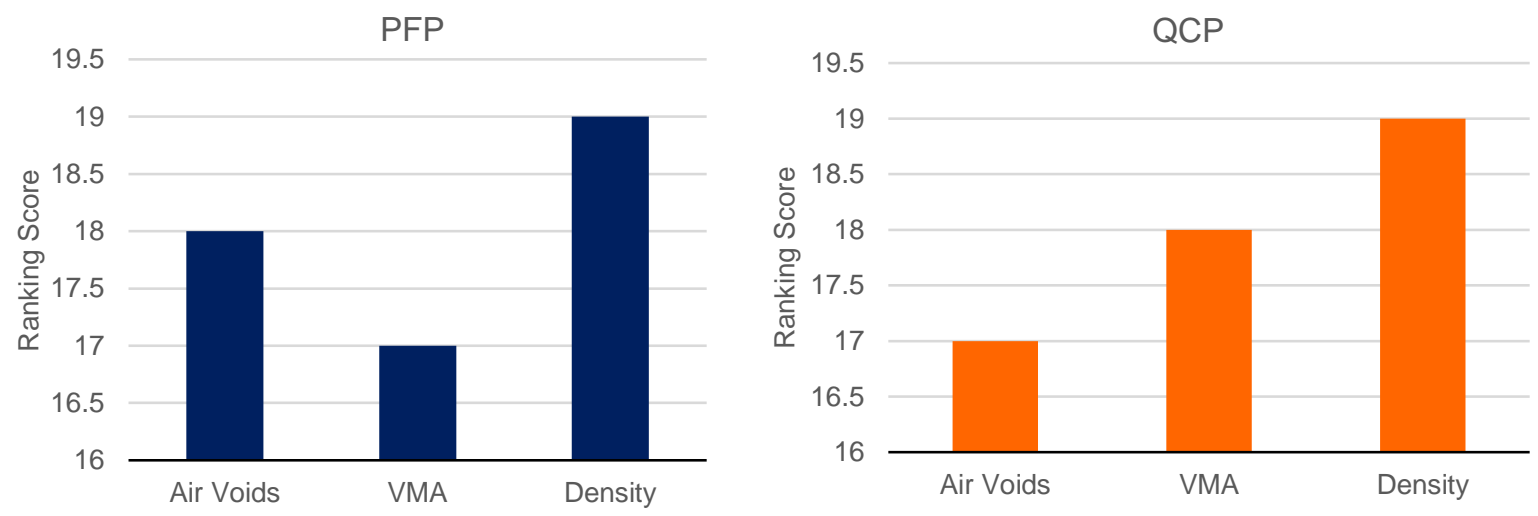

Figure A.29. Parameter driving pay loss. 


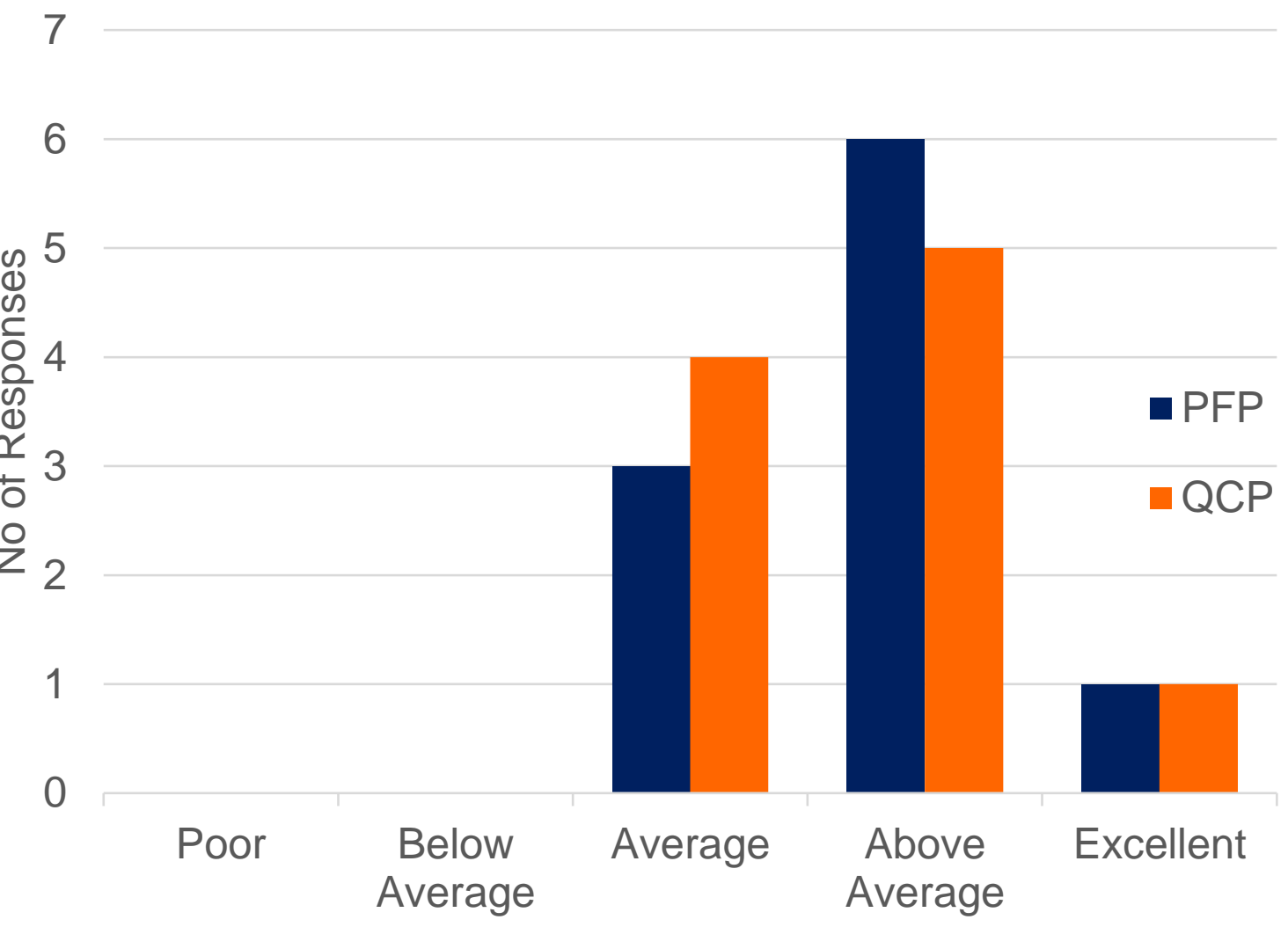

Figure A.30. Rate the QC programs.

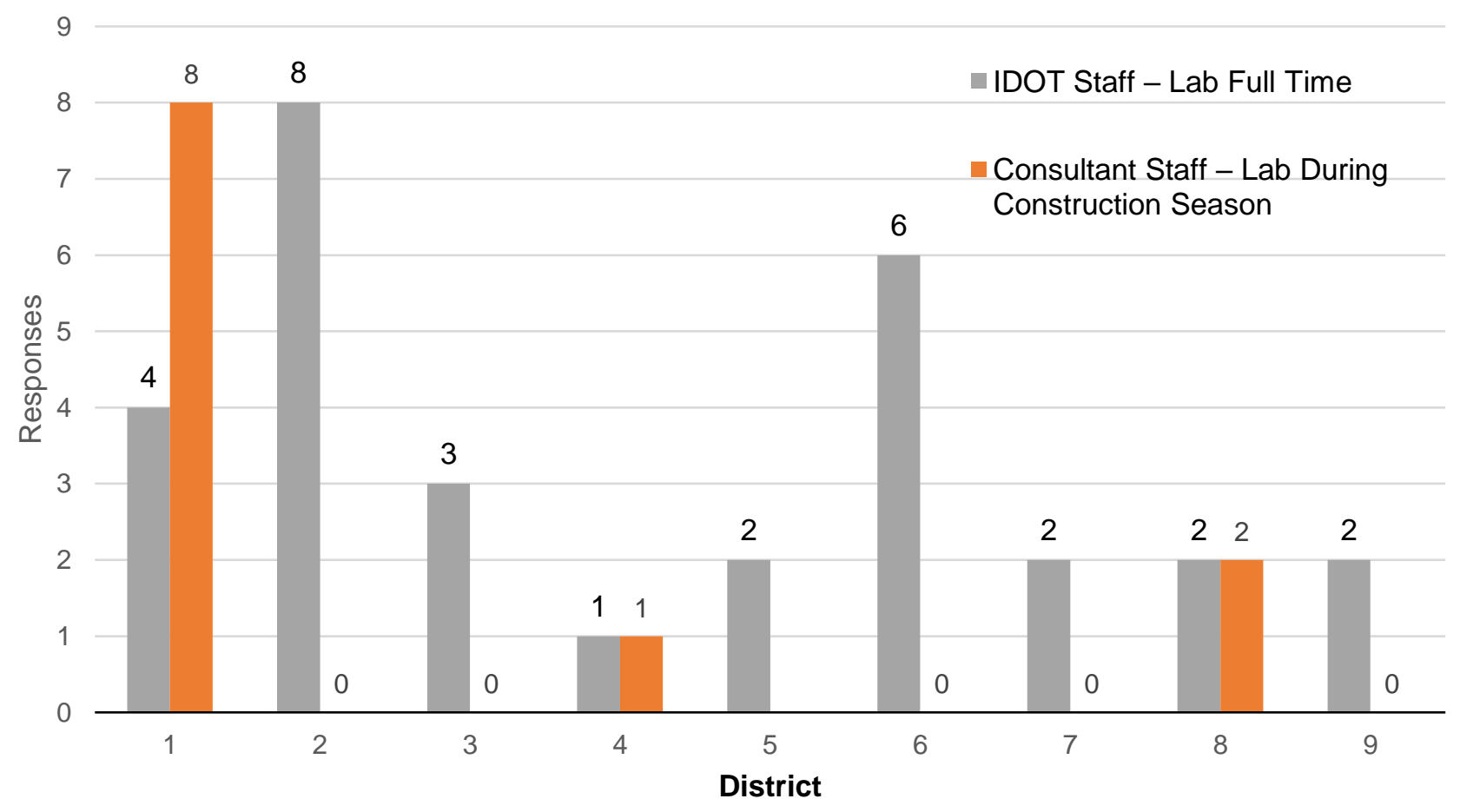

Figure A.31. Total number of personnel assigned to QC testing. 


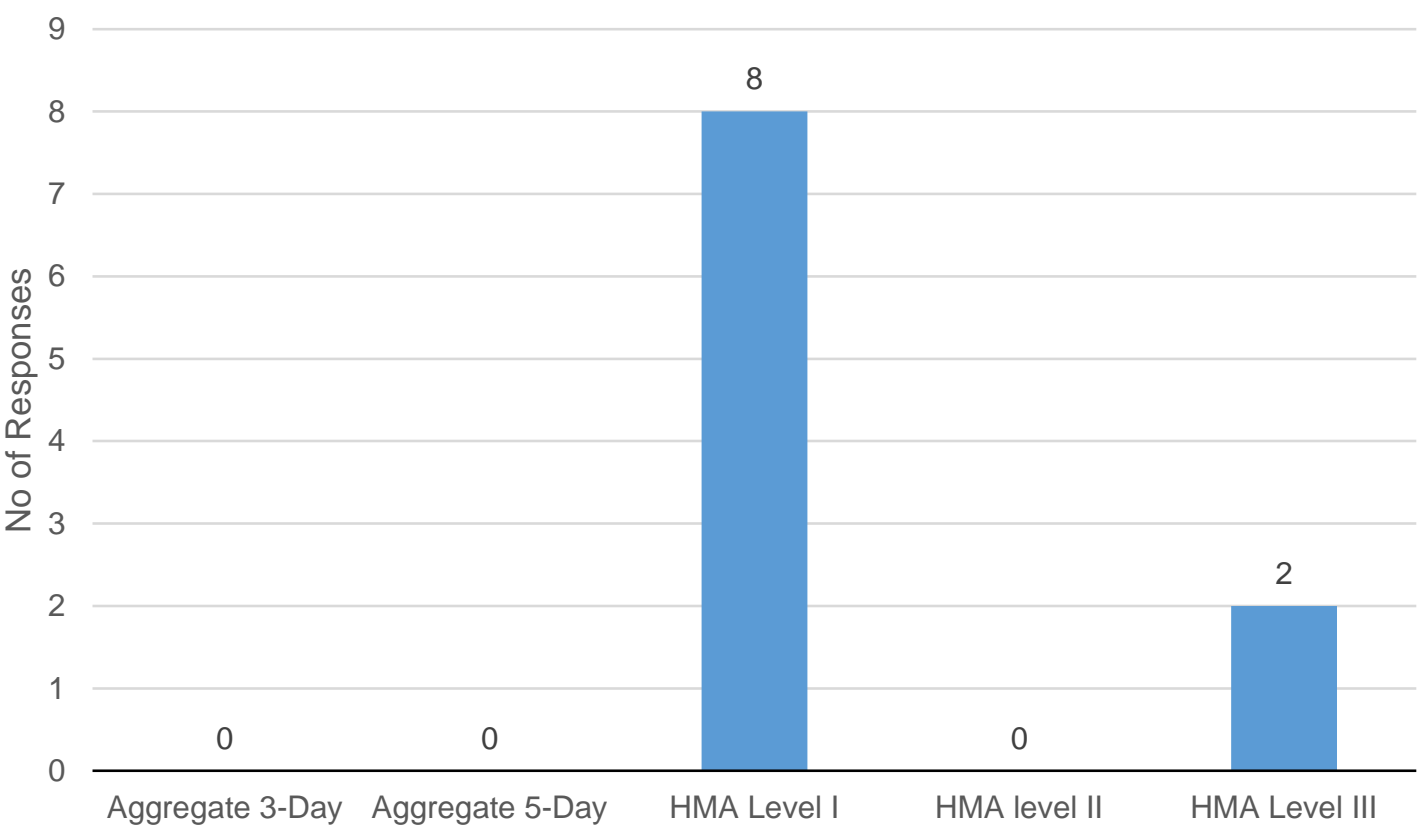

Figure A.32. What is the minimum level of training required for a technician performing volumetric testing?

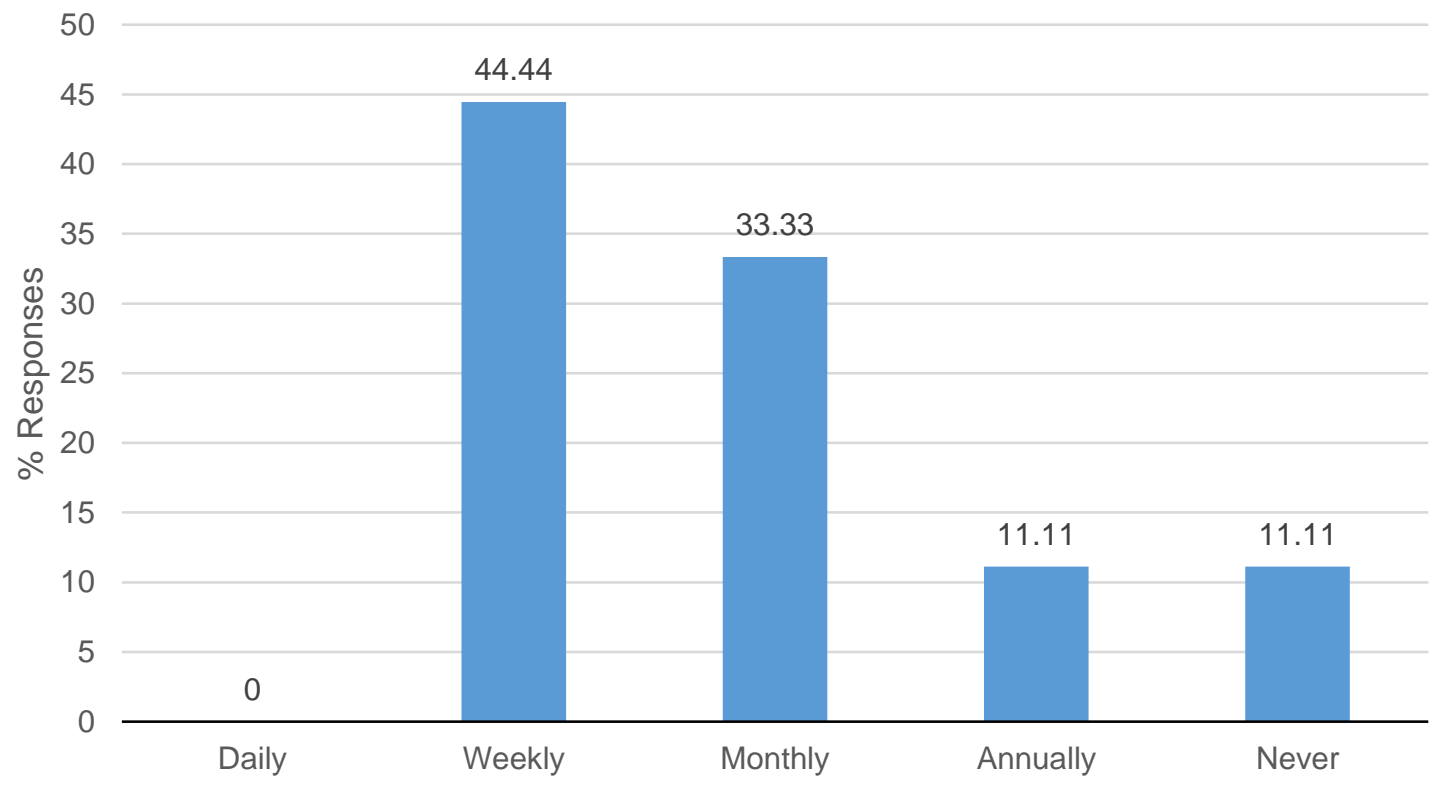

Figure A.33. How often is the lift test performed on the ignition oven? 


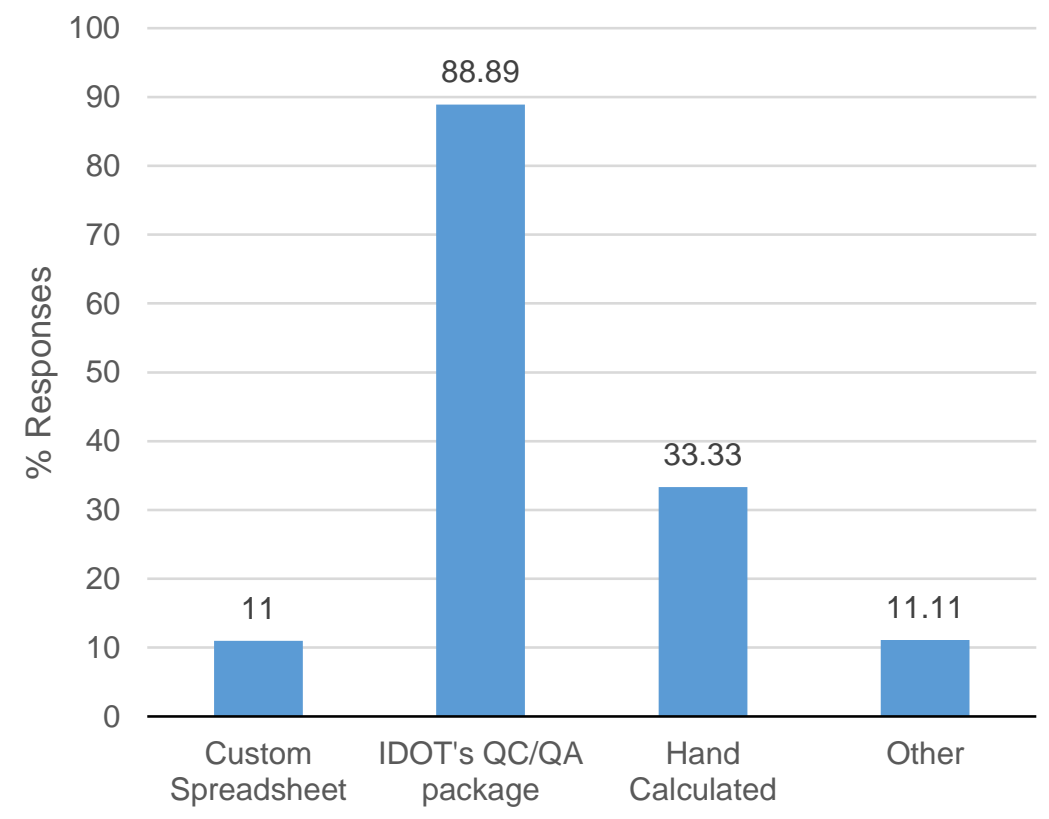

Figure A.34. How are volumetric parameters $\left(G_{m m}, G_{m b}, V M A\right.$, etc. $)$ calculated?

Table A.13. Provide the Following Information for Gyratory Compactors

\begin{tabular}{|c|c|c|c|c|c|c|}
\hline District & Make \& Model & Location & $\begin{array}{c}\text { Measured } \\
\text { Internal } \\
\text { Angle }\end{array}$ & $\begin{array}{c}\text { Frequency of } \\
\text { internal angle } \\
\text { correction } \\
\text { (months) }\end{array}$ & $\begin{array}{c}\text { Measured } \\
\text { Pressure }\end{array}$ & $\begin{array}{c}\text { Frequency of } \\
\text { pressure } \\
\text { correction } \\
\text { (months) }\end{array}$ \\
\hline \multirow{3}{*}{1} & Pine AFG2 (8005) & $\begin{array}{c}\text { District central } \\
\text { laboratory }\end{array}$ & 1.17 & $>$ Every year & 600 & $>$ Every year \\
\hline & Pine AFG2 (8118) & $\begin{array}{c}\text { District central } \\
\text { laboratory }\end{array}$ & 1.16 & $>$ Every year & 600 & $>$ Every year \\
\hline & Pine AFG2 (8687) & $\begin{array}{c}\text { District central } \\
\text { laboratory }\end{array}$ & 1.16 & $>$ Every year & 600 & $>$ Every year \\
\hline \multirow{3}{*}{2} & $\begin{array}{c}\text { Dixon }=\text { Troxler }- \\
5850\end{array}$ & $\begin{array}{c}\text { District central } \\
\text { laboratory }\end{array}$ & 1.14 & $>$ Every year & 605 & $>$ Every year \\
\hline & $\begin{array}{c}\text { Rockford = } \\
\text { Troxler - } 5850\end{array}$ & Satellite laboratory & 1.15 & $>$ Every year & 600 & $>$ Every year \\
\hline & $\begin{array}{l}\text { Quad Cities = } \\
\text { Troxler - } 4140\end{array}$ & Satellite laboratory & 1.16 & $>$ Every year & 600 & $>$ Every year \\
\hline \multirow{2}{*}{3} & Troxler 4140 & $\begin{array}{c}\text { District central } \\
\text { laboratory }\end{array}$ & 1.15 & $>$ Every year & 600 & $>$ Every year \\
\hline & Troxler 4140 & $\begin{array}{c}\text { District central } \\
\text { laboratory }\end{array}$ & 1.15 & $>$ Every year & 600 & > Every year \\
\hline \multirow{2}{*}{4} & Troxler 4140 & $\begin{array}{c}\text { District central } \\
\text { laboratory }\end{array}$ & 1.17 & > Every year & 600 & $>$ Every year \\
\hline & Pine AFGC125XA & $\begin{array}{l}\text { District central } \\
\text { laboratory }\end{array}$ & 1.15 & $>$ Every year & 600 & > Every year \\
\hline 5 & Troxler 4140 & $\begin{array}{l}\text { District central } \\
\text { laboratory }\end{array}$ & 1.15 & $>$ Every year & 600 & $>$ Every year \\
\hline
\end{tabular}




\begin{tabular}{|c|c|c|c|c|c|c|}
\hline \multirow{7}{*}{ District } & Make \& Model & Location & $\begin{array}{c}\text { Measured } \\
\text { Internal } \\
\text { Angle }\end{array}$ & $\begin{array}{c}\text { Frequency of } \\
\text { internal angle } \\
\text { correction } \\
\text { (months) }\end{array}$ & $\begin{array}{c}\text { Measured } \\
\text { Pressure }\end{array}$ & $\begin{array}{c}\text { Frequency of } \\
\text { pressure } \\
\text { correction } \\
\text { (months) }\end{array}$ \\
\cline { 2 - 7 } & $\begin{array}{c}\text { Pine AFG2 } \\
\text { (backup - do not } \\
\text { use for testing) }\end{array}$ & $\begin{array}{c}\text { District central } \\
\text { laboratory }\end{array}$ & 1.16 & > Every year & 600 & $>$ Every year \\
\hline \multirow{2}{*}{6} & Troxler 4140 & $\begin{array}{c}\text { District central } \\
\text { laboratory }\end{array}$ & 1.18 & $>$ Every year & 605 & $>$ Every year \\
\cline { 2 - 7 } & Troxler 5850 & $\begin{array}{c}\text { District central } \\
\text { laboratory }\end{array}$ & 1.17 & $>$ Every year & 600 & $>$ Every year \\
\cline { 2 - 7 } & Troxler 5850 & Satellite laboratory & 1.16 & $>$ Every year & 600 & $>$ Every year \\
\cline { 2 - 7 } & Troxler 5850 & $\begin{array}{c}\text { District central } \\
\text { laboratory }\end{array}$ & 1.14 & $>$ Every year & 595 & $>$ Every year \\
\hline \multirow{2}{*}{8} & Troxler 4140 & $\begin{array}{c}\text { District central } \\
\text { laboratory }\end{array}$ & 1.16 & $>$ Every year & 600 & $>$ Every year \\
\cline { 2 - 7 } & Pine AFG2AS & $\begin{array}{c}\text { District central } \\
\text { laboratory }\end{array}$ & 1.16 & $>$ Every year & 600 & $>$ Every year \\
\hline \multirow{2}{*}{9} & Pine AFG2A & $\begin{array}{c}\text { District central } \\
\text { laboratory }\end{array}$ & 1.16 & $>$ Every year & 600 & $>$ Every year \\
\cline { 2 - 7 } & Pine G2 & $\begin{array}{c}\text { District central } \\
\text { laboratory }\end{array}$ & 1.16 & District central \\
laboratory & 1.16 & $>$ Every year & 600 & $>$ Every year \\
\hline
\end{tabular}

Tables A.14 and A.15 are the districts' responses. There are ten responses because two responses were received from the same district. CBM responses are not included; questionnaires were addressed only to district personnel.

Table A.14. If Multiple Gyratory Compactors Are Used, How Is the Decision Made on What Gyratory Compactor to Use for What Materials/Projects?

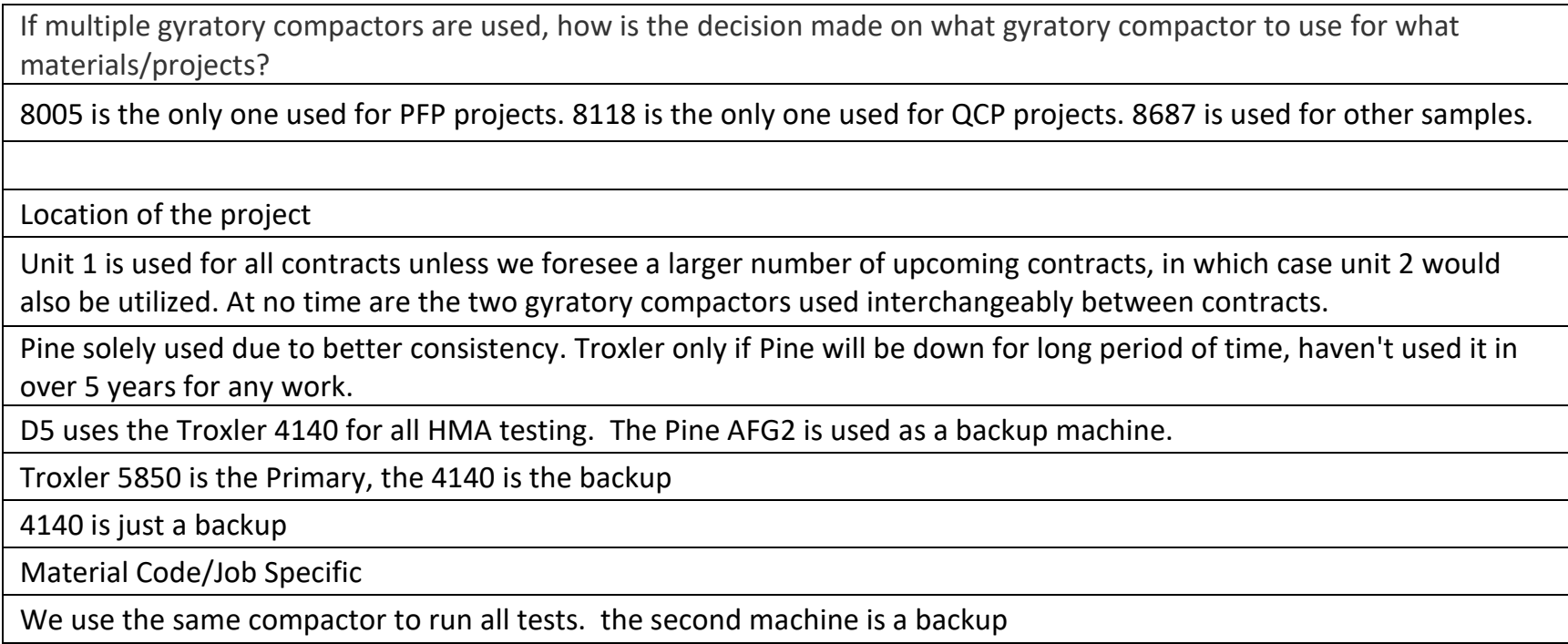


Table A.15. Is a Review Process Used for Checking Test Results before Determining Pay?

\begin{tabular}{|c|c|}
\hline Answer & Explanation \\
\hline Yes & $\begin{array}{l}\text { Technician performs the test and calculation. The Senior lab tech for HMA checks all numbers and calculations. The } \\
\text { District Lab Supervisor will review a portion of the test samples (paying particular attention to out of tolerance results). } \\
\text { These results are sent to the Field Inspector and Mixtures Area Supervisor for the Asphalt plant. They review all results } \\
\text { before submitting to the Contractor and a Phase III consultant. The Phase III consultant performs all pay calculations to } \\
\text { ensure uniformity throughout the District. }\end{array}$ \\
\hline Yes & $\begin{array}{l}\text { The lab technician will review their notes for a "double check". No other review of the material test results is done. The } \\
\text { Mixtures Control Engineer then reviews final test results put into the QC/QA Package that are outside the acceptable } \\
\text { limits of the PFP/QCP provision used. Those results are submitted to CBC for review and recommended additional } \\
\text { credits. If allowed to remain in-place, those sublots are placed into a separate sheet and the additional credit from CBC is } \\
\text { calculated. The sublot is then at "final pay" status. }\end{array}$ \\
\hline \multicolumn{2}{|l|}{ No } \\
\hline Yes & $\begin{array}{l}\text { The bituminous mixtures unit collaborates with the area laboratory personnel to confirm final pay factors prior to sending } \\
\text { them to the contract resident engineer }\end{array}$ \\
\hline Yes & $\begin{array}{l}\text { Results are hand calculated in the lab. Reviewed by different personnel while being entered into the QCQA Package. } \\
\text { Double checked by another staff member after placing in PWL. }\end{array}$ \\
\hline Yes & $\begin{array}{l}\text { Both the Mixtures Control Engineer and Construction R.E. compile data and enter into the QC/QA package. A pay factor } \\
\text { is calculated by both and compared. }\end{array}$ \\
\hline Yes & $\begin{array}{l}\text { Lab Supervisor reviews results before submitting to HMA Supervisor, who checks all data before giving to Mixtures } \\
\text { Control Engineer. Mixtures Control Engineer reviews all test results before sending out memo for pay / disincentive. }\end{array}$ \\
\hline Yes & tech's check each other's math \\
\hline \multicolumn{2}{|l|}{ No } \\
\hline Yes & $\begin{array}{l}\text { The lab supervisor checks all of the work before entering in QC/QA program. The Mixtures Control Engineer reviews the } \\
\text { results and compares with contractor results. If there is a discrepancy, we will check our equipment and possibly retest } \\
\text { the result in question depending on what we find. }\end{array}$ \\
\hline
\end{tabular}

Table A.16. Information for Your HMA Ovens

\begin{tabular}{|c|c|c|}
\hline Oven & $\begin{array}{l}\text { Does your lab use temperature alarms } \\
\text { for ovens? }\end{array}$ & Response \\
\hline Despatch LAC2-18 18cf & Yes & Annually \\
\hline 5 Despatch / LAC2-18-6 / 18 cu.ft. & Yes & Annually \\
\hline Despatch LAC-18 & Yes & Annually \\
\hline Grieve; Model SA-550; 70.9 cuft & $\begin{array}{l}\text { Yes (NIST Digital Thermometers } \\
\text { equipped with set-point alarms) }\end{array}$ & Annually \\
\hline Despatch LAD2-24-3 Grieve model 333 & No & Annually \\
\hline $\begin{array}{l}\text { Grieve Model SA-550 30 Cu. Ft. - Central District } \\
\text { Lab Shellab Model HF 25-2 } \sim 27 \mathrm{Cu} \text {. Ft. - Satellite } \\
\text { Lab }\end{array}$ & Yes & Annually \\
\hline Gilson $270 \mathrm{~A} 27 \mathrm{cu} \mathrm{ft}$ & Yes & Annually \\
\hline $\begin{array}{l}\text { Blue M Electric DC-206F (for compaction) Despatch } \\
\text { LBB2-27-2 (for samples before splitting) }\end{array}$ & Yes & As needed \\
\hline $\begin{array}{l}\text { Blue M - model } 326 \text { Batch Oven 51"x50"x24" } \\
\text { Dispatch - model LBB1-69A-1 30"x22"x18" } \\
\text { Horizontal - model } 168532 \text { '×67"x26" Blue M - } \\
\text { model DC series oven } 25^{\prime} \times 22 " \times 20^{\prime \prime}\end{array}$ & Yes & Annually \\
\hline
\end{tabular}




\section{APPENDIX B: EARLY DEVELOPMENT OF QA PROGRAMS IN THE US}

The 1956 AASHO Road Test is the milestone that changed the "recipe" or method specifications for road construction in the United States. During the test track construction, a large number of test results were noncompliant with specification limits (Highway Research Board, 1962). It was clear that specifying materials and methods was not enough; controlling the construction process, evaluating the end product, and reducing variability was found to be necessary.

According to the 1962 report of the House Committee on Oversights and Investigation of Congress, test data for road construction were often out of specifications and were not enough to determine the quality of construction (NCHRP, 1979). Verification performed by State DOT personnel was introduced to reveal improper testing and reporting in some federally funded highway projects. This became known as independent assurance (IA). The Federal Highway Administration (2011) recommends that results coming from an IA program should not be used for acceptance of the product; instead, they should only be used for verification of procedures.

In the 1970s, QA programs adopted a statistically oriented approach and quality assurance responsibilities were assigned differently. Contractors performed QC tests to control the production and construction of HMA. For acceptance, agencies performed tests to ensure that the quality delivered by the contractor complied with their requirements. Agency testing was typically used for quantifying the quality delivered and calculating contractor payment. This was required on Federalaid projects until 1995. With responsibilities assigned this way, the possibility of legal proceedings by the contractor and/or producer were reduced and flexibility in contractor operations was allowed (NCHRP Synthesis 38, 1976).

Before statistical methods for acceptance were specified, acceptance of HMA was a matter of engineering judgment, which led to controversial decisions (NCHRP Synthesis 65, 1979). This triggered a need for change. By 1976, 33 state transportation agencies were already using or planning to use a statistically oriented QA program. In fact, many state transportation agencies penalized unit prices if the product did not satisfy the required quality statistics. By then, agencies performed random sampling and used statistical probability for acceptance testing or relied on product certification. Bonus incentives were not permissible on federal-aid projects (NCHRP Synthesis 38, 1976). Few states used a statistical approach for HMA acceptance until SuperPave was implemented in the 1990s. 


\section{APPENDIX C: STATISTICAL ANALYSIS RESULTS}

\section{C.1 AV ANALYSIS RESULTS}

Table C.1. AV Analysis Results Summary

\begin{tabular}{|c|c|c|c|c|c|c|c|c|c|c|c|c|}
\hline $\begin{array}{l}\text { ICT } \\
\text { Code }\end{array}$ & Year & Mix Code & District & $\begin{array}{l}\text { Quality } \\
\text { Program }\end{array}$ & $\begin{array}{c}\text { MW } \\
\text { P-Value }\end{array}$ & $\begin{array}{l}\text { Levene's } \\
\text { P-Value }\end{array}$ & $\begin{array}{l}\text { Contractor } \\
\text { SW P-Value }\end{array}$ & $\begin{array}{c}\text { Agency SW } \\
\text { P-Value }\end{array}$ & $\begin{array}{c}\text { Contractor } \\
\text { Mean }\end{array}$ & $\begin{array}{l}\text { Agency } \\
\text { Mean }\end{array}$ & $\begin{array}{l}\text { Contractor } \\
\text { St. Dev. }\end{array}$ & $\begin{array}{l}\text { Agency } \\
\text { St. Dev. }\end{array}$ \\
\hline 1 & 2015 & $19524 \mathrm{R}$ & 1 & $\mathrm{QCP}$ & 0.33 & 0.66 & & & 4.1 & 2.9 & 0.28 & 0.49 \\
\hline 2 & 2017 & 19524R & 1 & QCP & 1.00 & & & & 2.9 & 2.9 & 0.07 & 0.00 \\
\hline 3 & 2017 & $19524 R$ & 1 & QCP & 1.00 & & & & 3.9 & 4.0 & 1.27 & 0.00 \\
\hline 4 & 2016 & 19524R & 1 & QCP & 0.28 & 0.39 & 0.65 & 0.81 & 4.0 & 3.6 & 0.55 & 0.96 \\
\hline 5 & 2015 & $19514 R$ & 1 & QCP & & & & & 5.2 & & 0.00 & \\
\hline 6 & 2015 & 19514R & 1 & QCP & 0.67 & & & & 4.6 & 4.2 & 0.28 & 0.00 \\
\hline 7 & 2015 & 19524R & 1 & QCP & 0.59 & 0.25 & 0.17 & 0.00 & 4.4 & 4.1 & 0.47 & 0.17 \\
\hline 8 & 2015 & 19524R & 1 & QCP & & & & & 4.4 & & 0.00 & \\
\hline 9 & 2015 & 19524R & 1 & PFP & 0.45 & 0.46 & 0.10 & 0.59 & 4.4 & 4.1 & 0.59 & 0.77 \\
\hline 10 & 2015 & 19512R & 1 & QCP & 0.50 & & 0.78 & & 4.0 & 4.8 & 0.38 & 0.00 \\
\hline 11 & 2015 & $19512 R$ & 1 & QCP & 1.00 & & & & 3.8 & 4.1 & 0.50 & 0.00 \\
\hline 12 & 2015 & $19522 R$ & 1 & QCP & 0.03 & 0.02 & 0.15 & 0.02 & 3.9 & 3.1 & 0.50 & 1.08 \\
\hline 13 & 2017 & 19522R & 1 & QCP & 0.33 & 0.69 & & & 4.4 & 5.9 & 0.35 & 0.21 \\
\hline 14 & 2015 & 19510R & 1 & QCP & 0.50 & & 1.00 & & 3.9 & 4.5 & 0.10 & 0.00 \\
\hline 15 & 2015 & 19510R & 1 & QCP & & & & & 4.2 & & 0.71 & \\
\hline 16 & 2015 & 19510R & 1 & QCP & 0.85 & 0.23 & 0.98 & 0.28 & 4.2 & 4.1 & 0.32 & 0.56 \\
\hline 17 & 2015 & $19512 \mathrm{R}$ & 1 & QCP & 1.00 & & & & 4.2 & 3.9 & 0.00 & 1.56 \\
\hline 18 & 2015 & 19510R & 1 & QCP & 0.13 & 0.63 & 0.22 & & 3.1 & 2.2 & 0.24 & 0.28 \\
\hline 19 & 2015 & 19536R & 1 & QCP & & & & 0.00 & & 4.2 & & 1.44 \\
\hline 20 & 2017 & 19525R & 1 & QCP & 0.53 & 0.90 & 0.65 & & 4.0 & 4.8 & 0.95 & 0.64 \\
\hline 21 & 2015 & 19524R & 1 & QCP & 0.67 & & & & 3.8 & 3.2 & 0.07 & 0.00 \\
\hline 22 & 2015 & 19524R & 1 & QCP & 1.00 & & & & 4.1 & 4.3 & 0.64 & 0.00 \\
\hline 23 & 2015 & $19512 \mathrm{R}$ & 1 & QCP & 0.50 & & 1.00 & & 2.8 & 3.2 & 0.05 & 0.00 \\
\hline 24 & 2016 & $19532 R$ & 1 & QCP & 1.00 & 0.00 & & & 3.0 & 2.7 & 0.00 & 0.57 \\
\hline 25 & 2017 & $19532 R$ & 1 & QCP & 0.40 & & 0.44 & & 4.1 & 3.3 & 0.62 & 0.00 \\
\hline 26 & 2017 & 19510R & 1 & QCP & 1.00 & & & & 4.0 & 4.3 & 0.00 & 0.00 \\
\hline 27 & 2015 & 19510R & 1 & QCP & 0.25 & 0.93 & 0.56 & 0.00 & 3.6 & 4.0 & 0.35 & 0.29 \\
\hline 28 & 2017 & 19665R & 1 & QCP & & & & & 2.7 & & 0.00 & \\
\hline
\end{tabular}




\begin{tabular}{|c|c|c|c|c|c|c|c|c|c|c|c|c|}
\hline $\begin{array}{l}\text { ICT } \\
\text { Code }\end{array}$ & Year & Mix Code & District & $\begin{array}{l}\text { Quality } \\
\text { Program }\end{array}$ & $\begin{array}{c}\text { MW } \\
\text { P-Value }\end{array}$ & $\begin{array}{c}\text { Levene's } \\
\text { P-Value }\end{array}$ & $\begin{array}{l}\text { Contractor } \\
\text { SW P-Value }\end{array}$ & $\begin{array}{c}\text { Agency SW } \\
\text { P-Value }\end{array}$ & $\begin{array}{c}\text { Contractor } \\
\text { Mean }\end{array}$ & $\begin{array}{l}\text { Agency } \\
\text { Mean }\end{array}$ & $\begin{array}{c}\text { Contractor } \\
\text { St. Dev. }\end{array}$ & $\begin{array}{l}\text { Agency } \\
\text { St. Dev. }\end{array}$ \\
\hline 29 & 2015 & $19665 R$ & 1 & $\mathrm{QCP}$ & 0.91 & 0.10 & 0.16 & 0.22 & 2.8 & 2.9 & 0.14 & 0.44 \\
\hline 30 & 2017 & 19524R & 1 & QCP & 0.67 & 0.17 & 0.52 & 0.96 & 4.2 & 4.3 & 0.52 & 0.89 \\
\hline 31 & 2017 & 19525R & 1 & QCP & 0.67 & & & & 4.4 & 4.6 & 0.21 & 0.00 \\
\hline 32 & 2016 & 19510R & 1 & QCP & 0.50 & & 0.46 & & 3.2 & 2.7 & 0.10 & 0.00 \\
\hline 33 & 2015 & 19525R & 1 & QCP & & & 0.65 & & 4.1 & & 0.59 & \\
\hline 34 & 2016 & $19512 R$ & 1 & QCP & & & 0.99 & & 3.3 & & 0.26 & \\
\hline 35 & 2015 & $19512 R$ & 1 & QCP & 0.67 & & & & 3.7 & 3.0 & 0.39 & 0.00 \\
\hline 36 & 2015 & $19522 R$ & 1 & QCP & 0.43 & & 0.33 & & 3.9 & 4.9 & 0.61 & 0.00 \\
\hline 37 & 2015 & $19522 R$ & 1 & QCP & & & & & & 5.1 & & 0.00 \\
\hline 38 & 2015 & 19524R & 1 & QCP & 0.05 & 0.08 & 0.33 & 0.61 & 4.3 & 5.5 & 0.70 & 1.39 \\
\hline 39 & 2015 & 19510R & 1 & QCP & 0.93 & 0.45 & 0.34 & & 2.8 & 3.0 & 0.56 & 0.85 \\
\hline 40 & 2015 & 19510R & 1 & $\mathrm{QCP}$ & & & & & 4.3 & & 0.00 & \\
\hline 41 & 2015 & 19510R & 1 & QCP & 1.00 & 0.83 & & & 3.1 & 3.1 & 1.13 & 1.48 \\
\hline 42 & 2015 & 19524R & 1 & QCP & & & 0.32 & & 4.5 & & 0.44 & \\
\hline 43 & 2015 & $19524 R$ & 1 & QCP & 0.55 & 0.76 & 0.39 & 0.63 & 3.8 & 4.0 & 0.74 & 0.82 \\
\hline 44 & 2015 & 19510R & 1 & PFP & 0.90 & 0.44 & 0.22 & 0.31 & 3.9 & 3.9 & 0.43 & 0.53 \\
\hline 45 & 2015 & 19510R & 1 & PFP & & & & & 3.1 & & 0.00 & \\
\hline 46 & 2015 & $19524 R$ & 1 & $\mathrm{QCP}$ & 0.20 & 0.37 & 0.56 & 0.61 & 4.6 & 5.8 & 0.53 & 0.93 \\
\hline 47 & 2015 & 19655R & 1 & PFP & 0.02 & 0.00 & 0.77 & 0.98 & 3.4 & 4.3 & 0.59 & 1.41 \\
\hline 48 & 2015 & 19536R & 1 & PFP & 0.75 & 0.00 & 0.74 & 0.51 & 4.9 & 5.1 & 0.58 & 1.37 \\
\hline 49 & 2017 & 19510R & 1 & QCP & 0.40 & & 0.31 & & 3.1 & 3.7 & 0.43 & 0.00 \\
\hline 50 & 2017 & 19510R & 1 & QCP & 0.44 & & 0.56 & & 3.2 & 4.2 & 0.66 & 0.00 \\
\hline 51 & 2016 & 19510R & 1 & QCP & 0.27 & 0.86 & & 0.26 & 4.2 & 5.0 & 0.71 & 0.78 \\
\hline 52 & 2017 & $19524 R$ & 1 & QCP & 0.67 & & & & 4.1 & 5.3 & 0.99 & 0.00 \\
\hline 53 & 2017 & 19525R & 1 & QCP & 0.67 & & 0.50 & & 3.6 & 4.4 & 0.69 & 0.00 \\
\hline 54 & 2017 & 19525R & 1 & PFP & 0.04 & 0.26 & 0.52 & 0.40 & 4.1 & 4.6 & 0.57 & 0.37 \\
\hline 55 & 2016 & $19525 R$ & 1 & QCP & 0.17 & 0.20 & 0.67 & 1.00 & 4.3 & 5.0 & 0.61 & 0.20 \\
\hline 56 & 2016 & 19536R & 1 & QCP & & & & & 5.0 & & 0.28 & \\
\hline 57 & 2015 & 19536R & 1 & PFP & 0.73 & 0.10 & 0.00 & 0.01 & 4.5 & 4.4 & 1.06 & 1.70 \\
\hline 58 & 2015 & $19524 R$ & 1 & QCP & 0.02 & 0.57 & 0.06 & 0.83 & 3.1 & 1.5 & 0.48 & 0.65 \\
\hline 59 & 2017 & $19524 R$ & 1 & $\mathrm{QCP}$ & 0.10 & 0.75 & 0.04 & 0.58 & 3.4 & 1.9 & 0.20 & 0.26 \\
\hline 60 & 2015 & $19522 R$ & 1 & QCP & 0.97 & 0.30 & 0.10 & 0.27 & 4.5 & 4.1 & 0.44 & 0.87 \\
\hline 61 & 2015 & $19522 R$ & 1 & QCP & 0.05 & 0.36 & 0.74 & 0.82 & 3.8 & 2.7 & 0.69 & 1.03 \\
\hline 62 & 2015 & 19510R & 1 & QCP & 0.67 & & & & 2.8 & 2.3 & 0.49 & 0.00 \\
\hline 63 & 2015 & 19510R & 1 & PFP & 0.78 & 0.22 & 0.07 & 0.66 & 3.2 & 3.0 & 1.51 & 0.84 \\
\hline
\end{tabular}




\begin{tabular}{|c|c|c|c|c|c|c|c|c|c|c|c|c|}
\hline $\begin{array}{c}\mathrm{ICT} \\
\text { Code }\end{array}$ & Year & Mix Code & District & $\begin{array}{l}\text { Quality } \\
\text { Program }\end{array}$ & $\begin{array}{c}\text { MW } \\
\text { P-Value }\end{array}$ & $\begin{array}{l}\text { Levene's } \\
\text { P-Value }\end{array}$ & $\begin{array}{l}\text { Contractor } \\
\text { SW P-Value }\end{array}$ & $\begin{array}{c}\text { Agency SW } \\
\text { P-Value }\end{array}$ & $\begin{array}{c}\text { Contractor } \\
\text { Mean }\end{array}$ & $\begin{array}{c}\text { Agency } \\
\text { Mean }\end{array}$ & $\begin{array}{c}\text { Contractor } \\
\text { St. Dev. }\end{array}$ & $\begin{array}{l}\text { Agency } \\
\text { St. Dev. }\end{array}$ \\
\hline 64 & 2017 & $19524 R$ & 1 & $\mathrm{QCP}$ & 1.00 & & & & 4.7 & 5.5 & 0.00 & 0.00 \\
\hline 65 & 2017 & $19524 R$ & 1 & PFP & 0.62 & 1.00 & 0.41 & 0.66 & 3.9 & 3.9 & 0.59 & 0.60 \\
\hline 66 & 2017 & $19524 R$ & 1 & QCP & 0.67 & & & & 3.6 & 4.4 & 0.00 & 0.00 \\
\hline 67 & 2017 & 19510R & 1 & QCP & 0.10 & 0.22 & 0.14 & 0.02 & 2.7 & 1.8 & 0.09 & 0.26 \\
\hline 68 & 2015 & $19532 R$ & 1 & QCP & 0.96 & 0.66 & 0.26 & 0.36 & 3.7 & 3.6 & 0.70 & 0.79 \\
\hline 69 & 2017 & 19510R & 1 & QCP & 1.00 & 0.38 & 0.86 & 0.97 & 3.8 & 4.2 & 0.80 & 1.65 \\
\hline 70 & 2016 & 19510R & 1 & QCP & 1.00 & & & & 3.6 & 4.0 & 0.57 & 0.00 \\
\hline 71 & 2017 & $19524 R$ & 1 & PFP & & & & & 4.2 & & 0.00 & \\
\hline 72 & 2017 & 19510R & 1 & QCP & 0.80 & 0.58 & & 0.19 & 3.6 & 3.5 & 0.21 & 0.49 \\
\hline 73 & 2017 & 19510R & 1 & QCP & 0.80 & 0.05 & 0.00 & 0.00 & 3.8 & 3.5 & 0.12 & 0.69 \\
\hline 74 & 2016 & 19525R & 1 & QCP & 0.07 & 0.23 & 0.80 & & 4.4 & 5.6 & 0.46 & 0.07 \\
\hline 75 & 2017 & 19665R & 1 & QCP & 1.00 & 0.34 & & & 4.2 & 4.4 & 0.42 & 1.56 \\
\hline 76 & 2017 & 19655R & 1 & QCP & 0.33 & 0.00 & & & 3.1 & 3.6 & 0.57 & 0.00 \\
\hline 77 & 2017 & 19665R & 1 & QCP & 0.60 & 0.29 & 0.00 & & 4.0 & 4.2 & 0.35 & 0.07 \\
\hline 78 & 2015 & $19512 \mathrm{R}$ & 1 & QCP & 0.37 & 0.17 & 0.47 & 0.68 & 3.7 & 4.2 & 0.59 & 1.05 \\
\hline 79 & 2015 & $19522 \mathrm{R}$ & 1 & PFP & 0.71 & 0.71 & & 0.14 & 3.9 & 4.1 & 0.46 & 0.94 \\
\hline 80 & 2017 & $19522 \mathrm{R}$ & 1 & QCP & 0.44 & 0.23 & 0.07 & & 3.2 & 3.0 & 0.54 & 0.08 \\
\hline 81 & 2015 & $19522 \mathrm{R}$ & 1 & QCP & & & & & & 6.9 & & 0.00 \\
\hline 82 & 2015 & 19514R & 1 & QCP & 0.35 & 0.20 & 0.18 & 0.49 & 3.8 & 4.4 & 0.58 & 0.97 \\
\hline 83 & 2015 & $19524 R$ & 1 & QCP & 0.56 & 0.83 & 0.49 & 0.16 & 4.0 & 4.4 & 0.90 & 0.75 \\
\hline 84 & 2015 & $19512 \mathrm{R}$ & 1 & QCP & 0.96 & 0.17 & 0.11 & 0.42 & 3.9 & 3.9 & 0.44 & 0.71 \\
\hline 85 & 2015 & $19512 \mathrm{R}$ & 1 & QCP & 1.00 & & 0.36 & & 4.0 & 4.1 & 0.79 & 0.00 \\
\hline 86 & 2015 & 19525R & 1 & PFP & & & 0.15 & & 4.5 & & 0.47 & \\
\hline 87 & 2015 & 19510R & 1 & QCP & 0.80 & & 0.68 & & 4.2 & 4.3 & 0.24 & 0.00 \\
\hline 88 & 2017 & 19510R & 1 & $\mathrm{QCP}$ & 0.26 & 0.59 & 0.09 & 0.29 & 3.9 & 3.5 & 0.81 & 1.01 \\
\hline 89 & 2017 & $19532 \mathrm{R}$ & 1 & QCP & 1.00 & & & & 3.9 & 3.9 & 0.64 & 0.00 \\
\hline 90 & 2016 & $19524 R$ & 1 & QCP & 1.00 & & 0.51 & & 3.6 & 3.8 & 0.57 & 0.00 \\
\hline 91 & 2016 & 19524R & 1 & QCP & & & & & & 3.8 & & 0.78 \\
\hline 92 & 2017 & 19536R & 1 & QCP & 1.00 & & & & 3.4 & 3.4 & 0.00 & 0.00 \\
\hline 93 & 2015 & 19536R & 1 & QCP & 0.18 & 0.97 & 0.72 & 0.17 & 3.9 & 3.3 & 0.61 & 0.55 \\
\hline 94 & 2015 & $19524 R$ & 1 & QCP & 0.80 & 0.17 & 0.00 & 0.41 & 4.9 & 5.3 & 0.23 & 0.77 \\
\hline 95 & 2015 & $19512 \mathrm{R}$ & 1 & QCP & 0.36 & 0.74 & 0.04 & & 3.3 & 3.7 & 0.56 & 0.56 \\
\hline 96 & 2015 & $19512 \mathrm{R}$ & 1 & QCP & 0.07 & 0.51 & 0.94 & 0.64 & 3.1 & 2.7 & 0.28 & 0.38 \\
\hline 97 & 2015 & 19514R & 1 & QCP & 0.83 & 0.36 & 0.12 & 0.08 & 4.3 & 4.4 & 0.86 & 1.30 \\
\hline 98 & 2017 & $19522 \mathrm{R}$ & 1 & $\mathrm{QCP}$ & 1.00 & & & & 3.5 & 4.3 & 0.00 & 0.00 \\
\hline
\end{tabular}




\begin{tabular}{|c|c|c|c|c|c|c|c|c|c|c|c|c|}
\hline $\begin{array}{c}\text { ICT } \\
\text { Code }\end{array}$ & Year & Mix Code & District & $\begin{array}{l}\text { Quality } \\
\text { Program }\end{array}$ & $\begin{array}{c}\text { MW } \\
\text { P-Value }\end{array}$ & $\begin{array}{c}\text { Levene's } \\
\text { P-Value }\end{array}$ & $\begin{array}{l}\text { Contractor } \\
\text { SW P-Value }\end{array}$ & $\begin{array}{c}\text { Agency SW } \\
\text { P-Value }\end{array}$ & $\begin{array}{c}\text { Contractor } \\
\text { Mean }\end{array}$ & $\begin{array}{l}\text { Agency } \\
\text { Mean }\end{array}$ & $\begin{array}{c}\text { Contractor } \\
\text { St. Dev. }\end{array}$ & $\begin{array}{l}\text { Agency } \\
\text { St. Dev. }\end{array}$ \\
\hline 99 & 2017 & $19522 R$ & 1 & $\mathrm{QCP}$ & 0.57 & & 0.22 & & 4.5 & 3.4 & 0.65 & 0.00 \\
\hline 100 & 2016 & $19522 R$ & 1 & QCP & 0.04 & 0.10 & 0.47 & 0.18 & 3.5 & 2.8 & 0.56 & 0.94 \\
\hline 101 & 2015 & 19510R & 1 & QCP & 0.67 & & & & 3.2 & 2.7 & 0.42 & 0.00 \\
\hline 102 & 2015 & 19510R & 1 & QCP & & & 0.57 & & 3.0 & & 0.51 & \\
\hline 103 & 2015 & 19510R & 1 & QCP & 0.33 & 0.41 & & & 2.8 & 1.8 & 0.42 & 0.14 \\
\hline 104 & 2015 & 19510R & 1 & QCP & 0.67 & & & & 3.4 & 2.7 & 0.00 & 0.00 \\
\hline 105 & 2017 & 19510R & 1 & QCP & 0.02 & 0.16 & 0.49 & 0.37 & 2.7 & 2.2 & 0.11 & 0.27 \\
\hline 108 & 2017 & $19532 R$ & 1 & QCP & 0.40 & 0.91 & 0.49 & & 3.3 & 2.4 & 0.69 & 0.64 \\
\hline 107 & 2017 & $19532 R$ & 1 & QCP & 0.37 & 0.96 & 0.27 & 0.69 & 4.0 & 3.5 & 0.79 & 0.71 \\
\hline 108 & 2017 & $19532 R$ & 1 & QCP & 0.72 & 0.71 & 0.50 & 0.43 & 4.2 & 4.2 & 0.82 & 0.95 \\
\hline 109 & 2015 & 19536R & 1 & QCP & 0.50 & & 0.33 & & 5.5 & 3.6 & 2.02 & 0.00 \\
\hline 110 & 2015 & 19536R & 1 & $\mathrm{QCP}$ & 0.50 & & 0.46 & & 4.2 & 4.9 & 0.21 & 0.00 \\
\hline 111 & 2015 & $19524 R$ & 1 & QCP & 0.50 & & 0.00 & & 4.3 & 4.9 & 0.40 & 0.00 \\
\hline 112 & 2015 & 19524R & 1 & QCP & 1.00 & & & & 4.6 & 4.7 & 0.71 & 0.00 \\
\hline 113 & 2015 & $19524 R$ & 1 & QCP & 0.86 & 0.79 & 0.68 & 0.11 & 5.0 & 5.2 & 0.86 & 0.76 \\
\hline 114 & 2017 & 19510R & 1 & QCP & 1.00 & 0.31 & & & 3.7 & 3.9 & 0.21 & 0.85 \\
\hline 115 & 2017 & 19510R & 1 & QCP & & & 0.64 & & 2.8 & & 0.46 & \\
\hline 116 & 2016 & 19510R & 1 & $\mathrm{QCP}$ & & & & & & 3.3 & & 0.28 \\
\hline 117 & 2017 & 19510R & 1 & $\mathrm{QCP}$ & 0.11 & 0.35 & 0.00 & 0.15 & 3.8 & 3.5 & 0.06 & 0.13 \\
\hline 118 & 2016 & 19510R & 1 & QCP & 0.04 & 0.00 & 0.04 & & 2.6 & 2.3 & 0.14 & 0.00 \\
\hline 119 & 2017 & 19510R & 1 & QCP & 0.40 & 0.71 & 0.36 & & 3.3 & 3.6 & 0.26 & 0.14 \\
\hline 120 & 2017 & 19510R & 1 & QCP & 1.00 & 0.65 & & & 3.7 & 3.9 & 0.35 & 0.64 \\
\hline 121 & 2017 & 19510R & 1 & QCP & 0.33 & 0.00 & & & 4.0 & 4.1 & 0.07 & 0.00 \\
\hline 122 & 2015 & 19522R & 1 & QCP & 0.67 & & & & 4.1 & 4.8 & 0.64 & 0.00 \\
\hline 123 & 2015 & 19522R & 1 & QCP & 1.00 & & 0.92 & & 3.8 & 4.0 & 0.65 & 0.00 \\
\hline 124 & 2017 & 19524R & 1 & QCP & 1.00 & & & & 3.3 & 2.9 & 0.00 & 0.00 \\
\hline 125 & 2017 & 19524R & 1 & QCP & 0.50 & 0.45 & 0.22 & 0.24 & 3.3 & 2.9 & 0.44 & 0.81 \\
\hline 126 & 2017 & 19524R & 1 & PFP & & & 0.95 & & 3.1 & & 0.54 & \\
\hline 127 & 2016 & 19524R & 1 & QCP & 0.67 & & & & 3.9 & 4.8 & 0.57 & 0.00 \\
\hline 128 & 2017 & 19524R & 1 & QCP & 0.67 & & 0.23 & & 3.9 & 4.6 & 0.66 & 0.00 \\
\hline 129 & 2017 & 19524R & 1 & QCP & 1.00 & 0.99 & 0.49 & & 3.5 & 3.6 & 0.46 & 0.35 \\
\hline 130 & 2017 & 19524R & 1 & QCP & 1.00 & 0.51 & & & 5.5 & 5.7 & 0.35 & 0.84 \\
\hline 131 & 2015 & 19510R & 1 & QCP & 1.00 & & & & 2.7 & 3.1 & 0.00 & 0.00 \\
\hline 132 & 2015 & 19510R & 1 & QCP & 0.45 & 0.03 & 0.90 & 0.16 & 2.3 & 2.3 & 0.57 & 1.24 \\
\hline 133 & 2015 & 19536R & 1 & PFP & 0.31 & 0.28 & 0.48 & 0.31 & 3.7 & 3.1 & 0.77 & 1.15 \\
\hline
\end{tabular}




\begin{tabular}{|c|c|c|c|c|c|c|c|c|c|c|c|c|}
\hline $\begin{array}{c}\text { ICT } \\
\text { Code }\end{array}$ & Year & Mix Code & District & $\begin{array}{l}\text { Quality } \\
\text { Program }\end{array}$ & $\begin{array}{c}\text { MW } \\
\text { P-Value }\end{array}$ & $\begin{array}{c}\text { Levene's } \\
\text { P-Value }\end{array}$ & $\begin{array}{l}\text { Contractor } \\
\text { SW P-Value }\end{array}$ & $\begin{array}{c}\text { Agency SW } \\
\text { P-Value }\end{array}$ & $\begin{array}{c}\text { Contractor } \\
\text { Mean }\end{array}$ & $\begin{array}{l}\text { Agency } \\
\text { Mean }\end{array}$ & $\begin{array}{c}\text { Contractor } \\
\text { St. Dev. }\end{array}$ & $\begin{array}{l}\text { Agency } \\
\text { St. Dev. }\end{array}$ \\
\hline 134 & 2015 & $19522 R$ & 1 & PFP & & & & & 3.8 & & 1.06 & \\
\hline 135 & 2015 & $19522 R$ & 1 & QCP & 0.27 & 0.36 & 0.68 & & 4.2 & 4.6 & 0.24 & 0.42 \\
\hline 136 & 2015 & 19536R & 1 & QCP & 1.00 & & & & 5.5 & 5.7 & 0.00 & 0.00 \\
\hline 137 & 2015 & $19524 R$ & 1 & QCP & 0.91 & 0.16 & 0.16 & 0.47 & 3.5 & 3.5 & 0.21 & 0.52 \\
\hline 138 & 2015 & 19510R & 1 & QCP & 1.00 & 0.89 & & & 3.4 & 3.4 & 1.91 & 2.26 \\
\hline 139 & 2015 & 19510R & 1 & QCP & 1.00 & & & & 4.5 & 4.9 & 0.00 & 0.00 \\
\hline 140 & 2015 & $19524 R$ & 1 & QCP & 0.01 & 0.23 & 0.29 & 0.11 & 4.0 & 3.4 & 0.40 & 0.53 \\
\hline 141 & 2015 & 19665R & 1 & QCP & 0.81 & 0.23 & 0.02 & 0.31 & 3.0 & 3.1 & 0.73 & 0.50 \\
\hline 142 & 2015 & 19524R & 1 & QCP & 0.20 & 0.37 & & 0.19 & 3.0 & 1.8 & 0.99 & 0.49 \\
\hline 143 & 2015 & 19524R & 1 & QCP & 0.29 & 0.31 & 0.97 & 0.98 & 3.7 & 3.2 & 0.39 & 0.74 \\
\hline 144 & 2017 & 19510R & 1 & QCP & 0.86 & 0.23 & 0.30 & & 3.2 & 3.3 & 0.41 & 0.78 \\
\hline 145 & 2017 & 19510R & 1 & $\mathrm{QCP}$ & 1.00 & & & & 3.3 & 3.2 & 0.17 & 0.00 \\
\hline 146 & 2017 & 19510R & 1 & QCP & 0.20 & 0.92 & 0.47 & & 2.9 & 2.2 & 0.23 & 0.21 \\
\hline 147 & 2015 & 19510R & 1 & QCP & 0.67 & & & & 3.1 & 3.5 & 0.07 & 0.00 \\
\hline 148 & 2017 & $19522 R$ & 1 & QCP & 0.40 & & 0.76 & & 3.3 & 4.3 & 0.46 & 0.00 \\
\hline 149 & 2015 & $19522 R$ & 1 & QCP & 0.39 & 0.63 & 0.20 & 0.30 & 4.2 & 4.7 & 0.66 & 0.79 \\
\hline 150 & 2015 & 19536R & 1 & QCP & 0.02 & 0.69 & 0.31 & 1.00 & 4.2 & 5.3 & 0.45 & 0.30 \\
\hline 151 & 2017 & 19524R & 1 & QCP & 0.33 & 0.26 & & & 4.1 & 5.7 & 0.08 & 0.38 \\
\hline 152 & 2017 & $19524 R$ & 1 & $\mathrm{QCP}$ & & & & 0.03 & & 3.1 & & 0.53 \\
\hline 153 & 2017 & 19524R & 1 & QCP & 0.33 & 0.56 & & & 4.6 & 5.5 & 0.30 & 0.64 \\
\hline 154 & 2015 & 19525R & 1 & QCP & 1.00 & & 0.90 & & 4.2 & 4.8 & 0.55 & 0.00 \\
\hline 155 & 2017 & 19525R & 1 & QCP & 0.67 & & & & 3.7 & 3.9 & 0.22 & 0.00 \\
\hline 156 & 2015 & 19525R & 1 & QCP & 1.00 & 0.66 & 0.66 & & 4.8 & 4.8 & 0.26 & 0.28 \\
\hline 157 & 2015 & 19524R & 1 & QCP & 1.00 & 0.41 & 0.73 & 1.00 & 4.4 & 4.7 & 0.40 & 0.80 \\
\hline 158 & 2017 & 18436R & 1 & QCP & 0.67 & 0.84 & & & 3.0 & 2.4 & 1.00 & 0.78 \\
\hline 159 & 2016 & 19655R & 1 & QCP & 0.67 & 0.27 & 0.35 & & 3.6 & 3.2 & 0.91 & 1.70 \\
\hline 160 & 2017 & 19655R & 1 & QCP & 0.40 & & 0.13 & & 2.8 & 3.4 & 0.50 & 0.00 \\
\hline 161 & 2015 & 19525R & 1 & QCP & 0.39 & 0.97 & 0.54 & 0.64 & 4.2 & 4.6 & 0.65 & 0.61 \\
\hline 162 & 2017 & 19653R & 1 & QCP & 0.24 & 0.13 & 0.01 & 1.00 & 4.7 & 5.7 & 0.49 & 1.10 \\
\hline 163 & 2016 & 19665R & 1 & PFP & 0.17 & 0.00 & 0.91 & & 3.7 & 4.6 & 0.55 & 0.00 \\
\hline 164 & 2017 & 19665R & 1 & QCP & 0.80 & & 0.13 & & 2.6 & 3.0 & 0.47 & 0.00 \\
\hline 165 & 2015 & 19512R & 1 & QCP & 0.26 & 0.95 & 0.42 & 0.99 & 3.6 & 2.8 & 0.77 & 0.76 \\
\hline 166 & 2015 & $19512 R$ & 1 & QCP & 0.53 & 0.29 & & 0.07 & 2.6 & 2.2 & 0.85 & 0.43 \\
\hline 167 & 2017 & 19525R & 1 & QCP & 0.70 & 0.84 & 0.73 & 0.94 & 4.1 & 3.3 & 0.81 & 0.95 \\
\hline 168 & 2017 & 19525R & 1 & QCP & 0.80 & 0.67 & & 0.83 & 4.0 & 3.4 & 1.20 & 0.95 \\
\hline
\end{tabular}




\begin{tabular}{|c|c|c|c|c|c|c|c|c|c|c|c|c|}
\hline $\begin{array}{c}\mathrm{ICT} \\
\text { Code }\end{array}$ & Year & Mix Code & District & $\begin{array}{l}\text { Quality } \\
\text { Program }\end{array}$ & $\begin{array}{c}\text { MW } \\
\text { P-Value }\end{array}$ & $\begin{array}{l}\text { Levene's } \\
\text { P-Value }\end{array}$ & $\begin{array}{l}\text { Contractor } \\
\text { SW P-Value }\end{array}$ & $\begin{array}{c}\text { Agency SW } \\
\text { P-Value }\end{array}$ & $\begin{array}{c}\text { Contractor } \\
\text { Mean }\end{array}$ & $\begin{array}{l}\text { Agency } \\
\text { Mean }\end{array}$ & $\begin{array}{c}\text { Contractor } \\
\text { St. Dev. }\end{array}$ & $\begin{array}{l}\text { Agency } \\
\text { St. Dev. }\end{array}$ \\
\hline 169 & 2017 & 19525R & 1 & $\mathrm{QCP}$ & 0.50 & & 0.64 & & 3.7 & 4.0 & 0.15 & 0.00 \\
\hline 170 & 2017 & 19525R & 1 & PFP & 0.56 & 0.22 & 0.78 & 0.21 & 3.8 & 3.6 & 0.56 & 0.31 \\
\hline 171 & 2017 & 19655R & 1 & PFP & 0.81 & 0.09 & 0.11 & 0.53 & 3.2 & 3.8 & 0.67 & 1.65 \\
\hline 172 & 2015 & $19512 R$ & 1 & QCP & & & & & 3.0 & & 0.00 & \\
\hline 173 & 2015 & $19522 R$ & 1 & $\mathrm{QCP}$ & & & & & 3.0 & & 0.00 & \\
\hline 174 & 2015 & $19522 R$ & 1 & QCP & & & 0.49 & & 3.7 & & 0.53 & \\
\hline 175 & 2015 & 19536R & 1 & QCP & 0.53 & 0.85 & & 0.00 & 2.5 & 1.6 & 0.71 & 1.13 \\
\hline 176 & 2015 & 19510R & 1 & QCP & 0.20 & 0.00 & 0.00 & & 4.4 & 5.1 & 0.17 & 0.00 \\
\hline 177 & 2015 & 19510R & 1 & QCP & & & & & & 5.9 & & 0.00 \\
\hline 178 & 2015 & 19510R & 1 & $\mathrm{QCP}$ & 0.17 & 0.49 & 0.26 & 0.26 & 3.2 & 3.6 & 0.48 & 0.33 \\
\hline 179 & 2015 & $19522 \mathrm{R}$ & 1 & QCP & & & 0.06 & & 3.6 & & 0.30 & \\
\hline 180 & 2015 & $19522 R$ & 1 & QCP & & & 0.53 & & 4.0 & & 0.39 & \\
\hline 181 & 2015 & $19522 \mathrm{R}$ & 1 & $\mathrm{QCP}$ & & & 0.06 & & 3.9 & & 0.37 & \\
\hline 182 & 2015 & $19522 R$ & 1 & $\mathrm{QCP}$ & 0.29 & & 0.05 & & 3.7 & 3.3 & 0.29 & 0.00 \\
\hline 183 & 2015 & 19524R & 1 & PFP & 0.02 & 0.64 & 0.69 & 1.00 & 4.6 & 5.6 & 0.46 & 0.34 \\
\hline 184 & 2015 & 19510R & 1 & QCP & & & 0.92 & & 3.6 & & 0.36 & \\
\hline 185 & 2015 & 19510R & 1 & QCP & 0.03 & 0.71 & 0.09 & 0.00 & 3.0 & 2.0 & 0.19 & 0.15 \\
\hline 186 & 2017 & 19510R & 1 & QCP & 1.00 & & 0.88 & & 3.3 & 3.3 & 0.45 & 0.00 \\
\hline 187 & 2015 & $19522 R$ & 1 & QCP & 0.50 & & 0.60 & & 3.8 & 4.4 & 0.44 & 0.00 \\
\hline 188 & 2015 & 19524R & 1 & QCP & 1.00 & & 0.69 & & 3.6 & 3.4 & 0.26 & 0.00 \\
\hline 189 & 2015 & $19524 \mathrm{R}$ & 1 & QCP & 0.13 & 0.33 & 0.86 & & 3.6 & 2.1 & 0.31 & 0.07 \\
\hline 190 & 2015 & 19510R & 1 & QCP & 0.14 & 0.89 & 0.13 & & 3.2 & 3.7 & 0.26 & 0.21 \\
\hline 191 & 2015 & 19510R & 1 & QCP & 0.67 & & & & 3.4 & 3.8 & 0.00 & 0.00 \\
\hline 192 & 2015 & 19510R & 1 & PFP & 0.25 & 0.15 & 0.11 & 0.83 & 3.2 & 3.5 & 0.48 & 0.80 \\
\hline 193 & 2015 & 19510R & 1 & QCP & 0.67 & 0.48 & & & 2.9 & 3.2 & 0.14 & 0.35 \\
\hline 194 & 2015 & 19510R & 1 & QCP & 0.79 & 0.67 & 0.85 & & 2.9 & 3.0 & 0.35 & 0.35 \\
\hline 195 & 2015 & 19510R & 1 & QCP & & & 0.97 & & 3.1 & & 0.16 & \\
\hline 196 & 2017 & 19510R & 1 & QCP & 1.00 & & & & 3.1 & 3.4 & 0.00 & 0.00 \\
\hline 197 & 2017 & 19510R & 1 & QCP & 0.67 & & & & 3.2 & 2.9 & 0.07 & 0.00 \\
\hline 198 & 2017 & 19510R & 1 & QCP & 1.00 & & & & 3.7 & 3.9 & 0.49 & 0.00 \\
\hline 199 & 2017 & 19510R & 1 & QCP & 0.50 & & & 0.36 & 3.2 & 4.6 & 0.00 & 0.26 \\
\hline 200 & 2017 & 19510R & 1 & $\mathrm{QCP}$ & 0.67 & & & & 3.1 & 3.9 & 0.85 & 0.00 \\
\hline 201 & 2017 & 19510R & 1 & $\mathrm{QCP}$ & 0.67 & & 0.26 & & 3.2 & 3.5 & 0.42 & 0.00 \\
\hline 202 & 2017 & 19510R & 1 & $\mathrm{QCP}$ & 0.40 & & 0.68 & & 3.6 & 3.3 & 0.08 & 0.00 \\
\hline 203 & 2017 & 19510R & 1 & $\mathrm{QCP}$ & 1.00 & & & & 3.1 & 3.0 & 0.07 & 0.00 \\
\hline
\end{tabular}




\begin{tabular}{|c|c|c|c|c|c|c|c|c|c|c|c|c|}
\hline $\begin{array}{l}\text { ICT } \\
\text { Code }\end{array}$ & Year & Mix Code & District & $\begin{array}{l}\text { Quality } \\
\text { Program }\end{array}$ & $\begin{array}{c}\text { MW } \\
\text { P-Value }\end{array}$ & $\begin{array}{l}\text { Levene's } \\
\text { P-Value }\end{array}$ & $\begin{array}{l}\text { Contractor } \\
\text { SW P-Value }\end{array}$ & $\begin{array}{c}\text { Agency SW } \\
\text { P-Value }\end{array}$ & $\begin{array}{c}\text { Contractor } \\
\text { Mean }\end{array}$ & $\begin{array}{l}\text { Agency } \\
\text { Mean }\end{array}$ & $\begin{array}{c}\text { Contractor } \\
\text { St. Dev. }\end{array}$ & $\begin{array}{l}\text { Agency } \\
\text { St. Dev. }\end{array}$ \\
\hline 204 & 2015 & 19665R & 1 & PFP & 0.95 & 0.01 & 0.63 & 0.80 & 3.6 & 3.5 & 0.26 & 0.61 \\
\hline 205 & 2015 & 19665R & 1 & PFP & 0.61 & 0.16 & 0.00 & 0.06 & 3.3 & 3.6 & 0.53 & 0.81 \\
\hline 206 & 2015 & 19665R & 1 & PFP & 0.46 & 0.93 & 0.17 & 0.19 & 3.0 & 2.8 & 0.50 & 0.49 \\
\hline 207 & 2015 & $19522 \mathrm{R}$ & 1 & QCP & 0.34 & 0.83 & 0.27 & 0.40 & 3.1 & 4.1 & 1.04 & 1.16 \\
\hline 208 & 2015 & $19524 R$ & 1 & QCP & 0.20 & 0.00 & 0.26 & 0.44 & 3.5 & 2.7 & 0.34 & 1.09 \\
\hline 209 & 2015 & 19524R & 1 & QCP & 0.37 & 0.02 & 0.48 & 0.14 & 4.0 & 4.4 & 0.46 & 0.85 \\
\hline 210 & 2015 & 19524R & 1 & QCP & 0.50 & & 0.58 & & 3.9 & 5.1 & 0.67 & 0.00 \\
\hline 211 & 2015 & 19524R & 1 & QCP & 0.17 & 0.39 & 0.54 & 0.46 & 4.3 & 4.8 & 0.32 & 0.52 \\
\hline 212 & 2015 & $19524 R$ & 1 & QCP & & & & & & 5.3 & & 0.00 \\
\hline 213 & 2017 & 19522R & 1 & QCP & & & 1.00 & & 3.1 & & 0.20 & \\
\hline 214 & 2015 & 19536R & 1 & PFP & 0.43 & 0.04 & 0.05 & 0.38 & 3.6 & 3.4 & 0.43 & 0.76 \\
\hline 215 & 2015 & 19510R & 1 & QCP & 1.00 & & & & 3.3 & 3.7 & 0.00 & 0.00 \\
\hline 216 & 2015 & 19510R & 1 & QCP & 0.67 & 0.84 & 0.27 & 0.63 & 3.3 & 3.4 & 0.51 & 0.52 \\
\hline 217 & 2015 & 19510R & 1 & QCP & 0.67 & & & & 3.4 & 3.5 & 0.07 & 0.00 \\
\hline 218 & 2015 & 19510R & 1 & QCP & 0.38 & 0.33 & 0.52 & 0.13 & 4.3 & 4.7 & 0.41 & 0.69 \\
\hline 219 & 2015 & 19510R & 1 & QCP & 1.00 & & & & 3.0 & 3.0 & 0.35 & 0.00 \\
\hline 220 & 2015 & 19510R & 1 & QCP & 0.67 & & & & 3.5 & 4.3 & 0.78 & 0.00 \\
\hline 221 & 2015 & $19522 \mathrm{R}$ & 1 & QCP & 1.00 & & & & 2.1 & 2.2 & 0.00 & 0.00 \\
\hline 222 & 2015 & $19522 \mathrm{R}$ & 1 & QCP & 0.46 & 0.72 & 0.40 & 0.78 & 3.2 & 2.8 & 1.02 & 1.15 \\
\hline 223 & 2015 & 19536R & 1 & QCP & 0.27 & 0.62 & 0.86 & 0.39 & 4.7 & 5.2 & 0.42 & 0.54 \\
\hline 224 & 2015 & 19536R & 1 & QCP & 0.75 & & 0.33 & & 4.5 & 4.7 & 0.61 & 0.00 \\
\hline 225 & 2015 & 19536R & 1 & QCP & 0.09 & 0.25 & 0.01 & 0.26 & 3.6 & 4.4 & 0.52 & 0.24 \\
\hline 226 & 2015 & 19536R & 1 & QCP & & & & & 4.3 & & 0.00 & \\
\hline 227 & 2016 & 19536R & 1 & QCP & & & & & 3.7 & & 0.00 & \\
\hline 228 & 2015 & 19524R & 1 & PFP & 0.19 & 0.25 & 0.98 & 0.66 & 3.6 & 3.9 & 0.51 & 0.33 \\
\hline 229 & 2016 & 19524R & 1 & QCP & & & & & 3.3 & & 1.70 & \\
\hline 230 & 2016 & 19524R & 1 & QCP & & & & 0.22 & & 3.6 & & 0.59 \\
\hline 231 & 2015 & 19655R & 1 & QCP & 0.70 & 0.70 & 0.64 & 0.10 & 3.4 & 3.7 & 0.92 & 1.01 \\
\hline 232 & 2016 & $19522 \mathrm{R}$ & 1 & QCP & 0.80 & 0.57 & 0.67 & & 3.8 & 4.2 & 0.60 & 0.78 \\
\hline 233 & 2015 & $19522 \mathrm{R}$ & 1 & QCP & & & & & 4.8 & & 0.00 & \\
\hline 234 & 2015 & $19522 R$ & 1 & QCP & & & & & 4.0 & & 0.00 & \\
\hline 235 & 2017 & 19524R & 1 & QCP & 1.00 & 0.44 & & & 4.1 & 4.4 & 0.35 & 0.99 \\
\hline 236 & 2017 & 19524R & 1 & QCP & 1.00 & & & & 3.4 & 2.5 & 0.00 & 0.00 \\
\hline 237 & 2017 & 19524R & 1 & QCP & 0.67 & & & & 3.7 & 4.7 & 0.14 & 0.00 \\
\hline 238 & 2017 & 19524R & 1 & QCP & 1.00 & & & & 3.7 & 3.2 & 0.00 & 0.00 \\
\hline
\end{tabular}




\begin{tabular}{|c|c|c|c|c|c|c|c|c|c|c|c|c|}
\hline $\begin{array}{l}\text { ICT } \\
\text { Code }\end{array}$ & Year & Mix Code & District & $\begin{array}{l}\text { Quality } \\
\text { Program }\end{array}$ & $\begin{array}{c}\text { MW } \\
\text { P-Value }\end{array}$ & $\begin{array}{l}\text { Levene's } \\
\text { P-Value }\end{array}$ & $\begin{array}{l}\text { Contractor } \\
\text { SW P-Value }\end{array}$ & $\begin{array}{c}\text { Agency SW } \\
\text { P-Value }\end{array}$ & $\begin{array}{c}\text { Contractor } \\
\text { Mean }\end{array}$ & $\begin{array}{l}\text { Agency } \\
\text { Mean }\end{array}$ & $\begin{array}{c}\text { Contractor } \\
\text { St. Dev. }\end{array}$ & $\begin{array}{l}\text { Agency } \\
\text { St. Dev. }\end{array}$ \\
\hline 239 & 2017 & 19524R & 1 & PFP & 0.29 & 0.72 & 0.28 & & 3.5 & 3.8 & 0.28 & 0.28 \\
\hline 240 & 2017 & $19524 R$ & 1 & QCP & 1.00 & & & & 3.3 & 2.0 & 0.00 & 0.00 \\
\hline 241 & 2017 & $19524 R$ & 1 & QCP & 0.33 & 0.60 & & & 4.7 & 6.0 & 0.28 & 0.56 \\
\hline 242 & 2017 & 19514R & 1 & QCP & 1.00 & & & & 4.3 & 4.6 & 0.00 & 0.00 \\
\hline 243 & 2015 & $19514 R$ & 1 & QCP & 0.37 & 0.23 & 0.43 & 0.16 & 4.0 & 4.6 & 0.89 & 1.94 \\
\hline 244 & 2017 & $19524 R$ & 1 & QCP & 0.46 & 0.18 & 0.56 & 0.09 & 3.9 & 4.7 & 0.41 & 1.01 \\
\hline 245 & 2017 & 19524R & 1 & QCP & 0.17 & 0.63 & 0.58 & 0.21 & 4.5 & 5.4 & 0.67 & 0.50 \\
\hline 246 & 2015 & 19525R & 1 & QCP & 0.63 & 0.19 & 0.73 & 0.27 & 3.8 & 3.6 & 0.29 & 0.70 \\
\hline 247 & 2017 & $19525 R$ & 1 & QCP & 1.00 & & 0.84 & & 3.8 & 4.0 & 0.35 & 0.00 \\
\hline 248 & 2017 & 19525R & 1 & QCP & 1.00 & & & & 3.3 & 3.4 & 0.00 & 0.00 \\
\hline 249 & 2017 & 19525R & 1 & QCP & 0.86 & 0.27 & 0.58 & & 4.2 & 4.5 & 0.35 & 0.65 \\
\hline 250 & 2015 & 19525R & 1 & QCP & 0.82 & 0.36 & 0.15 & 1.00 & 3.8 & 3.6 & 0.45 & 0.20 \\
\hline 251 & 2017 & $19525 R$ & 1 & QCP & 1.00 & & & & 4.6 & 4.7 & 0.00 & 0.00 \\
\hline 252 & 2017 & 19525R & 1 & QCP & 1.00 & & & & 4.5 & 4.2 & 0.57 & 0.00 \\
\hline 253 & 2016 & 19510R & 1 & QCP & 1.00 & & & & 2.6 & 2.7 & 0.00 & 0.00 \\
\hline 254 & 2016 & 19510R & 1 & QCP & & & & & 2.6 & & 0.14 & \\
\hline 255 & 2016 & 19510R & 1 & QCP & 1.00 & & & & 3.8 & 4.7 & 0.00 & 0.00 \\
\hline 256 & 2016 & 19510R & 1 & QCP & 0.80 & 0.65 & 0.33 & & 3.1 & 3.2 & 0.59 & 0.28 \\
\hline 257 & 2017 & 19510R & 1 & QCP & 1.00 & & & & 3.1 & 2.8 & 0.35 & 0.00 \\
\hline 258 & 2017 & 19510R & 1 & QCP & 1.00 & & & & 3.7 & 3.7 & 0.42 & 0.00 \\
\hline 259 & 2017 & 19510R & 1 & QCP & 0.33 & 0.66 & & & 2.9 & 3.8 & 0.28 & 0.49 \\
\hline 260 & 2017 & 19510R & 1 & QCP & 0.67 & & & & 2.9 & 3.3 & 0.21 & 0.00 \\
\hline 261 & 2017 & 19525R & 1 & QCP & 0.28 & 0.22 & 0.39 & 0.64 & 4.1 & 4.8 & 0.52 & 0.92 \\
\hline 262 & 2017 & 19536R & 1 & QCP & 0.67 & & & & 3.4 & 3.7 & 0.07 & 0.00 \\
\hline 263 & 2015 & 19536R & 1 & QCP & 1.00 & & 0.41 & & 3.0 & 3.1 & 0.47 & 0.00 \\
\hline 264 & 2017 & 19524R & 1 & QCP & 1.00 & & 0.84 & & 4.7 & 5.1 & 0.70 & 0.00 \\
\hline 265 & 2017 & 19524R & 1 & QCP & 0.50 & 0.63 & 0.25 & 0.70 & 3.2 & 3.5 & 0.38 & 0.56 \\
\hline 266 & 2017 & 19524R & 1 & QCP & 1.00 & & 0.94 & & 4.0 & 3.6 & 1.07 & 0.00 \\
\hline 267 & 2015 & 19665R & 1 & QCP & 0.12 & 0.67 & 0.75 & 0.78 & 3.9 & 4.3 & 0.38 & 0.25 \\
\hline 268 & 2015 & 19525R & 1 & QCP & 0.22 & 0.29 & 0.89 & & 3.6 & 4.2 & 0.34 & 0.57 \\
\hline 269 & 2015 & 19510R & 1 & QCP & 0.03 & 0.96 & 0.01 & 0.33 & 3.3 & 5.1 & 1.07 & 0.97 \\
\hline 270 & 2015 & 19524R & 1 & PFP & 0.00 & 0.64 & 0.10 & 0.04 & 3.4 & 4.6 & 0.90 & 0.77 \\
\hline 271 & 2015 & 19510R & 1 & QCP & 0.67 & 0.86 & 0.61 & 0.30 & 3.2 & 3.0 & 0.45 & 0.51 \\
\hline 272 & 2016 & 19514R & 1 & QCP & 0.11 & 0.28 & 0.02 & 0.70 & 4.9 & 5.7 & 0.46 & 0.74 \\
\hline 273 & 2016 & 19514R & 1 & QCP & 0.06 & 0.90 & 0.10 & 0.00 & 4.1 & 4.6 & 0.77 & 0.79 \\
\hline
\end{tabular}




\begin{tabular}{|c|c|c|c|c|c|c|c|c|c|c|c|c|}
\hline $\begin{array}{c}\text { ICT } \\
\text { Code }\end{array}$ & Year & Mix Code & District & $\begin{array}{l}\text { Quality } \\
\text { Program }\end{array}$ & $\begin{array}{c}\text { MW } \\
\text { P-Value }\end{array}$ & $\begin{array}{l}\text { Levene's } \\
\text { P-Value }\end{array}$ & $\begin{array}{l}\text { Contractor } \\
\text { SW P-Value }\end{array}$ & $\begin{array}{c}\text { Agency SW } \\
\text { P-Value }\end{array}$ & $\begin{array}{c}\text { Contractor } \\
\text { Mean }\end{array}$ & $\begin{array}{c}\text { Agency } \\
\text { Mean }\end{array}$ & $\begin{array}{l}\text { Contractor } \\
\text { St. Dev. }\end{array}$ & $\begin{array}{l}\text { Agency } \\
\text { St. Dev. }\end{array}$ \\
\hline 274 & 2017 & 19510R & 1 & $\mathrm{QCP}$ & 0.93 & 0.22 & 0.34 & & 3.7 & 3.5 & 0.69 & 1.56 \\
\hline 275 & 2017 & 19510R & 1 & QCP & 0.79 & 0.05 & 0.02 & 0.18 & 2.9 & 3.0 & 0.65 & 1.15 \\
\hline 276 & 2017 & 19510R & 1 & QCP & 1.00 & & 0.41 & & 2.8 & 2.8 & 0.47 & 0.00 \\
\hline 277 & 2016 & $19512 \mathrm{R}$ & 1 & QCP & 0.02 & 0.76 & 0.80 & 0.58 & 4.1 & 4.8 & 0.40 & 0.43 \\
\hline 278 & 2017 & $19524 \mathrm{R}$ & 1 & QCP & 0.11 & 0.57 & 0.19 & & 3.6 & 4.4 & 0.56 & 0.21 \\
\hline 279 & 2017 & $19524 \mathrm{R}$ & 1 & QCP & 0.20 & 0.37 & 0.36 & & 3.6 & 4.2 & 0.26 & 0.07 \\
\hline 280 & 2017 & $19525 R$ & 1 & PFP & 0.00 & 0.25 & 0.12 & 0.81 & 3.5 & 4.1 & 0.74 & 0.95 \\
\hline 281 & 2017 & $19525 R$ & 1 & QCP & 0.89 & 0.90 & 0.18 & 0.69 & 3.9 & 3.9 & 0.75 & 0.80 \\
\hline 282 & 2015 & 19510R & 1 & QCP & 0.80 & 0.58 & & 0.38 & 3.5 & 3.3 & 0.42 & 1.03 \\
\hline 283 & 2015 & $19524 \mathrm{R}$ & 1 & QCP & 0.71 & 0.95 & 0.54 & 0.39 & 4.1 & 3.9 & 0.36 & 0.41 \\
\hline 284 & 2015 & $19522 \mathrm{R}$ & 1 & QCP & & & & & & 5.0 & & 0.00 \\
\hline 285 & 2016 & $19522 \mathrm{R}$ & 1 & QCP & & & & & 5.1 & & 0.00 & \\
\hline 286 & 2016 & $19522 \mathrm{R}$ & 1 & QCP & & & 0.00 & & 3.0 & & 0.06 & \\
\hline 287 & 2015 & $19522 \mathrm{R}$ & 1 & QCP & 0.67 & & & & 2.8 & 2.3 & 0.00 & 0.07 \\
\hline 288 & 2016 & $19532 R$ & 1 & QCP & 0.40 & 0.77 & 0.88 & & 3.6 & 4.1 & 0.45 & 0.49 \\
\hline 289 & 2017 & 19510R & 1 & QCP & 1.00 & & & & 3.8 & 3.2 & 0.00 & 0.00 \\
\hline 290 & 2016 & 19510R & 1 & QCP & & & & & & 3.1 & & 0.78 \\
\hline 291 & 2017 & 19510R & 1 & QCP & 0.39 & 0.21 & 0.13 & 0.84 & 2.9 & 2.4 & 0.34 & 0.70 \\
\hline 292 & 2015 & $19524 \mathrm{R}$ & 1 & QCP & 1.00 & 0.27 & 0.23 & & 3.9 & 4.0 & 0.56 & 1.13 \\
\hline 293 & 2016 & $19524 R$ & 1 & QCP & & & & & & 5.1 & & 0.00 \\
\hline 294 & 2016 & 19524R & 1 & QCP & 1.00 & & & & 4.4 & 4.2 & 0.00 & 0.00 \\
\hline 295 & 2015 & 19510R & 1 & QCP & 0.54 & 0.42 & 0.13 & 0.49 & 4.0 & 4.3 & 0.77 & 0.57 \\
\hline 296 & 2015 & 19665R & 1 & PFP & 0.02 & 0.61 & 0.37 & 0.54 & 3.4 & 2.8 & 0.71 & 0.80 \\
\hline 297 & 2017 & 19510R & 1 & QCP & 1.00 & & 0.16 & & 3.1 & 3.0 & 0.32 & 0.00 \\
\hline 298 & 2016 & 19510R & 1 & QCP & 1.00 & & & & 2.9 & 2.9 & 0.21 & 0.00 \\
\hline 299 & 2016 & 19524R & 1 & QCP & 1.00 & & 1.00 & & 3.2 & 3.2 & 0.30 & 0.00 \\
\hline 300 & 2016 & $19524 R$ & 1 & QCP & 1.00 & & & & 3.3 & 3.0 & 0.35 & 0.00 \\
\hline 301 & 2015 & 19536R & 1 & PFP & & & & & 4.0 & & 0.00 & \\
\hline 302 & 2015 & 19536R & 1 & QCP & 0.33 & 0.13 & & & 4.0 & 3.1 & 0.07 & 0.71 \\
\hline 303 & 2015 & 19536R & 1 & PFP & 0.07 & 0.15 & 0.08 & 0.09 & 3.4 & 2.8 & 1.24 & 0.79 \\
\hline 304 & 2015 & 19536R & 1 & QCP & & & 0.52 & & 4.5 & & 0.91 & \\
\hline 305 & 2015 & $19512 \mathrm{R}$ & 1 & QCP & 0.18 & 0.25 & 0.90 & 0.64 & 2.9 & 2.4 & 0.24 & 0.46 \\
\hline 306 & 2017 & $19525 R$ & 1 & QCP & 0.33 & & 0.72 & & 3.5 & 4.6 & 0.33 & 0.00 \\
\hline 307 & 2017 & $19525 R$ & 1 & QCP & 1.00 & & & & 4.3 & 4.2 & 0.00 & 0.00 \\
\hline 308 & 2016 & 19525R & 1 & QCP & 0.57 & & 0.04 & & 4.5 & 4.9 & 0.43 & 0.00 \\
\hline
\end{tabular}




\begin{tabular}{|c|c|c|c|c|c|c|c|c|c|c|c|c|}
\hline $\begin{array}{l}\text { ICT } \\
\text { Code }\end{array}$ & Year & Mix Code & District & $\begin{array}{l}\text { Quality } \\
\text { Program }\end{array}$ & $\begin{array}{c}\text { MW } \\
\text { P-Value }\end{array}$ & $\begin{array}{l}\text { Levene's } \\
\text { P-Value }\end{array}$ & $\begin{array}{l}\text { Contractor } \\
\text { SW P-Value }\end{array}$ & $\begin{array}{c}\text { Agency SW } \\
\text { P-Value }\end{array}$ & $\begin{array}{c}\text { Contractor } \\
\text { Mean }\end{array}$ & $\begin{array}{l}\text { Agency } \\
\text { Mean }\end{array}$ & $\begin{array}{c}\text { Contractor } \\
\text { St. Dev. }\end{array}$ & $\begin{array}{l}\text { Agency } \\
\text { St. Dev. }\end{array}$ \\
\hline 309 & 2017 & 19525R & 1 & PFP & 0.64 & 0.22 & 0.12 & 0.00 & 3.6 & 3.7 & 0.62 & 1.04 \\
\hline 310 & 2017 & $19512 R$ & 1 & QCP & & & & & 4.5 & & 0.07 & \\
\hline 311 & 2017 & $19512 R$ & 1 & QCP & & & & & 4.4 & & 0.00 & \\
\hline 312 & 2017 & 19536R & 1 & QCP & 0.33 & 0.31 & & & 4.6 & 5.5 & 0.21 & 0.85 \\
\hline 313 & 2016 & 19536R & 1 & QCP & & & 0.78 & & 3.7 & & 0.25 & \\
\hline 314 & 2017 & 19510R & 1 & QCP & 0.33 & 0.58 & & & 3.1 & 2.1 & 0.42 & 0.21 \\
\hline 315 & 2017 & 19510R & 1 & QCP & 0.50 & & 0.46 & & 3.2 & 2.6 & 0.21 & 0.00 \\
\hline 316 & 2017 & 19510R & 1 & QCP & 0.74 & 0.38 & 0.61 & 1.00 & 3.0 & 2.7 & 0.57 & 1.00 \\
\hline 317 & 2017 & 19510R & 1 & QCP & & & & & 2.9 & & 0.00 & \\
\hline 318 & 2017 & 19665R & 1 & QCP & 1.00 & & & & 4.2 & 6.4 & 0.00 & 0.00 \\
\hline 319 & 2017 & 19665R & 1 & PFP & 0.23 & 0.14 & 0.00 & 0.73 & 3.9 & 3.1 & 1.50 & 0.40 \\
\hline 320 & 2017 & $19525 R$ & 1 & QCP & 1.00 & & & & 4.8 & 5.2 & 0.00 & 0.00 \\
\hline 321 & 2017 & $19522 R$ & 1 & QCP & & & 0.07 & & 3.8 & & 0.66 & \\
\hline 322 & 2017 & $19522 R$ & 1 & QCP & & & & & 3.4 & & 0.00 & \\
\hline 323 & 2017 & 19653R & 1 & PFP & 0.52 & 0.67 & 0.16 & 0.46 & 3.6 & 3.5 & 0.64 & 0.60 \\
\hline 324 & 2017 & 19655 & 1 & PFP & 0.79 & 0.11 & 0.09 & 0.20 & 3.6 & 3.6 & 0.59 & 0.47 \\
\hline 325 & 2015 & $19532 R$ & 1 & QCP & 0.70 & 0.07 & 1.00 & 0.27 & 3.6 & 3.7 & 0.20 & 1.08 \\
\hline 326 & 2017 & $19532 R$ & 1 & QCP & & & & & 3.6 & & 0.28 & \\
\hline 327 & 2017 & $19532 R$ & 1 & QCP & 0.67 & & & & 4.4 & 4.2 & 0.07 & 0.00 \\
\hline 328 & 2017 & $19524 R$ & 1 & QCP & 0.73 & & 0.28 & & 3.8 & 3.3 & 0.63 & 0.00 \\
\hline 329 & 2017 & $19524 R$ & 1 & QCP & 0.20 & 0.15 & 0.41 & 0.69 & 3.9 & 3.1 & 0.46 & 0.85 \\
\hline 330 & 2017 & $19524 R$ & 1 & QCP & 0.07 & 0.78 & 0.15 & 0.59 & 3.8 & 4.3 & 0.48 & 0.51 \\
\hline 331 & 2017 & $19522 \mathrm{R}$ & 1 & QCP & 0.62 & 0.58 & 0.48 & 0.10 & 3.9 & 4.0 & 0.52 & 0.43 \\
\hline 332 & 2015 & $19522 R$ & 1 & QCP & 0.57 & & 0.04 & & 3.9 & 4.5 & 0.63 & 0.00 \\
\hline 333 & 2015 & $19522 \mathrm{R}$ & 1 & QCP & & & & & 3.9 & & 0.00 & \\
\hline 334 & 2015 & $19524 R$ & 1 & PFP & 0.13 & 0.31 & 0.02 & 0.65 & 3.6 & 3.0 & 0.50 & 0.73 \\
\hline 335 & 2015 & $19524 R$ & 1 & QCP & 0.69 & 0.87 & 0.23 & 0.75 & 4.3 & 4.2 & 0.64 & 0.68 \\
\hline 336 & 2015 & $19524 R$ & 1 & QCP & 1.00 & & & & 4.9 & 4.9 & 0.07 & 0.00 \\
\hline 337 & 2015 & $19522 \mathrm{R}$ & 1 & QCP & 0.14 & 0.14 & 0.03 & 0.09 & 3.7 & 2.8 & 0.61 & 1.02 \\
\hline 338 & 2015 & $19524 R$ & 1 & QCP & 0.09 & 0.99 & 0.01 & 0.60 & 4.3 & 3.8 & 0.53 & 0.49 \\
\hline 339 & 2015 & $19522 R$ & 1 & QCP & & & & & 3.4 & & 0.42 & \\
\hline 340 & 2015 & $19524 R$ & 1 & QCP & 0.05 & 0.43 & 0.07 & 0.41 & 3.4 & 4.1 & 0.33 & 0.47 \\
\hline 341 & 2015 & $19524 R$ & 1 & PFP & & & & & 3.0 & & 0.14 & \\
\hline 342 & 2015 & 19510R & 1 & QCP & 0.80 & & 0.44 & & 3.7 & 3.6 & 0.94 & 0.00 \\
\hline 343 & 2015 & 19510R & 1 & PFP & 0.06 & 0.55 & 0.14 & 0.33 & 2.8 & 2.4 & 0.39 & 0.46 \\
\hline
\end{tabular}




\begin{tabular}{|c|c|c|c|c|c|c|c|c|c|c|c|c|}
\hline $\begin{array}{l}\text { ICT } \\
\text { Code }\end{array}$ & Year & Mix Code & District & $\begin{array}{l}\text { Quality } \\
\text { Program }\end{array}$ & $\begin{array}{c}\text { MW } \\
\text { P-Value }\end{array}$ & $\begin{array}{l}\text { Levene's } \\
\text { P-Value }\end{array}$ & $\begin{array}{l}\text { Contractor } \\
\text { SW P-Value }\end{array}$ & $\begin{array}{c}\text { Agency SW } \\
\text { P-Value }\end{array}$ & $\begin{array}{c}\text { Contractor } \\
\text { Mean }\end{array}$ & $\begin{array}{l}\text { Agency } \\
\text { Mean }\end{array}$ & $\begin{array}{c}\text { Contractor } \\
\text { St. Dev. }\end{array}$ & $\begin{array}{l}\text { Agency } \\
\text { St. Dev. }\end{array}$ \\
\hline 344 & 2015 & 19510R & 1 & $\mathrm{QCP}$ & 0.21 & 0.20 & 0.37 & 0.90 & 2.9 & 2.0 & 0.39 & 0.82 \\
\hline 345 & 2015 & 19510R & 1 & PFP & 0.65 & 0.57 & 0.55 & 0.61 & 3.4 & 3.2 & 0.67 & 0.92 \\
\hline 346 & 2015 & 19510R & 1 & QCP & & & & & & 3.4 & & 0.00 \\
\hline 347 & 2015 & 19510R & 1 & QCP & 0.80 & & 0.40 & & 3.1 & 3.4 & 0.45 & 0.00 \\
\hline 348 & 2015 & 19510R & 1 & PFP & 0.27 & 0.17 & 0.08 & 0.00 & 3.2 & 3.4 & 0.45 & 0.72 \\
\hline 349 & 2015 & 19510R & 1 & QCP & & & 0.14 & & 3.4 & & 0.67 & \\
\hline 350 & 2015 & 19510R & 1 & QCP & 0.50 & & 0.00 & & 3.6 & 2.4 & 0.64 & 0.00 \\
\hline 351 & 2015 & 19510R & 1 & QCP & 1.00 & 0.59 & & & 3.6 & 3.5 & 0.71 & 0.35 \\
\hline 352 & 2015 & 19510R & 1 & QCP & 0.67 & & & & 3.4 & 3.9 & 0.07 & 0.00 \\
\hline 353 & 2015 & $19522 R$ & 1 & QCP & & & & & & 3.0 & & 0.00 \\
\hline 354 & 2015 & 19536R & 1 & QCP & 0.68 & 0.01 & 0.56 & 0.39 & 4.4 & 4.8 & 0.34 & 2.05 \\
\hline 355 & 2015 & 19536R & 1 & QCP & 1.00 & 0.97 & 0.80 & 0.27 & 4.4 & 4.2 & 0.62 & 0.67 \\
\hline 356 & 2015 & 19536R & 1 & PFP & 0.05 & 0.04 & 0.74 & 0.11 & 3.8 & 4.2 & 0.51 & 0.89 \\
\hline 357 & 2016 & $19524 R$ & 1 & QCP & 1.00 & & & & 3.5 & 3.4 & 0.00 & 0.00 \\
\hline 358 & 2017 & $19524 R$ & 1 & QCP & 0.97 & 0.65 & 0.17 & 0.33 & 3.9 & 3.8 & 0.74 & 0.58 \\
\hline 359 & 2015 & 19665R & 1 & QCP & 0.57 & 0.03 & 0.77 & 0.19 & 3.2 & 3.1 & 0.67 & 2.03 \\
\hline 360 & 2015 & 19665R & 1 & PFP & & & 0.43 & & 3.3 & & 0.75 & \\
\hline 361 & 2017 & 19510R & 1 & QCP & 0.86 & 0.67 & 0.25 & 0.00 & 3.0 & 3.1 & 0.68 & 0.87 \\
\hline 362 & 2015 & 19655R & 1 & PFP & & & 0.77 & & 3.5 & & 0.55 & \\
\hline 363 & 2016 & $19522 \mathrm{R}$ & 1 & QCP & 0.75 & 0.14 & 0.89 & 0.60 & 4.0 & 4.0 & 0.36 & 0.67 \\
\hline 364 & 2016 & $19524 \mathrm{R}$ & 1 & QCP & & & & & 3.8 & & 0.00 & \\
\hline 365 & 2016 & 19514R & 1 & QCP & 1.00 & & & & 3.5 & 3.5 & 0.00 & 0.00 \\
\hline 366 & 2016 & 19536R & 1 & QCP & 1.00 & & & & 3.4 & 3.4 & 0.28 & 0.00 \\
\hline 367 & 2016 & $19532 R$ & 1 & QCP & 0.10 & 0.50 & 1.00 & 0.00 & 4.6 & 4.1 & 0.30 & 0.17 \\
\hline 368 & 2017 & $19522 \mathrm{R}$ & 1 & QCP & 1.00 & & 0.60 & & 4.3 & 3.8 & 0.64 & 0.00 \\
\hline 369 & 2017 & $19522 \mathrm{R}$ & 1 & QCP & 0.20 & & 0.12 & & 3.7 & 5.2 & 0.62 & 0.00 \\
\hline 370 & 2017 & $19524 R$ & 1 & QCP & 0.20 & 0.21 & 0.20 & 0.41 & 4.2 & 5.0 & 0.65 & 1.14 \\
\hline 371 & 2017 & $19524 \mathrm{R}$ & 1 & PFP & 0.11 & 0.91 & 0.84 & 0.04 & 4.2 & 4.9 & 0.73 & 0.65 \\
\hline 372 & 2017 & 19510R & 1 & QCP & 0.57 & & 0.01 & & 2.9 & 3.1 & 0.28 & 0.00 \\
\hline 373 & 2017 & 19510R & 1 & QCP & 1.00 & 0.51 & 0.44 & & 4.2 & 4.4 & 0.61 & 0.22 \\
\hline 374 & 2017 & 19510R & 1 & QCP & 1.00 & & & & 3.1 & 2.4 & 0.00 & 0.00 \\
\hline 375 & 2017 & 19525R & 1 & $\mathrm{QCP}$ & 0.40 & 0.51 & 0.09 & 0.08 & 4.3 & 5.2 & 1.01 & 1.77 \\
\hline 376 & 2017 & 19510R & 1 & $\mathrm{QCP}$ & 0.63 & 0.17 & 0.40 & 0.00 & 3.2 & 2.8 & 0.40 & 0.98 \\
\hline 377 & 2017 & 19510R & 1 & $\mathrm{QCP}$ & 1.00 & 0.57 & 0.97 & 0.54 & 2.9 & 2.9 & 0.26 & 0.36 \\
\hline 378 & 2017 & 19653R & 1 & $\mathrm{QCP}$ & & & & & 3.7 & & 0.00 & \\
\hline
\end{tabular}




\begin{tabular}{|c|c|c|c|c|c|c|c|c|c|c|c|c|}
\hline $\begin{array}{l}\text { ICT } \\
\text { Code }\end{array}$ & Year & Mix Code & District & $\begin{array}{l}\text { Quality } \\
\text { Program }\end{array}$ & $\begin{array}{c}\text { MW } \\
\text { P-Value }\end{array}$ & $\begin{array}{l}\text { Levene's } \\
\text { P-Value }\end{array}$ & $\begin{array}{l}\text { Contractor } \\
\text { SW P-Value }\end{array}$ & $\begin{array}{c}\text { Agency SW } \\
\text { P-Value }\end{array}$ & $\begin{array}{c}\text { Contractor } \\
\text { Mean }\end{array}$ & $\begin{array}{l}\text { Agency } \\
\text { Mean }\end{array}$ & $\begin{array}{c}\text { Contractor } \\
\text { St. Dev. }\end{array}$ & $\begin{array}{l}\text { Agency } \\
\text { St. Dev. }\end{array}$ \\
\hline 379 & 2017 & 19653R & 1 & PFP & 0.77 & 0.06 & 0.02 & 0.49 & 3.5 & 3.6 & 0.70 & 1.09 \\
\hline 380 & 2017 & $19525 R$ & 1 & PFP & & & & & & 4.1 & & 1.20 \\
\hline 381 & 2017 & $19525 R$ & 1 & PFP & 0.25 & 0.21 & 0.45 & 0.94 & 4.6 & 5.2 & 0.74 & 1.33 \\
\hline 382 & 2017 & 19655R & 1 & PFP & 0.81 & 0.13 & 0.05 & 0.09 & 3.4 & 3.5 & 0.80 & 1.35 \\
\hline 383 & 2017 & 19510R & 1 & QCP & 0.09 & 0.53 & 0.82 & 0.87 & 3.2 & 2.8 & 0.51 & 0.61 \\
\hline 384 & 2017 & 19665R & 1 & PFP & 0.30 & 0.49 & 0.00 & 0.20 & 4.4 & 5.0 & 1.94 & 2.37 \\
\hline 385 & 2017 & 19665R & 1 & QCP & 0.80 & 0.34 & 0.77 & 0.82 & 3.7 & 3.6 & 0.66 & 0.98 \\
\hline 386 & 2015 & $19512 R$ & 1 & QCP & 0.73 & 0.58 & 0.22 & & 3.3 & 3.6 & 1.06 & 1.20 \\
\hline 387 & 2015 & $19514 R$ & 1 & QCP & 0.67 & & & & 4.1 & 4.5 & 0.35 & 0.00 \\
\hline 388 & 2015 & 19522R & 1 & QCP & 0.67 & & & & 3.7 & 3.4 & 0.00 & 0.00 \\
\hline 389 & 2016 & $19606 \mathrm{~F}$ & 2 & PFP & 0.60 & 0.34 & 0.00 & 0.01 & 3.7 & 3.8 & 0.63 & 0.76 \\
\hline 390 & 2014 & $19514 R$ & 2 & QCP & 0.13 & 0.60 & 0.18 & 0.55 & 3.5 & 3.1 & 0.62 & 0.72 \\
\hline 391 & 2015 & $19514 R$ & 2 & QCP & & & & & 4.2 & & 0.00 & \\
\hline 392 & 2015 & 19604FR & 2 & QCP & 0.73 & 0.72 & 0.82 & 0.57 & 2.8 & 2.7 & 0.91 & 1.10 \\
\hline 393 & 2015 & $19514 R$ & 2 & QCP & 0.41 & 0.56 & 0.36 & 0.18 & 4.3 & 4.8 & 1.14 & 0.89 \\
\hline 394 & 2016 & $19512 R$ & 4 & QCP & & & & & 3.5 & & 0.00 & \\
\hline 395 & 2016 & 19535R & 2 & QCP & 0.44 & 0.53 & 0.38 & 0.07 & 4.9 & 5.4 & 1.29 & 1.00 \\
\hline 396 & 2015 & 19534R & 2 & PFP & 0.18 & 0.38 & 0.14 & 0.58 & 4.2 & 4.0 & 0.57 & 0.65 \\
\hline 397 & 2015 & $19532 R$ & 2 & PFP & 0.06 & 0.91 & 0.27 & 0.47 & 4.1 & 3.9 & 0.59 & 0.58 \\
\hline 398 & 2015 & $19514 R$ & 2 & QCP & 0.25 & 0.39 & 0.20 & 0.48 & 4.1 & 3.8 & 0.63 & 0.77 \\
\hline 399 & 2017 & 19514R & 2 & QCP & 0.80 & & 0.03 & & 4.0 & 4.4 & 0.70 & 0.00 \\
\hline 400 & 2015 & 19524R & 2 & QCP & 0.27 & 0.72 & 0.01 & 0.27 & 3.7 & 3.3 & 0.97 & 1.08 \\
\hline 401 & 2015 & 19514R & 2 & QCP & 0.01 & 0.25 & 0.99 & 0.62 & 3.8 & 2.9 & 0.63 & 0.42 \\
\hline 402 & 2015 & 19604FR & 2 & QCP & 0.69 & 0.81 & 0.99 & 0.96 & 3.9 & 3.6 & 0.79 & 0.93 \\
\hline 403 & 2015 & 19604FR & 2 & QCP & 0.69 & 0.99 & 0.53 & 1.00 & 3.9 & 3.5 & 0.92 & 0.92 \\
\hline 404 & 2015 & 19514R & 2 & QCP & 0.46 & 0.77 & 0.60 & 0.50 & 4.7 & 4.2 & 1.13 & 1.29 \\
\hline 405 & 2016 & 19604FR & 2 & QCP & 0.58 & 0.49 & 0.87 & 0.07 & 3.9 & 3.8 & 0.67 & 0.54 \\
\hline 406 & 2016 & 19514R & 2 & QCP & 0.37 & 0.73 & 0.00 & 0.00 & 4.6 & 4.4 & 0.97 & 0.90 \\
\hline 407 & 2016 & 19516R & 2 & QCP & 1.00 & 0.33 & & & 4.4 & 4.9 & 0.28 & 1.06 \\
\hline 408 & 2017 & 19514R & 2 & QCP & 0.70 & 0.72 & 0.46 & 0.83 & 3.7 & 3.6 & 0.89 & 0.95 \\
\hline 409 & 2017 & $19512 R$ & 2 & QCP & 0.12 & 0.91 & 0.70 & 0.94 & 3.3 & 2.5 & 0.93 & 0.84 \\
\hline 410 & 2017 & $19512 \mathrm{R}$ & 2 & QCP & 0.94 & 0.16 & 0.17 & 0.60 & 4.1 & 4.2 & 1.36 & 0.54 \\
\hline 411 & 2017 & 19514R & 2 & QCP & 0.05 & 0.36 & 0.04 & 0.02 & 4.4 & 3.5 & 0.88 & 0.58 \\
\hline 412 & 2016 & 19516R & 2 & QCP & 1.00 & 0.33 & & & 4.4 & 4.9 & 0.28 & 1.06 \\
\hline 413 & 2016 & 19513R & 2 & QCP & 0.33 & 1.00 & & & 3.6 & 3.1 & 0.07 & 0.07 \\
\hline
\end{tabular}




\begin{tabular}{|c|c|c|c|c|c|c|c|c|c|c|c|c|}
\hline $\begin{array}{c}\text { ICT } \\
\text { Code }\end{array}$ & Year & Mix Code & District & $\begin{array}{l}\text { Quality } \\
\text { Program }\end{array}$ & $\begin{array}{c}\text { MW } \\
\text { P-Value }\end{array}$ & $\begin{array}{l}\text { Levene's } \\
\text { P-Value }\end{array}$ & $\begin{array}{l}\text { Contractor } \\
\text { SW P-Value }\end{array}$ & $\begin{array}{c}\text { Agency SW } \\
\text { P-Value }\end{array}$ & $\begin{array}{c}\text { Contractor } \\
\text { Mean }\end{array}$ & $\begin{array}{l}\text { Agency } \\
\text { Mean }\end{array}$ & $\begin{array}{c}\text { Contractor } \\
\text { St. Dev. }\end{array}$ & $\begin{array}{l}\text { Agency } \\
\text { St. Dev. }\end{array}$ \\
\hline 414 & 2017 & 19514R & 2 & $\mathrm{QCP}$ & 1.00 & & 0.07 & & 4.7 & 4.7 & 1.09 & 0.00 \\
\hline 415 & 2015 & 19514R & 2 & QCP & 0.42 & 0.39 & 0.55 & 0.23 & 4.6 & 4.2 & 0.81 & 1.07 \\
\hline 416 & 2017 & 19513R & 2 & QCP & & & & & 3.6 & & 0.00 & \\
\hline 417 & 2015 & 19514R & 2 & QCP & 0.83 & 0.28 & 0.02 & 0.57 & 3.9 & 3.7 & 0.53 & 0.83 \\
\hline 418 & 2016 & 19514R & 2 & QCP & 0.13 & 0.41 & 0.37 & 0.49 & 4.4 & 4.0 & 0.86 & 0.71 \\
\hline 419 & 2017 & $19512 R$ & 2 & QCP & 0.02 & 0.36 & 0.54 & 0.00 & 3.8 & 4.7 & 0.51 & 0.23 \\
\hline 420 & 2015 & $19512 R$ & 2 & QCP & 0.10 & 0.66 & 0.35 & 0.54 & 4.3 & 4.1 & 0.78 & 0.84 \\
\hline 421 & 2015 & $19512 R$ & 2 & QCP & 0.90 & 0.22 & 0.99 & 0.34 & 3.6 & 3.6 & 1.00 & 1.38 \\
\hline 422 & 2015 & 19534R & 2 & PFP & 0.80 & 0.11 & 0.00 & 0.01 & 3.8 & 3.8 & 0.59 & 0.76 \\
\hline 423 & 2015 & 19534R & 2 & PFP & 0.26 & 0.62 & 0.26 & 0.12 & 3.8 & 3.9 & 0.46 & 0.51 \\
\hline 424 & 2016 & 19534R & 2 & PFP & 0.77 & 0.17 & 0.60 & 0.72 & 4.0 & 3.9 & 0.54 & 0.77 \\
\hline 425 & 2017 & $19532 R$ & 2 & PFP & 0.94 & 0.80 & 0.19 & 0.99 & 4.1 & 4.0 & 0.80 & 0.87 \\
\hline 426 & 2015 & $19532 R$ & 2 & PFP & 0.74 & 0.18 & 0.13 & 0.25 & 2.9 & 3.5 & 1.21 & 0.38 \\
\hline 427 & 2017 & $19535 R$ & 2 & PFP & 0.34 & 0.49 & 0.31 & 0.73 & 4.6 & 4.9 & 0.85 & 0.66 \\
\hline 428 & 2015 & 19535R & 2 & PFP & 0.78 & 0.52 & 0.09 & 0.04 & 4.3 & 4.3 & 0.65 & 0.49 \\
\hline 429 & 2016 & $19512 R$ & 2 & QCP & 0.44 & 0.40 & 0.13 & 0.14 & 4.3 & 4.1 & 1.13 & 1.36 \\
\hline 430 & 2015 & 19654R & 2 & PFP & 0.72 & 0.60 & 0.12 & 0.24 & 4.1 & 4.0 & 0.89 & 0.81 \\
\hline 431 & 2015 & 19514R & 2 & QCP & 1.00 & 0.78 & & & 4.6 & 4.4 & 1.20 & 0.85 \\
\hline 432 & 2015 & $19514 R$ & 2 & $\mathrm{QCP}$ & 0.96 & 0.67 & 0.61 & 0.80 & 4.7 & 4.6 & 1.34 & 1.58 \\
\hline 433 & 2015 & $19514 R$ & 2 & QCP & 0.71 & 0.45 & 0.56 & 0.24 & 4.5 & 4.6 & 0.70 & 0.95 \\
\hline 434 & 2016 & 19532R & 2 & PFP & 0.24 & 0.52 & 0.01 & 0.25 & 3.8 & 3.6 & 0.58 & 0.63 \\
\hline 435 & 2015 & $19512 \mathrm{R}$ & 2 & QCP & 0.73 & 0.64 & 0.45 & 0.78 & 4.8 & 4.6 & 0.77 & 0.87 \\
\hline 436 & 2016 & 19654R & 2 & PFP & 0.30 & 0.62 & 0.12 & 0.51 & 4.0 & 4.1 & 0.94 & 1.01 \\
\hline 437 & 2016 & 19654R & 2 & QCP & 0.29 & 0.00 & 0.15 & & 3.9 & 4.0 & 0.12 & 0.00 \\
\hline 438 & 2016 & 19524R & 2 & QCP & 1.00 & 0.64 & 0.08 & 0.19 & 4.1 & 4.2 & 0.82 & 0.99 \\
\hline 439 & 2017 & 19524R & 4 & QCP & & & & & 3.2 & & 0.00 & \\
\hline 440 & 2016 & 19534R & 2 & PFP & 0.18 & 0.96 & 0.01 & 0.14 & 4.0 & 4.1 & 0.51 & 0.50 \\
\hline 441 & 2016 & 19524R & 2 & PFP & 0.17 & 0.57 & 0.94 & 0.96 & 4.6 & 5.2 & 0.77 & 0.93 \\
\hline 442 & 2016 & 19534R & 2 & PFP & 0.61 & 0.77 & 0.16 & 0.13 & 3.7 & 3.7 & 0.58 & 0.61 \\
\hline 443 & 2015 & 19524R & 2 & QCP & 0.13 & 0.02 & 0.06 & 0.14 & 3.9 & 3.7 & 0.58 & 0.90 \\
\hline 444 & 2015 & 19525R & 2 & QCP & 0.67 & 0.50 & & 0.04 & 4.7 & 4.3 & 0.99 & 0.78 \\
\hline 445 & 2015 & 19532R & 2 & PFP & 0.00 & 0.90 & 0.06 & 0.02 & 3.9 & 4.4 & 0.65 & 0.66 \\
\hline 446 & 2015 & 19605FR & 2 & QCP & 0.95 & 0.55 & 0.34 & 0.66 & 4.0 & 3.9 & 0.62 & 0.51 \\
\hline 447 & 2015 & 19532R & 2 & QCP & 1.00 & 0.48 & & & 4.9 & 5.0 & 0.28 & 0.71 \\
\hline 448 & 2015 & 19654R & 2 & PFP & 0.00 & 0.01 & 0.71 & 0.00 & 3.8 & 4.5 & 0.56 & 0.86 \\
\hline
\end{tabular}




\begin{tabular}{|c|c|c|c|c|c|c|c|c|c|c|c|c|}
\hline $\begin{array}{c}\mathrm{ICT} \\
\text { Code }\end{array}$ & Year & Mix Code & District & $\begin{array}{c}\text { Quality } \\
\text { Program }\end{array}$ & $\begin{array}{c}\text { MW } \\
\text { P-Value }\end{array}$ & $\begin{array}{l}\text { Levene's } \\
\text { P-Value }\end{array}$ & $\begin{array}{l}\text { Contractor } \\
\text { SW P-Value }\end{array}$ & $\begin{array}{c}\text { Agency SW } \\
\text { P-Value }\end{array}$ & $\begin{array}{c}\text { Contractor } \\
\text { Mean }\end{array}$ & $\begin{array}{c}\text { Agency } \\
\text { Mean }\end{array}$ & $\begin{array}{l}\text { Contractor } \\
\text { St. Dev. }\end{array}$ & $\begin{array}{l}\text { Agency } \\
\text { St. Dev. }\end{array}$ \\
\hline 449 & 2015 & $19524 R$ & 2 & QCP & 1.00 & 0.03 & 0.98 & 0.37 & 3.9 & 4.0 & 0.56 & 1.06 \\
\hline 450 & 2015 & 19515R & 2 & QCP & & & & 0.63 & & 5.5 & & 0.53 \\
\hline 451 & 2016 & 19515R & 2 & QCP & 0.01 & 0.79 & 0.63 & 0.55 & 4.3 & 5.0 & 0.69 & 0.73 \\
\hline 452 & 2014 & 19604FR & 2 & QCP & 0.54 & 0.12 & 0.73 & 0.04 & 3.9 & 4.0 & 0.58 & 0.91 \\
\hline 453 & 2015 & $19605 F R$ & 2 & QCP & 0.50 & 0.84 & 0.24 & 0.71 & 3.8 & 4.2 & 0.81 & 0.96 \\
\hline 454 & 2015 & 19525R & 2 & QCP & 0.49 & 0.60 & 0.92 & 0.81 & 4.7 & 5.5 & 0.89 & 1.24 \\
\hline 455 & 2015 & 19515R & 2 & QCP & 0.01 & 0.00 & 0.02 & 0.23 & 3.7 & 4.4 & 0.63 & 1.11 \\
\hline 456 & 2016 & 19525R & 2 & QCP & 0.28 & 0.32 & 0.13 & 0.38 & 4.0 & 4.6 & 0.63 & 1.00 \\
\hline 457 & 2015 & 19525R & 2 & QCP & 0.40 & 0.76 & 0.90 & 1.00 & 4.3 & 4.9 & 0.55 & 0.70 \\
\hline 458 & 2015 & $19532 R$ & 2 & PFP & 0.00 & 0.03 & 0.01 & 0.50 & 3.5 & 3.9 & 0.51 & 0.70 \\
\hline 459 & 2015 & $19532 R$ & 2 & QCP & 0.80 & & 0.04 & & 3.9 & 3.5 & 0.61 & 0.00 \\
\hline 460 & 2015 & 19654R & 2 & PFP & 0.62 & 0.00 & 0.02 & 0.00 & 3.9 & 4.1 & 0.65 & 1.31 \\
\hline 461 & 2015 & $19526 \mathrm{R}$ & 2 & QCP & 1.00 & & & & 4.7 & 5.9 & 0.00 & 0.00 \\
\hline 462 & 2017 & $19515 R$ & 2 & QCP & 0.39 & 0.03 & 0.01 & 0.01 & 4.6 & 4.9 & 0.72 & 0.22 \\
\hline 463 & 2017 & 19604FR & 2 & QCP & 0.56 & 0.11 & 0.09 & & 4.1 & 3.9 & 0.21 & 0.49 \\
\hline 464 & 2017 & 19532 & 2 & PFP & 0.90 & 0.91 & 0.55 & 0.95 & 4.0 & 4.0 & 0.95 & 0.91 \\
\hline 465 & 2017 & 19513R & 2 & QCP & 0.62 & 0.80 & 0.56 & & 4.7 & 4.2 & 1.29 & 0.71 \\
\hline 466 & 2017 & 19535R & 2 & PFP & 0.86 & 0.81 & 0.28 & 0.73 & 4.8 & 4.8 & 0.56 & 0.62 \\
\hline 467 & 2015 & $19524 R$ & 3 & QCP & 0.08 & 0.59 & 0.09 & 0.11 & 4.3 & 3.5 & 1.05 & 0.83 \\
\hline 468 & 2017 & $19524 R$ & 1 & QCP & 0.67 & & & & 4.1 & 3.5 & 0.03 & 0.00 \\
\hline 469 & 2017 & 19524R & 3 & PFP & & & & & 5.2 & & 0.00 & \\
\hline 470 & 2017 & 19524R & 1 & PFP & & & 0.02 & & 4.8 & & 0.41 & \\
\hline 471 & 2016 & 19524R & 3 & QCP & 0.40 & & 0.37 & & 4.0 & 4.9 & 0.26 & 0.00 \\
\hline 472 & 2017 & $19522 \mathrm{R}$ & 3 & QCP & 0.50 & & 0.72 & & 5.2 & 4.6 & 0.06 & 0.00 \\
\hline 473 & 2015 & 19535R & 3 & PFP & & & & 0.14 & & 4.5 & & 1.12 \\
\hline 474 & 2017 & 19510R & 1 & QCP & 0.56 & 0.65 & 0.92 & & 3.6 & 3.1 & 0.66 & 0.71 \\
\hline 475 & 2017 & 19510R & 1 & QCP & 0.05 & 0.78 & 0.40 & 0.90 & 3.8 & 3.1 & 0.52 & 0.42 \\
\hline 476 & 2016 & 19524R & 3 & QCP & 1.00 & 0.84 & & & 4.2 & 4.3 & 0.64 & 0.49 \\
\hline 477 & 2017 & 19525R & 1 & PFP & 0.05 & 0.79 & 0.76 & 0.41 & 4.3 & 3.4 & 0.66 & 0.47 \\
\hline 478 & 2017 & 19534R & 3 & QCP & 0.20 & 0.00 & 0.00 & & 4.7 & 3.5 & 0.23 & 0.00 \\
\hline 479 & 2016 & $19524 R$ & 3 & QCP & 0.67 & & & & 5.0 & 5.2 & 0.21 & 0.00 \\
\hline 480 & 2017 & 19524R & 1 & PFP & 0.39 & 0.27 & 0.75 & & 4.1 & 3.5 & 0.64 & 0.99 \\
\hline 481 & 2017 & $19524 \mathrm{R}$ & 3 & QCP & & & 0.07 & & 3.6 & & 0.41 & \\
\hline 482 & 2015 & $19522 \mathrm{R}$ & 3 & QCP & 0.40 & 0.85 & & 0.30 & 3.5 & 4.1 & 0.42 & 0.64 \\
\hline 483 & 2015 & $19522 R$ & 3 & $\mathrm{QCP}$ & 1.00 & & & 0.76 & 2.9 & 2.8 & 0.00 & 0.91 \\
\hline
\end{tabular}




\begin{tabular}{|c|c|c|c|c|c|c|c|c|c|c|c|c|}
\hline $\begin{array}{c}\text { ICT } \\
\text { Code }\end{array}$ & Year & Mix Code & District & $\begin{array}{l}\text { Quality } \\
\text { Program }\end{array}$ & $\begin{array}{c}\text { MW } \\
\text { P-Value }\end{array}$ & $\begin{array}{l}\text { Levene's } \\
\text { P-Value }\end{array}$ & $\begin{array}{l}\text { Contractor } \\
\text { SW P-Value }\end{array}$ & $\begin{array}{c}\text { Agency SW } \\
\text { P-Value }\end{array}$ & $\begin{array}{c}\text { Contractor } \\
\text { Mean }\end{array}$ & $\begin{array}{c}\text { Agency } \\
\text { Mean }\end{array}$ & $\begin{array}{c}\text { Contractor } \\
\text { St. Dev. }\end{array}$ & $\begin{array}{l}\text { Agency } \\
\text { St. Dev. }\end{array}$ \\
\hline 484 & 2015 & 19536R & 1 & $\mathrm{QCP}$ & & & 0.00 & & 3.6 & & 0.35 & \\
\hline 485 & 2015 & 19536R & 1 & $\mathrm{QCP}$ & 0.67 & 0.69 & & & 3.8 & 3.2 & 0.71 & 0.42 \\
\hline 486 & 2016 & $19512 R$ & 1 & QCP & 0.71 & 0.30 & 0.03 & 0.38 & 3.5 & 3.5 & 0.46 & 0.64 \\
\hline 487 & 2016 & 19514R & 3 & QCP & 0.20 & 0.37 & 0.36 & & 3.5 & 4.1 & 0.26 & 0.07 \\
\hline 488 & 2015 & 19534R & 3 & PFP & & & & 0.79 & & 4.6 & & 1.01 \\
\hline 489 & 2015 & 19534R & 3 & PFP & & & & 0.87 & & 4.1 & & 0.50 \\
\hline 490 & 2017 & $19524 R$ & 1 & QCP & 0.01 & 0.82 & 0.05 & 0.86 & 4.0 & 5.4 & 0.50 & 0.53 \\
\hline 491 & 2016 & $19512 R$ & 1 & QCP & 0.01 & 0.63 & 0.82 & 0.73 & 3.8 & 4.8 & 0.68 & 0.55 \\
\hline 492 & 2017 & 19534R & 3 & PFP & & & & 0.53 & & 4.2 & & 0.58 \\
\hline 493 & 2017 & $19532 R$ & 3 & PFP & 0.34 & & & 0.22 & 3.6 & 4.0 & 0.00 & 0.43 \\
\hline 494 & 2017 & 19510R & 1 & QCP & 0.14 & 0.26 & 0.52 & 0.78 & 3.7 & 4.3 & 0.66 & 0.25 \\
\hline 495 & 2017 & 19654R & 3 & QCP & 0.54 & 0.25 & 0.03 & 0.40 & 3.3 & 3.3 & 0.70 & 0.41 \\
\hline 496 & 2017 & 19510R & 4 & PFP & 0.68 & 0.53 & 0.32 & 0.26 & 3.7 & 3.6 & 0.46 & 0.54 \\
\hline 497 & 2015 & 19515R & 4 & $\mathrm{QCP}$ & 1.00 & & 0.79 & & 3.8 & 3.9 & 1.02 & 0.00 \\
\hline 498 & 2016 & 19515R & 4 & QCP & & & 0.16 & & 4.0 & & 1.12 & \\
\hline 499 & 2016 & $19522 \mathrm{R}$ & 4 & PFP & & & & & 4.7 & & 0.21 & \\
\hline 500 & 2016 & 19522R & 4 & PFP & 0.12 & 0.53 & 0.00 & 0.14 & 4.4 & 4.1 & 0.75 & 0.81 \\
\hline 501 & 2016 & 19532R & 3 & PFP & 0.67 & 0.64 & 0.25 & 0.30 & 4.1 & 4.2 & 0.47 & 0.43 \\
\hline 502 & 2015 & 19653R & 4 & PFP & & & & 0.18 & & 4.7 & & 0.91 \\
\hline 503 & 2016 & 19654R & 4 & PFP & & & 0.17 & & 4.2 & & 0.52 & \\
\hline 504 & 2017 & 19654R & 4 & PFP & 0.18 & 0.89 & 0.04 & 0.08 & 3.9 & 4.2 & 0.93 & 0.96 \\
\hline 505 & 2016 & 19654R & 4 & PFP & 0.08 & 0.01 & 0.46 & 0.27 & 4.1 & 3.8 & 0.36 & 0.65 \\
\hline 506 & 2017 & 19510R & 4 & QCP & & & & & 2.4 & & 0.00 & \\
\hline 507 & 2015 & 19515R & 4 & QCP & & & & & 5.6 & & 3.32 & \\
\hline 508 & 2016 & $19524 \mathrm{R}$ & 4 & PFP & 0.10 & 0.34 & 0.01 & 0.99 & 4.4 & 4.0 & 0.50 & 0.68 \\
\hline 509 & 2016 & 19525R & 4 & PFP & & & & & 4.5 & & 0.00 & \\
\hline 510 & 2015 & 19525R & 4 & PFP & 0.02 & 0.17 & 0.55 & 0.75 & 4.8 & 4.0 & 0.56 & 0.88 \\
\hline 511 & 2015 & 19535R & 3 & PFP & & & & 0.07 & & 4.2 & & 0.55 \\
\hline 512 & 2016 & 19510R & 4 & PFP & 0.50 & 0.51 & 0.54 & 0.84 & 3.9 & 3.8 & 0.69 & 0.87 \\
\hline 513 & 2016 & 19510R & 4 & PFP & 0.43 & 0.71 & 0.93 & 0.63 & 3.8 & 3.6 & 0.45 & 0.38 \\
\hline 514 & 2017 & 19510R & 4 & QCP & 0.06 & 0.68 & 0.33 & 0.11 & 3.3 & 2.8 & 0.41 & 0.46 \\
\hline 515 & 2017 & 19515R & 4 & $\mathrm{QCP}$ & 1.00 & & & & 4.2 & 4.4 & 0.00 & 0.00 \\
\hline 516 & 2017 & $19514 \mathrm{R}$ & 4 & PFP & & & 0.64 & & 3.8 & & 0.70 & \\
\hline 517 & 2015 & 19515R & 4 & QCP & & & & & 4.2 & & 0.35 & \\
\hline 518 & 2015 & 19524R & 4 & PFP & 0.01 & 0.56 & 0.10 & 0.38 & 5.1 & 4.4 & 0.45 & 0.56 \\
\hline
\end{tabular}




\begin{tabular}{|c|c|c|c|c|c|c|c|c|c|c|c|c|}
\hline $\begin{array}{c}\text { ICT } \\
\text { Code }\end{array}$ & Year & Mix Code & District & $\begin{array}{l}\text { Quality } \\
\text { Program }\end{array}$ & $\begin{array}{c}\text { MW } \\
\text { P-Value }\end{array}$ & $\begin{array}{c}\text { Levene's } \\
\text { P-Value }\end{array}$ & $\begin{array}{l}\text { Contractor } \\
\text { SW P-Value }\end{array}$ & $\begin{array}{c}\text { Agency SW } \\
\text { P-Value }\end{array}$ & $\begin{array}{c}\text { Contractor } \\
\text { Mean }\end{array}$ & $\begin{array}{l}\text { Agency } \\
\text { Mean }\end{array}$ & $\begin{array}{c}\text { Contractor } \\
\text { St. Dev. }\end{array}$ & $\begin{array}{l}\text { Agency } \\
\text { St. Dev. }\end{array}$ \\
\hline 519 & 2016 & $19512 R$ & 4 & PFP & & & & & 4.2 & & 0.00 & \\
\hline 520 & 2017 & $19522 R$ & 4 & QCP & & & 0.41 & & 3.6 & & 0.25 & \\
\hline 521 & 2015 & 19524R & 4 & PFP & 0.00 & 0.23 & 0.66 & 0.28 & 5.2 & 3.9 & 0.28 & 0.52 \\
\hline 522 & 2016 & $19512 R$ & 4 & PFP & & & & & 3.9 & & 0.00 & \\
\hline 523 & 2015 & 19514R & 4 & QCP & & & 0.06 & & 5.2 & & 0.74 & \\
\hline 524 & 2016 & $19514 R$ & 4 & PFP & 0.84 & 0.62 & 0.82 & 0.38 & 4.1 & 4.0 & 0.79 & 0.66 \\
\hline 525 & 2015 & $19514 R$ & 4 & PFP & 0.02 & 0.75 & 0.09 & 0.09 & 5.2 & 3.9 & 0.65 & 0.82 \\
\hline 526 & 2015 & $19524 R$ & 5 & QCP & 0.14 & 0.61 & 0.92 & & 4.1 & 3.5 & 0.43 & 0.49 \\
\hline 527 & 2015 & 19514R & 5 & QCP & 0.80 & & 0.01 & & 4.0 & 3.8 & 0.34 & 0.00 \\
\hline 528 & 2016 & 19514R & 5 & QCP & & & 0.22 & & 4.6 & & 0.44 & \\
\hline 529 & 2015 & $19514 R$ & 5 & QCP & 0.84 & 0.00 & 0.09 & & 4.4 & 4.5 & 0.49 & 0.00 \\
\hline 530 & 2016 & $19514 R$ & 5 & QCP & & & 0.00 & & 4.4 & & 0.29 & \\
\hline 531 & 2016 & $19524 R$ & 5 & QCP & & & 0.33 & & 4.4 & & 0.44 & \\
\hline 532 & 2017 & 19605FR & 5 & QCP & 0.06 & 0.79 & 0.41 & 0.07 & 4.1 & 3.4 & 0.62 & 0.66 \\
\hline 533 & 2015 & $19605 F R$ & 5 & QCP & 0.45 & 0.76 & 0.94 & 0.00 & 3.9 & 3.5 & 0.64 & 0.73 \\
\hline 534 & 2015 & $19524 \mathrm{R}$ & 5 & QCP & 0.34 & 0.50 & 0.36 & 1.00 & 4.2 & 4.5 & 0.55 & 0.30 \\
\hline 535 & 2016 & $19514 R$ & 5 & QCP & 0.29 & & 0.11 & & 4.5 & 3.5 & 0.55 & 0.00 \\
\hline 536 & 2017 & 19524R & 5 & QCP & 0.90 & 0.08 & 0.33 & & 4.4 & 4.5 & 0.52 & 1.20 \\
\hline 537 & 2015 & 19534R & 5 & $\mathrm{QCP}$ & 0.29 & & 0.42 & & 3.5 & 4.7 & 0.24 & 0.00 \\
\hline 538 & 2015 & $19534 R$ & 5 & PFP & 0.28 & 0.68 & 0.12 & 0.69 & 3.9 & 4.3 & 0.46 & 0.53 \\
\hline 539 & 2017 & 19535R & 5 & QCP & 0.15 & 0.21 & 0.00 & & 4.0 & 5.1 & 0.52 & 0.07 \\
\hline 540 & 2017 & $19512 \mathrm{R}$ & 6 & QCP & & & & & 4.3 & & 0.00 & \\
\hline 541 & 2017 & 19513R & 5 & QCP & & & & & & 4.3 & & 0.78 \\
\hline 542 & 2017 & 19532R & 5 & PFP & & & & 0.30 & & 3.8 & & 0.32 \\
\hline 543 & 2016 & 19534R & 5 & QCP & & & & & & 3.0 & & 0.00 \\
\hline 544 & 2017 & 19534R & 5 & PFP & & & & 0.76 & & 4.6 & & 1.16 \\
\hline 545 & 2017 & 19523R & 5 & QCP & 0.91 & 0.42 & 0.65 & 0.00 & 3.8 & 3.9 & 0.63 & 0.87 \\
\hline 546 & 2015 & 19534R & 5 & PFP & 0.13 & 0.34 & 0.82 & 0.68 & 4.1 & 4.5 & 0.34 & 0.50 \\
\hline 547 & 2016 & 19513R & 5 & QCP & 0.22 & & 0.85 & & 4.0 & 5.1 & 0.61 & 0.00 \\
\hline 548 & 2016 & 19514R & 5 & QCP & & & 0.14 & & 4.0 & & 0.55 & \\
\hline 549 & 2015 & 19532R & 5 & PFP & 0.85 & 0.36 & 0.76 & 0.35 & 4.1 & 4.1 & 0.41 & 0.56 \\
\hline 550 & 2015 & 19535R & 5 & PFP & 0.24 & 0.78 & 0.43 & & 3.2 & 4.0 & 0.68 & 0.35 \\
\hline 551 & 2015 & 19523R & 5 & QCP & 0.36 & 0.29 & 0.24 & 0.13 & 3.8 & 3.3 & 0.55 & 0.77 \\
\hline 552 & 2015 & 19505R & 5 & QCP & & & 0.63 & & 4.2 & & 0.64 & \\
\hline 553 & 2015 & 19534R & 5 & PFP & 0.15 & 0.92 & 0.39 & 0.36 & 3.8 & 4.4 & 0.66 & 0.53 \\
\hline
\end{tabular}




\begin{tabular}{|c|c|c|c|c|c|c|c|c|c|c|c|c|}
\hline $\begin{array}{l}\text { ICT } \\
\text { Code }\end{array}$ & Year & Mix Code & District & $\begin{array}{l}\text { Quality } \\
\text { Program }\end{array}$ & $\begin{array}{c}\text { MW } \\
\text { P-Value }\end{array}$ & $\begin{array}{l}\text { Levene's } \\
\text { P-Value }\end{array}$ & $\begin{array}{l}\text { Contractor } \\
\text { SW P-Value }\end{array}$ & $\begin{array}{c}\text { Agency SW } \\
\text { P-Value }\end{array}$ & $\begin{array}{c}\text { Contractor } \\
\text { Mean }\end{array}$ & $\begin{array}{l}\text { Agency } \\
\text { Mean }\end{array}$ & $\begin{array}{c}\text { Contractor } \\
\text { St. Dev. }\end{array}$ & $\begin{array}{l}\text { Agency } \\
\text { St. Dev. }\end{array}$ \\
\hline 554 & 2017 & 19534R & 5 & PFP & 0.34 & 0.15 & 0.21 & 0.34 & 4.0 & 4.3 & 0.30 & 0.47 \\
\hline 555 & 2016 & 19513R & 5 & QCP & & & & & 4.8 & & 0.00 & \\
\hline 556 & 2016 & 19513R & 5 & QCP & 1.00 & & & & 4.8 & 4.8 & 0.21 & 0.00 \\
\hline 557 & 2015 & $19532 R$ & 5 & PFP & 0.91 & 0.58 & 0.65 & 0.73 & 4.3 & 4.3 & 0.43 & 0.29 \\
\hline 558 & 2016 & $19532 R$ & 5 & PFP & 0.52 & 0.96 & 0.40 & 0.73 & 4.1 & 4.0 & 0.38 & 0.35 \\
\hline 559 & 2016 & 19535R & 5 & PFP & 0.31 & 0.33 & 0.76 & 0.33 & 3.8 & 4.1 & 0.41 & 0.59 \\
\hline 560 & 2017 & 19535R & 5 & QCP & & & 1.00 & & 4.0 & & 0.10 & \\
\hline 561 & 2015 & 19524R & 5 & QCP & 0.80 & & 0.75 & & 3.8 & 4.0 & 0.55 & 0.00 \\
\hline 562 & 2015 & $19524 R$ & 5 & QCP & 0.66 & 0.31 & 0.68 & & 3.8 & 4.0 & 0.57 & 0.85 \\
\hline 563 & 2017 & 19532R & 5 & PFP & 0.00 & 0.97 & 0.00 & 0.89 & 4.2 & 3.6 & 0.37 & 0.35 \\
\hline 564 & 2015 & 19523R & 6 & QCP & 0.64 & 0.26 & 0.17 & 0.95 & 3.7 & 3.7 & 0.52 & 0.36 \\
\hline 565 & 2015 & $19513 R$ & 6 & QCP & 0.05 & 0.73 & 0.51 & 0.74 & 3.6 & 4.5 & 0.69 & 0.74 \\
\hline 566 & 2016 & $19524 \mathrm{R}$ & 6 & PFP & 0.12 & & & 0.14 & 3.0 & 4.2 & 0.00 & 0.63 \\
\hline 567 & 2016 & 19513R & 6 & PFP & & & & & & 3.9 & & 0.00 \\
\hline 568 & 2015 & 19513R & 6 & QCP & 0.10 & 0.80 & 0.04 & 0.22 & 3.9 & 3.5 & 0.44 & 0.44 \\
\hline 569 & 2015 & $19522 \mathrm{R}$ & 6 & PFP & 0.18 & 0.93 & 0.05 & 0.26 & 5.0 & 4.3 & 0.90 & 0.94 \\
\hline 570 & 2015 & $19522 R$ & 6 & PFP & 0.01 & 0.04 & 0.02 & 0.99 & 4.0 & 4.5 & 0.68 & 0.95 \\
\hline 571 & 2015 & 19513R & 6 & QCP & 0.25 & 0.83 & 0.10 & 0.85 & 4.0 & 4.3 & 0.48 & 0.41 \\
\hline 572 & 2015 & 19513R & 6 & QCP & 0.33 & 0.65 & 0.16 & 0.39 & 4.3 & 4.6 & 0.68 & 0.74 \\
\hline 573 & 2015 & 19523R & 6 & PFP & 0.47 & 0.80 & 0.00 & 0.87 & 4.9 & 4.4 & 1.08 & 1.18 \\
\hline 574 & 2015 & 19513R & 6 & QCP & 0.00 & 0.86 & 0.57 & 0.12 & 4.0 & 4.6 & 0.44 & 0.39 \\
\hline 575 & 2015 & 19523R & 6 & QCP & 0.06 & 0.92 & 0.99 & 0.09 & 3.6 & 4.2 & 0.70 & 0.68 \\
\hline 576 & 2015 & 19523R & 6 & QCP & & & 0.41 & & 4.3 & & 0.39 & \\
\hline 577 & 2017 & 19523R & 8 & QCP & 0.05 & 0.19 & 0.50 & 0.54 & 3.9 & 4.6 & 0.38 & 0.62 \\
\hline 578 & 2015 & 19534R & 6 & PFP & 0.03 & 0.43 & 0.27 & 0.81 & 3.9 & 4.3 & 0.60 & 0.72 \\
\hline 579 & 2016 & 19534R & 6 & PFP & 0.78 & 0.28 & 0.35 & 0.57 & 4.6 & 4.6 & 0.29 & 0.59 \\
\hline 580 & 2015 & $19522 R$ & 6 & PFP & 0.00 & 0.03 & 0.06 & 0.22 & 4.7 & 4.1 & 0.45 & 0.68 \\
\hline 581 & 2015 & 19513R & 6 & QCP & 0.14 & 0.79 & 0.49 & 0.34 & 4.2 & 3.9 & 0.42 & 0.35 \\
\hline 582 & 2017 & $19522 \mathrm{R}$ & 6 & QCP & 0.17 & & 0.36 & & 3.5 & 4.1 & 0.25 & 0.00 \\
\hline 583 & 2015 & 19535R & 6 & PFP & 0.64 & 0.87 & 0.07 & 0.32 & 4.3 & 4.5 & 1.03 & 1.00 \\
\hline 584 & 2015 & 19535R & 6 & QCP & 1.00 & & 0.30 & & 3.5 & 3.8 & 0.40 & 0.00 \\
\hline 585 & 2015 & 19535R & 6 & PFP & 0.24 & 0.04 & 0.39 & 0.27 & 4.5 & 4.9 & 0.26 & 0.67 \\
\hline 586 & 2016 & 19514R & 6 & QCP & 0.99 & 0.20 & 0.11 & 0.64 & 4.4 & 4.4 & 0.62 & 1.07 \\
\hline 587 & 2015 & 19513R & 6 & QCP & 0.86 & 0.30 & 0.67 & 0.14 & 3.8 & 3.6 & 0.42 & 0.61 \\
\hline 588 & 2015 & $19522 R$ & 6 & QCP & 0.77 & 0.06 & 0.17 & 0.98 & 4.1 & 4.1 & 0.68 & 1.21 \\
\hline
\end{tabular}




\begin{tabular}{|c|c|c|c|c|c|c|c|c|c|c|c|c|}
\hline $\begin{array}{l}\text { ICT } \\
\text { Code }\end{array}$ & Year & Mix Code & District & $\begin{array}{l}\text { Quality } \\
\text { Program }\end{array}$ & $\begin{array}{c}\text { MW } \\
\text { P-Value }\end{array}$ & $\begin{array}{c}\text { Levene's } \\
\text { P-Value }\end{array}$ & $\begin{array}{l}\text { Contractor } \\
\text { SW P-Value }\end{array}$ & $\begin{array}{c}\text { Agency SW } \\
\text { P-Value }\end{array}$ & $\begin{array}{c}\text { Contractor } \\
\text { Mean }\end{array}$ & $\begin{array}{l}\text { Agency } \\
\text { Mean }\end{array}$ & $\begin{array}{c}\text { Contractor } \\
\text { St. Dev. }\end{array}$ & $\begin{array}{l}\text { Agency } \\
\text { St. Dev. }\end{array}$ \\
\hline 589 & 2016 & $19532 R$ & 6 & PFP & & & & 0.06 & & 4.5 & & 0.67 \\
\hline 590 & 2015 & $19532 R$ & 6 & PFP & 0.32 & 0.29 & 0.77 & 0.69 & 4.1 & 4.0 & 0.44 & 0.53 \\
\hline 591 & 2016 & $19532 R$ & 6 & QCP & 0.29 & & 0.30 & & 3.8 & 3.1 & 0.60 & 0.00 \\
\hline 592 & 2015 & $19524 R$ & 6 & QCP & 0.55 & 0.23 & 0.69 & & 3.9 & 3.7 & 0.48 & 0.07 \\
\hline 593 & 2015 & $19512 R$ & 6 & QCP & 0.24 & 0.10 & 0.98 & 0.11 & 4.1 & 4.4 & 0.37 & 0.57 \\
\hline 594 & 2015 & 19535R & 6 & PFP & 0.68 & 0.03 & 0.47 & 0.12 & 4.1 & 4.1 & 0.46 & 0.73 \\
\hline 595 & 2017 & 19535R & 6 & PFP & 0.05 & 0.63 & 0.54 & 0.15 & 3.3 & 3.7 & 0.37 & 0.43 \\
\hline 596 & 2016 & 19535R & 6 & QCP & 1.00 & & 0.95 & & 4.1 & 4.1 & 0.68 & 0.00 \\
\hline 597 & 2017 & 19513R & 6 & QCP & 0.37 & 0.90 & 0.86 & 0.88 & 4.0 & 4.3 & 0.57 & 0.45 \\
\hline 598 & 2017 & 19513R & 6 & QCP & 0.27 & 0.77 & 0.20 & 0.05 & 4.2 & 4.0 & 0.36 & 0.29 \\
\hline 599 & 2017 & $19513 R$ & 6 & QCP & 0.84 & 0.85 & 0.23 & & 4.6 & 4.8 & 0.59 & 0.49 \\
\hline 600 & 2016 & $19513 R$ & 6 & $\mathrm{QCP}$ & & & & & 5.5 & & 0.00 & \\
\hline 601 & 2016 & $19513 R$ & 6 & PFP & & & & & & 4.1 & & 0.21 \\
\hline 602 & 2016 & $19513 R$ & 6 & QCP & 0.00 & 0.88 & 0.00 & 0.20 & 3.7 & 4.5 & 0.70 & 0.67 \\
\hline 603 & 2016 & $19513 R$ & 6 & QCP & 0.12 & 0.23 & 0.06 & 0.41 & 4.0 & 4.6 & 0.55 & 0.25 \\
\hline 604 & 2016 & $19514 R$ & 6 & QCP & 1.00 & & 0.64 & & 4.6 & 4.6 & 0.15 & 0.00 \\
\hline 605 & 2015 & $19512 \mathrm{R}$ & 6 & QCP & 0.52 & 0.56 & 0.41 & 0.62 & 3.5 & 3.9 & 0.59 & 0.69 \\
\hline 606 & 2016 & $19524 R$ & 6 & $\mathrm{QCP}$ & 0.32 & 0.99 & 0.42 & 0.09 & 3.9 & 4.3 & 0.76 & 0.70 \\
\hline 607 & 2015 & $19513 R$ & 6 & $\mathrm{QCP}$ & 1.00 & & 0.02 & & 4.0 & 3.6 & 0.84 & 0.00 \\
\hline 608 & 2017 & $19513 R$ & 6 & QCP & 0.18 & 0.94 & 0.07 & 0.54 & 4.3 & 4.5 & 0.40 & 0.36 \\
\hline 609 & 2016 & 19513R & 6 & QCP & 0.00 & 0.68 & 0.79 & 0.04 & 3.8 & 4.7 & 0.56 & 0.61 \\
\hline 610 & 2017 & $19513 R$ & 6 & QCP & 0.02 & 0.15 & 0.10 & 0.04 & 3.7 & 4.7 & 0.54 & 0.83 \\
\hline 611 & 2016 & $19513 R$ & 6 & QCP & 0.49 & 0.24 & 0.51 & & 3.9 & 4.4 & 0.52 & 0.92 \\
\hline 612 & 2017 & $19532 R$ & 6 & PFP & 0.00 & 0.08 & 0.51 & 0.28 & 3.8 & 4.2 & 0.29 & 0.44 \\
\hline 613 & 2016 & $19524 R$ & 6 & PFP & 0.02 & 0.06 & 0.65 & 0.82 & 4.7 & 4.1 & 0.42 & 0.72 \\
\hline 614 & 2016 & 19513R & 6 & QCP & 0.10 & 0.40 & 0.50 & 0.87 & 4.2 & 4.9 & 0.82 & 0.52 \\
\hline 615 & 2016 & $19514 R$ & 6 & QCP & 0.01 & 0.88 & 0.58 & 0.01 & 3.7 & 4.4 & 0.49 & 0.45 \\
\hline 616 & 2016 & 19534R & 7 & PFP & 0.45 & 0.01 & 0.73 & 0.73 & 4.6 & 4.5 & 0.28 & 0.78 \\
\hline 617 & 2016 & $19524 R$ & 6 & QCP & 0.26 & 0.93 & 0.58 & 0.37 & 3.9 & 4.1 & 0.54 & 0.50 \\
\hline 618 & 2016 & $19532 R$ & 6 & PFP & 0.24 & 0.14 & 0.14 & 0.21 & 3.6 & 3.8 & 0.48 & 0.65 \\
\hline 619 & 2016 & $19523 R$ & 6 & $\mathrm{QCP}$ & 0.29 & & 0.71 & & 3.5 & 4.1 & 0.39 & 0.00 \\
\hline 620 & 2016 & $19524 R$ & 6 & QCP & 0.37 & 0.42 & 0.65 & 0.11 & 3.9 & 4.6 & 1.05 & 1.38 \\
\hline 621 & 2016 & 19534R & 6 & PFP & 0.76 & 0.13 & 0.66 & 0.08 & 3.6 & 3.6 & 0.42 & 0.63 \\
\hline 622 & 2016 & 19513R & 6 & QCP & 0.80 & 0.34 & 0.57 & 0.13 & 4.3 & 4.3 & 0.50 & 0.72 \\
\hline 623 & 2016 & $19512 \mathrm{R}$ & 6 & QCP & 0.75 & 0.30 & 0.43 & 0.19 & 4.1 & 4.0 & 0.51 & 0.32 \\
\hline
\end{tabular}




\begin{tabular}{|c|c|c|c|c|c|c|c|c|c|c|c|c|}
\hline $\begin{array}{l}\text { ICT } \\
\text { Code }\end{array}$ & Year & Mix Code & District & $\begin{array}{l}\text { Quality } \\
\text { Program }\end{array}$ & $\begin{array}{c}\text { MW } \\
\text { P-Value }\end{array}$ & $\begin{array}{l}\text { Levene's } \\
\text { P-Value }\end{array}$ & $\begin{array}{l}\text { Contractor } \\
\text { SW P-Value }\end{array}$ & $\begin{array}{c}\text { Agency SW } \\
\text { P-Value }\end{array}$ & $\begin{array}{c}\text { Contractor } \\
\text { Mean }\end{array}$ & $\begin{array}{l}\text { Agency } \\
\text { Mean }\end{array}$ & $\begin{array}{c}\text { Contractor } \\
\text { St. Dev. }\end{array}$ & $\begin{array}{l}\text { Agency } \\
\text { St. Dev. }\end{array}$ \\
\hline 624 & 2017 & $19514 R$ & 6 & $\mathrm{QCP}$ & 0.21 & 0.11 & 0.25 & 0.02 & 4.3 & 5.0 & 0.84 & 0.29 \\
\hline 625 & 2017 & $19522 R$ & 6 & PFP & & & & & 3.6 & & 0.00 & \\
\hline 626 & 2017 & 19514R & 6 & QCP & 1.00 & 0.08 & 0.01 & 0.02 & 4.6 & 4.2 & 0.60 & 1.15 \\
\hline 627 & 2017 & $19513 R$ & 6 & QCP & 0.11 & 0.02 & 0.06 & 0.00 & 3.7 & 4.0 & 0.52 & 0.06 \\
\hline 628 & 2015 & 19524 & 7 & PFP & 0.93 & 0.17 & 0.10 & 0.94 & 4.2 & 4.6 & 0.79 & 1.68 \\
\hline 629 & 2016 & 19532R & 7 & QCP & 1.00 & & 0.46 & & 4.1 & 4.0 & 0.42 & 0.00 \\
\hline 630 & 2015 & $19532 R$ & 7 & PFP & & & 0.76 & & 3.7 & & 0.74 & \\
\hline 631 & 2016 & $19523 R$ & 7 & QCP & 0.70 & 0.70 & 0.32 & 0.58 & 4.5 & 4.8 & 0.91 & 0.67 \\
\hline 632 & 2016 & $19532 R$ & 7 & QCP & 0.14 & 0.52 & 0.06 & & 3.6 & 3.9 & 0.22 & 0.28 \\
\hline 633 & 2017 & $19532 R$ & 7 & PFP & 0.56 & 0.18 & 0.28 & 0.90 & 4.6 & 4.3 & 0.90 & 0.48 \\
\hline 634 & 2017 & $19524 R$ & 7 & PFP & & & & & & 5.1 & & 0.00 \\
\hline 635 & 2016 & 19523 & 7 & QCP & 0.95 & 0.55 & 0.80 & & 3.8 & 3.6 & 0.67 & 0.85 \\
\hline 636 & 2017 & 19523 & 7 & QCP & & & & & & 4.6 & & 0.00 \\
\hline 637 & 2016 & 19523 & 7 & QCP & 0.67 & 0.08 & & & 4.9 & 4.1 & 0.07 & 1.06 \\
\hline 638 & 2017 & 19523 & 7 & QCP & 1.00 & & 0.16 & & 4.4 & 4.6 & 0.62 & 0.00 \\
\hline 639 & 2017 & $19534 R$ & 7 & QCP & & & & 0.99 & & 4.0 & & 0.89 \\
\hline 640 & 2016 & 19534R & 7 & PFP & & & & 0.02 & & 4.1 & & 0.78 \\
\hline 641 & 2016 & 19534R & 7 & QCP & 0.01 & 0.70 & 0.40 & 0.20 & 3.5 & 4.3 & 0.46 & 0.51 \\
\hline 642 & 2016 & $19524 R$ & 7 & QCP & 0.45 & 0.77 & 0.28 & 0.01 & 3.1 & 3.5 & 1.22 & 1.09 \\
\hline 643 & 2016 & $19523 R$ & 7 & QCP & 0.93 & 0.12 & 0.98 & & 3.7 & 3.7 & 0.32 & 0.78 \\
\hline 644 & 2015 & 19534R & 7 & PFP & & & & & & 4.0 & & 0.00 \\
\hline 645 & 2015 & $19534 R$ & 7 & PFP & & & & 1.00 & & 4.1 & & 0.91 \\
\hline 646 & 2016 & 19534R & 7 & QCP & & & & & 3.9 & & 0.35 & \\
\hline 647 & 2015 & $19534 R$ & 7 & QCP & 1.00 & 0.79 & & 0.74 & 3.1 & 3.1 & 0.71 & 1.22 \\
\hline 648 & 2016 & 19523R & 9 & QCP & 0.00 & 0.24 & 0.11 & 0.19 & 4.2 & 3.4 & 0.57 & 0.33 \\
\hline 649 & 2016 & 19605FR & 9 & QCP & 0.05 & 0.01 & 0.50 & 0.01 & 4.0 & 3.5 & 0.48 & 0.11 \\
\hline 650 & 2015 & $19534 R$ & 7 & PFP & 0.94 & 0.89 & 0.84 & 0.14 & 3.5 & 3.5 & 0.49 & 0.52 \\
\hline 651 & 2015 & 19523R & 7 & PFP & 0.30 & 0.85 & 0.69 & 0.12 & 3.8 & 4.1 & 0.49 & 0.56 \\
\hline 652 & 2015 & 19523R & 7 & QCP & 0.74 & 0.66 & 0.98 & 0.28 & 4.3 & 3.8 & 1.41 & 1.17 \\
\hline 653 & 2016 & $19524 R$ & 7 & QCP & 0.57 & 0.48 & 0.73 & 0.48 & 4.2 & 4.8 & 0.86 & 1.20 \\
\hline 654 & 2016 & 19534R & 7 & QCP & 1.00 & & & & 3.4 & 3.7 & 0.92 & 0.00 \\
\hline 655 & 2015 & 19534R & 7 & PFP & 0.09 & 0.45 & 0.79 & 0.09 & 4.6 & 4.1 & 0.58 & 0.77 \\
\hline 656 & 2016 & 19654R & 7 & PFP & & & & & & 3.4 & & 0.00 \\
\hline 657 & 2016 & 19654R & 7 & PFP & & & & & & 4.2 & & 0.00 \\
\hline 658 & 2015 & 19654R & 7 & PFP & 0.60 & 0.98 & 0.74 & 0.50 & 3.9 & 4.0 & 0.77 & 0.79 \\
\hline
\end{tabular}




\begin{tabular}{|c|c|c|c|c|c|c|c|c|c|c|c|c|}
\hline $\begin{array}{c}\text { ICT } \\
\text { Code }\end{array}$ & Year & Mix Code & District & $\begin{array}{l}\text { Quality } \\
\text { Program }\end{array}$ & $\begin{array}{c}\text { MW } \\
\text { P-Value }\end{array}$ & $\begin{array}{c}\text { Levene's } \\
\text { P-Value }\end{array}$ & $\begin{array}{l}\text { Contractor } \\
\text { SW P-Value }\end{array}$ & $\begin{array}{c}\text { Agency SW } \\
\text { P-Value }\end{array}$ & $\begin{array}{c}\text { Contractor } \\
\text { Mean }\end{array}$ & $\begin{array}{l}\text { Agency } \\
\text { Mean }\end{array}$ & $\begin{array}{c}\text { Contractor } \\
\text { St. Dev. }\end{array}$ & $\begin{array}{l}\text { Agency } \\
\text { St. Dev. }\end{array}$ \\
\hline 659 & 2016 & 19654R & 7 & PFP & 0.63 & 0.50 & 0.51 & 0.78 & 4.4 & 4.0 & 0.33 & 0.50 \\
\hline 660 & 2016 & 19654R & 7 & PFP & 0.40 & 0.99 & 0.87 & 0.37 & 4.1 & 3.9 & 0.76 & 0.77 \\
\hline 661 & 2017 & 19654R & 7 & PFP & 0.71 & 0.85 & 0.64 & 0.27 & 4.5 & 4.4 & 0.64 & 0.69 \\
\hline 662 & 2016 & $19532 R$ & 7 & PFP & 0.60 & 0.63 & 0.27 & 0.93 & 4.1 & 4.2 & 0.71 & 0.64 \\
\hline 663 & 2017 & $19532 R$ & 7 & PFP & 1.00 & & & & 5.5 & 5.7 & 0.00 & 0.00 \\
\hline 664 & 2017 & 19523R & 7 & QCP & 0.40 & 0.62 & 0.64 & & 4.0 & 4.4 & 0.31 & 0.14 \\
\hline 665 & 2015 & 19505R & 7 & PFP & & & 0.10 & & 3.7 & & 0.32 & \\
\hline 666 & 2015 & $19532 R$ & 7 & PFP & 0.45 & 0.53 & 0.67 & 0.40 & 4.3 & 4.2 & 0.81 & 0.74 \\
\hline 667 & 2016 & $19532 R$ & 7 & PFP & 0.26 & 0.76 & 0.37 & 0.12 & 4.1 & 4.3 & 0.70 & 0.74 \\
\hline 668 & 2015 & $19532 R$ & 7 & PFP & & & & 0.87 & & 4.1 & & 0.69 \\
\hline 669 & 2016 & 19654R & 7 & PFP & 0.60 & 0.75 & 0.93 & 0.98 & 4.0 & 4.1 & 0.71 & 0.76 \\
\hline 670 & 2015 & 19654R & 7 & PFP & 0.97 & 0.51 & 0.02 & 0.54 & 4.0 & 3.9 & 0.59 & 0.74 \\
\hline 671 & 2016 & $19532 R$ & 7 & PFP & 0.99 & 0.64 & 0.04 & 0.42 & 4.1 & 4.2 & 0.76 & 0.84 \\
\hline 672 & 2017 & 19533R & 7 & PFP & 0.63 & 0.90 & 0.74 & 0.98 & 4.1 & 3.9 & 0.66 & 0.65 \\
\hline 673 & 2017 & $19532 R$ & 7 & PFP & 0.75 & 0.91 & 0.06 & 0.43 & 4.1 & 4.3 & 0.88 & 0.88 \\
\hline 674 & 2017 & $19532 R$ & 7 & PFP & 0.59 & 0.80 & 0.50 & 0.25 & 4.4 & 4.5 & 0.62 & 0.70 \\
\hline 675 & 2017 & $19532 R$ & 7 & PFP & & & & & & 3.9 & & 0.00 \\
\hline 676 & 2017 & 19532R & 7 & PFP & 0.78 & 0.07 & 0.33 & 0.67 & 4.3 & 4.0 & 0.88 & 0.31 \\
\hline 677 & 2016 & $19523 R$ & 8 & $\mathrm{QCP}$ & & & & & & 4.3 & & 0.00 \\
\hline 678 & 2016 & $19523 R$ & 8 & QCP & 0.67 & 0.75 & & & 4.0 & 3.7 & 0.57 & 0.85 \\
\hline 679 & 2016 & 19523R & 8 & QCP & 0.40 & & 0.80 & & 4.1 & 3.3 & 0.40 & 0.00 \\
\hline 680 & 2016 & 19523R & 8 & QCP & 0.05 & 0.73 & 0.93 & 0.39 & 4.2 & 5.1 & 0.84 & 0.90 \\
\hline 681 & 2016 & 19534R & 8 & QCP & 0.01 & 0.18 & 0.06 & 0.30 & 4.1 & 3.3 & 0.65 & 0.32 \\
\hline 682 & 2015 & 19534R & 8 & QCP & 0.14 & & 0.31 & & 4.0 & 3.6 & 0.35 & 0.00 \\
\hline 683 & 2015 & 19534R & 8 & QCP & 0.11 & 0.09 & 0.05 & 0.98 & 4.2 & 3.8 & 0.35 & 0.58 \\
\hline 684 & 2015 & 19534R & 8 & QCP & 0.53 & 0.29 & 0.11 & 0.26 & 4.3 & 4.4 & 0.59 & 0.83 \\
\hline 685 & 2015 & 19524R & 8 & QCP & 0.58 & 0.58 & 0.74 & 0.42 & 4.1 & 4.2 & 0.47 & 0.34 \\
\hline 686 & 2017 & 19524R & 8 & QCP & 0.63 & 0.76 & 0.18 & 0.06 & 4.3 & 4.4 & 1.02 & 1.14 \\
\hline 687 & 2015 & 19535R & 8 & QCP & 0.05 & 0.13 & 0.03 & 0.28 & 4.8 & 4.2 & 0.70 & 0.97 \\
\hline 688 & 2017 & 19505R & 8 & QCP & 0.43 & 0.59 & 0.01 & 0.21 & 4.5 & 4.3 & 0.84 & 1.04 \\
\hline 689 & 2015 & 19505R & 8 & QCP & 0.53 & 0.11 & 0.51 & & 3.3 & 3.2 & 0.94 & 0.07 \\
\hline 690 & 2015 & 19606R & 8 & QCP & 0.29 & 0.57 & 0.21 & & 4.4 & 3.9 & 0.51 & 0.57 \\
\hline 691 & 2015 & 19654R & 8 & PFP & 0.29 & 0.38 & 0.11 & 0.66 & 4.1 & 3.8 & 0.93 & 0.80 \\
\hline 692 & 2015 & 19654R & 8 & PFP & 0.32 & 0.90 & 0.28 & 0.86 & 4.6 & 4.3 & 0.90 & 0.93 \\
\hline 693 & 2015 & 19534R & 8 & QCP & 0.25 & 0.10 & 0.45 & 0.46 & 3.7 & 4.6 & 0.93 & 0.21 \\
\hline
\end{tabular}




\begin{tabular}{|c|c|c|c|c|c|c|c|c|c|c|c|c|}
\hline $\begin{array}{c}\text { ICT } \\
\text { Code }\end{array}$ & Year & Mix Code & District & $\begin{array}{l}\text { Quality } \\
\text { Program }\end{array}$ & $\begin{array}{c}\text { MW } \\
\text { P-Value }\end{array}$ & $\begin{array}{c}\text { Levene's } \\
\text { P-Value }\end{array}$ & $\begin{array}{l}\text { Contractor } \\
\text { SW P-Value }\end{array}$ & $\begin{array}{c}\text { Agency SW } \\
\text { P-Value }\end{array}$ & $\begin{array}{c}\text { Contractor } \\
\text { Mean }\end{array}$ & $\begin{array}{l}\text { Agency } \\
\text { Mean }\end{array}$ & $\begin{array}{c}\text { Contractor } \\
\text { St. Dev. }\end{array}$ & $\begin{array}{l}\text { Agency } \\
\text { St. Dev. }\end{array}$ \\
\hline 694 & 2015 & 19654R & 8 & PFP & 0.08 & 0.24 & 0.88 & 0.41 & 4.0 & 3.5 & 0.97 & 0.72 \\
\hline 695 & 2015 & $19654 \mathrm{R}$ & 8 & PFP & 0.02 & 0.65 & 0.43 & 0.66 & 4.1 & 3.7 & 0.69 & 0.63 \\
\hline 696 & 2015 & $19654 \mathrm{R}$ & 8 & PFP & 0.13 & 0.47 & 0.37 & 0.28 & 4.0 & 3.6 & 0.69 & 0.79 \\
\hline 697 & 2015 & $19535 R$ & 8 & QCP & 0.83 & 0.80 & 0.81 & 0.88 & 4.0 & 3.9 & 0.51 & 0.41 \\
\hline 698 & 2015 & $19601 R$ & 8 & QCP & & & & & 1.7 & & 0.00 & \\
\hline 699 & 2016 & $19523 R$ & 8 & QCP & 0.02 & 0.17 & 0.42 & 0.00 & 4.6 & 3.7 & 0.57 & 0.17 \\
\hline 700 & 2016 & 19523R & 8 & QCP & & & & & & 2.9 & & 0.21 \\
\hline 701 & 2016 & $19532 R$ & 8 & PFP & 1.00 & 0.80 & 0.67 & 0.24 & 3.3 & 3.3 & 0.52 & 0.56 \\
\hline 702 & 2016 & $19524 R$ & 8 & QCP & 0.51 & 0.72 & 0.06 & 0.86 & 3.4 & 3.2 & 0.42 & 0.46 \\
\hline 703 & 2017 & 19524R & 8 & QCP & 0.67 & & & & 3.5 & 3.1 & 0.42 & 0.00 \\
\hline 704 & 2016 & 19524R & 8 & QCP & & & 0.33 & & 3.5 & & 0.59 & \\
\hline 705 & 2016 & 19524R & 8 & QCP & 1.00 & & & & 5.2 & 5.2 & 0.00 & 0.00 \\
\hline 706 & 2016 & $19524 \mathrm{R}$ & 8 & QCP & 0.67 & & & & 3.8 & 4.0 & 0.14 & 0.00 \\
\hline 707 & 2016 & 19533R & 8 & QCP & 0.52 & 0.03 & 0.00 & 0.09 & 4.1 & 3.9 & 0.44 & 1.01 \\
\hline 708 & 2016 & 19534R & 8 & PFP & 0.94 & 0.77 & 0.46 & 0.75 & 4.0 & 3.9 & 1.02 & 0.93 \\
\hline 709 & 2016 & 19534R & 8 & QCP & 0.31 & 0.18 & 0.11 & 0.01 & 4.0 & 4.2 & 0.73 & 1.20 \\
\hline 710 & 2016 & $19504 \mathrm{R}$ & 8 & QCP & 0.80 & 0.49 & 0.88 & & 3.9 & 4.1 & 0.82 & 0.28 \\
\hline 711 & 2016 & 19523R & 8 & QCP & 1.00 & 0.73 & 0.64 & & 3.6 & 3.6 & 0.31 & 0.35 \\
\hline 712 & 2016 & 19605R & 8 & QCP & 0.67 & & & & 4.4 & 3.6 & 0.64 & 0.00 \\
\hline 713 & 2016 & 19534R & 8 & QCP & 0.06 & 0.50 & 0.82 & & 4.2 & 3.0 & 0.58 & 0.71 \\
\hline 714 & 2017 & 19654R & 8 & PFP & & & & & & 2.2 & & 0.00 \\
\hline 715 & 2017 & 19654R & 8 & PFP & 0.12 & 0.07 & 0.15 & 0.65 & 4.3 & 4.1 & 0.68 & 0.86 \\
\hline 716 & 2017 & $19523 R$ & 8 & QCP & 0.54 & 0.35 & 0.32 & 0.92 & 3.9 & 3.7 & 0.59 & 0.82 \\
\hline 717 & 2017 & $19523 R$ & 8 & QCP & 0.62 & 0.93 & 0.01 & 0.48 & 4.7 & 4.6 & 0.86 & 0.83 \\
\hline 718 & 2017 & 19524R & 8 & QCP & 0.50 & & 0.85 & & 5.0 & 4.5 & 0.37 & 0.00 \\
\hline 719 & 2017 & 19524R & 8 & QCP & 0.93 & 0.58 & 0.03 & & 4.7 & 4.6 & 0.55 & 0.21 \\
\hline 720 & 2017 & $19605 R$ & 8 & QCP & 0.93 & 0.56 & 0.58 & & 3.9 & 3.9 & 0.43 & 0.57 \\
\hline 721 & 2015 & 19533R & 9 & QCP & 0.15 & 0.91 & 0.75 & 0.50 & 3.6 & 2.9 & 0.99 & 0.92 \\
\hline 722 & 2016 & 19606FR & 9 & QCP & 0.27 & 0.82 & 0.27 & 0.40 & 4.3 & 3.6 & 1.23 & 1.36 \\
\hline 723 & 2015 & 19605FR & 9 & QCP & 0.40 & 0.95 & 0.36 & 0.70 & 3.5 & 3.1 & 0.53 & 0.56 \\
\hline 724 & 2017 & 19513R & 9 & PFP & & & & & & 4.1 & & 0.00 \\
\hline 725 & 2016 & $19532 R$ & 9 & QCP & 0.67 & & & & 4.6 & 4.1 & 0.14 & 0.00 \\
\hline 726 & 2016 & 19534R & 9 & QCP & 0.31 & 0.16 & 0.08 & 0.05 & 4.1 & 3.7 & 0.68 & 1.07 \\
\hline 727 & 2016 & 19534R & 9 & QCP & 0.54 & 0.91 & 0.63 & 0.62 & 3.9 & 3.7 & 0.71 & 0.69 \\
\hline 728 & 2017 & 19524R & 8 & QCP & 0.81 & 1.00 & 0.70 & 0.87 & 3.3 & 2.9 & 1.52 & 1.45 \\
\hline
\end{tabular}




\begin{tabular}{|c|c|c|c|c|c|c|c|c|c|c|c|c|}
\hline $\begin{array}{l}\text { ICT } \\
\text { Code }\end{array}$ & Year & Mix Code & District & $\begin{array}{l}\text { Quality } \\
\text { Program }\end{array}$ & $\begin{array}{c}\text { MW } \\
\text { P-Value }\end{array}$ & $\begin{array}{l}\text { Levene's } \\
\text { P-Value }\end{array}$ & $\begin{array}{l}\text { Contractor } \\
\text { SW P-Value }\end{array}$ & $\begin{array}{c}\text { Agency SW } \\
\text { P-Value }\end{array}$ & $\begin{array}{c}\text { Contractor } \\
\text { Mean }\end{array}$ & $\begin{array}{l}\text { Agency } \\
\text { Mean }\end{array}$ & $\begin{array}{c}\text { Contractor } \\
\text { St. Dev. }\end{array}$ & $\begin{array}{l}\text { Agency } \\
\text { St. Dev. }\end{array}$ \\
\hline 729 & 2017 & 19524R & 8 & $\mathrm{QCP}$ & 0.39 & 0.56 & 0.04 & 0.14 & 3.6 & 3.3 & 0.91 & 1.20 \\
\hline 730 & 2017 & 19535R & 8 & QCP & 0.54 & 0.31 & 0.44 & 0.26 & 4.4 & 3.5 & 0.83 & 1.46 \\
\hline 731 & 2017 & $19532 R$ & 8 & QCP & 0.11 & 0.89 & 0.07 & 0.01 & 3.7 & 4.2 & 1.01 & 1.06 \\
\hline 732 & 2017 & 19532R & 9 & QCP & 0.25 & & 0.00 & & 5.4 & 4.1 & 0.44 & 0.00 \\
\hline 733 & 2015 & $19532 R$ & 9 & QCP & 0.97 & 0.13 & 0.95 & 0.78 & 4.2 & 4.4 & 0.68 & 1.26 \\
\hline 734 & 2015 & 19532R & 9 & PFP & 0.16 & 0.63 & 0.65 & 0.99 & 4.0 & 4.3 & 0.57 & 0.63 \\
\hline 735 & 2016 & 19532R & 9 & PFP & 0.00 & 0.59 & 0.14 & 0.94 & 4.3 & 3.8 & 0.63 & 0.57 \\
\hline 736 & 2016 & 19532R & 9 & QCP & & & & & 3.8 & & 0.00 & \\
\hline 737 & 2017 & $19532 R$ & 9 & QCP & & & & & 3.7 & & 0.00 & \\
\hline 738 & 2015 & 19532R & 9 & PFP & 0.17 & 0.52 & 0.98 & 0.29 & 4.5 & 5.0 & 0.78 & 0.58 \\
\hline 739 & 2016 & 19532R & 9 & PFP & 0.15 & 0.56 & 0.00 & 0.55 & 4.4 & 4.3 & 0.73 & 0.68 \\
\hline 740 & 2016 & 19606FR & 9 & QCP & 0.50 & & 0.50 & & 3.1 & 3.8 & 0.78 & 0.00 \\
\hline 741 & 2016 & 19606FR & 9 & QCP & 1.00 & & & & 4.5 & 4.5 & 0.49 & 0.00 \\
\hline 742 & 2016 & 19606FR & 9 & QCP & 0.37 & 0.80 & 0.55 & 0.21 & 2.8 & 3.0 & 0.47 & 0.51 \\
\hline 743 & 2016 & 19605FR & 9 & QCP & 0.94 & 0.73 & 0.96 & 0.97 & 4.2 & 4.2 & 0.61 & 0.65 \\
\hline 744 & 2017 & 19534R & 9 & QCP & 0.33 & & & & 3.0 & 2.5 & 0.00 & 0.00 \\
\hline 745 & 2016 & 19534R & 9 & QCP & 0.67 & & & & 4.2 & 3.6 & 0.14 & 0.00 \\
\hline 746 & 2016 & 19534R & 9 & QCP & 0.67 & & 0.86 & & 2.9 & 3.3 & 0.32 & 0.00 \\
\hline 747 & 2016 & 19534R & 9 & QCP & 0.61 & 0.30 & 0.60 & & 3.6 & 3.3 & 0.47 & 0.78 \\
\hline 748 & 2016 & 19534R & 9 & QCP & 0.89 & 0.13 & 0.39 & 1.00 & 3.9 & 3.8 & 0.38 & 0.10 \\
\hline 749 & 2015 & 19523R & 9 & QCP & 1.00 & & 0.46 & & 4.2 & 4.7 & 1.71 & 0.00 \\
\hline 750 & 2015 & 19523R & 9 & QCP & 0.90 & 0.50 & 0.49 & 0.38 & 3.5 & 3.4 & 0.77 & 1.00 \\
\hline 751 & 2015 & 19534R & 9 & PFP & 0.11 & 0.63 & 0.18 & & 4.0 & 5.1 & 0.84 & 0.35 \\
\hline 752 & 2015 & 19534R & 9 & QCP & 1.00 & & 0.18 & & 3.9 & 3.0 & 1.04 & 0.00 \\
\hline 753 & 2015 & 19534R & 9 & QCP & 1.00 & & 0.78 & & 3.6 & 3.5 & 0.50 & 0.00 \\
\hline 754 & 2017 & 19534R & 9 & QCP & 0.57 & & 0.31 & & 3.9 & 3.5 & 0.79 & 0.00 \\
\hline 755 & 2015 & 19606FR & 9 & QCP & 1.00 & & & & 5.9 & 4.8 & 2.19 & 0.00 \\
\hline 756 & 2015 & 19606FR & 9 & QCP & 1.00 & & & & 3.8 & 3.9 & 0.00 & 0.00 \\
\hline 757 & 2016 & 19535 & 9 & PFP & 0.00 & 0.45 & 0.32 & 0.63 & 3.8 & 3.4 & 0.64 & 0.71 \\
\hline 758 & 2016 & $19522 \mathrm{R}$ & 9 & QCP & 0.21 & 0.89 & 0.11 & 0.01 & 3.5 & 3.9 & 0.60 & 0.63 \\
\hline 759 & 2017 & $19532 R$ & 9 & PFP & 0.00 & 0.31 & 0.60 & 0.35 & 4.2 & 3.8 & 0.66 & 0.73 \\
\hline 760 & 2016 & 19523R & 9 & QCP & & & & & 4.7 & & 0.00 & \\
\hline 761 & 2016 & 19523R & 9 & QCP & & & & & 3.6 & & 0.00 & \\
\hline 762 & 2017 & 19523R & 9 & QCP & 0.02 & 0.01 & 0.31 & 0.25 & 4.1 & 3.5 & 0.65 & 1.08 \\
\hline 763 & 2017 & 19532R & 9 & PFP & 0.41 & 0.16 & 0.80 & 0.25 & 3.9 & 3.6 & 0.53 & 0.85 \\
\hline
\end{tabular}




\begin{tabular}{|c|c|c|c|c|c|c|c|c|c|c|c|c|}
\hline $\begin{array}{c}\mathrm{ICT} \\
\text { Code }\end{array}$ & Year & Mix Code & District & $\begin{array}{l}\text { Quality } \\
\text { Program }\end{array}$ & $\begin{array}{c}\text { MW } \\
\text { P-Value }\end{array}$ & $\begin{array}{l}\text { Levene's } \\
\text { P-Value }\end{array}$ & $\begin{array}{l}\text { Contractor } \\
\text { SW P-Value }\end{array}$ & $\begin{array}{c}\text { Agency SW } \\
\text { P-Value }\end{array}$ & $\begin{array}{c}\text { Contractor } \\
\text { Mean }\end{array}$ & $\begin{array}{c}\text { Agency } \\
\text { Mean }\end{array}$ & $\begin{array}{c}\text { Contractor } \\
\text { St. Dev. }\end{array}$ & $\begin{array}{l}\text { Agency } \\
\text { St. Dev. }\end{array}$ \\
\hline 764 & 2015 & 19534R & 9 & $\mathrm{QCP}$ & 0.38 & 0.68 & 0.26 & & 4.8 & 5.8 & 1.19 & 0.57 \\
\hline 765 & 2015 & 19533R & 9 & QCP & 1.00 & & 0.54 & & 4.2 & 4.3 & 0.72 & 0.00 \\
\hline 766 & 2015 & 19533R & 9 & QCP & 1.00 & 0.28 & 0.99 & 0.35 & 3.9 & 3.9 & 0.59 & 0.29 \\
\hline 767 & 2015 & 19533R & 9 & QCP & 0.44 & 0.14 & 0.32 & 0.17 & 3.3 & 3.2 & 0.30 & 0.55 \\
\hline 768 & 2015 & 19533R & 9 & QCP & 0.87 & 0.12 & 0.44 & 0.25 & 3.3 & 3.5 & 1.15 & 2.24 \\
\hline 769 & 2015 & 19533R & 9 & QCP & 0.86 & & 0.41 & & 4.1 & 4.2 & 0.88 & 0.00 \\
\hline 770 & 2015 & 19533R & 9 & QCP & 0.38 & 0.45 & 0.01 & 0.73 & 3.6 & 3.7 & 0.79 & 0.40 \\
\hline 771 & 2015 & $19534 \mathrm{R}$ & 9 & QCP & 0.87 & 0.45 & 0.03 & 1.00 & 3.1 & 3.2 & 0.94 & 1.34 \\
\hline 772 & 2015 & 19606FR & 9 & QCP & 0.67 & 0.89 & & & 4.2 & 4.6 & 1.48 & 1.77 \\
\hline 773 & 2015 & 19606 & 9 & QCP & 0.80 & 0.60 & 0.51 & 0.62 & 4.2 & 4.7 & 1.14 & 1.73 \\
\hline 774 & 2016 & 19606FR & 9 & QCP & 0.10 & 0.67 & 0.84 & 0.19 & 3.1 & 2.4 & 0.35 & 0.49 \\
\hline 775 & 2015 & 19606FR & 9 & QCP & 0.93 & 0.53 & 0.32 & & 4.1 & 4.1 & 0.56 & 0.71 \\
\hline 776 & 2015 & 19606FR & 9 & QCP & 0.64 & 0.68 & 0.43 & & 3.6 & 3.9 & 0.47 & 0.49 \\
\hline 777 & 2015 & 19606FR & 9 & QCP & 0.97 & 0.30 & 0.45 & 0.16 & 3.9 & 3.9 & 1.01 & 1.61 \\
\hline 778 & 2015 & 19606FR & 9 & QCP & 1.00 & & 0.46 & & 3.7 & 3.5 & 0.42 & 0.00 \\
\hline 779 & 2016 & 19606FR & 9 & QCP & 0.55 & 1.00 & 0.32 & 0.58 & 4.7 & 4.3 & 1.01 & 1.00 \\
\hline 780 & 2015 & 19606FR & 9 & QCP & 0.86 & 0.52 & 0.23 & 0.86 & 3.5 & 3.5 & 0.45 & 0.32 \\
\hline 781 & 2015 & 19606FR & 9 & QCP & & & & & & 3.7 & & 0.00 \\
\hline 782 & 2015 & 19534R & 9 & QCP & 0.10 & 0.43 & 0.53 & 0.02 & 3.4 & 4.2 & 0.67 & 0.40 \\
\hline 783 & 2016 & 19534R & 9 & QCP & 0.28 & 0.86 & 0.31 & & 3.7 & 3.1 & 0.73 & 0.42 \\
\hline 784 & 2016 & 19533R & 9 & QCP & 0.43 & 0.55 & 0.54 & & 4.2 & 3.4 & 1.27 & 1.56 \\
\hline 785 & 2016 & 19523R & 9 & QCP & 1.00 & & & & 3.9 & 3.8 & 0.99 & 0.00 \\
\hline 786 & 2016 & $19523 R$ & 9 & QCP & 1.00 & & 0.82 & & 4.2 & 4.1 & 0.60 & 0.00 \\
\hline 787 & 2017 & $19523 R$ & 9 & QCP & 0.13 & 0.29 & 0.02 & & 3.5 & 2.6 & 0.72 & 0.14 \\
\hline 788 & 2017 & 19523R & 9 & QCP & 0.14 & 0.00 & 0.67 & 0.02 & 3.8 & 3.5 & 0.54 & 0.06 \\
\hline 789 & 2016 & 19605FR & 9 & QCP & 1.00 & 0.00 & & & 5.4 & 5.3 & 0.21 & 0.00 \\
\hline 790 & 2016 & 19605FR & 9 & QCP & 0.67 & & & & 4.4 & 3.4 & 0.49 & 0.00 \\
\hline 791 & 2017 & 19605FR & 9 & QCP & 0.33 & 0.00 & & & 3.9 & 3.2 & 0.00 & 0.14 \\
\hline 792 & 2017 & 19605FR & 9 & QCP & 1.00 & & 0.33 & & 4.4 & 3.8 & 0.59 & 0.00 \\
\hline 793 & 2015 & $\begin{array}{c}\text { HMA } \\
\text { Binder }\end{array}$ & 9 & QCP & 0.02 & 0.08 & 0.04 & 0.43 & 4.4 & 3.9 & 0.73 & 1.00 \\
\hline 794 & 2015 & $\begin{array}{c}\text { HMA } \\
\text { Binder }\end{array}$ & 9 & $\mathrm{QCP}$ & 0.41 & 0.42 & 0.32 & 0.02 & 4.5 & 4.7 & 0.83 & 0.59 \\
\hline 795 & 2015 & $\begin{array}{c}\text { HMA } \\
\text { Binder }\end{array}$ & 9 & $\mathrm{QCP}$ & 0.03 & 0.97 & 0.15 & 0.97 & 4.1 & 3.1 & 0.60 & 0.62 \\
\hline
\end{tabular}




\begin{tabular}{|c|c|c|c|c|c|c|c|c|c|c|c|c|}
\hline $\begin{array}{c}\text { ICT } \\
\text { Code }\end{array}$ & Year & Mix Code & District & $\begin{array}{l}\text { Quality } \\
\text { Program }\end{array}$ & $\begin{array}{c}\text { MW } \\
\text { P-Value }\end{array}$ & $\begin{array}{l}\text { Levene's } \\
\text { P-Value }\end{array}$ & $\begin{array}{l}\text { Contractor } \\
\text { SW P-Value }\end{array}$ & $\begin{array}{c}\text { Agency SW } \\
\text { P-Value }\end{array}$ & $\begin{array}{c}\text { Contractor } \\
\text { Mean }\end{array}$ & $\begin{array}{l}\text { Agency } \\
\text { Mean }\end{array}$ & $\begin{array}{c}\text { Contractor } \\
\text { St. Dev. }\end{array}$ & $\begin{array}{l}\text { Agency } \\
\text { St. Dev. }\end{array}$ \\
\hline 796 & 2015 & $\begin{array}{l}\text { HMA } \\
\text { Binder }\end{array}$ & 9 & QCP & 0.64 & 0.19 & 0.69 & & 5.0 & 4.3 & 0.55 & 1.13 \\
\hline 797 & 2016 & 19535 & 9 & PFP & 0.43 & 0.62 & 0.13 & 0.02 & 4.1 & 4.2 & 0.71 & 0.79 \\
\hline 798 & 2016 & 19535 & 9 & PFP & 0.65 & 0.99 & 0.01 & 0.39 & 3.8 & 3.7 & 0.85 & 0.74 \\
\hline 799 & 2016 & 19532R & 9 & PFP & 0.46 & 0.19 & 0.05 & 0.03 & 4.0 & 4.3 & 0.83 & 1.05 \\
\hline 800 & 2016 & $19532 R$ & 9 & PFP & 0.04 & 0.65 & 0.73 & 0.14 & 4.3 & 3.5 & 0.65 & 0.47 \\
\hline 801 & 2017 & 19533R & 9 & QCP & 0.43 & 0.20 & 0.06 & 0.22 & 3.9 & 4.0 & 0.54 & 0.24 \\
\hline 802 & 2016 & 19533R & 9 & QCP & 0.98 & 0.13 & 0.75 & 0.92 & 4.6 & 4.4 & 0.75 & 1.40 \\
\hline 803 & 2017 & 19534R & 9 & PFP & 0.40 & 0.18 & 0.00 & 0.38 & 3.9 & 4.2 & 0.78 & 1.02 \\
\hline 804 & 2017 & $19532 R$ & 9 & PFP & 0.18 & 0.55 & 0.01 & 0.02 & 4.2 & 4.1 & 0.60 & 0.54 \\
\hline 805 & 2015 & 19533R & 9 & QCP & 0.58 & 0.42 & 0.11 & 0.64 & 3.9 & 4.2 & 0.62 & 0.31 \\
\hline 806 & 2016 & 19534R & 9 & QCP & 0.36 & 0.39 & 0.35 & & 4.3 & 3.7 & 0.81 & 0.21 \\
\hline 807 & 2015 & 19534R & 9 & QCP & 0.80 & & 0.58 & & 3.7 & 3.1 & 0.49 & 0.00 \\
\hline 808 & 2016 & 19534R & 9 & QCP & 0.73 & 0.74 & 0.17 & 0.33 & 3.7 & 3.4 & 1.24 & 1.09 \\
\hline 809 & 2016 & 19606FR & 9 & QCP & 1.00 & & & & 4.2 & 4.2 & 0.07 & 0.00 \\
\hline 810 & 2016 & 19534R & 9 & QCP & 0.67 & & 0.35 & & 5.0 & 4.9 & 0.29 & 0.00 \\
\hline 811 & 2015 & 19605FR & 9 & QCP & 0.33 & 1.00 & & & 3.6 & 3.2 & 0.14 & 0.14 \\
\hline 812 & 2015 & 19605FR & 9 & $\mathrm{QCP}$ & 0.53 & 0.59 & 0.86 & 0.21 & 3.4 & 3.2 & 1.12 & 0.92 \\
\hline 813 & 2015 & 19605FR & 9 & QCP & 0.50 & 0.25 & 0.64 & 0.00 & 2.9 & 3.0 & 0.15 & 0.06 \\
\hline 814 & 2016 & 19606FR & 9 & QCP & 0.86 & 0.88 & 0.07 & 0.71 & 2.0 & 2.0 & 0.59 & 0.55 \\
\hline 815 & 2016 & 19533R & 9 & QCP & 0.76 & 0.00 & 0.02 & & 3.7 & 3.1 & 1.12 & 0.00 \\
\hline 816 & 2015 & 19523R & 9 & $\mathrm{QCP}$ & 0.60 & 0.79 & 0.85 & 0.66 & 3.6 & 3.5 & 0.84 & 0.77 \\
\hline 817 & 2016 & 19523R & 9 & QCP & 0.57 & & 0.92 & & 3.4 & 3.9 & 0.43 & 0.00 \\
\hline 818 & 2015 & 19523R & 9 & QCP & 1.00 & & 0.79 & & 3.1 & 3.5 & 0.93 & 0.00 \\
\hline 819 & 2015 & 19523R & 9 & QCP & 0.87 & 0.87 & 0.86 & 1.00 & 4.5 & 4.5 & 0.64 & 0.50 \\
\hline 820 & 2015 & 19523R & 9 & QCP & 0.28 & 0.67 & 0.95 & & 3.2 & 3.5 & 0.31 & 0.14 \\
\hline 821 & 2016 & $19532 \mathrm{R}$ & 9 & QCP & 0.53 & 0.24 & 0.50 & 0.17 & 3.2 & 3.0 & 0.39 & 0.61 \\
\hline 822 & 2016 & $19532 R$ & 9 & QCP & 0.57 & 0.00 & 0.08 & & 3.2 & 2.9 & 0.72 & 0.00 \\
\hline 823 & 2016 & $19522 \mathrm{R}$ & 9 & QCP & 0.41 & 0.74 & 0.13 & 0.02 & 5.3 & 5.0 & 0.51 & 0.40 \\
\hline 824 & 2016 & $19532 \mathrm{R}$ & 9 & QCP & & & & & & & & \\
\hline 825 & 2016 & $19532 \mathrm{R}$ & 9 & QCP & & & & 0.57 & & 2.6 & & 0.36 \\
\hline 826 & 2016 & 19606FR & 9 & QCP & 0.50 & & & 0.46 & 4.1 & 5.0 & 0.00 & 0.62 \\
\hline 827 & 2017 & 19605FR & 9 & QCP & 0.33 & & & & 2.5 & 2.1 & 0.00 & 0.00 \\
\hline 828 & 2017 & $19532 R$ & 9 & QCP & 0.25 & 0.72 & 0.25 & 0.04 & 4.1 & 3.8 & 0.53 & 0.42 \\
\hline 829 & 2017 & $19524 \mathrm{R}$ & 9 & QCP & 0.57 & & 0.92 & & 4.3 & 4.9 & 0.43 & 0.00 \\
\hline
\end{tabular}




\begin{tabular}{|c|c|c|c|c|c|c|c|c|c|c|c|c|}
\hline $\begin{array}{c}\mathrm{ICT} \\
\text { Code }\end{array}$ & Year & Mix Code & District & $\begin{array}{c}\text { Quality } \\
\text { Program }\end{array}$ & $\begin{array}{c}\text { MW } \\
\text { P-Value }\end{array}$ & $\begin{array}{l}\text { Levene's } \\
\text { P-Value }\end{array}$ & $\begin{array}{l}\text { Contractor } \\
\text { SW P-Value }\end{array}$ & $\begin{array}{c}\text { Agency SW } \\
\text { P-Value }\end{array}$ & $\begin{array}{c}\text { Contractor } \\
\text { Mean }\end{array}$ & $\begin{array}{l}\text { Agency } \\
\text { Mean }\end{array}$ & $\begin{array}{c}\text { Contractor } \\
\text { St. Dev. }\end{array}$ & $\begin{array}{l}\text { Agency } \\
\text { St. Dev. }\end{array}$ \\
\hline 830 & 2017 & $19534 R$ & 9 & $\mathrm{QCP}$ & 1.00 & 0.09 & 0.06 & 0.51 & 4.0 & 3.8 & 0.62 & 1.12 \\
\hline 831 & 2016 & $19532 R$ & 9 & PFP & & & 0.64 & & 4.4 & & 0.15 & \\
\hline 832 & 2016 & $19523 R$ & 9 & QCP & 0.40 & 0.83 & 0.47 & & 3.9 & 3.4 & 0.58 & 0.35 \\
\hline 833 & 2016 & 19535R & 9 & PFP & & & & & 8.1 & & 0.00 & \\
\hline 834 & 2017 & $19523 R$ & 9 & QCP & 1.00 & 0.76 & 0.46 & 0.36 & 4.2 & 4.2 & 0.21 & 0.26 \\
\hline 835 & 2017 & $19532 R$ & 9 & PFP & & & & & 3.8 & & 0.00 & \\
\hline 836 & 2017 & $19532 R$ & 9 & PFP & 0.57 & & 0.63 & & 3.9 & 4.4 & 0.33 & 0.00 \\
\hline
\end{tabular}




\section{C.2 VMA ANALYSIS RESULTS}

Table C.2. VMA Analysis Results Summary

\begin{tabular}{|c|c|c|c|c|c|c|c|c|c|c|c|c|}
\hline $\begin{array}{c}\text { ICT } \\
\text { Code }\end{array}$ & Year & Mix Code & District & $\begin{array}{c}\text { Quality } \\
\text { Program }\end{array}$ & $\begin{array}{c}\text { MW } \\
\text { P-Value }\end{array}$ & $\begin{array}{l}\text { Levene's } \\
\text { P-Value }\end{array}$ & $\begin{array}{l}\text { Contractor } \\
\text { SW P-Value }\end{array}$ & $\begin{array}{c}\text { Agency SW } \\
\text { P-Value }\end{array}$ & $\begin{array}{c}\text { Contractor } \\
\text { Mean }\end{array}$ & $\begin{array}{c}\text { Agency } \\
\text { Mean }\end{array}$ & $\begin{array}{c}\text { Contractor } \\
\text { St. Dev. }\end{array}$ & $\begin{array}{l}\text { Agency } \\
\text { St. Dev. }\end{array}$ \\
\hline 1 & 2015 & 19524R & 1 & $\mathrm{QCP}$ & 0.33 & 0.86 & & & 15.4 & 14.2 & 0.35 & 0.28 \\
\hline 2 & 2017 & $19524 \mathrm{R}$ & 1 & QCP & 1.00 & & & & 14.6 & 14.7 & 0.14 & 0.00 \\
\hline 3 & 2017 & $19524 R$ & 1 & QCP & 1.00 & & & & 15.3 & 15.0 & 1.06 & 0.00 \\
\hline 4 & 2016 & $19524 \mathrm{R}$ & 1 & QCP & 0.66 & 0.83 & 0.05 & 0.10 & 15.2 & 15.0 & 0.56 & 0.67 \\
\hline 5 & 2015 & $19514 \mathrm{R}$ & 1 & QCP & & & & & 15.3 & & 0.00 & \\
\hline 6 & 2015 & $19514 \mathrm{R}$ & 1 & QCP & 0.67 & & & & 15.0 & 14.6 & 0.00 & 0.00 \\
\hline 7 & 2015 & $19524 \mathrm{R}$ & 1 & QCP & 0.76 & 0.17 & 0.03 & 0.00 & 14.9 & 14.9 & 0.19 & 0.35 \\
\hline 8 & 2015 & $19524 R$ & 1 & QCP & & & & & 15.0 & & 0.14 & \\
\hline 9 & 2015 & $19524 R$ & 1 & PFP & 0.04 & 0.57 & 0.07 & 0.60 & 15.1 & 14.7 & 0.26 & 0.32 \\
\hline 10 & 2015 & $19512 \mathrm{R}$ & 1 & QCP & 0.50 & & 0.00 & & 13.6 & 13.7 & 0.06 & 0.00 \\
\hline 11 & 2015 & $19512 R$ & 1 & QCP & 0.67 & & & & 12.8 & 13.0 & 0.00 & 0.00 \\
\hline 12 & 2015 & $19522 R$ & 1 & QCP & 0.07 & 0.06 & 0.06 & 0.10 & 13.3 & 12.4 & 0.61 & 1.15 \\
\hline 13 & 2017 & $19522 \mathrm{R}$ & 1 & QCP & 0.33 & 0.00 & & & 13.4 & 14.0 & 0.00 & 0.64 \\
\hline 14 & 2015 & 19510R & 1 & QCP & 1.00 & & 0.00 & & 17.8 & 17.8 & 0.06 & 0.00 \\
\hline 15 & 2015 & 19510R & 1 & QCP & & & & & 17.8 & & 0.00 & \\
\hline 16 & 2015 & 19510R & 1 & QCP & 0.01 & 0.05 & 0.00 & 0.56 & 17.9 & 17.4 & 0.16 & 0.42 \\
\hline 17 & 2015 & $19512 \mathrm{R}$ & 1 & QCP & 0.67 & & & & 13.9 & 12.9 & 0.00 & 0.53 \\
\hline 18 & 2015 & 19510R & 1 & QCP & 0.13 & 0.77 & 0.41 & & 18.1 & 17.6 & 0.13 & 0.07 \\
\hline 19 & 2015 & 19536R & 1 & QCP & & & & 0.00 & & 14.8 & & 1.21 \\
\hline 20 & 2017 & 19525R & 1 & QCP & 0.13 & 0.40 & 0.71 & & 15.4 & 16.4 & 0.39 & 0.64 \\
\hline 21 & 2015 & $19524 R$ & 1 & QCP & 0.67 & & & & 14.9 & 14.3 & 0.07 & 0.00 \\
\hline 22 & 2015 & $19524 \mathrm{R}$ & 1 & QCP & 1.00 & & & & 15.1 & 15.4 & 0.64 & 0.00 \\
\hline 23 & 2015 & $19512 R$ & 1 & QCP & 1.00 & & 0.84 & & 12.7 & 12.5 & 0.28 & 0.00 \\
\hline 24 & 2016 & $19532 R$ & 1 & QCP & 0.33 & 0.25 & & & 12.9 & 12.2 & 0.14 & 0.71 \\
\hline 25 & 2017 & $19532 R$ & 1 & QCP & 0.80 & & 0.36 & & 13.8 & 13.2 & 0.54 & 0.00 \\
\hline 26 & 2017 & 19510R & 1 & QCP & 1.00 & & & & 18.1 & 18.4 & 0.00 & 0.00 \\
\hline 27 & 2015 & 19510R & 1 & QCP & 0.27 & 0.12 & 0.24 & 0.63 & 18.2 & 18.7 & 0.29 & 0.62 \\
\hline 28 & 2017 & 19665R & 1 & QCP & & & & & 16.9 & & 0.14 & \\
\hline 29 & 2015 & 19665R & 1 & QCP & 0.23 & 0.59 & 0.91 & 0.05 & 17.1 & 16.9 & 0.22 & 0.30 \\
\hline 30 & 2017 & 19524R & 1 & QCP & 0.47 & 0.20 & 0.30 & 0.95 & 14.9 & 15.0 & 0.46 & 0.77 \\
\hline 31 & 2017 & 19525R & 1 & QCP & 0.67 & & & & 15.2 & 15.7 & 0.07 & 0.00 \\
\hline
\end{tabular}




\begin{tabular}{|c|c|c|c|c|c|c|c|c|c|c|c|c|}
\hline $\begin{array}{c}\text { ICT } \\
\text { Code }\end{array}$ & Year & Mix Code & District & $\begin{array}{l}\text { Quality } \\
\text { Program }\end{array}$ & $\begin{array}{c}\text { MW } \\
\text { P-Value }\end{array}$ & $\begin{array}{l}\text { Levene's } \\
\text { P-Value }\end{array}$ & $\begin{array}{l}\text { Contractor } \\
\text { SW P-Value }\end{array}$ & $\begin{array}{c}\text { Agency SW } \\
\text { P-Value }\end{array}$ & $\begin{array}{c}\text { Contractor } \\
\text { Mean }\end{array}$ & $\begin{array}{l}\text { Agency } \\
\text { Mean }\end{array}$ & $\begin{array}{c}\text { Contractor } \\
\text { St. Dev. }\end{array}$ & $\begin{array}{l}\text { Agency } \\
\text { St. Dev. }\end{array}$ \\
\hline 32 & 2016 & 19510R & 1 & QCP & 0.50 & & 0.00 & & 18.5 & 17.7 & 0.06 & 0.00 \\
\hline 33 & 2015 & 19525R & 1 & QCP & & & 0.79 & & 16.0 & & 0.25 & \\
\hline 34 & 2016 & $19512 R$ & 1 & QCP & & & 0.82 & & 13.7 & & 0.29 & \\
\hline 35 & 2015 & $19512 R$ & 1 & QCP & 0.67 & & & & 14.5 & 13.6 & 0.21 & 0.00 \\
\hline 36 & 2015 & 19522R & 1 & QCP & 0.71 & & 0.90 & & 13.0 & 13.3 & 0.41 & 0.00 \\
\hline 37 & 2015 & 19522R & 1 & QCP & & & & & & 13.8 & & 0.00 \\
\hline 38 & 2015 & 19524R & 1 & QCP & 0.14 & 0.07 & 0.19 & 0.67 & 14.9 & 15.6 & 0.49 & 0.99 \\
\hline 39 & 2015 & 19510R & 1 & QCP & 0.27 & 0.54 & 0.57 & & 18.8 & 19.5 & 0.74 & 0.28 \\
\hline 40 & 2015 & 19510R & 1 & QCP & & & & & 19.7 & & 0.00 & \\
\hline 41 & 2015 & 19510R & 1 & QCP & 0.33 & & & & 19.9 & 20.5 & 0.00 & 0.00 \\
\hline 42 & 2015 & 19524R & 1 & QCP & & & 0.69 & & 15.4 & & 0.25 & \\
\hline 43 & 2015 & 19524R & 1 & QCP & 0.26 & 0.61 & 0.46 & 0.11 & 15.3 & 14.9 & 0.52 & 0.64 \\
\hline 44 & 2015 & 19510R & 1 & PFP & 0.20 & 0.90 & 0.24 & 0.40 & 18.3 & 18.2 & 0.31 & 0.32 \\
\hline 45 & 2015 & 19510R & 1 & PFP & & & & & 18.0 & & 0.00 & \\
\hline 46 & 2015 & 19524R & 1 & QCP & 0.94 & 0.24 & 0.65 & 0.39 & 16.1 & 16.0 & 0.32 & 0.68 \\
\hline 47 & 2015 & 19655R & 1 & PFP & 0.69 & 0.00 & 0.68 & 0.40 & 17.0 & 17.1 & 0.46 & 1.01 \\
\hline 48 & 2015 & 19536R & 1 & PFP & 0.34 & 0.07 & 0.25 & 0.78 & 15.3 & 15.0 & 0.57 & 0.96 \\
\hline 49 & 2017 & 19510R & 1 & QCP & 0.80 & & 0.49 & & 18.4 & 18.6 & 0.24 & 0.00 \\
\hline 50 & 2017 & 19510R & 1 & QCP & 0.89 & & 0.64 & & 18.5 & 18.6 & 0.43 & 0.00 \\
\hline 51 & 2016 & 19510R & 1 & QCP & 0.40 & 0.44 & & 0.79 & 19.5 & 19.9 & 0.14 & 0.46 \\
\hline 52 & 2017 & $19524 R$ & 1 & QCP & 0.67 & & & & 15.1 & 15.6 & 0.42 & 0.00 \\
\hline 53 & 2017 & $19525 R$ & 1 & QCP & 1.00 & & 0.63 & & 15.4 & 15.5 & 0.70 & 0.00 \\
\hline 54 & 2017 & $19525 R$ & 1 & PFP & 0.26 & 0.63 & 0.17 & 0.01 & 15.4 & 15.7 & 0.39 & 0.45 \\
\hline 55 & 2016 & $19525 R$ & 1 & QCP & 0.80 & 0.95 & 0.69 & 0.00 & 15.2 & 15.4 & 0.53 & 0.52 \\
\hline 56 & 2016 & $19536 R$ & 1 & $\mathrm{QCP}$ & & & & & 16.0 & & 0.28 & \\
\hline 57 & 2015 & 19536R & 1 & PFP & 0.98 & 0.15 & 0.16 & 0.01 & 15.4 & 15.4 & 0.64 & 0.97 \\
\hline 58 & 2015 & $19524 \mathrm{R}$ & 1 & QCP & 0.01 & 0.93 & 0.02 & 0.55 & 14.0 & 12.6 & 0.38 & 0.40 \\
\hline 59 & 2017 & $19524 R$ & 1 & QCP & 0.10 & 0.05 & 0.00 & 0.54 & 14.3 & 13.3 & 0.06 & 0.36 \\
\hline 60 & 2015 & $19522 \mathrm{R}$ & 1 & QCP & 0.09 & 0.56 & 0.49 & 0.67 & 13.7 & 13.1 & 0.42 & 0.61 \\
\hline 61 & 2015 & $19522 \mathrm{R}$ & 1 & QCP & & & & & 13.0 & & 0.21 & \\
\hline 62 & 2015 & 19510R & 1 & QCP & 0.67 & & & & 19.4 & 18.9 & 0.00 & 0.00 \\
\hline 63 & 2015 & 19510R & 1 & PFP & 0.83 & 0.10 & 0.53 & 0.21 & 18.1 & 17.8 & 0.97 & 0.44 \\
\hline 64 & 2017 & $19524 R$ & 1 & QCP & 1.00 & & & & 16.0 & 16.8 & 0.00 & 0.00 \\
\hline 65 & 2017 & $19524 R$ & 1 & PFP & 0.70 & 0.70 & 0.30 & 0.49 & 15.1 & 14.9 & 0.55 & 0.69 \\
\hline 66 & 2017 & $19524 R$ & 1 & QCP & 0.67 & & & & 15.0 & 15.7 & 0.42 & 0.00 \\
\hline
\end{tabular}




\begin{tabular}{|c|c|c|c|c|c|c|c|c|c|c|c|c|}
\hline $\begin{array}{c}\text { ICT } \\
\text { Code }\end{array}$ & Year & Mix Code & District & $\begin{array}{l}\text { Quality } \\
\text { Program }\end{array}$ & $\begin{array}{c}\text { MW } \\
\text { P-Value }\end{array}$ & $\begin{array}{l}\text { Levene's } \\
\text { P-Value }\end{array}$ & $\begin{array}{l}\text { Contractor } \\
\text { SW P-Value }\end{array}$ & $\begin{array}{c}\text { Agency SW } \\
\text { P-Value }\end{array}$ & $\begin{array}{c}\text { Contractor } \\
\text { Mean }\end{array}$ & $\begin{array}{c}\text { Agency } \\
\text { Mean }\end{array}$ & $\begin{array}{l}\text { Contractor } \\
\text { St. Dev. }\end{array}$ & $\begin{array}{l}\text { Agency } \\
\text { St. Dev. }\end{array}$ \\
\hline 67 & 2017 & 19510R & 1 & $\mathrm{QCP}$ & 0.10 & 0.00 & & 0.00 & 19.5 & 18.9 & 0.00 & 0.12 \\
\hline 68 & 2015 & $19532 R$ & 1 & QCP & 1.00 & & 0.78 & & 12.8 & 13.0 & 0.50 & 0.00 \\
\hline 69 & 2017 & 19510R & 1 & QCP & 0.70 & 0.75 & 0.33 & 0.25 & 18.9 & 18.7 & 0.59 & 0.76 \\
\hline 70 & 2016 & 19510R & 1 & QCP & 0.67 & & & & 18.5 & 18.8 & 0.28 & 0.00 \\
\hline 71 & 2017 & 19524R & 1 & PFP & & & & & 15.0 & & 0.00 & \\
\hline 72 & 2017 & 19510R & 1 & QCP & 0.20 & 0.47 & & 0.25 & 18.9 & 17.9 & 0.64 & 0.38 \\
\hline 73 & 2017 & 19510R & 1 & QCP & 0.20 & 0.18 & 0.64 & 0.19 & 18.8 & 18.1 & 0.15 & 0.49 \\
\hline 74 & 2016 & 19525R & 1 & QCP & 0.43 & 0.90 & 0.41 & & 15.6 & 16.1 & 0.43 & 0.35 \\
\hline 75 & 2017 & 19665R & 1 & QCP & 1.00 & 0.14 & & & 17.0 & 16.6 & 0.07 & 0.64 \\
\hline 76 & 2017 & 19655R & 1 & QCP & 1.00 & 0.00 & & & 16.1 & 16.0 & 0.28 & 0.00 \\
\hline 77 & 2017 & 19665R & 1 & QCP & 1.00 & 0.31 & 0.30 & & 16.6 & 16.5 & 0.32 & 0.07 \\
\hline 78 & 2015 & $19512 R$ & 1 & QCP & 0.62 & 0.04 & 0.44 & 0.17 & 14.0 & 14.2 & 0.24 & 0.59 \\
\hline 79 & 2015 & $19522 \mathrm{R}$ & 1 & PFP & 1.00 & 0.70 & & 0.22 & 13.5 & 13.4 & 0.35 & 0.73 \\
\hline 80 & 2017 & $19522 \mathrm{R}$ & 1 & QCP & 0.76 & 0.00 & 0.55 & & 13.0 & 13.0 & 0.43 & 0.00 \\
\hline 81 & 2015 & $19522 \mathrm{R}$ & 1 & QCP & & & & & & 15.7 & & 0.00 \\
\hline 82 & 2015 & $19514 \mathrm{R}$ & 1 & QCP & & & & & & & & \\
\hline 83 & 2015 & 19524R & 1 & QCP & 0.65 & 0.47 & 0.79 & 0.23 & 15.0 & 15.4 & 0.64 & 0.87 \\
\hline 84 & 2015 & $19512 \mathrm{R}$ & 1 & QCP & 1.00 & 0.36 & 0.40 & 0.57 & 13.4 & 13.4 & 0.46 & 0.62 \\
\hline 85 & 2015 & $19512 \mathrm{R}$ & 1 & QCP & 1.00 & & 0.62 & & 13.4 & 13.5 & 0.99 & 0.00 \\
\hline 86 & 2015 & $19525 R$ & 1 & PFP & & & 0.03 & & 15.2 & & 0.63 & \\
\hline 87 & 2015 & 19510R & 1 & QCP & 1.00 & & 0.63 & & 19.0 & 19.0 & 0.34 & 0.00 \\
\hline 88 & 2017 & 19510R & 1 & QCP & 0.07 & 0.87 & 0.57 & 0.74 & 18.6 & 18.2 & 0.36 & 0.38 \\
\hline 89 & 2017 & $19532 \mathrm{R}$ & 1 & QCP & 0.67 & & & & 13.5 & 13.9 & 0.35 & 0.00 \\
\hline 90 & 2016 & $19524 \mathrm{R}$ & 1 & QCP & 0.50 & & 0.46 & & 14.8 & 14.4 & 0.21 & 0.00 \\
\hline 91 & 2016 & $19524 R$ & 1 & $\mathrm{QCP}$ & & & & & & 14.5 & & 0.35 \\
\hline 92 & 2017 & 19536R & 1 & QCP & 1.00 & & & & 15.3 & 14.9 & 0.00 & 0.00 \\
\hline 93 & 2015 & 19536R & 1 & QCP & 0.10 & 0.15 & 0.15 & 0.93 & 14.7 & 14.2 & 0.72 & 0.20 \\
\hline 94 & 2015 & $19524 R$ & 1 & QCP & 0.86 & 0.23 & 0.74 & 0.91 & 15.7 & 16.2 & 0.39 & 1.10 \\
\hline 95 & 2015 & $19512 \mathrm{R}$ & 1 & QCP & 0.93 & 0.73 & 0.91 & & 13.1 & 13.3 & 0.71 & 0.70 \\
\hline 96 & 2015 & $19512 \mathrm{R}$ & 1 & QCP & 0.06 & 0.91 & 0.93 & 0.51 & 13.5 & 13.1 & 0.35 & 0.37 \\
\hline 97 & 2015 & $19514 \mathrm{R}$ & 1 & QCP & 0.39 & 0.39 & 0.43 & 0.07 & 15.5 & 15.2 & 0.56 & 0.83 \\
\hline 98 & 2017 & $19522 \mathrm{R}$ & 1 & QCP & 1.00 & & & & 13.1 & 14.1 & 0.00 & 0.00 \\
\hline 99 & 2017 & $19522 \mathrm{R}$ & 1 & QCP & 0.29 & & 0.46 & & 14.2 & 13.4 & 0.40 & 0.00 \\
\hline 100 & 2016 & $19522 \mathrm{R}$ & 1 & QCP & 0.00 & 0.19 & 0.10 & 0.13 & 13.5 & 12.8 & 0.43 & 0.65 \\
\hline 101 & 2015 & 19510R & 1 & QCP & 1.00 & & & & 18.4 & 18.0 & 0.49 & 0.00 \\
\hline
\end{tabular}




\begin{tabular}{|c|c|c|c|c|c|c|c|c|c|c|c|c|}
\hline $\begin{array}{c}\text { ICT } \\
\text { Code }\end{array}$ & Year & Mix Code & District & $\begin{array}{l}\text { Quality } \\
\text { Program }\end{array}$ & $\begin{array}{c}\text { MW } \\
\text { P-Value }\end{array}$ & $\begin{array}{l}\text { Levene's } \\
\text { P-Value }\end{array}$ & $\begin{array}{l}\text { Contractor } \\
\text { SW P-Value }\end{array}$ & $\begin{array}{c}\text { Agency SW } \\
\text { P-Value }\end{array}$ & $\begin{array}{c}\text { Contractor } \\
\text { Mean }\end{array}$ & $\begin{array}{l}\text { Agency } \\
\text { Mean }\end{array}$ & $\begin{array}{c}\text { Contractor } \\
\text { St. Dev. }\end{array}$ & $\begin{array}{l}\text { Agency } \\
\text { St. Dev. }\end{array}$ \\
\hline 102 & 2015 & 19510R & 1 & $\mathrm{QCP}$ & & & 0.00 & & 18.2 & & 0.06 & \\
\hline 103 & 2015 & 19510R & 1 & QCP & 0.67 & 0.59 & & & 18.2 & 17.8 & 0.42 & 0.21 \\
\hline 104 & 2015 & 19510R & 1 & QCP & 1.00 & & & & 18.3 & 18.4 & 0.42 & 0.00 \\
\hline 105 & 2017 & 19510R & 1 & QCP & 0.38 & 0.61 & 0.41 & 0.39 & 18.4 & 18.2 & 0.39 & 0.30 \\
\hline 108 & 2017 & 19532R & 1 & QCP & 0.80 & 0.96 & 0.00 & & 13.8 & 13.3 & 0.58 & 0.49 \\
\hline 107 & 2017 & 19532R & 1 & QCP & 0.40 & 0.66 & 0.60 & 0.22 & 14.1 & 13.7 & 0.67 & 0.44 \\
\hline 108 & 2017 & $19532 R$ & 1 & QCP & 0.73 & 0.50 & 0.29 & 0.89 & 14.3 & 14.4 & 0.57 & 0.76 \\
\hline 109 & 2015 & 19536R & 1 & QCP & 1.00 & & 0.19 & & 15.6 & 15.7 & 0.49 & 0.00 \\
\hline 110 & 2015 & 19536R & 1 & QCP & 1.00 & & 0.84 & & 14.9 & 15.2 & 0.35 & 0.00 \\
\hline 111 & 2015 & 19524R & 1 & QCP & 1.00 & & 0.64 & & 15.5 & 15.4 & 0.31 & 0.00 \\
\hline 112 & 2015 & 19524R & 1 & QCP & 0.67 & & & & 15.8 & 15.2 & 0.49 & 0.00 \\
\hline 113 & 2015 & 19524R & 1 & QCP & 0.91 & 0.51 & 0.22 & 0.01 & 15.6 & 15.5 & 0.87 & 0.59 \\
\hline 114 & 2017 & 19510R & 1 & QCP & 1.00 & 0.00 & & & 18.0 & 17.8 & 0.00 & 0.64 \\
\hline 115 & 2017 & 19510R & 1 & QCP & & & 0.88 & & 16.6 & & 0.45 & \\
\hline 116 & 2016 & 19510R & 1 & QCP & & & & & & 18.0 & & 0.14 \\
\hline 117 & 2017 & 19510R & 1 & QCP & 0.06 & 0.15 & 0.00 & 0.16 & 18.0 & 17.2 & 0.06 & 0.21 \\
\hline 118 & 2016 & 19510R & 1 & QCP & 0.04 & 0.00 & & 0.00 & 18.0 & 17.1 & 0.00 & 0.23 \\
\hline 119 & 2017 & 19510R & 1 & QCP & 0.80 & 0.00 & & & 17.8 & 18.1 & 0.00 & 0.42 \\
\hline 120 & 2017 & 19510R & 1 & QCP & 1.00 & 0.75 & & & 17.9 & 17.8 & 0.28 & 0.42 \\
\hline 121 & 2017 & 19510R & 1 & QCP & 0.33 & 0.59 & & & 18.1 & 17.8 & 0.07 & 0.14 \\
\hline 122 & 2015 & $19522 R$ & 1 & QCP & 1.00 & & & & 13.5 & 13.5 & 0.21 & 0.00 \\
\hline 123 & 2015 & $19522 R$ & 1 & QCP & 1.00 & & 0.82 & & 13.3 & 13.1 & 0.69 & 0.00 \\
\hline 124 & 2017 & $19524 \mathrm{R}$ & 1 & QCP & 1.00 & & & & 15.2 & 15.2 & 0.00 & 0.00 \\
\hline 125 & 2017 & $19524 \mathrm{R}$ & 1 & QCP & 0.30 & 0.09 & 0.00 & 0.00 & 14.6 & 14.0 & 0.12 & 0.52 \\
\hline 126 & 2017 & $19524 R$ & 1 & PFP & & & 0.00 & & 14.7 & & 0.35 & \\
\hline 127 & 2016 & $19524 \mathrm{R}$ & 1 & QCP & 1.00 & & & & 15.1 & 15.2 & 0.28 & 0.00 \\
\hline 128 & 2017 & $19524 \mathrm{R}$ & 1 & QCP & 0.33 & & 0.11 & & 15.1 & 15.6 & 0.44 & 0.00 \\
\hline 129 & 2017 & $19524 R$ & 1 & QCP & 1.00 & 0.83 & 0.89 & & 15.0 & 15.0 & 0.35 & 0.21 \\
\hline 130 & 2017 & $19524 R$ & 1 & QCP & 1.00 & 0.66 & & & 16.3 & 16.4 & 0.28 & 0.49 \\
\hline 131 & 2015 & 19510R & 1 & QCP & 1.00 & & & & 17.2 & 17.0 & 0.00 & 0.00 \\
\hline 132 & 2015 & 19510R & 1 & QCP & 0.32 & 0.70 & 0.12 & 0.33 & 18.5 & 18.2 & 0.48 & 0.42 \\
\hline 133 & 2015 & $19536 R$ & 1 & PFP & 0.01 & 0.43 & 0.94 & 0.96 & 14.9 & 14.2 & 0.41 & 0.55 \\
\hline 134 & 2015 & $19522 \mathrm{R}$ & 1 & PFP & & & & & 13.5 & & 0.78 & \\
\hline 135 & 2015 & $19522 \mathrm{R}$ & 1 & QCP & 0.67 & 0.40 & 1.00 & & 14.1 & 14.4 & 0.44 & 0.73 \\
\hline 136 & 2015 & 19536R & 1 & QCP & 1.00 & & & & 15.9 & 16.2 & 0.00 & 0.00 \\
\hline
\end{tabular}




\begin{tabular}{|c|c|c|c|c|c|c|c|c|c|c|c|c|}
\hline $\begin{array}{l}\text { ICT } \\
\text { Code }\end{array}$ & Year & Mix Code & District & $\begin{array}{l}\text { Quality } \\
\text { Program }\end{array}$ & $\begin{array}{c}\text { MW } \\
\text { P-Value }\end{array}$ & $\begin{array}{l}\text { Levene's } \\
\text { P-Value }\end{array}$ & $\begin{array}{l}\text { Contractor } \\
\text { SW P-Value }\end{array}$ & $\begin{array}{c}\text { Agency SW } \\
\text { P-Value }\end{array}$ & $\begin{array}{c}\text { Contractor } \\
\text { Mean }\end{array}$ & $\begin{array}{l}\text { Agency } \\
\text { Mean }\end{array}$ & $\begin{array}{l}\text { Contractor } \\
\text { St. Dev. }\end{array}$ & $\begin{array}{l}\text { Agency } \\
\text { St. Dev. }\end{array}$ \\
\hline 137 & 2015 & $19524 R$ & 1 & QCP & 0.69 & 0.45 & 0.95 & 0.70 & 14.3 & 14.4 & 0.20 & 0.33 \\
\hline 138 & 2015 & 19510R & 1 & QCP & 0.67 & 0.77 & & & 19.0 & 18.7 & 0.92 & 0.64 \\
\hline 139 & 2015 & 19510R & 1 & QCP & 1.00 & & & & 19.7 & 19.7 & 0.00 & 0.00 \\
\hline 140 & 2015 & 19524R & 1 & QCP & 0.00 & 0.13 & 0.00 & 0.19 & 14.6 & 14.0 & 0.23 & 0.33 \\
\hline 141 & 2015 & 19665R & 1 & QCP & 0.38 & 0.39 & 0.24 & 0.64 & 15.8 & 15.6 & 0.90 & 0.68 \\
\hline 142 & 2015 & 19524R & 1 & QCP & 0.20 & 0.33 & & 0.82 & 15.2 & 14.1 & 0.14 & 0.60 \\
\hline 143 & 2015 & 19524R & 1 & QCP & 0.18 & 0.24 & 0.41 & 0.10 & 14.4 & 14.0 & 0.39 & 0.83 \\
\hline 144 & 2017 & 19510R & 1 & QCP & 0.50 & 0.94 & 0.31 & & 18.6 & 18.5 & 0.31 & 0.21 \\
\hline 145 & 2017 & 19510R & 1 & QCP & 0.67 & & & & 18.9 & 18.8 & 0.00 & 0.00 \\
\hline 146 & 2017 & 19510R & 1 & QCP & 0.60 & 0.59 & 0.78 & & 18.1 & 17.9 & 0.25 & 0.35 \\
\hline 147 & 2015 & 19510R & 1 & QCP & 0.67 & & & & 18.1 & 18.2 & 0.07 & 0.00 \\
\hline 148 & 2017 & 19522R & 1 & QCP & 0.40 & & 0.85 & & 12.8 & 13.1 & 0.17 & 0.00 \\
\hline 149 & 2015 & $19522 R$ & 1 & QCP & 1.00 & & 0.22 & & 13.2 & 13.2 & 0.44 & 0.00 \\
\hline 150 & 2015 & 19536R & 1 & QCP & 0.10 & 0.02 & 0.04 & 0.90 & 14.8 & 15.5 & 0.17 & 0.55 \\
\hline 151 & 2017 & 19524R & 1 & QCP & 0.33 & 0.00 & & & 15.5 & 16.1 & 0.07 & 0.00 \\
\hline 152 & 2017 & 19524R & 1 & QCP & & & & 0.16 & & 13.6 & & 0.14 \\
\hline 153 & 2017 & 19524R & 1 & QCP & 0.67 & 0.82 & & & 14.9 & 15.5 & 0.64 & 0.85 \\
\hline 154 & 2015 & 19525R & 1 & QCP & 0.50 & & 0.46 & & 15.0 & 15.3 & 0.21 & 0.00 \\
\hline 155 & 2017 & 19525R & 1 & QCP & 0.67 & & & & 14.7 & 14.9 & 0.07 & 0.00 \\
\hline 156 & 2015 & 19525R & 1 & QCP & 0.38 & 0.57 & 0.22 & & 15.1 & 14.8 & 0.19 & 0.24 \\
\hline 157 & 2015 & $19524 R$ & 1 & QCP & 0.80 & 0.96 & 0.30 & 0.53 & 15.4 & 15.4 & 0.22 & 0.22 \\
\hline 158 & 2017 & 18436R & 1 & QCP & 1.00 & 0.69 & & & 16.2 & 16.1 & 0.21 & 0.35 \\
\hline 159 & 2016 & 19655R & 1 & QCP & 0.67 & 0.11 & 0.86 & & 16.5 & 16.9 & 0.32 & 0.85 \\
\hline 160 & 2017 & 19655R & 1 & QCP & 0.40 & & 0.22 & & 16.8 & 16.5 & 0.24 & 0.00 \\
\hline 161 & 2015 & $19525 R$ & 1 & QCP & 0.04 & 0.58 & 0.50 & 0.06 & 15.3 & 15.9 & 0.16 & 0.21 \\
\hline 162 & 2017 & 19653R & 1 & QCP & 0.29 & 0.15 & 0.48 & 0.84 & 16.6 & 16.9 & 0.16 & 0.35 \\
\hline 163 & 2016 & 19665R & 1 & PFP & 0.28 & 0.84 & 0.48 & & 17.3 & 17.6 & 0.24 & 0.14 \\
\hline 164 & 2017 & 19665R & 1 & QCP & 1.00 & & 1.00 & & 16.7 & 16.7 & 0.21 & 0.00 \\
\hline 165 & 2015 & $19512 R$ & 1 & QCP & 0.23 & 0.99 & 0.12 & 0.37 & 13.4 & 12.9 & 0.53 & 0.50 \\
\hline 166 & 2015 & $19512 R$ & 1 & QCP & 0.53 & 0.85 & & 0.17 & 12.8 & 12.6 & 0.28 & 0.31 \\
\hline 167 & 2017 & 19525R & 1 & QCP & 0.40 & 0.47 & 0.54 & 0.92 & 14.8 & 14.3 & 0.36 & 0.65 \\
\hline 168 & 2017 & 19525R & 1 & QCP & 0.20 & 0.36 & & 0.90 & 15.0 & 14.2 & 0.14 & 0.55 \\
\hline 169 & 2017 & 19525R & 1 & QCP & 1.00 & & 0.78 & & 15.3 & 15.1 & 0.25 & 0.00 \\
\hline 170 & 2017 & $19525 R$ & 1 & PFP & 0.51 & 0.10 & 0.43 & 0.91 & 15.0 & 15.2 & 0.62 & 0.27 \\
\hline 171 & 2017 & 19655R & 1 & PFP & 0.24 & 0.02 & 0.32 & 0.81 & 16.8 & 17.5 & 0.24 & 0.85 \\
\hline
\end{tabular}




\begin{tabular}{|c|c|c|c|c|c|c|c|c|c|c|c|c|}
\hline $\begin{array}{l}\text { ICT } \\
\text { Code }\end{array}$ & Year & Mix Code & District & $\begin{array}{l}\text { Quality } \\
\text { Program }\end{array}$ & $\begin{array}{c}\text { MW } \\
\text { P-Value }\end{array}$ & $\begin{array}{l}\text { Levene's } \\
\text { P-Value }\end{array}$ & $\begin{array}{l}\text { Contractor } \\
\text { SW P-Value }\end{array}$ & $\begin{array}{c}\text { Agency SW } \\
\text { P-Value }\end{array}$ & $\begin{array}{c}\text { Contractor } \\
\text { Mean }\end{array}$ & $\begin{array}{l}\text { Agency } \\
\text { Mean }\end{array}$ & $\begin{array}{l}\text { Contractor } \\
\text { St. Dev. }\end{array}$ & $\begin{array}{l}\text { Agency } \\
\text { St. Dev. }\end{array}$ \\
\hline 172 & 2015 & $19512 R$ & 1 & QCP & & & & & 13.5 & & 0.00 & \\
\hline 173 & 2015 & $19522 R$ & 1 & QCP & & & & & 12.9 & & 0.00 & \\
\hline 174 & 2015 & 19522R & 1 & QCP & & & 0.43 & & 13.2 & & 0.27 & \\
\hline 175 & 2015 & 19536R & 1 & QCP & 1.00 & 0.39 & & 0.27 & 14.2 & 14.1 & 0.21 & 0.80 \\
\hline 176 & 2015 & 19510R & 1 & QCP & 0.60 & 0.00 & 0.00 & & 19.4 & 19.1 & 0.75 & 0.00 \\
\hline 177 & 2015 & 19510R & 1 & QCP & & & & & & 19.9 & & 0.00 \\
\hline 178 & 2015 & 19510R & 1 & QCP & 0.42 & 0.54 & 0.00 & 0.09 & 19.0 & 18.9 & 0.40 & 0.28 \\
\hline 179 & 2015 & 19522R & 1 & QCP & & & 0.58 & & 12.9 & & 0.14 & \\
\hline 180 & 2015 & 19522R & 1 & QCP & & & 0.14 & & 13.0 & & 0.49 & \\
\hline 181 & 2015 & $19522 R$ & 1 & QCP & & & 0.06 & & 12.8 & & 0.34 & \\
\hline 182 & 2015 & $19522 R$ & 1 & QCP & 0.14 & & 0.38 & & 12.8 & 11.8 & 0.31 & 0.00 \\
\hline 183 & 2015 & 19524R & 1 & PFP & 0.01 & 0.63 & 0.38 & 0.93 & 15.3 & 16.4 & 0.30 & 0.37 \\
\hline 184 & 2015 & 19510R & 1 & QCP & & & 0.18 & & 19.2 & & 0.18 & \\
\hline 185 & 2015 & 19510R & 1 & QCP & 0.03 & 0.02 & 0.73 & 0.02 & 18.7 & 18.1 & 0.29 & 0.06 \\
\hline 186 & 2017 & 19510R & 1 & QCP & 0.50 & & 0.64 & & 19.0 & 18.5 & 0.15 & 0.00 \\
\hline 187 & 2015 & $19522 R$ & 1 & QCP & 0.50 & & 0.04 & & 13.3 & 13.8 & 0.57 & 0.00 \\
\hline 188 & 2015 & 19524R & 1 & QCP & 1.00 & & 0.22 & & 14.8 & 14.9 & 0.15 & 0.00 \\
\hline 189 & 2015 & 19524R & 1 & QCP & 0.13 & 0.00 & 0.02 & & 15.1 & 13.8 & 0.06 & 0.85 \\
\hline 190 & 2015 & 19510R & 1 & QCP & 0.93 & 0.49 & 0.96 & & 19.0 & 19.0 & 0.22 & 0.28 \\
\hline 191 & 2015 & 19510R & 1 & QCP & 0.67 & & & & 19.0 & 18.6 & 0.14 & 0.00 \\
\hline 192 & 2015 & 19510R & 1 & PFP & 0.85 & 0.16 & 0.01 & 0.51 & 18.8 & 18.9 & 0.40 & 0.66 \\
\hline 193 & 2015 & 19510R & 1 & QCP & 1.00 & 0.06 & & & 18.9 & 19.3 & 0.07 & 1.56 \\
\hline 194 & 2015 & 19510R & 1 & QCP & 0.42 & 0.46 & 0.81 & & 18.8 & 18.5 & 0.33 & 0.42 \\
\hline 195 & 2015 & 19510R & 1 & QCP & & & 0.83 & & 18.9 & & 0.27 & \\
\hline 196 & 2017 & 19510R & 1 & QCP & 1.00 & & & & 18.6 & 18.0 & 0.00 & 0.00 \\
\hline 197 & 2017 & 19510R & 1 & QCP & 1.00 & & & & 18.8 & 18.7 & 0.35 & 0.00 \\
\hline 198 & 2017 & 19510R & 1 & QCP & 1.00 & & & & 19.0 & 19.0 & 0.28 & 0.00 \\
\hline 199 & 2017 & 19510R & 1 & QCP & 1.00 & & & 0.75 & 18.8 & 19.4 & 0.00 & 0.66 \\
\hline 200 & 2017 & 19510R & 1 & QCP & 1.00 & & & & 18.9 & 19.1 & 0.57 & 0.00 \\
\hline 201 & 2017 & 19510R & 1 & QCP & 1.00 & & 0.55 & & 18.9 & 18.6 & 0.30 & 0.00 \\
\hline 202 & 2017 & 19510R & 1 & QCP & 0.40 & & 0.49 & & 19.2 & 18.7 & 0.24 & 0.00 \\
\hline 203 & 2017 & 19510R & 1 & QCP & 1.00 & & & & 18.6 & 18.6 & 0.07 & 0.00 \\
\hline 204 & 2015 & 19665R & 1 & PFP & 0.03 & 0.05 & 0.08 & 0.23 & 17.1 & 16.8 & 0.17 & 0.33 \\
\hline 205 & 2015 & 19665R & 1 & PFP & 0.35 & 0.51 & 0.00 & 0.19 & 16.9 & 16.7 & 0.55 & 0.66 \\
\hline 206 & 2015 & 19665R & 1 & PFP & 0.49 & 0.81 & 0.04 & 0.05 & 16.6 & 16.3 & 0.51 & 0.47 \\
\hline
\end{tabular}




\begin{tabular}{|c|c|c|c|c|c|c|c|c|c|c|c|c|}
\hline $\begin{array}{c}\text { ICT } \\
\text { Code }\end{array}$ & Year & Mix Code & District & $\begin{array}{l}\text { Quality } \\
\text { Program }\end{array}$ & $\begin{array}{c}\text { MW } \\
\text { P-Value }\end{array}$ & $\begin{array}{l}\text { Levene's } \\
\text { P-Value }\end{array}$ & $\begin{array}{l}\text { Contractor } \\
\text { SW P-Value }\end{array}$ & $\begin{array}{c}\text { Agency SW } \\
\text { P-Value }\end{array}$ & $\begin{array}{c}\text { Contractor } \\
\text { Mean }\end{array}$ & $\begin{array}{l}\text { Agency } \\
\text { Mean }\end{array}$ & $\begin{array}{l}\text { Contractor } \\
\text { St. Dev. }\end{array}$ & $\begin{array}{l}\text { Agency } \\
\text { St. Dev. }\end{array}$ \\
\hline 207 & 2015 & $19522 R$ & 1 & $\mathrm{QCP}$ & 0.15 & 0.61 & 0.34 & 0.53 & 12.3 & 13.1 & 0.62 & 0.82 \\
\hline 208 & 2015 & 19524R & 1 & QCP & 0.17 & 0.00 & 0.45 & 0.23 & 14.9 & 14.1 & 0.32 & 1.06 \\
\hline 209 & 2015 & 19524R & 1 & QCP & 0.98 & 0.00 & 0.06 & 0.02 & 15.0 & 14.7 & 0.56 & 1.37 \\
\hline 210 & 2015 & 19524R & 1 & QCP & 0.50 & & 0.00 & & 14.9 & 15.8 & 0.52 & 0.00 \\
\hline 211 & 2015 & 19524R & 1 & QCP & 0.73 & 0.68 & 0.59 & 0.99 & 15.4 & 15.6 & 0.43 & 0.35 \\
\hline 212 & 2015 & $19524 \mathrm{R}$ & 1 & QCP & & & & & & 16.0 & & 0.00 \\
\hline 213 & 2017 & 19522R & 1 & QCP & & & 0.00 & & 13.1 & & 0.12 & \\
\hline 214 & 2015 & 19536R & 1 & PFP & 0.02 & 0.26 & 0.17 & 0.09 & 15.0 & 14.6 & 0.35 & 0.47 \\
\hline 215 & 2015 & 19510R & 1 & QCP & 1.00 & & & & 18.2 & 18.3 & 0.00 & 0.00 \\
\hline 216 & 2015 & 19510R & 1 & QCP & 0.32 & 0.31 & 0.22 & 0.33 & 18.6 & 18.8 & 0.33 & 0.46 \\
\hline 217 & 2015 & 19510R & 1 & QCP & 0.67 & & & & 18.8 & 19.2 & 0.00 & 0.00 \\
\hline 218 & 2015 & 19510R & 1 & QCP & 0.08 & 0.27 & 0.11 & 0.05 & 19.5 & 20.0 & 0.25 & 0.46 \\
\hline 219 & 2015 & 19510R & 1 & QCP & 0.67 & & & & 18.4 & 18.7 & 0.07 & 0.00 \\
\hline 220 & 2015 & 19510R & 1 & QCP & 0.67 & & & & 18.7 & 19.9 & 0.49 & 0.00 \\
\hline 221 & 2015 & 19522R & 1 & QCP & 1.00 & & & & 12.3 & 12.1 & 0.00 & 0.00 \\
\hline 222 & 2015 & 19522R & 1 & QCP & 0.92 & 0.36 & 0.94 & 0.31 & 12.4 & 12.3 & 0.75 & 1.08 \\
\hline 223 & 2015 & 19536R & 1 & QCP & 0.03 & 0.83 & 0.25 & 0.85 & 15.2 & 15.9 & 0.31 & 0.34 \\
\hline 224 & 2015 & 19536R & 1 & QCP & 0.75 & & 0.85 & & 15.0 & 15.3 & 0.45 & 0.00 \\
\hline 225 & 2015 & 19536R & 1 & QCP & 0.03 & 0.37 & 0.42 & 0.06 & 14.6 & 15.3 & 0.26 & 0.45 \\
\hline 226 & 2015 & 19536R & 1 & QCP & & & & & 14.9 & & 0.00 & \\
\hline 227 & 2016 & $19536 R$ & 1 & QCP & & & & & 14.6 & & 0.00 & \\
\hline 228 & 2015 & $19524 \mathrm{R}$ & 1 & PFP & 0.84 & 0.69 & 1.00 & 0.75 & 15.0 & 15.0 & 0.40 & 0.46 \\
\hline 229 & 2016 & $19524 \mathrm{R}$ & 1 & QCP & & & & & 14.8 & & 0.85 & \\
\hline 230 & 2016 & $19524 \mathrm{R}$ & 1 & QCP & & & & 0.68 & & 14.4 & & 0.58 \\
\hline 231 & 2015 & 19655R & 1 & $\mathrm{QCP}$ & 0.85 & 0.43 & 0.23 & 0.32 & 15.6 & 15.7 & 0.59 & 0.72 \\
\hline 232 & 2016 & $19522 \mathrm{R}$ & 1 & QCP & 0.53 & 0.36 & 0.86 & & 13.3 & 12.9 & 0.53 & 0.92 \\
\hline 233 & 2015 & $19522 \mathrm{R}$ & 1 & QCP & & & & & 13.6 & & 0.00 & \\
\hline 234 & 2015 & $19522 \mathrm{R}$ & 1 & QCP & & & & & 13.5 & & 0.00 & \\
\hline 235 & 2017 & $19524 R$ & 1 & QCP & 0.67 & 0.87 & & & 15.6 & 15.8 & 0.64 & 0.78 \\
\hline 236 & 2017 & $19524 R$ & 1 & QCP & 1.00 & & & & 15.0 & 14.6 & 0.00 & 0.00 \\
\hline 237 & 2017 & $19524 \mathrm{R}$ & 1 & QCP & 0.67 & & & & 15.3 & 16.3 & 0.42 & 0.00 \\
\hline 238 & 2017 & $19524 R$ & 1 & QCP & 1.00 & & & & 15.5 & 14.8 & 0.00 & 0.00 \\
\hline 239 & 2017 & $19524 R$ & 1 & PFP & 0.29 & 0.14 & 0.03 & & 15.2 & 14.6 & 0.24 & 0.57 \\
\hline 240 & 2017 & $19524 R$ & 1 & QCP & 1.00 & & & & 15.0 & 13.8 & 0.00 & 0.00 \\
\hline 241 & 2017 & $19524 R$ & 1 & QCP & 0.33 & 0.59 & & & 15.8 & 17.8 & 0.14 & 0.28 \\
\hline
\end{tabular}




\begin{tabular}{|c|c|c|c|c|c|c|c|c|c|c|c|c|}
\hline $\begin{array}{c}\text { ICT } \\
\text { Code }\end{array}$ & Year & Mix Code & District & $\begin{array}{l}\text { Quality } \\
\text { Program }\end{array}$ & $\begin{array}{c}\text { MW } \\
\text { P-Value }\end{array}$ & $\begin{array}{l}\text { Levene's } \\
\text { P-Value }\end{array}$ & $\begin{array}{l}\text { Contractor } \\
\text { SW P-Value }\end{array}$ & $\begin{array}{c}\text { Agency SW } \\
\text { P-Value }\end{array}$ & $\begin{array}{c}\text { Contractor } \\
\text { Mean }\end{array}$ & $\begin{array}{l}\text { Agency } \\
\text { Mean }\end{array}$ & $\begin{array}{l}\text { Contractor } \\
\text { St. Dev. }\end{array}$ & $\begin{array}{l}\text { Agency } \\
\text { St. Dev. }\end{array}$ \\
\hline 242 & 2017 & 19514R & 1 & QCP & 1.00 & & & & 15.7 & 15.6 & 0.00 & 0.00 \\
\hline 243 & 2015 & $19514 R$ & 1 & QCP & 0.40 & & 0.48 & & 15.7 & 12.8 & 0.84 & 0.00 \\
\hline 244 & 2017 & 19524R & 1 & QCP & 0.34 & 0.22 & 0.06 & 0.64 & 14.8 & 15.3 & 0.27 & 0.61 \\
\hline 245 & 2017 & 19524R & 1 & QCP & 0.11 & 0.50 & 0.57 & 0.27 & 15.7 & 16.3 & 0.51 & 0.34 \\
\hline 246 & 2015 & 19525R & 1 & QCP & 0.40 & 0.65 & 0.65 & 0.78 & 15.9 & 16.1 & 0.31 & 0.21 \\
\hline 247 & 2017 & 19525R & 1 & QCP & 0.50 & & 0.25 & & 15.4 & 15.9 & 0.38 & 0.00 \\
\hline 248 & 2017 & 19525R & 1 & QCP & 1.00 & & & & 15.5 & 15.3 & 0.00 & 0.00 \\
\hline 249 & 2017 & 19525R & 1 & QCP & 0.10 & 0.02 & 0.00 & & 15.9 & 16.6 & 0.04 & 0.21 \\
\hline 250 & 2015 & 19525R & 1 & QCP & 0.83 & 0.26 & 0.93 & 0.25 & 15.5 & 15.5 & 0.29 & 0.11 \\
\hline 251 & 2017 & 19525R & 1 & QCP & 1.00 & & & & 15.1 & 15.8 & 0.00 & 0.00 \\
\hline 252 & 2017 & 19525R & 1 & QCP & 1.00 & & & & 15.3 & 15.3 & 0.42 & 0.00 \\
\hline 253 & 2016 & 19510R & 1 & QCP & 1.00 & & & & 17.8 & 17.7 & 0.00 & 0.00 \\
\hline 254 & 2016 & 19510R & 1 & QCP & & & & & 18.1 & & 0.00 & \\
\hline 255 & 2016 & 19510R & 1 & QCP & 1.00 & & & & 19.0 & 19.4 & 0.00 & 0.00 \\
\hline 256 & 2016 & 19510R & 1 & QCP & 0.60 & 0.79 & 0.00 & & 18.6 & 18.7 & 0.35 & 0.21 \\
\hline 257 & 2017 & 19510R & 1 & QCP & 1.00 & & & & 18.0 & 18.0 & 0.21 & 0.00 \\
\hline 258 & 2017 & 19510R & 1 & QCP & 0.67 & & & & 18.8 & 19.1 & 0.21 & 0.00 \\
\hline 259 & 2017 & 19510R & 1 & QCP & 0.33 & 0.59 & & & 17.7 & 18.5 & 0.28 & 0.14 \\
\hline 260 & 2017 & 19510R & 1 & QCP & 0.67 & & & & 17.6 & 18.0 & 0.00 & 0.00 \\
\hline 261 & 2017 & 19525R & 1 & QCP & 0.75 & 0.10 & 0.15 & 0.83 & 15.0 & 15.3 & 0.60 & 1.31 \\
\hline 262 & 2017 & 19536R & 1 & QCP & 1.00 & & & & 14.8 & 14.8 & 0.07 & 0.00 \\
\hline 263 & 2015 & 19536R & 1 & QCP & 1.00 & & 0.84 & & 14.7 & 14.6 & 0.35 & 0.00 \\
\hline 264 & 2017 & $19524 \mathrm{R}$ & 1 & QCP & 0.50 & & 0.70 & & 15.6 & 16.4 & 0.56 & 0.00 \\
\hline 265 & 2017 & $19524 \mathrm{R}$ & 1 & QCP & 0.20 & 0.25 & 0.64 & 0.00 & 14.5 & 15.2 & 0.15 & 0.40 \\
\hline 266 & 2017 & $19524 R$ & 1 & $\mathrm{QCP}$ & 1.00 & & 0.93 & & 15.0 & 14.8 & 0.94 & 0.00 \\
\hline 267 & 2015 & $19665 R$ & 1 & QCP & 0.23 & 0.98 & 0.01 & 0.43 & 16.2 & 16.5 & 0.31 & 0.28 \\
\hline 268 & 2015 & $19525 R$ & 1 & QCP & 0.50 & 0.51 & 0.63 & & 15.1 & 15.3 & 0.22 & 0.08 \\
\hline 269 & 2015 & 19510R & 1 & QCP & 0.21 & 0.20 & 0.09 & 0.52 & 18.8 & 20.2 & 1.04 & 1.82 \\
\hline 270 & 2015 & $19524 R$ & 1 & PFP & 0.00 & 0.36 & 0.07 & 0.31 & 14.2 & 15.0 & 0.60 & 0.44 \\
\hline 271 & 2015 & 19510R & 1 & QCP & 0.37 & 0.04 & 0.27 & 0.24 & 17.6 & 18.0 & 0.74 & 0.35 \\
\hline 272 & 2016 & $19514 \mathrm{R}$ & 1 & QCP & 0.03 & 0.34 & 0.03 & 0.03 & 15.8 & 16.8 & 0.42 & 0.63 \\
\hline 273 & 2016 & $19514 R$ & 1 & QCP & 0.01 & 0.51 & 0.11 & 0.52 & 15.3 & 16.3 & 0.60 & 0.78 \\
\hline 274 & 2017 & 19510R & 1 & QCP & 0.80 & 0.49 & 0.37 & & 18.9 & 18.9 & 0.73 & 1.06 \\
\hline 275 & 2017 & 19510R & 1 & QCP & 0.38 & 0.09 & 0.00 & 0.02 & 18.7 & 18.6 & 0.43 & 0.70 \\
\hline 276 & 2017 & 19510R & 1 & QCP & 1.00 & & 0.25 & & 18.4 & 18.5 & 0.38 & 0.00 \\
\hline
\end{tabular}




\begin{tabular}{|c|c|c|c|c|c|c|c|c|c|c|c|c|}
\hline $\begin{array}{l}\text { ICT } \\
\text { Code }\end{array}$ & Year & Mix Code & District & $\begin{array}{l}\text { Quality } \\
\text { Program }\end{array}$ & $\begin{array}{c}\text { MW } \\
\text { P-Value }\end{array}$ & $\begin{array}{l}\text { Levene's } \\
\text { P-Value }\end{array}$ & $\begin{array}{l}\text { Contractor } \\
\text { SW P-Value }\end{array}$ & $\begin{array}{c}\text { Agency SW } \\
\text { P-Value }\end{array}$ & $\begin{array}{c}\text { Contractor } \\
\text { Mean }\end{array}$ & $\begin{array}{l}\text { Agency } \\
\text { Mean }\end{array}$ & $\begin{array}{l}\text { Contractor } \\
\text { St. Dev. }\end{array}$ & $\begin{array}{l}\text { Agency } \\
\text { St. Dev. }\end{array}$ \\
\hline 277 & 2016 & $19512 R$ & 1 & QCP & 0.01 & 0.38 & 0.69 & 0.98 & 14.2 & 14.8 & 0.27 & 0.38 \\
\hline 278 & 2017 & 19524R & 1 & QCP & 0.18 & 0.59 & 0.80 & & 14.5 & 14.9 & 0.36 & 0.14 \\
\hline 279 & 2017 & 19524R & 1 & QCP & 0.60 & 0.55 & 0.00 & & 14.4 & 14.5 & 0.17 & 0.07 \\
\hline 280 & 2017 & 19525R & 1 & PFP & 0.09 & 0.18 & 0.07 & 0.43 & 15.2 & 15.6 & 0.54 & 0.72 \\
\hline 281 & 2017 & 19525R & 1 & QCP & 0.56 & 0.96 & 0.27 & 0.51 & 15.3 & 15.1 & 0.58 & 0.60 \\
\hline 282 & 2015 & 19510R & 1 & QCP & 0.27 & 0.27 & & 0.35 & 18.1 & 17.4 & 0.14 & 0.76 \\
\hline 283 & 2015 & 19524R & 1 & QCP & 0.75 & 0.89 & 0.54 & 0.13 & 14.5 & 14.4 & 0.36 & 0.36 \\
\hline 284 & 2015 & 19522R & 1 & QCP & & & & & & 13.5 & & 0.00 \\
\hline 285 & 2016 & $19522 R$ & 1 & QCP & & & & & 14.6 & & 0.00 & \\
\hline 286 & 2016 & $19522 R$ & 1 & QCP & & & 1.00 & & 13.4 & & 0.10 & \\
\hline 287 & 2015 & $19522 R$ & 1 & QCP & 0.67 & & & & 12.4 & 11.6 & 0.00 & 0.06 \\
\hline 288 & 2016 & 19532R & 1 & QCP & 1.00 & 0.59 & 0.30 & & 13.6 & 13.6 & 0.32 & 0.14 \\
\hline 289 & 2017 & 19510R & 1 & QCP & 1.00 & & & & 18.7 & 18.9 & 0.00 & 0.00 \\
\hline 290 & 2016 & 19510R & 1 & QCP & & & & & & 18.3 & & 0.00 \\
\hline 291 & 2017 & 19510R & 1 & QCP & 0.36 & 0.72 & 0.07 & 0.78 & 18.7 & 18.1 & 0.71 & 0.50 \\
\hline 292 & 2015 & 19524R & 1 & QCP & 0.53 & 0.48 & 0.62 & & 15.4 & 15.1 & 0.56 & 0.82 \\
\hline 293 & 2016 & 19524R & 1 & QCP & & & & & & 15.4 & & 0.00 \\
\hline 294 & 2016 & 19524R & 1 & QCP & 1.00 & & & & 15.3 & 14.9 & 0.00 & 0.00 \\
\hline 295 & 2015 & 19510R & 1 & QCP & 0.78 & 0.87 & 0.99 & 0.48 & 18.8 & 18.7 & 0.46 & 0.45 \\
\hline 296 & 2015 & 19665R & 1 & PFP & 0.00 & 0.95 & 0.92 & 0.07 & 17.0 & 16.3 & 0.60 & 0.60 \\
\hline 297 & 2017 & 19510R & 1 & QCP & 0.18 & & 0.04 & & 18.9 & 19.4 & 0.25 & 0.00 \\
\hline 298 & 2016 & 19510R & 1 & QCP & 1.00 & & & & 18.7 & 18.6 & 0.07 & 0.00 \\
\hline 299 & 2016 & 19524R & 1 & QCP & 1.00 & & 0.64 & & 14.7 & 14.6 & 0.15 & 0.00 \\
\hline 300 & 2016 & 19524R & 1 & QCP & 0.67 & & & & 14.8 & 14.6 & 0.14 & 0.00 \\
\hline 301 & 2015 & 19536R & 1 & PFP & & & & & 15.2 & & 0.00 & \\
\hline 302 & 2015 & 19536R & 1 & QCP & 0.33 & 1.00 & & & 15.6 & 15.0 & 0.14 & 0.14 \\
\hline 303 & 2015 & 19536R & 1 & PFP & 0.05 & 0.20 & 0.00 & 0.00 & 14.5 & 14.0 & 1.13 & 0.76 \\
\hline 304 & 2015 & 19536R & 1 & QCP & & & 0.37 & & 15.2 & & 1.12 & \\
\hline 305 & 2015 & $19512 R$ & 1 & QCP & 0.33 & & 0.93 & & 13.0 & 12.7 & 0.19 & 0.00 \\
\hline 306 & 2017 & $19525 R$ & 1 & QCP & 0.33 & & 0.03 & & 15.5 & 15.8 & 0.19 & 0.00 \\
\hline 307 & 2017 & 19525R & 1 & QCP & 1.00 & & & & 15.5 & 15.9 & 0.00 & 0.00 \\
\hline 308 & 2016 & 19525R & 1 & QCP & 0.86 & & 0.14 & & 15.6 & 16.0 & 0.56 & 0.00 \\
\hline 309 & 2017 & 19525R & 1 & PFP & 0.60 & 0.28 & 0.06 & 0.56 & 15.3 & 15.7 & 0.53 & 0.84 \\
\hline 310 & 2017 & $19512 R$ & 1 & QCP & & & & & 15.5 & & 0.28 & \\
\hline 311 & 2017 & $19512 R$ & 1 & QCP & & & & & 14.8 & & 0.00 & \\
\hline
\end{tabular}




\begin{tabular}{|c|c|c|c|c|c|c|c|c|c|c|c|c|}
\hline $\begin{array}{c}\text { ICT } \\
\text { Code }\end{array}$ & Year & Mix Code & District & $\begin{array}{l}\text { Quality } \\
\text { Program }\end{array}$ & $\begin{array}{c}\text { MW } \\
\text { P-Value }\end{array}$ & $\begin{array}{l}\text { Levene's } \\
\text { P-Value }\end{array}$ & $\begin{array}{l}\text { Contractor } \\
\text { SW P-Value }\end{array}$ & $\begin{array}{c}\text { Agency SW } \\
\text { P-Value }\end{array}$ & $\begin{array}{c}\text { Contractor } \\
\text { Mean }\end{array}$ & $\begin{array}{c}\text { Agency } \\
\text { Mean }\end{array}$ & $\begin{array}{l}\text { Contractor } \\
\text { St. Dev. }\end{array}$ & $\begin{array}{l}\text { Agency } \\
\text { St. Dev. }\end{array}$ \\
\hline 312 & 2017 & $19536 R$ & 1 & $\mathrm{QCP}$ & 0.67 & 0.59 & & & 15.9 & 16.2 & 0.35 & 0.71 \\
\hline 313 & 2016 & 19536R & 1 & QCP & & & 0.64 & & 15.2 & & 0.15 & \\
\hline 314 & 2017 & 19510R & 1 & QCP & 0.67 & 0.69 & & & 18.6 & 18.4 & 0.35 & 0.21 \\
\hline 315 & 2017 & 19510R & 1 & QCP & 0.50 & & 0.78 & & 18.5 & 19.1 & 0.25 & 0.00 \\
\hline 316 & 2017 & 19510R & 1 & QCP & 0.86 & 0.96 & 0.80 & 1.00 & 18.4 & 18.3 & 0.22 & 0.20 \\
\hline 317 & 2017 & 19510R & 1 & QCP & & & & & 18.3 & & 0.00 & \\
\hline 318 & 2017 & 19665R & 1 & QCP & 1.00 & & & & 17.7 & 18.8 & 0.00 & 0.00 \\
\hline 319 & 2017 & 19665R & 1 & PFP & 0.44 & 0.91 & 0.00 & 0.27 & 17.7 & 17.2 & 0.87 & 0.70 \\
\hline 320 & 2017 & 19525R & 1 & QCP & 1.00 & & & & 15.9 & 16.4 & 0.00 & 0.00 \\
\hline 321 & 2017 & 19522R & 1 & QCP & & & 0.39 & & 13.7 & & 0.30 & \\
\hline 322 & 2017 & 19522R & 1 & QCP & & & & & 13.0 & & 0.00 & \\
\hline 323 & 2017 & 19653R & 1 & PFP & 0.27 & 0.75 & 0.14 & 0.74 & 16.3 & 16.4 & 0.50 & 0.47 \\
\hline 324 & 2017 & 19655 & 1 & PFP & 0.42 & 0.22 & 0.05 & 0.02 & 17.6 & 17.5 & 0.51 & 0.43 \\
\hline 325 & 2015 & $19532 R$ & 1 & QCP & 0.70 & 0.26 & 0.88 & 0.06 & 13.4 & 13.7 & 0.42 & 1.10 \\
\hline 326 & 2017 & 19532R & 1 & QCP & & & & & 13.6 & & 0.00 & \\
\hline 327 & 2017 & 19532R & 1 & QCP & 0.67 & & & & 14.0 & 13.4 & 0.00 & 0.00 \\
\hline 328 & 2017 & 19524R & 1 & QCP & 1.00 & & 0.10 & & 15.2 & 15.3 & 0.46 & 0.00 \\
\hline 329 & 2017 & 19524R & 1 & QCP & 0.08 & 0.59 & 0.03 & 0.90 & 15.1 & 14.8 & 0.27 & 0.33 \\
\hline 330 & 2017 & 19524R & 1 & QCP & 0.10 & 0.90 & 0.96 & 0.08 & 15.2 & 15.4 & 0.32 & 0.33 \\
\hline 331 & 2017 & $19522 R$ & 1 & QCP & 0.32 & 0.36 & 0.34 & 0.00 & 13.5 & 13.6 & 0.48 & 0.34 \\
\hline 332 & 2015 & $19522 \mathrm{R}$ & 1 & QCP & 0.86 & & 0.38 & & 13.2 & 13.4 & 0.49 & 0.00 \\
\hline 333 & 2015 & 19522R & 1 & QCP & & & & & 13.6 & & 0.00 & \\
\hline 334 & 2015 & $19524 \mathrm{R}$ & 1 & PFP & 0.00 & 0.29 & 0.84 & 0.53 & 15.1 & 14.4 & 0.31 & 0.47 \\
\hline 335 & 2015 & $19524 \mathrm{R}$ & 1 & QCP & 0.18 & 0.48 & 0.38 & 0.14 & 15.7 & 15.3 & 0.55 & 0.38 \\
\hline 336 & 2015 & $19524 R$ & 1 & $\mathrm{QCP}$ & 0.67 & & & & 16.1 & 15.9 & 0.00 & 0.00 \\
\hline 337 & 2015 & $19522 \mathrm{R}$ & 1 & QCP & 0.12 & 0.97 & 0.24 & 0.65 & 12.9 & 12.5 & 0.41 & 0.37 \\
\hline 338 & 2015 & $19524 \mathrm{R}$ & 1 & QCP & 0.46 & 0.92 & 0.83 & 0.38 & 14.9 & 14.8 & 0.35 & 0.31 \\
\hline 339 & 2015 & $19522 \mathrm{R}$ & 1 & QCP & & & & & 12.7 & & 0.00 & \\
\hline 340 & 2015 & $19524 R$ & 1 & QCP & 0.45 & 0.27 & 0.02 & 0.00 & 14.4 & 14.4 & 0.10 & 0.17 \\
\hline 341 & 2015 & $19524 R$ & 1 & PFP & & & & & 14.8 & & 0.57 & \\
\hline 342 & 2015 & 19510R & 1 & QCP & 0.40 & & 0.01 & & 15.8 & 14.3 & 1.66 & 0.00 \\
\hline 343 & 2015 & 19510R & 1 & PFP & 0.00 & 0.18 & 0.02 & 0.11 & 18.4 & 17.5 & 0.32 & 0.48 \\
\hline 344 & 2015 & 19510R & 1 & QCP & 0.04 & 0.00 & 0.93 & & 18.6 & 18.1 & 0.19 & 0.00 \\
\hline 345 & 2015 & 19510R & 1 & PFP & 0.19 & 0.65 & 0.66 & 0.99 & 18.8 & 18.6 & 0.28 & 0.36 \\
\hline 346 & 2015 & 19510R & 1 & QCP & & & & & & 18.2 & & 0.00 \\
\hline
\end{tabular}




\begin{tabular}{|c|c|c|c|c|c|c|c|c|c|c|c|c|}
\hline $\begin{array}{c}\text { ICT } \\
\text { Code }\end{array}$ & Year & Mix Code & District & $\begin{array}{l}\text { Quality } \\
\text { Program }\end{array}$ & $\begin{array}{c}\text { MW } \\
\text { P-Value }\end{array}$ & $\begin{array}{l}\text { Levene's } \\
\text { P-Value }\end{array}$ & $\begin{array}{l}\text { Contractor } \\
\text { SW P-Value }\end{array}$ & $\begin{array}{c}\text { Agency SW } \\
\text { P-Value }\end{array}$ & $\begin{array}{c}\text { Contractor } \\
\text { Mean }\end{array}$ & $\begin{array}{l}\text { Agency } \\
\text { Mean }\end{array}$ & $\begin{array}{l}\text { Contractor } \\
\text { St. Dev. }\end{array}$ & $\begin{array}{l}\text { Agency } \\
\text { St. Dev. }\end{array}$ \\
\hline 347 & 2015 & 19510R & 1 & $\mathrm{QCP}$ & 1.00 & & 0.71 & & 18.3 & 18.2 & 0.39 & 0.00 \\
\hline 348 & 2015 & 19510R & 1 & PFP & 0.47 & 0.00 & 0.05 & 0.00 & 18.5 & 12.4 & 0.14 & 7.99 \\
\hline 349 & 2015 & 19510R & 1 & QCP & & & 0.41 & & 18.4 & & 0.47 & \\
\hline 350 & 2015 & 19510R & 1 & QCP & 0.50 & & 0.78 & & 18.5 & 18.2 & 0.25 & 0.00 \\
\hline 351 & 2015 & 19510R & 1 & QCP & 1.00 & 0.54 & & & 18.3 & 18.3 & 0.35 & 0.78 \\
\hline 352 & 2015 & 19510R & 1 & QCP & 0.67 & & & & 18.6 & 19.2 & 0.35 & 0.00 \\
\hline 353 & 2015 & 19522R & 1 & QCP & & & & & & 13.0 & & 0.00 \\
\hline 354 & 2015 & 19536R & 1 & QCP & 0.70 & 0.03 & 0.28 & 0.53 & 15.4 & 15.6 & 0.30 & 1.32 \\
\hline 355 & 2015 & 19536R & 1 & QCP & 0.64 & 0.41 & 0.98 & 0.09 & 15.1 & 14.9 & 0.56 & 0.37 \\
\hline 356 & 2015 & 19536R & 1 & PFP & 0.88 & 0.01 & 0.60 & 0.15 & 14.8 & 14.8 & 0.33 & 0.71 \\
\hline 357 & 2016 & 19524R & 1 & QCP & 1.00 & & & & 14.3 & 14.0 & 0.00 & 0.00 \\
\hline 358 & 2017 & 19524R & 1 & QCP & 0.58 & 0.36 & 0.25 & 0.49 & 15.1 & 14.8 & 0.54 & 0.33 \\
\hline 359 & 2015 & 19665R & 1 & QCP & 0.98 & 0.12 & 0.54 & 0.14 & 17.5 & 17.3 & 0.65 & 1.39 \\
\hline 360 & 2015 & 19665R & 1 & PFP & & & 0.56 & & 17.7 & & 0.70 & \\
\hline 361 & 2017 & 19510R & 1 & QCP & 0.46 & 0.48 & 0.31 & 0.13 & 18.1 & 18.0 & 0.35 & 0.54 \\
\hline 362 & 2015 & 19655R & 1 & PFP & & & 0.13 & & 17.3 & & 0.26 & \\
\hline 363 & 2016 & 19522R & 1 & QCP & 0.52 & 0.96 & 0.47 & 0.80 & 13.8 & 13.5 & 0.51 & 0.50 \\
\hline 364 & 2016 & 19524R & 1 & QCP & & & & & 14.8 & & 0.00 & \\
\hline 365 & 2016 & 19514R & 1 & QCP & 1.00 & & & & 14.8 & 14.4 & 0.00 & 0.00 \\
\hline 366 & 2016 & 19536R & 1 & QCP & 0.67 & & & & 14.7 & 14.4 & 0.14 & 0.00 \\
\hline 367 & 2016 & $19532 \mathrm{R}$ & 1 & QCP & 1.00 & 0.44 & 0.98 & 0.03 & 14.3 & 14.1 & 0.33 & 0.62 \\
\hline 368 & 2017 & $19522 \mathrm{R}$ & 1 & QCP & 0.33 & & 0.17 & & 13.7 & 13.4 & 0.13 & 0.00 \\
\hline 369 & 2017 & $19522 \mathrm{R}$ & 1 & QCP & 0.80 & & 0.33 & & 13.3 & 13.6 & 0.49 & 0.00 \\
\hline 370 & 2017 & $19524 \mathrm{R}$ & 1 & QCP & 0.65 & 0.23 & 0.33 & 0.34 & 15.1 & 15.1 & 0.31 & 0.53 \\
\hline 371 & 2017 & $19524 R$ & 1 & PFP & 0.31 & 0.84 & 0.01 & 0.30 & 15.0 & 15.2 & 0.57 & 0.49 \\
\hline 372 & 2017 & 19510R & 1 & QCP & 0.57 & & 0.21 & & 18.0 & 17.8 & 0.18 & 0.00 \\
\hline 373 & 2017 & 19510R & 1 & QCP & 0.93 & 0.41 & 0.33 & & 18.7 & 18.8 & 0.50 & 0.14 \\
\hline 374 & 2017 & 19510R & 1 & QCP & 1.00 & & & & 18.0 & 17.5 & 0.00 & 0.00 \\
\hline 375 & 2017 & $19525 R$ & 1 & QCP & 0.63 & 0.20 & 0.04 & 0.27 & 15.5 & 16.1 & 0.37 & 1.12 \\
\hline 376 & 2017 & 19510R & 1 & QCP & 0.51 & 0.19 & 0.27 & 0.42 & 18.4 & 17.9 & 0.29 & 0.68 \\
\hline 377 & 2017 & 19510R & 1 & QCP & 0.63 & 0.71 & 0.58 & 0.36 & 18.2 & 18.0 & 0.22 & 0.26 \\
\hline 378 & 2017 & $19653 R$ & 1 & QCP & & & & & 15.4 & & 0.00 & \\
\hline 379 & 2017 & $19653 R$ & 1 & PFP & 0.13 & 0.16 & 0.34 & 0.84 & 16.1 & 15.7 & 0.51 & 0.72 \\
\hline 380 & 2017 & $19525 R$ & 1 & PFP & & & & & & 15.2 & & 0.57 \\
\hline 381 & 2017 & 19525R & 1 & PFP & 0.22 & 0.11 & 0.38 & 0.10 & 15.1 & 15.4 & 0.34 & 0.74 \\
\hline
\end{tabular}




\begin{tabular}{|c|c|c|c|c|c|c|c|c|c|c|c|c|}
\hline $\begin{array}{l}\text { ICT } \\
\text { Code }\end{array}$ & Year & Mix Code & District & $\begin{array}{l}\text { Quality } \\
\text { Program }\end{array}$ & $\begin{array}{c}\text { MW } \\
\text { P-Value }\end{array}$ & $\begin{array}{l}\text { Levene's } \\
\text { P-Value }\end{array}$ & $\begin{array}{l}\text { Contractor } \\
\text { SW P-Value }\end{array}$ & $\begin{array}{c}\text { Agency SW } \\
\text { P-Value }\end{array}$ & $\begin{array}{c}\text { Contractor } \\
\text { Mean }\end{array}$ & $\begin{array}{l}\text { Agency } \\
\text { Mean }\end{array}$ & $\begin{array}{l}\text { Contractor } \\
\text { St. Dev. }\end{array}$ & $\begin{array}{l}\text { Agency } \\
\text { St. Dev. }\end{array}$ \\
\hline 382 & 2017 & 19655R & 1 & PFP & 0.12 & 0.07 & 0.71 & 0.27 & 16.5 & 16.1 & 0.41 & 0.76 \\
\hline 383 & 2017 & 19510R & 1 & QCP & 0.00 & 0.10 & 0.17 & 0.32 & 18.5 & 18.1 & 0.30 & 0.15 \\
\hline 384 & 2017 & 19665R & 1 & PFP & 0.32 & 0.61 & 0.00 & 0.02 & 17.0 & 17.4 & 1.59 & 1.83 \\
\hline 385 & 2017 & 19665R & 1 & QCP & 0.64 & 0.96 & 0.05 & 0.99 & 16.3 & 16.1 & 0.34 & 0.34 \\
\hline 386 & 2015 & $19512 R$ & 1 & QCP & 0.95 & 0.21 & 0.20 & & 13.5 & 13.4 & 0.61 & 1.13 \\
\hline 387 & 2015 & 19514R & 1 & QCP & 0.67 & & & & 15.2 & 14.6 & 0.07 & 0.00 \\
\hline 388 & 2015 & $19522 R$ & 1 & QCP & 0.67 & & & & 13.2 & 12.9 & 0.07 & 0.00 \\
\hline 389 & 2016 & $19606 \mathrm{~F}$ & 2 & PFP & 0.41 & 0.45 & 0.56 & 0.27 & 14.9 & 15.0 & 0.53 & 0.61 \\
\hline 390 & 2014 & 19514R & 2 & QCP & & & & & & & & \\
\hline 391 & 2015 & 19514R & 2 & QCP & & & & & 15.8 & & 0.00 & \\
\hline 392 & 2015 & 19604FR & 2 & QCP & 0.85 & 0.50 & 0.86 & 0.86 & 13.5 & 13.8 & 1.40 & 0.97 \\
\hline 393 & 2015 & 19514R & 2 & QCP & 0.63 & 0.36 & 0.65 & 0.52 & 15.1 & 15.3 & 0.79 & 0.54 \\
\hline 394 & 2016 & $19512 R$ & 4 & QCP & & & & & 13.1 & & 0.00 & \\
\hline 395 & 2016 & 19535R & 2 & QCP & 0.32 & 0.39 & 0.12 & 0.01 & 15.9 & 16.3 & 1.00 & 0.71 \\
\hline 396 & 2015 & 19534R & 2 & PFP & 0.30 & 0.30 & 0.07 & 0.30 & 15.4 & 15.3 & 0.49 & 0.57 \\
\hline 397 & 2015 & $19532 R$ & 2 & PFP & 0.27 & 0.99 & 0.18 & 0.27 & 13.4 & 13.3 & 0.43 & 0.43 \\
\hline 398 & 2015 & 19514R & 2 & QCP & 0.33 & 0.42 & 0.37 & 0.21 & 15.7 & 15.5 & 0.46 & 0.35 \\
\hline 399 & 2017 & 19514R & 2 & QCP & 0.80 & & 0.11 & & 15.6 & 16.0 & 0.63 & 0.00 \\
\hline 400 & 2015 & $19524 R$ & 2 & QCP & 0.50 & 0.80 & 0.17 & 0.36 & 15.4 & 15.1 & 0.71 & 0.53 \\
\hline 401 & 2015 & 19514R & 2 & QCP & 0.01 & 0.11 & 0.75 & 0.21 & 14.1 & 13.7 & 0.44 & 0.25 \\
\hline 402 & 2015 & 19604FR & 2 & QCP & 0.31 & 0.84 & 0.07 & 0.98 & 14.6 & 14.2 & 0.43 & 0.38 \\
\hline 403 & 2015 & 19604FR & 2 & QCP & 0.40 & 0.77 & 0.41 & 0.53 & 14.3 & 14.0 & 0.39 & 0.47 \\
\hline 404 & 2015 & 19514R & 2 & QCP & 0.76 & 0.56 & 0.67 & 0.26 & 15.0 & 14.8 & 0.62 & 0.82 \\
\hline 405 & 2016 & 19604FR & 2 & QCP & 0.03 & 0.01 & 0.12 & 0.15 & 14.8 & 14.5 & 0.43 & 0.19 \\
\hline 406 & 2016 & $19514 R$ & 2 & QCP & 0.00 & 0.16 & 0.01 & 0.00 & 15.6 & 15.2 & 0.59 & 0.44 \\
\hline 407 & 2016 & 19516R & 2 & QCP & 0.67 & 0.66 & & & 15.0 & 14.5 & 0.28 & 0.49 \\
\hline 408 & 2017 & 19514R & 2 & QCP & 0.28 & 0.58 & 0.99 & 0.47 & 15.5 & 15.0 & 0.65 & 0.78 \\
\hline 409 & 2017 & $19512 R$ & 2 & QCP & 0.02 & 0.59 & 0.66 & 0.61 & 13.4 & 12.7 & 0.60 & 0.46 \\
\hline 410 & 2017 & $19512 R$ & 2 & QCP & 0.59 & 0.02 & 0.88 & 0.65 & 13.8 & 13.4 & 0.68 & 0.13 \\
\hline 411 & 2017 & $19514 R$ & 2 & QCP & 0.03 & 0.02 & 0.27 & 0.23 & 15.8 & 15.3 & 0.77 & 0.24 \\
\hline 412 & 2016 & 19516R & 2 & QCP & 0.67 & 0.66 & & & 15.0 & 14.5 & 0.28 & 0.49 \\
\hline 413 & 2016 & 19513R & 2 & QCP & 0.33 & 0.00 & & & 14.0 & 13.6 & 0.00 & 0.21 \\
\hline 414 & 2017 & 19514R & 2 & QCP & 0.80 & & 0.72 & & 15.9 & 15.7 & 0.79 & 0.00 \\
\hline 415 & 2015 & $19514 R$ & 2 & QCP & 0.33 & 0.70 & 0.47 & 0.13 & 15.4 & 15.1 & 0.50 & 0.56 \\
\hline 416 & 2017 & 19513R & 2 & QCP & & & & & 14.4 & & 0.20 & \\
\hline
\end{tabular}




\begin{tabular}{|c|c|c|c|c|c|c|c|c|c|c|c|c|}
\hline $\begin{array}{l}\text { ICT } \\
\text { Code }\end{array}$ & Year & Mix Code & District & $\begin{array}{l}\text { Quality } \\
\text { Program }\end{array}$ & $\begin{array}{c}\text { MW } \\
\text { P-Value }\end{array}$ & $\begin{array}{l}\text { Levene's } \\
\text { P-Value }\end{array}$ & $\begin{array}{l}\text { Contractor } \\
\text { SW P-Value }\end{array}$ & $\begin{array}{c}\text { Agency SW } \\
\text { P-Value }\end{array}$ & $\begin{array}{c}\text { Contractor } \\
\text { Mean }\end{array}$ & $\begin{array}{l}\text { Agency } \\
\text { Mean }\end{array}$ & $\begin{array}{l}\text { Contractor } \\
\text { St. Dev. }\end{array}$ & $\begin{array}{l}\text { Agency } \\
\text { St. Dev. }\end{array}$ \\
\hline 417 & 2015 & $19514 R$ & 2 & QCP & 0.80 & 0.86 & 0.45 & 0.87 & 14.9 & 14.8 & 0.43 & 0.44 \\
\hline 418 & 2016 & 19514R & 2 & QCP & 0.06 & 0.31 & 0.51 & 0.39 & 14.8 & 14.4 & 0.69 & 0.54 \\
\hline 419 & 2017 & $19512 R$ & 2 & QCP & 0.15 & 0.22 & 0.02 & 0.00 & 13.8 & 14.2 & 0.51 & 0.17 \\
\hline 420 & 2015 & $19512 R$ & 2 & QCP & 0.34 & 0.66 & 0.33 & 0.84 & 13.6 & 13.4 & 0.76 & 0.82 \\
\hline 421 & 2015 & $19512 R$ & 2 & QCP & 0.81 & 0.11 & 0.02 & 0.00 & 12.9 & 12.6 & 0.73 & 1.12 \\
\hline 422 & 2015 & 19534R & 2 & PFP & 0.50 & 0.20 & 0.62 & 0.59 & 15.0 & 15.1 & 0.45 & 0.55 \\
\hline 423 & 2015 & 19534R & 2 & PFP & 0.21 & 0.09 & 0.10 & 0.62 & 14.4 & 14.5 & 0.31 & 0.44 \\
\hline 424 & 2016 & 19534R & 2 & PFP & 0.04 & 0.24 & 0.17 & 0.37 & 15.0 & 14.7 & 0.44 & 0.60 \\
\hline 425 & 2017 & 19532R & 2 & PFP & 0.24 & 0.94 & 0.67 & 0.57 & 14.5 & 13.9 & 1.17 & 1.19 \\
\hline 426 & 2015 & $19532 R$ & 2 & PFP & 0.80 & 0.59 & 0.00 & 1.00 & 12.6 & 12.9 & 0.64 & 0.40 \\
\hline 427 & 2017 & 19535R & 2 & PFP & 0.67 & 0.28 & 0.71 & 0.24 & 15.8 & 15.8 & 0.61 & 0.41 \\
\hline 428 & 2015 & 19535R & 2 & PFP & 0.57 & 0.85 & 0.27 & 0.69 & 15.4 & 15.5 & 0.38 & 0.37 \\
\hline 429 & 2016 & $19512 R$ & 2 & QCP & 0.58 & 0.44 & 0.23 & 0.85 & 14.8 & 14.6 & 1.22 & 1.45 \\
\hline 430 & 2015 & 19654R & 2 & PFP & 0.92 & 0.30 & 0.52 & 0.11 & 17.9 & 17.9 & 0.61 & 0.50 \\
\hline 431 & 2015 & 19514R & 2 & QCP & 0.67 & 0.85 & & & 15.6 & 15.3 & 0.99 & 0.78 \\
\hline 432 & 2015 & 19514R & 2 & QCP & 1.00 & 0.62 & 0.94 & 0.83 & 15.2 & 15.3 & 1.12 & 1.36 \\
\hline 433 & 2015 & 19514R & 2 & QCP & 0.27 & 0.67 & 0.09 & 0.46 & 15.6 & 15.3 & 0.50 & 0.59 \\
\hline 434 & 2016 & $19532 R$ & 2 & PFP & 0.96 & 0.47 & 0.00 & 0.07 & 13.4 & 13.4 & 0.48 & 0.53 \\
\hline 435 & 2015 & $19512 R$ & 2 & QCP & 0.57 & 0.38 & 0.97 & 0.65 & 14.1 & 14.3 & 0.68 & 0.50 \\
\hline 436 & 2016 & 19654R & 2 & PFP & 0.91 & 0.53 & 0.64 & 0.38 & 17.7 & 17.6 & 0.51 & 0.56 \\
\hline 437 & 2016 & 19654R & 2 & QCP & 0.29 & 0.00 & 0.14 & & 17.7 & 17.5 & 0.12 & 0.00 \\
\hline 438 & 2016 & 19524R & 2 & QCP & 0.43 & 0.69 & 0.32 & 0.46 & 15.0 & 14.6 & 0.61 & 0.42 \\
\hline 439 & 2017 & 19524R & 4 & QCP & & & & & 15.9 & & 0.00 & \\
\hline 440 & 2016 & 19534R & 2 & PFP & 0.08 & 0.67 & 0.03 & 0.01 & 15.1 & 15.0 & 0.35 & 0.38 \\
\hline 441 & 2016 & $19524 R$ & 2 & PFP & 0.83 & 0.40 & 0.73 & 0.74 & 16.0 & 16.1 & 0.69 & 0.92 \\
\hline 442 & 2016 & 19534R & 2 & PFP & 0.77 & 0.39 & 0.85 & 0.88 & 14.9 & 14.9 & 0.46 & 0.52 \\
\hline 443 & 2015 & 19524R & 2 & QCP & 0.06 & 0.08 & 0.18 & 0.11 & 14.4 & 14.1 & 0.70 & 0.99 \\
\hline 444 & 2015 & 19525R & 2 & QCP & 0.78 & 0.52 & & 0.34 & 15.3 & 15.0 & 0.99 & 0.80 \\
\hline 445 & 2015 & $19532 R$ & 2 & PFP & 0.00 & 0.47 & 0.47 & 0.11 & 13.5 & 13.8 & 0.50 & 0.55 \\
\hline 446 & 2015 & 19605FR & 2 & QCP & 0.06 & 0.02 & 0.06 & 0.01 & 14.9 & 14.5 & 0.31 & 0.71 \\
\hline 447 & 2015 & $19532 R$ & 2 & QCP & 1.00 & 0.31 & & & 13.4 & 13.3 & 0.07 & 0.28 \\
\hline 448 & 2015 & 19654R & 2 & PFP & 0.00 & 0.00 & 0.02 & 0.00 & 16.6 & 17.0 & 0.40 & 0.67 \\
\hline 449 & 2015 & 19524R & 2 & QCP & 0.26 & 0.08 & 0.51 & 0.67 & 15.1 & 14.8 & 0.54 & 0.89 \\
\hline 450 & 2015 & 19515R & 2 & QCP & & & & 0.75 & & 15.6 & & 0.37 \\
\hline 451 & 2016 & 19515R & 2 & QCP & 0.24 & 0.45 & 0.43 & 0.66 & 15.1 & 15.4 & 0.56 & 0.46 \\
\hline
\end{tabular}




\begin{tabular}{|c|c|c|c|c|c|c|c|c|c|c|c|c|}
\hline $\begin{array}{l}\text { ICT } \\
\text { Code }\end{array}$ & Year & Mix Code & District & $\begin{array}{l}\text { Quality } \\
\text { Program }\end{array}$ & $\begin{array}{c}\text { MW } \\
\text { P-Value }\end{array}$ & $\begin{array}{l}\text { Levene's } \\
\text { P-Value }\end{array}$ & $\begin{array}{l}\text { Contractor } \\
\text { SW P-Value }\end{array}$ & $\begin{array}{c}\text { Agency SW } \\
\text { P-Value }\end{array}$ & $\begin{array}{c}\text { Contractor } \\
\text { Mean }\end{array}$ & $\begin{array}{l}\text { Agency } \\
\text { Mean }\end{array}$ & $\begin{array}{l}\text { Contractor } \\
\text { St. Dev. }\end{array}$ & $\begin{array}{l}\text { Agency } \\
\text { St. Dev. }\end{array}$ \\
\hline 452 & 2014 & 19604FR & 2 & QCP & 0.26 & 0.23 & 0.82 & 0.01 & 15.0 & 15.1 & 0.65 & 0.92 \\
\hline 453 & 2015 & 19605FR & 2 & QCP & 0.80 & 0.52 & 0.64 & 0.50 & 14.9 & 15.1 & 0.46 & 0.78 \\
\hline 454 & 2015 & 19525R & 2 & QCP & 0.97 & 0.45 & 0.63 & 0.48 & 15.5 & 15.8 & 0.69 & 1.12 \\
\hline 455 & 2015 & 19515R & 2 & QCP & 0.04 & 0.00 & 0.14 & 0.36 & 14.8 & 15.3 & 0.44 & 0.86 \\
\hline 456 & 2016 & 19525R & 2 & QCP & 0.08 & 0.41 & 0.68 & 0.27 & 15.2 & 16.2 & 0.49 & 0.70 \\
\hline 457 & 2015 & 19525R & 2 & QCP & 1.00 & 0.72 & 0.51 & 0.25 & 15.4 & 15.3 & 0.57 & 0.76 \\
\hline 458 & 2015 & $19532 R$ & 2 & PFP & 0.07 & 0.02 & 0.05 & 0.00 & 13.6 & 13.7 & 0.48 & 0.68 \\
\hline 459 & 2015 & 19532R & 2 & QCP & 0.40 & & 0.27 & & 13.5 & 12.7 & 0.69 & 0.00 \\
\hline 460 & 2015 & 19654R & 2 & PFP & 0.62 & 0.00 & 0.13 & 0.25 & 16.4 & 16.6 & 0.42 & 0.78 \\
\hline 461 & 2015 & 19526R & 2 & QCP & 1.00 & & & & 15.9 & 15.5 & 0.00 & 0.00 \\
\hline 462 & 2017 & 19515R & 2 & QCP & 0.02 & 0.01 & 0.60 & 0.20 & 15.0 & 15.7 & 0.60 & 0.13 \\
\hline 463 & 2017 & 19604FR & 2 & QCP & 1.00 & 0.23 & 0.91 & & 14.8 & 14.8 & 0.23 & 0.42 \\
\hline 464 & 2017 & 19532 & 2 & PFP & 0.34 & 0.86 & 0.50 & 0.62 & 14.6 & 13.8 & 1.34 & 1.25 \\
\hline 465 & 2017 & 19513R & 2 & QCP & 0.40 & 1.00 & 0.60 & & 15.8 & 15.3 & 0.90 & 0.64 \\
\hline 466 & 2017 & 19535R & 2 & PFP & 0.17 & 0.60 & 0.13 & 0.04 & 15.9 & 15.7 & 0.39 & 0.32 \\
\hline 467 & 2015 & 19524R & 3 & QCP & 0.03 & 0.28 & 0.57 & 0.28 & 15.3 & 14.5 & 0.88 & 0.56 \\
\hline 468 & 2017 & 19524R & 1 & QCP & 0.67 & & & & 15.6 & 14.8 & 0.00 & 0.00 \\
\hline 469 & 2017 & 19524R & 3 & PFP & & & & & 15.4 & & 0.00 & \\
\hline 470 & 2017 & 19524R & 1 & PFP & & & 0.03 & & 15.5 & & 0.22 & \\
\hline 471 & 2016 & 19524R & 3 & QCP & 1.00 & & 0.26 & & 14.2 & 14.3 & 0.24 & 0.00 \\
\hline 472 & 2017 & $19522 R$ & 3 & QCP & 0.50 & & 0.00 & & 14.2 & 13.7 & 0.17 & 0.00 \\
\hline 473 & 2015 & 19535R & 3 & PFP & & & & 0.18 & & 14.9 & & 0.66 \\
\hline 474 & 2017 & 19510R & 1 & QCP & 0.78 & 0.42 & 0.62 & & 19.1 & 18.9 & 0.40 & 0.57 \\
\hline 475 & 2017 & 19510R & 1 & QCP & 0.04 & 0.49 & 0.07 & 0.43 & 18.9 & 18.4 & 0.29 & 0.40 \\
\hline 476 & 2016 & $19524 R$ & 3 & QCP & 0.67 & 0.92 & & & 15.5 & 15.1 & 0.49 & 0.57 \\
\hline 477 & 2017 & 19525R & 1 & PFP & 0.02 & 0.55 & 0.83 & 1.00 & 15.3 & 14.5 & 0.52 & 0.30 \\
\hline 478 & 2017 & 19534R & 3 & QCP & 0.20 & 0.69 & 0.00 & & 15.3 & 14.8 & 0.12 & 0.14 \\
\hline 479 & 2016 & 19524R & 3 & QCP & 1.00 & & & & 15.9 & 16.0 & 0.21 & 0.00 \\
\hline 480 & 2017 & 19524R & 1 & PFP & 0.15 & 0.42 & 0.06 & & 14.9 & 14.3 & 0.44 & 0.57 \\
\hline 481 & 2017 & $19524 R$ & 3 & QCP & & & 0.57 & & 14.7 & & 0.32 & \\
\hline 482 & 2015 & $19522 R$ & 3 & QCP & 0.20 & 0.12 & & 0.31 & 13.6 & 14.0 & 0.02 & 0.28 \\
\hline 483 & 2015 & $19522 R$ & 3 & QCP & 0.50 & & & 0.96 & 13.5 & 12.5 & 0.00 & 0.28 \\
\hline 484 & 2015 & 19536R & 1 & QCP & & & 0.00 & & 14.1 & & 0.23 & \\
\hline 485 & 2015 & 19536R & 1 & QCP & 0.67 & 0.48 & & & 14.4 & 14.2 & 0.14 & 0.35 \\
\hline 486 & 2016 & $19512 R$ & 1 & QCP & 0.65 & 0.37 & 0.55 & 0.80 & 13.7 & 13.7 & 0.22 & 0.15 \\
\hline
\end{tabular}




\begin{tabular}{|c|c|c|c|c|c|c|c|c|c|c|c|c|}
\hline $\begin{array}{l}\text { ICT } \\
\text { Code }\end{array}$ & Year & Mix Code & District & $\begin{array}{l}\text { Quality } \\
\text { Program }\end{array}$ & $\begin{array}{c}\text { MW } \\
\text { P-Value }\end{array}$ & $\begin{array}{l}\text { Levene's } \\
\text { P-Value }\end{array}$ & $\begin{array}{l}\text { Contractor } \\
\text { SW P-Value }\end{array}$ & $\begin{array}{c}\text { Agency SW } \\
\text { P-Value }\end{array}$ & $\begin{array}{c}\text { Contractor } \\
\text { Mean }\end{array}$ & $\begin{array}{l}\text { Agency } \\
\text { Mean }\end{array}$ & $\begin{array}{l}\text { Contractor } \\
\text { St. Dev. }\end{array}$ & $\begin{array}{l}\text { Agency } \\
\text { St. Dev. }\end{array}$ \\
\hline 487 & 2016 & $19514 R$ & 3 & QCP & 1.00 & 0.71 & 0.36 & & 15.4 & 15.4 & 0.26 & 0.14 \\
\hline 488 & 2015 & 19534R & 3 & PFP & & & & 0.12 & & 15.0 & & 0.61 \\
\hline 489 & 2015 & 19534R & 3 & PFP & & & & 0.56 & & 14.6 & & 0.40 \\
\hline 490 & 2017 & 19524R & 1 & QCP & 0.01 & 0.56 & 0.00 & 0.28 & 14.6 & 15.7 & 0.44 & 0.30 \\
\hline 491 & 2016 & $19512 R$ & 1 & QCP & & & 0.14 & & 13.6 & & 0.68 & \\
\hline 492 & 2017 & 19534R & 3 & PFP & & & & 0.85 & & 15.2 & & 0.49 \\
\hline 493 & 2017 & $19532 R$ & 3 & PFP & 0.42 & & & 0.02 & 14.0 & 14.1 & 0.00 & 0.35 \\
\hline 494 & 2017 & 19510R & 1 & QCP & 0.11 & 0.93 & 0.15 & 0.00 & 19.4 & 19.8 & 0.27 & 0.23 \\
\hline 495 & 2017 & 19654R & 3 & QCP & 0.83 & 0.83 & 0.30 & 0.66 & 16.9 & 16.7 & 0.67 & 0.59 \\
\hline 496 & 2017 & 19510R & 4 & PFP & 0.34 & 0.54 & 0.21 & 0.85 & 18.3 & 18.1 & 0.46 & 0.39 \\
\hline 497 & 2015 & 19515R & 4 & QCP & 0.75 & & 0.99 & & 15.5 & 15.1 & 0.60 & 0.00 \\
\hline 498 & 2016 & 19515R & 4 & QCP & & & 0.43 & & 15.6 & & 0.54 & \\
\hline 499 & 2016 & $19522 R$ & 4 & PFP & & & & & 14.1 & & 0.07 & \\
\hline 500 & 2016 & $19522 R$ & 4 & PFP & 0.00 & 0.99 & 0.00 & 0.15 & 14.2 & 13.6 & 0.64 & 0.64 \\
\hline 501 & 2016 & $19532 R$ & 3 & PFP & 0.27 & 0.13 & 0.68 & 0.02 & 13.6 & 13.4 & 0.47 & 0.33 \\
\hline 502 & 2015 & 19653R & 4 & PFP & & & & 0.71 & & 17.4 & & 0.57 \\
\hline 503 & 2016 & 19654R & 4 & PFP & & & 0.86 & & 17.5 & & 0.46 & \\
\hline 504 & 2017 & 19654R & 4 & PFP & 0.32 & 0.59 & 0.11 & 0.06 & 17.3 & 17.5 & 0.54 & 0.60 \\
\hline 505 & 2016 & 19654R & 4 & PFP & 0.00 & 0.41 & 0.15 & 0.13 & 17.5 & 17.0 & 0.34 & 0.42 \\
\hline 506 & 2017 & 19510R & 4 & QCP & & & & & 18.7 & & 0.00 & \\
\hline 507 & 2015 & $19515 R$ & 4 & QCP & & & & & 16.3 & & 2.33 & \\
\hline 508 & 2016 & 19524R & 4 & PFP & 0.02 & 0.95 & 0.11 & 0.52 & 15.5 & 15.1 & 0.42 & 0.41 \\
\hline 509 & 2016 & 19525R & 4 & PFP & & & & & 15.5 & & 0.00 & \\
\hline 510 & 2015 & 19525R & 4 & PFP & 0.00 & 0.67 & 0.09 & 0.35 & 16.1 & 15.1 & 0.70 & 0.62 \\
\hline 511 & 2015 & $19535 R$ & 3 & PFP & & & & 0.17 & & 15.0 & & 0.48 \\
\hline 512 & 2016 & 19510R & 4 & PFP & 0.10 & 0.90 & 0.19 & 0.24 & 18.7 & 18.6 & 0.32 & 0.34 \\
\hline 513 & 2016 & 19510R & 4 & PFP & 0.55 & 0.51 & 0.28 & 0.27 & 18.6 & 18.6 & 0.45 & 0.34 \\
\hline 514 & 2017 & 19510R & 4 & QCP & 0.29 & 0.31 & 0.49 & 0.00 & 18.0 & 17.9 & 0.22 & 0.31 \\
\hline 515 & 2017 & 19515R & 4 & QCP & 1.00 & & & & 15.9 & 15.6 & 0.00 & 0.00 \\
\hline 516 & 2017 & $19514 R$ & 4 & PFP & & & 0.35 & & 15.2 & & 0.46 & \\
\hline 517 & 2015 & 19515R & 4 & QCP & & & & & 15.2 & & 0.14 & \\
\hline 518 & 2015 & 19524R & 4 & PFP & 0.00 & 0.36 & 0.50 & 0.27 & 16.3 & 15.3 & 0.42 & 0.59 \\
\hline 519 & 2016 & $19512 R$ & 4 & PFP & & & & & 14.2 & & 0.00 & \\
\hline 520 & 2017 & $19522 R$ & 4 & QCP & & & 0.71 & & 13.9 & & 0.39 & \\
\hline 521 & 2015 & 19524R & 4 & PFP & 0.00 & 0.56 & 0.55 & 0.79 & 16.4 & 15.3 & 0.30 & 0.42 \\
\hline
\end{tabular}




\begin{tabular}{|c|c|c|c|c|c|c|c|c|c|c|c|c|}
\hline $\begin{array}{c}\text { ICT } \\
\text { Code }\end{array}$ & Year & Mix Code & District & $\begin{array}{l}\text { Quality } \\
\text { Program }\end{array}$ & $\begin{array}{c}\text { MW } \\
\text { P-Value }\end{array}$ & $\begin{array}{l}\text { Levene's } \\
\text { P-Value }\end{array}$ & $\begin{array}{l}\text { Contractor } \\
\text { SW P-Value }\end{array}$ & $\begin{array}{c}\text { Agency SW } \\
\text { P-Value }\end{array}$ & $\begin{array}{c}\text { Contractor } \\
\text { Mean }\end{array}$ & $\begin{array}{c}\text { Agency } \\
\text { Mean }\end{array}$ & $\begin{array}{l}\text { Contractor } \\
\text { St. Dev. }\end{array}$ & $\begin{array}{l}\text { Agency } \\
\text { St. Dev. }\end{array}$ \\
\hline 522 & 2016 & $19512 \mathrm{R}$ & 4 & PFP & & & & & 14.8 & & 0.00 & \\
\hline 523 & 2015 & 19514R & 4 & QCP & & & 0.05 & & 15.7 & & 0.90 & \\
\hline 524 & 2016 & 19514R & 4 & PFP & 0.83 & 0.70 & 0.37 & 0.96 & 15.1 & 15.0 & 0.39 & 0.34 \\
\hline 525 & 2015 & 19514R & 4 & PFP & 0.01 & 0.07 & 0.85 & 0.03 & 16.3 & 14.9 & 0.17 & 0.57 \\
\hline 526 & 2015 & 19524R & 5 & QCP & 0.14 & 0.87 & 0.12 & & 15.7 & 15.3 & 0.36 & 0.30 \\
\hline 527 & 2015 & 19514R & 5 & QCP & 0.80 & & 0.65 & & 15.1 & 14.8 & 0.40 & 0.00 \\
\hline 528 & 2016 & 19514R & 5 & QCP & & & 0.78 & & 16.3 & & 0.25 & \\
\hline 529 & 2015 & 19514R & 5 & QCP & & & 0.05 & & 15.6 & & 0.18 & \\
\hline 530 & 2016 & 19514R & 5 & QCP & & & 1.00 & & 15.4 & & 0.10 & \\
\hline 531 & 2016 & 19524R & 5 & QCP & & & 0.52 & & 16.2 & & 0.46 & \\
\hline 532 & 2017 & 19605FR & 5 & QCP & 0.04 & 0.82 & 0.13 & 0.94 & 14.1 & 13.7 & 0.33 & 0.35 \\
\hline 533 & 2015 & 19605FR & 5 & QCP & 0.43 & 0.47 & 0.68 & 0.12 & 13.8 & 13.4 & 0.63 & 0.89 \\
\hline 534 & 2015 & 19524R & 5 & QCP & 0.50 & & 0.42 & & 16.3 & 15.9 & 0.33 & 0.00 \\
\hline 535 & 2016 & 19514R & 5 & QCP & 0.29 & & 0.83 & & 15.7 & 14.7 & 0.50 & 0.00 \\
\hline 536 & 2017 & 19524R & 5 & QCP & 0.86 & 0.05 & 0.00 & & 15.4 & 15.0 & 0.38 & 0.99 \\
\hline 537 & 2015 & 19534R & 5 & QCP & 0.57 & & 0.92 & & 15.3 & 15.5 & 0.18 & 0.00 \\
\hline 538 & 2015 & 19534R & 5 & PFP & 0.63 & 0.79 & 0.16 & 0.91 & 15.8 & 15.9 & 0.31 & 0.25 \\
\hline 539 & 2017 & 19535R & 5 & QCP & 0.15 & 0.47 & 0.01 & & 15.8 & 16.5 & 0.38 & 0.12 \\
\hline 540 & 2017 & $19512 R$ & 6 & QCP & & & & & 14.1 & & 0.00 & \\
\hline 541 & 2017 & $19513 R$ & 5 & QCP & & & & & & 15.3 & & 0.35 \\
\hline 542 & 2017 & $19532 \mathrm{R}$ & 5 & PFP & & & & 0.23 & & 13.7 & & 0.33 \\
\hline 543 & 2016 & $19534 \mathrm{R}$ & 5 & QCP & & & & & & 15.2 & & 0.00 \\
\hline 544 & 2017 & $19534 \mathrm{R}$ & 5 & PFP & & & & 0.94 & & 15.7 & & 0.95 \\
\hline 545 & 2017 & $19523 R$ & 5 & QCP & 0.69 & 0.40 & 0.81 & 0.90 & 15.1 & 15.1 & 0.30 & 0.42 \\
\hline 546 & 2015 & $19534 R$ & 5 & PFP & 0.50 & 0.24 & 0.60 & 0.44 & 15.9 & 15.7 & 0.38 & 0.20 \\
\hline 547 & 2016 & $19513 R$ & 5 & QCP & 0.67 & & 0.52 & & 15.6 & 16.1 & 0.41 & 0.00 \\
\hline 548 & 2016 & $19514 \mathrm{R}$ & 5 & QCP & & & 0.01 & & 15.5 & & 0.13 & \\
\hline 549 & 2015 & $19532 R$ & 5 & PFP & 0.01 & 0.85 & 0.10 & 0.66 & 14.2 & 13.6 & 0.49 & 0.43 \\
\hline 550 & 2015 & 19535R & 5 & PFP & 0.04 & 0.29 & 0.47 & & 14.7 & 15.3 & 0.38 & 0.07 \\
\hline 551 & 2015 & $19523 R$ & 5 & QCP & 0.01 & 0.14 & 0.53 & 0.11 & 15.3 & 14.5 & 0.35 & 0.58 \\
\hline 552 & 2015 & 19505R & 5 & QCP & & & 0.31 & & 15.8 & & 0.77 & \\
\hline 553 & 2015 & $19534 R$ & 5 & PFP & 0.29 & 0.77 & 0.69 & 0.25 & 15.6 & 15.3 & 0.53 & 0.38 \\
\hline 554 & 2017 & $19534 R$ & 5 & PFP & 0.13 & 0.37 & 0.32 & 0.01 & 15.9 & 15.7 & 0.24 & 0.31 \\
\hline 555 & 2016 & 19513R & 5 & QCP & & & & & 15.7 & & 0.00 & \\
\hline 556 & 2016 & $19513 R$ & 5 & QCP & 0.67 & & & & 16.1 & 15.8 & 0.00 & 0.00 \\
\hline
\end{tabular}




\begin{tabular}{|c|c|c|c|c|c|c|c|c|c|c|c|c|}
\hline $\begin{array}{c}\text { ICT } \\
\text { Code }\end{array}$ & Year & Mix Code & District & $\begin{array}{l}\text { Quality } \\
\text { Program }\end{array}$ & $\begin{array}{c}\text { MW } \\
\text { P-Value }\end{array}$ & $\begin{array}{l}\text { Levene's } \\
\text { P-Value }\end{array}$ & $\begin{array}{l}\text { Contractor } \\
\text { SW P-Value }\end{array}$ & $\begin{array}{c}\text { Agency SW } \\
\text { P-Value }\end{array}$ & $\begin{array}{c}\text { Contractor } \\
\text { Mean }\end{array}$ & $\begin{array}{l}\text { Agency } \\
\text { Mean }\end{array}$ & $\begin{array}{l}\text { Contractor } \\
\text { St. Dev. }\end{array}$ & $\begin{array}{l}\text { Agency } \\
\text { St. Dev. }\end{array}$ \\
\hline 557 & 2015 & $19532 R$ & 5 & PFP & 0.12 & 0.46 & 0.53 & 0.57 & 14.1 & 13.8 & 0.33 & 0.21 \\
\hline 558 & 2016 & $19532 R$ & 5 & PFP & 0.14 & 0.14 & 0.02 & 0.02 & 14.1 & 13.9 & 0.28 & 0.45 \\
\hline 559 & 2016 & 19535R & 5 & PFP & 0.41 & 0.25 & 0.05 & 0.99 & 15.8 & 15.6 & 0.22 & 0.34 \\
\hline 560 & 2017 & 19535R & 5 & QCP & & & 0.78 & & 16.0 & & 0.25 & \\
\hline 561 & 2015 & 19524R & 5 & QCP & 0.80 & & 0.58 & & 15.4 & 15.1 & 0.34 & 0.00 \\
\hline 562 & 2015 & 19524R & 5 & QCP & 0.44 & 0.85 & 0.62 & & 15.8 & 15.6 & 0.34 & 0.28 \\
\hline 563 & 2017 & $19532 R$ & 5 & PFP & 0.00 & 0.08 & 0.39 & 0.48 & 14.4 & 13.8 & 0.21 & 0.34 \\
\hline 564 & 2015 & 19523R & 6 & QCP & 0.12 & 0.86 & 0.25 & 0.41 & 14.7 & 14.8 & 0.37 & 0.34 \\
\hline 565 & 2015 & 19513R & 6 & QCP & 0.36 & 0.26 & 0.35 & 0.15 & 14.6 & 14.7 & 0.33 & 0.50 \\
\hline 566 & 2016 & 19524R & 6 & PFP & 0.30 & & & 0.43 & 14.3 & 14.8 & 0.00 & 0.46 \\
\hline 567 & 2016 & 19513R & 6 & PFP & & & & & & 14.5 & & 0.00 \\
\hline 568 & 2015 & 19513R & 6 & QCP & 0.72 & 0.15 & 0.75 & 0.84 & 14.6 & 14.5 & 0.35 & 0.61 \\
\hline 569 & 2015 & $19522 \mathrm{R}$ & 6 & PFP & 0.04 & 0.64 & 0.08 & 0.04 & 14.1 & 13.5 & 0.51 & 0.67 \\
\hline 570 & 2015 & $19522 R$ & 6 & PFP & 0.00 & 0.06 & 0.32 & 0.89 & 13.5 & 14.0 & 0.42 & 0.56 \\
\hline 571 & 2015 & 19513R & 6 & QCP & 0.93 & 0.05 & 0.62 & 0.99 & 15.1 & 15.1 & 0.27 & 0.50 \\
\hline 572 & 2015 & 19513R & 6 & QCP & 0.86 & 0.68 & 0.12 & 0.84 & 15.5 & 15.4 & 0.54 & 0.35 \\
\hline 573 & 2015 & 19523R & 6 & PFP & 0.23 & 0.95 & 0.11 & 0.74 & 15.8 & 15.3 & 0.91 & 0.94 \\
\hline 574 & 2015 & 19513R & 6 & QCP & 0.77 & 0.97 & 0.97 & 0.48 & 14.8 & 14.8 & 0.64 & 0.61 \\
\hline 575 & 2015 & $19523 R$ & 6 & QCP & 0.05 & 0.77 & 0.51 & 0.56 & 14.7 & 15.1 & 0.38 & 0.32 \\
\hline 576 & 2015 & $19523 R$ & 6 & QCP & & & 0.22 & & 15.0 & & 0.15 & \\
\hline 577 & 2017 & $19523 R$ & 8 & QCP & 0.80 & 0.06 & 0.06 & 0.72 & 14.6 & 14.6 & 0.18 & 0.36 \\
\hline 578 & 2015 & $19534 \mathrm{R}$ & 6 & PFP & 0.57 & 0.27 & 0.46 & 0.08 & 15.2 & 15.2 & 0.43 & 0.55 \\
\hline 579 & 2016 & $19534 \mathrm{R}$ & 6 & PFP & 0.38 & 0.83 & 0.58 & 0.37 & 15.5 & 15.2 & 0.43 & 0.50 \\
\hline 580 & 2015 & $19522 \mathrm{R}$ & 6 & PFP & 0.00 & 0.16 & 0.91 & 0.12 & 14.3 & 14.0 & 0.39 & 0.51 \\
\hline 581 & 2015 & $19513 R$ & 6 & $\mathrm{QCP}$ & 0.08 & 0.38 & 0.16 & 0.77 & 15.1 & 14.8 & 0.31 & 0.19 \\
\hline 582 & 2017 & $19522 \mathrm{R}$ & 6 & QCP & 0.67 & & 0.42 & & 13.2 & 13.4 & 0.28 & 0.00 \\
\hline 583 & 2015 & 19535R & 6 & PFP & 0.69 & 0.26 & 0.02 & 0.64 & 15.5 & 15.5 & 0.96 & 0.67 \\
\hline 584 & 2015 & 19535R & 6 & QCP & 1.00 & & 0.91 & & 15.1 & 15.3 & 0.35 & 0.00 \\
\hline 585 & 2015 & 19535R & 6 & PFP & 0.80 & 0.80 & 0.03 & 0.31 & 15.4 & 15.3 & 0.37 & 0.33 \\
\hline 586 & 2016 & $19514 R$ & 6 & QCP & 0.45 & 0.23 & 0.85 & 0.59 & 15.2 & 15.6 & 0.49 & 0.82 \\
\hline 587 & 2015 & 19513R & 6 & QCP & 0.31 & 0.94 & 0.87 & 0.46 & 14.4 & 14.1 & 0.43 & 0.40 \\
\hline 588 & 2015 & $19522 \mathrm{R}$ & 6 & QCP & 0.22 & 0.58 & 0.00 & 0.00 & 14.3 & 13.9 & 0.58 & 0.35 \\
\hline 589 & 2016 & $19532 R$ & 6 & PFP & & & & 0.51 & & 14.5 & & 0.55 \\
\hline 590 & 2015 & $19532 R$ & 6 & PFP & 0.03 & 0.16 & 0.03 & 0.66 & 14.2 & 13.8 & 0.61 & 0.49 \\
\hline 591 & 2016 & $19532 R$ & 6 & QCP & 0.67 & & & & 13.6 & 13.3 & 0.07 & 0.00 \\
\hline
\end{tabular}




\begin{tabular}{|c|c|c|c|c|c|c|c|c|c|c|c|c|}
\hline $\begin{array}{c}\text { ICT } \\
\text { Code }\end{array}$ & Year & Mix Code & District & $\begin{array}{l}\text { Quality } \\
\text { Program }\end{array}$ & $\begin{array}{c}\text { MW } \\
\text { P-Value }\end{array}$ & $\begin{array}{l}\text { Levene's } \\
\text { P-Value }\end{array}$ & $\begin{array}{l}\text { Contractor } \\
\text { SW P-Value }\end{array}$ & $\begin{array}{c}\text { Agency SW } \\
\text { P-Value }\end{array}$ & $\begin{array}{c}\text { Contractor } \\
\text { Mean }\end{array}$ & $\begin{array}{c}\text { Agency } \\
\text { Mean }\end{array}$ & $\begin{array}{l}\text { Contractor } \\
\text { St. Dev. }\end{array}$ & $\begin{array}{l}\text { Agency } \\
\text { St. Dev. }\end{array}$ \\
\hline 592 & 2015 & 19524R & 6 & $\mathrm{QCP}$ & 0.44 & 0.00 & 0.98 & & 15.3 & 15.1 & 0.30 & 0.00 \\
\hline 593 & 2015 & $19512 R$ & 6 & QCP & 0.76 & 0.11 & 0.03 & & 14.0 & 13.9 & 0.24 & 0.57 \\
\hline 594 & 2015 & 19535R & 6 & PFP & 0.05 & 0.13 & 0.42 & 0.05 & 15.7 & 15.5 & 0.38 & 0.52 \\
\hline 595 & 2017 & 19535R & 6 & PFP & & & & 0.69 & & 15.6 & & 0.28 \\
\hline 596 & 2016 & 19535R & 6 & QCP & 1.00 & & 0.22 & & 15.2 & 15.3 & 0.44 & 0.00 \\
\hline 597 & 2017 & 19513R & 6 & QCP & & & & & & 14.7 & & 0.00 \\
\hline 598 & 2017 & 19513R & 6 & QCP & 0.27 & 0.07 & 1.00 & 0.00 & 15.3 & 15.1 & 0.31 & 0.06 \\
\hline 599 & 2017 & 19513R & 6 & QCP & 1.00 & 0.66 & & & 15.7 & 15.8 & 0.49 & 0.28 \\
\hline 600 & 2016 & 19513R & 6 & QCP & & & & & 15.7 & & 0.00 & \\
\hline 601 & 2016 & 19513R & 6 & PFP & & & & & & 15.3 & & 0.07 \\
\hline 602 & 2016 & 19513R & 6 & QCP & 0.06 & 0.72 & 0.12 & 0.07 & 14.6 & 15.0 & 0.51 & 0.57 \\
\hline 603 & 2016 & 19513R & 6 & QCP & 0.67 & & & & 14.5 & 15.3 & 0.28 & 0.00 \\
\hline 604 & 2016 & 19514R & 6 & QCP & 0.67 & & & & 16.3 & 15.9 & 0.35 & 0.00 \\
\hline 605 & 2015 & $19512 R$ & 6 & QCP & 0.67 & & 0.01 & & 13.2 & 13.2 & 0.29 & 0.00 \\
\hline 606 & 2016 & $19524 \mathrm{R}$ & 6 & QCP & 0.07 & 0.94 & 0.07 & 0.46 & 15.5 & 15.9 & 0.25 & 0.21 \\
\hline 607 & 2015 & 19513R & 6 & QCP & 0.67 & & & & 14.7 & 15.2 & 0.35 & 0.00 \\
\hline 608 & 2017 & 19513R & 6 & QCP & 0.06 & 0.71 & 0.30 & & 15.3 & 16.1 & 0.29 & 0.14 \\
\hline 609 & 2016 & 19513R & 6 & QCP & 0.03 & 0.17 & 0.91 & 0.70 & 14.8 & 15.4 & 0.32 & 0.55 \\
\hline 610 & 2017 & 19513R & 6 & QCP & 0.01 & 0.48 & 0.60 & 0.12 & 14.7 & 15.4 & 0.27 & 0.37 \\
\hline 611 & 2016 & $19513 R$ & 6 & QCP & 0.22 & & 0.48 & & 15.1 & 15.4 & 0.18 & 0.00 \\
\hline 612 & 2017 & $19532 \mathrm{R}$ & 6 & PFP & 0.04 & 0.44 & 0.35 & 0.14 & 13.8 & 14.0 & 0.35 & 0.42 \\
\hline 613 & 2016 & $19524 \mathrm{R}$ & 6 & PFP & 0.00 & 0.06 & 0.98 & 0.59 & 16.4 & 15.7 & 0.33 & 0.56 \\
\hline 614 & 2016 & $19513 R$ & 6 & QCP & 0.04 & 0.93 & 0.01 & 0.64 & 15.0 & 15.9 & 0.71 & 0.65 \\
\hline 615 & 2016 & $19514 \mathrm{R}$ & 6 & QCP & 0.00 & 0.64 & 0.21 & 0.15 & 15.0 & 15.5 & 0.26 & 0.30 \\
\hline 616 & 2016 & $19534 R$ & 7 & PFP & 0.01 & 0.15 & 0.69 & 0.44 & 16.6 & 16.0 & 0.33 & 0.55 \\
\hline 617 & 2016 & $19524 \mathrm{R}$ & 6 & QCP & 0.97 & 0.62 & 0.08 & 0.47 & 15.3 & 15.3 & 0.60 & 0.48 \\
\hline 618 & 2016 & $19532 \mathrm{R}$ & 6 & PFP & 0.11 & 0.45 & 0.77 & 0.96 & 13.9 & 13.7 & 0.41 & 0.48 \\
\hline 619 & 2016 & $19523 R$ & 6 & QCP & 0.86 & & 0.52 & & 15.0 & 14.7 & 0.34 & 0.00 \\
\hline 620 & 2016 & $19524 R$ & 6 & QCP & 0.89 & 0.63 & 0.93 & 0.43 & 15.1 & 15.0 & 0.58 & 0.66 \\
\hline 621 & 2016 & $19534 R$ & 6 & PFP & 0.00 & 0.66 & 0.01 & 0.31 & 15.4 & 14.7 & 0.51 & 0.57 \\
\hline 622 & 2016 & 19513R & 6 & QCP & 0.22 & 0.78 & 0.23 & 0.23 & 15.6 & 15.3 & 0.37 & 0.38 \\
\hline 623 & 2016 & $19512 R$ & 6 & QCP & 0.31 & 0.31 & 0.76 & & 14.0 & 13.7 & 0.35 & 0.07 \\
\hline 624 & 2017 & $19514 R$ & 6 & QCP & 0.33 & 0.00 & & & 15.9 & 16.1 & 0.14 & 0.00 \\
\hline 625 & 2017 & $19522 \mathrm{R}$ & 6 & PFP & & & & & 13.5 & & 0.00 & \\
\hline 626 & 2017 & 19514R & 6 & QCP & 1.00 & 0.17 & 0.03 & & 16.4 & 16.1 & 0.43 & 0.92 \\
\hline
\end{tabular}




\begin{tabular}{|c|c|c|c|c|c|c|c|c|c|c|c|c|}
\hline $\begin{array}{l}\text { ICT } \\
\text { Code }\end{array}$ & Year & Mix Code & District & $\begin{array}{l}\text { Quality } \\
\text { Program }\end{array}$ & $\begin{array}{c}\text { MW } \\
\text { P-Value }\end{array}$ & $\begin{array}{l}\text { Levene's } \\
\text { P-Value }\end{array}$ & $\begin{array}{l}\text { Contractor } \\
\text { SW P-Value }\end{array}$ & $\begin{array}{c}\text { Agency SW } \\
\text { P-Value }\end{array}$ & $\begin{array}{c}\text { Contractor } \\
\text { Mean }\end{array}$ & $\begin{array}{l}\text { Agency } \\
\text { Mean }\end{array}$ & $\begin{array}{l}\text { Contractor } \\
\text { St. Dev. }\end{array}$ & $\begin{array}{l}\text { Agency } \\
\text { St. Dev. }\end{array}$ \\
\hline 627 & 2017 & $19513 R$ & 6 & QCP & & & & & & 15.9 & & 0.07 \\
\hline 628 & 2015 & 19524 & 7 & PFP & 1.00 & 0.14 & 0.43 & 0.88 & 15.9 & 15.9 & 0.54 & 1.22 \\
\hline 629 & 2016 & 19532R & 7 & QCP & 1.00 & & 0.70 & & 13.9 & 13.6 & 0.56 & 0.00 \\
\hline 630 & 2015 & 19532R & 7 & PFP & & & 0.93 & & 13.4 & & 0.67 & \\
\hline 631 & 2016 & 19523R & 7 & QCP & 0.50 & 0.83 & 0.30 & 0.64 & 15.7 & 16.0 & 0.64 & 0.76 \\
\hline 632 & 2016 & 19532R & 7 & QCP & 0.36 & 0.32 & 0.32 & & 13.7 & 14.0 & 0.30 & 0.49 \\
\hline 633 & 2017 & $19532 R$ & 7 & PFP & 0.88 & 0.01 & 0.04 & 0.96 & 14.5 & 14.1 & 0.90 & 0.22 \\
\hline 634 & 2017 & 19524R & 7 & PFP & & & & & & 14.9 & & 0.00 \\
\hline 635 & 2016 & 19523 & 7 & QCP & 0.57 & 0.54 & 0.99 & & 15.5 & 15.1 & 0.61 & 0.78 \\
\hline 636 & 2017 & 19523 & 7 & QCP & & & & & & 15.7 & & 0.00 \\
\hline 637 & 2016 & 19523 & 7 & QCP & 0.33 & 0.94 & & & 16.6 & 15.2 & 0.78 & 0.85 \\
\hline 638 & 2017 & 19523 & 7 & QCP & 0.80 & & 0.09 & & 16.3 & 15.7 & 0.65 & 0.00 \\
\hline 639 & 2017 & 19534R & 7 & QCP & & & & 0.01 & & 14.8 & & 0.49 \\
\hline 640 & 2016 & 19534R & 7 & PFP & & & & 0.44 & & 15.1 & & 0.40 \\
\hline 641 & 2016 & 19534R & 7 & QCP & 0.06 & 0.14 & 0.65 & 0.25 & 15.4 & 16.0 & 0.26 & 0.47 \\
\hline 642 & 2016 & 19524R & 7 & QCP & 0.06 & 0.62 & 0.04 & 0.00 & 15.1 & 15.9 & 1.21 & 0.97 \\
\hline 643 & 2016 & 19523R & 7 & QCP & 0.64 & 0.34 & 0.08 & & 15.3 & 15.1 & 0.44 & 0.71 \\
\hline 644 & 2015 & 19534R & 7 & PFP & & & & & & 14.9 & & 0.00 \\
\hline 645 & 2015 & 19534R & 7 & PFP & & & & 0.35 & & 15.5 & & 0.91 \\
\hline 646 & 2016 & 19534R & 7 & QCP & & & & & 15.2 & & 0.21 & \\
\hline 647 & 2015 & $19534 R$ & 7 & QCP & 0.53 & 0.69 & & 0.24 & 14.8 & 14.0 & 0.49 & 0.99 \\
\hline 648 & 2016 & 19523R & 9 & QCP & 0.00 & 0.00 & 0.07 & 0.00 & 15.6 & 14.7 & 0.56 & 0.05 \\
\hline 649 & 2016 & 19605FR & 9 & QCP & 0.17 & 0.25 & 0.02 & 0.00 & 15.7 & 15.3 & 0.31 & 0.12 \\
\hline 650 & 2015 & 19534R & 7 & PFP & 0.76 & 0.11 & 0.83 & 0.56 & 15.3 & 15.4 & 0.29 & 0.53 \\
\hline 651 & 2015 & $19523 R$ & 7 & PFP & 0.13 & 0.87 & 0.75 & 0.46 & 15.1 & 14.8 & 0.40 & 0.46 \\
\hline 652 & 2015 & 19523R & 7 & QCP & 0.31 & 0.90 & 0.90 & 0.78 & 15.5 & 14.9 & 0.99 & 0.97 \\
\hline 653 & 2016 & 19524R & 7 & QCP & 0.18 & 0.43 & 0.16 & 0.39 & 15.4 & 15.0 & 0.40 & 0.58 \\
\hline 654 & 2016 & 19534R & 7 & QCP & 0.67 & & & & 15.8 & 15.2 & 0.64 & 0.00 \\
\hline 655 & 2015 & 19534R & 7 & PFP & 0.15 & 0.23 & 0.94 & 0.17 & 15.8 & 15.5 & 0.36 & 0.57 \\
\hline 656 & 2016 & 19654R & 7 & PFP & & & & & & 16.5 & & 0.00 \\
\hline 657 & 2016 & 19654R & 7 & PFP & & & & & & 16.4 & & 0.00 \\
\hline 658 & 2015 & 19654R & 7 & PFP & 0.52 & 0.34 & 0.11 & 0.06 & 16.9 & 16.7 & 0.87 & 0.69 \\
\hline 659 & 2016 & 19654R & 7 & PFP & 0.46 & 0.37 & 0.24 & 0.90 & 17.5 & 17.1 & 0.31 & 0.55 \\
\hline 660 & 2016 & 19654R & 7 & PFP & 0.26 & 0.93 & 0.06 & 0.20 & 17.8 & 17.7 & 0.59 & 0.59 \\
\hline 661 & 2017 & 19654R & 7 & PFP & 0.39 & 0.85 & 0.83 & 0.25 & 18.1 & 17.8 & 0.63 & 0.68 \\
\hline
\end{tabular}




\begin{tabular}{|c|c|c|c|c|c|c|c|c|c|c|c|c|}
\hline $\begin{array}{l}\text { ICT } \\
\text { Code }\end{array}$ & Year & Mix Code & District & $\begin{array}{l}\text { Quality } \\
\text { Program }\end{array}$ & $\begin{array}{c}\text { MW } \\
\text { P-Value }\end{array}$ & $\begin{array}{l}\text { Levene's } \\
\text { P-Value }\end{array}$ & $\begin{array}{l}\text { Contractor } \\
\text { SW P-Value }\end{array}$ & $\begin{array}{c}\text { Agency SW } \\
\text { P-Value }\end{array}$ & $\begin{array}{c}\text { Contractor } \\
\text { Mean }\end{array}$ & $\begin{array}{l}\text { Agency } \\
\text { Mean }\end{array}$ & $\begin{array}{l}\text { Contractor } \\
\text { St. Dev. }\end{array}$ & $\begin{array}{l}\text { Agency } \\
\text { St. Dev. }\end{array}$ \\
\hline 662 & 2016 & $19532 R$ & 7 & PFP & 0.41 & 0.58 & 0.44 & 0.40 & 14.5 & 14.4 & 0.59 & 0.52 \\
\hline 663 & 2017 & $19532 R$ & 7 & PFP & 1.00 & & & & 15.8 & 15.6 & 0.00 & 0.00 \\
\hline 664 & 2017 & 19523R & 7 & QCP & 0.40 & 0.62 & 0.64 & & 15.3 & 15.5 & 0.15 & 0.07 \\
\hline 665 & 2015 & 19505R & 7 & PFP & & & 0.86 & & 15.7 & & 0.57 & \\
\hline 666 & 2015 & $19532 R$ & 7 & PFP & 0.01 & 0.47 & 0.64 & 0.15 & 13.9 & 13.6 & 0.66 & 0.60 \\
\hline 667 & 2016 & 19532R & 7 & PFP & 0.58 & 0.94 & 0.59 & 0.09 & 13.8 & 13.7 & 0.61 & 0.61 \\
\hline 668 & 2015 & $19532 R$ & 7 & PFP & & & & 0.33 & & 13.8 & & 0.60 \\
\hline 669 & 2016 & 19654R & 7 & PFP & 0.77 & 0.88 & 0.44 & 0.37 & 17.7 & 17.8 & 0.62 & 0.64 \\
\hline 670 & 2015 & 19654R & 7 & PFP & 0.76 & 0.24 & 0.05 & 0.07 & 17.7 & 17.9 & 0.38 & 0.57 \\
\hline 671 & 2016 & $19532 R$ & 7 & PFP & 0.68 & 0.93 & 0.14 & 0.34 & 14.2 & 14.1 & 0.66 & 0.67 \\
\hline 672 & 2017 & 19533R & 7 & PFP & 0.05 & 0.91 & 0.63 & 0.92 & 16.1 & 15.6 & 0.47 & 0.47 \\
\hline 673 & 2017 & 19532R & 7 & PFP & 0.56 & 0.46 & 0.87 & 0.71 & 13.8 & 13.5 & 0.95 & 0.78 \\
\hline 674 & 2017 & $19532 R$ & 7 & PFP & 0.48 & 0.82 & 0.53 & 0.34 & 14.2 & 14.0 & 0.48 & 0.54 \\
\hline 675 & 2017 & $19532 R$ & 7 & PFP & & & & & & 13.7 & & 0.00 \\
\hline 676 & 2017 & $19532 R$ & 7 & PFP & 0.83 & 0.23 & 0.23 & 0.14 & 14.7 & 14.4 & 0.74 & 0.39 \\
\hline 677 & 2016 & 19523R & 8 & QCP & & & & & & 14.9 & & 0.00 \\
\hline 678 & 2016 & 19523R & 8 & QCP & 1.00 & 0.84 & & & 14.5 & 14.5 & 0.49 & 0.64 \\
\hline 679 & 2016 & 19523R & 8 & QCP & 0.40 & & 0.27 & & 15.7 & 15.1 & 0.29 & 0.00 \\
\hline 680 & 2016 & 19523R & 8 & QCP & 0.32 & 0.12 & 0.12 & 0.89 & 15.7 & 16.0 & 0.48 & 0.75 \\
\hline 681 & 2016 & 19534R & 8 & QCP & 0.02 & 0.52 & 0.67 & 0.21 & 15.4 & 14.6 & 0.61 & 0.43 \\
\hline 682 & 2015 & $19534 R$ & 8 & QCP & 0.14 & & 0.31 & & 15.2 & 14.3 & 0.20 & 0.00 \\
\hline 683 & 2015 & 19534R & 8 & QCP & 0.00 & 0.03 & 0.04 & 0.22 & 15.7 & 14.9 & 0.31 & 0.59 \\
\hline 684 & 2015 & 19534R & 8 & QCP & 0.50 & 0.49 & 0.37 & 0.21 & 15.5 & 15.7 & 0.58 & 0.72 \\
\hline 685 & 2015 & 19524R & 8 & QCP & 0.18 & 0.25 & 0.54 & 0.79 & 15.2 & 14.9 & 0.44 & 0.24 \\
\hline 686 & 2017 & $19524 R$ & 8 & QCP & 0.89 & 0.74 & 0.27 & 0.14 & 15.2 & 15.1 & 0.78 & 0.89 \\
\hline 687 & 2015 & 19535R & 8 & QCP & 0.45 & 0.00 & 0.09 & 0.01 & 15.2 & 14.8 & 0.56 & 1.30 \\
\hline 688 & 2017 & $19505 R$ & 8 & QCP & 0.63 & 0.50 & 0.13 & 0.32 & 15.3 & 15.2 & 0.62 & 0.81 \\
\hline 689 & 2015 & 19505R & 8 & QCP & 0.53 & 0.18 & 0.22 & & 14.0 & 13.4 & 0.59 & 0.07 \\
\hline 690 & 2015 & 19606R & 8 & QCP & 0.84 & 0.16 & 0.49 & & 15.4 & 15.2 & 0.55 & 1.06 \\
\hline 691 & 2015 & 19654R & 8 & PFP & 0.05 & 0.45 & 0.02 & 0.16 & 17.9 & 17.6 & 0.64 & 0.56 \\
\hline 692 & 2015 & 19654R & 8 & PFP & 0.10 & 0.80 & 0.44 & 0.69 & 18.2 & 17.7 & 0.56 & 0.61 \\
\hline 693 & 2015 & 19534R & 8 & QCP & 0.71 & 0.63 & 0.46 & 0.78 & 15.1 & 15.4 & 0.78 & 0.50 \\
\hline 694 & 2015 & 19654R & 8 & PFP & 0.63 & 0.67 & 0.43 & 0.35 & 17.8 & 17.6 & 0.74 & 0.66 \\
\hline 695 & 2015 & 19654R & 8 & PFP & 0.04 & 0.36 & 0.54 & 0.68 & 18.0 & 17.7 & 0.57 & 0.49 \\
\hline 696 & 2015 & 19654R & 8 & PFP & 0.01 & 0.73 & 0.17 & 0.70 & 18.0 & 17.4 & 0.60 & 0.64 \\
\hline
\end{tabular}




\begin{tabular}{|c|c|c|c|c|c|c|c|c|c|c|c|c|}
\hline $\begin{array}{l}\text { ICT } \\
\text { Code }\end{array}$ & Year & Mix Code & District & $\begin{array}{l}\text { Quality } \\
\text { Program }\end{array}$ & $\begin{array}{c}\text { MW } \\
\text { P-Value }\end{array}$ & $\begin{array}{l}\text { Levene's } \\
\text { P-Value }\end{array}$ & $\begin{array}{l}\text { Contractor } \\
\text { SW P-Value }\end{array}$ & $\begin{array}{c}\text { Agency SW } \\
\text { P-Value }\end{array}$ & $\begin{array}{c}\text { Contractor } \\
\text { Mean }\end{array}$ & $\begin{array}{l}\text { Agency } \\
\text { Mean }\end{array}$ & $\begin{array}{l}\text { Contractor } \\
\text { St. Dev. }\end{array}$ & $\begin{array}{l}\text { Agency } \\
\text { St. Dev. }\end{array}$ \\
\hline 697 & 2015 & 19535R & 8 & QCP & 0.40 & 0.86 & 0.61 & 0.49 & 15.8 & 15.5 & 0.48 & 0.40 \\
\hline 698 & 2015 & 19601R & 8 & QCP & & & & & 11.2 & & 0.00 & \\
\hline 699 & 2016 & 19523R & 8 & QCP & 0.62 & 0.24 & 0.40 & 0.42 & 15.4 & 15.2 & 0.42 & 0.68 \\
\hline 700 & 2016 & 19523R & 8 & QCP & & & & & & 14.6 & & 0.21 \\
\hline 701 & 2016 & $19532 R$ & 8 & PFP & 0.15 & 0.75 & 0.24 & 0.59 & 13.5 & 13.0 & 0.53 & 0.47 \\
\hline 702 & 2016 & 19524R & 8 & QCP & 0.84 & 0.85 & 0.83 & 0.92 & 15.4 & 15.3 & 0.34 & 0.35 \\
\hline 703 & 2017 & 19524R & 8 & QCP & 1.00 & & & & 14.7 & 14.7 & 0.35 & 0.00 \\
\hline 704 & 2016 & 19524R & 8 & QCP & & & 0.30 & & 15.1 & & 0.32 & \\
\hline 705 & 2016 & 19524R & 8 & QCP & 0.67 & & & & 16.2 & 16.0 & 0.07 & 0.00 \\
\hline 706 & 2016 & 19524R & 8 & QCP & 1.00 & & & & 15.2 & 15.1 & 0.07 & 0.00 \\
\hline 707 & 2016 & 19533R & 8 & QCP & & & 0.04 & & 15.6 & & 0.22 & \\
\hline 708 & 2016 & 19534R & 8 & PFP & 0.11 & 0.99 & 0.27 & 0.13 & 16.0 & 15.6 & 0.77 & 0.76 \\
\hline 709 & 2016 & 19534R & 8 & QCP & 1.00 & 0.33 & 0.21 & 0.03 & 15.3 & 15.1 & 0.72 & 1.03 \\
\hline 710 & 2016 & $19504 R$ & 8 & QCP & 0.67 & 0.40 & 0.13 & & 13.3 & 13.2 & 0.47 & 0.78 \\
\hline 711 & 2016 & 19523R & 8 & QCP & 1.00 & 0.42 & 0.00 & & 15.7 & 15.7 & 0.12 & 0.21 \\
\hline 712 & 2016 & 19605R & 8 & QCP & 0.67 & & & & 15.6 & 14.8 & 0.35 & 0.00 \\
\hline 713 & 2016 & 19534R & 8 & QCP & 0.76 & 0.14 & 0.53 & & 15.6 & 15.3 & 0.53 & 1.08 \\
\hline 714 & 2017 & 19654R & 8 & PFP & & & & & & 16.5 & & 0.00 \\
\hline 715 & 2017 & 19654R & 8 & PFP & 0.82 & 0.24 & 0.30 & 0.11 & 18.1 & 18.0 & 0.49 & 0.57 \\
\hline 716 & 2017 & 19523R & 8 & QCP & 0.75 & 0.63 & 0.85 & 0.52 & 16.0 & 15.9 & 0.57 & 0.66 \\
\hline 717 & 2017 & $19523 R$ & 8 & QCP & 0.89 & 0.93 & 0.00 & 0.07 & 16.0 & 15.8 & 0.49 & 0.46 \\
\hline 718 & 2017 & 19524R & 8 & QCP & 0.25 & & 0.89 & & 15.6 & 15.0 & 0.32 & 0.00 \\
\hline 719 & 2017 & 19524R & 8 & QCP & 0.93 & 0.51 & 0.61 & & 16.0 & 16.0 & 0.49 & 0.17 \\
\hline 720 & 2017 & $19605 R$ & 8 & QCP & 0.93 & 0.00 & 0.52 & & 14.9 & 14.7 & 0.46 & 0.00 \\
\hline 721 & 2015 & 19533R & 9 & QCP & 0.06 & 0.82 & 0.82 & 0.08 & 14.6 & 13.8 & 0.70 & 0.61 \\
\hline 722 & 2016 & $19606 \mathrm{FR}$ & 9 & QCP & 0.20 & 0.79 & 0.28 & 0.32 & 15.2 & 14.6 & 1.09 & 1.22 \\
\hline 723 & 2015 & 19605FR & 9 & QCP & 0.30 & 0.80 & 0.25 & 0.00 & 14.5 & 13.8 & 0.38 & 0.46 \\
\hline 724 & 2017 & 19513R & 9 & PFP & & & & & & 15.5 & & 0.00 \\
\hline 725 & 2016 & $19532 R$ & 9 & QCP & 0.67 & & & & 13.8 & 13.1 & 0.85 & 0.00 \\
\hline 726 & 2016 & $19534 R$ & 9 & QCP & 0.25 & 0.42 & 0.01 & 0.15 & 15.3 & 14.9 & 0.56 & 0.72 \\
\hline 727 & 2016 & 19534R & 9 & QCP & 0.64 & 0.80 & 0.99 & 0.25 & 15.3 & 15.1 & 0.53 & 0.43 \\
\hline 728 & 2017 & 19524R & 8 & QCP & 0.29 & 0.77 & 0.27 & 0.83 & 16.2 & 15.0 & 1.08 & 1.42 \\
\hline 729 & 2017 & 19524R & 8 & QCP & 0.26 & 0.65 & 0.03 & 0.18 & 15.1 & 14.8 & 0.74 & 0.91 \\
\hline 730 & 2017 & $19535 R$ & 8 & QCP & 0.61 & 0.02 & 0.97 & 0.07 & 15.0 & 13.4 & 0.65 & 2.82 \\
\hline 731 & 2017 & $19532 R$ & 8 & QCP & 0.77 & 0.69 & 0.17 & 0.00 & 13.3 & 13.4 & 0.93 & 0.79 \\
\hline
\end{tabular}




\begin{tabular}{|c|c|c|c|c|c|c|c|c|c|c|c|c|}
\hline $\begin{array}{l}\text { ICT } \\
\text { Code }\end{array}$ & Year & Mix Code & District & $\begin{array}{l}\text { Quality } \\
\text { Program }\end{array}$ & $\begin{array}{c}\text { MW } \\
\text { P-Value }\end{array}$ & $\begin{array}{l}\text { Levene's } \\
\text { P-Value }\end{array}$ & $\begin{array}{l}\text { Contractor } \\
\text { SW P-Value }\end{array}$ & $\begin{array}{c}\text { Agency SW } \\
\text { P-Value }\end{array}$ & $\begin{array}{c}\text { Contractor } \\
\text { Mean }\end{array}$ & $\begin{array}{l}\text { Agency } \\
\text { Mean }\end{array}$ & $\begin{array}{l}\text { Contractor } \\
\text { St. Dev. }\end{array}$ & $\begin{array}{l}\text { Agency } \\
\text { St. Dev. }\end{array}$ \\
\hline 732 & 2017 & $19532 R$ & 9 & QCP & 0.25 & & 0.02 & & 14.6 & 13.1 & 0.69 & 0.00 \\
\hline 733 & 2015 & $19532 R$ & 9 & QCP & 0.65 & 0.29 & 0.80 & 0.19 & 13.6 & 13.4 & 0.33 & 0.50 \\
\hline 734 & 2015 & 19532R & 9 & PFP & 0.92 & 1.00 & 0.00 & 0.02 & 13.8 & 13.8 & 0.51 & 0.50 \\
\hline 735 & 2016 & 19532R & 9 & PFP & 0.00 & 0.64 & 0.00 & 0.16 & 13.9 & 13.6 & 0.56 & 0.51 \\
\hline 736 & 2016 & 19532R & 9 & QCP & & & & & 13.9 & & 0.00 & \\
\hline 737 & 2017 & 19532R & 9 & QCP & & & & & 13.9 & & 0.00 & \\
\hline 738 & 2015 & $19532 R$ & 9 & PFP & 0.82 & 0.74 & 0.95 & 0.08 & 14.2 & 14.5 & 0.81 & 0.68 \\
\hline 739 & 2016 & 19532R & 9 & PFP & 0.00 & 0.57 & 0.04 & 0.08 & 14.0 & 13.7 & 0.57 & 0.62 \\
\hline 740 & 2016 & 19606FR & 9 & QCP & 1.00 & & 0.88 & & 14.8 & 14.9 & 0.45 & 0.00 \\
\hline 741 & 2016 & 19606FR & 9 & QCP & 0.67 & & & & 15.5 & 15.2 & 0.28 & 0.00 \\
\hline 742 & 2016 & 19606FR & 9 & QCP & 0.61 & 0.79 & 0.88 & 0.53 & 14.7 & 14.8 & 0.45 & 0.39 \\
\hline 743 & 2016 & 19605FR & 9 & QCP & 0.69 & 0.46 & 0.46 & 0.39 & 15.7 & 15.6 & 0.59 & 0.75 \\
\hline 744 & 2017 & 19534R & 9 & QCP & 0.33 & & & & 14.3 & 13.7 & 0.00 & 0.00 \\
\hline 745 & 2016 & 19534R & 9 & QCP & 0.67 & & & & 15.6 & 14.9 & 0.21 & 0.00 \\
\hline 746 & 2016 & 19534R & 9 & QCP & 1.00 & & 0.98 & & 15.1 & 15.1 & 0.29 & 0.00 \\
\hline 747 & 2016 & 19534R & 9 & QCP & 0.11 & 0.93 & 0.40 & & 15.3 & 14.8 & 0.32 & 0.21 \\
\hline 748 & 2016 & 19534R & 9 & QCP & 0.10 & 0.60 & 0.19 & 0.46 & 15.6 & 15.3 & 0.34 & 0.21 \\
\hline 749 & 2015 & 19523R & 9 & QCP & 1.00 & & 0.91 & & 15.4 & 15.3 & 0.88 & 0.00 \\
\hline 750 & 2015 & 19523R & 9 & QCP & 0.47 & 0.46 & 0.37 & 0.58 & 14.5 & 14.2 & 0.49 & 0.67 \\
\hline 751 & 2015 & 19534R & 9 & PFP & 0.80 & 0.84 & 0.51 & & 15.7 & 15.7 & 0.41 & 0.35 \\
\hline 752 & 2015 & $19534 R$ & 9 & QCP & 1.00 & & 0.22 & & 15.5 & 14.5 & 0.87 & 0.00 \\
\hline 753 & 2015 & 19534R & 9 & QCP & 0.50 & & 0.46 & & 15.6 & 15.1 & 0.42 & 0.00 \\
\hline 754 & 2017 & 19534R & 9 & QCP & 0.29 & & 0.20 & & 15.6 & 14.8 & 0.27 & 0.00 \\
\hline 755 & 2015 & 19606FR & 9 & QCP & 1.00 & & & & 16.8 & 15.8 & 1.41 & 0.00 \\
\hline 756 & 2015 & $19606 \mathrm{FR}$ & 9 & QCP & 1.00 & & & & 15.5 & 15.3 & 0.00 & 0.00 \\
\hline 757 & 2016 & 19535 & 9 & PFP & 0.01 & 0.31 & 0.01 & 0.29 & 15.5 & 15.3 & 0.53 & 0.60 \\
\hline 758 & 2016 & $19522 R$ & 9 & QCP & 0.80 & 0.89 & 0.27 & & 12.8 & 13.1 & 0.70 & 0.49 \\
\hline 759 & 2017 & $19532 R$ & 9 & PFP & 0.00 & 0.89 & 0.00 & 0.00 & 13.8 & 13.5 & 0.62 & 0.61 \\
\hline 760 & 2016 & 19523R & 9 & QCP & & & & & 16.2 & & 0.00 & \\
\hline 761 & 2016 & $19523 R$ & 9 & QCP & & & & & 15.5 & & 0.00 & \\
\hline 762 & 2017 & 19523R & 9 & QCP & 0.01 & 0.42 & 0.02 & 0.01 & 15.4 & 14.7 & 0.82 & 0.96 \\
\hline 763 & 2017 & $19532 R$ & 9 & PFP & 0.66 & 0.43 & 0.26 & 0.30 & 13.6 & 13.5 & 0.58 & 0.74 \\
\hline 764 & 2015 & 19534R & 9 & QCP & 1.00 & 0.72 & 0.57 & & 15.9 & 16.1 & 0.89 & 0.92 \\
\hline 765 & 2015 & 19533R & 9 & QCP & 1.00 & & 0.13 & & 15.5 & 15.9 & 0.72 & 0.00 \\
\hline 766 & 2015 & 19533R & 9 & QCP & 0.74 & 0.99 & 0.68 & 0.49 & 15.2 & 15.1 & 0.44 & 0.40 \\
\hline
\end{tabular}




\begin{tabular}{|c|c|c|c|c|c|c|c|c|c|c|c|c|}
\hline $\begin{array}{l}\text { ICT } \\
\text { Code }\end{array}$ & Year & Mix Code & District & $\begin{array}{l}\text { Quality } \\
\text { Program }\end{array}$ & $\begin{array}{c}\text { MW } \\
\text { P-Value }\end{array}$ & $\begin{array}{l}\text { Levene's } \\
\text { P-Value }\end{array}$ & $\begin{array}{l}\text { Contractor } \\
\text { SW P-Value }\end{array}$ & $\begin{array}{c}\text { Agency SW } \\
\text { P-Value }\end{array}$ & $\begin{array}{c}\text { Contractor } \\
\text { Mean }\end{array}$ & $\begin{array}{l}\text { Agency } \\
\text { Mean }\end{array}$ & $\begin{array}{c}\text { Contractor } \\
\text { St. Dev. }\end{array}$ & $\begin{array}{l}\text { Agency } \\
\text { St. Dev. }\end{array}$ \\
\hline 767 & 2015 & 19533R & 9 & QCP & 0.39 & 0.30 & 0.60 & 0.46 & 14.9 & 14.7 & 0.28 & 0.42 \\
\hline 768 & 2015 & 19533R & 9 & QCP & 0.83 & 0.19 & 0.37 & 0.53 & 14.5 & 14.2 & 1.25 & 2.18 \\
\hline 769 & 2015 & 19533R & 9 & QCP & 0.57 & & 0.01 & & 15.4 & 15.1 & 0.46 & 0.00 \\
\hline 770 & 2015 & 19533R & 9 & QCP & 0.79 & 0.91 & 0.09 & 0.19 & 14.9 & 15.0 & 0.53 & 0.49 \\
\hline 771 & 2015 & 19534R & 9 & QCP & 0.96 & 0.86 & 0.46 & 0.82 & 15.2 & 15.2 & 0.77 & 0.81 \\
\hline 772 & 2015 & 19606FR & 9 & QCP & 1.00 & 0.87 & & & 15.0 & 14.9 & 1.56 & 1.91 \\
\hline 773 & 2015 & 19606 & 9 & QCP & 0.80 & 0.78 & 1.00 & 0.60 & 15.7 & 15.4 & 0.90 & 1.12 \\
\hline 774 & 2016 & 19606FR & 9 & QCP & 0.10 & 0.32 & 0.64 & 0.84 & 14.9 & 14.2 & 0.15 & 0.35 \\
\hline 775 & 2015 & 19606FR & 9 & QCP & 0.43 & 0.82 & 0.65 & & 15.3 & 15.0 & 0.31 & 0.28 \\
\hline 776 & 2015 & 19606FR & 9 & QCP & 0.71 & 0.56 & 0.02 & & 14.8 & 14.6 & 0.56 & 0.21 \\
\hline 777 & 2015 & 19606FR & 9 & QCP & 0.68 & 0.30 & 0.98 & 0.55 & 15.4 & 15.1 & 0.62 & 0.99 \\
\hline 778 & 2015 & 19606FR & 9 & QCP & 0.50 & & 0.64 & & 14.9 & 14.4 & 0.31 & 0.00 \\
\hline 779 & 2016 & 19606FR & 9 & QCP & 0.39 & 0.68 & 0.12 & 0.93 & 15.6 & 15.3 & 0.51 & 0.63 \\
\hline 780 & 2015 & 19606FR & 9 & QCP & 0.27 & 0.71 & 0.49 & 0.88 & 14.9 & 14.5 & 0.45 & 0.37 \\
\hline 781 & 2015 & 19606FR & 9 & QCP & & & & & & 15.1 & & 0.00 \\
\hline 782 & 2015 & 19534R & 9 & QCP & 0.68 & 0.94 & 0.33 & 0.52 & 15.3 & 15.4 & 0.53 & 0.46 \\
\hline 783 & 2016 & 19534R & 9 & QCP & 0.69 & 0.35 & 0.67 & & 15.7 & 15.4 & 0.48 & 0.71 \\
\hline 784 & 2016 & 19533R & 9 & QCP & 0.43 & 0.77 & 0.45 & & 15.4 & 14.8 & 0.74 & 0.71 \\
\hline 785 & 2016 & 19523R & 9 & QCP & 1.00 & & & & 15.6 & 15.2 & 0.49 & 0.00 \\
\hline 786 & 2016 & 19523R & 9 & QCP & 1.00 & & 0.25 & & 15.4 & 15.4 & 0.38 & 0.00 \\
\hline 787 & 2017 & 19523R & 9 & QCP & 0.13 & 0.00 & 0.72 & & 14.9 & 14.1 & 0.58 & 0.00 \\
\hline 788 & 2017 & 19523R & 9 & QCP & 0.11 & 0.02 & 0.99 & 0.02 & 15.2 & 14.9 & 0.31 & 0.06 \\
\hline 789 & 2016 & 19605FR & 9 & QCP & 1.00 & 0.00 & & & 16.4 & 16.4 & 0.35 & 0.00 \\
\hline 790 & 2016 & 19605FR & 9 & QCP & 0.67 & & & & 15.9 & 15.1 & 0.78 & 0.00 \\
\hline 791 & 2017 & 19605FR & 9 & QCP & 0.33 & 0.00 & & & 14.8 & 14.4 & 0.14 & 0.00 \\
\hline 792 & 2017 & 19605FR & 9 & QCP & 0.50 & & 1.00 & & 15.6 & 14.9 & 0.10 & 0.00 \\
\hline 793 & 2015 & $\begin{array}{c}\text { HMA } \\
\text { Binder }\end{array}$ & 9 & QCP & 0.04 & 0.06 & 0.64 & 0.47 & 14.0 & 13.6 & 0.61 & 0.86 \\
\hline 794 & 2015 & $\begin{array}{l}\text { HMA } \\
\text { Binder }\end{array}$ & 9 & QCP & 0.16 & 0.06 & 0.95 & 0.53 & 13.7 & 14.2 & 0.65 & 0.29 \\
\hline 795 & 2015 & $\begin{array}{c}\text { HMA } \\
\text { Binder }\end{array}$ & 9 & QCP & 0.01 & 0.60 & 0.53 & 0.68 & 14.8 & 13.9 & 0.41 & 0.52 \\
\hline 796 & 2015 & $\begin{array}{c}\text { HMA } \\
\text { Binder }\end{array}$ & 9 & QCP & 0.36 & 0.21 & 0.35 & & 16.2 & 15.4 & 0.64 & 1.27 \\
\hline 797 & 2016 & 19535 & 9 & PFP & 0.70 & 0.51 & 0.09 & 0.10 & 16.4 & 16.4 & 0.52 & 0.60 \\
\hline
\end{tabular}




\begin{tabular}{|c|c|c|c|c|c|c|c|c|c|c|c|c|}
\hline $\begin{array}{l}\text { ICT } \\
\text { Code }\end{array}$ & Year & Mix Code & District & $\begin{array}{l}\text { Quality } \\
\text { Program }\end{array}$ & $\begin{array}{c}\text { MW } \\
\text { P-Value }\end{array}$ & $\begin{array}{l}\text { Levene's } \\
\text { P-Value }\end{array}$ & $\begin{array}{l}\text { Contractor } \\
\text { SW P-Value }\end{array}$ & $\begin{array}{c}\text { Agency SW } \\
\text { P-Value }\end{array}$ & $\begin{array}{c}\text { Contractor } \\
\text { Mean }\end{array}$ & $\begin{array}{l}\text { Agency } \\
\text { Mean }\end{array}$ & $\begin{array}{l}\text { Contractor } \\
\text { St. Dev. }\end{array}$ & $\begin{array}{l}\text { Agency } \\
\text { St. Dev. }\end{array}$ \\
\hline 798 & 2016 & 19535 & 9 & PFP & 0.78 & 0.78 & 0.01 & 0.19 & 16.0 & 16.1 & 0.69 & 0.49 \\
\hline 799 & 2016 & $19532 R$ & 9 & PFP & 0.92 & 0.23 & 0.40 & 0.03 & 14.7 & 14.8 & 0.61 & 0.76 \\
\hline 800 & 2016 & 19532R & 9 & PFP & 0.19 & 0.97 & 0.08 & 0.76 & 14.7 & 14.3 & 0.49 & 0.43 \\
\hline 801 & 2017 & 19533R & 9 & QCP & 0.63 & 0.14 & 0.04 & 0.41 & 15.4 & 15.5 & 0.33 & 0.13 \\
\hline 802 & 2016 & 19533R & 9 & QCP & 0.86 & 0.09 & 0.45 & 0.96 & 15.8 & 16.0 & 0.71 & 1.45 \\
\hline 803 & 2017 & 19534R & 9 & PFP & 0.82 & 0.16 & 0.28 & 0.62 & 15.9 & 15.9 & 0.68 & 0.89 \\
\hline 804 & 2017 & $19532 R$ & 9 & PFP & 0.04 & 0.20 & 0.05 & 0.03 & 14.6 & 14.4 & 0.43 & 0.34 \\
\hline 805 & 2015 & 19533R & 9 & QCP & 0.66 & 0.54 & 0.13 & & 15.4 & 15.1 & 0.61 & 0.71 \\
\hline 806 & 2016 & 19534R & 9 & QCP & 0.36 & 0.44 & 0.35 & & 15.9 & 15.5 & 0.48 & 0.14 \\
\hline 807 & 2015 & 19534R & 9 & QCP & 0.40 & & 0.90 & & 15.4 & 14.6 & 0.42 & 0.00 \\
\hline 808 & 2016 & 19534R & 9 & QCP & 0.53 & 0.70 & 0.14 & 0.29 & 15.3 & 15.0 & 0.86 & 0.73 \\
\hline 809 & 2016 & 19606FR & 9 & QCP & 1.00 & & & & 14.4 & 14.3 & 0.28 & 0.00 \\
\hline 810 & 2016 & 19534R & 9 & QCP & 0.33 & & 0.49 & & 16.3 & 16.0 & 0.16 & 0.00 \\
\hline 811 & 2015 & 19605FR & 9 & QCP & 0.33 & 0.82 & & & 14.6 & 14.0 & 0.21 & 0.28 \\
\hline 812 & 2015 & 19605FR & 9 & QCP & 0.03 & 0.80 & 0.41 & 0.06 & 14.3 & 13.7 & 0.61 & 0.56 \\
\hline 813 & 2015 & 19605FR & 9 & QCP & 0.70 & 0.25 & 0.64 & 0.00 & 14.0 & 13.9 & 0.15 & 0.06 \\
\hline 814 & 2016 & 19606FR & 9 & QCP & 0.29 & 0.64 & 0.16 & 0.66 & 13.2 & 12.8 & 0.80 & 0.64 \\
\hline 815 & 2016 & 19533R & 9 & QCP & 0.50 & & 0.27 & & 14.8 & 14.2 & 0.70 & 0.00 \\
\hline 816 & 2015 & 19523R & 9 & QCP & 0.04 & 0.58 & 0.25 & 0.35 & 15.2 & 14.8 & 0.55 & 0.62 \\
\hline 817 & 2016 & 19523R & 9 & QCP & 1.00 & & 0.21 & & 14.8 & 14.9 & 0.40 & 0.00 \\
\hline 818 & 2015 & $19523 R$ & 9 & QCP & 1.00 & & 0.91 & & 14.7 & 14.4 & 0.69 & 0.00 \\
\hline 819 & 2015 & 19523R & 9 & QCP & 0.57 & 0.40 & 0.73 & 0.00 & 15.7 & 15.6 & 0.48 & 0.23 \\
\hline 820 & 2015 & 19523R & 9 & QCP & 0.06 & 0.58 & 0.65 & & 14.8 & 14.4 & 0.18 & 0.07 \\
\hline 821 & 2016 & $19532 R$ & 9 & QCP & 0.42 & 0.02 & 0.00 & 0.05 & 13.0 & 12.8 & 0.22 & 0.55 \\
\hline 822 & 2016 & $19532 R$ & 9 & QCP & 0.42 & 0.00 & 0.62 & & 13.0 & 13.4 & 0.57 & 0.00 \\
\hline 823 & 2016 & $19522 R$ & 9 & QCP & 0.50 & & 0.64 & & 14.6 & 14.2 & 0.15 & 0.00 \\
\hline 824 & 2016 & $19532 R$ & 9 & QCP & & & & & & & & \\
\hline 825 & 2016 & $19532 R$ & 9 & QCP & & & & 0.56 & & 12.8 & & 0.35 \\
\hline 826 & 2016 & $19606 \mathrm{FR}$ & 9 & QCP & 0.50 & & & 1.00 & 15.4 & 15.8 & 0.00 & 0.30 \\
\hline 827 & 2017 & 19605FR & 9 & QCP & 0.67 & 0.82 & & & 14.7 & 14.6 & 0.28 & 0.21 \\
\hline 828 & 2017 & $19532 R$ & 9 & QCP & 0.49 & 0.98 & 0.01 & 0.28 & 13.8 & 13.7 & 0.37 & 0.35 \\
\hline 829 & 2017 & 19524R & 9 & QCP & 0.29 & & 0.49 & & 15.6 & 16.1 & 0.31 & 0.00 \\
\hline 830 & 2017 & 19534R & 9 & QCP & 0.81 & 0.15 & 0.71 & 0.30 & 15.3 & 15.1 & 0.49 & 0.81 \\
\hline 831 & 2016 & $19532 R$ & 9 & PFP & & & 0.22 & & 14.3 & & 0.87 & \\
\hline 832 & 2016 & 19523R & 9 & QCP & 0.27 & 0.84 & 0.52 & & 15.1 & 14.3 & 0.45 & 0.28 \\
\hline
\end{tabular}




\begin{tabular}{|c|c|c|c|c|c|c|c|c|c|c|c|c|}
\hline $\begin{array}{l}\text { ICT } \\
\text { Code }\end{array}$ & Year & Mix Code & District & $\begin{array}{l}\text { Quality } \\
\text { Program }\end{array}$ & $\begin{array}{c}\text { MW } \\
\text { P-Value }\end{array}$ & $\begin{array}{l}\text { Levene's } \\
\text { P-Value }\end{array}$ & $\begin{array}{l}\text { Contractor } \\
\text { SW P-Value }\end{array}$ & $\begin{array}{c}\text { Agency SW } \\
\text { P-Value }\end{array}$ & $\begin{array}{c}\text { Contractor } \\
\text { Mean }\end{array}$ & $\begin{array}{l}\text { Agency } \\
\text { Mean }\end{array}$ & $\begin{array}{l}\text { Contractor } \\
\text { St. Dev. }\end{array}$ & $\begin{array}{l}\text { Agency } \\
\text { St. Dev. }\end{array}$ \\
\hline 833 & 2016 & $19535 R$ & 9 & PFP & & & & & 18.6 & & 0.00 & \\
\hline 834 & 2017 & $19523 R$ & 9 & QCP & 0.30 & 0.60 & 0.64 & 1.00 & 15.8 & 15.5 & 0.31 & 0.20 \\
\hline 835 & 2017 & $19532 R$ & 9 & PFP & & & & & 13.8 & & 0.00 & \\
\hline 836 & 2017 & $19532 R$ & 9 & PFP & 0.86 & & 0.57 & & 13.9 & 14.1 & 0.27 & 0.00 \\
\hline
\end{tabular}




\section{C.3 DENSITY ANALYSIS RESULTS}

Table C.3. Density Analysis Results Summary

\begin{tabular}{|c|c|c|c|c|c|c|c|c|c|c|c|c|}
\hline $\begin{array}{c}\text { ICT } \\
\text { Code }\end{array}$ & Year & Mix Code & District & $\begin{array}{l}\text { Quality } \\
\text { Program }\end{array}$ & $\begin{array}{c}\text { MW } \\
\text { P-Value }\end{array}$ & $\begin{array}{l}\text { Levene's } \\
\text { P-Value }\end{array}$ & $\begin{array}{l}\text { Contractor } \\
\text { SW P-Value }\end{array}$ & $\begin{array}{l}\text { Agency SW } \\
\text { P-Value }\end{array}$ & $\begin{array}{c}\text { Contractor } \\
\text { Mean }\end{array}$ & $\begin{array}{l}\text { Agency } \\
\text { Mean }\end{array}$ & $\begin{array}{c}\text { Contractor } \\
\text { St. Dev. }\end{array}$ & $\begin{array}{l}\text { Agency } \\
\text { St. Dev. }\end{array}$ \\
\hline 2 & 2015 & $19524 R$ & 1 & $\mathrm{QCP}$ & & & & 0.55 & & 95.4 & & 1.46 \\
\hline 3 & 2017 & 19524R & 1 & QCP & 0.58 & 0.37 & & 0.20 & 92.3 & 92.7 & 1.98 & 1.34 \\
\hline 4 & 2017 & $19524 \mathrm{R}$ & 1 & QCP & & & & 0.02 & & 94.2 & & 1.56 \\
\hline 5 & 2016 & 19524R & 1 & QCP & & & & 0.44 & & 93.4 & & 1.54 \\
\hline 6 & 2015 & 19514R & 1 & QCP & & & & 0.99 & & 92.7 & & 1.68 \\
\hline 7 & 2015 & $19524 R$ & 1 & QCP & & & & 0.47 & & 94.1 & & 1.39 \\
\hline 8 & 2015 & 19524R & 1 & QCP & & & & 0.39 & & 91.2 & & 1.42 \\
\hline 9 & 2015 & $19524 \mathrm{R}$ & 1 & PFP & 0.83 & 0.28 & 0.02 & 0.28 & 91.8 & 92.0 & 2.46 & 2.17 \\
\hline 10 & 2015 & $19512 R$ & 1 & QCP & & & & 0.36 & & 93.6 & & 1.02 \\
\hline 11 & 2015 & $19512 \mathrm{R}$ & 1 & QCP & & & & 0.01 & & 91.9 & & 1.51 \\
\hline 12 & 2015 & $19522 \mathrm{R}$ & 1 & QCP & & & & 0.51 & & 93.8 & & 1.20 \\
\hline 13 & 2017 & $19522 \mathrm{R}$ & 1 & QCP & & & & 0.00 & & 92.9 & & 3.19 \\
\hline 14 & 2015 & 19510R & 1 & QCP & & & & 0.04 & & 93.4 & & 1.62 \\
\hline 16 & 2015 & $19512 R$ & 1 & QCP & & & & 0.55 & & 94.9 & & 1.00 \\
\hline 17 & 2015 & 19510R & 1 & QCP & & & & 0.03 & & 93.6 & & 2.30 \\
\hline 18 & 2015 & $19536 R$ & 1 & $\mathrm{QCP}$ & & & & 0.01 & & 91.9 & & 1.51 \\
\hline 20 & 2017 & 19525R & 1 & QCP & 0.44 & 0.74 & 0.48 & 0.11 & 92.6 & 93.2 & 2.09 & 1.98 \\
\hline 21 & 2015 & $19524 \mathrm{R}$ & 1 & QCP & & & & 0.38 & & 94.6 & & 1.51 \\
\hline 22 & 2015 & $19512 \mathrm{R}$ & 1 & QCP & 0.67 & & & & 92.2 & 94.6 & 1.34 & 0.00 \\
\hline 23 & 2016 & $19532 R$ & 1 & QCP & & & & 0.99 & & 93.6 & & 1.06 \\
\hline 24 & 2017 & $19532 \mathrm{R}$ & 1 & QCP & 0.88 & 0.48 & 0.04 & 0.35 & 93.3 & 93.3 & 1.17 & 1.55 \\
\hline 25 & 2017 & 19510R & 1 & QCP & & & 0.04 & & 93.5 & & 3.08 & \\
\hline 26 & 2015 & 19510R & 1 & QCP & & & & 0.22 & & 93.3 & & 1.62 \\
\hline 27 & 2015 & 19665R & 1 & QCP & 0.54 & 0.31 & & 0.53 & 94.7 & 95.2 & 0.49 & 2.49 \\
\hline 28 & 2017 & $19524 \mathrm{R}$ & 1 & QCP & & & & 0.82 & & 93.5 & & 1.55 \\
\hline 29 & 2017 & $19525 R$ & 1 & QCP & & & & 0.10 & & 93.6 & & 0.55 \\
\hline 30 & 2016 & $19512 R$ & 1 & QCP & & & 0.73 & & 95.0 & & 1.42 & \\
\hline 33 & 2015 & $19522 R$ & 1 & QCP & 0.80 & 0.93 & & 0.10 & 95.2 & 95.0 & 0.71 & 0.95 \\
\hline
\end{tabular}




\begin{tabular}{|c|c|c|c|c|c|c|c|c|c|c|c|c|}
\hline $\begin{array}{c}\text { ICT } \\
\text { Code }\end{array}$ & Year & Mix Code & District & $\begin{array}{l}\text { Quality } \\
\text { Program }\end{array}$ & $\begin{array}{c}\text { MW } \\
\text { P-Value }\end{array}$ & $\begin{array}{l}\text { Levene's } \\
\text { P-Value }\end{array}$ & $\begin{array}{l}\text { Contractor } \\
\text { SW P-Value }\end{array}$ & $\begin{array}{c}\text { Agency SW } \\
\text { P-Value }\end{array}$ & $\begin{array}{c}\text { Contractor } \\
\text { Mean }\end{array}$ & $\begin{array}{l}\text { Agency } \\
\text { Mean }\end{array}$ & $\begin{array}{c}\text { Contractor } \\
\text { St. Dev. }\end{array}$ & $\begin{array}{l}\text { Agency } \\
\text { St. Dev. }\end{array}$ \\
\hline 34 & 2015 & 19524R & 1 & QCP & & & & 0.00 & & 93.8 & & 2.58 \\
\hline 35 & 2015 & 19510R & 1 & QCP & 0.96 & 0.48 & 0.56 & 0.00 & 92.7 & 92.6 & 2.00 & 2.50 \\
\hline 36 & 2015 & 19510R & 1 & QCP & & & & 0.85 & & 91.5 & & 1.74 \\
\hline 37 & 2015 & 19510R & 1 & QCP & & & & 0.37 & & 92.4 & & 1.66 \\
\hline 38 & 2015 & 19524R & 1 & QCP & 0.67 & & & & 94.2 & 95.5 & 0.00 & 1.27 \\
\hline 39 & 2015 & 19524R & 1 & QCP & 0.01 & 0.91 & 0.00 & 0.05 & 96.0 & 95.0 & 1.43 & 1.41 \\
\hline 40 & 2015 & 19510R & 1 & PFP & 0.04 & 0.94 & 0.00 & 0.00 & 93.9 & 93.5 & 2.02 & 2.01 \\
\hline 41 & 2015 & 19510R & 1 & PFP & & & & & 95.7 & & 0.28 & \\
\hline 42 & 2015 & 19524R & 1 & QCP & & & & 0.00 & & 93.5 & & 1.70 \\
\hline 43 & 2015 & 19655R & 1 & PFP & 0.01 & 0.00 & 0.00 & 0.00 & 94.8 & 94.1 & 1.50 & 2.13 \\
\hline 44 & 2015 & 19536R & 1 & PFP & 0.01 & 0.29 & 0.00 & 0.00 & 92.1 & 91.5 & 2.24 & 2.05 \\
\hline 45 & 2017 & 19510R & 1 & QCP & 0.06 & 0.37 & 0.44 & 0.18 & 94.7 & 93.2 & 1.80 & 2.33 \\
\hline 46 & 2017 & 19510R & 1 & QCP & & & & 0.00 & & 93.8 & & 1.82 \\
\hline 47 & 2016 & 19510R & 1 & QCP & 1.00 & 0.43 & 0.36 & 0.55 & 92.1 & 92.0 & 1.24 & 2.07 \\
\hline 48 & 2017 & 19524R & 1 & QCP & 0.67 & & 0.23 & & 94.5 & 94.5 & 1.24 & 0.00 \\
\hline 49 & 2017 & 19525R & 1 & QCP & & & & 0.00 & & 93.9 & & 1.44 \\
\hline 50 & 2017 & 19525R & 1 & PFP & 0.35 & 0.95 & 0.00 & 0.00 & 93.8 & 94.0 & 2.13 & 2.14 \\
\hline 51 & 2016 & 19525R & 1 & QCP & 0.23 & 0.37 & & 0.00 & 94.8 & 93.5 & 0.49 & 2.07 \\
\hline 52 & 2016 & 19536R & 1 & QCP & & & 0.14 & & 93.1 & & 0.67 & \\
\hline 53 & 2015 & 19536R & 1 & PFP & 0.20 & 0.00 & 0.01 & 0.02 & 93.7 & 93.2 & 1.35 & 2.20 \\
\hline 54 & 2015 & $19524 R$ & 1 & QCP & & & & 0.02 & & 94.5 & & 2.10 \\
\hline 55 & 2017 & 19524R & 1 & QCP & & & & 0.07 & & 95.1 & & 1.29 \\
\hline 56 & 2015 & $19522 R$ & 1 & QCP & 0.48 & 0.84 & 0.81 & 0.64 & 95.4 & 95.6 & 0.85 & 0.91 \\
\hline 57 & 2015 & $19522 R$ & 1 & QCP & 0.62 & & & 0.00 & 96.2 & 95.3 & 0.00 & 1.23 \\
\hline 58 & 2015 & 19510R & 1 & QCP & 0.35 & 0.23 & 1.00 & 0.04 & 94.5 & 93.1 & 0.70 & 1.99 \\
\hline 59 & 2015 & 19510R & 1 & PFP & 0.03 & 0.75 & 0.00 & 0.36 & 94.2 & 93.3 & 1.98 & 1.87 \\
\hline 60 & 2017 & 19524R & 1 & QCP & 0.89 & 0.79 & 0.07 & 0.47 & 93.1 & 93.2 & 0.63 & 0.73 \\
\hline 61 & 2017 & 19524R & 1 & PFP & 0.74 & 0.21 & 0.00 & 0.00 & 93.4 & 93.3 & 0.85 & 1.04 \\
\hline 62 & 2017 & 19524R & 1 & QCP & & & & 0.70 & & 93.8 & & 1.08 \\
\hline 63 & 2017 & 19510R & 1 & QCP & & & & 0.12 & & 94.4 & & 1.26 \\
\hline 64 & 2015 & $19532 R$ & 1 & QCP & & & 0.45 & & 94.2 & & 1.61 & \\
\hline 65 & 2017 & 19510R & 1 & QCP & 0.01 & 0.66 & 0.02 & 0.11 & 94.7 & 93.6 & 1.13 & 1.00 \\
\hline 66 & 2017 & 19510R & 1 & QCP & & & & 0.16 & & 94.3 & & 1.88 \\
\hline 67 & 2016 & 19510R & 1 & QCP & 0.95 & 0.35 & 0.02 & 0.00 & 93.1 & 93.0 & 1.78 & 2.08 \\
\hline 69 & 2017 & 19524R & 1 & PFP & 0.68 & 0.07 & 0.01 & 0.00 & 91.3 & 91.2 & 2.78 & 3.41 \\
\hline
\end{tabular}




\begin{tabular}{|c|c|c|c|c|c|c|c|c|c|c|c|c|}
\hline $\begin{array}{c}\text { ICT } \\
\text { Code }\end{array}$ & Year & Mix Code & District & $\begin{array}{l}\text { Quality } \\
\text { Program }\end{array}$ & $\begin{array}{c}\text { MW } \\
\text { P-Value }\end{array}$ & $\begin{array}{l}\text { Levene's } \\
\text { P-Value }\end{array}$ & $\begin{array}{l}\text { Contractor } \\
\text { SW P-Value }\end{array}$ & $\begin{array}{c}\text { Agency SW } \\
\text { P-Value }\end{array}$ & $\begin{array}{c}\text { Contractor } \\
\text { Mean }\end{array}$ & $\begin{array}{l}\text { Agency } \\
\text { Mean }\end{array}$ & $\begin{array}{c}\text { Contractor } \\
\text { St. Dev. }\end{array}$ & $\begin{array}{l}\text { Agency } \\
\text { St. Dev. }\end{array}$ \\
\hline 70 & 2017 & 19655R & 1 & $\mathrm{QCP}$ & & & & 0.80 & & 94.9 & & 1.66 \\
\hline 71 & 2017 & 19665R & 1 & $\mathrm{QCP}$ & & & & 0.29 & & 94.4 & & 1.51 \\
\hline 72 & 2017 & 19665R & 1 & $\mathrm{QCP}$ & 0.23 & 0.96 & 0.02 & 0.04 & 95.1 & 94.1 & 2.64 & 2.68 \\
\hline 73 & 2015 & $19512 R$ & 1 & $\mathrm{QCP}$ & 0.09 & 0.45 & 0.01 & 0.43 & 93.8 & 95.3 & 1.37 & 1.75 \\
\hline 74 & 2015 & $19522 R$ & 1 & PFP & 0.20 & 0.23 & & 0.00 & 94.3 & 92.3 & 0.35 & 2.49 \\
\hline 75 & 2017 & $19522 R$ & 1 & QCP & & & & 0.02 & & 94.7 & & 2.00 \\
\hline 76 & 2015 & $19522 R$ & 1 & QCP & 0.40 & 0.00 & 0.06 & 0.00 & 94.1 & 92.0 & 0.63 & 6.36 \\
\hline 78 & 2015 & $19514 R$ & 1 & QCP & 0.27 & 0.84 & 0.00 & 0.11 & 93.7 & 94.0 & 0.94 & 0.97 \\
\hline 79 & 2015 & 19524R & 1 & QCP & & & & 0.06 & & 93.8 & & 1.75 \\
\hline 80 & 2015 & $19512 R$ & 1 & QCP & 0.67 & & & 0.02 & 94.7 & 95.2 & 0.00 & 1.50 \\
\hline 81 & 2015 & $19512 R$ & 1 & QCP & 0.18 & 0.08 & 0.22 & 0.01 & 95.1 & 94.4 & 1.15 & 1.78 \\
\hline 83 & 2015 & 19525R & 1 & PFP & 0.30 & 0.92 & 0.44 & 0.13 & 93.3 & 93.0 & 1.74 & 1.76 \\
\hline 84 & 2017 & 19510R & 1 & $\mathrm{QCP}$ & & & & 0.00 & & 93.2 & & 4.89 \\
\hline 85 & 2015 & 19510R & 1 & QCP & 0.24 & 0.44 & 0.44 & 0.13 & 94.3 & 92.8 & 1.10 & 2.17 \\
\hline 86 & 2017 & $19532 R$ & 1 & QCP & & & & 0.32 & & 93.5 & & 2.03 \\
\hline 87 & 2017 & 19536R & 1 & QCP & 0.86 & & & 0.25 & 93.4 & 93.0 & 0.00 & 1.26 \\
\hline 88 & 2015 & 19536R & 1 & QCP & 0.37 & 0.18 & & 0.28 & 92.0 & 92.9 & 2.05 & 1.20 \\
\hline 89 & 2015 & $19512 R$ & 1 & $\mathrm{QCP}$ & 0.67 & & & & 95.3 & 97.3 & 0.00 & 0.14 \\
\hline 90 & 2015 & $19512 R$ & 1 & $\mathrm{QCP}$ & 0.13 & 0.13 & & 0.96 & 97.4 & 96.1 & 0.07 & 0.83 \\
\hline 91 & 2015 & $19514 R$ & 1 & $\mathrm{QCP}$ & & & & 0.93 & & 95.5 & & 0.82 \\
\hline 92 & 2017 & $19522 R$ & 1 & QCP & 0.72 & 0.60 & 0.00 & 0.93 & 95.8 & 95.6 & 0.58 & 0.94 \\
\hline 93 & 2017 & $19522 R$ & 1 & QCP & & & & 0.00 & & 94.8 & & 1.76 \\
\hline 94 & 2016 & $19522 R$ & 1 & QCP & & & & 0.00 & & 94.2 & & 1.97 \\
\hline 95 & 2015 & 19510R & 1 & QCP & & & & 0.31 & & 94.9 & & 2.10 \\
\hline 96 & 2015 & 19510R & 1 & QCP & & & & 0.41 & & 93.2 & & 1.40 \\
\hline 97 & 2015 & 19510R & 1 & QCP & 0.43 & & & 0.19 & 94.9 & 93.8 & 0.00 & 1.51 \\
\hline 98 & 2015 & 19510R & 1 & QCP & & & & 0.06 & & 94.7 & & 1.38 \\
\hline 99 & 2017 & 19510R & 1 & QCP & & & & 0.08 & & 94.5 & & 1.78 \\
\hline 101 & 2017 & 19532R & 1 & QCP & & & & 0.07 & & 93.4 & & 1.48 \\
\hline 102 & 2017 & $19532 R$ & 1 & QCP & & & & 0.77 & & 93.7 & & 1.30 \\
\hline 103 & 2015 & 19536R & 1 & $\mathrm{QCP}$ & & & & 0.08 & & 93.3 & & 1.36 \\
\hline 104 & 2015 & 19536R & 1 & QCP & 0.82 & 0.53 & & 0.05 & 93.2 & 93.5 & 2.69 & 2.26 \\
\hline 105 & 2015 & 19524R & 1 & QCP & 0.01 & 0.33 & 0.25 & 0.42 & 95.7 & 92.3 & 0.76 & 1.76 \\
\hline 106 & 2015 & 19524R & 1 & QCP & & & & 0.48 & & 91.9 & & 2.00 \\
\hline 107 & 2015 & 19524R & 1 & QCP & & & & 0.68 & & 93.3 & & 1.88 \\
\hline
\end{tabular}




\begin{tabular}{|c|c|c|c|c|c|c|c|c|c|c|c|c|}
\hline $\begin{array}{c}\text { ICT } \\
\text { Code }\end{array}$ & Year & Mix Code & District & $\begin{array}{l}\text { Quality } \\
\text { Program }\end{array}$ & $\begin{array}{c}\text { MW } \\
\text { P-Value }\end{array}$ & $\begin{array}{l}\text { Levene's } \\
\text { P-Value }\end{array}$ & $\begin{array}{l}\text { Contractor } \\
\text { SW P-Value }\end{array}$ & $\begin{array}{c}\text { Agency SW } \\
\text { P-Value }\end{array}$ & $\begin{array}{c}\text { Contractor } \\
\text { Mean }\end{array}$ & $\begin{array}{l}\text { Agency } \\
\text { Mean }\end{array}$ & $\begin{array}{c}\text { Contractor } \\
\text { St. Dev. }\end{array}$ & $\begin{array}{l}\text { Agency } \\
\text { St. Dev. }\end{array}$ \\
\hline 108 & 2017 & 19510R & 1 & $\mathrm{QCP}$ & & & & 0.14 & & 93.0 & & 1.96 \\
\hline 109 & 2017 & 19510R & 1 & $\mathrm{QCP}$ & 0.28 & & & 0.00 & 95.1 & 93.2 & 0.00 & 2.31 \\
\hline 110 & 2016 & 19510R & 1 & $\mathrm{QCP}$ & & & 0.82 & & 93.1 & & 1.81 & \\
\hline 111 & 2017 & 19510R & 1 & $\mathrm{QCP}$ & & & & 0.13 & & 93.7 & & 1.77 \\
\hline 112 & 2016 & 19510R & 1 & $\mathrm{QCP}$ & 0.00 & 0.00 & 0.88 & 0.00 & 94.0 & 92.9 & 1.36 & 2.18 \\
\hline 113 & 2017 & 19510R & 1 & QCP & & & & 0.03 & & 94.8 & & 1.81 \\
\hline 114 & 2017 & 19510R & 1 & QCP & & & & 0.08 & & 94.5 & & 1.97 \\
\hline 115 & 2017 & 19510R & 1 & QCP & & & & 0.02 & & 92.8 & & 2.26 \\
\hline 116 & 2015 & 19522R & 1 & QCP & & & & 0.58 & & 92.1 & & 2.39 \\
\hline 117 & 2015 & $19522 \mathrm{R}$ & 1 & QCP & & & & 0.30 & & 93.5 & & 1.59 \\
\hline 118 & 2017 & 19524R & 1 & PFP & 0.00 & 0.93 & 0.00 & 0.00 & 94.8 & 95.5 & 1.37 & 1.38 \\
\hline 119 & 2017 & $19524 R$ & 1 & QCP & & & & 0.02 & & 95.1 & & 1.75 \\
\hline 120 & 2017 & $19524 \mathrm{R}$ & 1 & $\mathrm{QCP}$ & & & & 0.69 & & 94.8 & & 1.38 \\
\hline 121 & 2017 & $19524 \mathrm{R}$ & 1 & QCP & & & & 0.63 & & 94.4 & & 0.82 \\
\hline 122 & 2017 & $19524 R$ & 1 & QCP & & & & 0.94 & & 96.1 & & 1.27 \\
\hline 123 & 2016 & $19524 R$ & 1 & QCP & 0.19 & 0.27 & 0.16 & 0.07 & 94.6 & 93.6 & 1.77 & 2.40 \\
\hline 124 & 2017 & $19524 \mathrm{R}$ & 1 & QCP & & & & 0.08 & & 94.2 & & 1.62 \\
\hline 125 & 2015 & 19510R & 1 & $\mathrm{QCP}$ & & & & 0.39 & & 92.9 & & 1.14 \\
\hline 126 & 2015 & 19510R & 1 & $\mathrm{QCP}$ & 0.01 & 0.08 & 0.27 & 0.00 & 93.8 & 93.1 & 1.55 & 1.81 \\
\hline 127 & 2015 & 19536R & 1 & PFP & 0.22 & 0.01 & 0.00 & 0.54 & 92.8 & 92.5 & 1.33 & 1.75 \\
\hline 128 & 2015 & $19522 R$ & 1 & QCP & 1.00 & 0.51 & 0.31 & 0.40 & 94.1 & 93.7 & 1.55 & 2.81 \\
\hline 129 & 2015 & $19522 R$ & 1 & PFP & & & 0.19 & & 94.3 & & 1.08 & \\
\hline 130 & 2015 & 19536R & 1 & QCP & & & & 0.00 & & 91.0 & & 1.94 \\
\hline 131 & 2015 & $19524 R$ & 1 & QCP & 0.23 & 0.64 & 0.95 & 0.83 & 92.3 & 93.5 & 1.97 & 1.76 \\
\hline 132 & 2015 & 19510R & 1 & QCP & 0.73 & 0.37 & 0.17 & 0.03 & 92.5 & 92.6 & 1.09 & 1.65 \\
\hline 133 & 2015 & 19510R & 1 & QCP & & & & 0.31 & & 91.5 & & 2.22 \\
\hline 134 & 2015 & $19524 R$ & 1 & QCP & 0.00 & 0.95 & 0.34 & 0.38 & 92.8 & 91.9 & 2.02 & 2.00 \\
\hline 135 & 2015 & 19665R & 1 & QCP & & & & 0.04 & & 93.4 & & 1.44 \\
\hline 136 & 2015 & 19524R & 1 & QCP & & & & 0.34 & & 94.1 & & 1.72 \\
\hline 137 & 2015 & $19524 R$ & 1 & QCP & & & & 0.04 & & 94.5 & & 1.82 \\
\hline 139 & 2017 & 19510R & 1 & $\mathrm{QCP}$ & & & & 0.00 & & 92.7 & & 1.80 \\
\hline 140 & 2017 & 19510R & 1 & QCP & & & & 0.49 & & 91.9 & & 1.41 \\
\hline 141 & 2017 & 19510R & 1 & QCP & & & & 0.69 & & 94.7 & & 1.12 \\
\hline 142 & 2015 & 19510R & 1 & QCP & & & & 0.01 & & 93.3 & & 2.01 \\
\hline 144 & 2017 & $19522 R$ & 1 & QCP & & & & 1.00 & & 93.3 & & 0.65 \\
\hline
\end{tabular}




\begin{tabular}{|c|c|c|c|c|c|c|c|c|c|c|c|c|}
\hline $\begin{array}{c}\text { ICT } \\
\text { Code }\end{array}$ & Year & Mix Code & District & $\begin{array}{l}\text { Quality } \\
\text { Program }\end{array}$ & $\begin{array}{c}\text { MW } \\
\text { P-Value }\end{array}$ & $\begin{array}{l}\text { Levene's } \\
\text { P-Value }\end{array}$ & $\begin{array}{l}\text { Contractor } \\
\text { SW P-Value }\end{array}$ & $\begin{array}{c}\text { Agency SW } \\
\text { P-Value }\end{array}$ & $\begin{array}{c}\text { Contractor } \\
\text { Mean }\end{array}$ & $\begin{array}{l}\text { Agency } \\
\text { Mean }\end{array}$ & $\begin{array}{c}\text { Contractor } \\
\text { St. Dev. }\end{array}$ & $\begin{array}{l}\text { Agency } \\
\text { St. Dev. }\end{array}$ \\
\hline 145 & 2015 & $19522 \mathrm{R}$ & 1 & $\mathrm{QCP}$ & 0.51 & 0.73 & 0.13 & 0.19 & 94.9 & 94.7 & 1.54 & 1.41 \\
\hline 146 & 2015 & 19536R & 1 & QCP & 0.29 & 0.45 & & 0.24 & 93.9 & 93.0 & 0.49 & 1.72 \\
\hline 147 & 2017 & 19524R & 1 & QCP & & & & 0.48 & & 92.7 & & 2.07 \\
\hline 148 & 2017 & 19524R & 1 & QCP & & & & 0.41 & & 92.8 & & 2.04 \\
\hline 149 & 2017 & 19524R & 1 & QCP & & & & 0.54 & & 92.6 & & 1.67 \\
\hline 150 & 2015 & 19525R & 1 & QCP & 1.00 & & & & 94.8 & 94.8 & 0.00 & 0.00 \\
\hline 151 & 2015 & 19525R & 1 & $\mathrm{QCP}$ & & & & 0.00 & & 94.1 & & 1.60 \\
\hline 152 & 2017 & $19525 R$ & 1 & QCP & & & & 0.16 & & 93.9 & & 3.28 \\
\hline 153 & 2017 & 18436R & 1 & QCP & & & & 0.42 & & 94.7 & & 1.49 \\
\hline 154 & 2017 & 19655R & 1 & QCP & & & & 0.49 & & 94.9 & & 1.45 \\
\hline 155 & 2016 & 19655R & 1 & QCP & 0.37 & 0.32 & 1.00 & 0.10 & 94.7 & 95.0 & 1.24 & 1.66 \\
\hline 156 & 2015 & 19525R & 1 & QCP & 0.03 & 0.27 & 0.20 & 0.01 & 92.3 & 93.9 & 2.00 & 1.51 \\
\hline 157 & 2017 & 19653R & 1 & $\mathrm{QCP}$ & 0.10 & 0.37 & 0.48 & 0.60 & 94.0 & 95.8 & 2.17 & 1.71 \\
\hline 158 & 2016 & 19665R & 1 & PFP & 0.90 & 0.61 & 0.56 & 0.32 & 93.8 & 93.8 & 1.43 & 1.53 \\
\hline 159 & 2017 & 19665R & 1 & QCP & 0.87 & & & 0.39 & 95.0 & 95.2 & 0.00 & 0.98 \\
\hline 160 & 2015 & $19512 R$ & 1 & QCP & 0.25 & & & 0.00 & 97.4 & 95.8 & 0.00 & 0.70 \\
\hline 161 & 2015 & $19512 \mathrm{R}$ & 1 & QCP & & & & 0.05 & & 93.8 & & 1.37 \\
\hline 162 & 2017 & 19525R & 1 & $\mathrm{QCP}$ & 0.80 & & & 0.90 & 93.8 & 94.5 & 0.00 & 1.39 \\
\hline 163 & 2017 & 19525R & 1 & PFP & & & 0.20 & & 94.8 & & 1.46 & \\
\hline 164 & 2017 & 19525R & 1 & $\mathrm{QCP}$ & & & & 0.11 & & 94.3 & & 0.65 \\
\hline 165 & 2017 & 19525R & 1 & QCP & & & & 0.02 & & 94.0 & & 1.68 \\
\hline 166 & 2017 & 19655R & 1 & PFP & 0.01 & 0.94 & 0.44 & 0.06 & 94.5 & 95.1 & 1.66 & 1.65 \\
\hline 167 & 2015 & $19512 R$ & 1 & QCP & 0.01 & 0.02 & 0.65 & 0.60 & 94.1 & 91.8 & 0.62 & 1.86 \\
\hline 168 & 2015 & $19522 R$ & 1 & QCP & 0.30 & 0.11 & 0.39 & 0.00 & 94.6 & 93.1 & 0.86 & 2.47 \\
\hline 169 & 2015 & $19522 R$ & 1 & QCP & 0.27 & 0.56 & 0.36 & 0.07 & 94.8 & 93.2 & 1.32 & 2.30 \\
\hline 170 & 2015 & 19536R & 1 & QCP & & & & 0.63 & & 94.0 & & 1.40 \\
\hline 171 & 2015 & 19510R & 1 & QCP & & & & 0.10 & & 93.8 & & 1.73 \\
\hline 172 & 2015 & 19510R & 1 & QCP & & & & 0.17 & & 93.4 & & 2.22 \\
\hline 173 & 2015 & 19510R & 1 & QCP & 0.00 & 0.05 & 0.73 & 0.43 & 96.0 & 93.3 & 1.08 & 1.92 \\
\hline 178 & 2015 & $19522 \mathrm{R}$ & 1 & QCP & 0.26 & 0.25 & 0.71 & 0.36 & 95.9 & 95.4 & 0.72 & 0.26 \\
\hline 179 & 2015 & $19522 R$ & 1 & $\mathrm{QCP}$ & 0.60 & 0.00 & & 0.63 & 96.4 & 96.8 & 0.00 & 1.32 \\
\hline 180 & 2015 & $19522 R$ & 1 & QCP & 0.21 & 0.08 & & 0.59 & 94.9 & 95.8 & 0.07 & 1.35 \\
\hline 181 & 2015 & $19522 R$ & 1 & QCP & 0.56 & & & 0.41 & 96.2 & 95.1 & 0.00 & 1.54 \\
\hline 183 & 2015 & $19524 R$ & 1 & PFP & 0.47 & 0.00 & 0.50 & 0.00 & 92.9 & 92.5 & 1.82 & 2.53 \\
\hline 184 & 2015 & 19510R & 1 & QCP & 0.55 & 0.44 & 0.21 & 0.18 & 93.6 & 93.8 & 1.76 & 1.98 \\
\hline
\end{tabular}




\begin{tabular}{|c|c|c|c|c|c|c|c|c|c|c|c|c|}
\hline $\begin{array}{c}\text { ICT } \\
\text { Code }\end{array}$ & Year & Mix Code & District & $\begin{array}{l}\text { Quality } \\
\text { Program }\end{array}$ & $\begin{array}{c}\text { MW } \\
\text { P-Value }\end{array}$ & $\begin{array}{l}\text { Levene's } \\
\text { P-Value }\end{array}$ & $\begin{array}{l}\text { Contractor } \\
\text { SW P-Value }\end{array}$ & $\begin{array}{c}\text { Agency SW } \\
\text { P-Value }\end{array}$ & $\begin{array}{c}\text { Contractor } \\
\text { Mean }\end{array}$ & $\begin{array}{l}\text { Agency } \\
\text { Mean }\end{array}$ & $\begin{array}{c}\text { Contractor } \\
\text { St. Dev. }\end{array}$ & $\begin{array}{l}\text { Agency } \\
\text { St. Dev. }\end{array}$ \\
\hline 185 & 2015 & 19510R & 1 & $\mathrm{QCP}$ & 0.64 & 0.63 & 0.00 & 0.00 & 94.4 & 94.1 & 1.95 & 2.16 \\
\hline 186 & 2017 & 19510R & 1 & $\mathrm{QCP}$ & 0.15 & 0.21 & 0.08 & 0.00 & 92.6 & 93.0 & 1.37 & 1.77 \\
\hline 187 & 2015 & $19522 R$ & 1 & $\mathrm{QCP}$ & 0.51 & 0.45 & 0.57 & 0.01 & 93.7 & 93.5 & 1.20 & 1.03 \\
\hline 188 & 2015 & 19524R & 1 & $\mathrm{QCP}$ & 0.12 & 0.58 & 0.64 & 0.76 & 94.3 & 93.6 & 0.80 & 0.93 \\
\hline 189 & 2015 & 19524R & 1 & QCP & & & & 0.58 & & 95.3 & & 1.66 \\
\hline 190 & 2015 & 19510R & 1 & QCP & 0.34 & 0.41 & 0.00 & 0.00 & 94.7 & 94.5 & 1.56 & 1.72 \\
\hline 191 & 2015 & 19510R & 1 & PFP & 0.87 & 0.07 & 0.00 & 0.00 & 93.7 & 93.7 & 1.68 & 1.92 \\
\hline 192 & 2015 & 19510R & 1 & QCP & & & & 0.00 & & 94.1 & & 1.94 \\
\hline 193 & 2015 & 19510R & 1 & QCP & & & & 0.24 & & 93.1 & & 1.46 \\
\hline 194 & 2015 & 19510R & 1 & QCP & & & & 0.02 & & 95.3 & & 1.12 \\
\hline 195 & 2017 & 19510R & 1 & QCP & 0.11 & 0.39 & 0.32 & 0.35 & 95.0 & 94.2 & 1.00 & 1.30 \\
\hline 196 & 2017 & 19510R & 1 & $\mathrm{QCP}$ & & & & 0.33 & & 94.7 & & 1.26 \\
\hline 197 & 2017 & 19510R & 1 & $\mathrm{QCP}$ & 0.16 & 0.08 & 0.05 & 0.49 & 94.2 & 93.7 & 1.14 & 1.56 \\
\hline 198 & 2017 & 19510R & 1 & QCP & & & & 0.00 & & 93.3 & & 1.55 \\
\hline 199 & 2017 & 19510R & 1 & QCP & 0.77 & 0.79 & 0.62 & 0.20 & 94.0 & 93.9 & 1.26 & 1.34 \\
\hline 200 & 2017 & 19510R & 1 & QCP & & & & 0.57 & & 93.6 & & 1.61 \\
\hline 201 & 2017 & 19510R & 1 & QCP & & & & 0.70 & & 93.8 & & 1.80 \\
\hline 202 & 2017 & 19510R & 1 & $\mathrm{QCP}$ & & & & 0.03 & & 93.9 & & 2.21 \\
\hline 203 & 2015 & 19665R & 1 & PFP & 0.94 & 0.00 & 0.00 & 0.00 & 94.8 & 94.7 & 1.25 & 1.67 \\
\hline 204 & 2015 & 19665R & 1 & PFP & 0.61 & 0.83 & 0.15 & 0.61 & 94.6 & 94.6 & 0.96 & 0.94 \\
\hline 205 & 2015 & 19665R & 1 & PFP & 0.89 & 0.07 & 0.00 & 0.00 & 94.5 & 94.5 & 1.39 & 1.58 \\
\hline 206 & 2015 & $19522 R$ & 1 & QCP & & & & 0.17 & & 93.7 & & 2.09 \\
\hline 316 & 2015 & $19524 R$ & 1 & QCP & & & & 0.01 & & 93.4 & & 1.49 \\
\hline 317 & 2015 & $19524 R$ & 1 & QCP & 0.39 & 0.04 & 0.45 & 0.34 & 94.5 & 94.2 & 1.36 & 0.64 \\
\hline 318 & 2017 & $19522 R$ & 1 & QCP & 0.51 & & 0.19 & & 94.6 & 95.1 & 1.16 & 0.00 \\
\hline 319 & 2015 & 19536R & 1 & PFP & 0.46 & 0.99 & 0.00 & 0.00 & 93.5 & 93.4 & 1.41 & 1.41 \\
\hline 320 & 2015 & 19510R & 1 & QCP & 0.80 & & & 0.20 & 95.4 & 94.5 & 0.00 & 1.60 \\
\hline 321 & 2015 & 19510R & 1 & QCP & & & & 0.00 & & 93.7 & & 1.62 \\
\hline 322 & 2015 & 19510R & 1 & QCP & & & & 0.20 & & 93.7 & & 1.45 \\
\hline 323 & 2015 & 19510R & 1 & QCP & 0.33 & & & 0.00 & 95.3 & 93.4 & 0.00 & 3.41 \\
\hline 324 & 2015 & 19510R & 1 & $\mathrm{QCP}$ & & & & 0.01 & & 92.6 & & 2.60 \\
\hline 325 & 2015 & 19510R & 1 & QCP & & & & 0.02 & & 93.5 & & 1.94 \\
\hline 326 & 2015 & $19522 \mathrm{R}$ & 1 & QCP & 0.02 & 0.57 & 0.36 & 0.14 & 96.2 & 94.1 & 1.22 & 1.81 \\
\hline 327 & 2015 & 19536R & 1 & QCP & 0.87 & 0.79 & 0.13 & 0.02 & 93.8 & 93.7 & 1.17 & 1.37 \\
\hline 328 & 2015 & 19536R & 1 & QCP & & & & 0.00 & & 93.1 & & 1.23 \\
\hline
\end{tabular}




\begin{tabular}{|c|c|c|c|c|c|c|c|c|c|c|c|c|}
\hline $\begin{array}{l}\text { ICT } \\
\text { Code }\end{array}$ & Year & Mix Code & District & $\begin{array}{l}\text { Quality } \\
\text { Program }\end{array}$ & $\begin{array}{c}\text { MW } \\
\text { P-Value }\end{array}$ & $\begin{array}{l}\text { Levene's } \\
\text { P-Value }\end{array}$ & $\begin{array}{l}\text { Contractor } \\
\text { SW P-Value }\end{array}$ & $\begin{array}{c}\text { Agency SW } \\
\text { P-Value }\end{array}$ & $\begin{array}{c}\text { Contractor } \\
\text { Mean }\end{array}$ & $\begin{array}{l}\text { Agency } \\
\text { Mean }\end{array}$ & $\begin{array}{l}\text { Contractor } \\
\text { St. Dev. }\end{array}$ & $\begin{array}{l}\text { Agency } \\
\text { St. Dev. }\end{array}$ \\
\hline 329 & 2015 & 19536R & 1 & $\mathrm{QCP}$ & & & & 0.02 & & 93.2 & & 1.91 \\
\hline 330 & 2016 & 19536R & 1 & QCP & 1.00 & 1.00 & & & 93.0 & 93.0 & 0.28 & 0.28 \\
\hline 373 & 2015 & 19524R & 1 & PFP & 0.84 & 0.83 & 0.57 & 0.91 & 92.8 & 92.8 & 1.86 & 1.91 \\
\hline 374 & 2016 & 19524R & 1 & QCP & & & & 0.70 & & 93.4 & & 1.10 \\
\hline 375 & 2016 & 19524R & 1 & QCP & & & & 0.06 & & 92.1 & & 2.61 \\
\hline 376 & 2015 & 19655R & 1 & $\mathrm{QCP}$ & & & & 0.51 & & 94.6 & & 1.60 \\
\hline 377 & 2015 & 19522R & 1 & QCP & 0.40 & & & 0.18 & 94.0 & 91.9 & 0.00 & 0.78 \\
\hline 378 & 2016 & $19522 R$ & 1 & QCP & 0.11 & & & 0.94 & 96.4 & 93.0 & 0.00 & 1.69 \\
\hline 379 & 2015 & $19522 R$ & 1 & QCP & 0.03 & 0.54 & 0.36 & 0.50 & 96.2 & 94.0 & 1.22 & 1.85 \\
\hline 380 & 2017 & 19524R & 1 & PFP & 0.16 & 0.55 & 0.01 & 0.28 & 94.0 & 94.5 & 2.10 & 2.24 \\
\hline 381 & 2017 & 19524R & 1 & QCP & 0.47 & 0.12 & 0.11 & 0.09 & 94.4 & 95.3 & 2.28 & 1.20 \\
\hline 382 & 2017 & $19524 R$ & 1 & QCP & 0.22 & 0.64 & 0.09 & 0.32 & 93.3 & 93.8 & 1.15 & 0.94 \\
\hline 383 & 2017 & $19524 R$ & 1 & QCP & & & & 0.43 & & 93.4 & & 1.21 \\
\hline 384 & 2017 & 19524R & 1 & QCP & 0.62 & 0.58 & 0.90 & 0.67 & 93.7 & 93.3 & 1.29 & 1.68 \\
\hline 385 & 2017 & $19524 R$ & 1 & QCP & 0.88 & 0.73 & 0.03 & 0.30 & 94.2 & 94.2 & 1.75 & 2.13 \\
\hline 386 & 2017 & 19524R & 1 & QCP & & & & 0.45 & & 94.1 & & 1.02 \\
\hline 387 & 2015 & 19514R & 1 & QCP & 0.32 & 0.66 & 0.14 & 0.01 & 93.6 & 93.9 & 1.49 & 1.38 \\
\hline 388 & 2017 & 19514R & 1 & QCP & 0.04 & 0.56 & 0.76 & 0.04 & 95.0 & 94.2 & 0.64 & 0.84 \\
\hline 389 & 2017 & 19524R & 1 & QCP & 0.13 & 0.83 & 0.12 & 0.32 & 91.7 & 93.1 & 1.62 & 1.70 \\
\hline 391 & 2017 & 19524R & 1 & QCP & 0.79 & 0.29 & & 0.84 & 94.8 & 94.2 & 0.28 & 1.54 \\
\hline 392 & 2015 & 19525R & 1 & QCP & 0.47 & 0.61 & 0.30 & 0.08 & 94.5 & 94.8 & 1.24 & 1.10 \\
\hline 393 & 2017 & 19525R & 1 & QCP & & & & 0.92 & & 94.7 & & 1.29 \\
\hline 394 & 2017 & 19525R & 1 & QCP & & & & 0.14 & & 94.1 & & 1.31 \\
\hline 395 & 2015 & 19525R & 1 & QCP & & & & 0.12 & & 94.6 & & 1.51 \\
\hline 396 & 2017 & 19525R & 1 & QCP & & & 0.62 & & 94.9 & & 1.44 & \\
\hline 397 & 2017 & 19525R & 1 & QCP & & & & 0.79 & & 93.9 & & 1.58 \\
\hline 398 & 2017 & 19525R & 1 & QCP & & & & 0.71 & & 93.2 & & 1.19 \\
\hline 399 & 2017 & 19510R & 1 & QCP & & & & 0.00 & & 93.4 & & 2.43 \\
\hline 400 & 2016 & 19510R & 1 & QCP & 0.36 & 0.62 & 0.04 & 0.08 & 92.0 & 90.7 & 1.76 & 2.13 \\
\hline 401 & 2016 & 19510R & 1 & QCP & & & & 0.04 & & 94.8 & & 1.82 \\
\hline 402 & 2016 & 19510R & 1 & QCP & & & & 0.00 & & 92.7 & & 2.97 \\
\hline 403 & 2017 & 19510R & 1 & QCP & & & & 0.01 & & 94.6 & & 1.26 \\
\hline 404 & 2016 & 19510R & 1 & QCP & & & & 0.14 & & 94.6 & & 1.28 \\
\hline 405 & 2017 & 19510R & 1 & QCP & & & & 0.54 & & 93.2 & & 1.32 \\
\hline 406 & 2017 & 19510R & 1 & QCP & 0.69 & & & 0.34 & 93.5 & 92.5 & 0.00 & 1.66 \\
\hline
\end{tabular}




\begin{tabular}{|c|c|c|c|c|c|c|c|c|c|c|c|c|}
\hline $\begin{array}{l}\text { ICT } \\
\text { Code }\end{array}$ & Year & Mix Code & District & $\begin{array}{l}\text { Quality } \\
\text { Program }\end{array}$ & $\begin{array}{c}\text { MW } \\
\text { P-Value }\end{array}$ & $\begin{array}{l}\text { Levene's } \\
\text { P-Value }\end{array}$ & $\begin{array}{l}\text { Contractor } \\
\text { SW P-Value }\end{array}$ & $\begin{array}{c}\text { Agency SW } \\
\text { P-Value }\end{array}$ & $\begin{array}{c}\text { Contractor } \\
\text { Mean }\end{array}$ & $\begin{array}{l}\text { Agency } \\
\text { Mean }\end{array}$ & $\begin{array}{c}\text { Contractor } \\
\text { St. Dev. }\end{array}$ & $\begin{array}{l}\text { Agency } \\
\text { St. Dev. }\end{array}$ \\
\hline 407 & 2017 & 19525R & 1 & QCP & 0.15 & 0.94 & 0.13 & 0.00 & 93.9 & 93.4 & 1.21 & 1.25 \\
\hline 408 & 2015 & 19536R & 1 & QCP & 0.69 & 0.48 & 0.21 & 0.32 & 94.1 & 94.3 & 1.44 & 1.17 \\
\hline 409 & 2017 & 19536R & 1 & QCP & 0.74 & 0.66 & 0.06 & 0.01 & 93.8 & 93.9 & 1.13 & 1.01 \\
\hline 410 & 2017 & 19524R & 1 & QCP & & & & 0.20 & & 93.0 & & 2.71 \\
\hline 411 & 2017 & 19524R & 1 & QCP & 0.48 & 0.59 & 0.86 & 0.59 & 94.6 & 95.1 & 1.32 & 1.14 \\
\hline 412 & 2017 & 19524R & 1 & QCP & 0.16 & 0.00 & & 0.91 & 92.7 & 94.0 & 0.00 & 1.51 \\
\hline 414 & 2015 & 19665R & 1 & QCP & 0.98 & 0.86 & 0.12 & 0.02 & 94.9 & 94.9 & 1.04 & 1.01 \\
\hline 415 & 2015 & $19525 R$ & 1 & QCP & 0.29 & 0.54 & 0.31 & 0.14 & 94.7 & 95.1 & 1.34 & 1.49 \\
\hline 416 & 2015 & 19510R & 1 & QCP & & & & 0.00 & & 92.8 & & 2.35 \\
\hline 417 & 2015 & 19524R & 1 & PFP & 0.51 & 0.72 & 0.01 & 0.00 & 93.6 & 93.8 & 2.09 & 2.17 \\
\hline 418 & 2015 & 19510R & 1 & QCP & 0.29 & 0.24 & & 0.03 & 94.6 & 93.2 & 0.35 & 2.35 \\
\hline 419 & 2016 & $19514 R$ & 1 & QCP & & & & 0.00 & & 95.0 & & 1.72 \\
\hline 420 & 2016 & $19514 R$ & 1 & QCP & 0.04 & 0.62 & & 0.00 & 96.7 & 94.1 & 0.85 & 2.11 \\
\hline 421 & 2017 & 19510R & 1 & QCP & & & & 0.02 & & 92.9 & & 2.18 \\
\hline 422 & 2017 & 19510R & 1 & QCP & & & & 0.00 & & 94.2 & & 1.90 \\
\hline 423 & 2017 & 19510R & 1 & QCP & & & & 0.84 & & 94.5 & & 1.57 \\
\hline 424 & 2016 & $19512 R$ & 1 & QCP & & & & 0.78 & & 94.3 & & 0.71 \\
\hline 425 & 2017 & $19524 R$ & 1 & QCP & & & & 0.12 & & 93.9 & & 1.95 \\
\hline 426 & 2017 & $19524 R$ & 1 & QCP & & & & 0.79 & & 94.3 & & 1.54 \\
\hline 427 & 2017 & $19525 R$ & 1 & PFP & 0.00 & 0.26 & 0.00 & 0.00 & 93.3 & 93.9 & 1.88 & 2.01 \\
\hline 428 & 2017 & 19525R & 1 & QCP & & & & 0.00 & & 94.8 & & 1.93 \\
\hline 429 & 2015 & 19510R & 1 & QCP & 0.00 & 0.02 & 0.29 & 0.11 & 95.3 & 91.5 & 1.02 & 3.05 \\
\hline 430 & 2015 & 19524R & 1 & QCP & 0.00 & 0.11 & 0.81 & 0.12 & 95.9 & 93.5 & 0.69 & 1.46 \\
\hline 431 & 2015 & $19522 R$ & 1 & QCP & & & & & & 95.4 & & 0.00 \\
\hline 432 & 2016 & $19522 R$ & 1 & QCP & 0.08 & 0.75 & 0.48 & 0.57 & 95.4 & 94.2 & 1.12 & 0.88 \\
\hline 433 & 2016 & $19522 R$ & 1 & QCP & & & & 0.08 & & 94.2 & & 1.61 \\
\hline 434 & 2015 & $19522 R$ & 1 & QCP & 0.29 & & & 0.11 & 96.1 & 93.6 & 0.00 & 1.01 \\
\hline 435 & 2016 & 19532R & 1 & QCP & & & & 0.85 & & 93.3 & & 1.66 \\
\hline 436 & 2017 & 19510R & 1 & QCP & & & & 0.74 & & 95.2 & & 1.90 \\
\hline 437 & 2016 & 19510R & 1 & QCP & & & & 0.99 & & 92.2 & & 1.73 \\
\hline 438 & 2017 & 19510R & 1 & QCP & 0.63 & & & 0.01 & 93.9 & 92.4 & 0.00 & 2.86 \\
\hline 439 & 2015 & 19524R & 1 & QCP & 0.23 & 0.89 & 0.05 & 0.41 & 94.6 & 95.1 & 0.56 & 0.47 \\
\hline 440 & 2016 & 19524R & 1 & QCP & 0.67 & & 0.07 & & 93.8 & 96.2 & 1.65 & 0.00 \\
\hline 442 & 2015 & 19510R & 1 & QCP & 0.01 & 0.02 & 0.85 & 0.07 & 95.6 & 93.2 & 0.86 & 2.48 \\
\hline 443 & 2015 & 19665R & 1 & PFP & 0.09 & 0.00 & 0.01 & 0.00 & 94.7 & 94.8 & 1.44 & 1.78 \\
\hline
\end{tabular}




\begin{tabular}{|c|c|c|c|c|c|c|c|c|c|c|c|c|}
\hline $\begin{array}{c}\text { ICT } \\
\text { Code }\end{array}$ & Year & Mix Code & District & $\begin{array}{l}\text { Quality } \\
\text { Program }\end{array}$ & $\begin{array}{c}\text { MW } \\
\text { P-Value }\end{array}$ & $\begin{array}{l}\text { Levene's } \\
\text { P-Value }\end{array}$ & $\begin{array}{l}\text { Contractor } \\
\text { SW P-Value }\end{array}$ & $\begin{array}{c}\text { Agency SW } \\
\text { P-Value }\end{array}$ & $\begin{array}{c}\text { Contractor } \\
\text { Mean }\end{array}$ & $\begin{array}{l}\text { Agency } \\
\text { Mean }\end{array}$ & $\begin{array}{c}\text { Contractor } \\
\text { St. Dev. }\end{array}$ & $\begin{array}{l}\text { Agency } \\
\text { St. Dev. }\end{array}$ \\
\hline 444 & 2016 & 19510R & 1 & $\mathrm{QCP}$ & & & & 0.44 & & 93.7 & & 2.46 \\
\hline 445 & 2015 & 19536R & 1 & PFP & 0.91 & 0.59 & 0.00 & 0.09 & 93.6 & 93.5 & 1.33 & 1.40 \\
\hline 446 & 2015 & 19536R & 1 & PFP & 0.80 & 0.02 & 0.27 & & 93.6 & 93.9 & 0.10 & 0.57 \\
\hline 447 & 2015 & 19536R & 1 & QCP & & & & 0.07 & & 91.8 & & 1.87 \\
\hline 448 & 2015 & $19512 R$ & 1 & QCP & 1.00 & 0.49 & 1.00 & & 97.3 & 97.4 & 0.20 & 0.07 \\
\hline 449 & 2016 & $19525 R$ & 1 & QCP & & & & 0.88 & & 94.3 & & 1.76 \\
\hline 450 & 2017 & $19525 R$ & 1 & PFP & 0.13 & 0.38 & 0.12 & 0.04 & 94.1 & 94.5 & 1.53 & 1.69 \\
\hline 451 & 2017 & 19525R & 1 & QCP & 0.53 & 0.25 & & 0.58 & 93.0 & 94.1 & 2.90 & 1.81 \\
\hline 452 & 2017 & $19525 R$ & 1 & QCP & & & & 0.34 & & 94.6 & & 1.26 \\
\hline 454 & 2017 & $19512 R$ & 1 & QCP & 1.00 & 0.49 & 1.00 & & 97.3 & 97.4 & 0.20 & 0.07 \\
\hline 455 & 2017 & $19512 \mathrm{R}$ & 1 & QCP & & & & 0.17 & & 94.2 & & 1.65 \\
\hline 456 & 2017 & 19536R & 1 & QCP & & & & 0.18 & & 93.7 & & 1.66 \\
\hline 457 & 2016 & 19536R & 1 & QCP & & & & 0.91 & & 93.1 & & 2.14 \\
\hline 458 & 2017 & 19510R & 1 & QCP & 0.38 & 0.24 & 0.52 & 0.02 & 94.8 & 94.6 & 1.41 & 1.97 \\
\hline 459 & 2017 & 19510R & 1 & QCP & & & & 0.63 & & 93.9 & & 1.99 \\
\hline 460 & 2017 & 19510R & 1 & QCP & & & & 0.01 & & 94.5 & & 2.33 \\
\hline 461 & 2017 & 19665R & 1 & PFP & 0.81 & 0.22 & 0.61 & 0.09 & 94.6 & 94.6 & 1.33 & 1.57 \\
\hline 462 & 2017 & $19665 R$ & 1 & QCP & 0.40 & 0.64 & 0.22 & 0.60 & 95.7 & 95.1 & 1.31 & 1.11 \\
\hline 463 & 2017 & $19525 \mathrm{R}$ & 1 & QCP & 0.53 & 0.91 & 0.52 & & 95.2 & 96.0 & 1.03 & 0.71 \\
\hline 464 & 2017 & $19522 \mathrm{R}$ & 1 & QCP & 0.77 & 0.00 & 0.21 & 0.07 & 95.1 & 95.3 & 0.90 & 2.22 \\
\hline 465 & 2017 & $19522 \mathrm{R}$ & 1 & QCP & 0.01 & 0.66 & 0.00 & 0.28 & 94.4 & 95.2 & 0.98 & 1.05 \\
\hline 466 & 2017 & 19653R & 1 & PFP & 0.20 & 0.12 & 0.05 & 0.54 & 94.5 & 94.6 & 1.21 & 1.32 \\
\hline 467 & 2017 & 19655 & 1 & PFP & 0.00 & 0.56 & 0.00 & 0.00 & 95.2 & 95.5 & 1.22 & 1.26 \\
\hline 468 & 2015 & $19532 \mathrm{R}$ & 1 & QCP & 0.59 & 0.68 & 0.52 & 0.52 & 94.4 & 94.5 & 0.98 & 1.15 \\
\hline 469 & 2017 & $19532 R$ & 1 & $\mathrm{QCP}$ & 0.67 & & 0.04 & & 94.4 & 94.2 & 1.31 & 0.00 \\
\hline 470 & 2017 & $19532 \mathrm{R}$ & 1 & QCP & & & & 0.11 & & 95.7 & & 1.26 \\
\hline 471 & 2017 & $19524 \mathrm{R}$ & 1 & QCP & 0.00 & 0.00 & 0.08 & 0.13 & 94.7 & 93.5 & 0.64 & 1.42 \\
\hline 472 & 2017 & $19524 \mathrm{R}$ & 1 & QCP & 0.75 & 0.75 & 0.89 & 0.27 & 94.2 & 94.4 & 1.15 & 1.37 \\
\hline 473 & 2017 & $19522 \mathrm{R}$ & 1 & QCP & & & & 0.16 & & 95.4 & & 1.07 \\
\hline 474 & 2015 & $19522 \mathrm{R}$ & 1 & QCP & 1.00 & 0.24 & 0.27 & & 95.5 & 96.1 & 1.29 & 0.21 \\
\hline 475 & 2015 & $19522 \mathrm{R}$ & 1 & QCP & & & & 0.07 & & 92.4 & & 1.40 \\
\hline 476 & 2015 & $19524 \mathrm{R}$ & 1 & QCP & 0.84 & & & 0.31 & 94.5 & 94.2 & 0.00 & 1.98 \\
\hline 477 & 2015 & $19524 \mathrm{R}$ & 1 & PFP & 0.00 & 0.27 & 0.00 & 0.09 & 93.1 & 94.1 & 2.07 & 1.80 \\
\hline 478 & 2015 & $19524 \mathrm{R}$ & 1 & QCP & & & & 0.68 & & 92.3 & & 1.58 \\
\hline 479 & 2015 & $19522 R$ & 1 & QCP & 0.59 & 0.87 & 0.06 & 0.01 & 94.5 & 94.6 & 1.54 & 1.58 \\
\hline
\end{tabular}




\begin{tabular}{|c|c|c|c|c|c|c|c|c|c|c|c|c|}
\hline $\begin{array}{c}\mathrm{ICT} \\
\text { Code }\end{array}$ & Year & Mix Code & District & $\begin{array}{l}\text { Quality } \\
\text { Program }\end{array}$ & $\begin{array}{c}\text { MW } \\
\text { P-Value }\end{array}$ & $\begin{array}{l}\text { Levene's } \\
\text { P-Value }\end{array}$ & $\begin{array}{l}\text { Contractor } \\
\text { SW P-Value }\end{array}$ & $\begin{array}{c}\text { Agency SW } \\
\text { P-Value }\end{array}$ & $\begin{array}{c}\text { Contractor } \\
\text { Mean }\end{array}$ & $\begin{array}{l}\text { Agency } \\
\text { Mean }\end{array}$ & $\begin{array}{c}\text { Contractor } \\
\text { St. Dev. }\end{array}$ & $\begin{array}{l}\text { Agency } \\
\text { St. Dev. }\end{array}$ \\
\hline 480 & 2015 & $19522 \mathrm{R}$ & 1 & $\mathrm{QCP}$ & & & & 0.05 & & 94.8 & & 1.21 \\
\hline 481 & 2015 & 19524R & 1 & QCP & 0.72 & 0.40 & 0.00 & 0.00 & 93.6 & 93.4 & 2.00 & 2.17 \\
\hline 483 & 2015 & 19510R & 1 & QCP & 0.09 & 0.84 & 0.06 & 0.24 & 94.3 & 93.7 & 1.52 & 1.57 \\
\hline 484 & 2015 & 19510R & 1 & PFP & 0.97 & 0.00 & 0.00 & 0.00 & 93.8 & 93.5 & 2.26 & 2.94 \\
\hline 485 & 2015 & 19510R & 1 & QCP & 0.17 & 0.00 & 0.00 & 0.00 & 93.6 & 92.8 & 2.15 & 3.69 \\
\hline 486 & 2015 & 19510R & 1 & PFP & 0.44 & 0.51 & 0.00 & 0.00 & 94.3 & 94.1 & 2.34 & 2.46 \\
\hline 487 & 2015 & 19510R & 1 & QCP & & & & 0.18 & & 92.0 & & 1.84 \\
\hline 488 & 2015 & 19510R & 1 & PFP & 0.19 & 0.62 & 0.18 & 0.14 & 93.5 & 92.9 & 2.25 & 2.41 \\
\hline 489 & 2015 & 19510R & 1 & QCP & & & & 0.58 & & 91.4 & & 2.12 \\
\hline 490 & 2015 & 19510R & 1 & QCP & 0.55 & 0.47 & 0.13 & 0.67 & 94.6 & 94.7 & 1.49 & 1.73 \\
\hline 491 & 2015 & 19510R & 1 & QCP & & & & 0.15 & & 93.8 & & 1.98 \\
\hline 492 & 2015 & 19510R & 1 & QCP & 0.70 & & & 0.53 & 94.2 & 93.4 & 0.00 & 1.61 \\
\hline 493 & 2015 & 19522R & 1 & QCP & 0.45 & 0.67 & 0.06 & 0.18 & 94.5 & 94.7 & 1.54 & 1.63 \\
\hline 494 & 2015 & 19536R & 1 & QCP & & & & 0.87 & & 94.1 & & 1.30 \\
\hline 495 & 2015 & 19536R & 1 & QCP & 0.86 & 0.39 & 0.71 & 0.27 & 93.9 & 93.8 & 0.98 & 1.55 \\
\hline 496 & 2015 & 19536R & 1 & PFP & 0.15 & 0.49 & 0.02 & 0.30 & 93.0 & 92.7 & 1.91 & 2.02 \\
\hline 497 & 2016 & 19524R & 1 & QCP & & & 0.46 & & 94.2 & & 1.49 & \\
\hline 498 & 2017 & 19524R & 1 & QCP & & & & 0.14 & & 93.3 & & 1.00 \\
\hline 499 & 2015 & 19665R & 1 & QCP & 0.47 & 0.43 & 0.12 & 0.26 & 95.0 & 94.8 & 1.06 & 1.22 \\
\hline 500 & 2015 & 19665R & 1 & PFP & 0.53 & 0.87 & 0.01 & 0.10 & 94.1 & 94.2 & 1.42 & 1.43 \\
\hline 501 & 2017 & 19510R & 1 & QCP & & & & 0.01 & & 93.6 & & 1.71 \\
\hline 502 & 2015 & 19655R & 1 & PFP & 0.80 & 0.79 & 0.00 & 0.00 & 95.1 & 95.1 & 1.57 & 1.60 \\
\hline 503 & 2016 & $19522 R$ & 1 & QCP & 0.02 & 0.62 & 0.46 & 0.61 & 96.0 & 94.3 & 1.26 & 1.13 \\
\hline 504 & 2016 & 19524R & 1 & QCP & & & & 0.58 & & 94.0 & & 2.08 \\
\hline 505 & 2016 & $19514 R$ & 1 & $\mathrm{QCP}$ & 0.33 & 0.18 & 0.98 & 0.09 & 92.9 & 91.1 & 1.84 & 3.53 \\
\hline 506 & 2016 & 19536R & 1 & QCP & & & & 0.78 & & 93.1 & & 1.71 \\
\hline 507 & 2016 & $19532 R$ & 1 & QCP & 0.75 & & & 0.62 & 94.0 & 93.0 & 0.00 & 1.02 \\
\hline 508 & 2017 & $19522 R$ & 1 & QCP & 0.22 & 0.74 & 0.51 & 0.01 & 94.1 & 93.6 & 1.31 & 1.23 \\
\hline 511 & 2017 & $19524 R$ & 1 & QCP & & & & 0.00 & & 93.3 & & 1.11 \\
\hline 512 & 2017 & $19524 R$ & 1 & PFP & 0.45 & 0.13 & 0.15 & 0.04 & 93.7 & 93.4 & 1.97 & 2.40 \\
\hline 513 & 2017 & 19510R & 1 & QCP & & & & 0.05 & & 94.3 & & 1.47 \\
\hline 514 & 2017 & 19510R & 1 & $\mathrm{QCP}$ & & & & 0.00 & & 93.4 & & 1.80 \\
\hline 515 & 2017 & 19510R & 1 & QCP & 0.48 & 0.82 & 0.59 & 0.13 & 95.5 & 94.9 & 0.97 & 1.06 \\
\hline 516 & 2017 & $19525 R$ & 1 & $\mathrm{QCP}$ & 0.13 & 0.53 & 0.73 & 0.85 & 92.9 & 92.1 & 1.08 & 1.34 \\
\hline 517 & 2017 & 19510R & 1 & QCP & 0.51 & 0.28 & 0.01 & 0.13 & 94.2 & 94.0 & 1.50 & 1.73 \\
\hline
\end{tabular}




\begin{tabular}{|c|c|c|c|c|c|c|c|c|c|c|c|c|}
\hline $\begin{array}{c}\text { ICT } \\
\text { Code }\end{array}$ & Year & Mix Code & District & $\begin{array}{l}\text { Quality } \\
\text { Program }\end{array}$ & $\begin{array}{c}\text { MW } \\
\text { P-Value }\end{array}$ & $\begin{array}{l}\text { Levene's } \\
\text { P-Value }\end{array}$ & $\begin{array}{l}\text { Contractor } \\
\text { SW P-Value }\end{array}$ & $\begin{array}{c}\text { Agency SW } \\
\text { P-Value }\end{array}$ & $\begin{array}{c}\text { Contractor } \\
\text { Mean }\end{array}$ & $\begin{array}{l}\text { Agency } \\
\text { Mean }\end{array}$ & $\begin{array}{l}\text { Contractor } \\
\text { St. Dev. }\end{array}$ & $\begin{array}{l}\text { Agency } \\
\text { St. Dev. }\end{array}$ \\
\hline 518 & 2017 & 19510R & 1 & $\mathrm{QCP}$ & 0.17 & 0.99 & 0.23 & 0.06 & 94.3 & 93.8 & 1.75 & 1.74 \\
\hline 519 & 2017 & 19653R & 1 & PFP & 0.10 & 0.49 & 0.07 & 0.04 & 93.3 & 93.7 & 1.91 & 2.07 \\
\hline 520 & 2017 & $19525 R$ & 1 & PFP & 0.52 & 0.50 & 0.00 & 0.00 & 94.0 & 93.9 & 1.59 & 1.51 \\
\hline 521 & 2017 & 19525R & 1 & PFP & 0.80 & 0.84 & 0.27 & & 93.6 & 93.7 & 0.92 & 0.57 \\
\hline 522 & 2017 & 19655R & 1 & PFP & 0.15 & 0.31 & 0.00 & 0.88 & 95.3 & 96.1 & 1.37 & 0.98 \\
\hline 523 & 2017 & 19510R & 1 & QCP & 0.93 & & & 0.01 & 94.6 & 94.5 & 0.00 & 1.24 \\
\hline 524 & 2017 & 19665R & 1 & PFP & 0.80 & 0.73 & 0.05 & 0.00 & 94.3 & 94.3 & 2.09 & 2.17 \\
\hline 525 & 2017 & 19665R & 1 & QCP & & & & 0.01 & & 95.3 & & 1.70 \\
\hline 526 & 2015 & $19512 R$ & 1 & QCP & & & & 0.21 & & 91.1 & & 1.44 \\
\hline 527 & 2015 & 19514R & 1 & QCP & & & & 1.00 & & 90.9 & & 1.53 \\
\hline 529 & 2016 & $19606 \mathrm{~F}$ & 2 & PFP & 0.51 & 0.75 & 0.52 & 0.07 & 92.1 & 92.2 & 1.95 & 1.99 \\
\hline 530 & 2015 & 19514R & 2 & QCP & 0.75 & 0.51 & 0.21 & 0.02 & 94.0 & 93.8 & 2.10 & 2.35 \\
\hline 531 & 2014 & 19514R & 2 & QCP & & & & 0.12 & & 93.2 & & 1.86 \\
\hline 532 & 2015 & 19604FR & 2 & QCP & 0.17 & 0.03 & 0.20 & 0.05 & 94.1 & 92.9 & 2.00 & 3.08 \\
\hline 533 & 2015 & 19514R & 2 & QCP & & & & 0.12 & & 94.0 & & 2.00 \\
\hline 534 & 2016 & $19535 R$ & 2 & QCP & 0.95 & 0.59 & 0.28 & 0.64 & 97.7 & 97.6 & 2.12 & 2.39 \\
\hline 535 & 2015 & 19534R & 2 & PFP & 0.87 & 0.63 & 0.00 & 0.00 & 92.0 & 92.0 & 1.70 & 1.67 \\
\hline 536 & 2015 & $19532 R$ & 2 & PFP & 0.04 & 0.12 & 0.00 & 0.00 & 92.9 & 93.1 & 1.29 & 1.18 \\
\hline 537 & 2015 & $19514 \mathrm{R}$ & 2 & QCP & 0.00 & 0.10 & 0.84 & 0.73 & 92.4 & 93.3 & 1.82 & 1.54 \\
\hline 538 & 2017 & $19514 \mathrm{R}$ & 2 & QCP & 0.22 & 0.82 & 0.46 & 0.31 & 96.2 & 95.5 & 1.85 & 1.93 \\
\hline 539 & 2015 & $19524 \mathrm{R}$ & 2 & QCP & 0.04 & 0.00 & 0.05 & & 93.5 & 92.6 & 0.56 & 0.00 \\
\hline 540 & 2015 & $19514 R$ & 2 & QCP & 0.14 & 0.98 & 0.02 & 0.06 & 93.9 & 93.6 & 1.44 & 1.44 \\
\hline 541 & 2015 & 19604FR & 2 & QCP & 0.58 & 0.31 & 0.23 & 0.45 & 91.8 & 91.7 & 0.53 & 0.66 \\
\hline 542 & 2015 & 19604FR & 2 & QCP & 0.82 & 0.12 & 0.02 & 0.02 & 92.1 & 91.8 & 0.89 & 1.44 \\
\hline 543 & 2015 & $19514 \mathrm{R}$ & 2 & $\mathrm{QCP}$ & 0.13 & 0.77 & 0.36 & 0.78 & 93.0 & 92.6 & 1.20 & 1.25 \\
\hline 544 & 2016 & 19604FR & 2 & QCP & 0.00 & 0.97 & 0.20 & 0.01 & 92.7 & 91.3 & 0.96 & 0.96 \\
\hline 545 & 2016 & $19514 R$ & 2 & QCP & 0.00 & 0.59 & 0.32 & 0.00 & 91.6 & 94.0 & 2.12 & 2.27 \\
\hline 546 & 2016 & $19516 \mathrm{R}$ & 2 & QCP & 0.78 & 0.58 & 0.85 & 0.01 & 94.8 & 94.2 & 1.85 & 1.50 \\
\hline 547 & 2017 & $19514 R$ & 2 & QCP & 0.14 & 0.13 & 0.95 & 0.00 & 94.8 & 95.7 & 2.74 & 1.97 \\
\hline 548 & 2017 & $19512 \mathrm{R}$ & 2 & QCP & 0.91 & 0.88 & 0.00 & 0.00 & 94.7 & 94.4 & 1.60 & 1.57 \\
\hline 549 & 2017 & $19512 \mathrm{R}$ & 2 & QCP & 0.67 & 0.84 & 0.00 & 0.00 & 94.7 & 94.3 & 1.60 & 1.55 \\
\hline 553 & 2017 & $19514 R$ & 2 & QCP & 0.63 & 0.34 & 0.76 & 0.65 & 94.4 & 94.2 & 0.69 & 0.96 \\
\hline 554 & 2015 & $19514 R$ & 2 & QCP & 0.98 & 0.29 & 0.27 & 0.07 & 92.8 & 92.8 & 1.98 & 1.83 \\
\hline 555 & 2017 & $19514 \mathrm{R}$ & 2 & QCP & 0.75 & 0.91 & 0.35 & 0.18 & 93.5 & 93.6 & 1.74 & 1.76 \\
\hline 556 & 2015 & $19514 R$ & 2 & QCP & 0.24 & 0.77 & 0.80 & 0.80 & 93.1 & 93.3 & 1.55 & 1.59 \\
\hline
\end{tabular}




\begin{tabular}{|c|c|c|c|c|c|c|c|c|c|c|c|c|}
\hline $\begin{array}{c}\text { ICT } \\
\text { Code }\end{array}$ & Year & Mix Code & District & $\begin{array}{l}\text { Quality } \\
\text { Program }\end{array}$ & $\begin{array}{c}\text { MW } \\
\text { P-Value }\end{array}$ & $\begin{array}{l}\text { Levene's } \\
\text { P-Value }\end{array}$ & $\begin{array}{l}\text { Contractor } \\
\text { SW P-Value }\end{array}$ & $\begin{array}{c}\text { Agency SW } \\
\text { P-Value }\end{array}$ & $\begin{array}{c}\text { Contractor } \\
\text { Mean }\end{array}$ & $\begin{array}{l}\text { Agency } \\
\text { Mean }\end{array}$ & $\begin{array}{c}\text { Contractor } \\
\text { St. Dev. }\end{array}$ & $\begin{array}{l}\text { Agency } \\
\text { St. Dev. }\end{array}$ \\
\hline 557 & 2016 & 19514R & 2 & QCP & 0.23 & 0.14 & 0.00 & 0.00 & 93.0 & 92.7 & 1.86 & 2.05 \\
\hline 558 & 2015 & $19512 R$ & 2 & QCP & 0.54 & 0.63 & 0.02 & 0.03 & 93.7 & 93.6 & 1.68 & 1.62 \\
\hline 559 & 2017 & $19512 R$ & 2 & QCP & 0.10 & 0.95 & 0.02 & 0.04 & 94.3 & 93.6 & 2.07 & 2.10 \\
\hline 560 & 2015 & $19512 R$ & 2 & QCP & 0.83 & 0.62 & 0.62 & 0.80 & 92.8 & 92.8 & 1.88 & 1.97 \\
\hline 561 & 2015 & 19534R & 2 & PFP & 1.00 & 0.56 & 0.00 & 0.00 & 92.2 & 92.2 & 2.06 & 2.11 \\
\hline 562 & 2015 & 19534R & 2 & PFP & 0.24 & 0.04 & 0.02 & 0.00 & 92.7 & 92.3 & 1.81 & 2.13 \\
\hline 563 & 2016 & 19534R & 2 & PFP & 0.33 & 0.29 & 0.54 & 0.50 & 93.0 & 93.1 & 1.30 & 1.38 \\
\hline 564 & 2017 & $19532 R$ & 2 & PFP & 0.62 & 0.29 & 0.09 & 0.02 & 92.1 & 91.9 & 2.06 & 2.32 \\
\hline 565 & 2015 & 19535R & 2 & PFP & 0.46 & 0.28 & 0.78 & 0.67 & 92.4 & 92.8 & 1.63 & 1.29 \\
\hline 566 & 2017 & 19535R & 2 & PFP & 0.68 & 0.97 & 0.17 & 0.18 & 92.4 & 92.5 & 2.04 & 2.05 \\
\hline 567 & 2016 & $19512 R$ & 2 & QCP & & & & 0.12 & & 92.6 & & 1.93 \\
\hline 568 & 2015 & 19654R & 2 & PFP & 0.32 & 0.91 & 0.03 & 0.01 & 93.5 & 93.6 & 1.42 & 1.43 \\
\hline 569 & 2016 & $19532 R$ & 2 & PFP & 0.11 & 0.50 & 0.00 & 0.00 & 92.9 & 93.1 & 1.95 & 2.04 \\
\hline 570 & 2016 & 19654R & 2 & PFP & 0.15 & 0.74 & 0.00 & 0.00 & 93.1 & 93.3 & 1.95 & 1.93 \\
\hline 571 & 2016 & 19654R & 2 & QCP & 0.02 & 0.33 & 0.23 & 0.03 & 92.3 & 94.6 & 1.43 & 2.18 \\
\hline 572 & 2016 & 19524R & 2 & QCP & 0.20 & 0.66 & 0.64 & 0.12 & 91.4 & 92.2 & 2.76 & 2.58 \\
\hline 573 & 2017 & 19524R & 4 & QCP & 0.68 & 0.12 & 0.01 & 0.38 & 94.1 & 94.7 & 1.81 & 0.88 \\
\hline 574 & 2016 & 19534R & 2 & PFP & 0.26 & 0.33 & 0.34 & 0.46 & 93.0 & 93.1 & 1.29 & 1.36 \\
\hline 575 & 2016 & 19534R & 2 & PFP & 0.71 & 0.79 & 0.07 & 0.71 & 93.2 & 93.3 & 1.50 & 1.47 \\
\hline 576 & 2015 & 19524R & 2 & QCP & & & & 0.29 & & 94.2 & & 1.50 \\
\hline 577 & 2015 & $19525 R$ & 2 & QCP & 0.45 & 0.89 & 0.14 & 0.00 & 92.3 & 92.5 & 2.41 & 2.45 \\
\hline 578 & 2015 & $19532 R$ & 2 & PFP & 0.06 & 0.00 & 0.01 & 0.00 & 94.5 & 94.3 & 1.28 & 1.46 \\
\hline 579 & 2015 & 19605FR & 2 & $\mathrm{QCP}$ & & & & 0.50 & & 91.1 & & 2.15 \\
\hline 580 & 2015 & 19654R & 2 & PFP & 0.12 & 0.87 & 0.60 & 0.65 & 94.7 & 94.5 & 1.31 & 1.29 \\
\hline 581 & 2015 & $19515 R$ & 2 & $\mathrm{QCP}$ & 0.00 & 0.84 & 0.00 & 0.00 & 93.1 & 93.8 & 1.79 & 1.76 \\
\hline 582 & 2016 & 19515R & 2 & $\mathrm{QCP}$ & & & & 0.00 & & 94.1 & & 1.55 \\
\hline 583 & 2014 & 19604FR & 2 & QCP & & & & 0.00 & & 92.8 & & 1.54 \\
\hline 584 & 2015 & 19605FR & 2 & QCP & 0.01 & 0.20 & 0.77 & 0.00 & 92.2 & 89.4 & 1.24 & 0.40 \\
\hline 585 & 2015 & 19525R & 2 & QCP & 0.53 & 0.59 & 0.03 & 0.15 & 92.1 & 91.9 & 2.03 & 1.83 \\
\hline 586 & 2015 & $19515 R$ & 2 & $\mathrm{QCP}$ & & & & 0.00 & & 93.4 & & 1.72 \\
\hline 587 & 2016 & 19525R & 2 & QCP & & & & 0.10 & & 93.9 & & 2.03 \\
\hline 588 & 2015 & $19532 R$ & 2 & PFP & 0.98 & 0.68 & 0.44 & 0.14 & 94.7 & 94.7 & 1.28 & 1.32 \\
\hline 589 & 2015 & $19532 R$ & 2 & QCP & 0.12 & 0.03 & 0.19 & 0.00 & 94.6 & 94.4 & 1.27 & 1.45 \\
\hline 590 & 2015 & 19654R & 2 & PFP & 0.32 & 0.04 & 0.00 & 0.00 & 93.9 & 93.7 & 1.82 & 1.99 \\
\hline 591 & 2015 & 19526R & 2 & QCP & & & & & & 92.2 & & 0.92 \\
\hline
\end{tabular}




\begin{tabular}{|c|c|c|c|c|c|c|c|c|c|c|c|c|}
\hline $\begin{array}{c}\text { ICT } \\
\text { Code }\end{array}$ & Year & Mix Code & District & $\begin{array}{l}\text { Quality } \\
\text { Program }\end{array}$ & $\begin{array}{c}\text { MW } \\
\text { P-Value }\end{array}$ & $\begin{array}{l}\text { Levene's } \\
\text { P-Value }\end{array}$ & $\begin{array}{l}\text { Contractor } \\
\text { SW P-Value }\end{array}$ & $\begin{array}{c}\text { Agency SW } \\
\text { P-Value }\end{array}$ & $\begin{array}{c}\text { Contractor } \\
\text { Mean }\end{array}$ & $\begin{array}{l}\text { Agency } \\
\text { Mean }\end{array}$ & $\begin{array}{c}\text { Contractor } \\
\text { St. Dev. }\end{array}$ & $\begin{array}{l}\text { Agency } \\
\text { St. Dev. }\end{array}$ \\
\hline 595 & 2017 & 19515R & 2 & $\mathrm{QCP}$ & 0.65 & 0.51 & 0.64 & 0.98 & 93.3 & 93.2 & 1.12 & 1.30 \\
\hline 596 & 2017 & 19604FR & 2 & QCP & 0.17 & 0.12 & 0.06 & 0.85 & 92.6 & 92.2 & 0.66 & 0.92 \\
\hline 597 & 2017 & 19532 & 2 & PFP & 0.94 & 0.60 & 0.69 & 0.58 & 92.7 & 92.7 & 1.59 & 1.72 \\
\hline 598 & 2017 & 19513R & 2 & QCP & & & & 0.09 & & 93.5 & & 1.84 \\
\hline 599 & 2017 & 19535R & 2 & PFP & 0.98 & 0.63 & 0.79 & 0.16 & 93.2 & 93.1 & 1.66 & 1.79 \\
\hline 600 & 2017 & 19524R & 1 & QCP & & & & 0.86 & & 92.5 & & 1.54 \\
\hline 601 & 2017 & 19524R & 1 & PFP & 0.98 & 0.06 & 0.00 & 0.00 & 91.9 & 91.7 & 2.68 & 3.13 \\
\hline 602 & 2016 & $19524 R$ & 3 & QCP & & & & 0.36 & & 92.3 & & 1.80 \\
\hline 603 & 2017 & $19522 R$ & 3 & QCP & & & & 0.00 & & 94.1 & & 1.10 \\
\hline 604 & 2015 & 19535R & 3 & PFP & 0.03 & 0.00 & 0.17 & 0.33 & 92.3 & 91.8 & 1.17 & 1.66 \\
\hline 605 & 2017 & 19510R & 1 & QCP & & & & 0.01 & & 93.0 & & 1.48 \\
\hline 606 & 2017 & 19510R & 1 & $\mathrm{QCP}$ & 0.43 & 0.20 & 0.06 & 0.00 & 93.9 & 94.0 & 1.84 & 1.69 \\
\hline 607 & 2016 & $19524 R$ & 3 & $\mathrm{QCP}$ & 0.11 & 0.20 & 0.10 & 0.20 & 94.2 & 93.2 & 1.04 & 1.66 \\
\hline 608 & 2017 & 19534R & 3 & QCP & 0.12 & 0.73 & & 0.04 & 91.5 & 93.0 & 0.78 & 1.62 \\
\hline 609 & 2017 & $19524 R$ & 1 & PFP & 0.99 & 0.35 & 0.12 & 0.19 & 92.8 & 92.8 & 1.53 & 1.63 \\
\hline 610 & 2017 & 19524R & 3 & QCP & 0.32 & 0.30 & 0.73 & 0.01 & 94.0 & 94.2 & 1.12 & 1.52 \\
\hline 613 & 2015 & $19522 R$ & 3 & QCP & & & & 0.00 & & 93.9 & & 2.24 \\
\hline 614 & 2015 & $19522 R$ & 3 & $\mathrm{QCP}$ & & & & 0.63 & & 94.0 & & 1.40 \\
\hline 615 & 2016 & $19512 R$ & 1 & $\mathrm{QCP}$ & & & & 0.00 & & 93.3 & & 0.92 \\
\hline 616 & 2016 & $19514 R$ & 3 & $\mathrm{QCP}$ & & & & 0.00 & & 93.6 & & 1.31 \\
\hline 617 & 2015 & 19534R & 3 & PFP & 0.01 & 0.51 & 0.24 & 0.01 & 93.8 & 93.0 & 1.35 & 1.55 \\
\hline 618 & 2015 & 19534R & 3 & PFP & 0.18 & 0.02 & 0.83 & 0.00 & 93.1 & 93.3 & 0.96 & 1.47 \\
\hline 619 & 2017 & $19524 R$ & 1 & QCP & & & & 0.05 & & 93.2 & & 1.61 \\
\hline 620 & 2016 & $19512 R$ & 1 & QCP & & & & 0.00 & & 93.9 & & 1.11 \\
\hline 621 & 2017 & 19534R & 3 & PFP & 0.79 & 0.45 & 0.08 & 0.01 & 93.8 & 93.9 & 0.83 & 1.10 \\
\hline 622 & 2017 & $19532 R$ & 3 & PFP & 0.42 & 0.55 & 0.15 & 0.00 & 93.0 & 93.4 & 1.11 & 1.47 \\
\hline 623 & 2017 & 19510R & 1 & QCP & & & & 0.00 & & 93.1 & & 0.91 \\
\hline 624 & 2017 & 19654R & 3 & QCP & 0.01 & 0.88 & 0.23 & 0.17 & 91.5 & 94.1 & 1.61 & 1.86 \\
\hline 625 & 2017 & 19510R & 4 & PFP & 0.00 & 0.03 & 0.00 & 0.00 & 94.6 & 94.8 & 1.06 & 1.21 \\
\hline 626 & 2015 & 19515R & 4 & QCP & 0.02 & 0.33 & 0.17 & 0.32 & 93.8 & 94.8 & 0.66 & 1.03 \\
\hline 627 & 2016 & 19515R & 4 & $\mathrm{QCP}$ & 0.04 & 0.18 & 0.08 & 0.57 & 92.3 & 91.6 & 1.33 & 1.68 \\
\hline 628 & 2016 & $19522 R$ & 4 & PFP & 0.65 & 0.68 & 0.01 & 0.06 & 94.3 & 94.4 & 1.93 & 2.07 \\
\hline 629 & 2016 & 19522R & 4 & PFP & 0.37 & 0.28 & 0.00 & 0.00 & 93.5 & 93.6 & 1.81 & 1.90 \\
\hline 630 & 2016 & $19532 R$ & 3 & PFP & 0.42 & & & 0.00 & 93.1 & 93.7 & 0.00 & 1.26 \\
\hline 631 & 2015 & 19653R & 4 & PFP & & & 0.01 & & 94.4 & & 1.68 & \\
\hline
\end{tabular}




\begin{tabular}{|c|c|c|c|c|c|c|c|c|c|c|c|c|}
\hline $\begin{array}{c}\text { ICT } \\
\text { Code }\end{array}$ & Year & Mix Code & District & $\begin{array}{l}\text { Quality } \\
\text { Program }\end{array}$ & $\begin{array}{c}\text { MW } \\
\text { P-Value }\end{array}$ & $\begin{array}{l}\text { Levene's } \\
\text { P-Value }\end{array}$ & $\begin{array}{l}\text { Contractor } \\
\text { SW P-Value }\end{array}$ & $\begin{array}{c}\text { Agency SW } \\
\text { P-Value }\end{array}$ & $\begin{array}{c}\text { Contractor } \\
\text { Mean }\end{array}$ & $\begin{array}{l}\text { Agency } \\
\text { Mean }\end{array}$ & $\begin{array}{c}\text { Contractor } \\
\text { St. Dev. }\end{array}$ & $\begin{array}{l}\text { Agency } \\
\text { St. Dev. }\end{array}$ \\
\hline 632 & 2016 & 19654R & 4 & PFP & 0.19 & 0.26 & 0.00 & 0.00 & 94.0 & 94.3 & 1.98 & 2.16 \\
\hline 633 & 2017 & 19654R & 4 & PFP & 0.38 & 0.92 & 0.36 & 0.02 & 95.1 & 95.3 & 1.32 & 1.33 \\
\hline 634 & 2016 & 19654R & 4 & PFP & 0.37 & & & 0.17 & 93.5 & 94.6 & 0.00 & 1.77 \\
\hline 635 & 2017 & 19510R & 4 & QCP & 0.05 & 0.00 & 0.00 & 0.00 & 94.1 & 94.5 & 0.92 & 1.58 \\
\hline 636 & 2015 & 19515R & 4 & QCP & 0.32 & 0.48 & 0.02 & 0.01 & 94.4 & 94.2 & 1.24 & 1.36 \\
\hline 637 & 2016 & $19524 R$ & 4 & PFP & 0.10 & 0.73 & 0.00 & 0.82 & 93.1 & 93.8 & 1.44 & 1.34 \\
\hline 638 & 2016 & 19525R & 4 & PFP & 0.05 & 0.98 & 0.37 & 0.11 & 93.6 & 94.7 & 2.03 & 2.01 \\
\hline 639 & 2015 & $19525 R$ & 4 & PFP & 0.00 & 0.00 & 0.00 & 0.00 & 93.5 & 92.9 & 1.23 & 1.77 \\
\hline 640 & 2015 & 19535R & 3 & PFP & 0.00 & 0.63 & 0.00 & 0.00 & 93.3 & 92.9 & 1.26 & 1.31 \\
\hline 641 & 2016 & 19510R & 4 & PFP & 0.01 & 0.14 & 0.02 & 0.00 & 94.2 & 94.6 & 1.22 & 1.37 \\
\hline 642 & 2016 & 19510R & 4 & PFP & 0.84 & 0.37 & 0.00 & 0.10 & 93.8 & 93.7 & 1.71 & 1.55 \\
\hline 643 & 2017 & 19515R & 4 & $\mathrm{QCP}$ & 0.95 & 0.90 & 0.92 & 0.80 & 94.0 & 94.1 & 1.20 & 1.16 \\
\hline 644 & 2017 & $19514 \mathrm{R}$ & 4 & PFP & 0.92 & 0.22 & 0.12 & 0.92 & 94.0 & 93.9 & 1.28 & 1.42 \\
\hline 645 & 2015 & 19515R & 4 & QCP & 0.05 & 0.96 & 0.00 & 0.61 & 94.3 & 92.8 & 1.97 & 1.89 \\
\hline 646 & 2015 & $19524 R$ & 4 & PFP & 0.76 & 0.00 & 0.20 & 0.00 & 94.4 & 94.2 & 0.90 & 1.43 \\
\hline 647 & 2016 & $19512 \mathrm{R}$ & 4 & PFP & 0.00 & 0.00 & 0.15 & 0.00 & 95.0 & 96.1 & 1.03 & 1.55 \\
\hline 648 & 2017 & $19522 \mathrm{R}$ & 4 & QCP & 0.38 & 0.03 & 0.85 & 0.76 & 94.8 & 94.4 & 1.52 & 0.81 \\
\hline 649 & 2015 & $19514 R$ & 4 & $\mathrm{QCP}$ & 0.80 & 0.45 & 0.11 & 0.20 & 94.5 & 94.5 & 1.09 & 1.22 \\
\hline 650 & 2016 & $19514 \mathrm{R}$ & 4 & PFP & 0.37 & 0.21 & 0.00 & 0.62 & 96.0 & 95.6 & 2.23 & 1.99 \\
\hline 651 & 2015 & $19514 R$ & 4 & PFP & 0.30 & 0.00 & 0.78 & 0.00 & 94.1 & 93.7 & 0.89 & 1.59 \\
\hline 652 & 2015 & 19524R & 5 & QCP & 0.84 & 0.05 & 0.18 & 0.93 & 94.5 & 94.6 & 0.88 & 1.82 \\
\hline 653 & 2015 & $19514 R$ & 5 & QCP & 0.01 & 0.06 & 0.00 & 0.26 & 93.7 & 93.0 & 1.29 & 1.64 \\
\hline 654 & 2016 & $19514 R$ & 5 & QCP & & & & & 93.1 & & 0.00 & \\
\hline 655 & 2016 & $19514 R$ & 5 & QCP & & & 0.85 & & 93.6 & & 0.71 & \\
\hline 656 & 2015 & 19514R & 5 & QCP & & & & 0.82 & & 93.1 & & 1.68 \\
\hline 658 & 2015 & $19605 F R$ & 5 & QCP & 0.05 & 0.50 & 0.54 & 0.13 & 93.5 & 91.3 & 1.08 & 2.02 \\
\hline 659 & 2015 & $19524 R$ & 5 & QCP & & & & & & 89.6 & & 0.00 \\
\hline 734 & 2015 & 19534R & 5 & QCP & & & & 0.05 & & 93.5 & & 1.28 \\
\hline 735 & 2015 & 19534R & 5 & PFP & 0.45 & 0.62 & 0.02 & 0.01 & 93.6 & 93.5 & 1.53 & 1.47 \\
\hline 745 & 2017 & 19535R & 5 & QCP & & & 0.70 & & 93.6 & & 0.56 & \\
\hline 746 & 2017 & $19512 R$ & 6 & QCP & 0.15 & 0.34 & 0.16 & 0.05 & 94.1 & 94.6 & 0.78 & 1.13 \\
\hline 749 & 2015 & 19534R & 5 & PFP & 0.00 & 0.03 & 0.02 & 0.37 & 97.7 & 93.2 & 2.82 & 1.57 \\
\hline 750 & 2016 & 19513R & 5 & QCP & & & 0.11 & & 99.5 & & 0.63 & \\
\hline 751 & 2015 & 19532R & 5 & PFP & 0.55 & 0.00 & 0.39 & 0.02 & 94.5 & 94.3 & 0.66 & 1.37 \\
\hline 752 & 2015 & 19535R & 5 & PFP & 0.14 & 0.29 & & 0.55 & 94.6 & 93.1 & 0.28 & 1.56 \\
\hline
\end{tabular}




\begin{tabular}{|c|c|c|c|c|c|c|c|c|c|c|c|c|}
\hline $\begin{array}{c}\text { ICT } \\
\text { Code }\end{array}$ & Year & Mix Code & District & $\begin{array}{l}\text { Quality } \\
\text { Program }\end{array}$ & $\begin{array}{c}\text { MW } \\
\text { P-Value }\end{array}$ & $\begin{array}{l}\text { Levene's } \\
\text { P-Value }\end{array}$ & $\begin{array}{l}\text { Contractor } \\
\text { SW P-Value }\end{array}$ & $\begin{array}{c}\text { Agency SW } \\
\text { P-Value }\end{array}$ & $\begin{array}{c}\text { Contractor } \\
\text { Mean }\end{array}$ & $\begin{array}{l}\text { Agency } \\
\text { Mean }\end{array}$ & $\begin{array}{l}\text { Contractor } \\
\text { St. Dev. }\end{array}$ & $\begin{array}{l}\text { Agency } \\
\text { St. Dev. }\end{array}$ \\
\hline 753 & 2015 & 19523R & 5 & $\mathrm{QCP}$ & 0.04 & 0.05 & 0.15 & 0.95 & 95.0 & 94.1 & 0.97 & 1.59 \\
\hline 754 & 2015 & 19505R & 5 & QCP & 0.13 & & & 0.04 & 96.8 & 93.9 & 0.00 & 2.04 \\
\hline 756 & 2015 & 19534R & 5 & PFP & 0.85 & 0.74 & & 0.08 & 93.5 & 93.5 & 0.85 & 1.75 \\
\hline 757 & 2016 & 19513R & 5 & QCP & 0.33 & 0.08 & 0.23 & 0.97 & 94.3 & 94.8 & 0.85 & 1.43 \\
\hline 758 & 2016 & 19513R & 5 & QCP & & & 0.15 & & 94.7 & & 0.76 & \\
\hline 759 & 2015 & $19532 R$ & 5 & PFP & 1.00 & 0.37 & 0.14 & 0.78 & 94.4 & 94.4 & 0.70 & 0.97 \\
\hline 760 & 2016 & 19535R & 5 & PFP & & & & & 93.5 & & 1.34 & \\
\hline 761 & 2017 & $19532 R$ & 5 & PFP & & & & & 94.6 & & 0.14 & \\
\hline 762 & 2015 & 19523R & 6 & QCP & 0.05 & 0.00 & 0.06 & 0.36 & 93.2 & 93.9 & 0.63 & 1.48 \\
\hline 763 & 2015 & 19513R & 6 & QCP & 0.02 & 0.00 & 0.42 & 0.14 & 94.3 & 92.9 & 0.58 & 1.91 \\
\hline 765 & 2015 & 19513R & 6 & QCP & 0.29 & 0.00 & 0.52 & 0.20 & 93.9 & 93.7 & 0.70 & 1.61 \\
\hline 766 & 2016 & 19513R & 6 & PFP & 0.13 & 0.18 & 0.01 & 0.06 & 93.8 & 93.9 & 1.06 & 1.27 \\
\hline 767 & 2015 & $19522 R$ & 6 & PFP & 0.38 & 0.42 & 0.00 & 0.00 & 94.1 & 94.0 & 1.64 & 1.52 \\
\hline 768 & 2015 & $19522 \mathrm{R}$ & 6 & PFP & 0.19 & 0.00 & 0.01 & 0.47 & 94.3 & 94.0 & 0.82 & 1.48 \\
\hline 769 & 2015 & 19513R & 6 & QCP & 0.01 & 0.00 & 0.30 & 0.01 & 94.9 & 94.2 & 0.96 & 1.46 \\
\hline 770 & 2015 & 19513R & 6 & QCP & 0.12 & 0.04 & 0.20 & 0.26 & 94.4 & 93.6 & 0.99 & 1.76 \\
\hline 771 & 2015 & 19523R & 6 & PFP & 0.00 & 0.00 & 0.00 & 0.00 & 93.9 & 94.6 & 1.70 & 1.21 \\
\hline 772 & 2015 & 19513R & 6 & QCP & 0.14 & 0.00 & 0.02 & 0.00 & 93.4 & 93.8 & 0.27 & 1.42 \\
\hline 773 & 2015 & 19523R & 6 & QCP & 0.97 & 0.01 & 0.02 & 0.40 & 93.7 & 93.6 & 0.98 & 1.39 \\
\hline 774 & 2015 & 19523R & 6 & QCP & 0.41 & 0.79 & 0.00 & 0.18 & 92.3 & 92.2 & 1.26 & 1.29 \\
\hline 775 & 2016 & $19534 \mathrm{R}$ & 6 & PFP & & & & 0.06 & & 93.2 & & 1.61 \\
\hline 776 & 2015 & $19534 \mathrm{R}$ & 6 & PFP & & & & 0.00 & & 93.7 & & 1.32 \\
\hline 780 & 2015 & $19522 \mathrm{R}$ & 6 & PFP & 0.39 & 0.43 & 0.00 & 0.00 & 94.5 & 94.7 & 1.60 & 1.54 \\
\hline 781 & 2015 & 19513R & 6 & QCP & 0.61 & 0.78 & 0.05 & 0.27 & 94.5 & 94.0 & 1.22 & 1.49 \\
\hline 782 & 2017 & $19522 \mathrm{R}$ & 6 & $\mathrm{QCP}$ & 0.00 & 0.03 & 0.00 & 0.03 & 94.1 & 93.5 & 1.01 & 1.32 \\
\hline 783 & 2015 & $19535 R$ & 6 & PFP & & & & 0.03 & & 93.7 & & 1.68 \\
\hline 784 & 2015 & $19535 R$ & 6 & QCP & & & & 0.60 & & 94.0 & & 1.72 \\
\hline 785 & 2015 & 19535R & 6 & PFP & & & & 0.01 & & 93.2 & & 1.49 \\
\hline 786 & 2016 & $19514 R$ & 6 & QCP & 0.92 & 0.00 & 0.06 & 0.02 & 93.2 & 93.4 & 0.54 & 2.21 \\
\hline 787 & 2015 & 19513R & 6 & QCP & 0.08 & 0.00 & 0.02 & 0.01 & 93.2 & 91.7 & 0.06 & 1.97 \\
\hline 788 & 2015 & $19522 \mathrm{R}$ & 6 & QCP & & & & 0.27 & & 94.2 & & 1.50 \\
\hline 789 & 2015 & $19532 R$ & 6 & PFP & 0.17 & 0.08 & & 0.00 & 93.2 & 94.0 & 0.07 & 1.41 \\
\hline 790 & 2016 & $19532 R$ & 6 & QCP & & & & 0.28 & & 94.7 & & 1.01 \\
\hline 791 & 2015 & $19524 \mathrm{R}$ & 6 & QCP & & & & 0.12 & & 93.7 & & 1.18 \\
\hline 792 & 2015 & $19512 R$ & 6 & QCP & 0.50 & 0.00 & 0.02 & 0.74 & 93.5 & 93.4 & 0.44 & 1.10 \\
\hline
\end{tabular}




\begin{tabular}{|c|c|c|c|c|c|c|c|c|c|c|c|c|}
\hline $\begin{array}{c}\text { ICT } \\
\text { Code }\end{array}$ & Year & Mix Code & District & $\begin{array}{l}\text { Quality } \\
\text { Program }\end{array}$ & $\begin{array}{c}\text { MW } \\
\text { P-Value }\end{array}$ & $\begin{array}{l}\text { Levene's } \\
\text { P-Value }\end{array}$ & $\begin{array}{l}\text { Contractor } \\
\text { SW P-Value }\end{array}$ & $\begin{array}{c}\text { Agency SW } \\
\text { P-Value }\end{array}$ & $\begin{array}{c}\text { Contractor } \\
\text { Mean }\end{array}$ & $\begin{array}{l}\text { Agency } \\
\text { Mean }\end{array}$ & $\begin{array}{c}\text { Contractor } \\
\text { St. Dev. }\end{array}$ & $\begin{array}{l}\text { Agency } \\
\text { St. Dev. }\end{array}$ \\
\hline 793 & 2015 & 19535R & 6 & PFP & 0.22 & 0.29 & 0.02 & 0.00 & 94.4 & 93.4 & 0.87 & 1.70 \\
\hline 794 & 2017 & 19535R & 6 & PFP & & & & 0.54 & & 93.7 & & 1.40 \\
\hline 795 & 2016 & 19535R & 6 & QCP & & & & 0.69 & & 93.6 & & 1.04 \\
\hline 796 & 2017 & 19513R & 6 & QCP & 0.29 & 0.00 & 0.01 & 0.00 & 93.9 & 94.0 & 0.85 & 1.60 \\
\hline 797 & 2017 & 19513R & 6 & QCP & & & & 0.48 & & 94.1 & & 1.21 \\
\hline 798 & 2017 & $19513 R$ & 6 & QCP & 0.58 & 0.18 & & 0.07 & 94.4 & 94.0 & 0.14 & 1.22 \\
\hline 799 & 2016 & 19513R & 6 & PFP & 0.12 & 0.47 & 0.23 & 0.10 & 94.3 & 94.0 & 0.78 & 0.86 \\
\hline 801 & 2016 & 19513R & 6 & QCP & 0.25 & 0.02 & 0.29 & 0.04 & 93.5 & 93.8 & 0.47 & 1.10 \\
\hline 802 & 2016 & 19513R & 6 & QCP & & & & 0.61 & & 92.3 & & 2.10 \\
\hline 803 & 2016 & 19514R & 6 & QCP & & & & 0.37 & & 93.7 & & 1.52 \\
\hline 804 & 2015 & $19512 R$ & 6 & QCP & 0.36 & 0.01 & 0.81 & 0.14 & 94.7 & 94.5 & 0.72 & 1.36 \\
\hline 805 & 2016 & $19524 R$ & 6 & $\mathrm{QCP}$ & 0.03 & 0.00 & 0.00 & 0.03 & 93.7 & 94.0 & 0.83 & 1.29 \\
\hline 807 & 2017 & $19513 R$ & 6 & $\mathrm{QCP}$ & 0.86 & 0.28 & 0.19 & 0.00 & 95.0 & 94.9 & 0.86 & 1.31 \\
\hline 808 & 2015 & 19513R & 6 & QCP & 0.89 & 0.68 & & 0.75 & 95.3 & 95.4 & 0.71 & 1.54 \\
\hline 809 & 2017 & $19513 R$ & 6 & QCP & 0.08 & 0.03 & 0.07 & 0.09 & 94.6 & 93.7 & 0.47 & 1.28 \\
\hline 810 & 2016 & 19513R & 6 & QCP & 0.18 & 0.04 & 0.00 & 0.02 & 93.6 & 93.7 & 0.98 & 1.47 \\
\hline 811 & 2016 & 19513R & 6 & QCP & 0.00 & 0.38 & 0.02 & 0.56 & 95.9 & 93.8 & 1.04 & 1.44 \\
\hline 812 & 2017 & $19532 R$ & 6 & PFP & & & & 0.01 & & 94.6 & & 1.12 \\
\hline 813 & 2016 & $19514 R$ & 6 & QCP & 0.93 & 0.55 & 0.83 & 0.73 & 94.2 & 94.1 & 0.93 & 1.13 \\
\hline 814 & 2016 & 19534R & 7 & PFP & 0.34 & 0.48 & 0.03 & 0.19 & 93.9 & 94.1 & 1.28 & 1.37 \\
\hline 815 & 2016 & $19524 R$ & 6 & QCP & 0.00 & 0.31 & 0.04 & 0.00 & 93.7 & 94.7 & 1.21 & 1.50 \\
\hline 817 & 2016 & $19532 R$ & 6 & PFP & 0.38 & 0.25 & & 0.32 & 93.5 & 94.1 & 0.21 & 1.37 \\
\hline 818 & 2016 & $19524 R$ & 6 & QCP & & & & 0.66 & & 92.7 & & 1.57 \\
\hline 819 & 2016 & 19534R & 6 & PFP & & & & 0.06 & & 93.2 & & 1.61 \\
\hline 820 & 2016 & 19513R & 6 & QCP & 0.00 & 0.38 & 0.02 & 0.56 & 95.9 & 93.8 & 1.04 & 1.44 \\
\hline 821 & 2016 & $19512 R$ & 6 & QCP & 0.08 & 0.00 & 0.78 & 0.00 & 93.6 & 93.7 & 0.33 & 1.52 \\
\hline 822 & 2017 & $19514 R$ & 6 & QCP & 0.77 & 0.06 & & 0.02 & 94.2 & 94.1 & 0.07 & 1.95 \\
\hline 823 & 2017 & $19522 R$ & 6 & PFP & 0.10 & 0.37 & 0.00 & 0.04 & 93.5 & 92.6 & 2.03 & 2.34 \\
\hline 824 & 2017 & 19514R & 6 & QCP & & & & 0.82 & & 92.9 & & 1.47 \\
\hline 825 & 2017 & 19513R & 6 & QCP & 0.39 & 0.04 & 0.22 & 0.02 & 94.9 & 95.0 & 1.16 & 1.66 \\
\hline 826 & 2015 & 19524 & 7 & PFP & 0.36 & 0.17 & 0.51 & 0.26 & 93.2 & 93.8 & 0.67 & 1.36 \\
\hline 827 & 2015 & 19532R & 7 & PFP & 0.84 & 0.94 & 0.04 & 0.83 & 94.1 & 94.0 & 1.31 & 1.17 \\
\hline 828 & 2016 & 19523R & 7 & QCP & 0.26 & 0.92 & 0.07 & 0.86 & 93.5 & 93.9 & 1.43 & 1.45 \\
\hline 829 & 2016 & $19532 R$ & 7 & QCP & 0.24 & 0.25 & 0.85 & 0.16 & 93.5 & 93.8 & 1.14 & 1.28 \\
\hline 830 & 2016 & 19523 & 7 & QCP & & & & 0.98 & & 93.8 & & 1.34 \\
\hline
\end{tabular}




\begin{tabular}{|c|c|c|c|c|c|c|c|c|c|c|c|c|}
\hline $\begin{array}{c}\text { ICT } \\
\text { Code }\end{array}$ & Year & Mix Code & District & $\begin{array}{l}\text { Quality } \\
\text { Program }\end{array}$ & $\begin{array}{c}\text { MW } \\
\text { P-Value }\end{array}$ & $\begin{array}{l}\text { Levene's } \\
\text { P-Value }\end{array}$ & $\begin{array}{l}\text { Contractor } \\
\text { SW P-Value }\end{array}$ & $\begin{array}{c}\text { Agency SW } \\
\text { P-Value }\end{array}$ & $\begin{array}{c}\text { Contractor } \\
\text { Mean }\end{array}$ & $\begin{array}{l}\text { Agency } \\
\text { Mean }\end{array}$ & $\begin{array}{c}\text { Contractor } \\
\text { St. Dev. }\end{array}$ & $\begin{array}{l}\text { Agency } \\
\text { St. Dev. }\end{array}$ \\
\hline 831 & 2016 & 19523 & 7 & $\mathrm{QCP}$ & & & & 0.26 & & 93.0 & & 1.21 \\
\hline 832 & 2017 & 19523 & 7 & QCP & 0.88 & 0.07 & 0.00 & 0.48 & 92.1 & 92.3 & 2.34 & 1.29 \\
\hline 833 & 2016 & 19534R & 7 & QCP & 0.37 & 0.01 & 0.07 & 0.84 & 93.7 & 93.5 & 0.78 & 1.52 \\
\hline 834 & 2015 & 19534R & 7 & PFP & 0.50 & 0.10 & 0.78 & 0.79 & 93.6 & 93.2 & 0.97 & 1.50 \\
\hline 835 & 2015 & 19534R & 7 & PFP & 0.45 & 0.25 & 0.92 & 0.00 & 93.0 & 93.2 & 1.14 & 1.58 \\
\hline 836 & 2016 & 19534R & 7 & QCP & 0.00 & 0.00 & 0.59 & 0.04 & 94.1 & 93.2 & 0.77 & 1.52 \\
\hline 837 & 2015 & 19534R & 7 & $\mathrm{QCP}$ & 0.10 & 0.82 & 0.85 & 0.34 & 93.5 & 94.4 & 1.44 & 1.37 \\
\hline 838 & 2016 & $19523 R$ & 9 & QCP & & & & 0.67 & & 93.4 & & 0.70 \\
\hline 839 & 2016 & 19605FR & 9 & QCP & & & & 0.10 & & 93.3 & & 0.75 \\
\hline 840 & 2015 & 19534R & 7 & PFP & 0.93 & 0.46 & 0.08 & 0.01 & 93.7 & 93.6 & 1.66 & 1.79 \\
\hline 841 & 2015 & 19523R & 7 & QCP & 0.65 & 0.51 & 0.70 & 0.18 & 94.0 & 94.1 & 1.35 & 1.20 \\
\hline 842 & 2015 & 19523R & 7 & PFP & 0.84 & 0.32 & 0.33 & 0.02 & 92.9 & 92.9 & 1.78 & 1.91 \\
\hline 843 & 2016 & $19534 R$ & 7 & $\mathrm{QCP}$ & 0.02 & 0.01 & 0.51 & 0.01 & 93.0 & 94.2 & 0.47 & 1.65 \\
\hline 844 & 2015 & 19534R & 7 & PFP & 0.88 & 0.91 & 0.17 & 0.03 & 93.1 & 93.1 & 1.60 & 1.58 \\
\hline 845 & 2016 & 19654R & 7 & PFP & 0.94 & 0.07 & 0.00 & 0.00 & 94.3 & 94.3 & 1.63 & 1.83 \\
\hline 846 & 2015 & 19654R & 7 & PFP & 0.98 & 0.32 & 0.03 & 0.00 & 93.9 & 93.9 & 1.75 & 1.89 \\
\hline 847 & 2016 & 19654R & 7 & PFP & 0.94 & 0.25 & 0.02 & 0.03 & 95.2 & 95.1 & 1.11 & 1.33 \\
\hline 848 & 2016 & 19654R & 7 & PFP & 0.01 & 0.37 & 0.34 & 0.30 & 94.6 & 93.2 & 1.22 & 1.51 \\
\hline 849 & 2017 & 19654R & 7 & PFP & 0.15 & 0.47 & 0.01 & 0.00 & 94.9 & 95.1 & 1.25 & 1.31 \\
\hline 850 & 2016 & $19532 R$ & 7 & PFP & 0.78 & 0.48 & 0.00 & 0.02 & 93.6 & 93.7 & 1.69 & 1.75 \\
\hline 851 & 2017 & $19532 R$ & 7 & PFP & 0.01 & 0.01 & 0.00 & 0.03 & 93.9 & 94.1 & 0.96 & 1.09 \\
\hline 852 & 2017 & 19523R & 7 & QCP & 0.39 & 0.49 & 0.73 & 0.61 & 93.5 & 93.2 & 1.42 & 1.59 \\
\hline 853 & 2015 & 19505R & 7 & PFP & 0.04 & 0.98 & 0.43 & 0.26 & 94.4 & 94.1 & 0.61 & 0.60 \\
\hline 854 & 2015 & $19532 R$ & 7 & PFP & 0.02 & 0.00 & 0.06 & 0.00 & 93.2 & 93.6 & 0.66 & 1.22 \\
\hline 855 & 2016 & 19532R & 7 & PFP & 0.27 & 0.00 & 0.00 & 0.00 & 93.8 & 93.9 & 1.09 & 1.51 \\
\hline 856 & 2015 & 19654R & 7 & PFP & 0.65 & 0.06 & 1.00 & 0.00 & 95.2 & 94.5 & 0.30 & 1.75 \\
\hline 857 & 2016 & 19654R & 7 & PFP & 0.35 & 0.34 & 0.00 & 0.00 & 93.9 & 94.0 & 1.68 & 1.79 \\
\hline 858 & 2017 & 19533R & 7 & PFP & 0.37 & 0.18 & 0.01 & 0.18 & 93.5 & 93.3 & 1.27 & 1.45 \\
\hline 859 & 2017 & 19532R & 7 & PFP & 0.06 & 0.06 & 0.85 & 0.90 & 95.1 & 94.5 & 0.54 & 0.91 \\
\hline 861 & 2016 & $19523 R$ & 8 & QCP & 0.47 & & 0.51 & & 93.6 & 94.4 & 1.15 & 0.00 \\
\hline 862 & 2016 & $19523 R$ & 8 & $\mathrm{QCP}$ & & & 0.02 & & 94.2 & & 1.16 & \\
\hline 863 & 2016 & 19534R & 8 & QCP & 0.03 & 0.00 & 0.99 & 0.95 & 93.3 & 93.9 & 0.61 & 1.32 \\
\hline 864 & 2015 & 19534R & 8 & QCP & & & 0.42 & & 93.7 & & 0.59 & \\
\hline 865 & 2015 & 19534R & 8 & QCP & 0.05 & 0.23 & 0.47 & 1.00 & 93.9 & 93.2 & 0.57 & 0.20 \\
\hline 866 & 2015 & 19534R & 8 & QCP & 1.00 & & & & 92.0 & 92.7 & 0.00 & 0.00 \\
\hline
\end{tabular}




\begin{tabular}{|c|c|c|c|c|c|c|c|c|c|c|c|c|}
\hline $\begin{array}{c}\text { ICT } \\
\text { Code }\end{array}$ & Year & Mix Code & District & $\begin{array}{l}\text { Quality } \\
\text { Program }\end{array}$ & $\begin{array}{c}\text { MW } \\
\text { P-Value }\end{array}$ & $\begin{array}{l}\text { Levene's } \\
\text { P-Value }\end{array}$ & $\begin{array}{l}\text { Contractor } \\
\text { SW P-Value }\end{array}$ & $\begin{array}{c}\text { Agency SW } \\
\text { P-Value }\end{array}$ & $\begin{array}{c}\text { Contractor } \\
\text { Mean }\end{array}$ & $\begin{array}{l}\text { Agency } \\
\text { Mean }\end{array}$ & $\begin{array}{l}\text { Contractor } \\
\text { St. Dev. }\end{array}$ & $\begin{array}{l}\text { Agency } \\
\text { St. Dev. }\end{array}$ \\
\hline 869 & 2015 & 19535R & 8 & $\mathrm{QCP}$ & 0.00 & 0.39 & 0.67 & 0.46 & 92.5 & 95.7 & 1.19 & 0.81 \\
\hline 870 & 2015 & 19654R & 8 & PFP & 0.01 & 0.13 & 0.00 & 0.52 & 95.2 & 94.2 & 1.55 & 1.04 \\
\hline 871 & 2015 & 19534R & 8 & QCP & & & 0.09 & & 92.2 & & 1.67 & \\
\hline 873 & 2015 & 19654R & 8 & PFP & 0.34 & 0.08 & 0.00 & 0.27 & 94.7 & 94.4 & 1.65 & 0.74 \\
\hline 874 & 2015 & 19535R & 8 & QCP & & & 0.31 & & 94.1 & & 1.11 & \\
\hline 875 & 2015 & $19601 R$ & 8 & QCP & 0.07 & 0.20 & 0.00 & 0.06 & 95.6 & 95.3 & 0.96 & 1.16 \\
\hline 876 & 2016 & 19532R & 8 & PFP & 0.52 & 0.39 & 0.01 & & 93.2 & 93.9 & 1.41 & 0.35 \\
\hline 877 & 2016 & 19533R & 8 & QCP & 0.60 & 0.20 & 0.58 & 0.36 & 93.6 & 93.3 & 0.95 & 1.29 \\
\hline 878 & 2016 & 19534R & 8 & PFP & & & 0.20 & & 92.8 & & 0.69 & \\
\hline 879 & 2016 & 19504R & 8 & QCP & & & & & 93.5 & & 0.00 & \\
\hline 881 & 2017 & $19654 R$ & 8 & PFP & & & 0.04 & & 95.2 & & 0.76 & \\
\hline 882 & 2017 & $19523 R$ & 8 & $\mathrm{QCP}$ & 0.44 & 0.40 & 0.01 & 0.52 & 93.9 & 93.7 & 1.06 & 1.21 \\
\hline 883 & 2017 & $19523 R$ & 8 & $\mathrm{QCP}$ & & & & 0.57 & & 94.0 & & 1.12 \\
\hline 884 & 2015 & 19533R & 9 & QCP & & & & 0.68 & & 92.8 & & 2.13 \\
\hline 885 & 2016 & $19606 \mathrm{FR}$ & 9 & QCP & & & & 0.17 & & 92.0 & & 1.47 \\
\hline 886 & 2015 & 19605FR & 9 & QCP & & & & 0.63 & & 91.8 & & 1.09 \\
\hline 887 & 2016 & $19534 \mathrm{R}$ & 9 & QCP & & & & 0.68 & & 94.3 & & 1.08 \\
\hline 888 & 2016 & $19534 R$ & 9 & $\mathrm{QCP}$ & 0.11 & & 0.24 & & 93.7 & 91.1 & 1.08 & 0.00 \\
\hline 889 & 2016 & $19532 R$ & 9 & $\mathrm{QCP}$ & 0.09 & & 0.00 & & 94.7 & 93.1 & 0.86 & 0.00 \\
\hline 890 & 2017 & $19532 R$ & 9 & $\mathrm{QCP}$ & & & 0.64 & & 94.4 & & 0.83 & \\
\hline 891 & 2015 & $19532 R$ & 9 & QCP & 0.00 & 0.09 & 0.88 & 0.38 & 94.6 & 92.7 & 0.71 & 1.16 \\
\hline 892 & 2015 & $19532 R$ & 9 & PFP & & & & 0.48 & & 92.3 & & 0.80 \\
\hline 893 & 2016 & 19532R & 9 & PFP & 0.04 & 0.61 & 0.66 & 0.20 & 94.3 & 93.9 & 0.98 & 0.89 \\
\hline 894 & 2016 & 19606FR & 9 & QCP & & & & 0.28 & & 90.9 & & 0.78 \\
\hline 895 & 2016 & 19606FR & 9 & QCP & & & & 0.55 & & 91.3 & & 0.78 \\
\hline 896 & 2016 & 19606FR & 9 & QCP & & & & 0.41 & & 90.8 & & 1.14 \\
\hline 898 & 2016 & 19534R & 9 & QCP & 0.80 & 0.65 & & 0.37 & 93.6 & 93.5 & 0.71 & 0.54 \\
\hline 899 & 2017 & 19534R & 9 & QCP & & & & & & 93.8 & & 0.00 \\
\hline 900 & 2016 & 19534R & 9 & QCP & & & & 0.45 & & 93.3 & & 0.84 \\
\hline 901 & 2016 & 19534R & 9 & QCP & & & & 0.87 & & 92.6 & & 0.75 \\
\hline 902 & 2016 & $19534 R$ & 9 & $\mathrm{QCP}$ & & & & & 93.2 & & 0.00 & \\
\hline 903 & 2017 & 19534R & 9 & QCP & & & & 0.46 & & 94.2 & & 0.72 \\
\hline 904 & 2015 & 19534R & 9 & QCP & & & & 0.80 & & 92.2 & & 0.65 \\
\hline 905 & 2015 & 19534R & 9 & QCP & & & & 0.35 & & 93.0 & & 1.05 \\
\hline 906 & 2015 & 19606FR & 9 & QCP & & & & 0.08 & & 90.9 & & 1.98 \\
\hline
\end{tabular}




\begin{tabular}{|c|c|c|c|c|c|c|c|c|c|c|c|c|}
\hline $\begin{array}{c}\mathrm{ICT} \\
\text { Code }\end{array}$ & Year & Mix Code & District & $\begin{array}{l}\text { Quality } \\
\text { Program }\end{array}$ & $\begin{array}{c}\text { MW } \\
\text { P-Value }\end{array}$ & $\begin{array}{l}\text { Levene's } \\
\text { P-Value }\end{array}$ & $\begin{array}{l}\text { Contractor } \\
\text { SW P-Value }\end{array}$ & $\begin{array}{c}\text { Agency SW } \\
\text { P-Value }\end{array}$ & $\begin{array}{c}\text { Contractor } \\
\text { Mean }\end{array}$ & $\begin{array}{c}\text { Agency } \\
\text { Mean }\end{array}$ & $\begin{array}{c}\text { Contractor } \\
\text { St. Dev. }\end{array}$ & $\begin{array}{l}\text { Agency } \\
\text { St. Dev. }\end{array}$ \\
\hline 907 & 2015 & 19606FR & 9 & $\mathrm{QCP}$ & & & & & & 91.4 & & 0.96 \\
\hline 908 & 2016 & $19522 \mathrm{R}$ & 9 & QCP & 0.00 & 0.00 & 0.00 & 0.02 & 94.2 & 93.1 & 1.07 & 0.12 \\
\hline 909 & 2017 & 19523R & 9 & QCP & & & & 0.54 & & 94.2 & & 1.21 \\
\hline 910 & 2016 & 19523R & 9 & QCP & & & 0.48 & & 94.2 & & 1.44 & \\
\hline 911 & 2016 & 19523R & 9 & QCP & & & & & 93.8 & & 0.00 & \\
\hline 912 & 2015 & 19534R & 9 & QCP & & & & 0.18 & & 90.5 & & 1.92 \\
\hline 913 & 2015 & 19533R & 9 & QCP & & & & 0.06 & & 92.5 & & 0.65 \\
\hline 914 & 2015 & 19533R & 9 & QCP & 0.01 & 0.96 & 0.90 & 0.37 & 92.5 & 91.1 & 0.55 & 0.66 \\
\hline 915 & 2015 & 19533R & 9 & QCP & & & & 0.69 & & 92.9 & & 0.89 \\
\hline 916 & 2015 & 19533R & 9 & QCP & & & & 0.97 & & 92.2 & & 1.36 \\
\hline 917 & 2015 & 19533R & 9 & QCP & & & & 0.69 & & 91.7 & & 1.02 \\
\hline 918 & 2015 & 19533R & 9 & QCP & & & & 0.23 & & 91.6 & & 0.87 \\
\hline 919 & 2015 & 19534R & 9 & QCP & & & & 0.29 & & 89.5 & & 1.83 \\
\hline 921 & 2015 & 19606 & 9 & QCP & & & & 0.62 & & 89.7 & & 1.45 \\
\hline 922 & 2015 & 19606FR & 9 & QCP & & & & 0.17 & & 90.9 & & 0.89 \\
\hline 923 & 2016 & 19606FR & 9 & QCP & & & & 0.23 & & 91.9 & & 1.23 \\
\hline 924 & 2015 & 19606FR & 9 & QCP & & & & 0.56 & & 90.4 & & 1.18 \\
\hline 925 & 2016 & 19606FR & 9 & QCP & & & & 0.47 & & 91.5 & & 0.84 \\
\hline 926 & 2015 & 19534R & 9 & QCP & & & & 0.12 & & 92.4 & & 0.93 \\
\hline 927 & 2016 & 19534R & 9 & QCP & & & & 0.13 & & 94.3 & & 0.87 \\
\hline 928 & 2016 & 19533R & 9 & QCP & & & & 0.25 & & 94.0 & & 0.96 \\
\hline 929 & 2016 & 19523R & 9 & QCP & 0.96 & 0.46 & 0.00 & 0.23 & 92.7 & 92.2 & 1.38 & 1.85 \\
\hline 930 & 2016 & 19523R & 9 & QCP & & & & 0.69 & & 94.0 & & 0.90 \\
\hline 931 & 2017 & 19523R & 9 & QCP & & & & 0.11 & & 93.2 & & 0.53 \\
\hline 932 & 2017 & 19523R & 9 & QCP & & & & 0.58 & & 93.6 & & 0.72 \\
\hline 933 & 2016 & 19605FR & 9 & QCP & & & & 0.63 & & 92.3 & & 0.86 \\
\hline 934 & 2017 & 19605FR & 9 & QCP & & & & 0.67 & & 91.9 & & 1.01 \\
\hline 935 & 2016 & 19605FR & 9 & QCP & & & & 0.58 & & 92.8 & & 1.52 \\
\hline 936 & 2015 & $\begin{array}{c}\text { HMA } \\
\text { Binder }\end{array}$ & 9 & $\mathrm{QCP}$ & & & & 0.97 & & 93.5 & & 1.07 \\
\hline 937 & 2015 & $\begin{array}{c}\text { HMA } \\
\text { Binder }\end{array}$ & 9 & $\mathrm{QCP}$ & & & & 0.28 & & 92.2 & & 0.97 \\
\hline 938 & 2015 & $\begin{array}{c}\text { HMA } \\
\text { Binder }\end{array}$ & 9 & $\mathrm{QCP}$ & & & & 0.46 & & 94.1 & & 0.96 \\
\hline 939 & 2016 & 19535 & 9 & PFP & & & & 0.11 & & 95.4 & & 0.90 \\
\hline
\end{tabular}




\begin{tabular}{|c|c|c|c|c|c|c|c|c|c|c|c|c|}
\hline $\begin{array}{c}\text { ICT } \\
\text { Code }\end{array}$ & Year & Mix Code & District & $\begin{array}{l}\text { Quality } \\
\text { Program }\end{array}$ & $\begin{array}{c}\text { MW } \\
\text { P-Value }\end{array}$ & $\begin{array}{l}\text { Levene's } \\
\text { P-Value }\end{array}$ & $\begin{array}{l}\text { Contractor } \\
\text { SW P-Value }\end{array}$ & $\begin{array}{c}\text { Agency SW } \\
\text { P-Value }\end{array}$ & $\begin{array}{c}\text { Contractor } \\
\text { Mean }\end{array}$ & $\begin{array}{l}\text { Agency } \\
\text { Mean }\end{array}$ & $\begin{array}{l}\text { Contractor } \\
\text { St. Dev. }\end{array}$ & $\begin{array}{l}\text { Agency } \\
\text { St. Dev. }\end{array}$ \\
\hline 940 & 2016 & 19535 & 9 & PFP & & & 0.78 & & 91.8 & & 2.26 & \\
\hline 941 & 2016 & $19532 R$ & 9 & PFP & 0.48 & 0.45 & 0.32 & 0.20 & 94.4 & 94.2 & 1.39 & 1.54 \\
\hline 942 & 2016 & $19532 R$ & 9 & PFP & 0.88 & 0.81 & 0.87 & 0.03 & 94.5 & 94.5 & 1.62 & 1.58 \\
\hline 943 & 2017 & 19533R & 9 & QCP & & & 0.75 & & 94.5 & & 1.10 & \\
\hline 944 & 2016 & 19533R & 9 & QCP & & & & 0.60 & & 92.8 & & 1.40 \\
\hline 945 & 2017 & 19534R & 9 & PFP & & & & & 93.4 & & 0.00 & \\
\hline 946 & 2015 & 19533R & 9 & $\mathrm{QCP}$ & & & & 0.40 & & 92.4 & & 0.97 \\
\hline 947 & 2016 & $19534 R$ & 9 & QCP & & & & 0.88 & & 93.1 & & 0.51 \\
\hline 948 & 2016 & 19534R & 9 & QCP & & & & 0.45 & & 93.8 & & 1.05 \\
\hline 949 & 2015 & 19534R & 9 & QCP & & & & 0.62 & & 93.3 & & 0.77 \\
\hline 950 & 2016 & 19606FR & 9 & QCP & & & & & & 93.0 & & 0.66 \\
\hline 951 & 2016 & 19534R & 9 & QCP & & & & 0.35 & & 92.9 & & 1.50 \\
\hline 952 & 2015 & 19605FR & 9 & QCP & & & & 0.00 & & 91.6 & & 1.04 \\
\hline 954 & 2015 & 19605FR & 9 & QCP & & & & 0.17 & & 92.0 & & 0.57 \\
\hline 955 & 2016 & 19606FR & 9 & QCP & & & & 0.85 & & 91.2 & & 1.24 \\
\hline 957 & 2015 & $19523 R$ & 9 & QCP & & & & 0.45 & & 93.1 & & 0.74 \\
\hline 958 & 2015 & $19523 R$ & 9 & QCP & & & & 0.04 & & 93.6 & & 0.66 \\
\hline 959 & 2016 & $19523 R$ & 9 & QCP & & & 0.97 & & 94.6 & & 1.10 & \\
\hline 960 & 2015 & $19523 R$ & 9 & QCP & & & & 0.59 & & 94.6 & & 1.18 \\
\hline 961 & 2015 & 19523R & 9 & QCP & & & & 0.97 & & 94.0 & & 0.89 \\
\hline 962 & 2016 & $19532 R$ & 9 & QCP & & & & 0.42 & & 93.5 & & 1.15 \\
\hline 963 & 2016 & 19606FR & 9 & QCP & & & & 0.65 & & 91.7 & & 0.62 \\
\hline 964 & 2017 & 19605FR & 9 & QCP & & & & & & 93.7 & & 0.14 \\
\hline 965 & 2017 & $19532 R$ & 9 & QCP & 0.00 & 0.07 & 0.38 & 0.81 & 94.5 & 92.0 & 0.77 & 1.56 \\
\hline 966 & 2017 & $19524 \mathrm{R}$ & 9 & QCP & & & & 0.30 & & 94.9 & & 0.65 \\
\hline 967 & 2017 & 19534R & 9 & QCP & & & & 0.35 & & 92.9 & & 1.50 \\
\hline
\end{tabular}




\section{C.4 GMM ANALYSIS RESULTS}

Table C.4. $\mathbf{G}_{\mathrm{mm}}$ Analysis Results Summary

\begin{tabular}{|c|c|c|c|c|c|c|c|c|c|c|c|c|}
\hline $\begin{array}{c}\text { ICT } \\
\text { Code }\end{array}$ & Year & Mix Code & District & $\begin{array}{l}\text { Quality } \\
\text { Program }\end{array}$ & $\begin{array}{c}\text { MW } \\
\text { P-Value }\end{array}$ & $\begin{array}{l}\text { Levene's } \\
\text { P-Value }\end{array}$ & $\begin{array}{l}\text { Contractor } \\
\text { SW P-Value }\end{array}$ & $\begin{array}{c}\text { Agency SW } \\
\text { P-Value }\end{array}$ & $\begin{array}{c}\text { Contractor } \\
\text { Mean }\end{array}$ & $\begin{array}{l}\text { Agency } \\
\text { Mean }\end{array}$ & $\begin{array}{c}\text { Contractor } \\
\text { St. Dev. }\end{array}$ & $\begin{array}{l}\text { Agency } \\
\text { St. Dev. }\end{array}$ \\
\hline 1 & 2015 & $19524 \mathrm{R}$ & 1 & QCP & 1.00 & 0.22 & & & 2.526 & 2.520 & 0.002 & 0.012 \\
\hline 2 & 2017 & 19524R & 1 & QCP & 0.67 & & & & 2.516 & 2.511 & 0.001 & 0.000 \\
\hline 3 & 2017 & 19524R & 1 & QCP & 0.67 & & & & 2.519 & 2.524 & 0.003 & 0.000 \\
\hline 4 & 2016 & 19524R & 1 & QCP & 0.79 & 0.82 & 0.89 & 0.59 & 2.519 & 2.517 & 0.007 & 0.007 \\
\hline 5 & 2015 & 19514R & 1 & QCP & & & & & 2.503 & & 0.000 & \\
\hline 6 & 2015 & 19514R & 1 & QCP & 0.67 & & & & 2.505 & 2.502 & 0.003 & 0.000 \\
\hline 7 & 2015 & 19524R & 1 & QCP & 0.74 & 0.38 & 0.33 & 0.00 & 2.492 & 2.490 & 0.008 & 0.011 \\
\hline 8 & 2015 & 19524R & 1 & QCP & & & & & 2.493 & & 0.001 & \\
\hline 9 & 2015 & 19524R & 1 & PFP & 0.53 & 0.42 & 0.79 & 0.30 & 2.491 & 2.494 & 0.007 & 0.009 \\
\hline 10 & 2015 & $19512 R$ & 1 & QCP & 0.50 & & 1.00 & & 2.514 & 2.526 & 0.006 & 0.000 \\
\hline 11 & 2015 & $19512 R$ & 1 & QCP & 1.00 & & & & 2.530 & 2.528 & 0.004 & 0.000 \\
\hline 12 & 2015 & $19522 R$ & 1 & QCP & 0.07 & 0.34 & 0.08 & 0.03 & 2.519 & 2.526 & 0.009 & 0.006 \\
\hline 13 & 2017 & $19522 \mathrm{R}$ & 1 & QCP & 0.33 & 0.59 & & & 2.548 & 2.571 & 0.007 & 0.004 \\
\hline 14 & 2015 & 19510R & 1 & QCP & 0.50 & & 0.00 & & 2.440 & 2.452 & 0.002 & 0.000 \\
\hline 15 & 2015 & 19510R & 1 & QCP & & & & & 2.455 & & 0.011 & \\
\hline 16 & 2015 & 19510R & 1 & QCP & 0.17 & 0.03 & 0.86 & 0.40 & 2.447 & 2.452 & 0.006 & 0.002 \\
\hline 17 & 2015 & $19512 R$ & 1 & QCP & 0.67 & & & & 2.530 & 2.547 & 0.000 & 0.010 \\
\hline 18 & 2015 & 19510R & 1 & QCP & 1.00 & 0.46 & 0.18 & & 2.425 & 2.426 & 0.007 & 0.002 \\
\hline 19 & 2015 & 19536R & 1 & QCP & & & & 0.54 & & 2.493 & & 0.004 \\
\hline 20 & 2017 & 19525R & 1 & QCP & 0.80 & 0.53 & 0.97 & & 2.501 & 2.502 & 0.012 & 0.004 \\
\hline 21 & 2015 & $19524 R$ & 1 & $\mathrm{QCP}$ & 0.67 & & & & 2.499 & 2.503 & 0.001 & 0.000 \\
\hline 22 & 2015 & 19524R & 1 & QCP & 1.00 & & & & 2.501 & 2.500 & 0.002 & 0.000 \\
\hline 23 & 2015 & 19512R & 1 & QCP & 0.50 & & 0.54 & & 2.518 & 2.525 & 0.004 & 0.000 \\
\hline 24 & 2016 & 19532R & 1 & QCP & 0.33 & 0.88 & & & 2.509 & 2.519 & 0.004 & 0.004 \\
\hline 25 & 2017 & 19532R & 1 & QCP & 1.00 & & 0.84 & & 2.514 & 2.512 & 0.006 & 0.000 \\
\hline 26 & 2017 & 19510R & 1 & QCP & 1.00 & & & & 2.439 & 2.448 & 0.000 & 0.000 \\
\hline 27 & 2015 & 19510R & 1 & QCP & 0.72 & 0.56 & 0.12 & 0.17 & 2.434 & 2.437 & 0.009 & 0.006 \\
\hline 28 & 2017 & 19665R & 1 & QCP & & & & & 2.424 & & 0.001 & \\
\hline 29 & 2015 & 19665R & 1 & QCP & 0.06 & 0.26 & 0.27 & 1.00 & 2.424 & 2.428 & 0.001 & 0.002 \\
\hline 30 & 2017 & 19524R & 1 & QCP & 0.93 & 0.78 & 0.05 & 0.59 & 2.504 & 2.505 & 0.008 & 0.007 \\
\hline 31 & 2017 & 19525R & 1 & QCP & 1.00 & & & & 2.502 & 2.499 & 0.006 & 0.000 \\
\hline
\end{tabular}




\begin{tabular}{|c|c|c|c|c|c|c|c|c|c|c|c|c|}
\hline $\begin{array}{l}\text { ICT } \\
\text { Code }\end{array}$ & Year & Mix Code & District & $\begin{array}{l}\text { Quality } \\
\text { Program }\end{array}$ & $\begin{array}{c}\text { MW } \\
\text { P-Value }\end{array}$ & $\begin{array}{l}\text { Levene's } \\
\text { P-Value }\end{array}$ & $\begin{array}{l}\text { Contractor } \\
\text { SW P-Value }\end{array}$ & $\begin{array}{c}\text { Agency SW } \\
\text { P-Value }\end{array}$ & $\begin{array}{c}\text { Contractor } \\
\text { Mean }\end{array}$ & $\begin{array}{l}\text { Agency } \\
\text { Mean }\end{array}$ & $\begin{array}{l}\text { Contractor } \\
\text { St. Dev. }\end{array}$ & $\begin{array}{l}\text { Agency } \\
\text { St. Dev. }\end{array}$ \\
\hline 32 & 2016 & 19510R & 1 & $\mathrm{QCP}$ & 0.50 & & 0.00 & & 2.413 & 2.422 & 0.001 & 0.000 \\
\hline 33 & 2015 & 19525R & 1 & QCP & & & 0.42 & & 2.505 & & 0.010 & \\
\hline 34 & 2016 & $19512 R$ & 1 & QCP & & & 0.57 & & 2.507 & & 0.006 & \\
\hline 35 & 2015 & $19512 R$ & 1 & QCP & 0.67 & & & & 2.505 & 2.490 & 0.002 & 0.000 \\
\hline 36 & 2015 & 19522R & 1 & QCP & 0.14 & & 0.35 & & 2.531 & 2.540 & 0.006 & 0.000 \\
\hline 37 & 2015 & 19522R & 1 & QCP & & & & & & 2.539 & & 0.000 \\
\hline 38 & 2015 & 19524R & 1 & QCP & 0.85 & 0.01 & 0.57 & 0.54 & 2.518 & 2.520 & 0.004 & 0.012 \\
\hline 39 & 2015 & 19510R & 1 & QCP & 1.00 & 0.54 & 0.08 & & 2.423 & 2.418 & 0.017 & 0.006 \\
\hline 40 & 2015 & 19510R & 1 & QCP & & & & & 2.425 & & 0.000 & \\
\hline 41 & 2015 & 19510R & 1 & QCP & 1.00 & 0.67 & & & 2.401 & 2.400 & 0.013 & 0.023 \\
\hline 42 & 2015 & 19524R & 1 & QCP & & & 0.60 & & 2.492 & & 0.008 & \\
\hline 43 & 2015 & 19524R & 1 & QCP & 0.00 & 0.03 & 0.78 & 0.97 & 2.480 & 2.494 & 0.006 & 0.002 \\
\hline 44 & 2015 & 19510R & 1 & PFP & 0.61 & 0.00 & 0.10 & 0.22 & 2.431 & 2.431 & 0.004 & 0.011 \\
\hline 45 & 2015 & 19510R & 1 & PFP & & & & & 2.426 & & 0.000 & \\
\hline 46 & 2015 & 19524R & 1 & QCP & 0.06 & 0.56 & 0.53 & 0.34 & 2.498 & 2.520 & 0.011 & 0.008 \\
\hline 47 & 2015 & $19655 R$ & 1 & PFP & 0.00 & 0.00 & 0.53 & 0.00 & 2.609 & 2.618 & 0.006 & 0.025 \\
\hline 48 & 2015 & 19536R & 1 & PFP & 0.23 & 0.20 & 0.10 & 0.15 & 2.704 & 2.716 & 0.020 & 0.029 \\
\hline 49 & 2017 & 19510R & 1 & QCP & 0.40 & & 0.40 & & 2.437 & 2.450 & 0.008 & 0.000 \\
\hline 50 & 2017 & 19510R & 1 & QCP & 0.22 & & 0.25 & & 2.437 & 2.456 & 0.010 & 0.000 \\
\hline 51 & 2016 & 19510R & 1 & QCP & 0.27 & 1.00 & & 0.98 & 2.435 & 2.447 & 0.009 & 0.012 \\
\hline 52 & 2017 & $19524 R$ & 1 & QCP & 0.67 & & & & 2.512 & 2.522 & 0.006 & 0.000 \\
\hline 53 & 2017 & $19525 R$ & 1 & QCP & 0.33 & & 0.48 & & 2.491 & 2.504 & 0.006 & 0.000 \\
\hline 54 & 2017 & $19525 R$ & 1 & PFP & 0.36 & 0.51 & 0.91 & 0.32 & 2.502 & 2.505 & 0.008 & 0.006 \\
\hline 55 & 2016 & $19525 R$ & 1 & QCP & 1.00 & 0.24 & 0.77 & 0.19 & 2.508 & 2.512 & 0.007 & 0.015 \\
\hline 56 & 2016 & 19536R & 1 & QCP & & & & & 2.500 & & 0.001 & \\
\hline 57 & 2015 & 19536R & 1 & PFP & 0.65 & 0.13 & 0.00 & 0.75 & 2.507 & 2.506 & 0.009 & 0.014 \\
\hline 58 & 2015 & $19524 R$ & 1 & QCP & 0.49 & 0.12 & 0.00 & 0.24 & 2.515 & 2.516 & 0.004 & 0.009 \\
\hline 59 & 2017 & $19524 R$ & 1 & QCP & 1.00 & 0.35 & 0.25 & 0.00 & 2.507 & 2.506 & 0.004 & 0.002 \\
\hline 60 & 2015 & $19522 \mathrm{R}$ & 1 & QCP & 0.37 & 0.80 & 0.26 & 0.30 & 2.540 & 2.544 & 0.006 & 0.007 \\
\hline 61 & 2015 & $19522 \mathrm{R}$ & 1 & QCP & 0.30 & 0.18 & 0.46 & 0.74 & 2.546 & 2.550 & 0.008 & 0.014 \\
\hline 62 & 2015 & 19510R & 1 & QCP & 1.00 & & & & 2.421 & 2.425 & 0.006 & 0.000 \\
\hline 63 & 2015 & 19510R & 1 & PFP & 0.98 & 0.85 & 0.01 & 0.41 & 2.449 & 2.448 & 0.009 & 0.009 \\
\hline 64 & 2017 & $19524 R$ & 1 & QCP & 1.00 & & & & 2.502 & 2.506 & 0.000 & 0.000 \\
\hline 65 & 2017 & $19524 \mathrm{R}$ & 1 & PFP & 0.74 & 0.36 & 0.17 & 0.83 & 2.509 & 2.512 & 0.006 & 0.004 \\
\hline 66 & 2017 & 19524R & 1 & QCP & 1.00 & & & & 2.505 & 2.503 & 0.012 & 0.000 \\
\hline
\end{tabular}




\begin{tabular}{|c|c|c|c|c|c|c|c|c|c|c|c|c|}
\hline $\begin{array}{l}\text { ICT } \\
\text { Code }\end{array}$ & Year & Mix Code & District & $\begin{array}{l}\text { Quality } \\
\text { Program }\end{array}$ & $\begin{array}{c}\text { MW } \\
\text { P-Value }\end{array}$ & $\begin{array}{l}\text { Levene's } \\
\text { P-Value }\end{array}$ & $\begin{array}{l}\text { Contractor } \\
\text { SW P-Value }\end{array}$ & $\begin{array}{c}\text { Agency SW } \\
\text { P-Value }\end{array}$ & $\begin{array}{c}\text { Contractor } \\
\text { Mean }\end{array}$ & $\begin{array}{l}\text { Agency } \\
\text { Mean }\end{array}$ & $\begin{array}{l}\text { Contractor } \\
\text { St. Dev. }\end{array}$ & $\begin{array}{l}\text { Agency } \\
\text { St. Dev. }\end{array}$ \\
\hline 67 & 2017 & 19510R & 1 & $\mathrm{QCP}$ & 0.10 & 1.00 & 0.00 & 0.00 & 2.419 & 2.414 & 0.001 & 0.001 \\
\hline 68 & 2015 & $19532 R$ & 1 & QCP & 0.28 & 0.33 & 0.70 & 0.39 & 2.537 & 2.532 & 0.005 & 0.007 \\
\hline 69 & 2017 & 19510R & 1 & QCP & 1.00 & 0.41 & 0.36 & 0.24 & 2.449 & 2.452 & 0.008 & 0.016 \\
\hline 70 & 2016 & 19510R & 1 & QCP & 0.67 & & & & 2.443 & 2.448 & 0.004 & 0.000 \\
\hline 71 & 2017 & $19524 R$ & 1 & PFP & & & & & 2.519 & & 0.000 & \\
\hline 72 & 2017 & 19510R & 1 & QCP & 0.20 & 0.70 & & 1.00 & 2.442 & 2.458 & 0.004 & 0.008 \\
\hline 73 & 2017 & 19510R & 1 & QCP & 0.10 & 0.05 & 0.00 & 0.54 & 2.447 & 2.454 & 0.001 & 0.004 \\
\hline 74 & 2016 & 19525R & 1 & QCP & 0.29 & 0.51 & 0.20 & & 2.492 & 2.504 & 0.012 & 0.004 \\
\hline 75 & 2017 & 19665R & 1 & QCP & 0.67 & 0.69 & & & 2.452 & 2.458 & 0.008 & 0.014 \\
\hline 76 & 2017 & 19655R & 1 & QCP & 0.33 & 0.00 & & & 2.450 & 2.457 & 0.004 & 0.000 \\
\hline 77 & 2017 & 19665R & 1 & QCP & 0.20 & 0.69 & 0.00 & & 2.453 & 2.458 & 0.001 & 0.001 \\
\hline 78 & 2015 & $19512 \mathrm{R}$ & 1 & QCP & 0.30 & 0.39 & 0.41 & 0.02 & 2.516 & 2.522 & 0.013 & 0.008 \\
\hline 79 & 2015 & $19522 \mathrm{R}$ & 1 & PFP & 0.71 & 0.32 & & 0.06 & 2.527 & 2.531 & 0.001 & 0.007 \\
\hline 80 & 2017 & $19522 R$ & 1 & QCP & 0.36 & 0.89 & 0.17 & & 2.526 & 2.529 & 0.006 & 0.004 \\
\hline 81 & 2015 & $19522 \mathrm{R}$ & 1 & QCP & & & & & & 2.531 & & 0.000 \\
\hline 82 & 2015 & 19514R & 1 & QCP & 0.10 & 0.92 & 0.10 & 0.36 & 2.504 & 2.513 & 0.010 & 0.009 \\
\hline 83 & 2015 & $19524 R$ & 1 & QCP & 0.50 & 0.51 & 0.18 & 0.58 & 2.501 & 2.499 & 0.003 & 0.004 \\
\hline 84 & 2015 & $19512 \mathrm{R}$ & 1 & QCP & 0.10 & 0.71 & 0.72 & 0.50 & 2.526 & 2.532 & 0.007 & 0.007 \\
\hline 85 & 2015 & $19512 \mathrm{R}$ & 1 & QCP & 1.00 & & 0.00 & & 2.525 & 2.524 & 0.008 & 0.000 \\
\hline 86 & 2015 & 19525R & 1 & PFP & & & 0.37 & & 2.552 & & 0.007 & \\
\hline 87 & 2015 & 19510R & 1 & QCP & 0.40 & & 0.97 & & 2.453 & 2.460 & 0.003 & 0.000 \\
\hline 88 & 2017 & 19510R & 1 & QCP & 0.43 & 0.90 & 0.39 & 0.37 & 2.447 & 2.451 & 0.009 & 0.010 \\
\hline 89 & 2017 & $19532 \mathrm{R}$ & 1 & QCP & 1.00 & & & & 2.538 & 2.534 & 0.006 & 0.000 \\
\hline 90 & 2016 & $19524 R$ & 1 & QCP & 0.50 & & 0.12 & & 2.501 & 2.508 & 0.008 & 0.000 \\
\hline 91 & 2016 & 19524R & 1 & QCP & & & & & & 2.504 & & 0.010 \\
\hline 92 & 2017 & 19536R & 1 & QCP & 1.00 & & & & 2.553 & 2.555 & 0.000 & 0.000 \\
\hline 93 & 2015 & 19536R & 1 & QCP & 0.52 & 0.48 & 0.12 & 0.30 & 2.740 & 2.744 & 0.012 & 0.006 \\
\hline 94 & 2015 & 19524R & 1 & QCP & 0.46 & 0.09 & 0.64 & 0.41 & 2.520 & 2.515 & 0.002 & 0.007 \\
\hline 95 & 2015 & $19512 \mathrm{R}$ & 1 & $\mathrm{QCP}$ & 0.21 & 0.45 & 0.93 & & 2.543 & 2.549 & 0.004 & 0.006 \\
\hline 96 & 2015 & $19512 \mathrm{R}$ & 1 & QCP & 0.36 & 0.84 & 0.23 & 0.93 & 2.533 & 2.537 & 0.007 & 0.006 \\
\hline 97 & 2015 & $19514 \mathrm{R}$ & 1 & QCP & 0.51 & 0.71 & 0.31 & 0.08 & 2.513 & 2.516 & 0.007 & 0.008 \\
\hline 98 & 2017 & 19522R & 1 & QCP & 1.00 & & & & 2.553 & 2.544 & 0.000 & 0.000 \\
\hline 99 & 2017 & $19522 \mathrm{R}$ & 1 & $\mathrm{QCP}$ & 0.57 & & 0.55 & & 2.543 & 2.536 & 0.006 & 0.000 \\
\hline 100 & 2016 & $19522 \mathrm{R}$ & 1 & QCP & 0.20 & 0.22 & 0.72 & 0.13 & 2.541 & 2.538 & 0.006 & 0.009 \\
\hline 101 & 2015 & 19510R & 1 & $\mathrm{QCP}$ & 0.67 & & & & 2.442 & 2.432 & 0.003 & 0.000 \\
\hline
\end{tabular}




\begin{tabular}{|c|c|c|c|c|c|c|c|c|c|c|c|c|}
\hline $\begin{array}{c}\text { ICT } \\
\text { Code }\end{array}$ & Year & Mix Code & District & $\begin{array}{l}\text { Quality } \\
\text { Program }\end{array}$ & $\begin{array}{c}\text { MW } \\
\text { P-Value }\end{array}$ & $\begin{array}{l}\text { Levene's } \\
\text { P-Value }\end{array}$ & $\begin{array}{l}\text { Contractor } \\
\text { SW P-Value }\end{array}$ & $\begin{array}{c}\text { Agency SW } \\
\text { P-Value }\end{array}$ & $\begin{array}{c}\text { Contractor } \\
\text { Mean }\end{array}$ & $\begin{array}{l}\text { Agency } \\
\text { Mean }\end{array}$ & $\begin{array}{c}\text { Contractor } \\
\text { St. Dev. }\end{array}$ & $\begin{array}{l}\text { Agency } \\
\text { St. Dev. }\end{array}$ \\
\hline 102 & 2015 & 19510R & 1 & $\mathrm{QCP}$ & & & 1.00 & & 2.445 & & 0.010 & \\
\hline 103 & 2015 & 19510R & 1 & QCP & 0.67 & 0.29 & & & 2.437 & 2.422 & 0.018 & 0.004 \\
\hline 104 & 2015 & 19510R & 1 & QCP & 0.67 & & & & 2.450 & 2.431 & 0.008 & 0.000 \\
\hline 105 & 2017 & 19510R & 1 & QCP & 0.05 & 0.66 & 0.42 & 0.01 & 2.429 & 2.419 & 0.005 & 0.004 \\
\hline 108 & 2017 & 19532R & 1 & QCP & 0.20 & 0.55 & 0.84 & & 2.529 & 2.517 & 0.004 & 0.001 \\
\hline 107 & 2017 & 19532R & 1 & QCP & 0.31 & 0.14 & 0.36 & 0.11 & 2.533 & 2.528 & 0.005 & 0.009 \\
\hline 108 & 2017 & $19532 R$ & 1 & QCP & 0.73 & 0.85 & 0.34 & 0.82 & 2.535 & 2.532 & 0.010 & 0.008 \\
\hline 109 & 2015 & 19536R & 1 & QCP & 0.50 & & 0.54 & & 2.741 & 2.703 & 0.030 & 0.000 \\
\hline 110 & 2015 & 19536R & 1 & QCP & 1.00 & & 0.13 & & 2.742 & 2.750 & 0.007 & 0.000 \\
\hline 111 & 2015 & 19524R & 1 & QCP & 0.50 & & & & 2.501 & 2.514 & 0.000 & 0.000 \\
\hline 112 & 2015 & 19524R & 1 & QCP & 0.67 & & & & 2.504 & 2.513 & 0.005 & 0.000 \\
\hline 113 & 2015 & 19524R & 1 & QCP & 0.34 & 0.30 & 0.46 & 0.25 & 2.510 & 2.515 & 0.008 & 0.004 \\
\hline 114 & 2017 & 19510R & 1 & QCP & 0.33 & 1.00 & & & 2.438 & 2.445 & 0.003 & 0.003 \\
\hline 115 & 2017 & 19510R & 1 & QCP & & & 0.00 & & 2.454 & & 0.002 & \\
\hline 116 & 2016 & 19510R & 1 & QCP & & & & & & 2.435 & & 0.004 \\
\hline 117 & 2017 & 19510R & 1 & QCP & 0.06 & 0.34 & 0.84 & 0.27 & 2.441 & 2.451 & 0.004 & 0.002 \\
\hline 118 & 2016 & 19510R & 1 & QCP & 0.04 & 0.54 & 0.78 & 0.00 & 2.423 & 2.433 & 0.003 & 0.004 \\
\hline 119 & 2017 & 19510R & 1 & QCP & 0.60 & 0.70 & 0.22 & & 2.436 & 2.440 & 0.009 & 0.011 \\
\hline 120 & 2017 & 19510R & 1 & QCP & 0.33 & 0.00 & & & 2.442 & 2.447 & 0.000 & 0.004 \\
\hline 121 & 2017 & 19510R & 1 & QCP & 0.67 & 0.75 & & & 2.442 & 2.447 & 0.004 & 0.003 \\
\hline 122 & 2015 & $19522 \mathrm{R}$ & 1 & QCP & 0.67 & & & & 2.526 & 2.538 & 0.008 & 0.000 \\
\hline 123 & 2015 & $19522 \mathrm{R}$ & 1 & QCP & 0.50 & & 0.25 & & 2.523 & 2.533 & 0.004 & 0.000 \\
\hline 124 & 2017 & $19524 R$ & 1 & QCP & 1.00 & & & & 2.487 & 2.474 & 0.000 & 0.000 \\
\hline 125 & 2017 & $19524 R$ & 1 & QCP & 0.80 & 0.76 & 0.88 & 0.84 & 2.501 & 2.502 & 0.005 & 0.004 \\
\hline 126 & 2017 & $19524 \mathrm{R}$ & 1 & PFP & & & 0.45 & & 2.493 & & 0.006 & \\
\hline 127 & 2016 & $19524 R$ & 1 & QCP & 0.67 & & & & 2.499 & 2.523 & 0.008 & 0.000 \\
\hline 128 & 2017 & $19524 R$ & 1 & QCP & 0.67 & & 0.55 & & 2.497 & 2.500 & 0.004 & 0.000 \\
\hline 129 & 2017 & $19524 R$ & 1 & QCP & 0.80 & 0.43 & 0.06 & & 2.493 & 2.494 & 0.003 & 0.004 \\
\hline 130 & 2017 & $19524 R$ & 1 & QCP & 1.00 & 0.35 & & & 2.501 & 2.502 & 0.015 & 0.004 \\
\hline 131 & 2015 & 19510R & 1 & QCP & 1.00 & & & & 2.437 & 2.449 & 0.000 & 0.000 \\
\hline 132 & 2015 & 19510R & 1 & QCP & 0.30 & 0.01 & 0.40 & 0.01 & 2.422 & 2.435 & 0.011 & 0.028 \\
\hline 133 & 2015 & 19536R & 1 & PFP & 0.53 & 0.27 & 0.17 & 0.14 & 2.702 & 2.705 & 0.011 & 0.016 \\
\hline 134 & 2015 & $19522 R$ & 1 & PFP & & & & & 2.532 & & 0.001 & \\
\hline 135 & 2015 & $19522 \mathrm{R}$ & 1 & QCP & 1.00 & 0.72 & 0.36 & & 2.526 & 2.527 & 0.008 & 0.004 \\
\hline 136 & 2015 & 19536R & 1 & QCP & 1.00 & & & & 2.738 & 2.730 & 0.000 & 0.000 \\
\hline
\end{tabular}




\begin{tabular}{|c|c|c|c|c|c|c|c|c|c|c|c|c|}
\hline $\begin{array}{c}\text { ICT } \\
\text { Code }\end{array}$ & Year & Mix Code & District & $\begin{array}{l}\text { Quality } \\
\text { Program }\end{array}$ & $\begin{array}{c}\text { MW } \\
\text { P-Value }\end{array}$ & $\begin{array}{c}\text { Levene's } \\
\text { P-Value }\end{array}$ & $\begin{array}{l}\text { Contractor } \\
\text { SW P-Value }\end{array}$ & $\begin{array}{c}\text { Agency SW } \\
\text { P-Value }\end{array}$ & $\begin{array}{c}\text { Contractor } \\
\text { Mean }\end{array}$ & $\begin{array}{l}\text { Agency } \\
\text { Mean }\end{array}$ & $\begin{array}{c}\text { Contractor } \\
\text { St. Dev. }\end{array}$ & $\begin{array}{l}\text { Agency } \\
\text { St. Dev. }\end{array}$ \\
\hline 137 & 2015 & 19524R & 1 & $\mathrm{QCP}$ & 0.17 & 0.37 & 0.10 & 0.09 & 2.512 & 2.506 & 0.003 & 0.006 \\
\hline 138 & 2015 & 19510R & 1 & QCP & 1.00 & 0.56 & & & 2.409 & 2.416 & 0.011 & 0.024 \\
\hline 139 & 2015 & 19510R & 1 & QCP & 1.00 & & & & 2.409 & 2.417 & 0.000 & 0.000 \\
\hline 140 & 2015 & 19524R & 1 & QCP & 0.89 & 0.75 & 0.32 & 0.59 & 2.503 & 2.503 & 0.006 & 0.006 \\
\hline 141 & 2015 & 19665R & 1 & QCP & 0.64 & 0.01 & 0.03 & 0.21 & 2.796 & 2.797 & 0.024 & 0.010 \\
\hline 142 & 2015 & 19524R & 1 & QCP & 0.40 & 0.83 & & 0.13 & 2.585 & 2.574 & 0.023 & 0.023 \\
\hline 143 & 2015 & 19524R & 1 & QCP & 0.50 & 0.48 & 0.69 & 0.69 & 2.611 & 2.605 & 0.012 & 0.009 \\
\hline 144 & 2017 & 19510R & 1 & QCP & 0.43 & 0.13 & 0.55 & & 2.418 & 2.412 & 0.004 & 0.009 \\
\hline 145 & 2017 & 19510R & 1 & QCP & 1.00 & & & & 2.412 & 2.412 & 0.001 & 0.000 \\
\hline 146 & 2017 & 19510R & 1 & QCP & 0.20 & 0.00 & 0.54 & & 2.426 & 2.413 & 0.004 & 0.000 \\
\hline 147 & 2015 & 19510R & 1 & QCP & 0.67 & & & & 2.437 & 2.433 & 0.000 & 0.000 \\
\hline 148 & 2017 & $19522 \mathrm{R}$ & 1 & QCP & 0.80 & & 0.18 & & 2.523 & 2.535 & 0.009 & 0.000 \\
\hline 149 & 2015 & $19522 \mathrm{R}$ & 1 & QCP & 0.97 & 0.56 & 0.82 & 0.80 & 2.523 & 2.523 & 0.009 & 0.006 \\
\hline 150 & 2015 & 19536R & 1 & QCP & 0.18 & 0.80 & 0.44 & 0.12 & 2.741 & 2.749 & 0.010 & 0.008 \\
\hline 151 & 2017 & 19524R & 1 & $\mathrm{QCP}$ & 0.33 & 0.90 & & & 2.495 & 2.514 & 0.004 & 0.005 \\
\hline 152 & 2017 & 19524R & 1 & QCP & & & & 0.02 & & 2.510 & & 0.012 \\
\hline 153 & 2017 & 19524R & 1 & QCP & 0.67 & 0.86 & & & 2.524 & 2.516 & 0.011 & 0.008 \\
\hline 154 & 2015 & 19525R & 1 & $\mathrm{QCP}$ & 0.50 & & 0.92 & & 2.538 & 2.548 & 0.007 & 0.000 \\
\hline 155 & 2017 & 19525R & 1 & $\mathrm{QCP}$ & 1.00 & & & & 2.540 & 2.538 & 0.007 & 0.000 \\
\hline 156 & 2015 & 19525R & 1 & $\mathrm{QCP}$ & 0.38 & 0.12 & 0.46 & & 2.552 & 2.559 & 0.009 & 0.001 \\
\hline 157 & 2015 & 19524R & 1 & $\mathrm{QCP}$ & 1.00 & 0.24 & 0.25 & 0.28 & 2.512 & 2.515 & 0.004 & 0.010 \\
\hline 158 & 2017 & 18436R & 1 & $\mathrm{QCP}$ & 0.67 & 0.21 & & & 2.586 & 2.576 & 0.013 & 0.002 \\
\hline 159 & 2016 & 19655R & 1 & $\mathrm{QCP}$ & 0.38 & 0.78 & 0.55 & & 2.583 & 2.570 & 0.009 & 0.009 \\
\hline 160 & 2017 & $19655 R$ & 1 & $\mathrm{QCP}$ & 0.40 & & 0.74 & & 2.564 & 2.582 & 0.008 & 0.000 \\
\hline 161 & 2015 & 19525R & 1 & $\mathrm{QCP}$ & 0.46 & 0.87 & 0.16 & 0.41 & 2.613 & 2.607 & 0.012 & 0.009 \\
\hline 162 & 2017 & 19653R & 1 & QCP & 0.19 & 0.47 & 0.12 & 0.17 & 2.471 & 2.484 & 0.012 & 0.017 \\
\hline 163 & 2016 & $19665 R$ & 1 & PFP & 0.17 & 0.87 & 0.95 & & 2.809 & 2.823 & 0.012 & 0.007 \\
\hline 164 & 2017 & 19665R & 1 & QCP & 0.80 & & 0.65 & & 2.811 & 2.817 & 0.015 & 0.000 \\
\hline 165 & 2015 & $19512 \mathrm{R}$ & 1 & $\mathrm{QCP}$ & 0.51 & 0.56 & 0.55 & 0.18 & 2.539 & 2.534 & 0.009 & 0.012 \\
\hline 166 & 2015 & $19512 \mathrm{R}$ & 1 & $\mathrm{QCP}$ & 0.67 & 0.36 & & 0.26 & 2.538 & 2.537 & 0.008 & 0.005 \\
\hline 167 & 2017 & $19525 R$ & 1 & $\mathrm{QCP}$ & 0.40 & 0.95 & 0.36 & 0.78 & 2.667 & 2.663 & 0.005 & 0.005 \\
\hline 168 & 2017 & 19525R & 1 & QCP & 0.80 & 0.24 & & 0.34 & 2.660 & 2.671 & 0.029 & 0.011 \\
\hline 169 & 2017 & $19525 \mathrm{R}$ & 1 & QCP & 0.50 & & 0.00 & & 2.648 & 2.661 & 0.006 & 0.000 \\
\hline 170 & 2017 & 19525R & 1 & PFP & 0.03 & 0.08 & 0.68 & 0.77 & 2.657 & 2.646 & 0.009 & 0.004 \\
\hline 171 & 2017 & 19655R & 1 & PFP & 0.88 & 0.11 & 0.16 & 0.36 & 2.952 & 2.952 & 0.015 & 0.035 \\
\hline
\end{tabular}




\begin{tabular}{|c|c|c|c|c|c|c|c|c|c|c|c|c|}
\hline $\begin{array}{c}\text { ICT } \\
\text { Code }\end{array}$ & Year & Mix Code & District & $\begin{array}{l}\text { Quality } \\
\text { Program }\end{array}$ & $\begin{array}{c}\text { MW } \\
\text { P-Value }\end{array}$ & $\begin{array}{l}\text { Levene's } \\
\text { P-Value }\end{array}$ & $\begin{array}{l}\text { Contractor } \\
\text { SW P-Value }\end{array}$ & $\begin{array}{c}\text { Agency SW } \\
\text { P-Value }\end{array}$ & $\begin{array}{c}\text { Contractor } \\
\text { Mean }\end{array}$ & $\begin{array}{l}\text { Agency } \\
\text { Mean }\end{array}$ & $\begin{array}{c}\text { Contractor } \\
\text { St. Dev. }\end{array}$ & $\begin{array}{l}\text { Agency } \\
\text { St. Dev. }\end{array}$ \\
\hline 172 & 2015 & $19512 R$ & 1 & $\mathrm{QCP}$ & & & & & 2.521 & & 0.000 & \\
\hline 173 & 2015 & 19522R & 1 & QCP & & & & & 2.532 & & 0.000 & \\
\hline 174 & 2015 & 19522R & 1 & QCP & & & 0.07 & & 2.539 & & 0.009 & \\
\hline 175 & 2015 & 19536R & 1 & QCP & 0.53 & 0.41 & & 0.39 & 2.694 & 2.662 & 0.010 & 0.035 \\
\hline 176 & 2015 & 19510R & 1 & QCP & 0.20 & 0.00 & 0.00 & & 2.432 & 2.446 & 0.012 & 0.000 \\
\hline 177 & 2015 & 19510R & 1 & QCP & & & & & & 2.440 & & 0.000 \\
\hline 178 & 2015 & 19510R & 1 & QCP & 0.12 & 0.08 & 0.36 & 0.71 & 2.429 & 2.438 & 0.006 & 0.012 \\
\hline 179 & 2015 & 19522R & 1 & QCP & & & 0.65 & & 2.523 & & 0.005 & \\
\hline 180 & 2015 & 19522R & 1 & QCP & & & 0.09 & & 2.527 & & 0.007 & \\
\hline 181 & 2015 & 19522R & 1 & QCP & & & 0.35 & & 2.531 & & 0.006 & \\
\hline 182 & 2015 & $19522 R$ & 1 & QCP & 0.86 & & 0.49 & & 2.529 & 2.532 & 0.007 & 0.000 \\
\hline 183 & 2015 & 19524R & 1 & PFP & 0.15 & 0.31 & 0.79 & 0.54 & 2.507 & 2.502 & 0.006 & 0.003 \\
\hline 184 & 2015 & 19510R & 1 & QCP & & & 0.29 & & 2.426 & & 0.006 & \\
\hline 185 & 2015 & 19510R & 1 & QCP & 0.63 & 0.32 & 0.71 & 0.27 & 2.426 & 2.425 & 0.002 & 0.001 \\
\hline 186 & 2017 & 19510R & 1 & QCP & 1.00 & & 1.00 & & 2.430 & 2.434 & 0.005 & 0.000 \\
\hline 187 & 2015 & $19522 \mathrm{R}$ & 1 & QCP & 1.00 & & 0.44 & & 2.525 & 2.526 & 0.007 & 0.000 \\
\hline 188 & 2015 & 19524R & 1 & QCP & 1.00 & & 0.47 & & 2.482 & 2.483 & 0.010 & 0.000 \\
\hline 189 & 2015 & 19524R & 1 & QCP & 0.80 & 0.34 & 0.95 & & 2.480 & 2.481 & 0.009 & 0.017 \\
\hline 190 & 2015 & 19510R & 1 & QCP & 0.14 & 0.54 & 0.82 & & 2.404 & 2.416 & 0.005 & 0.006 \\
\hline 191 & 2015 & 19510R & 1 & QCP & 0.67 & & & & 2.409 & 2.425 & 0.006 & 0.000 \\
\hline 192 & 2015 & 19510R & 1 & PFP & 0.01 & 0.47 & 0.33 & 0.12 & 2.408 & 2.417 & 0.007 & 0.009 \\
\hline 193 & 2015 & 19510R & 1 & QCP & 0.33 & 0.28 & & & 2.407 & 2.427 & 0.003 & 0.013 \\
\hline 194 & 2015 & 19510R & 1 & QCP & 0.03 & 0.76 & 0.98 & & 2.404 & 2.416 & 0.003 & 0.003 \\
\hline 195 & 2015 & 19510R & 1 & QCP & & & 0.86 & & 2.407 & & 0.005 & \\
\hline 196 & 2017 & 19510R & 1 & QCP & 1.00 & & & & 2.411 & 2.424 & 0.000 & 0.000 \\
\hline 197 & 2017 & 19510R & 1 & QCP & 0.67 & & & & 2.409 & 2.420 & 0.010 & 0.000 \\
\hline 198 & 2017 & 19510R & 1 & QCP & 1.00 & & & & 2.415 & 2.417 & 0.003 & 0.000 \\
\hline 199 & 2017 & 19510R & 1 & QCP & 0.50 & & & 0.84 & 2.411 & 2.422 & 0.000 & 0.007 \\
\hline 200 & 2017 & 19510R & 1 & QCP & 0.67 & & & & 2.407 & 2.414 & 0.002 & 0.000 \\
\hline 201 & 2017 & 19510R & 1 & QCP & 0.33 & & 0.34 & & 2.407 & 2.418 & 0.006 & 0.000 \\
\hline 202 & 2017 & 19510R & 1 & QCP & 0.40 & & 0.42 & & 2.410 & 2.417 & 0.005 & 0.000 \\
\hline 203 & 2017 & 19510R & 1 & QCP & 0.67 & & & & 2.410 & 2.422 & 0.002 & 0.000 \\
\hline 204 & 2015 & 19665R & 1 & PFP & & & 0.71 & & 2.432 & & 0.001 & \\
\hline 205 & 2015 & 19665R & 1 & PFP & 0.02 & 0.03 & 0.05 & 0.18 & 2.434 & 2.445 & 0.006 & 0.011 \\
\hline 206 & 2015 & 19665R & 1 & PFP & 0.35 & 0.52 & 0.13 & 0.86 & 2.434 & 2.436 & 0.006 & 0.007 \\
\hline
\end{tabular}




\begin{tabular}{|c|c|c|c|c|c|c|c|c|c|c|c|c|}
\hline $\begin{array}{l}\text { ICT } \\
\text { Code }\end{array}$ & Year & Mix Code & District & $\begin{array}{l}\text { Quality } \\
\text { Program }\end{array}$ & $\begin{array}{c}\text { MW } \\
\text { P-Value }\end{array}$ & $\begin{array}{l}\text { Levene's } \\
\text { P-Value }\end{array}$ & $\begin{array}{l}\text { Contractor } \\
\text { SW P-Value }\end{array}$ & $\begin{array}{c}\text { Agency SW } \\
\text { P-Value }\end{array}$ & $\begin{array}{c}\text { Contractor } \\
\text { Mean }\end{array}$ & $\begin{array}{l}\text { Agency } \\
\text { Mean }\end{array}$ & $\begin{array}{l}\text { Contractor } \\
\text { St. Dev. }\end{array}$ & $\begin{array}{l}\text { Agency } \\
\text { St. Dev. }\end{array}$ \\
\hline 207 & 2015 & $19522 R$ & 1 & $\mathrm{QCP}$ & 1.00 & 0.87 & 0.26 & 0.28 & 2.546 & 2.547 & 0.008 & 0.009 \\
\hline 208 & 2015 & $19524 R$ & 1 & QCP & 0.36 & 0.67 & 0.72 & 0.54 & 2.504 & 2.507 & 0.007 & 0.005 \\
\hline 209 & 2015 & $19524 R$ & 1 & QCP & 0.58 & 0.00 & 0.05 & 0.00 & 2.490 & 2.541 & 0.010 & 0.154 \\
\hline 210 & 2015 & $19524 R$ & 1 & QCP & 1.00 & & 0.00 & & 2.491 & 2.488 & 0.003 & 0.000 \\
\hline 211 & 2015 & $19524 R$ & 1 & QCP & 0.34 & 0.13 & 0.83 & 0.35 & 2.486 & 2.483 & 0.003 & 0.006 \\
\hline 212 & 2015 & $19524 R$ & 1 & QCP & & & & & & 2.498 & & 0.000 \\
\hline 213 & 2017 & $19522 \mathrm{R}$ & 1 & QCP & & & 0.36 & & 2.512 & & 0.003 & \\
\hline 214 & 2015 & 19536R & 1 & PFP & 0.00 & 0.64 & 0.49 & 0.88 & 2.471 & 2.481 & 0.005 & 0.006 \\
\hline 215 & 2015 & 19510R & 1 & QCP & 1.00 & & & & 2.456 & 2.458 & 0.000 & 0.000 \\
\hline 216 & 2015 & 19510R & 1 & QCP & 0.30 & 0.89 & 0.14 & 0.39 & 2.427 & 2.429 & 0.005 & 0.005 \\
\hline 217 & 2015 & 19510R & 1 & QCP & 0.67 & & & & 2.425 & 2.411 & 0.004 & 0.000 \\
\hline 218 & 2015 & 19510R & 1 & QCP & 0.55 & 0.00 & 0.26 & 0.42 & 2.427 & 2.429 & 0.002 & 0.015 \\
\hline 219 & 2015 & 19510R & 1 & QCP & 0.67 & & & & 2.427 & 2.424 & 0.001 & 0.000 \\
\hline 220 & 2015 & 19510R & 1 & QCP & 1.00 & & & & 2.425 & 2.426 & 0.004 & 0.000 \\
\hline 221 & 2015 & $19522 \mathrm{R}$ & 1 & QCP & 1.00 & & & & 2.521 & 2.520 & 0.000 & 0.000 \\
\hline 222 & 2015 & $19522 \mathrm{R}$ & 1 & QCP & 0.18 & 0.72 & 0.16 & 0.94 & 2.536 & 2.531 & 0.007 & 0.006 \\
\hline 223 & 2015 & 19536R & 1 & QCP & 0.08 & 0.84 & 0.54 & 0.16 & 2.496 & 2.491 & 0.003 & 0.003 \\
\hline 224 & 2015 & 19536R & 1 & QCP & 1.00 & & 0.82 & & 2.490 & 2.490 & 0.004 & 0.000 \\
\hline 225 & 2015 & 19536R & 1 & QCP & 0.29 & 0.08 & 0.40 & 0.09 & 2.488 & 2.493 & 0.006 & 0.002 \\
\hline 226 & 2015 & 19536R & 1 & QCP & & & & & 2.500 & & 0.000 & \\
\hline 227 & 2016 & 19536R & 1 & QCP & & & & & 2.492 & & 0.000 & \\
\hline 228 & 2015 & $19524 \mathrm{R}$ & 1 & PFP & 0.24 & 0.04 & 0.03 & 0.18 & 2.502 & 2.504 & 0.004 & 0.008 \\
\hline 229 & 2016 & $19524 \mathrm{R}$ & 1 & QCP & & & & & 2.502 & & 0.013 & \\
\hline 230 & 2016 & $19524 R$ & 1 & QCP & & & & 0.58 & & 2.508 & & 0.002 \\
\hline 231 & 2015 & 19655R & 1 & $\mathrm{QCP}$ & 0.98 & 0.34 & 0.37 & 0.43 & 2.470 & 2.470 & 0.005 & 0.007 \\
\hline 232 & 2016 & $19522 \mathrm{R}$ & 1 & QCP & 0.13 & 0.13 & 0.06 & & 2.535 & 2.553 & 0.003 & 0.008 \\
\hline 233 & 2015 & $19522 \mathrm{R}$ & 1 & QCP & & & & & 2.548 & & 0.000 & \\
\hline 234 & 2015 & $19522 \mathrm{R}$ & 1 & QCP & & & & & 2.545 & & 0.000 & \\
\hline 235 & 2017 & 19524R & 1 & $\mathrm{QCP}$ & 0.33 & 0.16 & & & 2.485 & 2.495 & 0.006 & 0.001 \\
\hline 236 & 2017 & $19524 \mathrm{R}$ & 1 & QCP & 1.00 & & & & 2.484 & 2.472 & 0.000 & 0.000 \\
\hline 237 & 2017 & $19524 \mathrm{R}$ & 1 & QCP & 0.67 & & & & 2.484 & 2.494 & 0.010 & 0.000 \\
\hline 238 & 2017 & $19524 \mathrm{R}$ & 1 & QCP & 1.00 & & & & 2.481 & 2.485 & 0.000 & 0.000 \\
\hline 239 & 2017 & 19524R & 1 & PFP & 0.07 & 0.10 & 0.51 & & 2.480 & 2.498 & 0.004 & 0.011 \\
\hline 240 & 2017 & $19524 \mathrm{R}$ & 1 & QCP & 1.00 & & & & 2.483 & 2.484 & 0.000 & 0.000 \\
\hline 241 & 2017 & 19524R & 1 & $\mathrm{QCP}$ & 1.00 & 0.13 & & & 2.491 & 2.475 & 0.003 & 0.028 \\
\hline
\end{tabular}




\begin{tabular}{|c|c|c|c|c|c|c|c|c|c|c|c|c|}
\hline $\begin{array}{l}\text { ICT } \\
\text { Code }\end{array}$ & Year & Mix Code & District & $\begin{array}{l}\text { Quality } \\
\text { Program }\end{array}$ & $\begin{array}{c}\text { MW } \\
\text { P-Value }\end{array}$ & $\begin{array}{l}\text { Levene's } \\
\text { P-Value }\end{array}$ & $\begin{array}{l}\text { Contractor } \\
\text { SW P-Value }\end{array}$ & $\begin{array}{c}\text { Agency SW } \\
\text { P-Value }\end{array}$ & $\begin{array}{c}\text { Contractor } \\
\text { Mean }\end{array}$ & $\begin{array}{l}\text { Agency } \\
\text { Mean }\end{array}$ & $\begin{array}{l}\text { Contractor } \\
\text { St. Dev. }\end{array}$ & $\begin{array}{l}\text { Agency } \\
\text { St. Dev. }\end{array}$ \\
\hline 242 & 2017 & $19514 R$ & 1 & $\mathrm{QCP}$ & 1.00 & & & & 2.486 & 2.502 & 0.000 & 0.000 \\
\hline 243 & 2015 & $19514 R$ & 1 & QCP & 0.03 & 0.00 & 0.41 & 0.93 & 2.482 & 2.498 & 0.001 & 0.012 \\
\hline 244 & 2017 & $19524 R$ & 1 & QCP & 0.40 & 0.19 & 0.98 & 1.00 & 2.518 & 2.524 & 0.004 & 0.009 \\
\hline 245 & 2017 & $19524 R$ & 1 & QCP & 0.29 & 0.08 & 0.30 & 0.09 & 2.506 & 2.501 & 0.006 & 0.002 \\
\hline 246 & 2015 & 19525R & 1 & QCP & 0.63 & 0.11 & 0.59 & 0.64 & 2.475 & 2.464 & 0.005 & 0.015 \\
\hline 247 & 2017 & 19525R & 1 & QCP & 1.00 & & 0.54 & & 2.489 & 2.490 & 0.004 & 0.000 \\
\hline 248 & 2017 & 19525R & 1 & QCP & 1.00 & & & & 2.476 & 2.486 & 0.000 & 0.000 \\
\hline 249 & 2017 & 19525R & 1 & QCP & 0.10 & 0.29 & 0.40 & & 2.488 & 2.499 & 0.004 & 0.001 \\
\hline 250 & 2015 & 19525R & 1 & QCP & 0.77 & 0.54 & 0.42 & 0.82 & 2.488 & 2.489 & 0.005 & 0.006 \\
\hline 251 & 2017 & 19525R & 1 & QCP & 1.00 & & & & 2.497 & 2.485 & 0.000 & 0.000 \\
\hline 252 & 2017 & $19525 R$ & 1 & QCP & 0.67 & & & & 2.491 & 2.484 & 0.001 & 0.000 \\
\hline 253 & 2016 & 19510R & 1 & QCP & 1.00 & & & & 2.436 & 2.440 & 0.000 & 0.000 \\
\hline 254 & 2016 & 19510R & 1 & QCP & & & & & 2.426 & & 0.005 & \\
\hline 255 & 2016 & 19510R & 1 & QCP & 1.00 & & & & 2.432 & 2.440 & 0.000 & 0.000 \\
\hline 256 & 2016 & 19510R & 1 & QCP & 0.20 & 0.13 & 0.00 & & 2.427 & 2.436 & 0.002 & 0.008 \\
\hline 257 & 2017 & 19510R & 1 & QCP & 0.67 & & & & 2.442 & 2.438 & 0.001 & 0.000 \\
\hline 258 & 2017 & 19510R & 1 & QCP & 1.00 & & & & 2.434 & 2.433 & 0.001 & 0.000 \\
\hline 259 & 2017 & 19510R & 1 & QCP & 1.00 & 0.41 & & & 2.441 & 2.441 & 0.002 & 0.001 \\
\hline 260 & 2017 & 19510R & 1 & QCP & 1.00 & & & & 2.443 & 2.444 & 0.006 & 0.000 \\
\hline 261 & 2017 & 19525R & 1 & QCP & 1.00 & 0.83 & 0.25 & 0.27 & 2.515 & 2.516 & 0.011 & 0.011 \\
\hline 262 & 2017 & 19536R & 1 & QCP & 0.67 & & & & 2.480 & 2.488 & 0.004 & 0.000 \\
\hline 263 & 2015 & 19536R & 1 & QCP & 1.00 & & 1.00 & & 2.477 & 2.478 & 0.001 & 0.000 \\
\hline 264 & 2017 & $19524 \mathrm{R}$ & 1 & $\mathrm{QCP}$ & 0.50 & & 0.00 & & 2.509 & 2.502 & 0.005 & 0.000 \\
\hline 265 & 2017 & $19524 R$ & 1 & QCP & 0.40 & 0.89 & 0.16 & 0.42 & 2.501 & 2.494 & 0.006 & 0.007 \\
\hline 266 & 2017 & 19524R & 1 & $\mathrm{QCP}$ & 0.40 & & 0.35 & & 2.507 & 2.503 & 0.003 & 0.000 \\
\hline 267 & 2015 & 19665R & 1 & QCP & 0.68 & 0.86 & 0.84 & 0.46 & 2.460 & 2.461 & 0.003 & 0.002 \\
\hline 268 & 2015 & $19525 R$ & 1 & QCP & 0.22 & 0.22 & 0.43 & & 2.485 & 2.499 & 0.006 & 0.012 \\
\hline 269 & 2015 & 19510R & 1 & QCP & 0.39 & 0.51 & 0.12 & 0.46 & 2.395 & 2.406 & 0.016 & 0.021 \\
\hline 270 & 2015 & 19524R & 1 & PFP & 0.07 & 0.53 & 0.01 & 0.00 & 2.490 & 2.496 & 0.010 & 0.008 \\
\hline 271 & 2015 & 19510R & 1 & QCP & 0.66 & 0.37 & 0.72 & 0.00 & 2.429 & 2.425 & 0.009 & 0.013 \\
\hline 272 & 2016 & 19514R & 1 & QCP & 0.31 & 0.44 & 0.24 & 0.86 & 2.481 & 2.477 & 0.006 & 0.008 \\
\hline 273 & 2016 & $19514 \mathrm{R}$ & 1 & QCP & 0.10 & 0.92 & 0.10 & 0.11 & 2.479 & 2.469 & 0.009 & 0.008 \\
\hline 274 & 2017 & 19510R & 1 & $\mathrm{QCP}$ & 0.67 & 0.30 & 0.33 & & 2.418 & 2.408 & 0.007 & 0.013 \\
\hline 275 & 2017 & 19510R & 1 & QCP & 0.53 & 0.38 & 0.34 & 0.04 & 2.412 & 2.409 & 0.007 & 0.009 \\
\hline 276 & 2017 & 19510R & 1 & QCP & 1.00 & & 0.24 & & 2.413 & 2.412 & 0.008 & 0.000 \\
\hline
\end{tabular}




\begin{tabular}{|c|c|c|c|c|c|c|c|c|c|c|c|c|}
\hline $\begin{array}{l}\text { ICT } \\
\text { Code }\end{array}$ & Year & Mix Code & District & $\begin{array}{l}\text { Quality } \\
\text { Program }\end{array}$ & $\begin{array}{c}\text { MW } \\
\text { P-Value }\end{array}$ & $\begin{array}{l}\text { Levene's } \\
\text { P-Value }\end{array}$ & $\begin{array}{l}\text { Contractor } \\
\text { SW P-Value }\end{array}$ & $\begin{array}{c}\text { Agency SW } \\
\text { P-Value }\end{array}$ & $\begin{array}{c}\text { Contractor } \\
\text { Mean }\end{array}$ & $\begin{array}{l}\text { Agency } \\
\text { Mean }\end{array}$ & $\begin{array}{l}\text { Contractor } \\
\text { St. Dev. }\end{array}$ & $\begin{array}{l}\text { Agency } \\
\text { St. Dev. }\end{array}$ \\
\hline 277 & 2016 & $19512 R$ & 1 & $\mathrm{QCP}$ & 0.56 & 0.49 & 0.03 & 0.42 & 2.493 & 2.494 & 0.008 & 0.005 \\
\hline 278 & 2017 & 19524R & 1 & QCP & 0.98 & 0.44 & 0.35 & & 2.480 & 2.482 & 0.010 & 0.013 \\
\hline 279 & 2017 & 19524R & 1 & QCP & 0.20 & 0.00 & 0.64 & & 2.485 & 2.493 & 0.003 & 0.000 \\
\hline 280 & 2017 & 19525R & 1 & PFP & 0.00 & 0.78 & 0.14 & 0.67 & 2.525 & 2.531 & 0.006 & 0.007 \\
\hline 281 & 2017 & 19525R & 1 & QCP & 0.22 & 0.65 & 0.77 & 0.82 & 2.529 & 2.533 & 0.005 & 0.007 \\
\hline 282 & 2015 & 19510R & 1 & QCP & 0.67 & 0.10 & & 0.48 & 2.444 & 2.448 & 0.001 & 0.011 \\
\hline 283 & 2015 & 19524R & 1 & QCP & 0.86 & 0.33 & 0.17 & 0.51 & 2.513 & 2.509 & 0.006 & 0.013 \\
\hline 284 & 2015 & 19522R & 1 & QCP & & & & & & 2.534 & & 0.000 \\
\hline 285 & 2016 & 19522R & 1 & QCP & & & & & 2.523 & & 0.000 & \\
\hline 286 & 2016 & 19522R & 1 & QCP & & & 0.88 & & 2.506 & & 0.005 & \\
\hline 287 & 2015 & $19522 R$ & 1 & QCP & 0.67 & & & & 2.524 & 2.531 & 0.000 & 0.003 \\
\hline 288 & 2016 & 19532R & 1 & QCP & 0.40 & 0.94 & 0.08 & & 2.505 & 2.515 & 0.011 & 0.008 \\
\hline 289 & 2017 & 19510R & 1 & QCP & 1.00 & & & & 2.429 & 2.415 & 0.000 & 0.000 \\
\hline 290 & 2016 & 19510R & 1 & QCP & & & & & & 2.420 & & 0.013 \\
\hline 291 & 2017 & 19510R & 1 & QCP & 0.04 & 0.81 & 0.23 & 0.00 & 2.426 & 2.411 & 0.004 & 0.003 \\
\hline 292 & 2015 & 19524R & 1 & QCP & 0.27 & 0.25 & 0.79 & & 2.488 & 2.496 & 0.005 & 0.010 \\
\hline 293 & 2016 & 19524R & 1 & QCP & & & & & & 2.517 & & 0.000 \\
\hline 294 & 2016 & 19524R & 1 & QCP & 1.00 & & & & 2.499 & 2.501 & 0.000 & 0.000 \\
\hline 295 & 2015 & 19510R & 1 & QCP & 1.00 & 0.04 & 0.32 & 0.64 & 2.428 & 2.431 & 0.010 & 0.004 \\
\hline 296 & 2015 & 19665R & 1 & PFP & 0.32 & 0.30 & 0.26 & 0.30 & 2.565 & 2.561 & 0.009 & 0.007 \\
\hline 297 & 2017 & 19510R & 1 & QCP & 0.18 & & 0.27 & & 2.416 & 2.401 & 0.004 & 0.000 \\
\hline 298 & 2016 & 19510R & 1 & QCP & 1.00 & & & & 2.416 & 2.415 & 0.008 & 0.000 \\
\hline 299 & 2016 & $19524 R$ & 1 & QCP & 0.50 & & & & 2.492 & 2.497 & 0.000 & 0.000 \\
\hline 300 & 2016 & $19524 R$ & 1 & QCP & 0.67 & & & & 2.490 & 2.495 & 0.004 & 0.000 \\
\hline 301 & 2015 & 19536R & 1 & PFP & & & & & 2.671 & & 0.000 & \\
\hline 302 & 2015 & 19536R & 1 & QCP & 0.67 & 0.37 & & & 2.660 & 2.648 & 0.006 & 0.021 \\
\hline 303 & 2015 & 19536R & 1 & PFP & 0.98 & 0.12 & 0.44 & 0.94 & 2.677 & 2.676 & 0.008 & 0.014 \\
\hline 304 & 2015 & 19536R & 1 & QCP & & & 0.51 & & 2.554 & & 0.013 & \\
\hline 305 & 2015 & $19512 \mathrm{R}$ & 1 & QCP & 0.25 & 0.89 & 0.44 & 0.94 & 2.518 & 2.510 & 0.010 & 0.010 \\
\hline 306 & 2017 & $19525 R$ & 1 & QCP & 0.33 & & 0.04 & & 2.502 & 2.518 & 0.004 & 0.000 \\
\hline 307 & 2017 & $19525 R$ & 1 & QCP & 1.00 & & & & 2.515 & 2.505 & 0.000 & 0.000 \\
\hline 308 & 2016 & 19525R & 1 & QCP & 1.00 & & 0.83 & & 2.513 & 2.514 & 0.010 & 0.000 \\
\hline 309 & 2017 & 19525R & 1 & PFP & 0.05 & 0.61 & 0.06 & 0.49 & 2.508 & 2.501 & 0.006 & 0.007 \\
\hline 310 & 2017 & $19512 \mathrm{R}$ & 1 & QCP & & & & & 2.489 & & 0.004 & \\
\hline 311 & 2017 & $19512 R$ & 1 & QCP & & & & & 2.507 & & 0.000 & \\
\hline
\end{tabular}




\begin{tabular}{|c|c|c|c|c|c|c|c|c|c|c|c|c|}
\hline $\begin{array}{c}\text { ICT } \\
\text { Code }\end{array}$ & Year & Mix Code & District & $\begin{array}{l}\text { Quality } \\
\text { Program }\end{array}$ & $\begin{array}{c}\text { MW } \\
\text { P-Value }\end{array}$ & $\begin{array}{c}\text { Levene's } \\
\text { P-Value }\end{array}$ & $\begin{array}{l}\text { Contractor } \\
\text { SW P-Value }\end{array}$ & $\begin{array}{c}\text { Agency SW } \\
\text { P-Value }\end{array}$ & $\begin{array}{c}\text { Contractor } \\
\text { Mean }\end{array}$ & $\begin{array}{l}\text { Agency } \\
\text { Mean }\end{array}$ & $\begin{array}{c}\text { Contractor } \\
\text { St. Dev. }\end{array}$ & $\begin{array}{l}\text { Agency } \\
\text { St. Dev. }\end{array}$ \\
\hline 312 & 2017 & 19536R & 1 & $\mathrm{QCP}$ & 0.33 & 0.00 & & & 2.537 & 2.554 & 0.013 & 0.000 \\
\hline 313 & 2016 & $19536 \mathrm{R}$ & 1 & QCP & & & 0.00 & & 2.527 & & 0.001 & \\
\hline 314 & 2017 & 19510R & 1 & QCP & 0.33 & 0.59 & & & 2.418 & 2.407 & 0.001 & 0.001 \\
\hline 315 & 2017 & 19510R & 1 & QCP & 0.50 & & 0.78 & & 2.418 & 2.409 & 0.003 & 0.000 \\
\hline 316 & 2017 & 19510R & 1 & QCP & 0.69 & 0.08 & 0.33 & 0.71 & 2.415 & 2.413 & 0.004 & 0.015 \\
\hline 317 & 2017 & 19510R & 1 & QCP & & & & & 2.416 & & 0.000 & \\
\hline 318 & 2017 & 19665R & 1 & QCP & 1.00 & & & & 2.557 & 2.565 & 0.000 & 0.000 \\
\hline 319 & 2017 & 19665R & 1 & PFP & 0.59 & 0.35 & 0.15 & 0.97 & 2.551 & 2.545 & 0.012 & 0.018 \\
\hline 320 & 2017 & $19525 R$ & 1 & QCP & 1.00 & & & & 2.510 & 2.502 & 0.000 & 0.000 \\
\hline 321 & 2017 & $19522 R$ & 1 & QCP & & & 0.77 & & 2.517 & & 0.009 & \\
\hline 322 & 2017 & $19522 \mathrm{R}$ & 1 & QCP & & & & & 2.522 & & 0.000 & \\
\hline 323 & 2017 & 19653R & 1 & PFP & 0.01 & 0.10 & 0.41 & 0.00 & 2.473 & 2.468 & 0.008 & 0.006 \\
\hline 324 & 2017 & 19655 & 1 & PFP & 0.08 & 0.73 & 0.13 & 0.10 & 2.582 & 2.584 & 0.007 & 0.007 \\
\hline 325 & 2015 & $19532 R$ & 1 & QCP & 1.00 & 0.82 & 0.70 & 0.14 & 2.515 & 2.513 & 0.006 & 0.007 \\
\hline 326 & 2017 & $19532 R$ & 1 & QCP & & & & & 2.516 & & 0.006 & \\
\hline 327 & 2017 & $19532 R$ & 1 & QCP & 0.67 & & & & 2.519 & 2.530 & 0.005 & 0.000 \\
\hline 328 & 2017 & 19524R & 1 & QCP & 0.18 & & 0.96 & & 2.492 & 2.477 & 0.004 & 0.000 \\
\hline 329 & 2017 & $19524 \mathrm{R}$ & 1 & QCP & 0.98 & 0.90 & 0.02 & 0.24 & 2.492 & 2.490 & 0.007 & 0.007 \\
\hline 330 & 2017 & $19524 \mathrm{R}$ & 1 & QCP & 0.44 & 0.77 & 0.82 & 0.51 & 2.494 & 2.497 & 0.005 & 0.006 \\
\hline 331 & 2017 & $19522 \mathrm{R}$ & 1 & QCP & 0.13 & 0.20 & 0.90 & 0.31 & 2.522 & 2.518 & 0.006 & 0.009 \\
\hline 332 & 2015 & $19522 \mathrm{R}$ & 1 & QCP & 0.86 & & 0.94 & & 2.543 & 2.553 & 0.012 & 0.000 \\
\hline 333 & 2015 & $19522 \mathrm{R}$ & 1 & QCP & & & & & 2.533 & & 0.000 & \\
\hline 334 & 2015 & $19524 \mathrm{R}$ & 1 & PFP & 0.03 & 0.39 & 0.97 & 0.65 & 2.503 & 2.510 & 0.005 & 0.003 \\
\hline 335 & 2015 & $19524 \mathrm{R}$ & 1 & QCP & 0.03 & 0.90 & 0.13 & 1.00 & 2.503 & 2.512 & 0.005 & 0.005 \\
\hline 336 & 2015 & $19524 \mathrm{R}$ & 1 & QCP & 0.67 & & & & 2.508 & 2.509 & 0.001 & 0.000 \\
\hline 337 & 2015 & $19522 \mathrm{R}$ & 1 & QCP & 1.00 & 0.01 & 0.26 & 0.36 & 2.537 & 2.533 & 0.008 & 0.019 \\
\hline 338 & 2015 & $19524 \mathrm{R}$ & 1 & QCP & 0.23 & 0.00 & 0.59 & 0.74 & 2.491 & 2.484 & 0.003 & 0.012 \\
\hline 339 & 2015 & $19522 \mathrm{R}$ & 1 & QCP & & & & & 2.527 & & 0.004 & \\
\hline 340 & 2015 & $19524 \mathrm{R}$ & 1 & QCP & 0.26 & 0.39 & 0.98 & 0.67 & 2.502 & 2.511 & 0.007 & 0.010 \\
\hline 341 & 2015 & $19524 \mathrm{R}$ & 1 & PFP & & & & & 2.485 & & 0.007 & \\
\hline 342 & 2015 & 19510R & 1 & QCP & 0.60 & & 0.00 & & 2.478 & 2.460 & 0.031 & 0.000 \\
\hline 343 & 2015 & 19510R & 1 & PFP & 0.51 & 0.39 & 0.06 & & 2.421 & 2.424 & 0.006 & 0.001 \\
\hline 344 & 2015 & 19510R & 1 & QCP & 0.54 & 0.31 & 0.47 & 0.75 & 2.420 & 2.416 & 0.008 & 0.013 \\
\hline 345 & 2015 & 19510R & 1 & PFP & 0.75 & 0.48 & 0.76 & 0.61 & 2.433 & 2.429 & 0.010 & 0.015 \\
\hline 346 & 2015 & 19510R & 1 & QCP & & & & & & 2.447 & & 0.000 \\
\hline
\end{tabular}




\begin{tabular}{|c|c|c|c|c|c|c|c|c|c|c|c|c|}
\hline $\begin{array}{l}\text { ICT } \\
\text { Code }\end{array}$ & Year & Mix Code & District & $\begin{array}{l}\text { Quality } \\
\text { Program }\end{array}$ & $\begin{array}{c}\text { MW } \\
\text { P-Value }\end{array}$ & $\begin{array}{l}\text { Levene's } \\
\text { P-Value }\end{array}$ & $\begin{array}{l}\text { Contractor } \\
\text { SW P-Value }\end{array}$ & $\begin{array}{c}\text { Agency SW } \\
\text { P-Value }\end{array}$ & $\begin{array}{c}\text { Contractor } \\
\text { Mean }\end{array}$ & $\begin{array}{l}\text { Agency } \\
\text { Mean }\end{array}$ & $\begin{array}{l}\text { Contractor } \\
\text { St. Dev. }\end{array}$ & $\begin{array}{l}\text { Agency } \\
\text { St. Dev. }\end{array}$ \\
\hline 347 & 2015 & 19510R & 1 & $\mathrm{QCP}$ & 0.40 & & 0.72 & & 2.433 & 2.447 & 0.006 & 0.000 \\
\hline 348 & 2015 & 19510R & 1 & PFP & 0.13 & 0.00 & 0.31 & 0.01 & 2.435 & 2.443 & 0.010 & 0.002 \\
\hline 349 & 2015 & 19510R & 1 & QCP & & & 0.21 & & 2.438 & & 0.009 & \\
\hline 350 & 2015 & 19510R & 1 & QCP & 0.50 & & 0.70 & & 2.440 & 2.418 & 0.006 & 0.000 \\
\hline 351 & 2015 & 19510R & 1 & QCP & 1.00 & 0.56 & & & 2.447 & 2.445 & 0.006 & 0.013 \\
\hline 352 & 2015 & 19510R & 1 & QCP & 1.00 & & & & 2.433 & 2.434 & 0.013 & 0.000 \\
\hline 353 & 2015 & $19522 \mathrm{R}$ & 1 & QCP & & & & & & 2.522 & & 0.000 \\
\hline 354 & 2015 & 19536R & 1 & QCP & 0.38 & 0.25 & 0.68 & 0.39 & 2.482 & 2.486 & 0.004 & 0.009 \\
\hline 355 & 2015 & 19536R & 1 & QCP & 0.90 & 0.71 & 0.10 & 0.10 & 2.488 & 2.489 & 0.004 & 0.006 \\
\hline 356 & 2015 & 19536R & 1 & PFP & 0.02 & 0.14 & 0.92 & 0.11 & 2.485 & 2.491 & 0.006 & 0.008 \\
\hline 357 & 2016 & $19524 R$ & 1 & QCP & 1.00 & & & & 2.493 & 2.501 & 0.000 & 0.000 \\
\hline 358 & 2017 & 19524R & 1 & QCP & 0.01 & 0.24 & 0.17 & 0.76 & 2.482 & 2.493 & 0.003 & 0.005 \\
\hline 359 & 2015 & 19665R & 1 & QCP & 0.03 & 0.39 & 0.23 & 0.55 & 2.587 & 2.604 & 0.006 & 0.009 \\
\hline 360 & 2015 & 19665R & 1 & PFP & & & 0.38 & & 2.585 & & 0.005 & \\
\hline 361 & 2017 & 19510R & 1 & QCP & 0.11 & 0.91 & 0.97 & 0.33 & 2.413 & 2.423 & 0.007 & 0.006 \\
\hline 362 & 2015 & 19655R & 1 & PFP & & & 0.04 & & 2.594 & & 0.010 & \\
\hline 363 & 2016 & $19522 R$ & 1 & QCP & 0.16 & 0.52 & 0.54 & 0.27 & 2.506 & 2.512 & 0.009 & 0.007 \\
\hline 364 & 2016 & $19524 \mathrm{R}$ & 1 & QCP & & & & & 2.486 & & 0.000 & \\
\hline 365 & 2016 & $19514 \mathrm{R}$ & 1 & QCP & 1.00 & & & & 2.488 & 2.499 & 0.000 & 0.000 \\
\hline 366 & 2016 & 19536R & 1 & QCP & 0.67 & & & & 2.469 & 2.477 & 0.001 & 0.000 \\
\hline 367 & 2016 & $19532 \mathrm{R}$ & 1 & QCP & 1.00 & 0.59 & 0.51 & 0.39 & 2.497 & 2.499 & 0.011 & 0.007 \\
\hline 368 & 2017 & $19522 \mathrm{R}$ & 1 & QCP & 1.00 & & 0.64 & & 2.523 & 2.518 & 0.011 & 0.000 \\
\hline 369 & 2017 & $19522 \mathrm{R}$ & 1 & QCP & 0.20 & & 0.43 & & 2.518 & 2.547 & 0.008 & 0.000 \\
\hline 370 & 2017 & $19524 R$ & 1 & QCP & 0.02 & 0.95 & 0.10 & 0.47 & 2.494 & 2.510 & 0.011 & 0.011 \\
\hline 371 & 2017 & 19524R & 1 & PFP & 0.86 & 0.23 & 0.41 & 0.37 & 2.501 & 2.499 & 0.009 & 0.014 \\
\hline 372 & 2017 & 19510R & 1 & QCP & 1.00 & & 0.52 & & 2.419 & 2.420 & 0.007 & 0.000 \\
\hline 373 & 2017 & 19510R & 1 & QCP & 0.80 & 0.81 & 0.08 & & 2.429 & 2.431 & 0.007 & 0.007 \\
\hline 374 & 2017 & 19510R & 1 & QCP & 1.00 & & & & 2.421 & 2.423 & 0.000 & 0.000 \\
\hline 375 & 2017 & 19525R & 1 & $\mathrm{QCP}$ & 0.80 & 0.44 & 0.00 & 0.35 & 2.475 & 2.479 & 0.006 & 0.011 \\
\hline 376 & 2017 & 19510R & 1 & QCP & 0.51 & 0.05 & 0.10 & 0.76 & 2.433 & 2.439 & 0.002 & 0.009 \\
\hline 377 & 2017 & 19510R & 1 & QCP & 0.40 & 0.78 & 0.24 & 0.69 & 2.433 & 2.440 & 0.006 & 0.007 \\
\hline 378 & 2017 & 19653R & 1 & QCP & & & & & 2.480 & & 0.000 & \\
\hline 379 & 2017 & 19653R & 1 & PFP & 0.00 & 0.07 & 0.21 & 0.20 & 2.464 & 2.476 & 0.008 & 0.012 \\
\hline 380 & 2017 & 19525R & 1 & PFP & & & & & & 2.479 & & 0.008 \\
\hline 381 & 2017 & 19525R & 1 & PFP & 0.86 & 0.43 & 0.05 & 0.01 & 2.491 & 2.493 & 0.009 & 0.013 \\
\hline
\end{tabular}




\begin{tabular}{|c|c|c|c|c|c|c|c|c|c|c|c|c|}
\hline $\begin{array}{l}\text { ICT } \\
\text { Code }\end{array}$ & Year & Mix Code & District & $\begin{array}{l}\text { Quality } \\
\text { Program }\end{array}$ & $\begin{array}{c}\text { MW } \\
\text { P-Value }\end{array}$ & $\begin{array}{l}\text { Levene's } \\
\text { P-Value }\end{array}$ & $\begin{array}{l}\text { Contractor } \\
\text { SW P-Value }\end{array}$ & $\begin{array}{c}\text { Agency SW } \\
\text { P-Value }\end{array}$ & $\begin{array}{c}\text { Contractor } \\
\text { Mean }\end{array}$ & $\begin{array}{l}\text { Agency } \\
\text { Mean }\end{array}$ & $\begin{array}{l}\text { Contractor } \\
\text { St. Dev. }\end{array}$ & $\begin{array}{l}\text { Agency } \\
\text { St. Dev. }\end{array}$ \\
\hline 382 & 2017 & 19655R & 1 & PFP & 0.05 & 0.37 & 0.16 & 0.32 & 2.427 & 2.435 & 0.007 & 0.009 \\
\hline 383 & 2017 & 19510R & 1 & QCP & 0.25 & 0.60 & 0.15 & 0.30 & 2.423 & 2.418 & 0.010 & 0.011 \\
\hline 384 & 2017 & 19665R & 1 & PFP & 0.53 & 0.36 & 0.28 & 0.22 & 2.437 & 2.438 & 0.006 & 0.008 \\
\hline 385 & 2017 & 19665R & 1 & QCP & 0.69 & 0.04 & 0.66 & 0.88 & 2.445 & 2.442 & 0.005 & 0.011 \\
\hline 386 & 2015 & $19512 \mathrm{R}$ & 1 & QCP & 0.55 & 0.10 & 0.89 & & 2.513 & 2.517 & 0.011 & 0.001 \\
\hline 387 & 2015 & $19514 R$ & 1 & QCP & 0.67 & & & & 2.500 & 2.517 & 0.008 & 0.000 \\
\hline 388 & 2015 & $19522 \mathrm{R}$ & 1 & QCP & 0.67 & & & & 2.532 & 2.522 & 0.011 & 0.000 \\
\hline 390 & 2014 & $19514 R$ & 2 & QCP & 0.92 & 0.62 & 0.67 & 0.10 & 2.498 & 2.497 & 0.009 & 0.010 \\
\hline 391 & 2015 & 19514R & 2 & QCP & & & & & 2.499 & & 0.000 & \\
\hline 392 & 2015 & 19604FR & 2 & QCP & 0.75 & 0.00 & 0.01 & 0.11 & 2.506 & 2.523 & 0.040 & 0.003 \\
\hline 393 & 2015 & 19514R & 2 & QCP & 0.22 & 0.15 & 0.18 & 0.29 & 2.522 & 2.526 & 0.007 & 0.013 \\
\hline 394 & 2016 & $19512 \mathrm{R}$ & 4 & QCP & & & & & 2.547 & & 0.000 & \\
\hline 395 & 2016 & 19535R & 2 & QCP & 0.04 & 0.28 & 0.02 & 0.00 & 2.662 & 2.673 & 0.009 & 0.006 \\
\hline 396 & 2015 & $19534 R$ & 2 & PFP & 0.16 & 0.34 & 0.38 & 0.07 & 2.508 & 2.510 & 0.008 & 0.010 \\
\hline 397 & 2015 & $19532 \mathrm{R}$ & 2 & PFP & 0.10 & 0.86 & 0.12 & 0.00 & 2.542 & 2.540 & 0.006 & 0.007 \\
\hline 398 & 2015 & 19514R & 2 & QCP & 0.09 & 0.12 & 0.15 & 0.91 & 2.500 & 2.495 & 0.005 & 0.008 \\
\hline 399 & 2017 & $19514 R$ & 2 & QCP & 1.00 & & 0.73 & & 2.501 & 2.500 & 0.003 & 0.000 \\
\hline 400 & 2015 & $19524 \mathrm{R}$ & 2 & QCP & 0.42 & 0.45 & 0.05 & 0.27 & 2.502 & 2.504 & 0.005 & 0.007 \\
\hline 401 & 2015 & 19514R & 2 & QCP & 0.80 & 0.59 & 0.35 & 0.35 & 2.498 & 2.499 & 0.008 & 0.006 \\
\hline 402 & 2015 & 19604FR & 2 & QCP & 0.31 & 0.77 & 0.02 & 0.87 & 2.486 & 2.492 & 0.009 & 0.011 \\
\hline 404 & 2015 & 19514R & 2 & QCP & 0.81 & 0.04 & 0.24 & 0.98 & 2.489 & 2.487 & 0.006 & 0.018 \\
\hline 405 & 2016 & 19604FR & 2 & QCP & 0.01 & 0.55 & 0.56 & 0.22 & 2.482 & 2.492 & 0.009 & 0.007 \\
\hline 406 & 2016 & 19514R & 2 & $\mathrm{QCP}$ & 0.00 & 0.64 & 0.61 & 0.50 & 2.476 & 2.490 & 0.008 & 0.009 \\
\hline 407 & 2016 & 19516R & 2 & QCP & 0.33 & 0.22 & & & 2.699 & 2.729 & 0.002 & 0.012 \\
\hline 408 & 2017 & 19514R & 2 & $\mathrm{QCP}$ & 0.06 & 0.36 & 0.20 & 0.84 & 2.489 & 2.500 & 0.008 & 0.004 \\
\hline 409 & 2017 & $19512 \mathrm{R}$ & 2 & QCP & 0.67 & 0.68 & 0.23 & 0.61 & 2.522 & 2.524 & 0.010 & 0.011 \\
\hline 410 & 2017 & $19512 \mathrm{R}$ & 2 & QCP & 0.13 & 0.40 & 0.01 & 0.67 & 2.521 & 2.533 & 0.016 & 0.009 \\
\hline 411 & 2017 & 19514R & 2 & QCP & 0.08 & 0.42 & 0.22 & 0.16 & 2.466 & 2.473 & 0.010 & 0.007 \\
\hline 412 & 2016 & 19516R & 2 & $\mathrm{QCP}$ & 0.33 & 0.22 & & & 2.699 & 2.729 & 0.002 & 0.012 \\
\hline 413 & 2016 & 19513R & 2 & QCP & 0.33 & 0.41 & & & 2.562 & 2.559 & 0.002 & 0.001 \\
\hline 414 & 2017 & $19514 \mathrm{R}$ & 2 & $\mathrm{QCP}$ & 0.80 & & 0.40 & & 2.510 & 2.517 & 0.013 & 0.000 \\
\hline 415 & 2015 & 19514R & 2 & QCP & 0.98 & 0.04 & 0.65 & 0.01 & 2.522 & 2.525 & 0.007 & 0.014 \\
\hline 416 & 2017 & 19513R & 2 & $\mathrm{QCP}$ & & & & & 2.526 & & 0.006 & \\
\hline 417 & 2015 & $19514 \mathrm{R}$ & 2 & QCP & 0.65 & 0.21 & 0.31 & 0.32 & 2.523 & 2.523 & 0.006 & 0.010 \\
\hline 418 & 2016 & 19514R & 2 & QCP & 0.37 & 0.24 & 0.00 & 0.00 & 2.531 & 2.534 & 0.011 & 0.014 \\
\hline
\end{tabular}




\begin{tabular}{|c|c|c|c|c|c|c|c|c|c|c|c|c|}
\hline $\begin{array}{l}\text { ICT } \\
\text { Code }\end{array}$ & Year & Mix Code & District & $\begin{array}{l}\text { Quality } \\
\text { Program }\end{array}$ & $\begin{array}{c}\text { MW } \\
\text { P-Value }\end{array}$ & $\begin{array}{l}\text { Levene's } \\
\text { P-Value }\end{array}$ & $\begin{array}{l}\text { Contractor } \\
\text { SW P-Value }\end{array}$ & $\begin{array}{c}\text { Agency SW } \\
\text { P-Value }\end{array}$ & $\begin{array}{c}\text { Contractor } \\
\text { Mean }\end{array}$ & $\begin{array}{l}\text { Agency } \\
\text { Mean }\end{array}$ & $\begin{array}{l}\text { Contractor } \\
\text { St. Dev. }\end{array}$ & $\begin{array}{l}\text { Agency } \\
\text { St. Dev. }\end{array}$ \\
\hline 419 & 2017 & $19512 \mathrm{R}$ & 2 & $\mathrm{QCP}$ & 0.64 & 0.00 & 0.38 & 0.01 & 2.532 & 1.525 & 0.012 & 1.392 \\
\hline 420 & 2015 & $19512 \mathrm{R}$ & 2 & QCP & 0.62 & 0.52 & 0.00 & 0.00 & 2.547 & 2.547 & 0.014 & 0.013 \\
\hline 421 & 2015 & $19512 R$ & 2 & QCP & 0.32 & 0.31 & 0.12 & 0.95 & 2.552 & 2.556 & 0.008 & 0.011 \\
\hline 422 & 2015 & 19534R & 2 & PFP & 0.45 & 0.01 & 0.19 & 0.04 & 2.520 & 2.521 & 0.006 & 0.004 \\
\hline 423 & 2015 & 19534R & 2 & PFP & 0.47 & 0.85 & 0.39 & 0.07 & 2.532 & 2.533 & 0.006 & 0.006 \\
\hline 424 & 2016 & $19534 R$ & 2 & PFP & 0.01 & 0.06 & 0.05 & 0.34 & 2.523 & 2.527 & 0.003 & 0.005 \\
\hline 425 & 2017 & $19532 \mathrm{R}$ & 2 & PFP & 0.12 & 0.73 & 0.04 & 0.01 & 2.530 & 2.537 & 0.017 & 0.015 \\
\hline 426 & 2015 & $19532 R$ & 2 & PFP & 1.00 & 0.59 & 0.88 & 0.73 & 2.552 & 2.555 & 0.013 & 0.008 \\
\hline 427 & 2017 & 19535R & 2 & PFP & 0.21 & 0.35 & 0.40 & 0.04 & 2.679 & 2.686 & 0.009 & 0.013 \\
\hline 428 & 2015 & 19535R & 2 & PFP & 0.19 & 0.74 & 0.09 & 0.34 & 2.677 & 2.673 & 0.007 & 0.006 \\
\hline 429 & 2016 & $19512 \mathrm{R}$ & 2 & QCP & 1.00 & 1.00 & 0.07 & 0.00 & 2.529 & 2.530 & 0.013 & 0.013 \\
\hline 430 & 2015 & 19654R & 2 & PFP & 0.15 & 0.78 & 0.16 & 0.42 & 3.101 & 3.096 & 0.013 & 0.012 \\
\hline 431 & 2015 & $19514 R$ & 2 & QCP & 1.00 & 0.00 & & & 2.523 & 2.524 & 0.000 & 0.001 \\
\hline 432 & 2015 & $19514 R$ & 2 & QCP & 0.13 & 0.11 & 0.25 & 0.76 & 2.531 & 2.526 & 0.007 & 0.004 \\
\hline 433 & 2015 & $19514 \mathrm{R}$ & 2 & QCP & 0.08 & 0.44 & 0.50 & 0.19 & 2.517 & 2.525 & 0.008 & 0.005 \\
\hline 434 & 2016 & $19532 R$ & 2 & PFP & 0.34 & 0.80 & 0.20 & 0.18 & 2.544 & 2.545 & 0.007 & 0.007 \\
\hline 435 & 2015 & $19512 \mathrm{R}$ & 2 & QCP & 0.59 & 0.57 & 0.74 & 0.41 & 2.544 & 2.545 & 0.006 & 0.007 \\
\hline 436 & 2016 & $19654 \mathrm{R}$ & 2 & PFP & 0.06 & 0.10 & 0.01 & 0.48 & 3.141 & 3.146 & 0.016 & 0.019 \\
\hline 437 & 2016 & $19654 \mathrm{R}$ & 2 & QCP & 0.82 & 0.00 & 0.00 & 0.00 & 3.138 & 2.099 & 0.006 & 1.817 \\
\hline 438 & 2016 & 19524R & 2 & QCP & 0.33 & 0.96 & 0.02 & 0.00 & 2.530 & 2.534 & 0.008 & 0.007 \\
\hline 439 & 2017 & $19524 \mathrm{R}$ & 4 & QCP & & & & & 2.493 & & 0.000 & \\
\hline 440 & 2016 & $19534 \mathrm{R}$ & 2 & PFP & 0.00 & 0.01 & 0.34 & 0.05 & 2.520 & 2.525 & 0.003 & 0.005 \\
\hline 441 & 2016 & $19524 \mathrm{R}$ & 2 & PFP & 0.48 & 0.04 & 0.41 & 0.78 & 2.500 & 2.503 & 0.008 & 0.003 \\
\hline 442 & 2016 & $19534 R$ & 2 & PFP & 0.74 & 0.26 & 0.64 & 0.87 & 2.516 & 2.516 & 0.006 & 0.004 \\
\hline 443 & 2015 & 19524R & 2 & QCP & 0.33 & 0.12 & 0.01 & 0.00 & 2.498 & 2.502 & 0.014 & 0.010 \\
\hline 444 & 2015 & 19525R & 2 & QCP & 0.22 & 0.28 & & 0.35 & 2.501 & 2.505 & 0.001 & 0.004 \\
\hline 445 & 2015 & $19532 \mathrm{R}$ & 2 & PFP & & & & 0.89 & & 2.521 & & 0.006 \\
\hline 446 & 2015 & 19605FR & 2 & QCP & 0.58 & 0.85 & 0.12 & 0.42 & 2.502 & 2.504 & 0.013 & 0.014 \\
\hline 447 & 2015 & $19532 \mathrm{R}$ & 2 & QCP & 0.67 & 0.92 & & & 2.539 & 2.542 & 0.011 & 0.010 \\
\hline 448 & 2015 & $19654 \mathrm{R}$ & 2 & PFP & 0.70 & & & 0.21 & 2.474 & 2.477 & 0.000 & 0.008 \\
\hline 449 & 2015 & $19524 \mathrm{R}$ & 2 & QCP & 0.00 & 0.14 & 0.58 & 0.06 & 2.482 & 2.492 & 0.007 & 0.004 \\
\hline 450 & 2015 & 19515R & 2 & QCP & & & & 0.17 & & 2.500 & & 0.005 \\
\hline 451 & 2016 & 19515R & 2 & $\mathrm{QCP}$ & 0.00 & 0.01 & 0.10 & 0.01 & 2.494 & 2.502 & 0.010 & 0.005 \\
\hline 452 & 2014 & 19604FR & 2 & QCP & 0.68 & 0.37 & 0.20 & 0.00 & 2.502 & 2.501 & 0.010 & 0.008 \\
\hline 453 & 2015 & 19605FR & 2 & QCP & 0.10 & 0.18 & 0.90 & 0.00 & 2.493 & 2.503 & 0.006 & 0.002 \\
\hline
\end{tabular}




\begin{tabular}{|c|c|c|c|c|c|c|c|c|c|c|c|c|}
\hline $\begin{array}{l}\text { ICT } \\
\text { Code }\end{array}$ & Year & Mix Code & District & $\begin{array}{l}\text { Quality } \\
\text { Program }\end{array}$ & $\begin{array}{c}\text { MW } \\
\text { P-Value }\end{array}$ & $\begin{array}{l}\text { Levene's } \\
\text { P-Value }\end{array}$ & $\begin{array}{l}\text { Contractor } \\
\text { SW P-Value }\end{array}$ & $\begin{array}{c}\text { Agency SW } \\
\text { P-Value }\end{array}$ & $\begin{array}{c}\text { Contractor } \\
\text { Mean }\end{array}$ & $\begin{array}{l}\text { Agency } \\
\text { Mean }\end{array}$ & $\begin{array}{l}\text { Contractor } \\
\text { St. Dev. }\end{array}$ & $\begin{array}{l}\text { Agency } \\
\text { St. Dev. }\end{array}$ \\
\hline 454 & 2015 & $19525 R$ & 2 & $\mathrm{QCP}$ & 0.03 & 0.77 & 0.08 & 0.80 & 2.496 & 2.509 & 0.004 & 0.005 \\
\hline 455 & 2015 & 19515R & 2 & QCP & 0.00 & 0.11 & 0.02 & 0.05 & 2.495 & 2.503 & 0.007 & 0.009 \\
\hline 456 & 2016 & 19525R & 2 & QCP & 0.92 & 0.21 & 0.82 & 1.00 & 2.498 & 2.497 & 0.009 & 0.003 \\
\hline 457 & 2015 & 19525R & 2 & QCP & 0.10 & 0.70 & 0.00 & 0.90 & 2.495 & 2.509 & 0.004 & 0.006 \\
\hline 458 & 2015 & 19532R & 2 & PFP & 0.07 & 0.12 & 0.58 & 0.01 & 2.512 & 2.516 & 0.007 & 0.008 \\
\hline 459 & 2015 & $19532 R$ & 2 & QCP & 0.40 & & 0.57 & & 2.510 & 2.518 & 0.006 & 0.000 \\
\hline 460 & 2015 & 19654R & 2 & PFP & 0.91 & 0.03 & 0.07 & 0.00 & 2.486 & 2.486 & 0.008 & 0.012 \\
\hline 461 & 2015 & 19526R & 2 & QCP & 1.00 & & & & 2.490 & 2.512 & 0.000 & 0.000 \\
\hline 462 & 2017 & 19515R & 2 & QCP & 0.84 & 0.83 & 0.01 & 0.09 & 2.504 & 2.501 & 0.006 & 0.006 \\
\hline 463 & 2017 & 19604FR & 2 & QCP & 0.11 & 0.56 & 0.80 & & 2.500 & 2.493 & 0.004 & 0.004 \\
\hline 464 & 2017 & 19532 & 2 & PFP & & & & & & & & \\
\hline 465 & 2017 & 19513R & 2 & QCP & 0.40 & 0.00 & 0.00 & 0.00 & 2.555 & 1.680 & 0.071 & 1.455 \\
\hline 466 & 2017 & 19535R & 2 & PFP & & & & & & & & \\
\hline 467 & 2015 & 19524R & 3 & QCP & 0.11 & 0.13 & 0.14 & 0.74 & 2.459 & 2.464 & 0.010 & 0.005 \\
\hline 468 & 2017 & 19524R & 1 & QCP & 0.67 & & & & 2.517 & 2.518 & 0.000 & 0.000 \\
\hline 469 & 2017 & 19524R & 3 & PFP & & & & & 2.524 & & 0.000 & \\
\hline 470 & 2017 & 19524R & 1 & PFP & & & 0.06 & & 2.517 & & 0.007 & \\
\hline 471 & 2016 & 19524R & 3 & QCP & 0.80 & & 0.68 & & 2.523 & 2.525 & 0.002 & 0.000 \\
\hline 472 & 2017 & $19522 R$ & 3 & QCP & 0.50 & & 0.00 & & 2.537 & 2.533 & 0.003 & 0.000 \\
\hline 473 & 2015 & $19535 R$ & 3 & PFP & & & & 0.22 & & 2.507 & & 0.009 \\
\hline 474 & 2017 & 19510R & 1 & QCP & 0.11 & 0.26 & 0.02 & & 2.428 & 2.418 & 0.013 & 0.002 \\
\hline 475 & 2017 & 19510R & 1 & QCP & 0.31 & 0.56 & 0.23 & 0.18 & 2.438 & 2.431 & 0.010 & 0.013 \\
\hline 476 & 2016 & 19524R & 3 & QCP & 0.33 & 0.75 & & & 2.473 & 2.478 & 0.001 & 0.002 \\
\hline 477 & 2017 & $19525 R$ & 1 & PFP & 0.63 & 0.32 & 0.28 & 0.81 & 2.662 & 2.660 & 0.010 & 0.015 \\
\hline 478 & 2017 & $19534 R$ & 3 & QCP & 0.20 & 0.53 & 0.46 & & 2.517 & 2.509 & 0.004 & 0.006 \\
\hline 479 & 2016 & 19524R & 3 & QCP & 0.67 & & & & 2.477 & 2.481 & 0.005 & 0.000 \\
\hline 480 & 2017 & $19524 R$ & 1 & PFP & 0.73 & 0.44 & 0.82 & & 2.490 & 2.493 & 0.006 & 0.008 \\
\hline 481 & 2017 & $19524 R$ & 3 & QCP & & & 0.34 & & 2.485 & & 0.008 & \\
\hline 482 & 2015 & $19522 \mathrm{R}$ & 3 & QCP & 0.60 & 0.39 & & 0.70 & 2.534 & 2.527 & 0.011 & 0.006 \\
\hline 483 & 2015 & $19522 \mathrm{R}$ & 3 & QCP & 1.00 & & & 0.64 & 2.522 & 2.535 & 0.000 & 0.015 \\
\hline 484 & 2015 & 19536R & 1 & QCP & & & 0.42 & & 2.706 & & 0.014 & \\
\hline 485 & 2015 & 19536R & 1 & QCP & 0.33 & 0.20 & & & 2.703 & 2.681 & 0.013 & 0.002 \\
\hline 486 & 2016 & $19512 R$ & 1 & QCP & 0.74 & 0.29 & 0.16 & 0.95 & 2.504 & 2.506 & 0.006 & 0.009 \\
\hline 487 & 2016 & $19514 \mathrm{R}$ & 3 & QCP & 0.20 & 0.70 & 0.84 & & 2.478 & 2.486 & 0.004 & 0.004 \\
\hline 488 & 2015 & 19534R & 3 & PFP & & & & 0.24 & & 2.499 & & 0.007 \\
\hline
\end{tabular}




\begin{tabular}{|c|c|c|c|c|c|c|c|c|c|c|c|c|}
\hline $\begin{array}{c}\text { ICT } \\
\text { Code }\end{array}$ & Year & Mix Code & District & $\begin{array}{l}\text { Quality } \\
\text { Program }\end{array}$ & $\begin{array}{c}\text { MW } \\
\text { P-Value }\end{array}$ & $\begin{array}{l}\text { Levene's } \\
\text { P-Value }\end{array}$ & $\begin{array}{l}\text { Contractor } \\
\text { SW P-Value }\end{array}$ & $\begin{array}{c}\text { Agency SW } \\
\text { P-Value }\end{array}$ & $\begin{array}{c}\text { Contractor } \\
\text { Mean }\end{array}$ & $\begin{array}{l}\text { Agency } \\
\text { Mean }\end{array}$ & $\begin{array}{l}\text { Contractor } \\
\text { St. Dev. }\end{array}$ & $\begin{array}{l}\text { Agency } \\
\text { St. Dev. }\end{array}$ \\
\hline 489 & 2015 & 19534R & 3 & PFP & & & & 0.07 & & 2.498 & & 0.009 \\
\hline 490 & 2017 & 19524R & 1 & QCP & 0.44 & 0.77 & 0.51 & 0.14 & 2.493 & 2.496 & 0.007 & 0.005 \\
\hline 491 & 2016 & $19512 R$ & 1 & QCP & 0.63 & 0.13 & 0.40 & 0.20 & 2.496 & 2.494 & 0.010 & 0.005 \\
\hline 492 & 2017 & 19534R & 3 & PFP & & & & 0.88 & & 2.486 & & 0.003 \\
\hline 493 & 2017 & 19532R & 3 & PFP & 0.21 & & & 0.27 & 2.489 & 2.497 & 0.000 & 0.006 \\
\hline 494 & 2017 & 19510R & 1 & QCP & 1.00 & 0.89 & 0.80 & 0.16 & 2.408 & 2.410 & 0.015 & 0.012 \\
\hline 495 & 2017 & 19654R & 3 & QCP & 0.94 & 0.74 & 0.53 & 0.92 & 2.477 & 2.478 & 0.007 & 0.007 \\
\hline 496 & 2017 & 19510R & 4 & PFP & 0.61 & 0.48 & 0.08 & 0.41 & 2.390 & 2.392 & 0.008 & 0.006 \\
\hline 497 & 2015 & 19515R & 4 & QCP & 0.50 & & 0.77 & & 2.465 & 2.473 & 0.007 & 0.000 \\
\hline 498 & 2016 & 19515R & 4 & QCP & & & 0.61 & & 2.630 & & 0.011 & \\
\hline 499 & 2016 & $19522 R$ & 4 & PFP & & & & & 2.535 & & 0.007 & \\
\hline 500 & 2016 & 19522R & 4 & PFP & 0.00 & 0.00 & 0.67 & 0.53 & 2.529 & 2.535 & 0.008 & 0.011 \\
\hline 501 & 2016 & 19532R & 3 & PFP & 0.00 & 0.41 & 0.09 & 0.67 & 2.473 & 2.481 & 0.004 & 0.006 \\
\hline 502 & 2015 & 19653R & 4 & PFP & & & & 0.49 & & 2.453 & & 0.010 \\
\hline 503 & 2016 & 19654R & 4 & PFP & & & 0.54 & & 2.442 & & 0.004 & \\
\hline 504 & 2017 & $19654 R$ & 4 & PFP & 0.29 & 0.08 & 0.11 & 0.68 & 2.434 & 2.437 & 0.009 & 0.006 \\
\hline 505 & 2016 & $19654 \mathrm{R}$ & 4 & PFP & 0.42 & 0.20 & 0.40 & 0.04 & 2.441 & 2.443 & 0.005 & 0.007 \\
\hline 506 & 2017 & 19510R & 4 & QCP & & & & & 2.445 & & 0.000 & \\
\hline 507 & 2015 & 19515R & 4 & QCP & & & & & 2.476 & & 0.008 & \\
\hline 508 & 2016 & $19524 R$ & 4 & PFP & 0.62 & 0.14 & 0.35 & 0.14 & 2.483 & 2.485 & 0.005 & 0.008 \\
\hline 509 & 2016 & $19525 R$ & 4 & PFP & & & & & 2.470 & & 0.000 & \\
\hline 510 & 2015 & $19525 R$ & 4 & PFP & 0.02 & 0.08 & 0.10 & 0.13 & 2.462 & 2.469 & 0.011 & 0.007 \\
\hline 511 & 2015 & 19535R & 3 & PFP & & & & 0.12 & & 2.459 & & 0.006 \\
\hline 512 & 2016 & 19510R & 4 & PFP & 0.62 & 0.68 & 0.51 & 0.36 & 2.453 & 2.454 & 0.012 & 0.011 \\
\hline 513 & 2016 & 19510R & 4 & PFP & 0.50 & 0.70 & 0.14 & 0.02 & 2.448 & 2.449 & 0.007 & 0.006 \\
\hline 514 & 2017 & 19510R & 4 & QCP & 0.00 & 0.97 & 0.67 & 0.98 & 2.584 & 2.574 & 0.004 & 0.004 \\
\hline 515 & 2017 & 19515R & 4 & QCP & 1.00 & & & & 2.452 & 2.456 & 0.000 & 0.000 \\
\hline 516 & 2017 & $19514 R$ & 4 & PFP & & & 0.60 & & 2.516 & & 0.005 & \\
\hline 517 & 2015 & 19515R & 4 & QCP & & & & & 2.473 & & 0.005 & \\
\hline 518 & 2015 & $19524 \mathrm{R}$ & 4 & PFP & 0.01 & 0.64 & 0.36 & 0.96 & 2.488 & 2.500 & 0.007 & 0.009 \\
\hline 519 & 2016 & $19512 \mathrm{R}$ & 4 & PFP & & & & & 2.501 & & 0.000 & \\
\hline 520 & 2017 & $19522 R$ & 4 & QCP & & & 0.06 & & 2.582 & & 0.005 & \\
\hline 521 & 2015 & $19524 R$ & 4 & PFP & 0.78 & 0.31 & 0.20 & 0.13 & 2.480 & 2.482 & 0.005 & 0.008 \\
\hline 522 & 2016 & $19512 \mathrm{R}$ & 4 & PFP & & & & & 2.532 & & 0.000 & \\
\hline 523 & 2015 & 19514R & 4 & QCP & & & 0.61 & & 2.491 & & 0.008 & \\
\hline
\end{tabular}




\begin{tabular}{|c|c|c|c|c|c|c|c|c|c|c|c|c|}
\hline $\begin{array}{l}\text { ICT } \\
\text { Code }\end{array}$ & Year & Mix Code & District & $\begin{array}{l}\text { Quality } \\
\text { Program }\end{array}$ & $\begin{array}{c}\text { MW } \\
\text { P-Value }\end{array}$ & $\begin{array}{l}\text { Levene's } \\
\text { P-Value }\end{array}$ & $\begin{array}{l}\text { Contractor } \\
\text { SW P-Value }\end{array}$ & $\begin{array}{c}\text { Agency SW } \\
\text { P-Value }\end{array}$ & $\begin{array}{c}\text { Contractor } \\
\text { Mean }\end{array}$ & $\begin{array}{l}\text { Agency } \\
\text { Mean }\end{array}$ & $\begin{array}{l}\text { Contractor } \\
\text { St. Dev. }\end{array}$ & $\begin{array}{l}\text { Agency } \\
\text { St. Dev. }\end{array}$ \\
\hline 524 & 2016 & $19514 R$ & 4 & PFP & 0.98 & 0.46 & 0.33 & 0.01 & 2.488 & 2.490 & 0.012 & 0.009 \\
\hline 525 & 2015 & $19514 R$ & 4 & PFP & 0.11 & 0.41 & 0.98 & 0.52 & 2.473 & 2.479 & 0.006 & 0.004 \\
\hline 526 & 2015 & $19524 R$ & 5 & QCP & 0.14 & 0.90 & 0.76 & & 2.445 & 2.452 & 0.003 & 0.002 \\
\hline 527 & 2015 & $19514 R$ & 5 & QCP & 0.60 & & 0.10 & & 2.455 & 2.460 & 0.007 & 0.000 \\
\hline 528 & 2016 & $19514 R$ & 5 & QCP & & & 0.73 & & 2.443 & & 0.004 & \\
\hline 529 & 2015 & $19514 R$ & 5 & QCP & 0.67 & 0.00 & 0.48 & & 2.486 & 2.485 & 0.011 & 0.000 \\
\hline 530 & 2016 & 19514R & 5 & QCP & & & 0.64 & & 2.486 & & 0.003 & \\
\hline 531 & 2016 & 19524R & 5 & QCP & & & 0.65 & & 2.484 & & 0.004 & \\
\hline 532 & 2017 & 19605FR & 5 & QCP & 0.20 & 0.85 & 0.19 & 0.25 & 2.474 & 2.467 & 0.009 & 0.008 \\
\hline 533 & 2015 & 19605FR & 5 & QCP & 0.97 & 0.85 & 0.77 & 0.34 & 2.481 & 2.481 & 0.008 & 0.007 \\
\hline 534 & 2015 & 19524R & 5 & QCP & 0.35 & 0.71 & 0.01 & 0.11 & 2.477 & 2.482 & 0.008 & 0.009 \\
\hline 535 & 2016 & 19514R & 5 & QCP & 0.29 & & 0.33 & & 2.476 & 2.484 & 0.003 & 0.000 \\
\hline 536 & 2017 & $19524 R$ & 5 & QCP & 0.08 & 0.62 & 0.49 & & 2.474 & 2.488 & 0.007 & 0.008 \\
\hline 537 & 2015 & $19534 R$ & 5 & QCP & 0.29 & & 0.05 & & 2.428 & 2.447 & 0.004 & 0.000 \\
\hline 538 & 2015 & $19534 \mathrm{R}$ & 5 & PFP & 0.01 & 0.44 & 0.57 & 0.91 & 2.424 & 2.437 & 0.005 & 0.006 \\
\hline 539 & 2017 & 19535R & 5 & QCP & 0.04 & 0.73 & 0.72 & & 2.417 & 2.430 & 0.004 & 0.002 \\
\hline 540 & 2017 & $19512 \mathrm{R}$ & 6 & QCP & & & & & 2.470 & & 0.000 & \\
\hline 541 & 2017 & 19513R & 5 & QCP & & & & & & 2.451 & & 0.008 \\
\hline 542 & 2017 & $19532 R$ & 5 & PFP & & & & 0.47 & & 2.462 & & 0.005 \\
\hline 543 & 2016 & 19534R & 5 & QCP & & & & & & 2.424 & & 0.000 \\
\hline 544 & 2017 & $19534 \mathrm{R}$ & 5 & PFP & & & & 0.00 & & 2.442 & & 0.001 \\
\hline 545 & 2017 & 19523R & 5 & QCP & 0.67 & 0.82 & 0.82 & 1.00 & 2.445 & 2.449 & 0.008 & 0.008 \\
\hline 546 & 2015 & $19534 \mathrm{R}$ & 5 & PFP & 0.01 & 0.63 & 0.18 & 0.83 & 2.440 & 2.459 & 0.008 & 0.006 \\
\hline 547 & 2016 & 19513R & 5 & QCP & 0.22 & & 0.01 & & 2.445 & 2.462 & 0.012 & 0.000 \\
\hline 548 & 2016 & 19514R & 5 & QCP & & & 0.96 & & 2.450 & & 0.010 & \\
\hline 549 & 2015 & $19532 \mathrm{R}$ & 5 & PFP & 0.00 & 0.48 & 0.90 & 0.06 & 2.468 & 2.482 & 0.007 & 0.005 \\
\hline 550 & 2015 & 19535R & 5 & PFP & 0.29 & 0.22 & 0.95 & & 2.458 & 2.463 & 0.010 & 0.001 \\
\hline 551 & 2015 & 19523R & 5 & QCP & 0.02 & 0.09 & 0.23 & 0.04 & 2.450 & 2.462 & 0.008 & 0.003 \\
\hline 552 & 2015 & 19505R & 5 & QCP & & & 0.71 & & 2.449 & & 0.010 & \\
\hline 553 & 2015 & $19534 \mathrm{R}$ & 5 & PFP & 0.11 & 0.77 & 0.01 & 0.21 & 2.439 & 2.462 & 0.018 & 0.019 \\
\hline 554 & 2017 & $19534 R$ & 5 & PFP & 0.00 & 0.23 & 0.86 & 0.96 & 2.434 & 2.454 & 0.006 & 0.009 \\
\hline 555 & 2016 & 19513R & 5 & QCP & & & & & 2.463 & & 0.000 & \\
\hline 556 & 2016 & 19513R & 5 & QCP & 0.67 & & & & 2.454 & 2.466 & 0.003 & 0.000 \\
\hline 557 & 2015 & $19532 R$ & 5 & PFP & 0.00 & 0.38 & 0.02 & 0.91 & 2.457 & 2.468 & 0.004 & 0.003 \\
\hline 558 & 2016 & $19532 R$ & 5 & PFP & 0.02 & 0.83 & 0.32 & 0.03 & 2.451 & 2.456 & 0.005 & 0.004 \\
\hline
\end{tabular}




\begin{tabular}{|c|c|c|c|c|c|c|c|c|c|c|c|c|}
\hline $\begin{array}{c}\text { ICT } \\
\text { Code }\end{array}$ & Year & Mix Code & District & $\begin{array}{l}\text { Quality } \\
\text { Program }\end{array}$ & $\begin{array}{c}\text { MW } \\
\text { P-Value }\end{array}$ & $\begin{array}{c}\text { Levene's } \\
\text { P-Value }\end{array}$ & $\begin{array}{l}\text { Contractor } \\
\text { SW P-Value }\end{array}$ & $\begin{array}{c}\text { Agency SW } \\
\text { P-Value }\end{array}$ & $\begin{array}{c}\text { Contractor } \\
\text { Mean }\end{array}$ & $\begin{array}{l}\text { Agency } \\
\text { Mean }\end{array}$ & $\begin{array}{c}\text { Contractor } \\
\text { St. Dev. }\end{array}$ & $\begin{array}{l}\text { Agency } \\
\text { St. Dev. }\end{array}$ \\
\hline 559 & 2016 & 19535R & 5 & PFP & 0.01 & 0.37 & 0.23 & 0.91 & 2.444 & 2.456 & 0.006 & 0.009 \\
\hline 560 & 2017 & 19535R & 5 & QCP & & & 0.11 & & 2.444 & & 0.008 & \\
\hline 561 & 2015 & 19524R & 5 & QCP & 0.20 & & 0.53 & & 2.443 & 2.464 & 0.010 & 0.000 \\
\hline 562 & 2015 & 19524R & 5 & QCP & 0.09 & 0.40 & 0.19 & & 2.430 & 2.451 & 0.010 & 0.013 \\
\hline 563 & 2017 & $19532 R$ & 5 & PFP & 0.02 & 0.73 & 0.00 & 0.64 & 2.466 & 2.472 & 0.006 & 0.005 \\
\hline 564 & 2015 & 19523R & 6 & QCP & 0.70 & 0.21 & 0.38 & 0.91 & 2.446 & 2.445 & 0.006 & 0.008 \\
\hline 565 & 2015 & 19513R & 6 & QCP & 0.40 & 0.08 & 0.06 & 0.51 & 2.452 & 2.463 & 0.016 & 0.005 \\
\hline 566 & 2016 & $19524 R$ & 6 & PFP & 0.12 & & & 0.45 & 2.422 & 2.432 & 0.000 & 0.004 \\
\hline 567 & 2016 & 19513R & 6 & PFP & & & & & & 2.456 & & 0.000 \\
\hline 568 & 2015 & 19513R & 6 & QCP & 0.45 & 0.75 & 0.09 & 0.51 & 2.453 & 2.448 & 0.008 & 0.006 \\
\hline 569 & 2015 & $19522 \mathrm{R}$ & 6 & PFP & 0.88 & 0.47 & 0.94 & 0.92 & 2.485 & 2.484 & 0.011 & 0.009 \\
\hline 570 & 2015 & $19522 \mathrm{R}$ & 6 & PFP & 0.53 & 0.83 & 0.05 & 0.81 & 2.477 & 2.478 & 0.009 & 0.009 \\
\hline 571 & 2015 & 19513R & 6 & QCP & 0.21 & 0.11 & 0.49 & 0.29 & 2.439 & 2.447 & 0.011 & 0.019 \\
\hline 572 & 2015 & 19513R & 6 & QCP & 0.18 & 0.90 & 0.32 & 0.86 & 2.434 & 2.442 & 0.010 & 0.008 \\
\hline 573 & 2015 & 19523R & 6 & PFP & 0.77 & 0.90 & 0.03 & 0.99 & 2.450 & 2.449 & 0.007 & 0.006 \\
\hline 574 & 2015 & 19513R & 6 & QCP & 0.05 & 0.13 & 0.46 & 0.44 & 2.444 & 2.455 & 0.013 & 0.007 \\
\hline 575 & 2015 & 19523R & 6 & QCP & 0.06 & 0.42 & 0.14 & 0.12 & 2.441 & 2.448 & 0.008 & 0.006 \\
\hline 576 & 2015 & 19523R & 6 & $\mathrm{QCP}$ & & & 0.98 & & 2.447 & & 0.007 & \\
\hline 577 & 2017 & 19523R & 8 & QCP & 0.23 & 0.82 & 0.68 & 0.06 & 2.454 & 2.460 & 0.006 & 0.005 \\
\hline 578 & 2015 & 19534R & 6 & PFP & 0.02 & 0.33 & 0.88 & 0.10 & 2.451 & 2.458 & 0.010 & 0.008 \\
\hline 579 & 2016 & 19534R & 6 & PFP & 0.06 & 0.41 & 0.91 & 0.85 & 2.460 & 2.469 & 0.006 & 0.004 \\
\hline 580 & 2015 & $19522 \mathrm{R}$ & 6 & PFP & 0.10 & 0.25 & 0.20 & 0.74 & 2.482 & 2.478 & 0.006 & 0.008 \\
\hline 581 & 2015 & 19513R & 6 & $\mathrm{QCP}$ & 0.47 & 0.50 & 0.34 & 0.46 & 2.453 & 2.451 & 0.005 & 0.006 \\
\hline 582 & 2017 & $19522 \mathrm{R}$ & 6 & QCP & 0.50 & & 0.44 & & 2.462 & 2.468 & 0.007 & 0.000 \\
\hline 583 & 2015 & 19535R & 6 & PFP & 0.80 & 0.51 & 0.81 & 0.77 & 2.422 & 2.421 & 0.007 & 0.010 \\
\hline 584 & 2015 & 19535R & 6 & QCP & 1.00 & & 0.83 & & 2.415 & 2.416 & 0.004 & 0.000 \\
\hline 585 & 2015 & 19535R & 6 & PFP & 0.27 & 0.15 & 0.80 & 0.07 & 2.430 & 2.437 & 0.005 & 0.010 \\
\hline 586 & 2016 & 19514R & 6 & QCP & 0.16 & 0.23 & 0.37 & 1.00 & 2.435 & 2.429 & 0.006 & 0.002 \\
\hline 587 & 2015 & 19513R & 6 & $\mathrm{QCP}$ & 0.37 & 0.38 & 0.01 & 0.01 & 2.465 & 2.465 & 0.004 & 0.006 \\
\hline 588 & 2015 & $19522 \mathrm{R}$ & 6 & $\mathrm{QCP}$ & 0.70 & 0.11 & 0.00 & 0.79 & 2.470 & 2.467 & 0.005 & 0.009 \\
\hline 589 & 2016 & $19532 \mathrm{R}$ & 6 & PFP & & & & 0.09 & & 2.464 & & 0.002 \\
\hline 590 & 2015 & 19532R & 6 & PFP & 0.00 & 0.00 & 0.61 & 0.58 & 2.454 & 2.463 & 0.010 & 0.005 \\
\hline 591 & 2016 & $19532 R$ & 6 & QCP & 1.00 & & 0.32 & & 2.459 & 2.462 & 0.006 & 0.000 \\
\hline 592 & 2015 & 19524R & 6 & QCP & 0.65 & 0.73 & 0.54 & & 2.427 & 2.426 & 0.004 & 0.002 \\
\hline 593 & 2015 & $19512 R$ & 6 & $\mathrm{QCP}$ & 0.03 & 0.10 & 0.06 & 0.05 & 2.472 & 2.480 & 0.009 & 0.004 \\
\hline
\end{tabular}




\begin{tabular}{|c|c|c|c|c|c|c|c|c|c|c|c|c|}
\hline $\begin{array}{l}\text { ICT } \\
\text { Code }\end{array}$ & Year & Mix Code & District & $\begin{array}{l}\text { Quality } \\
\text { Program }\end{array}$ & $\begin{array}{c}\text { MW } \\
\text { P-Value }\end{array}$ & $\begin{array}{l}\text { Levene's } \\
\text { P-Value }\end{array}$ & $\begin{array}{l}\text { Contractor } \\
\text { SW P-Value }\end{array}$ & $\begin{array}{c}\text { Agency SW } \\
\text { P-Value }\end{array}$ & $\begin{array}{c}\text { Contractor } \\
\text { Mean }\end{array}$ & $\begin{array}{l}\text { Agency } \\
\text { Mean }\end{array}$ & $\begin{array}{l}\text { Contractor } \\
\text { St. Dev. }\end{array}$ & $\begin{array}{l}\text { Agency } \\
\text { St. Dev. }\end{array}$ \\
\hline 594 & 2015 & 19535R & 6 & PFP & 0.01 & 0.22 & 0.95 & 0.49 & 2.428 & 2.434 & 0.009 & 0.007 \\
\hline 595 & 2017 & 19535R & 6 & PFP & 0.07 & 0.37 & 0.12 & 0.84 & 2.423 & 2.427 & 0.005 & 0.007 \\
\hline 596 & 2016 & 19535R & 6 & QCP & 1.00 & & 0.36 & & 2.442 & 2.446 & 0.008 & 0.000 \\
\hline 597 & 2017 & 19513R & 6 & QCP & 0.96 & 0.43 & 0.34 & 0.51 & 2.458 & 2.460 & 0.011 & 0.006 \\
\hline 598 & 2017 & 19513R & 6 & QCP & 0.45 & 0.84 & 0.89 & 0.57 & 2.449 & 2.452 & 0.006 & 0.006 \\
\hline 599 & 2017 & 19513R & 6 & QCP & 0.95 & 0.27 & 0.04 & & 2.451 & 2.455 & 0.008 & 0.001 \\
\hline 600 & 2016 & 19513R & 6 & QCP & & & & & 2.469 & & 0.000 & \\
\hline 601 & 2016 & 19513R & 6 & PFP & & & & & & 2.462 & & 0.002 \\
\hline 602 & 2016 & 19513R & 6 & QCP & 0.00 & 0.65 & 0.25 & 0.01 & 2.461 & 2.468 & 0.009 & 0.008 \\
\hline 603 & 2016 & 19513R & 6 & QCP & 0.35 & 0.92 & 0.95 & 0.28 & 2.459 & 2.464 & 0.008 & 0.008 \\
\hline 604 & 2016 & $19514 R$ & 6 & QCP & 1.00 & & 0.78 & & 2.484 & 2.489 & 0.010 & 0.000 \\
\hline 605 & 2015 & $19512 \mathrm{R}$ & 6 & QCP & 0.10 & 0.79 & 0.36 & 0.79 & 2.421 & 2.431 & 0.012 & 0.012 \\
\hline 606 & 2016 & $19524 R$ & 6 & QCP & 0.75 & 0.78 & 0.12 & 0.42 & 2.443 & 2.443 & 0.015 & 0.015 \\
\hline 607 & 2015 & 19513R & 6 & QCP & 1.00 & & 0.07 & & 2.446 & 2.443 & 0.005 & 0.000 \\
\hline 608 & 2017 & 19513R & 6 & QCP & 0.39 & 0.63 & 0.27 & 0.36 & 2.450 & 2.448 & 0.004 & 0.003 \\
\hline 609 & 2016 & 19513R & 6 & QCP & 0.26 & 0.01 & 0.05 & 0.01 & 2.443 & 2.446 & 0.010 & 0.004 \\
\hline 610 & 2017 & 19513R & 6 & QCP & 0.39 & 0.93 & 0.35 & 0.00 & 2.447 & 2.449 & 0.008 & 0.008 \\
\hline 611 & 2016 & 19513R & 6 & QCP & 0.53 & 0.66 & 0.53 & & 2.440 & 2.447 & 0.011 & 0.011 \\
\hline 612 & 2017 & $19532 R$ & 6 & PFP & 0.00 & 0.64 & 0.01 & 1.00 & 2.456 & 2.463 & 0.005 & 0.006 \\
\hline 613 & 2016 & 19524R & 6 & PFP & 0.83 & 0.31 & 0.64 & 0.23 & 2.438 & 2.438 & 0.004 & 0.003 \\
\hline 614 & 2016 & 19513R & 6 & QCP & 0.79 & 0.43 & 0.10 & 0.65 & 2.449 & 2.451 & 0.010 & 0.007 \\
\hline 615 & 2016 & $19514 \mathrm{R}$ & 6 & QCP & 0.56 & 0.81 & 0.16 & 0.60 & 2.414 & 2.416 & 0.006 & 0.005 \\
\hline 616 & 2016 & $19534 \mathrm{R}$ & 7 & PFP & 0.02 & 0.94 & 0.91 & 0.21 & 2.436 & 2.441 & 0.004 & 0.004 \\
\hline 617 & 2016 & $19524 R$ & 6 & QCP & 0.60 & 0.56 & 0.06 & 0.85 & 2.431 & 2.433 & 0.009 & 0.007 \\
\hline 618 & 2016 & $19532 \mathrm{R}$ & 6 & PFP & 0.00 & 0.00 & 0.16 & 0.27 & 2.452 & 2.461 & 0.009 & 0.004 \\
\hline 619 & 2016 & 19523R & 6 & QCP & 0.29 & & 0.10 & & 2.416 & 2.431 & 0.009 & 0.000 \\
\hline 620 & 2016 & $19524 \mathrm{R}$ & 6 & QCP & 0.03 & 0.94 & 0.18 & 0.06 & 2.421 & 2.436 & 0.012 & 0.011 \\
\hline 621 & 2016 & 19534R & 6 & PFP & 0.00 & 0.00 & 0.31 & 0.41 & 2.406 & 2.417 & 0.010 & 0.003 \\
\hline 622 & 2016 & 19513R & 6 & QCP & 0.72 & 0.38 & 0.13 & 0.68 & 2.432 & 2.433 & 0.006 & 0.009 \\
\hline 623 & 2016 & $19512 \mathrm{R}$ & 6 & QCP & 0.24 & 0.71 & 0.22 & 0.02 & 2.454 & 2.459 & 0.009 & 0.007 \\
\hline 624 & 2017 & $19514 \mathrm{R}$ & 6 & QCP & 0.32 & 0.19 & 0.24 & 0.02 & 2.443 & 2.449 & 0.008 & 0.003 \\
\hline 625 & 2017 & $19522 \mathrm{R}$ & 6 & PFP & & & & & 2.471 & & 0.000 & \\
\hline 626 & 2017 & 19514R & 6 & $\mathrm{QCP}$ & 0.05 & 0.15 & 0.15 & 0.02 & 2.440 & 2.436 & 0.002 & 0.004 \\
\hline 627 & 2017 & 19513R & 6 & QCP & 1.00 & 0.23 & 0.13 & 0.00 & 2.435 & 2.436 & 0.010 & 0.003 \\
\hline 628 & 2015 & 19524 & 7 & PFP & 0.33 & 0.20 & 0.85 & 0.11 & 2.440 & 2.445 & 0.003 & 0.006 \\
\hline
\end{tabular}




\begin{tabular}{|c|c|c|c|c|c|c|c|c|c|c|c|c|}
\hline $\begin{array}{l}\text { ICT } \\
\text { Code }\end{array}$ & Year & Mix Code & District & $\begin{array}{l}\text { Quality } \\
\text { Program }\end{array}$ & $\begin{array}{c}\text { MW } \\
\text { P-Value }\end{array}$ & $\begin{array}{l}\text { Levene's } \\
\text { P-Value }\end{array}$ & $\begin{array}{l}\text { Contractor } \\
\text { SW P-Value }\end{array}$ & $\begin{array}{c}\text { Agency SW } \\
\text { P-Value }\end{array}$ & $\begin{array}{c}\text { Contractor } \\
\text { Mean }\end{array}$ & $\begin{array}{l}\text { Agency } \\
\text { Mean }\end{array}$ & $\begin{array}{l}\text { Contractor } \\
\text { St. Dev. }\end{array}$ & $\begin{array}{l}\text { Agency } \\
\text { St. Dev. }\end{array}$ \\
\hline 629 & 2016 & $19532 R$ & 7 & $\mathrm{QCP}$ & 1.00 & & 0.46 & & 2.481 & 2.481 & 0.002 & 0.000 \\
\hline 630 & 2015 & $19532 R$ & 7 & PFP & & & 0.15 & & 2.486 & & 0.006 & \\
\hline 631 & 2016 & 19523R & 7 & QCP & 0.30 & 0.91 & 0.36 & 0.00 & 2.457 & 2.454 & 0.003 & 0.003 \\
\hline 632 & 2016 & $19532 R$ & 7 & QCP & 1.00 & 0.93 & 0.00 & & 2.477 & 2.478 & 0.005 & 0.004 \\
\hline 633 & 2017 & $19532 R$ & 7 & PFP & 0.22 & 0.93 & 0.02 & 0.41 & 2.478 & 2.483 & 0.006 & 0.006 \\
\hline 634 & 2017 & $19524 R$ & 7 & PFP & & & & & & 2.483 & & 0.000 \\
\hline 635 & 2016 & 19523 & 7 & QCP & 0.86 & 0.53 & 0.82 & & 2.429 & 2.431 & 0.008 & 0.003 \\
\hline 636 & 2017 & 19523 & 7 & QCP & & & & & & 2.442 & & 0.000 \\
\hline 637 & 2016 & 19523 & 7 & QCP & 0.33 & 0.34 & & & 2.425 & 2.439 & 0.013 & 0.004 \\
\hline 638 & 2017 & 19523 & 7 & QCP & 0.40 & & 0.66 & & 2.426 & 2.442 & 0.014 & 0.000 \\
\hline 639 & 2017 & $19534 R$ & 7 & QCP & & & & 0.51 & & 2.445 & & 0.011 \\
\hline 640 & 2016 & 19534R & 7 & PFP & & & & 0.02 & & 2.442 & & 0.007 \\
\hline 641 & 2016 & $19534 R$ & 7 & QCP & 0.43 & 0.60 & 0.72 & 0.61 & 2.429 & 2.424 & 0.009 & 0.006 \\
\hline 642 & 2016 & $19524 R$ & 7 & QCP & 0.12 & 0.51 & 0.16 & 0.49 & 2.433 & 2.426 & 0.006 & 0.005 \\
\hline 643 & 2016 & 19523R & 7 & QCP & 0.71 & 0.32 & 0.11 & & 2.425 & 2.425 & 0.007 & 0.001 \\
\hline 644 & 2015 & 19534R & 7 & PFP & & & & & & 2.451 & & 0.000 \\
\hline 645 & 2015 & 19534R & 7 & PFP & & & & 0.71 & & 2.446 & & 0.007 \\
\hline 646 & 2016 & $19534 \mathrm{R}$ & 7 & QCP & & & & & 2.448 & & 0.001 & \\
\hline 647 & 2015 & $19534 \mathrm{R}$ & 7 & QCP & 0.13 & 0.36 & & 0.23 & 2.435 & 2.455 & 0.001 & 0.006 \\
\hline 648 & 2016 & 19523R & 9 & QCP & 0.67 & & & & 2.443 & 2.459 & 0.000 & 0.002 \\
\hline 649 & 2016 & $19605 \mathrm{FR}$ & 9 & QCP & 0.87 & 0.27 & 0.41 & 0.00 & 2.440 & 2.440 & 0.005 & 0.002 \\
\hline 650 & 2015 & 19534R & 7 & PFP & 0.83 & 0.32 & 0.58 & 0.67 & 2.441 & 2.441 & 0.005 & 0.003 \\
\hline 651 & 2015 & 19523R & 7 & PFP & 0.12 & 0.30 & 0.17 & 0.51 & 2.465 & 2.468 & 0.002 & 0.004 \\
\hline 652 & 2015 & 19523R & 7 & QCP & 0.35 & 0.23 & 0.48 & 0.29 & 2.466 & 2.458 & 0.006 & 0.012 \\
\hline 653 & 2016 & 19524R & 7 & QCP & 0.02 & 0.72 & 0.01 & 0.38 & 2.455 & 2.472 & 0.011 & 0.009 \\
\hline 654 & 2016 & $19534 \mathrm{R}$ & 7 & QCP & 0.67 & & & & 2.447 & 2.452 & 0.006 & 0.000 \\
\hline 655 & 2015 & $19534 R$ & 7 & PFP & 0.76 & 0.85 & 0.64 & 0.40 & 2.442 & 2.440 & 0.006 & 0.006 \\
\hline 656 & 2016 & $19654 \mathrm{R}$ & 7 & PFP & & & & & & 2.380 & & 0.000 \\
\hline 657 & 2016 & 19654R & 7 & PFP & & & & & & 2.409 & & 0.000 \\
\hline 658 & 2015 & $19654 \mathrm{R}$ & 7 & PFP & 0.41 & 0.88 & 0.88 & 0.79 & 2.387 & 2.389 & 0.008 & 0.008 \\
\hline 659 & 2016 & 19654R & 7 & PFP & 0.40 & 0.09 & 0.99 & 0.64 & 2.378 & 2.382 & 0.007 & 0.002 \\
\hline 660 & 2016 & 19654R & 7 & PFP & 0.63 & 0.66 & 0.30 & 0.80 & 2.409 & 2.410 & 0.005 & 0.004 \\
\hline 661 & 2017 & 19654R & 7 & PFP & 0.04 & 0.25 & 0.07 & 0.04 & 2.414 & 2.417 & 0.003 & 0.005 \\
\hline 662 & 2016 & $19532 R$ & 7 & PFP & 0.08 & 0.13 & 0.43 & 0.79 & 2.475 & 2.479 & 0.005 & 0.004 \\
\hline 663 & 2017 & $19532 R$ & 7 & PFP & 1.00 & & & & 2.475 & 2.475 & 0.000 & 0.000 \\
\hline
\end{tabular}




\begin{tabular}{|c|c|c|c|c|c|c|c|c|c|c|c|c|}
\hline $\begin{array}{c}\text { ICT } \\
\text { Code }\end{array}$ & Year & Mix Code & District & $\begin{array}{l}\text { Quality } \\
\text { Program }\end{array}$ & $\begin{array}{c}\text { MW } \\
\text { P-Value }\end{array}$ & $\begin{array}{l}\text { Levene's } \\
\text { P-Value }\end{array}$ & $\begin{array}{l}\text { Contractor } \\
\text { SW P-Value }\end{array}$ & $\begin{array}{c}\text { Agency SW } \\
\text { P-Value }\end{array}$ & $\begin{array}{c}\text { Contractor } \\
\text { Mean }\end{array}$ & $\begin{array}{l}\text { Agency } \\
\text { Mean }\end{array}$ & $\begin{array}{c}\text { Contractor } \\
\text { St. Dev. }\end{array}$ & $\begin{array}{l}\text { Agency } \\
\text { St. Dev. }\end{array}$ \\
\hline 664 & 2017 & 19523R & 7 & $\mathrm{QCP}$ & 0.20 & 0.50 & 0.00 & & 2.456 & 2.465 & 0.006 & 0.002 \\
\hline 665 & 2015 & 19505R & 7 & PFP & & & 0.69 & & 2.429 & & 0.014 & \\
\hline 666 & 2015 & $19532 R$ & 7 & PFP & 0.31 & 0.22 & 0.71 & 0.03 & 2.486 & 2.485 & 0.005 & 0.006 \\
\hline 667 & 2016 & 19532R & 7 & PFP & 0.03 & 0.20 & 0.24 & 0.23 & 2.473 & 2.477 & 0.006 & 0.005 \\
\hline 668 & 2015 & $19532 R$ & 7 & PFP & & & & 0.57 & & 2.472 & & 0.006 \\
\hline 669 & 2016 & 19654R & 7 & PFP & 0.09 & 0.00 & 0.16 & 0.09 & 2.407 & 2.410 & 0.007 & 0.003 \\
\hline 670 & 2015 & 19654R & 7 & PFP & 0.65 & 0.78 & 0.02 & 0.64 & 2.409 & 2.408 & 0.004 & 0.004 \\
\hline 671 & 2016 & $19532 R$ & 7 & PFP & 0.12 & 0.84 & 0.24 & 0.02 & 2.476 & 2.478 & 0.005 & 0.005 \\
\hline 672 & 2017 & 19533R & 7 & PFP & 0.01 & 0.71 & 0.02 & 0.56 & 2.445 & 2.452 & 0.005 & 0.006 \\
\hline 673 & 2017 & $19532 R$ & 7 & PFP & 0.02 & 0.44 & 0.90 & 0.28 & 2.482 & 2.488 & 0.007 & 0.006 \\
\hline 674 & 2017 & $19532 R$ & 7 & PFP & 0.00 & 0.68 & 0.76 & 0.23 & 2.475 & 2.484 & 0.004 & 0.003 \\
\hline 675 & 2017 & $19532 R$ & 7 & PFP & & & & & & 2.482 & & 0.000 \\
\hline 676 & 2017 & $19532 R$ & 7 & PFP & 0.52 & 0.05 & 0.42 & 0.46 & 2.472 & 2.471 & 0.003 & 0.007 \\
\hline 677 & 2016 & 19523R & 8 & QCP & & & & & & 2.462 & & 0.000 \\
\hline 678 & 2016 & 19523R & 8 & QCP & 0.67 & 0.75 & & & 2.459 & 2.461 & 0.001 & 0.002 \\
\hline 679 & 2016 & 19523R & 8 & QCP & 0.80 & & 0.03 & & 2.439 & 2.439 & 0.004 & 0.000 \\
\hline 680 & 2016 & 19523R & 8 & QCP & 0.00 & 0.29 & 0.12 & 0.79 & 2.435 & 2.449 & 0.008 & 0.005 \\
\hline 681 & 2016 & 19534R & 8 & QCP & 0.39 & 0.97 & 0.35 & 0.97 & 2.427 & 2.430 & 0.007 & 0.007 \\
\hline 682 & 2015 & $19534 R$ & 8 & QCP & 0.29 & & 0.32 & & 2.427 & 2.436 & 0.005 & 0.000 \\
\hline 683 & 2015 & 19534R & 8 & QCP & 0.09 & 0.77 & 0.59 & 0.35 & 2.418 & 2.424 & 0.008 & 0.007 \\
\hline 684 & 2015 & 19534R & 8 & QCP & 0.78 & 0.96 & 0.68 & 0.18 & 2.398 & 2.399 & 0.005 & 0.005 \\
\hline 685 & 2015 & 19524R & 8 & QCP & 0.17 & 0.62 & 0.97 & 0.36 & 2.429 & 2.434 & 0.005 & 0.006 \\
\hline 686 & 2017 & $19524 R$ & 8 & QCP & 0.35 & 0.94 & 0.16 & 0.10 & 2.431 & 2.433 & 0.004 & 0.004 \\
\hline 687 & 2015 & 19535R & 8 & QCP & 0.00 & 0.00 & 0.17 & 0.00 & 2.380 & 2.378 & 0.005 & 0.026 \\
\hline 688 & 2017 & 19505R & 8 & QCP & 0.17 & 0.98 & 0.19 & 0.89 & 2.450 & 2.447 & 0.004 & 0.004 \\
\hline 689 & 2015 & 19505R & 8 & QCP & 0.40 & 0.14 & 0.41 & & 2.444 & 2.449 & 0.008 & 0.001 \\
\hline 690 & 2015 & 19606R & 8 & QCP & 0.07 & 0.13 & 0.07 & & 2.422 & 2.413 & 0.004 & 0.008 \\
\hline 691 & 2015 & $19654 \mathrm{R}$ & 8 & PFP & 0.68 & 0.16 & 0.62 & 0.69 & 2.352 & 2.352 & 0.006 & 0.005 \\
\hline 692 & 2015 & 19654R & 8 & PFP & 0.53 & 1.00 & 0.23 & 0.48 & 2.355 & 2.354 & 0.007 & 0.007 \\
\hline 693 & 2015 & 19534R & 8 & QCP & 0.04 & 0.23 & 0.95 & 0.57 & 2.388 & 2.396 & 0.003 & 0.005 \\
\hline 694 & 2015 & $19654 R$ & 8 & PFP & 0.00 & 0.53 & 0.52 & 0.72 & 2.378 & 2.366 & 0.007 & 0.006 \\
\hline 695 & 2015 & $19654 \mathrm{R}$ & 8 & PFP & 0.01 & 0.05 & 0.69 & 0.29 & 2.372 & 2.369 & 0.007 & 0.005 \\
\hline 696 & 2015 & 19654R & 8 & PFP & 0.88 & 0.75 & 0.07 & 0.18 & 2.372 & 2.372 & 0.005 & 0.005 \\
\hline 697 & 2015 & 19535R & 8 & QCP & 0.98 & 0.31 & 0.80 & 0.91 & 2.389 & 2.389 & 0.005 & 0.002 \\
\hline 698 & 2015 & 19601R & 8 & QCP & & & & & 2.481 & & 0.000 & \\
\hline
\end{tabular}




\begin{tabular}{|c|c|c|c|c|c|c|c|c|c|c|c|c|}
\hline $\begin{array}{c}\text { ICT } \\
\text { Code }\end{array}$ & Year & Mix Code & District & $\begin{array}{l}\text { Quality } \\
\text { Program }\end{array}$ & $\begin{array}{c}\text { MW } \\
\text { P-Value }\end{array}$ & $\begin{array}{l}\text { Levene's } \\
\text { P-Value }\end{array}$ & $\begin{array}{l}\text { Contractor } \\
\text { SW P-Value }\end{array}$ & $\begin{array}{c}\text { Agency SW } \\
\text { P-Value }\end{array}$ & $\begin{array}{c}\text { Contractor } \\
\text { Mean }\end{array}$ & $\begin{array}{l}\text { Agency } \\
\text { Mean }\end{array}$ & $\begin{array}{c}\text { Contractor } \\
\text { St. Dev. }\end{array}$ & $\begin{array}{l}\text { Agency } \\
\text { St. Dev. }\end{array}$ \\
\hline 699 & 2016 & $19523 R$ & 8 & $\mathrm{QCP}$ & 0.02 & 0.17 & 0.96 & 0.92 & 2.459 & 2.448 & 0.004 & 0.007 \\
\hline 700 & 2016 & 19523R & 8 & QCP & & & & & & 2.445 & & 0.002 \\
\hline 701 & 2016 & 19532R & 8 & PFP & 0.06 & 0.43 & 0.36 & 0.95 & 2.463 & 2.471 & 0.009 & 0.007 \\
\hline 702 & 2016 & 19524R & 8 & QCP & 0.40 & 0.22 & 0.76 & 0.42 & 2.443 & 2.441 & 0.004 & 0.002 \\
\hline 703 & 2017 & 19524R & 8 & QCP & 0.67 & & & & 2.463 & 2.446 & 0.002 & 0.000 \\
\hline 704 & 2016 & 19524R & 8 & QCP & & & 0.30 & & 2.431 & & 0.006 & \\
\hline 705 & 2016 & 19524R & 8 & QCP & 0.67 & & & & 2.442 & 2.444 & 0.002 & 0.000 \\
\hline 706 & 2016 & 19524R & 8 & QCP & 1.00 & & & & 2.440 & 2.443 & 0.005 & 0.000 \\
\hline 707 & 2016 & 19533R & 8 & QCP & 0.67 & 0.05 & 0.01 & 0.92 & 2.441 & 2.446 & 0.006 & 0.013 \\
\hline 708 & 2016 & 19534R & 8 & PFP & 0.18 & 0.81 & 0.16 & 0.54 & 2.426 & 2.429 & 0.008 & 0.007 \\
\hline 709 & 2016 & 19534R & 8 & QCP & 0.02 & 0.18 & 0.40 & 0.45 & 2.440 & 2.444 & 0.004 & 0.002 \\
\hline 710 & 2016 & 19504R & 8 & QCP & 0.67 & 0.88 & 0.05 & & 2.472 & 2.482 & 0.011 & 0.010 \\
\hline 711 & 2016 & 19523R & 8 & QCP & 1.00 & 0.91 & 0.33 & & 2.433 & 2.432 & 0.006 & 0.004 \\
\hline 712 & 2016 & 19605R & 8 & QCP & 0.67 & & & & 2.436 & 2.432 & 0.004 & 0.000 \\
\hline 713 & 2016 & 19534R & 8 & QCP & 0.06 & 0.47 & 0.01 & & 2.452 & 2.438 & 0.005 & 0.006 \\
\hline 714 & 2017 & 19654R & 8 & PFP & & & & & & 2.399 & & 0.000 \\
\hline 715 & 2017 & 19654R & 8 & PFP & 0.00 & 0.27 & 0.00 & 0.18 & 2.407 & 2.403 & 0.007 & 0.008 \\
\hline 716 & 2017 & 19523R & 8 & QCP & 0.83 & 0.36 & 0.57 & 0.54 & 2.427 & 2.427 & 0.004 & 0.006 \\
\hline 717 & 2017 & $19523 R$ & 8 & QCP & 0.87 & 0.44 & 0.56 & 0.92 & 2.444 & 2.445 & 0.008 & 0.011 \\
\hline 718 & 2017 & $19524 R$ & 8 & QCP & 1.00 & & 0.12 & & 2.414 & 2.419 & 0.005 & 0.000 \\
\hline 719 & 2017 & $19524 \mathrm{R}$ & 8 & QCP & 0.22 & 0.14 & 0.25 & & 2.432 & 2.424 & 0.004 & 0.008 \\
\hline 720 & 2017 & 19605R & 8 & QCP & 0.80 & 0.97 & 0.24 & & 2.443 & 2.441 & 0.005 & 0.004 \\
\hline 721 & 2015 & 19533R & 9 & QCP & 0.07 & 0.75 & 0.67 & 0.86 & 2.470 & 2.477 & 0.007 & 0.006 \\
\hline 724 & 2017 & $19513 R$ & 9 & PFP & & & & & & 2.459 & & 0.000 \\
\hline 725 & 2016 & $19532 \mathrm{R}$ & 9 & QCP & 1.00 & & & & 2.487 & 2.490 & 0.006 & 0.000 \\
\hline 726 & 2016 & $19534 R$ & 9 & QCP & 0.92 & 0.44 & 0.70 & 0.00 & 2.433 & 2.434 & 0.006 & 0.008 \\
\hline 727 & 2016 & 19534R & 9 & QCP & 0.54 & 0.88 & 0.68 & 1.00 & 2.430 & 2.429 & 0.004 & 0.003 \\
\hline 728 & 2017 & $19524 R$ & 8 & QCP & 0.98 & 0.19 & 0.74 & 0.20 & 2.418 & 2.420 & 0.004 & 0.008 \\
\hline 729 & 2017 & $19524 R$ & 8 & QCP & 0.56 & 0.19 & 0.67 & 0.80 & 2.429 & 2.431 & 0.003 & 0.006 \\
\hline 730 & 2017 & $19535 R$ & 8 & QCP & 0.14 & 0.01 & 0.79 & 0.13 & 2.432 & 2.454 & 0.005 & 0.029 \\
\hline 731 & 2017 & $19532 R$ & 8 & QCP & 0.03 & 0.72 & 0.72 & 0.05 & 2.488 & 2.495 & 0.005 & 0.005 \\
\hline 732 & 2017 & $19532 R$ & 9 & QCP & & & 0.11 & & 2.490 & & 0.008 & \\
\hline 733 & 2015 & $19532 R$ & 9 & QCP & 0.36 & 0.61 & 0.49 & 0.66 & 2.490 & 2.498 & 0.012 & 0.013 \\
\hline 734 & 2015 & $19532 R$ & 9 & PFP & 0.02 & 0.86 & 0.37 & 0.54 & 2.476 & 2.483 & 0.008 & 0.007 \\
\hline 735 & 2016 & $19532 R$ & 9 & PFP & 0.21 & 0.49 & 0.36 & 0.33 & 2.483 & 2.481 & 0.008 & 0.009 \\
\hline
\end{tabular}




\begin{tabular}{|c|c|c|c|c|c|c|c|c|c|c|c|c|}
\hline $\begin{array}{c}\text { ICT } \\
\text { Code }\end{array}$ & Year & Mix Code & District & $\begin{array}{l}\text { Quality } \\
\text { Program }\end{array}$ & $\begin{array}{c}\text { MW } \\
\text { P-Value }\end{array}$ & $\begin{array}{l}\text { Levene's } \\
\text { P-Value }\end{array}$ & $\begin{array}{l}\text { Contractor } \\
\text { SW P-Value }\end{array}$ & $\begin{array}{c}\text { Agency SW } \\
\text { P-Value }\end{array}$ & $\begin{array}{c}\text { Contractor } \\
\text { Mean }\end{array}$ & $\begin{array}{l}\text { Agency } \\
\text { Mean }\end{array}$ & $\begin{array}{c}\text { Contractor } \\
\text { St. Dev. }\end{array}$ & $\begin{array}{l}\text { Agency } \\
\text { St. Dev. }\end{array}$ \\
\hline 736 & 2016 & $19532 R$ & 9 & $\mathrm{QCP}$ & & & & & 2.468 & & 0.000 & \\
\hline 737 & 2017 & 19532R & 9 & QCP & & & & & 2.474 & & 0.000 & \\
\hline 738 & 2015 & 19532R & 9 & PFP & 0.03 & 0.38 & 0.09 & 0.31 & 2.480 & 2.486 & 0.006 & 0.004 \\
\hline 739 & 2016 & 19532R & 9 & PFP & 0.36 & 0.45 & 0.23 & 0.02 & 2.486 & 2.489 & 0.009 & 0.007 \\
\hline 744 & 2017 & 19534R & 9 & QCP & 1.00 & & & & 2.440 & 2.439 & 0.000 & 0.000 \\
\hline 745 & 2016 & 19534R & 9 & QCP & 0.67 & & & & 2.431 & 2.436 & 0.000 & 0.000 \\
\hline 746 & 2016 & 19534R & 9 & QCP & 0.33 & & 0.33 & & 2.418 & 2.425 & 0.003 & 0.000 \\
\hline 747 & 2016 & 19534R & 9 & QCP & 1.00 & 0.02 & 0.13 & & 2.427 & 2.427 & 0.002 & 0.009 \\
\hline 748 & 2016 & 19534R & 9 & QCP & 0.11 & 0.74 & 0.88 & 0.64 & 2.423 & 2.428 & 0.004 & 0.003 \\
\hline 749 & 2015 & 19523R & 9 & QCP & 0.50 & & 0.35 & & 2.451 & 2.464 & 0.012 & 0.000 \\
\hline 750 & 2015 & 19523R & 9 & QCP & 0.22 & 0.86 & 0.63 & 0.30 & 2.456 & 2.465 & 0.008 & 0.006 \\
\hline 751 & 2015 & 19534R & 9 & PFP & 0.04 & 0.00 & 0.82 & & 2.431 & 2.451 & 0.008 & 0.000 \\
\hline 752 & 2015 & 19534R & 9 & QCP & 1.00 & & 0.33 & & 2.429 & 2.436 & 0.006 & 0.000 \\
\hline 753 & 2015 & 19534R & 9 & QCP & 0.50 & & 0.36 & & 2.425 & 2.432 & 0.003 & 0.000 \\
\hline 754 & 2017 & 19534R & 9 & QCP & 1.00 & & 0.13 & & 2.432 & 2.435 & 0.010 & 0.000 \\
\hline 757 & 2016 & 19535 & 9 & PFP & 0.05 & 0.51 & 0.73 & 0.62 & 2.414 & 2.407 & 0.009 & 0.007 \\
\hline 758 & 2016 & $19522 \mathrm{R}$ & 9 & QCP & 0.01 & 0.73 & 0.01 & 0.09 & 2.492 & 2.501 & 0.005 & 0.004 \\
\hline 760 & 2016 & 19523R & 9 & QCP & & & & & 2.443 & & 0.000 & \\
\hline 761 & 2016 & $19523 R$ & 9 & QCP & & & & & 2.435 & & 0.000 & \\
\hline 762 & 2017 & $19523 R$ & 9 & QCP & 0.60 & 0.98 & 0.03 & & 2.451 & 2.450 & 0.018 & 0.012 \\
\hline 763 & 2017 & $19532 \mathrm{R}$ & 9 & PFP & 0.25 & 0.27 & 0.46 & 0.24 & 2.484 & 2.482 & 0.006 & 0.003 \\
\hline 764 & 2015 & $19534 R$ & 9 & QCP & 0.19 & 0.37 & 0.74 & & 2.456 & 2.470 & 0.006 & 0.009 \\
\hline 765 & 2015 & 19533R & 9 & QCP & 1.00 & & 0.30 & & 2.458 & 2.460 & 0.003 & 0.000 \\
\hline 766 & 2015 & 19533R & 9 & QCP & 0.07 & 0.60 & 0.09 & 0.03 & 2.457 & 2.463 & 0.005 & 0.006 \\
\hline 767 & 2015 & 19533R & 9 & QCP & 0.01 & 0.71 & 0.57 & 1.00 & 2.452 & 2.457 & 0.003 & 0.002 \\
\hline 768 & 2015 & 19533R & 9 & QCP & 0.02 & 0.89 & 0.04 & 0.15 & 2.459 & 2.471 & 0.008 & 0.007 \\
\hline 769 & 2015 & 19533R & 9 & QCP & 0.29 & & 0.77 & & 2.455 & 2.467 & 0.004 & 0.000 \\
\hline 770 & 2015 & 19533R & 9 & QCP & 0.01 & 0.54 & 0.63 & 0.46 & 2.455 & 2.463 & 0.004 & 0.002 \\
\hline 771 & 2015 & 19534R & 9 & QCP & 0.17 & 0.92 & 0.33 & 0.64 & 2.441 & 2.449 & 0.006 & 0.005 \\
\hline 782 & 2015 & $19534 \mathrm{R}$ & 9 & QCP & 0.00 & 0.47 & 0.89 & 0.85 & 2.436 & 2.446 & 0.003 & 0.003 \\
\hline 783 & 2016 & $19534 R$ & 9 & QCP & 0.28 & 0.31 & 0.75 & & 2.432 & 2.423 & 0.006 & 0.009 \\
\hline 784 & 2016 & 19533R & 9 & QCP & 0.50 & 0.27 & 0.12 & & 2.456 & 2.450 & 0.008 & 0.014 \\
\hline 785 & 2016 & $19523 R$ & 9 & QCP & 1.00 & & & & 2.448 & 2.447 & 0.006 & 0.000 \\
\hline 786 & 2016 & $19523 R$ & 9 & QCP & 1.00 & & 0.25 & & 2.456 & 2.452 & 0.004 & 0.000 \\
\hline 787 & 2017 & $19523 R$ & 9 & QCP & 0.40 & 0.85 & 0.02 & & 2.455 & 2.452 & 0.003 & 0.002 \\
\hline
\end{tabular}




\begin{tabular}{|c|c|c|c|c|c|c|c|c|c|c|c|c|}
\hline $\begin{array}{c}\text { ICT } \\
\text { Code }\end{array}$ & Year & Mix Code & District & $\begin{array}{l}\text { Quality } \\
\text { Program }\end{array}$ & $\begin{array}{c}\text { MW } \\
\text { P-Value }\end{array}$ & $\begin{array}{l}\text { Levene's } \\
\text { P-Value }\end{array}$ & $\begin{array}{l}\text { Contractor } \\
\text { SW P-Value }\end{array}$ & $\begin{array}{c}\text { Agency SW } \\
\text { P-Value }\end{array}$ & $\begin{array}{c}\text { Contractor } \\
\text { Mean }\end{array}$ & $\begin{array}{l}\text { Agency } \\
\text { Mean }\end{array}$ & $\begin{array}{c}\text { Contractor } \\
\text { St. Dev. }\end{array}$ & $\begin{array}{l}\text { Agency } \\
\text { St. Dev. }\end{array}$ \\
\hline 797 & 2016 & 19535 & 9 & PFP & 0.42 & 0.59 & 0.48 & & 2.412 & 2.407 & 0.005 & 0.006 \\
\hline 798 & 2016 & 19535 & 9 & PFP & 0.08 & 0.57 & 0.14 & 0.78 & 2.415 & 2.410 & 0.004 & 0.003 \\
\hline 799 & 2016 & 19532R & 9 & PFP & 0.30 & 0.44 & 1.00 & 0.58 & 2.462 & 2.465 & 0.006 & 0.004 \\
\hline 800 & 2016 & $19532 R$ & 9 & PFP & 0.06 & 0.48 & 0.60 & 0.68 & 2.466 & 2.459 & 0.007 & 0.004 \\
\hline 801 & 2017 & 19533R & 9 & QCP & 1.00 & & 0.47 & & 2.449 & 2.449 & 0.006 & 0.000 \\
\hline 802 & 2016 & 19533R & 9 & QCP & 0.05 & 0.49 & 0.90 & 0.69 & 2.453 & 2.444 & 0.006 & 0.007 \\
\hline 803 & 2017 & 19534R & 9 & PFP & 0.10 & 0.95 & 0.41 & 0.43 & 2.436 & 2.443 & 0.006 & 0.006 \\
\hline 804 & 2017 & $19532 R$ & 9 & PFP & 0.95 & 0.49 & 0.48 & 0.96 & 2.470 & 2.470 & 0.006 & 0.007 \\
\hline 805 & 2015 & 19533R & 9 & QCP & 0.09 & 0.05 & 0.18 & 0.60 & 2.459 & 2.470 & 0.005 & 0.011 \\
\hline 806 & 2016 & 19534R & 9 & QCP & 0.36 & 0.16 & 0.59 & & 2.434 & 2.431 & 0.007 & 0.001 \\
\hline 807 & 2015 & $19534 R$ & 9 & QCP & 0.40 & & 0.54 & & 2.434 & 2.444 & 0.003 & 0.000 \\
\hline 808 & 2016 & 19534R & 9 & QCP & 0.64 & 0.54 & 0.11 & 0.92 & 2.438 & 2.436 & 0.005 & 0.007 \\
\hline 809 & 2016 & 19606FR & 9 & QCP & & & & & & & & \\
\hline 810 & 2016 & 19534R & 9 & QCP & 1.00 & & 0.25 & & 2.442 & 2.443 & 0.005 & 0.000 \\
\hline 815 & 2016 & 19533R & 9 & QCP & 0.29 & 0.00 & 0.06 & & 2.457 & 2.461 & 0.005 & 0.000 \\
\hline 816 & 2015 & 19523R & 9 & QCP & 0.00 & 0.44 & 0.99 & 0.70 & 2.451 & 2.461 & 0.006 & 0.004 \\
\hline 817 & 2016 & 19523R & 9 & QCP & 0.86 & & 0.33 & & 2.463 & 2.465 & 0.005 & 0.000 \\
\hline 818 & 2015 & 19523R & 9 & QCP & 0.33 & & 0.60 & & 2.452 & 2.463 & 0.006 & 0.000 \\
\hline 819 & 2015 & 19523R & 9 & QCP & 0.17 & 0.78 & 0.95 & 1.00 & 2.463 & 2.471 & 0.008 & 0.006 \\
\hline 820 & 2015 & 19523R & 9 & QCP & 0.06 & 0.90 & 0.35 & & 2.451 & 2.467 & 0.005 & 0.004 \\
\hline 821 & 2016 & $19532 R$ & 9 & QCP & 0.77 & 0.96 & 0.12 & 0.68 & 2.484 & 2.485 & 0.005 & 0.005 \\
\hline 822 & 2016 & $19532 R$ & 9 & QCP & 0.50 & & 0.00 & & 2.490 & 2.473 & 0.011 & 0.000 \\
\hline 823 & 2016 & $19522 \mathrm{R}$ & 9 & QCP & 0.79 & 0.18 & 0.01 & 0.02 & 2.491 & 2.491 & 0.008 & 0.003 \\
\hline 828 & 2017 & $19532 R$ & 9 & QCP & 0.24 & 0.53 & 0.44 & 0.40 & 2.491 & 2.486 & 0.008 & 0.009 \\
\hline 829 & 2017 & $19524 \mathrm{R}$ & 9 & QCP & 1.00 & & 0.54 & & 2.442 & 2.443 & 0.005 & 0.000 \\
\hline 830 & 2017 & $19534 \mathrm{R}$ & 9 & $\mathrm{QCP}$ & 0.11 & 1.00 & 0.45 & 0.16 & 2.446 & 2.442 & 0.005 & 0.004 \\
\hline 831 & 2016 & $19532 R$ & 9 & PFP & & & 0.57 & & 2.477 & & 0.015 & \\
\hline 832 & 2016 & 19523R & 9 & QCP & 0.27 & 0.85 & 0.56 & & 2.453 & 2.459 & 0.003 & 0.002 \\
\hline 833 & 2016 & 19535R & 9 & PFP & & & & & 2.430 & & 0.000 & \\
\hline 834 & 2017 & 19523R & 9 & $\mathrm{QCP}$ & 0.40 & 0.62 & 0.38 & 0.94 & 2.439 & 2.448 & 0.013 & 0.009 \\
\hline 835 & 2017 & $19532 R$ & 9 & PFP & & & & & 2.474 & & 0.000 & \\
\hline 836 & 2017 & 19532R & 9 & PFP & 0.29 & & 0.52 & & 2.470 & 2.475 & 0.003 & 0.000 \\
\hline
\end{tabular}




\section{C.5 $\mathrm{G}_{\mathrm{MB}}$ ANALYSIS RESULTS}

Table C.5. $\mathbf{G}_{\mathrm{mb}}$ Analysis Results Summary

\begin{tabular}{|c|c|c|c|c|c|c|c|c|c|c|c|c|}
\hline $\begin{array}{c}\text { ICT } \\
\text { Code }\end{array}$ & Year & Mix Code & District & $\begin{array}{l}\text { Quality } \\
\text { Program }\end{array}$ & $\begin{array}{c}\text { MW } \\
\text { P-Value }\end{array}$ & $\begin{array}{l}\text { Levene's } \\
\text { P-Value }\end{array}$ & $\begin{array}{l}\text { Contractor } \\
\text { SW P-Value }\end{array}$ & $\begin{array}{c}\text { Agency SW } \\
\text { P-Value }\end{array}$ & $\begin{array}{c}\text { Contractor } \\
\text { Mean }\end{array}$ & $\begin{array}{l}\text { Agency } \\
\text { Mean }\end{array}$ & $\begin{array}{c}\text { Contractor } \\
\text { St. Dev. }\end{array}$ & $\begin{array}{l}\text { Agency } \\
\text { St. Dev. }\end{array}$ \\
\hline 1 & 2015 & 19524R & 1 & $\mathrm{QCP}$ & 0.33 & 0.00 & & & 2.422 & 2.447 & 0.008 & 0.000 \\
\hline 2 & 2017 & 19524R & 1 & QCP & 0.67 & & & & 2.444 & 2.439 & 0.004 & 0.000 \\
\hline 3 & 2017 & $19524 \mathrm{R}$ & 1 & QCP & 1.00 & & & & 2.421 & 2.423 & 0.029 & 0.000 \\
\hline 4 & 2016 & $19524 \mathrm{R}$ & 1 & QCP & 0.32 & 0.43 & 0.68 & 0.44 & 2.419 & 2.428 & 0.012 & 0.019 \\
\hline 5 & 2015 & 19514R & 1 & QCP & & & & & 2.374 & & 0.000 & \\
\hline 6 & 2015 & 19514R & 1 & QCP & 0.67 & & & & 2.390 & 2.397 & 0.004 & 0.000 \\
\hline 7 & 2015 & 19524R & 1 & QCP & 0.64 & 0.63 & 0.47 & 0.00 & 2.383 & 2.388 & 0.006 & 0.006 \\
\hline 8 & 2015 & 19524R & 1 & QCP & & & & & 2.383 & & 0.001 & \\
\hline 9 & 2015 & 19524R & 1 & PFP & 0.17 & 0.31 & 0.18 & 0.39 & 2.382 & 2.392 & 0.009 & 0.013 \\
\hline 10 & 2015 & $19512 \mathrm{R}$ & 1 & QCP & 0.50 & & 0.46 & & 2.414 & 2.404 & 0.004 & 0.000 \\
\hline 11 & 2015 & $19512 \mathrm{R}$ & 1 & QCP & 0.67 & & & & 2.434 & 2.425 & 0.009 & 0.000 \\
\hline 12 & 2015 & $19522 \mathrm{R}$ & 1 & QCP & 0.03 & 0.04 & 0.04 & 0.02 & 2.421 & 2.448 & 0.017 & 0.033 \\
\hline 13 & 2017 & $19522 \mathrm{R}$ & 1 & QCP & 0.33 & 0.38 & & & 2.438 & 2.421 & 0.003 & 0.009 \\
\hline 14 & 2015 & 19510R & 1 & QCP & 1.00 & & 0.41 & & 2.345 & 2.341 & 0.005 & 0.000 \\
\hline 15 & 2015 & 19510R & 1 & QCP & & & & & 2.352 & & 0.006 & \\
\hline 16 & 2015 & 19510R & 1 & QCP & 0.35 & 0.02 & 0.00 & 0.47 & 2.346 & 2.351 & 0.004 & 0.013 \\
\hline 17 & 2015 & $19512 R$ & 1 & QCP & 0.67 & & & & 2.424 & 2.449 & 0.000 & 0.028 \\
\hline 18 & 2015 & 19510R & 1 & QCP & 0.13 & 0.19 & 0.22 & & 2.351 & 2.372 & 0.002 & 0.006 \\
\hline 19 & 2015 & 19536R & 1 & QCP & & & & 0.19 & & 2.388 & & 0.035 \\
\hline 20 & 2017 & $19525 R$ & 1 & QCP & 0.53 & 0.44 & 0.42 & & 2.401 & 2.384 & 0.013 & 0.020 \\
\hline 21 & 2015 & 19524R & 1 & QCP & 0.67 & & & & 2.406 & 2.423 & 0.000 & 0.000 \\
\hline 22 & 2015 & $19524 \mathrm{R}$ & 1 & QCP & 1.00 & & & & 2.401 & 2.392 & 0.018 & 0.000 \\
\hline 23 & 2015 & $19512 \mathrm{R}$ & 1 & QCP & 1.00 & & 0.19 & & 2.450 & 2.445 & 0.005 & 0.000 \\
\hline 24 & 2016 & 19532R & 1 & QCP & 0.33 & 0.20 & & & 2.434 & 2.451 & 0.003 & 0.018 \\
\hline 25 & 2017 & $19532 R$ & 1 & QCP & 0.40 & & 0.51 & & 2.410 & 2.430 & 0.016 & 0.000 \\
\hline 26 & 2017 & 19510R & 1 & QCP & 1.00 & & & & 2.342 & 2.343 & 0.000 & 0.000 \\
\hline 27 & 2015 & 19510R & 1 & QCP & 0.57 & 0.63 & 0.91 & 0.89 & 2.346 & 2.340 & 0.008 & 0.010 \\
\hline 28 & 2017 & 19665R & 1 & QCP & & & & & 2.359 & & 0.001 & \\
\hline 29 & 2015 & $19665 R$ & 1 & QCP & 0.63 & 0.13 & 0.85 & 0.27 & 2.356 & 2.357 & 0.004 & 0.011 \\
\hline 30 & 2017 & 19524R & 1 & QCP & 0.89 & 0.33 & 0.88 & 0.75 & 2.399 & 2.398 & 0.013 & 0.019 \\
\hline 31 & 2017 & 19525R & 1 & $\mathrm{QCP}$ & 0.67 & & & & 2.393 & 2.384 & 0.000 & 0.000 \\
\hline
\end{tabular}




\begin{tabular}{|c|c|c|c|c|c|c|c|c|c|c|c|c|}
\hline $\begin{array}{c}\mathrm{ICT} \\
\text { Code }\end{array}$ & Year & Mix Code & District & $\begin{array}{l}\text { Quality } \\
\text { Program }\end{array}$ & $\begin{array}{c}\text { MW } \\
\text { P-Value }\end{array}$ & $\begin{array}{c}\text { Levene's } \\
\text { P-Value }\end{array}$ & $\begin{array}{l}\text { Contractor } \\
\text { SW P-Value }\end{array}$ & $\begin{array}{c}\text { Agency SW } \\
\text { P-Value }\end{array}$ & $\begin{array}{c}\text { Contractor } \\
\text { Mean }\end{array}$ & $\begin{array}{l}\text { Agency } \\
\text { Mean }\end{array}$ & $\begin{array}{c}\text { Contractor } \\
\text { St. Dev. }\end{array}$ & $\begin{array}{l}\text { Agency } \\
\text { St. Dev. }\end{array}$ \\
\hline 32 & 2016 & 19510R & 1 & QCP & 0.50 & & 0.30 & & 2.336 & 2.356 & 0.003 & 0.000 \\
\hline 33 & 2015 & 19525R & 1 & QCP & & & 0.99 & & 2.402 & & 0.011 & \\
\hline 34 & 2016 & $19512 \mathrm{R}$ & 1 & QCP & & & 0.83 & & 2.426 & & 0.008 & \\
\hline 35 & 2015 & $19512 R$ & 1 & QCP & 0.67 & & & & 2.412 & 2.432 & 0.008 & 0.000 \\
\hline 36 & 2015 & $19522 \mathrm{R}$ & 1 & QCP & 0.43 & & 0.30 & & 2.431 & 2.415 & 0.016 & 0.000 \\
\hline 37 & 2015 & $19522 \mathrm{R}$ & 1 & QCP & & & & & & 2.410 & & 0.000 \\
\hline 38 & 2015 & $19524 R$ & 1 & QCP & 0.10 & 0.15 & 0.29 & 0.95 & 2.411 & 2.387 & 0.017 & 0.029 \\
\hline 39 & 2015 & 19510R & 1 & QCP & 0.80 & 0.92 & 0.02 & & 2.355 & 2.346 & 0.018 & 0.015 \\
\hline 40 & 2015 & 19510R & 1 & QCP & & & & & 2.321 & & 0.000 & \\
\hline 41 & 2015 & 19510R & 1 & QCP & 1.00 & 1.00 & & & 2.326 & 2.326 & 0.013 & 0.013 \\
\hline 42 & 2015 & $19524 R$ & 1 & QCP & & & 0.11 & & 2.380 & & 0.006 & \\
\hline 43 & 2015 & $19524 R$ & 1 & QCP & 0.30 & 0.74 & 0.47 & 0.57 & 2.386 & 2.394 & 0.017 & 0.019 \\
\hline 44 & 2015 & 19510R & 1 & PFP & 0.87 & 0.44 & 0.88 & 0.21 & 2.338 & 2.337 & 0.010 & 0.012 \\
\hline 45 & 2015 & 19510R & 1 & PFP & & & & & 2.352 & & 0.000 & \\
\hline 46 & 2015 & $19524 R$ & 1 & QCP & 0.74 & 0.24 & 0.63 & 0.29 & 2.383 & 2.375 & 0.008 & 0.018 \\
\hline 47 & 2015 & 19655R & 1 & PFP & 0.07 & 0.00 & 0.50 & 0.80 & 2.520 & 2.506 & 0.014 & 0.033 \\
\hline 48 & 2015 & 19536R & 1 & PFP & 0.55 & 0.14 & 0.43 & 0.46 & 2.571 & 2.576 & 0.019 & 0.029 \\
\hline 49 & 2017 & 19510R & 1 & QCP & 1.00 & & 0.16 & & 2.361 & 2.359 & 0.008 & 0.000 \\
\hline 50 & 2017 & 19510R & 1 & QCP & 0.44 & & 0.19 & & 2.360 & 2.353 & 0.008 & 0.000 \\
\hline 51 & 2016 & 19510R & 1 & QCP & 0.67 & 0.73 & & 0.66 & 2.332 & 2.323 & 0.008 & 0.015 \\
\hline 52 & 2017 & 19524R & 1 & QCP & 0.67 & & & & 2.409 & 2.389 & 0.018 & 0.000 \\
\hline 53 & 2017 & $19525 R$ & 1 & QCP & 1.00 & & 0.56 & & 2.401 & 2.395 & 0.021 & 0.000 \\
\hline 54 & 2017 & 19525R & 1 & PFP & 0.16 & 0.39 & 0.14 & 0.25 & 2.399 & 2.391 & 0.011 & 0.008 \\
\hline 55 & 2016 & $19525 R$ & 1 & QCP & 0.17 & 0.88 & 0.43 & 0.38 & 2.400 & 2.387 & 0.012 & 0.010 \\
\hline 56 & 2016 & 19536R & 1 & QCP & & & & & 2.375 & & 0.006 & \\
\hline 57 & 2015 & 19536R & 1 & PFP & 0.75 & 0.14 & 0.03 & 0.01 & 2.394 & 2.395 & 0.021 & 0.033 \\
\hline 58 & 2015 & $19524 R$ & 1 & QCP & 0.01 & 0.59 & 0.34 & 0.23 & 2.438 & 2.476 & 0.012 & 0.009 \\
\hline 59 & 2017 & $19524 R$ & 1 & QCP & 0.10 & 0.73 & 0.46 & 0.17 & 2.421 & 2.457 & 0.004 & 0.006 \\
\hline 60 & 2015 & $19522 \mathrm{R}$ & 1 & QCP & 0.34 & 0.69 & 0.60 & 0.71 & 2.427 & 2.439 & 0.014 & 0.018 \\
\hline 61 & 2015 & $19522 \mathrm{R}$ & 1 & QCP & 0.02 & 0.46 & 0.01 & 0.04 & 2.448 & 2.481 & 0.012 & 0.017 \\
\hline 62 & 2015 & 19510R & 1 & QCP & 0.67 & & & & 2.356 & 2.370 & 0.005 & 0.000 \\
\hline 63 & 2015 & 19510R & 1 & PFP & 0.98 & 0.16 & 0.24 & 0.20 & 2.371 & 2.375 & 0.031 & 0.016 \\
\hline 64 & 2017 & $19524 R$ & 1 & $\mathrm{QCP}$ & 1.00 & & & & 2.384 & 2.367 & 0.000 & 0.000 \\
\hline 65 & 2017 & 19524R & 1 & PFP & 0.43 & 0.63 & 0.46 & 0.33 & 2.410 & 2.414 & 0.013 & 0.016 \\
\hline 66 & 2017 & 19524R & 1 & QCP & 0.67 & & & & 2.415 & 2.394 & 0.012 & 0.000 \\
\hline
\end{tabular}




\begin{tabular}{|c|c|c|c|c|c|c|c|c|c|c|c|c|}
\hline $\begin{array}{l}\text { ICT } \\
\text { Code }\end{array}$ & Year & Mix Code & District & $\begin{array}{l}\text { Quality } \\
\text { Program }\end{array}$ & $\begin{array}{c}\text { MW } \\
\text { P-Value }\end{array}$ & $\begin{array}{l}\text { Levene's } \\
\text { P-Value }\end{array}$ & $\begin{array}{l}\text { Contractor } \\
\text { SW P-Value }\end{array}$ & $\begin{array}{c}\text { Agency SW } \\
\text { P-Value }\end{array}$ & $\begin{array}{c}\text { Contractor } \\
\text { Mean }\end{array}$ & $\begin{array}{l}\text { Agency } \\
\text { Mean }\end{array}$ & $\begin{array}{l}\text { Contractor } \\
\text { St. Dev. }\end{array}$ & $\begin{array}{l}\text { Agency } \\
\text { St. Dev. }\end{array}$ \\
\hline 67 & 2017 & 19510R & 1 & $\mathrm{QCP}$ & 0.10 & 0.17 & 0.00 & 0.00 & 2.353 & 2.371 & 0.002 & 0.006 \\
\hline 68 & 2015 & $19532 R$ & 1 & QCP & 0.70 & 0.84 & 0.36 & 0.40 & 2.443 & 2.441 & 0.016 & 0.012 \\
\hline 69 & 2017 & 19510R & 1 & QCP & 0.70 & 0.47 & 0.12 & 0.55 & 2.355 & 2.350 & 0.016 & 0.028 \\
\hline 70 & 2016 & 19510R & 1 & QCP & 1.00 & & & & 2.356 & 2.349 & 0.009 & 0.000 \\
\hline 71 & 2017 & $19524 \mathrm{R}$ & 1 & PFP & & & & & 2.413 & & 0.000 & \\
\hline 72 & 2017 & 19510R & 1 & QCP & 0.20 & 0.66 & & 0.50 & 2.355 & 2.371 & 0.010 & 0.008 \\
\hline 73 & 2017 & 19510R & 1 & QCP & 0.50 & 0.06 & 0.36 & 0.39 & 2.353 & 2.368 & 0.003 & 0.015 \\
\hline 74 & 2016 & 19525R & 1 & QCP & 0.07 & 0.80 & 0.46 & & 2.383 & 2.365 & 0.010 & 0.006 \\
\hline 75 & 2017 & 19665R & 1 & QCP & 1.00 & 0.15 & & & 2.349 & 2.350 & 0.003 & 0.024 \\
\hline 76 & 2017 & 19655R & 1 & QCP & 1.00 & 0.00 & & & 2.375 & 2.369 & 0.009 & 0.000 \\
\hline 77 & 2017 & 19665R & 1 & QCP & 0.60 & 0.22 & 0.00 & & 2.356 & 2.355 & 0.009 & 0.001 \\
\hline 78 & 2015 & $19512 \mathrm{R}$ & 1 & QCP & 0.65 & 0.00 & 0.32 & 0.89 & 2.424 & 2.415 & 0.007 & 0.024 \\
\hline 79 & 2015 & $19522 \mathrm{R}$ & 1 & PFP & 0.71 & 0.85 & & 0.06 & 2.428 & 2.426 & 0.013 & 0.021 \\
\hline 80 & 2017 & $19522 \mathrm{R}$ & 1 & QCP & 0.33 & 0.17 & 0.54 & & 2.445 & 2.453 & 0.013 & 0.001 \\
\hline 81 & 2015 & $19522 \mathrm{R}$ & 1 & QCP & & & & & & 2.357 & & 0.000 \\
\hline 82 & 2015 & 19514R & 1 & QCP & 0.86 & 0.06 & 0.16 & 0.68 & 2.408 & 2.404 & 0.007 & 0.016 \\
\hline 83 & 2015 & $19524 \mathrm{R}$ & 1 & QCP & 0.53 & 0.99 & 0.74 & 0.37 & 2.400 & 2.389 & 0.021 & 0.020 \\
\hline 84 & 2015 & $19512 \mathrm{R}$ & 1 & QCP & 0.48 & 0.12 & 0.42 & 0.20 & 2.426 & 2.433 & 0.011 & 0.018 \\
\hline 85 & 2015 & $19512 \mathrm{R}$ & 1 & QCP & 1.00 & & 0.24 & & 2.424 & 2.421 & 0.024 & 0.000 \\
\hline 86 & 2015 & 19525R & 1 & PFP & & & 0.35 & & 2.436 & & 0.012 & \\
\hline 87 & 2015 & 19510R & 1 & QCP & 0.80 & & 0.78 & & 2.350 & 2.353 & 0.004 & 0.000 \\
\hline 88 & 2017 & 19510R & 1 & QCP & 0.20 & 0.45 & 0.56 & 0.89 & 2.352 & 2.364 & 0.012 & 0.017 \\
\hline 89 & 2017 & $19532 \mathrm{R}$ & 1 & QCP & 1.00 & & & & 2.440 & 2.435 & 0.011 & 0.000 \\
\hline 90 & 2016 & $19524 \mathrm{R}$ & 1 & QCP & 1.00 & & 0.93 & & 2.411 & 2.413 & 0.008 & 0.000 \\
\hline 91 & 2016 & 19524R & 1 & QCP & & & & & & 2.410 & & 0.010 \\
\hline 92 & 2017 & 19536R & 1 & QCP & 1.00 & & & & 2.465 & 2.467 & 0.000 & 0.000 \\
\hline 93 & 2015 & 19536R & 1 & QCP & 0.17 & 0.36 & 0.79 & 0.00 & 2.634 & 2.654 & 0.022 & 0.010 \\
\hline 94 & 2015 & 19524R & 1 & QCP & 0.63 & 0.19 & 0.14 & 0.82 & 2.395 & 2.382 & 0.007 & 0.021 \\
\hline 95 & 2015 & $19512 \mathrm{R}$ & 1 & QCP & 0.93 & 0.41 & 0.26 & & 2.460 & 2.456 & 0.014 & 0.021 \\
\hline 96 & 2015 & $19512 \mathrm{R}$ & 1 & QCP & 0.03 & 0.61 & 0.51 & 0.41 & 2.455 & 2.469 & 0.007 & 0.008 \\
\hline 97 & 2015 & $19514 R$ & 1 & QCP & 0.97 & 0.45 & 0.48 & 0.07 & 2.403 & 2.405 & 0.018 & 0.025 \\
\hline 98 & 2017 & $19522 \mathrm{R}$ & 1 & QCP & 1.00 & & & & 2.463 & 2.435 & 0.000 & 0.000 \\
\hline 99 & 2017 & $19522 \mathrm{R}$ & 1 & QCP & 0.57 & & 0.02 & & 2.429 & 2.451 & 0.012 & 0.000 \\
\hline 100 & 2016 & $19522 \mathrm{R}$ & 1 & QCP & 0.02 & 0.12 & 0.18 & 0.14 & 2.450 & 2.468 & 0.013 & 0.021 \\
\hline 101 & 2015 & 19510R & 1 & QCP & 1.00 & & & & 2.363 & 2.367 & 0.013 & 0.000 \\
\hline
\end{tabular}




\begin{tabular}{|c|c|c|c|c|c|c|c|c|c|c|c|c|}
\hline $\begin{array}{c}\text { ICT } \\
\text { Code }\end{array}$ & Year & Mix Code & District & $\begin{array}{l}\text { Quality } \\
\text { Program }\end{array}$ & $\begin{array}{c}\text { MW } \\
\text { P-Value }\end{array}$ & $\begin{array}{l}\text { Levene's } \\
\text { P-Value }\end{array}$ & $\begin{array}{l}\text { Contractor } \\
\text { SW P-Value }\end{array}$ & $\begin{array}{c}\text { Agency SW } \\
\text { P-Value }\end{array}$ & $\begin{array}{c}\text { Contractor } \\
\text { Mean }\end{array}$ & $\begin{array}{l}\text { Agency } \\
\text { Mean }\end{array}$ & $\begin{array}{c}\text { Contractor } \\
\text { St. Dev. }\end{array}$ & $\begin{array}{l}\text { Agency } \\
\text { St. Dev. }\end{array}$ \\
\hline 102 & 2015 & 19510R & 1 & QCP & & & 0.54 & & 2.372 & & 0.004 & \\
\hline 103 & 2015 & 19510R & 1 & QCP & 0.33 & 0.00 & & & 2.370 & 2.379 & 0.008 & 0.000 \\
\hline 104 & 2015 & 19510R & 1 & QCP & 1.00 & & & & 2.367 & 2.366 & 0.007 & 0.000 \\
\hline 105 & 2017 & 19510R & 1 & QCP & 0.38 & 0.91 & 0.27 & 0.10 & 2.364 & 2.367 & 0.006 & 0.007 \\
\hline 108 & 2017 & $19532 R$ & 1 & QCP & 0.80 & 0.90 & 0.33 & & 2.444 & 2.458 & 0.014 & 0.013 \\
\hline 107 & 2017 & $19532 R$ & 1 & QCP & 0.71 & 0.53 & 0.62 & 0.70 & 2.431 & 2.438 & 0.020 & 0.011 \\
\hline 108 & 2017 & 19532R & 1 & QCP & 0.76 & 0.52 & 0.99 & 0.54 & 2.428 & 2.426 & 0.016 & 0.021 \\
\hline 109 & 2015 & 19536R & 1 & QCP & 1.00 & & 0.10 & & 2.591 & 2.605 & 0.027 & 0.000 \\
\hline 110 & 2015 & 19536R & 1 & QCP & 0.50 & & 0.54 & & 2.625 & 2.615 & 0.007 & 0.000 \\
\hline 111 & 2015 & 19524R & 1 & QCP & 1.00 & & 0.09 & & 2.394 & 2.391 & 0.010 & 0.000 \\
\hline 112 & 2015 & 19524R & 1 & QCP & 1.00 & & & & 2.388 & 2.394 & 0.013 & 0.000 \\
\hline 113 & 2015 & 19524R & 1 & QCP & 0.51 & 0.66 & 0.04 & 0.00 & 2.385 & 2.385 & 0.023 & 0.018 \\
\hline 114 & 2017 & 19510R & 1 & QCP & 1.00 & 0.19 & & & 2.349 & 2.350 & 0.003 & 0.018 \\
\hline 115 & 2017 & 19510R & 1 & QCP & & & 0.95 & & 2.386 & & 0.012 & \\
\hline 116 & 2016 & 19510R & 1 & QCP & & & & & & 2.355 & & 0.001 \\
\hline 117 & 2017 & 19510R & 1 & QCP & 0.06 & 0.29 & 0.64 & 0.20 & 2.349 & 2.364 & 0.002 & 0.004 \\
\hline 118 & 2016 & 19510R & 1 & QCP & 0.04 & 0.08 & 0.75 & 0.00 & 2.359 & 2.377 & 0.002 & 0.006 \\
\hline 119 & 2017 & 19510R & 1 & QCP & 1.00 & 0.04 & 0.46 & & 2.355 & 2.352 & 0.002 & 0.014 \\
\hline 120 & 2017 & 19510R & 1 & QCP & 1.00 & 0.73 & & & 2.353 & 2.352 & 0.008 & 0.012 \\
\hline 121 & 2017 & 19510R & 1 & QCP & 1.00 & 0.46 & & & 2.345 & 2.347 & 0.006 & 0.002 \\
\hline 122 & 2015 & $19522 \mathrm{R}$ & 1 & QCP & 0.67 & & & & 2.423 & 2.416 & 0.008 & 0.000 \\
\hline 123 & 2015 & $19522 \mathrm{R}$ & 1 & QCP & 1.00 & & 0.84 & & 2.429 & 2.432 & 0.014 & 0.000 \\
\hline 124 & 2017 & $19524 \mathrm{R}$ & 1 & QCP & 1.00 & & & & 2.404 & 2.403 & 0.000 & 0.000 \\
\hline 125 & 2017 & $19524 \mathrm{R}$ & 1 & QCP & 0.60 & 0.27 & 0.36 & 0.00 & 2.418 & 2.430 & 0.008 & 0.020 \\
\hline 126 & 2017 & $19524 \mathrm{R}$ & 1 & PFP & & & 0.08 & & 2.416 & & 0.010 & \\
\hline 127 & 2016 & $19524 \mathrm{R}$ & 1 & QCP & 1.00 & & & & 2.402 & 2.401 & 0.006 & 0.000 \\
\hline 128 & 2017 & $19524 \mathrm{R}$ & 1 & QCP & 0.67 & & 0.75 & & 2.399 & 2.386 & 0.014 & 0.000 \\
\hline 129 & 2017 & $19524 R$ & 1 & QCP & 1.00 & 0.84 & 0.91 & & 2.405 & 2.406 & 0.009 & 0.006 \\
\hline 130 & 2017 & $19524 R$ & 1 & QCP & 1.00 & 0.36 & & & 2.364 & 2.360 & 0.005 & 0.017 \\
\hline 131 & 2015 & 19510R & 1 & QCP & 1.00 & & & & 2.371 & 2.372 & 0.000 & 0.000 \\
\hline 132 & 2015 & 19510R & 1 & QCP & 0.01 & 0.15 & 0.01 & 0.52 & 2.365 & 2.380 & 0.008 & 0.013 \\
\hline 133 & 2015 & 19536R & 1 & PFP & 0.05 & 0.49 & 0.87 & 0.86 & 2.603 & 2.623 & 0.016 & 0.020 \\
\hline 134 & 2015 & $19522 \mathrm{R}$ & 1 & PFP & & & & & 2.437 & & 0.026 & \\
\hline 135 & 2015 & $19522 \mathrm{R}$ & 1 & QCP & 0.67 & 0.44 & 0.99 & & 2.420 & 2.412 & 0.009 & 0.014 \\
\hline 136 & 2015 & 19536R & 1 & QCP & 1.00 & & & & 2.588 & 2.574 & 0.000 & 0.000 \\
\hline
\end{tabular}




\begin{tabular}{|c|c|c|c|c|c|c|c|c|c|c|c|c|}
\hline $\begin{array}{l}\text { ICT } \\
\text { Code }\end{array}$ & Year & Mix Code & District & $\begin{array}{l}\text { Quality } \\
\text { Program }\end{array}$ & $\begin{array}{c}\text { MW } \\
\text { P-Value }\end{array}$ & $\begin{array}{l}\text { Levene's } \\
\text { P-Value }\end{array}$ & $\begin{array}{l}\text { Contractor } \\
\text { SW P-Value }\end{array}$ & $\begin{array}{c}\text { Agency SW } \\
\text { P-Value }\end{array}$ & $\begin{array}{c}\text { Contractor } \\
\text { Mean }\end{array}$ & $\begin{array}{l}\text { Agency } \\
\text { Mean }\end{array}$ & $\begin{array}{l}\text { Contractor } \\
\text { St. Dev. }\end{array}$ & $\begin{array}{l}\text { Agency } \\
\text { St. Dev. }\end{array}$ \\
\hline 137 & 2015 & 19524R & 1 & $\mathrm{QCP}$ & 0.49 & 0.58 & 0.77 & 0.95 & 2.424 & 2.420 & 0.007 & 0.009 \\
\hline 138 & 2015 & 19510R & 1 & QCP & 0.67 & 0.93 & & & 2.328 & 2.335 & 0.035 & 0.032 \\
\hline 139 & 2015 & 19510R & 1 & QCP & 1.00 & & & & 2.300 & 2.299 & 0.000 & 0.000 \\
\hline 140 & 2015 & 19524R & 1 & QCP & 0.00 & 0.46 & 0.01 & 0.37 & 2.404 & 2.417 & 0.008 & 0.010 \\
\hline 141 & 2015 & $19665 R$ & 1 & QCP & 0.92 & 0.15 & 0.07 & 0.29 & 2.714 & 2.711 & 0.031 & 0.020 \\
\hline 142 & 2015 & 19524R & 1 & QCP & 0.20 & 0.11 & & 1.00 & 2.507 & 2.528 & 0.001 & 0.018 \\
\hline 143 & 2015 & 19524R & 1 & QCP & 0.52 & 0.40 & 0.37 & 0.54 & 2.516 & 2.522 & 0.011 & 0.019 \\
\hline 144 & 2017 & 19510R & 1 & QCP & 0.43 & 0.76 & 0.45 & & 2.341 & 2.334 & 0.009 & 0.008 \\
\hline 145 & 2017 & 19510R & 1 & QCP & 0.67 & & & & 2.332 & 2.335 & 0.003 & 0.000 \\
\hline 146 & 2017 & 19510R & 1 & QCP & 0.40 & 0.97 & 0.58 & & 2.355 & 2.361 & 0.007 & 0.006 \\
\hline 147 & 2015 & 19510R & 1 & QCP & 0.67 & & & & 2.363 & 2.347 & 0.002 & 0.000 \\
\hline 148 & 2017 & $19522 \mathrm{R}$ & 1 & QCP & 0.40 & & 0.20 & & 2.439 & 2.427 & 0.008 & 0.000 \\
\hline 149 & 2015 & $19522 \mathrm{R}$ & 1 & QCP & 0.37 & 0.84 & 0.49 & 0.45 & 2.418 & 2.405 & 0.022 & 0.023 \\
\hline 150 & 2015 & 19536R & 1 & QCP & 0.05 & 0.02 & 0.34 & 0.61 & 2.625 & 2.603 & 0.005 & 0.016 \\
\hline 151 & 2017 & 19524R & 1 & QCP & 0.33 & 0.52 & & & 2.394 & 2.370 & 0.002 & 0.005 \\
\hline 152 & 2017 & $19524 R$ & 1 & QCP & & & & 0.02 & & 2.433 & & 0.002 \\
\hline 153 & 2017 & 19524R & 1 & QCP & 0.67 & 0.81 & & & 2.408 & 2.380 & 0.018 & 0.024 \\
\hline 154 & 2015 & 19525R & 1 & QCP & 1.00 & & 0.78 & & 2.431 & 2.426 & 0.008 & 0.000 \\
\hline 155 & 2017 & 19525R & 1 & QCP & 0.67 & & & & 2.448 & 2.438 & 0.001 & 0.000 \\
\hline 156 & 2015 & 19525R & 1 & QCP & 0.38 & 0.16 & 0.94 & & 2.431 & 2.436 & 0.003 & 0.007 \\
\hline 157 & 2015 & 19524R & 1 & QCP & 0.80 & 0.59 & 1.00 & 0.54 & 2.401 & 2.397 & 0.007 & 0.011 \\
\hline 158 & 2017 & $18436 \mathrm{R}$ & 1 & QCP & 0.67 & 0.91 & & & 2.509 & 2.513 & 0.013 & 0.016 \\
\hline 159 & 2016 & 19655R & 1 & QCP & 1.00 & 0.18 & 0.64 & & 2.491 & 2.488 & 0.016 & 0.035 \\
\hline 160 & 2017 & 19655R & 1 & QCP & 1.00 & & 0.65 & & 2.492 & 2.495 & 0.009 & 0.000 \\
\hline 161 & 2015 & 19525R & 1 & QCP & 0.07 & 0.48 & 0.42 & 0.28 & 2.504 & 2.488 & 0.007 & 0.010 \\
\hline 162 & 2017 & 19653R & 1 & QCP & 0.52 & 0.01 & 0.29 & 0.00 & 2.354 & 2.342 & 0.004 & 0.016 \\
\hline 163 & 2016 & 19665R & 1 & PFP & 0.28 & 0.86 & 0.74 & & 2.705 & 2.693 & 0.011 & 0.006 \\
\hline 164 & 2017 & 19665R & 1 & QCP & 0.80 & & 0.67 & & 2.738 & 2.732 & 0.007 & 0.000 \\
\hline 165 & 2015 & $19512 R$ & 1 & QCP & 0.71 & 0.78 & 0.08 & 0.34 & 2.449 & 2.462 & 0.015 & 0.017 \\
\hline 166 & 2015 & $19512 R$ & 1 & QCP & 0.53 & 0.34 & & 0.22 & 2.472 & 2.480 & 0.013 & 0.007 \\
\hline 167 & 2017 & 19525R & 1 & QCP & 0.70 & 0.66 & 0.84 & 0.67 & 2.559 & 2.574 & 0.018 & 0.025 \\
\hline 168 & 2017 & 19525R & 1 & QCP & 0.20 & 0.34 & & 0.05 & 2.555 & 2.580 & 0.005 & 0.021 \\
\hline 169 & 2017 & 19525R & 1 & QCP & 1.00 & & 0.54 & & 2.551 & 2.554 & 0.004 & 0.000 \\
\hline 170 & 2017 & 19525R & 1 & PFP & 0.51 & 0.04 & 0.65 & 0.86 & 2.557 & 2.551 & 0.018 & 0.006 \\
\hline 171 & 2017 & 19655R & 1 & PFP & 0.55 & 0.01 & 0.99 & 0.92 & 2.859 & 2.841 & 0.009 & 0.041 \\
\hline
\end{tabular}




\begin{tabular}{|c|c|c|c|c|c|c|c|c|c|c|c|c|}
\hline $\begin{array}{c}\text { ICT } \\
\text { Code }\end{array}$ & Year & Mix Code & District & $\begin{array}{l}\text { Quality } \\
\text { Program }\end{array}$ & $\begin{array}{c}\text { MW } \\
\text { P-Value }\end{array}$ & $\begin{array}{c}\text { Levene's } \\
\text { P-Value }\end{array}$ & $\begin{array}{l}\text { Contractor } \\
\text { SW P-Value }\end{array}$ & $\begin{array}{c}\text { Agency SW } \\
\text { P-Value }\end{array}$ & $\begin{array}{c}\text { Contractor } \\
\text { Mean }\end{array}$ & $\begin{array}{l}\text { Agency } \\
\text { Mean }\end{array}$ & $\begin{array}{c}\text { Contractor } \\
\text { St. Dev. }\end{array}$ & $\begin{array}{l}\text { Agency } \\
\text { St. Dev. }\end{array}$ \\
\hline 172 & 2015 & $19512 \mathrm{R}$ & 1 & $\mathrm{QCP}$ & & & & & 2.445 & & 0.000 & \\
\hline 173 & 2015 & $19522 \mathrm{R}$ & 1 & QCP & & & & & 2.455 & & 0.000 & \\
\hline 174 & 2015 & $19522 \mathrm{R}$ & 1 & QCP & & & 0.30 & & 2.446 & & 0.010 & \\
\hline 175 & 2015 & 19536R & 1 & QCP & 0.53 & 0.67 & & 0.08 & 2.626 & 2.620 & 0.010 & 0.021 \\
\hline 176 & 2015 & 19510R & 1 & QCP & 0.60 & 0.00 & 0.00 & & 2.325 & 2.322 & 0.015 & 0.000 \\
\hline 177 & 2015 & 19510R & 1 & QCP & & & & & & 2.297 & & 0.000 \\
\hline 178 & 2015 & 19510R & 1 & QCP & 0.97 & 0.85 & 0.02 & 0.82 & 2.351 & 2.350 & 0.009 & 0.008 \\
\hline 179 & 2015 & $19522 \mathrm{R}$ & 1 & QCP & & & 0.92 & & 2.432 & & 0.006 & \\
\hline 180 & 2015 & $19522 \mathrm{R}$ & 1 & QCP & & & 0.50 & & 2.427 & & 0.014 & \\
\hline 181 & 2015 & $19522 \mathrm{R}$ & 1 & QCP & & & 0.57 & & 2.434 & & 0.009 & \\
\hline 182 & 2015 & $19522 R$ & 1 & QCP & 0.14 & & 0.98 & & 2.435 & 2.449 & 0.007 & 0.000 \\
\hline 183 & 2015 & $19524 R$ & 1 & PFP & 0.01 & 0.66 & 0.45 & 0.79 & 2.393 & 2.363 & 0.009 & 0.007 \\
\hline 184 & 2015 & 19510R & 1 & QCP & & & 0.34 & & 2.338 & & 0.005 & \\
\hline 185 & 2015 & 19510R & 1 & QCP & 0.03 & 0.75 & 0.85 & 0.02 & 2.353 & 2.376 & 0.005 & 0.004 \\
\hline 186 & 2017 & 19510R & 1 & QCP & 1.00 & & 0.82 & & 2.352 & 2.353 & 0.006 & 0.000 \\
\hline 187 & 2015 & $19522 \mathrm{R}$ & 1 & QCP & 0.50 & & 0.06 & & 2.429 & 2.414 & 0.016 & 0.000 \\
\hline 188 & 2015 & $19524 \mathrm{R}$ & 1 & QCP & 0.80 & & 0.80 & & 2.395 & 2.398 & 0.004 & 0.000 \\
\hline 189 & 2015 & $19524 R$ & 1 & QCP & 0.13 & 0.01 & 0.02 & & 2.392 & 2.430 & 0.002 & 0.019 \\
\hline 190 & 2015 & 19510R & 1 & QCP & 0.64 & 0.93 & 0.77 & & 2.326 & 2.328 & 0.003 & 0.002 \\
\hline 191 & 2015 & 19510R & 1 & QCP & 1.00 & & & & 2.328 & 2.332 & 0.006 & 0.000 \\
\hline 192 & 2015 & 19510R & 1 & PFP & 0.89 & 0.10 & 0.04 & 0.76 & 2.332 & 2.332 & 0.011 & 0.020 \\
\hline 193 & 2015 & 19510R & 1 & QCP & 0.33 & 0.00 & & & 2.337 & 2.351 & 0.000 & 0.002 \\
\hline 194 & 2015 & 19510R & 1 & QCP & 0.21 & 0.43 & 0.19 & & 2.335 & 2.345 & 0.008 & 0.011 \\
\hline 195 & 2015 & 19510R & 1 & QCP & & & 0.58 & & 2.332 & & 0.007 & \\
\hline 196 & 2017 & 19510R & 1 & QCP & 1.00 & & & & 2.337 & 2.342 & 0.000 & 0.000 \\
\hline 197 & 2017 & 19510R & 1 & QCP & 0.67 & & & & 2.334 & 2.349 & 0.008 & 0.000 \\
\hline 198 & 2017 & 19510R & 1 & QCP & 1.00 & & & & 2.327 & 2.323 & 0.009 & 0.000 \\
\hline 199 & 2017 & 19510R & 1 & QCP & 0.50 & & & 0.64 & 2.334 & 2.311 & 0.000 & 0.005 \\
\hline 200 & 2017 & 19510R & 1 & QCP & 1.00 & & & & 2.332 & 2.320 & 0.017 & 0.000 \\
\hline 201 & 2017 & 19510R & 1 & QCP & 1.00 & & 0.81 & & 2.331 & 2.334 & 0.008 & 0.000 \\
\hline 202 & 2017 & 19510R & 1 & QCP & 0.40 & & 0.61 & & 2.323 & 2.337 & 0.006 & 0.000 \\
\hline 203 & 2017 & 19510R & 1 & QCP & 0.67 & & & & 2.336 & 2.349 & 0.001 & 0.000 \\
\hline 204 & 2015 & 19665R & 1 & PFP & & & 0.99 & & 2.345 & & 0.006 & \\
\hline 205 & 2015 & 19665R & 1 & PFP & 0.90 & 0.32 & 0.00 & 0.30 & 2.353 & 2.357 & 0.014 & 0.019 \\
\hline 206 & 2015 & 19665R & 1 & PFP & 0.49 & 0.94 & 0.26 & 0.10 & 2.362 & 2.368 & 0.013 & 0.013 \\
\hline
\end{tabular}




\begin{tabular}{|c|c|c|c|c|c|c|c|c|c|c|c|c|}
\hline $\begin{array}{c}\text { ICT } \\
\text { Code }\end{array}$ & Year & Mix Code & District & $\begin{array}{l}\text { Quality } \\
\text { Program }\end{array}$ & $\begin{array}{c}\text { MW } \\
\text { P-Value }\end{array}$ & $\begin{array}{l}\text { Levene's } \\
\text { P-Value }\end{array}$ & $\begin{array}{l}\text { Contractor } \\
\text { SW P-Value }\end{array}$ & $\begin{array}{c}\text { Agency SW } \\
\text { P-Value }\end{array}$ & $\begin{array}{c}\text { Contractor } \\
\text { Mean }\end{array}$ & $\begin{array}{l}\text { Agency } \\
\text { Mean }\end{array}$ & $\begin{array}{c}\text { Contractor } \\
\text { St. Dev. }\end{array}$ & $\begin{array}{l}\text { Agency } \\
\text { St. Dev. }\end{array}$ \\
\hline 207 & 2015 & $19522 R$ & 1 & QCP & 0.13 & 0.68 & 0.45 & 0.65 & 2.466 & 2.442 & 0.019 & 0.024 \\
\hline 208 & 2015 & 19524R & 1 & QCP & 0.34 & 0.00 & 0.51 & 0.25 & 2.417 & 2.439 & 0.009 & 0.031 \\
\hline 209 & 2015 & 19524R & 1 & QCP & 0.53 & 0.00 & 0.20 & 0.01 & 2.390 & 2.392 & 0.016 & 0.038 \\
\hline 210 & 2015 & 19524R & 1 & QCP & 0.50 & & 0.28 & & 2.392 & 2.360 & 0.017 & 0.000 \\
\hline 211 & 2015 & 19524R & 1 & QCP & 0.01 & 0.73 & 0.40 & 0.87 & 2.379 & 2.361 & 0.008 & 0.007 \\
\hline 212 & 2015 & 19524R & 1 & QCP & & & & & & 2.360 & & 0.000 \\
\hline 213 & 2017 & $19522 \mathrm{R}$ & 1 & QCP & & & 0.78 & & 2.434 & & 0.003 & \\
\hline 214 & 2015 & 19536R & 1 & PFP & 0.01 & 0.14 & 0.29 & 0.22 & 2.382 & 2.397 & 0.010 & 0.015 \\
\hline 215 & 2015 & 19510R & 1 & QCP & 1.00 & & & & 2.374 & 2.366 & 0.000 & 0.000 \\
\hline 216 & 2015 & 19510R & 1 & QCP & 0.91 & 0.02 & 0.56 & 0.69 & 2.346 & 2.353 & 0.010 & 0.022 \\
\hline 217 & 2015 & 19510R & 1 & QCP & 0.67 & & & & 2.343 & 2.326 & 0.002 & 0.000 \\
\hline 218 & 2015 & 19510R & 1 & QCP & 0.55 & 0.64 & 0.79 & 0.33 & 2.322 & 2.317 & 0.009 & 0.011 \\
\hline 219 & 2015 & 19510R & 1 & QCP & 1.00 & & & & 2.356 & 2.352 & 0.010 & 0.000 \\
\hline 220 & 2015 & 19510R & 1 & QCP & 0.67 & & & & 2.341 & 2.322 & 0.014 & 0.000 \\
\hline 221 & 2015 & $19522 \mathrm{R}$ & 1 & QCP & 1.00 & & & & 2.467 & 2.464 & 0.000 & 0.000 \\
\hline 222 & 2015 & $19522 \mathrm{R}$ & 1 & QCP & 0.72 & 0.64 & 0.86 & 0.81 & 2.454 & 2.459 & 0.023 & 0.027 \\
\hline 223 & 2015 & 19536R & 1 & QCP & 0.08 & 0.68 & 0.73 & 0.37 & 2.378 & 2.363 & 0.009 & 0.011 \\
\hline 224 & 2015 & 19536R & 1 & QCP & 0.75 & & 0.38 & & 2.378 & 2.374 & 0.012 & 0.000 \\
\hline 225 & 2015 & $19536 \mathrm{R}$ & 1 & QCP & 0.06 & 0.14 & 0.13 & 0.28 & 2.398 & 2.383 & 0.008 & 0.003 \\
\hline 226 & 2015 & 19536R & 1 & QCP & & & & & 2.392 & & 0.000 & \\
\hline 227 & 2016 & $19536 \mathrm{R}$ & 1 & QCP & & & & & 2.400 & & 0.000 & \\
\hline 228 & 2015 & $19524 \mathrm{R}$ & 1 & PFP & 0.38 & 0.90 & 1.00 & 0.98 & 2.411 & 2.406 & 0.010 & 0.011 \\
\hline 229 & 2016 & $19524 \mathrm{R}$ & 1 & QCP & & & & & 2.419 & & 0.030 & \\
\hline 230 & 2016 & $19524 \mathrm{R}$ & 1 & QCP & & & & 0.34 & & 2.419 & & 0.014 \\
\hline 231 & 2015 & $19655 R$ & 1 & QCP & 0.66 & 0.61 & 0.52 & 0.10 & 2.385 & 2.379 & 0.020 & 0.023 \\
\hline 232 & 2016 & $19522 \mathrm{R}$ & 1 & QCP & 0.80 & 0.41 & 0.71 & & 2.438 & 2.446 & 0.017 & 0.027 \\
\hline 233 & 2015 & $19522 \mathrm{R}$ & 1 & QCP & & & & & 2.425 & & 0.000 & \\
\hline 234 & 2015 & $19522 \mathrm{R}$ & 1 & QCP & & & & & 2.442 & & 0.000 & \\
\hline 235 & 2017 & $19524 R$ & 1 & QCP & 1.00 & 0.68 & & & 2.385 & 2.384 & 0.014 & 0.024 \\
\hline 236 & 2017 & $19524 \mathrm{R}$ & 1 & QCP & 1.00 & & & & 2.399 & 2.409 & 0.000 & 0.000 \\
\hline 237 & 2017 & $19524 \mathrm{R}$ & 1 & QCP & 0.67 & & & & 2.393 & 2.376 & 0.013 & 0.000 \\
\hline 238 & 2017 & $19524 R$ & 1 & QCP & 1.00 & & & & 2.390 & 2.406 & 0.000 & 0.000 \\
\hline 239 & 2017 & $19524 R$ & 1 & PFP & 0.14 & 0.72 & 0.87 & & 2.394 & 2.404 & 0.007 & 0.004 \\
\hline 240 & 2017 & $19524 \mathrm{R}$ & 1 & QCP & 1.00 & & & & 2.402 & 2.434 & 0.000 & 0.000 \\
\hline 241 & 2017 & $19524 R$ & 1 & QCP & 0.33 & 0.34 & & & 2.374 & 2.326 & 0.004 & 0.013 \\
\hline
\end{tabular}




\begin{tabular}{|c|c|c|c|c|c|c|c|c|c|c|c|c|}
\hline $\begin{array}{c}\text { ICT } \\
\text { Code }\end{array}$ & Year & Mix Code & District & $\begin{array}{l}\text { Quality } \\
\text { Program }\end{array}$ & $\begin{array}{c}\text { MW } \\
\text { P-Value }\end{array}$ & $\begin{array}{l}\text { Levene's } \\
\text { P-Value }\end{array}$ & $\begin{array}{l}\text { Contractor } \\
\text { SW P-Value }\end{array}$ & $\begin{array}{c}\text { Agency SW } \\
\text { P-Value }\end{array}$ & $\begin{array}{c}\text { Contractor } \\
\text { Mean }\end{array}$ & $\begin{array}{l}\text { Agency } \\
\text { Mean }\end{array}$ & $\begin{array}{c}\text { Contractor } \\
\text { St. Dev. }\end{array}$ & $\begin{array}{l}\text { Agency } \\
\text { St. Dev. }\end{array}$ \\
\hline 242 & 2017 & $19514 \mathrm{R}$ & 1 & QCP & 1.00 & & & & 2.380 & 2.386 & 0.000 & 0.000 \\
\hline 243 & 2015 & 19514R & 1 & QCP & 0.69 & 0.18 & 0.38 & 0.38 & 2.384 & 2.383 & 0.021 & 0.051 \\
\hline 244 & 2017 & 19524R & 1 & QCP & 0.29 & 0.11 & 0.44 & 0.54 & 2.420 & 2.405 & 0.006 & 0.020 \\
\hline 245 & 2017 & 19524R & 1 & QCP & 0.06 & 0.86 & 0.08 & 0.27 & 2.393 & 2.367 & 0.012 & 0.012 \\
\hline 246 & 2015 & 19525R & 1 & QCP & 0.40 & 0.58 & 0.03 & 0.22 & 2.382 & 2.376 & 0.007 & 0.004 \\
\hline 247 & 2017 & 19525R & 1 & QCP & 1.00 & & 0.51 & & 2.395 & 2.390 & 0.011 & 0.000 \\
\hline 248 & 2017 & 19525R & 1 & QCP & 1.00 & & & & 2.394 & 2.401 & 0.000 & 0.000 \\
\hline 249 & 2017 & 19525R & 1 & QCP & 1.00 & 0.08 & 0.30 & & 2.382 & 2.385 & 0.006 & 0.017 \\
\hline 250 & 2015 & 19525R & 1 & QCP & 0.52 & 0.70 & 0.42 & 0.95 & 2.393 & 2.400 & 0.009 & 0.011 \\
\hline 251 & 2017 & 19525R & 1 & QCP & 1.00 & & & & 2.381 & 2.367 & 0.000 & 0.000 \\
\hline 252 & 2017 & 19525R & 1 & QCP & 1.00 & & & & 2.379 & 2.381 & 0.011 & 0.000 \\
\hline 253 & 2016 & 19510R & 1 & QCP & 1.00 & & & & 2.372 & 2.374 & 0.000 & 0.000 \\
\hline 254 & 2016 & 19510R & 1 & QCP & & & & & 2.363 & & 0.001 & \\
\hline 255 & 2016 & 19510R & 1 & QCP & 1.00 & & & & 2.339 & 2.325 & 0.000 & 0.000 \\
\hline 256 & 2016 & 19510R & 1 & QCP & 0.80 & 0.23 & 0.00 & & 2.351 & 2.358 & 0.013 & 0.002 \\
\hline 257 & 2017 & 19510R & 1 & QCP & 1.00 & & & & 2.368 & 2.370 & 0.009 & 0.000 \\
\hline 258 & 2017 & 19510R & 1 & QCP & 1.00 & & & & 2.344 & 2.343 & 0.010 & 0.000 \\
\hline 259 & 2017 & 19510R & 1 & QCP & 0.33 & 0.73 & & & 2.370 & 2.349 & 0.008 & 0.012 \\
\hline 260 & 2017 & 19510R & 1 & QCP & 0.67 & & & & 2.374 & 2.363 & 0.001 & 0.000 \\
\hline 261 & 2017 & $19525 R$ & 1 & QCP & 0.36 & 0.17 & 0.41 & 0.59 & 2.412 & 2.396 & 0.017 & 0.033 \\
\hline 262 & 2017 & $19536 R$ & 1 & QCP & 0.67 & & & & 2.398 & 2.395 & 0.002 & 0.000 \\
\hline 263 & 2015 & 19536R & 1 & QCP & 1.00 & & 0.34 & & 2.402 & 2.400 & 0.011 & 0.000 \\
\hline 264 & 2017 & $19524 \mathrm{R}$ & 1 & QCP & 0.50 & & 0.93 & & 2.392 & 2.374 & 0.015 & 0.000 \\
\hline 265 & 2017 & $19524 \mathrm{R}$ & 1 & QCP & 0.10 & 0.28 & 0.84 & 0.68 & 2.422 & 2.407 & 0.004 & 0.009 \\
\hline 266 & 2017 & $19524 \mathrm{R}$ & 1 & QCP & 1.00 & & 0.88 & & 2.408 & 2.413 & 0.029 & 0.000 \\
\hline 267 & 2015 & 19665R & 1 & QCP & 0.05 & 0.43 & 0.26 & 0.88 & 2.364 & 2.353 & 0.009 & 0.005 \\
\hline 268 & 2015 & $19525 R$ & 1 & QCP & 0.83 & 0.38 & 0.46 & & 2.396 & 2.394 & 0.009 & 0.002 \\
\hline 269 & 2015 & 19510R & 1 & QCP & 0.11 & 0.46 & 0.02 & 0.65 & 2.316 & 2.283 & 0.027 & 0.036 \\
\hline 270 & 2015 & $19524 R$ & 1 & PFP & 0.00 & 0.46 & 0.24 & 0.40 & 2.406 & 2.382 & 0.017 & 0.013 \\
\hline 271 & 2015 & 19510R & 1 & QCP & 0.43 & 0.58 & 0.04 & 0.18 & 2.353 & 2.351 & 0.009 & 0.008 \\
\hline 272 & 2016 & $19514 R$ & 1 & QCP & 0.03 & 0.42 & 0.01 & 0.59 & 2.359 & 2.335 & 0.012 & 0.017 \\
\hline 273 & 2016 & $19514 R$ & 1 & QCP & 0.03 & 0.79 & 0.31 & 0.16 & 2.378 & 2.355 & 0.019 & 0.021 \\
\hline 274 & 2017 & 19510R & 1 & QCP & 1.00 & 0.62 & 0.82 & & 2.330 & 2.324 & 0.020 & 0.024 \\
\hline 275 & 2017 & 19510R & 1 & QCP & 0.83 & 0.08 & 0.00 & 0.01 & 2.341 & 2.338 & 0.013 & 0.022 \\
\hline 276 & 2017 & 19510R & 1 & QCP & 1.00 & & 1.00 & & 2.347 & 2.344 & 0.009 & 0.000 \\
\hline
\end{tabular}




\begin{tabular}{|c|c|c|c|c|c|c|c|c|c|c|c|c|}
\hline $\begin{array}{c}\text { ICT } \\
\text { Code }\end{array}$ & Year & Mix Code & District & $\begin{array}{l}\text { Quality } \\
\text { Program }\end{array}$ & $\begin{array}{c}\text { MW } \\
\text { P-Value }\end{array}$ & $\begin{array}{l}\text { Levene's } \\
\text { P-Value }\end{array}$ & $\begin{array}{l}\text { Contractor } \\
\text { SW P-Value }\end{array}$ & $\begin{array}{c}\text { Agency SW } \\
\text { P-Value }\end{array}$ & $\begin{array}{c}\text { Contractor } \\
\text { Mean }\end{array}$ & $\begin{array}{l}\text { Agency } \\
\text { Mean }\end{array}$ & $\begin{array}{c}\text { Contractor } \\
\text { St. Dev. }\end{array}$ & $\begin{array}{l}\text { Agency } \\
\text { St. Dev. }\end{array}$ \\
\hline 277 & 2016 & $19512 \mathrm{R}$ & 1 & $\mathrm{QCP}$ & 0.01 & 0.31 & 0.92 & 0.80 & 2.390 & 2.373 & 0.007 & 0.011 \\
\hline 278 & 2017 & 19524R & 1 & QCP & 0.15 & 0.89 & 0.89 & & 2.391 & 2.375 & 0.012 & 0.007 \\
\hline 279 & 2017 & 19524R & 1 & QCP & 0.60 & 0.19 & 0.36 & & 2.395 & 2.390 & 0.005 & 0.001 \\
\hline 280 & 2017 & 19525R & 1 & PFP & 0.07 & 0.30 & 0.36 & 0.48 & 2.437 & 2.426 & 0.017 & 0.021 \\
\hline 281 & 2017 & 19525R & 1 & QCP & 0.78 & 0.87 & 0.26 & 0.73 & 2.431 & 2.434 & 0.018 & 0.017 \\
\hline 282 & 2015 & 19510R & 1 & QCP & 0.80 & 0.76 & & 0.93 & 2.358 & 2.368 & 0.012 & 0.022 \\
\hline 283 & 2015 & 19524R & 1 & QCP & 0.86 & 0.77 & 0.52 & 0.11 & 2.409 & 2.410 & 0.009 & 0.008 \\
\hline 284 & 2015 & 19522R & 1 & QCP & & & & & & 2.408 & & 0.000 \\
\hline 285 & 2016 & 19522R & 1 & QCP & & & & & 2.395 & & 0.000 & \\
\hline 286 & 2016 & 19522R & 1 & QCP & & & 0.46 & & 2.430 & & 0.004 & \\
\hline 287 & 2015 & 19522R & 1 & QCP & 0.67 & & & & 2.453 & 2.475 & 0.000 & 0.002 \\
\hline 288 & 2016 & 19532R & 1 & QCP & 1.00 & 0.89 & 0.78 & & 2.414 & 2.413 & 0.005 & 0.004 \\
\hline 289 & 2017 & 19510R & 1 & QCP & 1.00 & & & & 2.336 & 2.337 & 0.000 & 0.000 \\
\hline 290 & 2016 & 19510R & 1 & QCP & & & & & & 2.347 & & 0.006 \\
\hline 291 & 2017 & 19510R & 1 & QCP & 0.64 & 0.11 & 0.12 & 0.37 & 2.355 & 2.353 & 0.007 & 0.018 \\
\hline 292 & 2015 & 19524R & 1 & QCP & 0.53 & 0.65 & 0.08 & & 2.391 & 2.397 & 0.015 & 0.018 \\
\hline 293 & 2016 & 19524R & 1 & QCP & & & & & & 2.388 & & 0.000 \\
\hline 294 & 2016 & 19524R & 1 & QCP & 1.00 & & & & 2.389 & 2.396 & 0.000 & 0.000 \\
\hline 295 & 2015 & 19510R & 1 & QCP & 0.41 & 0.64 & 0.74 & 0.49 & 2.331 & 2.326 & 0.014 & 0.012 \\
\hline 296 & 2015 & 19665R & 1 & PFP & 0.05 & 0.95 & 0.92 & 0.26 & 2.477 & 2.491 & 0.019 & 0.019 \\
\hline 297 & 2017 & 19510R & 1 & QCP & 0.18 & & 0.13 & & 2.342 & 2.328 & 0.007 & 0.000 \\
\hline 298 & 2016 & 19510R & 1 & QCP & 1.00 & & & & 2.348 & 2.346 & 0.004 & 0.000 \\
\hline 299 & 2016 & $19524 \mathrm{R}$ & 1 & QCP & 1.00 & & 0.86 & & 2.412 & 2.416 & 0.008 & 0.000 \\
\hline 300 & 2016 & $19524 \mathrm{R}$ & 1 & QCP & 0.67 & & & & 2.409 & 2.419 & 0.005 & 0.000 \\
\hline 301 & 2015 & $19536 \mathrm{R}$ & 1 & PFP & & & & & 2.564 & & 0.000 & \\
\hline 302 & 2015 & 19536R & 1 & QCP & 0.33 & 0.25 & & & 2.555 & 2.565 & 0.007 & 0.001 \\
\hline 303 & 2015 & 19536R & 1 & PFP & 0.06 & 0.22 & 0.01 & 0.01 & 2.586 & 2.601 & 0.034 & 0.023 \\
\hline 304 & 2015 & 19536R & 1 & QCP & & & 0.49 & & 2.439 & & 0.034 & \\
\hline 305 & 2015 & $19512 R$ & 1 & QCP & 0.39 & 0.25 & 1.00 & 0.78 & 2.445 & 2.451 & 0.007 & 0.003 \\
\hline 306 & 2017 & $19525 R$ & 1 & QCP & 0.33 & & 0.04 & & 2.413 & 2.401 & 0.006 & 0.000 \\
\hline 307 & 2017 & $19525 R$ & 1 & QCP & 1.00 & & & & 2.407 & 2.401 & 0.000 & 0.000 \\
\hline 308 & 2016 & 19525R & 1 & QCP & 0.86 & & 0.33 & & 2.399 & 2.390 & 0.015 & 0.000 \\
\hline 309 & 2017 & 19525R & 1 & PFP & 0.70 & 0.15 & 0.04 & 0.06 & 2.417 & 2.408 & 0.015 & 0.028 \\
\hline 310 & 2017 & $19512 R$ & 1 & QCP & & & & & 2.379 & & 0.003 & \\
\hline 311 & 2017 & $19512 R$ & 1 & QCP & & & & & 2.396 & & 0.000 & \\
\hline
\end{tabular}




\begin{tabular}{|c|c|c|c|c|c|c|c|c|c|c|c|c|}
\hline $\begin{array}{c}\text { ICT } \\
\text { Code }\end{array}$ & Year & Mix Code & District & $\begin{array}{l}\text { Quality } \\
\text { Program }\end{array}$ & $\begin{array}{c}\text { MW } \\
\text { P-Value }\end{array}$ & $\begin{array}{l}\text { Levene's } \\
\text { P-Value }\end{array}$ & $\begin{array}{l}\text { Contractor } \\
\text { SW P-Value }\end{array}$ & $\begin{array}{c}\text { Agency SW } \\
\text { P-Value }\end{array}$ & $\begin{array}{c}\text { Contractor } \\
\text { Mean }\end{array}$ & $\begin{array}{l}\text { Agency } \\
\text { Mean }\end{array}$ & $\begin{array}{c}\text { Contractor } \\
\text { St. Dev. }\end{array}$ & $\begin{array}{l}\text { Agency } \\
\text { St. Dev. }\end{array}$ \\
\hline 312 & 2017 & 19536R & 1 & QCP & 0.67 & 0.84 & & & 2.421 & 2.415 & 0.017 & 0.022 \\
\hline 313 & 2016 & 19536R & 1 & QCP & & & 0.75 & & 2.435 & & 0.007 & \\
\hline 314 & 2017 & 19510R & 1 & QCP & 0.67 & 0.62 & & & 2.343 & 2.356 & 0.012 & 0.006 \\
\hline 315 & 2017 & 19510R & 1 & QCP & 1.00 & & 0.46 & & 2.342 & 2.345 & 0.006 & 0.000 \\
\hline 316 & 2017 & 19510R & 1 & QCP & 0.74 & 0.98 & 0.45 & 0.64 & 2.342 & 2.348 & 0.010 & 0.009 \\
\hline 317 & 2017 & 19510R & 1 & QCP & & & & & 2.347 & & 0.000 & \\
\hline 318 & 2017 & 19665R & 1 & QCP & 1.00 & & & & 2.450 & 2.402 & 0.000 & 0.000 \\
\hline 319 & 2017 & 19665R & 1 & PFP & 0.36 & 0.52 & 0.00 & 0.28 & 2.452 & 2.467 & 0.031 & 0.017 \\
\hline 320 & 2017 & 19525R & 1 & QCP & 1.00 & & & & 2.390 & 2.371 & 0.000 & 0.000 \\
\hline 321 & 2017 & $19522 R$ & 1 & QCP & & & 0.84 & & 2.421 & & 0.010 & \\
\hline 322 & 2017 & 19522R & 1 & QCP & & & & & 2.436 & & 0.000 & \\
\hline 323 & 2017 & 19653R & 1 & PFP & 0.46 & 0.45 & 0.02 & 0.60 & 2.383 & 2.382 & 0.016 & 0.014 \\
\hline 324 & 2017 & 19655 & 1 & PFP & 0.26 & 0.47 & 0.25 & 0.01 & 2.490 & 2.492 & 0.015 & 0.014 \\
\hline 325 & 2015 & $19532 R$ & 1 & QCP & 0.70 & 0.23 & 0.74 & 0.06 & 2.425 & 2.419 & 0.011 & 0.029 \\
\hline 326 & 2017 & $19532 R$ & 1 & QCP & & & & & 2.425 & & 0.001 & \\
\hline 327 & 2017 & $19532 R$ & 1 & QCP & 0.67 & & & & 2.410 & 2.425 & 0.006 & 0.000 \\
\hline 328 & 2017 & $19524 \mathrm{R}$ & 1 & QCP & 1.00 & & 0.27 & & 2.397 & 2.395 & 0.014 & 0.000 \\
\hline 329 & 2017 & $19524 \mathrm{R}$ & 1 & QCP & 0.03 & 0.14 & 0.48 & 0.66 & 2.396 & 2.414 & 0.008 & 0.015 \\
\hline 330 & 2017 & $19524 \mathrm{R}$ & 1 & QCP & 0.07 & 0.79 & 0.86 & 0.04 & 2.400 & 2.390 & 0.010 & 0.010 \\
\hline 331 & 2017 & $19522 \mathrm{R}$ & 1 & QCP & 0.05 & 0.09 & 0.11 & 0.08 & 2.425 & 2.417 & 0.014 & 0.008 \\
\hline 332 & 2015 & $19522 \mathrm{R}$ & 1 & QCP & 0.86 & & 0.08 & & 2.443 & 2.438 & 0.015 & 0.000 \\
\hline 333 & 2015 & $19522 \mathrm{R}$ & 1 & QCP & & & & & 2.434 & & 0.000 & \\
\hline 334 & 2015 & $19524 \mathrm{R}$ & 1 & PFP & 0.01 & 0.24 & 0.57 & 0.37 & 2.412 & 2.435 & 0.010 & 0.016 \\
\hline 335 & 2015 & $19524 \mathrm{R}$ & 1 & QCP & 0.33 & 0.76 & 0.06 & 0.16 & 2.395 & 2.406 & 0.017 & 0.014 \\
\hline 336 & 2015 & $19524 \mathrm{R}$ & 1 & QCP & 1.00 & & & & 2.386 & 2.386 & 0.001 & 0.000 \\
\hline 337 & 2015 & $19522 \mathrm{R}$ & 1 & QCP & 0.03 & 0.43 & 0.27 & 0.34 & 2.442 & 2.461 & 0.013 & 0.008 \\
\hline 338 & 2015 & $19524 R$ & 1 & QCP & 0.73 & 0.15 & 0.18 & 0.56 & 2.385 & 2.391 & 0.014 & 0.005 \\
\hline 339 & 2015 & $19522 \mathrm{R}$ & 1 & QCP & & & & & 2.441 & & 0.007 & \\
\hline 340 & 2015 & $19524 R$ & 1 & QCP & 0.05 & 0.82 & 0.50 & 0.84 & 2.417 & 2.407 & 0.003 & 0.004 \\
\hline 341 & 2015 & $19524 \mathrm{R}$ & 1 & PFP & & & & & 2.412 & & 0.011 & \\
\hline 342 & 2015 & 19510R & 1 & QCP & 0.80 & & 0.92 & & 2.385 & 2.371 & 0.028 & 0.000 \\
\hline 343 & 2015 & 19510R & 1 & PFP & 0.09 & 0.34 & 0.49 & & 2.354 & 2.371 & 0.009 & 0.013 \\
\hline 344 & 2015 & 19510R & 1 & $\mathrm{QCP}$ & 0.04 & 0.03 & 0.22 & 0.84 & 2.350 & 2.367 & 0.002 & 0.007 \\
\hline 345 & 2015 & 19510R & 1 & PFP & 0.65 & 0.60 & 0.26 & 0.08 & 2.349 & 2.352 & 0.010 & 0.013 \\
\hline 346 & 2015 & 19510R & 1 & QCP & & & & & & 2.363 & & 0.000 \\
\hline
\end{tabular}




\begin{tabular}{|c|c|c|c|c|c|c|c|c|c|c|c|c|}
\hline $\begin{array}{c}\text { ICT } \\
\text { Code }\end{array}$ & Year & Mix Code & District & $\begin{array}{l}\text { Quality } \\
\text { Program }\end{array}$ & $\begin{array}{c}\text { MW } \\
\text { P-Value }\end{array}$ & $\begin{array}{c}\text { Levene's } \\
\text { P-Value }\end{array}$ & $\begin{array}{l}\text { Contractor } \\
\text { SW P-Value }\end{array}$ & $\begin{array}{c}\text { Agency SW } \\
\text { P-Value }\end{array}$ & $\begin{array}{c}\text { Contractor } \\
\text { Mean }\end{array}$ & $\begin{array}{l}\text { Agency } \\
\text { Mean }\end{array}$ & $\begin{array}{c}\text { Contractor } \\
\text { St. Dev. }\end{array}$ & $\begin{array}{l}\text { Agency } \\
\text { St. Dev. }\end{array}$ \\
\hline 347 & 2015 & 19510R & 1 & QCP & 0.80 & & 0.91 & & 2.358 & 2.363 & 0.013 & 0.000 \\
\hline 348 & 2015 & 19510R & 1 & PFP & 0.18 & 0.39 & 0.27 & 0.02 & 2.357 & 2.354 & 0.006 & 0.009 \\
\hline 349 & 2015 & 19510R & 1 & QCP & & & 0.80 & & 2.354 & & 0.014 & \\
\hline 350 & 2015 & 19510R & 1 & QCP & 1.00 & & 0.44 & & 2.353 & 2.359 & 0.011 & 0.000 \\
\hline 351 & 2015 & 19510R & 1 & QCP & 1.00 & 0.61 & & & 2.359 & 2.361 & 0.011 & 0.021 \\
\hline 352 & 2015 & 19510R & 1 & QCP & 0.67 & & & & 2.351 & 2.338 & 0.011 & 0.000 \\
\hline 353 & 2015 & $19522 R$ & 1 & QCP & & & & & & 2.446 & & 0.000 \\
\hline 354 & 2015 & 19536R & 1 & QCP & 0.73 & 0.04 & 0.33 & 0.51 & 2.372 & 2.369 & 0.010 & 0.043 \\
\hline 355 & 2015 & 19536R & 1 & QCP & 0.76 & 0.95 & 0.55 & 0.36 & 2.380 & 2.385 & 0.012 & 0.013 \\
\hline 356 & 2015 & 19536R & 1 & PFP & 0.53 & 0.01 & 0.79 & 0.07 & 2.389 & 2.386 & 0.011 & 0.022 \\
\hline 357 & 2016 & $19524 R$ & 1 & QCP & 1.00 & & & & 2.406 & 2.416 & 0.000 & 0.000 \\
\hline 358 & 2017 & $19524 R$ & 1 & QCP & 0.34 & 0.52 & 0.45 & 0.97 & 2.386 & 2.398 & 0.017 & 0.012 \\
\hline 359 & 2015 & 19665R & 1 & QCP & 0.67 & 0.10 & 0.34 & 0.28 & 2.505 & 2.522 & 0.020 & 0.045 \\
\hline 360 & 2015 & 19665R & 1 & PFP & & & 0.41 & & 2.499 & & 0.022 & \\
\hline 361 & 2017 & 19510R & 1 & QCP & 0.40 & 0.50 & 0.26 & 0.17 & 2.340 & 2.349 & 0.011 & 0.017 \\
\hline 362 & 2015 & 19655R & 1 & PFP & & & 0.22 & & 2.503 & & 0.009 & \\
\hline 363 & 2016 & $19522 \mathrm{R}$ & 1 & QCP & 0.52 & 0.74 & 0.33 & 0.69 & 2.407 & 2.412 & 0.013 & 0.015 \\
\hline 364 & 2016 & $19524 R$ & 1 & QCP & & & & & 2.391 & & 0.000 & \\
\hline 365 & 2016 & $19514 \mathrm{R}$ & 1 & QCP & 1.00 & & & & 2.402 & 2.411 & 0.000 & 0.000 \\
\hline 366 & 2016 & 19536R & 1 & QCP & 0.67 & & & & 2.385 & 2.392 & 0.007 & 0.000 \\
\hline 367 & 2016 & $19532 \mathrm{R}$ & 1 & QCP & 0.20 & 0.75 & 0.11 & 0.27 & 2.383 & 2.396 & 0.008 & 0.011 \\
\hline 368 & 2017 & $19522 \mathrm{R}$ & 1 & QCP & 0.33 & & 0.26 & & 2.415 & 2.422 & 0.006 & 0.000 \\
\hline 369 & 2017 & $19522 \mathrm{R}$ & 1 & QCP & 0.60 & & 0.98 & & 2.426 & 2.414 & 0.013 & 0.000 \\
\hline 370 & 2017 & $19524 \mathrm{R}$ & 1 & QCP & 0.50 & 0.12 & 0.08 & 0.33 & 2.390 & 2.384 & 0.009 & 0.018 \\
\hline 371 & 2017 & 19524R & 1 & PFP & 0.06 & 0.57 & 0.13 & 0.03 & 2.397 & 2.378 & 0.018 & 0.013 \\
\hline 372 & 2017 & 19510R & 1 & QCP & 0.86 & & 0.56 & & 2.350 & 2.346 & 0.006 & 0.000 \\
\hline 373 & 2017 & 19510R & 1 & QCP & 1.00 & 0.14 & 0.12 & & 2.328 & 2.323 & 0.015 & 0.001 \\
\hline 374 & 2017 & 19510R & 1 & QCP & 1.00 & & & & 2.345 & 2.364 & 0.000 & 0.000 \\
\hline 375 & 2017 & 19525R & 1 & QCP & 0.40 & 0.48 & 0.15 & 0.27 & 2.368 & 2.350 & 0.019 & 0.035 \\
\hline 376 & 2017 & 19510R & 1 & QCP & 0.34 & 0.41 & 0.24 & 0.64 & 2.356 & 2.370 & 0.011 & 0.018 \\
\hline 377 & 2017 & 19510R & 1 & QCP & 0.29 & 0.43 & 0.91 & 0.94 & 2.363 & 2.369 & 0.005 & 0.009 \\
\hline 378 & 2017 & 19653R & 1 & QCP & & & & & 2.388 & & 0.000 & \\
\hline 379 & 2017 & 19653R & 1 & PFP & 0.18 & 0.08 & 0.14 & 0.13 & 2.379 & 2.386 & 0.016 & 0.025 \\
\hline 380 & 2017 & 19525R & 1 & PFP & & & & & & 2.380 & & 0.022 \\
\hline 381 & 2017 & 19525R & 1 & PFP & 0.11 & 0.20 & 0.06 & 0.54 & 2.376 & 2.363 & 0.013 & 0.024 \\
\hline
\end{tabular}




\begin{tabular}{|c|c|c|c|c|c|c|c|c|c|c|c|c|}
\hline $\begin{array}{c}\text { ICT } \\
\text { Code }\end{array}$ & Year & Mix Code & District & $\begin{array}{l}\text { Quality } \\
\text { Program }\end{array}$ & $\begin{array}{c}\text { MW } \\
\text { P-Value }\end{array}$ & $\begin{array}{c}\text { Levene's } \\
\text { P-Value }\end{array}$ & $\begin{array}{l}\text { Contractor } \\
\text { SW P-Value }\end{array}$ & $\begin{array}{c}\text { Agency SW } \\
\text { P-Value }\end{array}$ & $\begin{array}{c}\text { Contractor } \\
\text { Mean }\end{array}$ & $\begin{array}{l}\text { Agency } \\
\text { Mean }\end{array}$ & $\begin{array}{c}\text { Contractor } \\
\text { St. Dev. }\end{array}$ & $\begin{array}{l}\text { Agency } \\
\text { St. Dev. }\end{array}$ \\
\hline 382 & 2017 & 19655R & 1 & PFP & 0.27 & 0.14 & 0.27 & 0.20 & 2.345 & 2.351 & 0.015 & 0.026 \\
\hline 383 & 2017 & 19510R & 1 & QCP & 0.04 & 0.49 & 0.01 & 0.23 & 2.344 & 2.351 & 0.009 & 0.007 \\
\hline 384 & 2017 & 19665R & 1 & PFP & 0.23 & 0.57 & 0.00 & 0.06 & 2.330 & 2.316 & 0.046 & 0.055 \\
\hline 385 & 2017 & 19665R & 1 & QCP & 1.00 & 0.90 & 0.50 & 0.95 & 2.356 & 2.355 & 0.013 & 0.014 \\
\hline 386 & 2015 & $19512 R$ & 1 & QCP & 0.76 & 0.27 & 0.05 & & 2.429 & 2.427 & 0.019 & 0.031 \\
\hline 387 & 2015 & 19514R & 1 & QCP & 0.67 & & & & 2.398 & 2.403 & 0.000 & 0.000 \\
\hline 388 & 2015 & 19522R & 1 & QCP & 1.00 & & & & 2.439 & 2.436 & 0.011 & 0.000 \\
\hline 389 & 2016 & $19606 \mathrm{~F}$ & 2 & PFP & & & & & & & & \\
\hline 390 & 2014 & 19514R & 2 & QCP & 0.12 & 0.72 & 0.15 & 0.74 & 2.413 & 2.420 & 0.013 & 0.015 \\
\hline 391 & 2015 & 19514R & 2 & QCP & & & & & 2.395 & & 0.000 & \\
\hline 392 & 2015 & 19604FR & 2 & QCP & 0.55 & 0.56 & 0.89 & 0.71 & 2.470 & 2.454 & 0.038 & 0.028 \\
\hline 393 & 2015 & 19514R & 2 & QCP & 0.46 & 0.28 & 0.55 & 0.65 & 2.413 & 2.404 & 0.023 & 0.014 \\
\hline 394 & 2016 & $19512 \mathrm{R}$ & 4 & QCP & & & & & 2.457 & & 0.000 & \\
\hline 395 & 2016 & 19535R & 2 & QCP & 0.92 & 0.62 & 0.18 & 0.01 & 2.532 & 2.529 & 0.028 & 0.024 \\
\hline 396 & 2015 & $19534 \mathrm{R}$ & 2 & PFP & 0.04 & 0.84 & 0.50 & 0.13 & 2.403 & 2.409 & 0.014 & 0.015 \\
\hline 397 & 2015 & $19532 R$ & 2 & PFP & 0.18 & 0.74 & 0.33 & 0.40 & 2.438 & 2.441 & 0.013 & 0.013 \\
\hline 398 & 2015 & 19514R & 2 & QCP & 0.46 & 0.70 & 0.06 & 0.30 & 2.397 & 2.402 & 0.014 & 0.012 \\
\hline 399 & 2017 & $19514 \mathrm{R}$ & 2 & QCP & 0.80 & & 0.08 & & 2.402 & 2.390 & 0.019 & 0.000 \\
\hline 400 & 2015 & $19524 \mathrm{R}$ & 2 & QCP & 0.27 & 0.84 & 0.05 & 0.28 & 2.410 & 2.422 & 0.020 & 0.020 \\
\hline 401 & 2015 & 19514R & 2 & QCP & 0.00 & 0.13 & 0.92 & 0.96 & 2.404 & 2.425 & 0.012 & 0.007 \\
\hline 402 & 2015 & 19604FR & 2 & QCP & 0.40 & 0.83 & 0.21 & 0.82 & 2.389 & 2.402 & 0.015 & 0.013 \\
\hline 403 & 2015 & 19604FR & 2 & QCP & 0.63 & 0.96 & 0.78 & 0.57 & 2.400 & 2.413 & 0.015 & 0.017 \\
\hline 404 & 2015 & $19514 R$ & 2 & QCP & 0.66 & 0.96 & 0.58 & 0.28 & 2.372 & 2.382 & 0.023 & 0.023 \\
\hline 405 & 2016 & 19604FR & 2 & QCP & 0.01 & 0.59 & 0.19 & 0.87 & 2.385 & 2.397 & 0.010 & 0.009 \\
\hline 406 & 2016 & $19514 \mathrm{R}$ & 2 & QCP & 0.00 & 0.72 & 0.00 & 0.00 & 2.363 & 2.380 & 0.018 & 0.017 \\
\hline 407 & 2016 & 19516R & 2 & QCP & 0.67 & 0.66 & & & 2.581 & 2.597 & 0.009 & 0.016 \\
\hline 408 & 2017 & $19514 R$ & 2 & QCP & 0.40 & 0.84 & 0.83 & 0.78 & 2.397 & 2.409 & 0.020 & 0.020 \\
\hline 409 & 2017 & $19512 \mathrm{R}$ & 2 & QCP & 0.01 & 0.70 & 0.73 & 0.57 & 2.438 & 2.460 & 0.017 & 0.014 \\
\hline 410 & 2017 & $19512 \mathrm{R}$ & 2 & QCP & 0.27 & 0.04 & 0.60 & 0.67 & 2.419 & 2.428 & 0.021 & 0.005 \\
\hline 411 & 2017 & $19514 R$ & 2 & QCP & 0.01 & 0.05 & 0.05 & 0.03 & 2.357 & 2.386 & 0.023 & 0.009 \\
\hline 412 & 2016 & $19516 \mathrm{R}$ & 2 & QCP & 0.67 & 0.66 & & & 2.581 & 2.597 & 0.009 & 0.016 \\
\hline 413 & 2016 & $19513 R$ & 2 & QCP & 0.33 & 0.75 & & & 2.471 & 2.480 & 0.001 & 0.002 \\
\hline 414 & 2017 & $19514 R$ & 2 & QCP & 0.80 & & 0.73 & & 2.393 & 2.399 & 0.025 & 0.000 \\
\hline 415 & 2015 & $19514 \mathrm{R}$ & 2 & QCP & 0.14 & 0.84 & 0.63 & 0.10 & 2.406 & 2.419 & 0.018 & 0.016 \\
\hline 416 & 2017 & 19513R & 2 & QCP & & & & & 2.434 & & 0.006 & \\
\hline
\end{tabular}




\begin{tabular}{|c|c|c|c|c|c|c|c|c|c|c|c|c|}
\hline $\begin{array}{c}\text { ICT } \\
\text { Code }\end{array}$ & Year & Mix Code & District & $\begin{array}{l}\text { Quality } \\
\text { Program }\end{array}$ & $\begin{array}{c}\text { MW } \\
\text { P-Value }\end{array}$ & $\begin{array}{c}\text { Levene's } \\
\text { P-Value }\end{array}$ & $\begin{array}{l}\text { Contractor } \\
\text { SW P-Value }\end{array}$ & $\begin{array}{c}\text { Agency SW } \\
\text { P-Value }\end{array}$ & $\begin{array}{c}\text { Contractor } \\
\text { Mean }\end{array}$ & $\begin{array}{l}\text { Agency } \\
\text { Mean }\end{array}$ & $\begin{array}{c}\text { Contractor } \\
\text { St. Dev. }\end{array}$ & $\begin{array}{l}\text { Agency } \\
\text { St. Dev. }\end{array}$ \\
\hline 417 & 2015 & 19514R & 2 & QCP & 0.62 & 0.51 & 0.93 & 0.17 & 2.424 & 2.429 & 0.011 & 0.015 \\
\hline 418 & 2016 & 19514R & 2 & QCP & 0.03 & 0.05 & 0.77 & 0.63 & 2.419 & 2.431 & 0.020 & 0.013 \\
\hline 419 & 2017 & $19512 R$ & 2 & QCP & 0.02 & 0.00 & 0.00 & 0.01 & 2.435 & 1.454 & 0.012 & 1.327 \\
\hline 420 & 2015 & $19512 R$ & 2 & QCP & 0.07 & 0.93 & 0.05 & 0.20 & 2.436 & 2.443 & 0.018 & 0.018 \\
\hline 421 & 2015 & $19512 R$ & 2 & QCP & 0.93 & 0.20 & 0.08 & 0.01 & 2.459 & 2.464 & 0.023 & 0.032 \\
\hline 422 & 2015 & 19534R & 2 & PFP & 0.69 & 0.24 & 0.33 & 0.10 & 2.424 & 2.425 & 0.014 & 0.017 \\
\hline 423 & 2015 & 19534R & 2 & PFP & 0.27 & 0.20 & 0.54 & 0.77 & 2.437 & 2.434 & 0.009 & 0.012 \\
\hline 424 & 2016 & 19534R & 2 & PFP & 0.23 & 0.30 & 0.36 & 0.54 & 2.422 & 2.429 & 0.013 & 0.017 \\
\hline 425 & 2017 & $19532 R$ & 2 & PFP & 0.42 & 0.78 & 0.60 & 0.45 & 2.427 & 2.435 & 0.030 & 0.033 \\
\hline 426 & 2015 & $19532 R$ & 2 & PFP & 0.23 & 0.11 & 0.01 & 0.64 & 2.478 & 2.465 & 0.019 & 0.005 \\
\hline 427 & 2017 & 19535R & 2 & PFP & 0.94 & 0.51 & 0.59 & 0.19 & 2.556 & 2.553 & 0.019 & 0.015 \\
\hline 428 & 2015 & $19535 R$ & 2 & PFP & 0.51 & 0.62 & 0.17 & 0.56 & 2.563 & 2.557 & 0.014 & 0.011 \\
\hline 429 & 2016 & $19512 \mathrm{R}$ & 2 & QCP & 0.37 & 0.47 & 0.74 & 0.56 & 2.419 & 2.427 & 0.031 & 0.036 \\
\hline 430 & 2015 & 19654R & 2 & PFP & 0.78 & 0.37 & 0.27 & 0.12 & 2.973 & 2.972 & 0.022 & 0.018 \\
\hline 431 & 2015 & $19514 R$ & 2 & QCP & 1.00 & 0.78 & & & 2.409 & 2.412 & 0.029 & 0.021 \\
\hline 432 & 2015 & 19514R & 2 & QCP & 0.94 & 0.61 & 0.87 & 0.87 & 2.411 & 2.409 & 0.031 & 0.038 \\
\hline 433 & 2015 & 19514R & 2 & QCP & 0.68 & 0.68 & 0.16 & 0.41 & 2.403 & 2.408 & 0.017 & 0.020 \\
\hline 434 & 2016 & $19532 R$ & 2 & PFP & 0.06 & 0.86 & 0.00 & 0.07 & 2.446 & 2.452 & 0.014 & 0.015 \\
\hline 435 & 2015 & $19512 \mathrm{R}$ & 2 & QCP & 0.55 & 0.86 & 0.43 & 0.81 & 2.423 & 2.427 & 0.018 & 0.017 \\
\hline 436 & 2016 & $19654 \mathrm{R}$ & 2 & PFP & 0.94 & 0.63 & 0.89 & 0.29 & 3.016 & 3.016 & 0.021 & 0.022 \\
\hline 437 & 2016 & 19654R & 2 & QCP & 0.50 & 0.00 & 0.27 & 0.00 & 3.016 & 2.014 & 0.003 & 1.744 \\
\hline 438 & 2016 & $19524 R$ & 2 & QCP & 0.90 & 0.81 & 0.52 & 0.26 & 2.426 & 2.429 & 0.018 & 0.018 \\
\hline 439 & 2017 & 19524R & 4 & QCP & & & & & 2.412 & & 0.000 & \\
\hline 440 & 2016 & $19534 R$ & 2 & PFP & 0.51 & 0.76 & 0.06 & 0.14 & 2.419 & 2.420 & 0.011 & 0.011 \\
\hline 441 & 2016 & 19524R & 2 & PFP & 0.29 & 0.53 & 0.80 & 0.75 & 2.386 & 2.373 & 0.020 & 0.025 \\
\hline 442 & 2016 & 19534R & 2 & PFP & 0.38 & 0.89 & 1.00 & 0.65 & 2.423 & 2.426 & 0.011 & 0.012 \\
\hline 443 & 2015 & 19524R & 2 & QCP & 0.05 & 0.01 & 0.67 & 0.10 & 2.400 & 2.409 & 0.017 & 0.027 \\
\hline 444 & 2015 & 19525R & 2 & QCP & 0.33 & 0.60 & & 0.11 & 2.384 & 2.397 & 0.023 & 0.020 \\
\hline 445 & 2015 & $19532 R$ & 2 & PFP & & & & 0.19 & & 2.411 & & 0.015 \\
\hline 446 & 2015 & 19605FR & 2 & QCP & 0.11 & 0.04 & 0.74 & 0.01 & 2.401 & 2.405 & 0.009 & 0.017 \\
\hline 447 & 2015 & $19532 \mathrm{R}$ & 2 & QCP & 1.00 & 0.59 & & & 2.415 & 2.414 & 0.004 & 0.008 \\
\hline 448 & 2015 & 19654R & 2 & PFP & 0.83 & & & 0.00 & 2.369 & 2.366 & 0.000 & 0.019 \\
\hline 449 & 2015 & 19524R & 2 & QCP & 0.42 & 0.05 & 0.97 & 0.46 & 2.385 & 2.391 & 0.015 & 0.027 \\
\hline 450 & 2015 & 19515R & 2 & QCP & & & & 0.52 & & 2.364 & & 0.010 \\
\hline 451 & 2016 & 19515R & 2 & QCP & 0.17 & 0.94 & 0.77 & 0.23 & 2.386 & 2.377 & 0.018 & 0.019 \\
\hline
\end{tabular}




\begin{tabular}{|c|c|c|c|c|c|c|c|c|c|c|c|c|}
\hline $\begin{array}{l}\text { ICT } \\
\text { Code }\end{array}$ & Year & Mix Code & District & $\begin{array}{l}\text { Quality } \\
\text { Program }\end{array}$ & $\begin{array}{c}\text { MW } \\
\text { P-Value }\end{array}$ & $\begin{array}{l}\text { Levene's } \\
\text { P-Value }\end{array}$ & $\begin{array}{l}\text { Contractor } \\
\text { SW P-Value }\end{array}$ & $\begin{array}{c}\text { Agency SW } \\
\text { P-Value }\end{array}$ & $\begin{array}{c}\text { Contractor } \\
\text { Mean }\end{array}$ & $\begin{array}{l}\text { Agency } \\
\text { Mean }\end{array}$ & $\begin{array}{c}\text { Contractor } \\
\text { St. Dev. }\end{array}$ & $\begin{array}{l}\text { Agency } \\
\text { St. Dev. }\end{array}$ \\
\hline 452 & 2014 & 19604FR & 2 & $\mathrm{QCP}$ & 0.52 & 0.35 & 0.21 & 0.15 & 2.404 & 2.402 & 0.019 & 0.024 \\
\hline 453 & 2015 & 19605FR & 2 & QCP & 1.00 & 0.71 & 0.57 & 0.64 & 2.398 & 2.396 & 0.017 & 0.023 \\
\hline 454 & 2015 & $19525 R$ & 2 & QCP & 0.74 & 0.51 & 0.78 & 0.52 & 2.380 & 2.373 & 0.021 & 0.031 \\
\hline 455 & 2015 & $19515 R$ & 2 & QCP & 0.06 & 0.00 & 0.39 & 0.14 & 2.402 & 2.394 & 0.014 & 0.024 \\
\hline 456 & 2016 & $19525 R$ & 2 & QCP & 0.27 & 0.28 & 0.45 & 0.30 & 2.397 & 2.381 & 0.013 & 0.023 \\
\hline 457 & 2015 & 19525R & 2 & QCP & 0.80 & 0.81 & 0.64 & 0.46 & 2.389 & 2.387 & 0.014 & 0.017 \\
\hline 458 & 2015 & $19532 R$ & 2 & PFP & 0.03 & 0.05 & 0.25 & 0.04 & 2.424 & 2.418 & 0.013 & 0.017 \\
\hline 459 & 2015 & $19532 R$ & 2 & QCP & 0.40 & & 0.24 & & 2.413 & 2.430 & 0.017 & 0.000 \\
\hline 460 & 2015 & $19654 \mathrm{R}$ & 2 & PFP & 0.59 & 0.00 & 0.90 & 0.03 & 2.390 & 2.383 & 0.012 & 0.025 \\
\hline 461 & 2015 & 19526R & 2 & QCP & 1.00 & & & & 2.372 & 2.365 & 0.000 & 0.000 \\
\hline 462 & 2017 & 19515R & 2 & QCP & 0.23 & 0.01 & 0.35 & 0.01 & 2.389 & 2.379 & 0.017 & 0.003 \\
\hline 463 & 2017 & 19604FR & 2 & QCP & 1.00 & 0.07 & 0.98 & & 2.398 & 2.397 & 0.006 & 0.016 \\
\hline 464 & 2017 & 19532 & 2 & PFP & & & & & & & & \\
\hline 465 & 2017 & $19513 R$ & 2 & QCP & 0.92 & 0.00 & 0.01 & 0.02 & 2.435 & 1.609 & 0.094 & 1.394 \\
\hline 466 & 2017 & 19535R & 2 & PFP & & & & & & & & \\
\hline 467 & 2015 & $19524 R$ & 3 & QCP & 0.02 & 0.35 & 0.40 & 0.46 & 2.354 & 2.378 & 0.025 & 0.017 \\
\hline 468 & 2017 & 19524R & 1 & QCP & 0.67 & & & & 2.415 & 2.431 & 0.000 & 0.000 \\
\hline 469 & 2017 & 19524R & 3 & PFP & & & & & 2.392 & & 0.000 & \\
\hline 470 & 2017 & $19524 R$ & 1 & PFP & & & 0.04 & & 2.397 & & 0.008 & \\
\hline 471 & 2016 & $19524 R$ & 3 & QCP & 0.40 & & 0.33 & & 2.422 & 2.402 & 0.005 & 0.000 \\
\hline 472 & 2017 & $19522 \mathrm{R}$ & 3 & QCP & 0.50 & & 0.00 & & 2.407 & 2.417 & 0.002 & 0.000 \\
\hline 473 & 2015 & 19535R & 3 & PFP & & & & 0.22 & & 2.395 & & 0.022 \\
\hline 474 & 2017 & 19510R & 1 & QCP & 1.00 & 0.42 & 0.58 & & 2.340 & 2.343 & 0.012 & 0.016 \\
\hline 475 & 2017 & 19510R & 1 & QCP & 0.08 & 0.93 & 0.10 & 0.95 & 2.346 & 2.356 & 0.008 & 0.008 \\
\hline 476 & 2016 & 19524R & 3 & QCP & 1.00 & 0.82 & & & 2.370 & 2.373 & 0.014 & 0.011 \\
\hline 477 & 2017 & 19525R & 1 & PFP & 0.02 & 0.28 & 0.79 & 0.90 & 2.549 & 2.568 & 0.014 & 0.006 \\
\hline 478 & 2017 & 19534R & 3 & QCP & 0.20 & 0.28 & 0.36 & & 2.398 & 2.421 & 0.003 & 0.006 \\
\hline 479 & 2016 & 19524R & 3 & QCP & 1.00 & & & & 2.354 & 2.351 & 0.010 & 0.000 \\
\hline 480 & 2017 & 19524R & 1 & PFP & 0.15 & 0.33 & 0.24 & & 2.389 & 2.406 & 0.013 & 0.018 \\
\hline 481 & 2017 & 19524R & 3 & QCP & & & 0.36 & & 2.395 & & 0.010 & \\
\hline 482 & 2015 & $19522 \mathrm{R}$ & 3 & QCP & 0.20 & 0.09 & & 0.00 & 2.445 & 2.423 & 0.001 & 0.012 \\
\hline 483 & 2015 & $19522 \mathrm{R}$ & 3 & QCP & 0.50 & & & 0.00 & 2.449 & 2.465 & 0.000 & 0.010 \\
\hline 484 & 2015 & 19536R & 1 & QCP & & & 0.88 & & 2.608 & & 0.005 & \\
\hline 485 & 2015 & 19536R & 1 & QCP & 0.67 & 0.65 & & & 2.600 & 2.594 & 0.007 & 0.013 \\
\hline 486 & 2016 & 19512R & 1 & QCP & 0.93 & 0.38 & 0.87 & 0.36 & 2.416 & 2.417 & 0.007 & 0.009 \\
\hline
\end{tabular}




\begin{tabular}{|c|c|c|c|c|c|c|c|c|c|c|c|c|}
\hline $\begin{array}{c}\text { ICT } \\
\text { Code }\end{array}$ & Year & Mix Code & District & $\begin{array}{l}\text { Quality } \\
\text { Program }\end{array}$ & $\begin{array}{c}\text { MW } \\
\text { P-Value }\end{array}$ & $\begin{array}{c}\text { Levene's } \\
\text { P-Value }\end{array}$ & $\begin{array}{l}\text { Contractor } \\
\text { SW P-Value }\end{array}$ & $\begin{array}{c}\text { Agency SW } \\
\text { P-Value }\end{array}$ & $\begin{array}{c}\text { Contractor } \\
\text { Mean }\end{array}$ & $\begin{array}{l}\text { Agency } \\
\text { Mean }\end{array}$ & $\begin{array}{c}\text { Contractor } \\
\text { St. Dev. }\end{array}$ & $\begin{array}{l}\text { Agency } \\
\text { St. Dev. }\end{array}$ \\
\hline 487 & 2016 & $19514 R$ & 3 & QCP & 0.60 & 0.49 & 0.00 & & 2.391 & 2.386 & 0.010 & 0.004 \\
\hline 488 & 2015 & $19534 R$ & 3 & PFP & & & & 0.20 & & 2.385 & & 0.020 \\
\hline 489 & 2015 & 19534R & 3 & PFP & & & & 0.48 & & 2.396 & & 0.012 \\
\hline 490 & 2017 & 19524R & 1 & QCP & 0.01 & 0.67 & 0.01 & 0.96 & 2.394 & 2.361 & 0.011 & 0.008 \\
\hline 491 & 2016 & $19512 \mathrm{R}$ & 1 & QCP & 0.00 & 0.13 & 0.14 & 0.52 & 2.402 & 2.374 & 0.019 & 0.010 \\
\hline 492 & 2017 & $19534 \mathrm{R}$ & 3 & PFP & & & & 0.88 & & 2.381 & & 0.014 \\
\hline 493 & 2017 & $19532 R$ & 3 & PFP & 0.53 & & & 0.37 & 2.400 & 2.397 & 0.000 & 0.010 \\
\hline 494 & 2017 & 19510R & 1 & QCP & 0.14 & 0.82 & 0.34 & 0.27 & 2.320 & 2.306 & 0.009 & 0.007 \\
\hline 495 & 2017 & 19654R & 3 & QCP & 0.79 & 0.63 & 0.12 & 0.08 & 2.396 & 2.397 & 0.017 & 0.014 \\
\hline 496 & 2017 & 19510R & 4 & PFP & 0.28 & 0.69 & 0.21 & 0.29 & 2.301 & 2.305 & 0.011 & 0.010 \\
\hline 497 & 2015 & 19515R & 4 & QCP & 0.75 & & 0.95 & & 2.372 & 2.376 & 0.020 & 0.000 \\
\hline 498 & 2016 & $19515 R$ & 4 & QCP & & & 0.68 & & 2.524 & & 0.021 & \\
\hline 499 & 2016 & $19522 \mathrm{R}$ & 4 & PFP & & & & & 2.417 & & 0.003 & \\
\hline 500 & 2016 & $19522 \mathrm{R}$ & 4 & PFP & 0.00 & 0.42 & 0.00 & 0.11 & 2.419 & 2.431 & 0.017 & 0.019 \\
\hline 501 & 2016 & $19532 R$ & 3 & PFP & 0.25 & 0.13 & 0.77 & 0.02 & 2.372 & 2.376 & 0.013 & 0.009 \\
\hline 502 & 2015 & $19653 R$ & 4 & PFP & & & & 0.12 & & 2.337 & & 0.018 \\
\hline 503 & 2016 & $19654 \mathrm{R}$ & 4 & PFP & & & 0.41 & & 2.340 & & 0.012 & \\
\hline 504 & 2017 & $19654 R$ & 4 & PFP & 0.33 & 0.59 & 0.06 & 0.08 & 2.340 & 2.335 & 0.017 & 0.019 \\
\hline 505 & 2016 & $19654 R$ & 4 & PFP & 0.03 & 0.33 & 0.17 & 0.29 & 2.342 & 2.350 & 0.010 & 0.012 \\
\hline 506 & 2017 & 19510R & 4 & QCP & & & & & 2.386 & & 0.000 & \\
\hline 507 & 2015 & 19515R & 4 & QCP & & & & & 2.338 & & 0.074 & \\
\hline 508 & 2016 & $19524 R$ & 4 & PFP & 0.07 & 0.68 & 0.15 & 0.73 & 2.374 & 2.386 & 0.015 & 0.013 \\
\hline 509 & 2016 & 19525R & 4 & PFP & & & & & 2.358 & & 0.000 & \\
\hline 510 & 2015 & 19525R & 4 & PFP & 0.00 & 0.98 & 0.10 & 0.53 & 2.344 & 2.370 & 0.019 & 0.019 \\
\hline 511 & 2015 & 19535R & 3 & PFP & & & & 0.14 & & 2.354 & & 0.013 \\
\hline 512 & 2016 & 19510R & 4 & PFP & 0.23 & 0.38 & 0.83 & 0.23 & 2.357 & 2.362 & 0.010 & 0.013 \\
\hline 513 & 2016 & 19510R & 4 & PFP & 0.34 & 0.97 & 0.61 & 0.95 & 2.356 & 2.360 & 0.011 & 0.011 \\
\hline 514 & 2017 & 19510R & 4 & QCP & 0.22 & 0.59 & 0.36 & 0.25 & 2.499 & 2.503 & 0.008 & 0.009 \\
\hline 515 & 2017 & 19515R & 4 & QCP & 1.00 & & & & 2.349 & 2.348 & 0.000 & 0.000 \\
\hline 516 & 2017 & 19514R & 4 & PFP & & & 0.24 & & 2.420 & & 0.015 & \\
\hline 517 & 2015 & 19515R & 4 & QCP & & & & & 2.370 & & 0.004 & \\
\hline 518 & 2015 & 19524R & 4 & PFP & 0.00 & 0.66 & 0.28 & 0.40 & 2.361 & 2.391 & 0.011 & 0.014 \\
\hline 519 & 2016 & $19512 R$ & 4 & PFP & & & & & 2.396 & & 0.000 & \\
\hline 520 & 2017 & $19522 \mathrm{R}$ & 4 & QCP & & & 0.55 & & 2.491 & & 0.010 & \\
\hline 521 & 2015 & 19524R & 4 & PFP & 0.00 & 0.89 & 0.45 & 0.25 & 2.352 & 2.386 & 0.009 & 0.009 \\
\hline
\end{tabular}




\begin{tabular}{|c|c|c|c|c|c|c|c|c|c|c|c|c|}
\hline $\begin{array}{c}\text { ICT } \\
\text { Code }\end{array}$ & Year & Mix Code & District & $\begin{array}{l}\text { Quality } \\
\text { Program }\end{array}$ & $\begin{array}{c}\text { MW } \\
\text { P-Value }\end{array}$ & $\begin{array}{l}\text { Levene's } \\
\text { P-Value }\end{array}$ & $\begin{array}{l}\text { Contractor } \\
\text { SW P-Value }\end{array}$ & $\begin{array}{c}\text { Agency SW } \\
\text { P-Value }\end{array}$ & $\begin{array}{c}\text { Contractor } \\
\text { Mean }\end{array}$ & $\begin{array}{l}\text { Agency } \\
\text { Mean }\end{array}$ & $\begin{array}{c}\text { Contractor } \\
\text { St. Dev. }\end{array}$ & $\begin{array}{l}\text { Agency } \\
\text { St. Dev. }\end{array}$ \\
\hline 522 & 2016 & $19512 \mathrm{R}$ & 4 & PFP & & & & & 2.434 & & 0.000 & \\
\hline 523 & 2015 & 19514R & 4 & QCP & & & 0.07 & & 2.362 & & 0.024 & \\
\hline 524 & 2016 & 19514R & 4 & PFP & 0.82 & 0.89 & 0.33 & 0.10 & 2.386 & 2.390 & 0.010 & 0.011 \\
\hline 525 & 2015 & 19514R & 4 & PFP & 0.01 & 0.54 & 0.41 & 0.13 & 2.346 & 2.383 & 0.012 & 0.017 \\
\hline 526 & 2015 & 19524R & 5 & QCP & 0.07 & 0.95 & 0.82 & & 2.344 & 2.367 & 0.011 & 0.008 \\
\hline 527 & 2015 & $19514 R$ & 5 & QCP & 0.60 & & 0.43 & & 2.357 & 2.367 & 0.011 & 0.000 \\
\hline 528 & 2016 & $19514 R$ & 5 & QCP & & & 0.39 & & 2.330 & & 0.007 & \\
\hline 529 & 2015 & 19514R & 5 & QCP & 0.80 & 0.20 & 0.33 & & 2.376 & 2.374 & 0.006 & 0.001 \\
\hline 530 & 2016 & 19514R & 5 & QCP & & & 0.09 & & 2.376 & & 0.011 & \\
\hline 531 & 2016 & 19524R & 5 & QCP & & & 0.39 & & 2.374 & & 0.014 & \\
\hline 532 & 2017 & 19605FR & 5 & QCP & 0.05 & 0.93 & 0.81 & 0.74 & 2.372 & 2.384 & 0.010 & 0.010 \\
\hline 533 & 2015 & 19605FR & 5 & QCP & 0.79 & 0.49 & 0.65 & 0.10 & 2.385 & 2.393 & 0.015 & 0.021 \\
\hline 534 & 2015 & 19524R & 5 & QCP & 0.87 & 0.35 & 0.24 & 0.19 & 2.374 & 2.371 & 0.011 & 0.005 \\
\hline 535 & 2016 & $19514 R$ & 5 & QCP & 0.29 & & 0.24 & & 2.366 & 2.397 & 0.014 & 0.000 \\
\hline 536 & 2017 & $19524 \mathrm{R}$ & 5 & QCP & 0.78 & 0.13 & 0.01 & & 2.366 & 2.377 & 0.012 & 0.023 \\
\hline 537 & 2015 & $19534 R$ & 5 & QCP & 0.29 & & 0.57 & & 2.342 & 2.332 & 0.004 & 0.000 \\
\hline 538 & 2015 & $19534 \mathrm{R}$ & 5 & PFP & 0.71 & 0.84 & 0.30 & 0.89 & 2.330 & 2.332 & 0.008 & 0.009 \\
\hline 539 & 2017 & 19535R & 5 & QCP & 0.15 & 0.00 & 0.00 & & 2.320 & 2.307 & 0.012 & 0.000 \\
\hline 540 & 2017 & $19512 \mathrm{R}$ & 6 & QCP & & & & & 2.364 & & 0.000 & \\
\hline 541 & 2017 & 19513R & 5 & QCP & & & & & & 2.346 & & 0.013 \\
\hline 542 & 2017 & $19532 \mathrm{R}$ & 5 & PFP & & & & 0.39 & & 2.368 & & 0.008 \\
\hline 543 & 2016 & $19534 R$ & 5 & QCP & & & & & & 2.352 & & 0.000 \\
\hline 544 & 2017 & $19534 \mathrm{R}$ & 5 & PFP & & & & 0.76 & & 2.328 & & 0.030 \\
\hline 545 & 2017 & $19523 R$ & 5 & QCP & 0.79 & 0.36 & 0.73 & 0.54 & 2.352 & 2.353 & 0.010 & 0.014 \\
\hline 546 & 2015 & $19534 \mathrm{R}$ & 5 & PFP & 0.17 & 0.53 & 0.67 & 0.34 & 2.339 & 2.347 & 0.010 & 0.007 \\
\hline 547 & 2016 & 19513R & 5 & QCP & 0.67 & & 0.37 & & 2.346 & 2.337 & 0.009 & 0.000 \\
\hline 548 & 2016 & $19514 R$ & 5 & QCP & & & 0.17 & & 2.352 & & 0.006 & \\
\hline 549 & 2015 & $19532 R$ & 5 & PFP & 0.04 & 0.87 & 0.24 & 0.68 & 2.367 & 2.381 & 0.012 & 0.012 \\
\hline 550 & 2015 & 19535R & 5 & PFP & 0.13 & 0.88 & 0.28 & & 2.379 & 2.366 & 0.011 & 0.006 \\
\hline 551 & 2015 & $19523 R$ & 5 & QCP & 0.00 & 0.09 & 0.87 & 0.07 & 2.357 & 2.381 & 0.010 & 0.017 \\
\hline 552 & 2015 & 19505R & 5 & QCP & & & 0.04 & & 2.345 & & 0.019 & \\
\hline 553 & 2015 & $19534 R$ & 5 & PFP & 0.24 & 0.35 & 0.30 & 0.70 & 2.346 & 2.354 & 0.013 & 0.006 \\
\hline 554 & 2017 & $19534 R$ & 5 & PFP & 0.00 & 0.10 & 0.79 & 0.14 & 2.336 & 2.349 & 0.005 & 0.008 \\
\hline 555 & 2016 & 19513R & 5 & QCP & & & & & 2.346 & & 0.000 & \\
\hline 556 & 2016 & $19513 R$ & 5 & QCP & 0.67 & & & & 2.338 & 2.348 & 0.002 & 0.000 \\
\hline
\end{tabular}




\begin{tabular}{|c|c|c|c|c|c|c|c|c|c|c|c|c|}
\hline $\begin{array}{c}\text { ICT } \\
\text { Code }\end{array}$ & Year & Mix Code & District & $\begin{array}{l}\text { Quality } \\
\text { Program }\end{array}$ & $\begin{array}{c}\text { MW } \\
\text { P-Value }\end{array}$ & $\begin{array}{l}\text { Levene's } \\
\text { P-Value }\end{array}$ & $\begin{array}{l}\text { Contractor } \\
\text { SW P-Value }\end{array}$ & $\begin{array}{c}\text { Agency SW } \\
\text { P-Value }\end{array}$ & $\begin{array}{c}\text { Contractor } \\
\text { Mean }\end{array}$ & $\begin{array}{l}\text { Agency } \\
\text { Mean }\end{array}$ & $\begin{array}{c}\text { Contractor } \\
\text { St. Dev. }\end{array}$ & $\begin{array}{l}\text { Agency } \\
\text { St. Dev. }\end{array}$ \\
\hline 557 & 2015 & $19532 R$ & 5 & PFP & 0.03 & 0.53 & 0.82 & 0.69 & 2.350 & 2.362 & 0.008 & 0.005 \\
\hline 558 & 2016 & $19532 R$ & 5 & PFP & 0.08 & 0.51 & 0.33 & 0.89 & 2.350 & 2.359 & 0.008 & 0.010 \\
\hline 559 & 2016 & 19535R & 5 & PFP & 0.14 & 0.08 & 0.23 & 0.78 & 2.351 & 2.357 & 0.005 & 0.010 \\
\hline 560 & 2017 & 19535R & 5 & QCP & & & 0.58 & & 2.345 & & 0.007 & \\
\hline 561 & 2015 & 19524R & 5 & QCP & 0.40 & & 0.11 & & 2.352 & 2.365 & 0.009 & 0.000 \\
\hline 562 & 2015 & 19524R & 5 & QCP & 0.10 & 0.80 & 0.39 & & 2.339 & 2.353 & 0.009 & 0.008 \\
\hline 563 & 2017 & 19532R & 5 & PFP & 0.00 & 0.51 & 0.83 & 0.95 & 2.361 & 2.382 & 0.005 & 0.006 \\
\hline 564 & 2015 & 19523R & 6 & QCP & 0.36 & 0.85 & 0.61 & 1.00 & 2.356 & 2.353 & 0.011 & 0.010 \\
\hline 565 & 2015 & 19513R & 6 & QCP & 0.36 & 0.07 & 0.11 & 0.70 & 2.362 & 2.352 & 0.009 & 0.018 \\
\hline 566 & 2016 & 19524R & 6 & PFP & 0.19 & & & 0.30 & 2.349 & 2.331 & 0.000 & 0.014 \\
\hline 567 & 2016 & 19513R & 6 & PFP & & & & & & 2.360 & & 0.000 \\
\hline 568 & 2015 & 19513R & 6 & QCP & 0.30 & 0.30 & 0.78 & 0.96 & 2.356 & 2.363 & 0.009 & 0.014 \\
\hline 569 & 2015 & $19522 \mathrm{R}$ & 6 & PFP & 0.06 & 0.67 & 0.02 & 0.03 & 2.361 & 2.377 & 0.015 & 0.020 \\
\hline 570 & 2015 & $19522 \mathrm{R}$ & 6 & PFP & 0.00 & 0.03 & 0.31 & 0.74 & 2.376 & 2.365 & 0.012 & 0.018 \\
\hline 571 & 2015 & 19513R & 6 & QCP & 0.93 & 0.21 & 0.17 & 0.89 & 2.341 & 2.342 & 0.008 & 0.012 \\
\hline 572 & 2015 & $19513 R$ & 6 & QCP & 0.72 & 0.82 & 0.16 & 0.17 & 2.331 & 2.329 & 0.015 & 0.011 \\
\hline 573 & 2015 & 19523R & 6 & PFP & 0.46 & 0.95 & 0.01 & 0.87 & 2.330 & 2.341 & 0.026 & 0.027 \\
\hline 574 & 2015 & 19513R & 6 & QCP & 0.57 & 0.70 & 0.75 & 0.83 & 2.347 & 2.342 & 0.017 & 0.014 \\
\hline 575 & 2015 & $19523 R$ & 6 & QCP & 0.29 & 0.81 & 0.39 & 0.18 & 2.354 & 2.345 & 0.013 & 0.014 \\
\hline 576 & 2015 & $19523 R$ & 6 & QCP & & & 0.56 & & 2.343 & & 0.003 & \\
\hline 577 & 2017 & $19523 R$ & 8 & QCP & 0.14 & 0.09 & 0.01 & 0.40 & 2.358 & 2.349 & 0.007 & 0.012 \\
\hline 578 & 2015 & $19534 R$ & 6 & PFP & 0.26 & 0.37 & 0.92 & 0.06 & 2.355 & 2.351 & 0.013 & 0.015 \\
\hline 579 & 2016 & $19534 \mathrm{R}$ & 6 & PFP & 0.32 & 0.89 & 0.18 & 0.45 & 2.346 & 2.355 & 0.010 & 0.012 \\
\hline 580 & 2015 & $19522 \mathrm{R}$ & 6 & PFP & 0.00 & 0.08 & 0.67 & 0.48 & 2.365 & 2.377 & 0.010 & 0.013 \\
\hline 581 & 2015 & $19513 R$ & 6 & QCP & 0.08 & 0.25 & 0.32 & 0.46 & 2.350 & 2.355 & 0.009 & 0.005 \\
\hline 582 & 2017 & $19522 \mathrm{R}$ & 6 & QCP & 0.33 & & 0.44 & & 2.376 & 2.367 & 0.008 & 0.000 \\
\hline 583 & 2015 & 19535R & 6 & PFP & 0.49 & 0.36 & 0.03 & 0.37 & 2.317 & 2.313 & 0.026 & 0.019 \\
\hline 584 & 2015 & 19535R & 6 & QCP & 0.67 & & 0.51 & & 2.330 & 2.324 & 0.009 & 0.000 \\
\hline 585 & 2015 & 19535R & 6 & PFP & 0.27 & 0.65 & 0.05 & 0.19 & 2.322 & 2.318 & 0.010 & 0.008 \\
\hline 586 & 2016 & $19514 R$ & 6 & QCP & 0.81 & 0.22 & 0.81 & 0.71 & 2.328 & 2.321 & 0.015 & 0.025 \\
\hline 587 & 2015 & 19513R & 6 & QCP & 0.85 & 0.90 & 0.56 & 0.68 & 2.372 & 2.375 & 0.011 & 0.011 \\
\hline 588 & 2015 & $19522 R$ & 6 & $\mathrm{QCP}$ & 0.87 & 0.04 & 0.06 & 0.17 & 2.370 & 2.366 & 0.015 & 0.028 \\
\hline 589 & 2016 & $19532 R$ & 6 & PFP & & & & 0.05 & & 2.352 & & 0.015 \\
\hline 590 & 2015 & $19532 R$ & 6 & PFP & 0.00 & 0.57 & 0.31 & 0.68 & 2.353 & 2.364 & 0.013 & 0.012 \\
\hline 591 & 2016 & $19532 R$ & 6 & QCP & 0.29 & & 0.02 & & 2.365 & 2.385 & 0.013 & 0.000 \\
\hline
\end{tabular}




\begin{tabular}{|c|c|c|c|c|c|c|c|c|c|c|c|c|}
\hline $\begin{array}{c}\text { ICT } \\
\text { Code }\end{array}$ & Year & Mix Code & District & $\begin{array}{l}\text { Quality } \\
\text { Program }\end{array}$ & $\begin{array}{c}\text { MW } \\
\text { P-Value }\end{array}$ & $\begin{array}{c}\text { Levene's } \\
\text { P-Value }\end{array}$ & $\begin{array}{l}\text { Contractor } \\
\text { SW P-Value }\end{array}$ & $\begin{array}{c}\text { Agency SW } \\
\text { P-Value }\end{array}$ & $\begin{array}{c}\text { Contractor } \\
\text { Mean }\end{array}$ & $\begin{array}{l}\text { Agency } \\
\text { Mean }\end{array}$ & $\begin{array}{c}\text { Contractor } \\
\text { St. Dev. }\end{array}$ & $\begin{array}{l}\text { Agency } \\
\text { St. Dev. }\end{array}$ \\
\hline 592 & 2015 & $19524 \mathrm{R}$ & 6 & QCP & 0.87 & 0.00 & 0.61 & & 2.333 & 2.336 & 0.010 & 0.000 \\
\hline 593 & 2015 & $19512 R$ & 6 & QCP & 0.97 & 0.67 & 0.41 & 0.08 & 2.371 & 2.372 & 0.010 & 0.011 \\
\hline 594 & 2015 & 19535R & 6 & PFP & 0.13 & 0.00 & 0.46 & 0.39 & 2.329 & 2.335 & 0.009 & 0.018 \\
\hline 595 & 2017 & 19535R & 6 & PFP & 0.19 & 0.57 & 0.83 & 0.99 & 2.342 & 2.336 & 0.012 & 0.010 \\
\hline 596 & 2016 & 19535R & 6 & QCP & 1.00 & & 0.17 & & 2.341 & 2.345 & 0.014 & 0.000 \\
\hline 597 & 2017 & 19513R & 6 & QCP & 0.22 & 0.87 & 0.74 & 0.25 & 2.360 & 2.355 & 0.008 & 0.008 \\
\hline 598 & 2017 & 19513R & 6 & QCP & 0.09 & 0.60 & 0.35 & 0.08 & 2.345 & 2.354 & 0.010 & 0.007 \\
\hline 599 & 2017 & 19513R & 6 & QCP & 1.00 & 0.76 & 0.47 & & 2.339 & 2.338 & 0.014 & 0.013 \\
\hline 600 & 2016 & 19513R & 6 & QCP & & & & & 2.334 & & 0.000 & \\
\hline 601 & 2016 & 19513R & 6 & PFP & & & & & & 2.363 & & 0.004 \\
\hline 602 & 2016 & 19513R & 6 & QCP & 0.00 & 0.58 & 0.00 & 0.01 & 2.370 & 2.358 & 0.015 & 0.016 \\
\hline 603 & 2016 & 19513R & 6 & QCP & 0.10 & 0.08 & 0.01 & 0.23 & 2.361 & 2.352 & 0.019 & 0.006 \\
\hline 604 & 2016 & $19514 R$ & 6 & QCP & 1.00 & & 0.75 & & 2.370 & 2.375 & 0.007 & 0.000 \\
\hline 605 & 2015 & $19512 \mathrm{R}$ & 6 & QCP & 0.94 & 0.28 & 0.01 & 0.88 & 2.335 & 2.337 & 0.015 & 0.008 \\
\hline 606 & 2016 & $19524 \mathrm{R}$ & 6 & QCP & 0.19 & 0.19 & 0.19 & 0.99 & 2.348 & 2.338 & 0.012 & 0.005 \\
\hline 607 & 2015 & $19513 R$ & 6 & QCP & 1.00 & & 0.43 & & 2.349 & 2.354 & 0.019 & 0.000 \\
\hline 608 & 2017 & 19513R & 6 & QCP & 0.15 & 0.86 & 0.59 & 0.11 & 2.346 & 2.338 & 0.010 & 0.009 \\
\hline 609 & 2016 & 19513R & 6 & QCP & 0.00 & 0.33 & 0.61 & 0.02 & 2.350 & 2.331 & 0.011 & 0.013 \\
\hline 610 & 2017 & $19513 R$ & 6 & QCP & 0.00 & 0.06 & 0.19 & 0.02 & 2.356 & 2.335 & 0.008 & 0.014 \\
\hline 611 & 2016 & 19513R & 6 & QCP & 0.71 & 0.17 & 0.30 & & 2.345 & 2.341 & 0.006 & 0.011 \\
\hline 612 & 2017 & $19532 \mathrm{R}$ & 6 & PFP & 0.07 & 0.20 & 0.01 & 0.18 & 2.364 & 2.359 & 0.009 & 0.012 \\
\hline 613 & 2016 & $19524 \mathrm{R}$ & 6 & PFP & 0.01 & 0.09 & 0.54 & 0.85 & 2.322 & 2.338 & 0.010 & 0.016 \\
\hline 614 & 2016 & $19513 R$ & 6 & QCP & 0.16 & 0.95 & 0.02 & 0.59 & 2.345 & 2.331 & 0.020 & 0.018 \\
\hline 615 & 2016 & $19514 \mathrm{R}$ & 6 & QCP & 0.00 & 0.64 & 0.37 & 0.00 & 2.325 & 2.310 & 0.009 & 0.007 \\
\hline 616 & 2016 & $19534 \mathrm{R}$ & 7 & PFP & 0.08 & 0.05 & 0.23 & 0.48 & 2.322 & 2.332 & 0.008 & 0.017 \\
\hline 617 & 2016 & $19524 \mathrm{R}$ & 6 & QCP & 0.47 & 0.49 & 0.03 & 0.96 & 2.336 & 2.333 & 0.016 & 0.012 \\
\hline 618 & 2016 & $19532 \mathrm{R}$ & 6 & PFP & 0.17 & 0.16 & 0.63 & 0.54 & 2.364 & 2.369 & 0.010 & 0.014 \\
\hline 619 & 2016 & $19523 R$ & 6 & QCP & 1.00 & & 0.88 & & 2.332 & 2.331 & 0.006 & 0.000 \\
\hline 620 & 2016 & $19524 R$ & 6 & QCP & 0.59 & 0.34 & 0.22 & 0.25 & 2.326 & 2.323 & 0.017 & 0.024 \\
\hline 621 & 2016 & $19534 R$ & 6 & PFP & 0.04 & 0.26 & 0.12 & 0.05 & 2.318 & 2.329 & 0.012 & 0.016 \\
\hline 622 & 2016 & 19513R & 6 & QCP & 0.55 & 0.39 & 0.15 & 0.78 & 2.327 & 2.329 & 0.009 & 0.013 \\
\hline 623 & 2016 & $19512 R$ & 6 & QCP & 0.18 & 0.03 & 0.17 & 0.06 & 2.353 & 2.359 & 0.009 & 0.003 \\
\hline 624 & 2017 & $19514 R$ & 6 & $\mathrm{QCP}$ & 0.38 & 0.03 & 0.50 & 0.02 & 2.338 & 2.328 & 0.016 & 0.003 \\
\hline 625 & 2017 & $19522 \mathrm{R}$ & 6 & PFP & & & & & 2.383 & & 0.000 & \\
\hline 626 & 2017 & 19514R & 6 & QCP & 1.00 & 0.10 & 0.00 & 0.02 & 2.329 & 2.333 & 0.013 & 0.024 \\
\hline
\end{tabular}




\begin{tabular}{|c|c|c|c|c|c|c|c|c|c|c|c|c|}
\hline $\begin{array}{l}\text { ICT } \\
\text { Code }\end{array}$ & Year & Mix Code & District & $\begin{array}{l}\text { Quality } \\
\text { Program }\end{array}$ & $\begin{array}{c}\text { MW } \\
\text { P-Value }\end{array}$ & $\begin{array}{l}\text { Levene's } \\
\text { P-Value }\end{array}$ & $\begin{array}{l}\text { Contractor } \\
\text { SW P-Value }\end{array}$ & $\begin{array}{c}\text { Agency SW } \\
\text { P-Value }\end{array}$ & $\begin{array}{c}\text { Contractor } \\
\text { Mean }\end{array}$ & $\begin{array}{l}\text { Agency } \\
\text { Mean }\end{array}$ & $\begin{array}{l}\text { Contractor } \\
\text { St. Dev. }\end{array}$ & $\begin{array}{l}\text { Agency } \\
\text { St. Dev. }\end{array}$ \\
\hline 627 & 2017 & 19513R & 6 & $\mathrm{QCP}$ & 0.14 & 0.02 & 0.84 & 0.00 & 2.346 & 2.338 & 0.012 & 0.001 \\
\hline 628 & 2015 & 19524 & 7 & PFP & 1.00 & 0.17 & 0.30 & 0.92 & 2.338 & 2.334 & 0.017 & 0.036 \\
\hline 629 & 2016 & 19532R & 7 & QCP & 1.00 & & 0.33 & & 2.378 & 2.382 & 0.012 & 0.000 \\
\hline 630 & 2015 & $19532 R$ & 7 & PFP & & & 0.99 & & 2.394 & & 0.018 & \\
\hline 631 & 2016 & $19523 R$ & 7 & QCP & 0.40 & 0.95 & 0.23 & 0.54 & 2.345 & 2.335 & 0.021 & 0.020 \\
\hline 632 & 2016 & 19532R & 7 & QCP & 0.36 & 0.40 & 0.18 & & 2.388 & 2.381 & 0.008 & 0.011 \\
\hline 633 & 2017 & $19532 R$ & 7 & PFP & 0.36 & 0.02 & 0.07 & 0.65 & 2.364 & 2.377 & 0.024 & 0.007 \\
\hline 634 & 2017 & 19524R & 7 & PFP & & & & & & 2.358 & & 0.000 \\
\hline 635 & 2016 & 19523 & 7 & QCP & 0.57 & 0.61 & 0.76 & & 2.337 & 2.344 & 0.016 & 0.018 \\
\hline 636 & 2017 & 19523 & 7 & QCP & & & & & & 2.330 & & 0.000 \\
\hline 637 & 2016 & 19523 & 7 & QCP & 0.33 & 0.72 & & & 2.308 & 2.340 & 0.015 & 0.023 \\
\hline 638 & 2017 & 19523 & 7 & QCP & 0.80 & & 0.44 & & 2.319 & 2.330 & 0.018 & 0.000 \\
\hline 639 & 2017 & 19534R & 7 & QCP & & & & 0.17 & & 2.348 & & 0.014 \\
\hline 640 & 2016 & 19534R & 7 & PFP & & & & 0.03 & & 2.341 & & 0.015 \\
\hline 641 & 2016 & 19534R & 7 & QCP & 0.00 & 0.33 & 0.58 & 0.82 & 2.345 & 2.319 & 0.008 & 0.012 \\
\hline 642 & 2016 & $19524 R$ & 7 & QCP & 0.07 & 0.81 & 0.02 & 0.01 & 2.360 & 2.342 & 0.032 & 0.029 \\
\hline 643 & 2016 & 19523R & 7 & QCP & 0.86 & 0.19 & 0.46 & & 2.335 & 2.337 & 0.009 & 0.019 \\
\hline 644 & 2015 & 19534R & 7 & PFP & & & & & & 2.354 & & 0.000 \\
\hline 645 & 2015 & 19534R & 7 & PFP & & & & 0.56 & & 2.347 & & 0.022 \\
\hline 646 & 2016 & 19534R & 7 & QCP & & & & & 2.354 & & 0.008 & \\
\hline 647 & 2015 & 19534R & 7 & QCP & 0.53 & 0.75 & & 0.54 & 2.360 & 2.379 & 0.015 & 0.028 \\
\hline 648 & 2016 & 19523R & 9 & QCP & 0.67 & & & & 2.351 & 2.374 & 0.000 & 0.005 \\
\hline 649 & 2016 & 19605FR & 9 & QCP & 0.18 & 0.21 & 0.79 & 0.00 & 2.342 & 2.355 & 0.014 & 0.005 \\
\hline 650 & 2015 & $19534 \mathrm{R}$ & 7 & PFP & 0.91 & 0.27 & 0.99 & 0.60 & 2.356 & 2.356 & 0.009 & 0.014 \\
\hline 651 & 2015 & 19523R & 7 & PFP & 0.51 & 0.84 & 0.73 & 0.79 & 2.372 & 2.368 & 0.011 & 0.013 \\
\hline 652 & 2015 & 19523R & 7 & QCP & 0.91 & 0.89 & 0.88 & 0.71 & 2.361 & 2.364 & 0.030 & 0.029 \\
\hline 653 & 2016 & 19524R & 7 & QCP & 0.54 & 0.50 & 0.02 & 0.41 & 2.351 & 2.353 & 0.015 & 0.021 \\
\hline 654 & 2016 & 19534R & 7 & QCP & 1.00 & & & & 2.364 & 2.361 & 0.017 & 0.000 \\
\hline 655 & 2015 & 19534R & 7 & PFP & 0.07 & 0.28 & 0.79 & 0.12 & 2.331 & 2.340 & 0.010 & 0.015 \\
\hline 656 & 2016 & 19654R & 7 & PFP & & & & & & 2.299 & & 0.000 \\
\hline 657 & 2016 & $19654 R$ & 7 & PFP & & & & & & 2.307 & & 0.000 \\
\hline 658 & 2015 & 19654R & 7 & PFP & 0.79 & 0.37 & 0.23 & 0.07 & 2.294 & 2.295 & 0.022 & 0.018 \\
\hline 659 & 2016 & 19654R & 7 & PFP & 0.29 & 0.48 & 0.57 & 0.80 & 2.274 & 2.286 & 0.009 & 0.014 \\
\hline 660 & 2016 & 19654R & 7 & PFP & 0.23 & 0.82 & 0.21 & 0.48 & 2.311 & 2.317 & 0.017 & 0.017 \\
\hline 661 & 2017 & 19654R & 7 & PFP & 0.40 & 0.86 & 0.49 & 0.25 & 2.306 & 2.312 & 0.017 & 0.018 \\
\hline
\end{tabular}




\begin{tabular}{|c|c|c|c|c|c|c|c|c|c|c|c|c|}
\hline $\begin{array}{l}\text { ICT } \\
\text { Code }\end{array}$ & Year & Mix Code & District & $\begin{array}{l}\text { Quality } \\
\text { Program }\end{array}$ & $\begin{array}{c}\text { MW } \\
\text { P-Value }\end{array}$ & $\begin{array}{l}\text { Levene's } \\
\text { P-Value }\end{array}$ & $\begin{array}{l}\text { Contractor } \\
\text { SW P-Value }\end{array}$ & $\begin{array}{c}\text { Agency SW } \\
\text { P-Value }\end{array}$ & $\begin{array}{c}\text { Contractor } \\
\text { Mean }\end{array}$ & $\begin{array}{l}\text { Agency } \\
\text { Mean }\end{array}$ & $\begin{array}{l}\text { Contractor } \\
\text { St. Dev. }\end{array}$ & $\begin{array}{l}\text { Agency } \\
\text { St. Dev. }\end{array}$ \\
\hline 662 & 2016 & $19532 R$ & 7 & PFP & 0.99 & 0.56 & 0.36 & 0.44 & 2.375 & 2.374 & 0.016 & 0.015 \\
\hline 663 & 2017 & $19532 R$ & 7 & PFP & 1.00 & & & & 2.338 & 2.335 & 0.000 & 0.000 \\
\hline 664 & 2017 & 19523R & 7 & QCP & 0.80 & 0.57 & 1.00 & & 2.358 & 2.356 & 0.005 & 0.002 \\
\hline 665 & 2015 & 19505R & 7 & PFP & & & 0.19 & & 2.340 & & 0.013 & \\
\hline 666 & 2015 & $19532 R$ & 7 & PFP & 0.47 & 0.37 & 0.76 & 0.37 & 2.379 & 2.381 & 0.019 & 0.017 \\
\hline 667 & 2016 & 19532R & 7 & PFP & 0.86 & 0.84 & 0.72 & 0.12 & 2.371 & 2.370 & 0.016 & 0.017 \\
\hline 668 & 2015 & $19532 R$ & 7 & PFP & & & & 0.53 & & 2.369 & & 0.017 \\
\hline 669 & 2016 & 19654R & 7 & PFP & 0.95 & 0.88 & 0.73 & 0.92 & 2.311 & 2.312 & 0.017 & 0.018 \\
\hline 670 & 2015 & $19654 R$ & 7 & PFP & 0.84 & 0.28 & 0.01 & 0.68 & 2.315 & 2.313 & 0.011 & 0.016 \\
\hline 671 & 2016 & 19532R & 7 & PFP & 0.81 & 0.92 & 0.44 & 0.30 & 2.373 & 2.375 & 0.018 & 0.018 \\
\hline 672 & 2017 & 19533R & 7 & PFP & 0.19 & 0.97 & 0.94 & 0.62 & 2.344 & 2.355 & 0.013 & 0.014 \\
\hline 673 & 2017 & 19532R & 7 & PFP & 0.86 & 0.57 & 0.33 & 0.34 & 2.381 & 2.382 & 0.025 & 0.022 \\
\hline 674 & 2017 & $19532 R$ & 7 & PFP & 0.48 & 0.93 & 0.42 & 0.12 & 2.367 & 2.372 & 0.014 & 0.015 \\
\hline 675 & 2017 & 19532R & 7 & PFP & & & & & & 2.385 & & 0.000 \\
\hline 676 & 2017 & 19532R & 7 & PFP & 0.78 & 0.11 & 0.25 & 0.65 & 2.365 & 2.373 & 0.021 & 0.009 \\
\hline 677 & 2016 & $19523 R$ & 8 & QCP & & & & & & 2.356 & & 0.000 \\
\hline 678 & 2016 & 19523R & 8 & QCP & 0.67 & 0.83 & & & 2.361 & 2.369 & 0.014 & 0.018 \\
\hline 679 & 2016 & 19523R & 8 & QCP & 0.40 & & 0.17 & & 2.340 & 2.358 & 0.009 & 0.000 \\
\hline 680 & 2016 & 19523R & 8 & QCP & 0.29 & 0.32 & 0.54 & 0.64 & 2.332 & 2.324 & 0.015 & 0.020 \\
\hline 681 & 2016 & 19534R & 8 & QCP & 0.01 & 0.45 & 0.72 & 0.67 & 2.328 & 2.351 & 0.016 & 0.011 \\
\hline 682 & 2015 & 19534R & 8 & QCP & 0.14 & & 0.80 & & 2.329 & 2.349 & 0.006 & 0.000 \\
\hline 683 & 2015 & 19534R & 8 & QCP & 0.03 & 0.01 & 0.33 & 0.72 & 2.318 & 2.332 & 0.007 & 0.015 \\
\hline 684 & 2015 & 19534R & 8 & QCP & 0.53 & 0.25 & 0.20 & 0.11 & 2.295 & 2.293 & 0.014 & 0.021 \\
\hline 685 & 2015 & 19524R & 8 & QCP & 0.85 & 0.49 & 0.58 & 0.83 & 2.331 & 2.333 & 0.011 & 0.008 \\
\hline 686 & 2017 & 19524R & 8 & QCP & 1.00 & 0.86 & 0.17 & 0.04 & 2.326 & 2.326 & 0.023 & 0.024 \\
\hline 687 & 2015 & 19535R & 8 & QCP & 0.27 & 0.02 & 0.06 & 0.09 & 2.266 & 2.277 & 0.016 & 0.028 \\
\hline 688 & 2017 & 19505R & 8 & QCP & 0.78 & 0.61 & 0.04 & 0.32 & 2.341 & 2.341 & 0.019 & 0.023 \\
\hline 689 & 2015 & 19505R & 8 & QCP & 0.53 & 0.07 & 0.37 & & 2.363 & 2.371 & 0.016 & 0.001 \\
\hline 690 & 2015 & 19606R & 8 & QCP & 1.00 & 0.27 & 1.00 & & 2.316 & 2.319 & 0.014 & 0.022 \\
\hline 691 & 2015 & 19654R & 8 & PFP & 0.18 & 0.39 & 0.02 & 0.66 & 2.256 & 2.263 & 0.019 & 0.016 \\
\hline 692 & 2015 & $19654 R$ & 8 & PFP & 0.46 & 0.90 & 0.62 & 0.79 & 2.246 & 2.252 & 0.017 & 0.018 \\
\hline 693 & 2015 & 19534R & 8 & QCP & 0.25 & 0.21 & 0.50 & 0.12 & 2.300 & 2.285 & 0.023 & 0.008 \\
\hline 694 & 2015 & 19654R & 8 & PFP & 1.00 & 0.53 & 0.90 & 0.41 & 2.283 & 2.284 & 0.022 & 0.019 \\
\hline 695 & 2015 & 19654R & 8 & PFP & 0.10 & 0.44 & 0.43 & 0.29 & 2.275 & 2.280 & 0.016 & 0.014 \\
\hline 696 & 2015 & 19654R & 8 & PFP & 0.12 & 0.62 & 0.11 & 0.19 & 2.277 & 2.287 & 0.017 & 0.019 \\
\hline
\end{tabular}




\begin{tabular}{|c|c|c|c|c|c|c|c|c|c|c|c|c|}
\hline $\begin{array}{c}\text { ICT } \\
\text { Code }\end{array}$ & Year & Mix Code & District & $\begin{array}{l}\text { Quality } \\
\text { Program }\end{array}$ & $\begin{array}{c}\text { MW } \\
\text { P-Value }\end{array}$ & $\begin{array}{c}\text { Levene's } \\
\text { P-Value }\end{array}$ & $\begin{array}{l}\text { Contractor } \\
\text { SW P-Value }\end{array}$ & $\begin{array}{c}\text { Agency SW } \\
\text { P-Value }\end{array}$ & $\begin{array}{c}\text { Contractor } \\
\text { Mean }\end{array}$ & $\begin{array}{l}\text { Agency } \\
\text { Mean }\end{array}$ & $\begin{array}{c}\text { Contractor } \\
\text { St. Dev. }\end{array}$ & $\begin{array}{l}\text { Agency } \\
\text { St. Dev. }\end{array}$ \\
\hline 697 & 2015 & 19535R & 8 & QCP & 0.81 & 0.43 & 0.70 & 0.91 & 2.294 & 2.297 & 0.013 & 0.008 \\
\hline 698 & 2015 & $19601 R$ & 8 & QCP & & & & & 2.440 & & 0.000 & \\
\hline 699 & 2016 & $19523 R$ & 8 & QCP & 0.27 & 0.91 & 0.38 & 0.51 & 2.347 & 2.357 & 0.012 & 0.011 \\
\hline 700 & 2016 & 19523R & 8 & QCP & & & & & & 2.375 & & 0.006 \\
\hline 701 & 2016 & $19532 R$ & 8 & PFP & 0.15 & 0.69 & 0.52 & 0.15 & 2.382 & 2.391 & 0.012 & 0.011 \\
\hline 702 & 2016 & $19524 R$ & 8 & QCP & 0.84 & 0.74 & 0.50 & 0.83 & 2.361 & 2.363 & 0.010 & 0.011 \\
\hline 703 & 2017 & $19524 R$ & 8 & QCP & 1.00 & & & & 2.377 & 2.371 & 0.009 & 0.000 \\
\hline 704 & 2016 & $19524 R$ & 8 & QCP & & & 0.34 & & 2.346 & & 0.009 & \\
\hline 705 & 2016 & 19524R & 8 & QCP & 0.67 & & & & 2.315 & 2.318 & 0.001 & 0.000 \\
\hline 706 & 2016 & $19524 R$ & 8 & QCP & 1.00 & & & & 2.347 & 2.346 & 0.001 & 0.000 \\
\hline 707 & 2016 & 19533R & 8 & QCP & 0.34 & 0.14 & 0.00 & 0.96 & 2.341 & 2.352 & 0.009 & 0.016 \\
\hline 708 & 2016 & $19534 R$ & 8 & PFP & 0.42 & 0.91 & 0.20 & 0.39 & 2.328 & 2.333 & 0.022 & 0.021 \\
\hline 709 & 2016 & $19534 \mathrm{R}$ & 8 & QCP & 0.46 & 0.30 & 0.12 & 0.02 & 2.342 & 2.342 & 0.019 & 0.028 \\
\hline 710 & 2016 & $19504 R$ & 8 & QCP & 0.80 & 0.59 & 0.05 & & 2.377 & 2.381 & 0.013 & 0.017 \\
\hline 711 & 2016 & $19523 R$ & 8 & QCP & 1.00 & 0.27 & 0.00 & & 2.345 & 2.346 & 0.002 & 0.006 \\
\hline 712 & 2016 & 19605R & 8 & QCP & 0.67 & & & & 2.330 & 2.345 & 0.011 & 0.000 \\
\hline 713 & 2016 & $19534 R$ & 8 & QCP & 0.42 & 0.24 & 0.73 & & 2.349 & 2.365 & 0.014 & 0.025 \\
\hline 714 & 2017 & $19654 \mathrm{R}$ & 8 & PFP & & & & & & 2.347 & & 0.000 \\
\hline 715 & 2017 & $19654 \mathrm{R}$ & 8 & PFP & 0.71 & 0.29 & 0.31 & 0.10 & 2.304 & 2.306 & 0.015 & 0.017 \\
\hline 716 & 2017 & 19523R & 8 & QCP & 0.54 & 0.74 & 0.54 & 0.81 & 2.332 & 2.337 & 0.017 & 0.019 \\
\hline 717 & 2017 & 19523R & 8 & QCP & 0.87 & 0.85 & 0.00 & 0.54 & 2.328 & 2.333 & 0.016 & 0.014 \\
\hline 718 & 2017 & $19524 \mathrm{R}$ & 8 & QCP & 0.25 & & 0.48 & & 2.294 & 2.309 & 0.008 & 0.000 \\
\hline 719 & 2017 & 19524R & 8 & QCP & 0.93 & 0.34 & 0.32 & & 2.319 & 2.313 & 0.013 & 0.003 \\
\hline 720 & 2017 & $19605 R$ & 8 & QCP & 0.80 & 0.95 & 0.67 & & 2.349 & 2.346 & 0.012 & 0.010 \\
\hline 721 & 2015 & 19533R & 9 & QCP & 0.07 & 0.79 & 0.73 & 0.31 & 2.382 & 2.406 & 0.021 & 0.018 \\
\hline 724 & 2017 & 19513R & 9 & PFP & & & & & & 2.358 & & 0.000 \\
\hline 725 & 2016 & $19532 \mathrm{R}$ & 9 & QCP & 0.67 & & & & 2.373 & 2.388 & 0.010 & 0.000 \\
\hline 726 & 2016 & 19534R & 9 & QCP & 0.55 & 0.34 & 0.21 & 0.70 & 2.336 & 2.345 & 0.015 & 0.022 \\
\hline 727 & 2016 & 19534R & 9 & QCP & 0.78 & 1.00 & 0.90 & 0.48 & 2.337 & 2.341 & 0.016 & 0.015 \\
\hline 728 & 2017 & $19524 \mathrm{R}$ & 8 & QCP & 0.61 & 0.91 & 0.53 & 0.97 & 2.339 & 2.351 & 0.037 & 0.037 \\
\hline 729 & 2017 & $19524 \mathrm{R}$ & 8 & QCP & 0.33 & 0.73 & 0.01 & 0.10 & 2.343 & 2.350 & 0.022 & 0.026 \\
\hline 730 & 2017 & 19535R & 8 & QCP & 0.57 & 0.04 & 0.69 & 0.08 & 2.326 & 2.368 & 0.018 & 0.063 \\
\hline 731 & 2017 & $19532 R$ & 8 & QCP & 0.40 & 0.85 & 0.14 & 0.01 & 2.397 & 2.390 & 0.025 & 0.023 \\
\hline 732 & 2017 & $19532 R$ & 9 & QCP & & & 0.70 & & 2.351 & & 0.011 & \\
\hline 733 & 2015 & $19532 R$ & 9 & QCP & 0.61 & 0.11 & 0.99 & 0.38 & 2.385 & 2.389 & 0.010 & 0.020 \\
\hline
\end{tabular}




\begin{tabular}{|c|c|c|c|c|c|c|c|c|c|c|c|c|}
\hline $\begin{array}{c}\text { ICT } \\
\text { Code }\end{array}$ & Year & Mix Code & District & $\begin{array}{l}\text { Quality } \\
\text { Program }\end{array}$ & $\begin{array}{c}\text { MW } \\
\text { P-Value }\end{array}$ & $\begin{array}{c}\text { Levene's } \\
\text { P-Value }\end{array}$ & $\begin{array}{l}\text { Contractor } \\
\text { SW P-Value }\end{array}$ & $\begin{array}{c}\text { Agency SW } \\
\text { P-Value }\end{array}$ & $\begin{array}{c}\text { Contractor } \\
\text { Mean }\end{array}$ & $\begin{array}{l}\text { Agency } \\
\text { Mean }\end{array}$ & $\begin{array}{c}\text { Contractor } \\
\text { St. Dev. }\end{array}$ & $\begin{array}{l}\text { Agency } \\
\text { St. Dev. }\end{array}$ \\
\hline 734 & 2015 & $19532 R$ & 9 & PFP & 0.91 & 0.79 & 0.03 & 0.05 & 2.379 & 2.378 & 0.013 & 0.014 \\
\hline 735 & 2016 & $19532 R$ & 9 & PFP & 0.00 & 0.19 & 0.01 & 0.40 & 2.376 & 2.386 & 0.016 & 0.012 \\
\hline 736 & 2016 & $19532 R$ & 9 & QCP & & & & & 2.375 & & 0.000 & \\
\hline 737 & 2017 & 19532R & 9 & QCP & & & & & 2.382 & & 0.000 & \\
\hline 738 & 2015 & $19532 R$ & 9 & PFP & 0.81 & 0.46 & 0.97 & 0.06 & 2.369 & 2.361 & 0.022 & 0.016 \\
\hline 739 & 2016 & $19532 R$ & 9 & PFP & 0.30 & 0.43 & 0.10 & 0.91 & 2.376 & 2.383 & 0.018 & 0.021 \\
\hline 744 & 2017 & 19534R & 9 & QCP & 1.00 & & & & 2.368 & 2.378 & 0.000 & 0.000 \\
\hline 745 & 2016 & 19534R & 9 & QCP & 0.67 & & & & 2.329 & 2.348 & 0.004 & 0.000 \\
\hline 746 & 2016 & 19534R & 9 & QCP & 1.00 & & 0.95 & & 2.348 & 2.345 & 0.008 & 0.000 \\
\hline 747 & 2016 & 19534R & 9 & QCP & 0.33 & 0.73 & 0.76 & & 2.338 & 2.348 & 0.010 & 0.010 \\
\hline 748 & 2016 & 19534R & 9 & QCP & 0.29 & 0.17 & 0.05 & 0.64 & 2.330 & 2.337 & 0.010 & 0.003 \\
\hline 749 & 2015 & 19523R & 9 & QCP & 1.00 & & 0.85 & & 2.348 & 2.348 & 0.031 & 0.000 \\
\hline 750 & 2015 & 19523R & 9 & QCP & 0.40 & 0.41 & 0.09 & 0.60 & 2.371 & 2.382 & 0.014 & 0.019 \\
\hline 751 & 2015 & 19534R & 9 & PFP & 0.80 & 0.87 & 0.12 & & 2.332 & 2.327 & 0.014 & 0.008 \\
\hline 752 & 2015 & $19534 R$ & 9 & QCP & 1.00 & & 0.20 & & 2.335 & 2.362 & 0.024 & 0.000 \\
\hline 753 & 2015 & $19534 R$ & 9 & QCP & 1.00 & & 0.80 & & 2.337 & 2.347 & 0.014 & 0.000 \\
\hline 754 & 2017 & $19534 \mathrm{R}$ & 9 & QCP & 0.57 & & 0.38 & & 2.336 & 2.350 & 0.010 & 0.000 \\
\hline 757 & 2016 & 19535 & 9 & PFP & 0.53 & 0.33 & 0.52 & 0.19 & 2.323 & 2.328 & 0.014 & 0.018 \\
\hline 758 & 2016 & $19522 \mathrm{R}$ & 9 & QCP & 0.66 & 0.83 & 0.05 & 0.00 & 2.404 & 2.404 & 0.014 & 0.012 \\
\hline 759 & 2017 & $19532 \mathrm{R}$ & 9 & PFP & & & & & & & & \\
\hline 760 & 2016 & $19523 R$ & 9 & QCP & & & & & 2.329 & & 0.000 & \\
\hline 761 & 2016 & $19523 R$ & 9 & QCP & & & & & 2.348 & & 0.000 & \\
\hline 762 & 2017 & $19523 \mathrm{R}$ & 9 & QCP & 0.03 & 0.62 & 0.32 & & 2.349 & 2.388 & 0.024 & 0.010 \\
\hline 763 & 2017 & $19532 \mathrm{R}$ & 9 & PFP & 0.66 & 0.20 & 0.54 & 0.43 & 2.388 & 2.393 & 0.014 & 0.022 \\
\hline 764 & 2015 & $19534 \mathrm{R}$ & 9 & QCP & 0.86 & 0.87 & 0.34 & & 2.337 & 2.327 & 0.025 & 0.022 \\
\hline 765 & 2015 & 19533R & 9 & QCP & 1.00 & & 0.19 & & 2.355 & 2.353 & 0.020 & 0.000 \\
\hline 766 & 2015 & 19533R & 9 & QCP & 0.84 & 0.42 & 0.67 & 0.19 & 2.361 & 2.366 & 0.012 & 0.007 \\
\hline 767 & 2015 & 19533R & 9 & QCP & 0.26 & 0.09 & 0.43 & 0.19 & 2.371 & 2.379 & 0.007 & 0.015 \\
\hline 768 & 2015 & $19533 R$ & 9 & QCP & 0.91 & 0.17 & 0.58 & 0.39 & 2.379 & 2.385 & 0.032 & 0.058 \\
\hline 769 & 2015 & 19533R & 9 & QCP & 0.57 & & 0.05 & & 2.354 & 2.363 & 0.017 & 0.000 \\
\hline 770 & 2015 & 19533R & 9 & QCP & 0.82 & 0.63 & 0.01 & 0.36 & 2.366 & 2.372 & 0.017 & 0.011 \\
\hline 771 & 2015 & $19534 R$ & 9 & QCP & 0.71 & 0.85 & 0.22 & 0.64 & 2.366 & 2.358 & 0.021 & 0.021 \\
\hline 782 & 2015 & $19534 R$ & 9 & QCP & 0.40 & 0.75 & 0.48 & 0.22 & 2.353 & 2.344 & 0.015 & 0.012 \\
\hline 783 & 2016 & $19534 \mathrm{R}$ & 9 & QCP & 0.69 & 0.53 & 0.94 & & 2.342 & 2.347 & 0.016 & 0.018 \\
\hline 784 & 2016 & 19533R & 9 & QCP & 0.43 & 0.69 & 0.44 & & 2.353 & 2.367 & 0.025 & 0.025 \\
\hline
\end{tabular}




\begin{tabular}{|c|c|c|c|c|c|c|c|c|c|c|c|c|}
\hline $\begin{array}{c}\text { ICT } \\
\text { Code }\end{array}$ & Year & Mix Code & District & $\begin{array}{l}\text { Quality } \\
\text { Program }\end{array}$ & $\begin{array}{c}\text { MW } \\
\text { P-Value }\end{array}$ & $\begin{array}{c}\text { Levene's } \\
\text { P-Value }\end{array}$ & $\begin{array}{l}\text { Contractor } \\
\text { SW P-Value }\end{array}$ & $\begin{array}{c}\text { Agency SW } \\
\text { P-Value }\end{array}$ & $\begin{array}{c}\text { Contractor } \\
\text { Mean }\end{array}$ & $\begin{array}{l}\text { Agency } \\
\text { Mean }\end{array}$ & $\begin{array}{l}\text { Contractor } \\
\text { St. Dev. }\end{array}$ & $\begin{array}{l}\text { Agency } \\
\text { St. Dev. }\end{array}$ \\
\hline 785 & 2016 & 19523R & 9 & $\mathrm{QCP}$ & 1.00 & & & & 2.353 & 2.355 & 0.018 & 0.000 \\
\hline 786 & 2016 & 19523R & 9 & QCP & 1.00 & & 0.86 & & 2.353 & 2.352 & 0.012 & 0.000 \\
\hline 787 & 2017 & 19523R & 9 & QCP & 0.13 & 0.12 & 0.18 & & 2.369 & 2.387 & 0.017 & 0.001 \\
\hline 788 & 2017 & 19523R & 9 & QCP & & & & & & 2.366 & & 0.002 \\
\hline 789 & 2016 & 19605FR & 9 & QCP & & & & & & & & \\
\hline 790 & 2016 & 19605FR & 9 & QCP & & & & & & & & \\
\hline 791 & 2017 & 19605FR & 9 & QCP & & & & & & & & \\
\hline 792 & 2017 & 19605FR & 9 & QCP & & & & & & & & \\
\hline 793 & 2015 & $\begin{array}{c}\text { HMA } \\
\text { Binder }\end{array}$ & 9 & QCP & & & & & & & & \\
\hline 794 & 2015 & $\begin{array}{c}\text { HMA } \\
\text { Binder }\end{array}$ & 9 & $\mathrm{QCP}$ & & & & & & & & \\
\hline 795 & 2015 & $\begin{array}{l}\text { HMA } \\
\text { Binder }\end{array}$ & 9 & QCP & 0.03 & 0.93 & 0.46 & 0.46 & 2.353 & 2.374 & 0.013 & 0.013 \\
\hline 797 & 2016 & 19535 & 9 & PFP & 0.50 & 0.48 & 0.82 & & 2.315 & 2.307 & 0.016 & 0.005 \\
\hline 798 & 2016 & 19535 & 9 & PFP & 0.71 & 0.96 & 0.01 & 0.24 & 2.324 & 2.320 & 0.019 & 0.016 \\
\hline 799 & 2016 & $19532 R$ & 9 & PFP & 0.02 & 0.89 & 0.92 & 0.19 & 2.364 & 2.336 & 0.019 & 0.018 \\
\hline 800 & 2016 & $19532 R$ & 9 & PFP & 0.15 & 0.68 & 0.02 & 0.63 & 2.360 & 2.373 & 0.013 & 0.010 \\
\hline 801 & 2017 & 19533R & 9 & QCP & 0.77 & & 0.64 & & 2.351 & 2.346 & 0.011 & 0.000 \\
\hline 802 & 2016 & 19533R & 9 & QCP & 0.87 & 0.07 & 0.56 & 1.00 & 2.341 & 2.336 & 0.019 & 0.041 \\
\hline 803 & 2017 & 19534R & 9 & PFP & 0.96 & 0.14 & 0.61 & 0.42 & 2.341 & 2.336 & 0.020 & 0.034 \\
\hline 804 & 2017 & $19532 R$ & 9 & PFP & 0.13 & 0.96 & 0.08 & 0.63 & 2.365 & 2.375 & 0.012 & 0.011 \\
\hline 805 & 2015 & 19533R & 9 & QCP & 0.81 & 0.82 & 0.11 & 0.00 & 2.362 & 2.365 & 0.018 & 0.017 \\
\hline 806 & 2016 & 19534R & 9 & QCP & 0.21 & 0.46 & 0.06 & & 2.329 & 2.343 & 0.016 & 0.005 \\
\hline 807 & 2015 & 19534R & 9 & QCP & 0.40 & & 0.90 & & 2.344 & 2.368 & 0.012 & 0.000 \\
\hline 808 & 2016 & 19534R & 9 & QCP & 0.79 & 0.88 & 0.41 & 0.73 & 2.346 & 2.352 & 0.029 & 0.028 \\
\hline 809 & 2016 & 19606FR & 9 & QCP & & & & & & & & \\
\hline 810 & 2016 & 19534R & 9 & QCP & 1.00 & & 0.46 & & 2.321 & 2.323 & 0.004 & 0.000 \\
\hline 815 & 2016 & 19533R & 9 & QCP & 0.29 & 0.00 & 0.02 & & 2.366 & 2.384 & 0.025 & 0.000 \\
\hline 816 & 2015 & 19523R & 9 & QCP & 0.16 & 0.44 & 0.72 & 0.93 & 2.358 & 2.369 & 0.016 & 0.020 \\
\hline 817 & 2016 & 19523R & 9 & QCP & 0.57 & & 0.37 & & 2.380 & 2.368 & 0.010 & 0.000 \\
\hline 818 & 2015 & 19523R & 9 & QCP & 1.00 & & 0.98 & & 2.375 & 2.377 & 0.020 & 0.000 \\
\hline 819 & 2015 & $19523 R$ & 9 & QCP & 0.48 & 1.00 & 0.91 & 0.09 & 2.354 & 2.359 & 0.012 & 0.010 \\
\hline 820 & 2015 & 19523R & 9 & QCP & 0.17 & 0.23 & 0.39 & & 2.372 & 2.380 & 0.005 & 0.001 \\
\hline 821 & 2016 & $19532 R$ & 9 & QCP & 0.49 & 0.17 & 0.00 & 0.43 & 2.403 & 2.410 & 0.008 & 0.014 \\
\hline
\end{tabular}




\begin{tabular}{|c|c|c|c|c|c|c|c|c|c|c|c|c|}
\hline $\begin{array}{c}\text { ICT } \\
\text { Code }\end{array}$ & Year & Mix Code & District & $\begin{array}{l}\text { Quality } \\
\text { Program }\end{array}$ & $\begin{array}{c}\text { MW } \\
\text { P-Value }\end{array}$ & $\begin{array}{l}\text { Levene's } \\
\text { P-Value }\end{array}$ & $\begin{array}{l}\text { Contractor } \\
\text { SW P-Value }\end{array}$ & $\begin{array}{c}\text { Agency SW } \\
\text { P-Value }\end{array}$ & $\begin{array}{c}\text { Contractor } \\
\text { Mean }\end{array}$ & $\begin{array}{l}\text { Agency } \\
\text { Mean }\end{array}$ & $\begin{array}{c}\text { Contractor } \\
\text { St. Dev. }\end{array}$ & $\begin{array}{l}\text { Agency } \\
\text { St. Dev. }\end{array}$ \\
\hline 822 & 2016 & $19532 R$ & 9 & $\mathrm{QCP}$ & 1.00 & & 0.40 & & 2.400 & 2.402 & 0.019 & 0.000 \\
\hline 823 & 2016 & $19522 R$ & 9 & $\mathrm{QCP}$ & 0.05 & 0.85 & 0.31 & 0.02 & 2.360 & 2.369 & 0.006 & 0.006 \\
\hline 828 & 2017 & $19532 R$ & 9 & $\mathrm{QCP}$ & 0.59 & 0.90 & 0.27 & 0.67 & 2.389 & 2.391 & 0.010 & 0.008 \\
\hline 829 & 2017 & $19524 R$ & 9 & QCP & 0.29 & & 0.39 & & 2.337 & 2.324 & 0.008 & 0.000 \\
\hline 830 & 2017 & 19534R & 9 & $\mathrm{QCP}$ & 0.71 & 0.07 & 0.14 & 0.37 & 2.347 & 2.348 & 0.013 & 0.024 \\
\hline 831 & 2016 & $19532 R$ & 9 & PFP & & & 0.19 & & 2.367 & & 0.015 & \\
\hline 832 & 2016 & 19523R & 9 & QCP & 0.27 & 0.83 & 0.11 & & 2.357 & 2.377 & 0.013 & 0.008 \\
\hline 833 & 2016 & 19535R & 9 & PFP & & & & & 2.232 & & 0.000 & \\
\hline 834 & 2017 & 19523R & 9 & QCP & 0.30 & 0.65 & 0.36 & 0.90 & 2.336 & 2.345 & 0.008 & 0.006 \\
\hline 835 & 2017 & $19532 R$ & 9 & PFP & & & & & 2.379 & & 0.000 & \\
\hline 836 & 2017 & $19532 R$ & 9 & PFP & 0.57 & & 0.34 & & 2.375 & 2.365 & 0.007 & 0.000 \\
\hline
\end{tabular}




\section{APPENDIX D: ROUND ROBIN RESULTS}

\section{D.1 ROUND ROBIN RESULTS}

Table D.1. $\mathbf{G}_{\mathrm{mb}}$ Analysis Results Summary

\begin{tabular}{|c|c|c|c|c|c|c|c|c|}
\hline Year & $\begin{array}{c}\text { District/ } \\
\text { CBM }\end{array}$ & $\begin{array}{c}\text { Gyratory Compactor } \\
\text { Type } \\
\end{array}$ & $\mathrm{G}_{\mathrm{mm}} \# 1$ & $\mathrm{G}_{\mathrm{mm}} \# 2$ & $\mathrm{G}_{\mathrm{mm}}$ Avg. & $\begin{array}{c}\text { Gmb } \\
\text { Gyro \#1 }\end{array}$ & $\mathrm{G}_{\mathrm{mb}}$ Gyro\#2 & $\begin{array}{l}\mathrm{G}_{\mathrm{mb}} \\
\text { Avg. }\end{array}$ \\
\hline 2015 & 1 & Troxler 4141 & 2.468 & 2.463 & 2.466 & 2.313 & 2.312 & 2.313 \\
\hline 2015 & 2 & Troxler 5850 & 2.473 & 2.469 & 2.471 & 2.337 & 2.337 & 2.337 \\
\hline 2015 & 9 & Troxler 4140 & 2.473 & 2.467 & 2.47 & 2.327 & 2.314 & 2.321 \\
\hline 2015 & 9 & Pine AFG1 & 2.461 & 2.468 & 2.465 & 2.321 & 2.319 & 2.32 \\
\hline 2015 & & Troxler 4140 & 2.467 & 2.466 & 2.467 & 2.342 & 2.345 & 2.344 \\
\hline 2015 & & Pine AFG2 & 2.467 & 2.467 & 2.467 & 2.341 & 2.345 & 2.343 \\
\hline 2015 & 1 & Pine AFG2 & 2.463 & 2.459 & 2.461 & 2.317 & 2.307 & 2.312 \\
\hline 2015 & 2 & Troxler 4140 & 2.464 & 2.466 & 2.465 & 2.325 & 2.333 & 2.329 \\
\hline 2015 & 2 & Troxler 4141 & 2.468 & 2.475 & 2.472 & 2.325 & 2.325 & 2.325 \\
\hline 2015 & 2 & Troxler 5850 & 2.465 & 2.467 & 2.466 & 2.345 & 2.341 & 2.343 \\
\hline 2015 & 5 & Troxler 4140 & 2.478 & 2.478 & 2.478 & 2.324 & 2.32 & 2.322 \\
\hline 2015 & 6 & Troxler 4140 & 2.465 & 2.464 & 2.465 & 2.315 & 2.325 & 2.32 \\
\hline 2015 & 6 & Troxler 4140 & 2.462 & 2.466 & 2.464 & 2.32 & 2.327 & 2.324 \\
\hline 2015 & 6 & Troxler 5850 & 2.465 & 2.464 & 2.465 & 2.315 & 2.325 & 2.32 \\
\hline 2015 & 8 & Pine AFG2 & 2.462 & 2.461 & 2.462 & 2.328 & 2.327 & 2.328 \\
\hline 2015 & 8 & Troxler 4140 & 2.462 & 2.461 & 2.462 & 2.33 & 2.328 & 2.329 \\
\hline 2015 & 8 & Troxler 4140 & 2.462 & 2.461 & 2.462 & 2.332 & 2.33 & 2.331 \\
\hline 2015 & 9 & Pine AFG2 & 2.46 & 2.462 & 2.461 & 2.343 & 2.338 & 2.341 \\
\hline 2015 & 1 & Pine AFGC125X & 2.477 & 2.474 & 2.476 & 2.346 & 2.345 & 2.346 \\
\hline 2015 & 1 & Troxler 4141 & 2.464 & 2.463 & 2.464 & 2.309 & 2.304 & 2.307 \\
\hline 2015 & 1 & Pine AFGB1 & 2.481 & 2.48 & 2.481 & 2.306 & 2.306 & 2.306 \\
\hline 2015 & 1 & Pine AFG2 & 2.473 & 2.474 & 2.474 & 2.325 & 2.322 & 2.324 \\
\hline 2015 & 1 & Troxler 4141 & 2.471 & 2.467 & 2.469 & 2.304 & 2.306 & 2.305 \\
\hline 2015 & 1 & Pine AFGB1 & 2.448 & 2.452 & 2.45 & 2.321 & 2.32 & 2.321 \\
\hline 2015 & 1 & Pine AFGB1 & 2.485 & 2.486 & 2.486 & 2.307 & 2.31 & 2.309 \\
\hline 2015 & 5 & IPC Servopac 2500 & 2.468 & 2.473 & 2.471 & 2.309 & 2.312 & 2.311 \\
\hline 2015 & 5 & Troxler 4140 & 2.469 & 2.47 & 2.47 & 2.327 & 2.33 & 2.329 \\
\hline 2015 & 6 & Troxler 4141 & 2.472 & 2.471 & 2.472 & 2.327 & 2.327 & 2.327 \\
\hline 2015 & 2 & Troxler 5850 & 2.471 & 2.473 & 2.472 & 2.321 & 2.319 & 2.32 \\
\hline 2015 & 5 & Troxler 5850 & 2.469 & 2.472 & 2.471 & 2.333 & 2.338 & 2.336 \\
\hline 2015 & 8 & Troxler 5850 & 2.469 & 2.467 & 2.468 & 2.309 & 2.318 & 2.314 \\
\hline 2015 & 8 & Troxler 4141 & 2.469 & 2.472 & 2.471 & 2.316 & 2.313 & 2.315 \\
\hline 2015 & 6 & Troxler 4141 & 2.472 & 2.475 & 2.474 & 2.319 & 2.322 & 2.321 \\
\hline 2016 & 9 & Pine AFG2 & 2.464 & 2.468 & 2.466 & 2.356 & 2.355 & 2.356 \\
\hline 2016 & 9 & Pine AFG1 & 2.463 & 2.468 & 2.466 & 2.332 & 2.343 & 2.338 \\
\hline 2016 & & Pine AFG2 & 2.468 & 2.466 & 2.467 & 2.355 & 2.354 & 2.355 \\
\hline 2016 & & Troxler 4140 & 2.469 & 2.467 & 2.468 & 2.331 & 2.331 & 2.331 \\
\hline 2016 & 1 & Pine AFG2 & 2.466 & 2.464 & 2.465 & 2.323 & 2.323 & 2.323 \\
\hline 2016 & 1 & Pine AFG2 & 2.466 & 2.464 & 2.465 & 2.322 & 2.332 & 2.327 \\
\hline
\end{tabular}




\begin{tabular}{|c|c|c|c|c|c|c|c|c|}
\hline Year & $\begin{array}{l}\text { District/ } \\
\text { CBM }\end{array}$ & $\begin{array}{c}\text { Gyratory Compactor } \\
\text { Type }\end{array}$ & $\mathrm{G}_{\mathrm{mm}} \# 1$ & $\mathrm{G}_{\mathrm{mm}} \# 2$ & Gmm Avg. & $\begin{array}{c}\text { Gmb } \\
\text { Gyro \#1 }\end{array}$ & Gmb Gyro\#2 & $\begin{array}{l}\text { Gmb } \\
\text { Avg. }\end{array}$ \\
\hline 2016 & 2 & Troxler 4140 & 2.46 & 2.461 & 2.461 & 2.34 & 2.339 & 2.34 \\
\hline 2016 & 2 & Troxler 4141 & 2.46 & 2.46 & 2.46 & 2.345 & 2.349 & 2.347 \\
\hline 2016 & 2 & Troxler 5850 & 2.468 & 2.469 & 2.469 & 2.346 & 2.348 & 2.347 \\
\hline 2016 & 1 & Pine AFGB1 & 2.467 & 2.47 & 2.469 & 2.379 & 2.379 & 2.379 \\
\hline 2016 & 5 & Troxler 4140 & 2.466 & 2.468 & 2.467 & 2.332 & 2.33 & 2.331 \\
\hline 2016 & 6 & Troxler 4141 & 2.458 & 2.465 & 2.462 & 2.336 & 2.331 & 2.334 \\
\hline 2016 & 8 & Pine AFG2 & 2.457 & 2.458 & 2.458 & 2.335 & 2.344 & 2.34 \\
\hline 2016 & 8 & Troxler 4140 & 2.457 & 2.458 & 2.458 & 2.337 & 2.336 & 2.337 \\
\hline 2016 & 8 & Troxler 4140 & 2.457 & 2.458 & 2.458 & 2.339 & 2.334 & 2.337 \\
\hline 2016 & 9 & Pine AFG2 & 2.479 & 2.481 & 2.48 & 2.348 & 2.344 & 2.346 \\
\hline 2016 & 1 & Troxler 4141 & 2.455 & 2.457 & 2.456 & 2.331 & 2.325 & 2.328 \\
\hline 2016 & 1 & Pine AFG2 & 2.464 & 2.469 & 2.467 & 2.327 & 2.335 & 2.331 \\
\hline 2016 & 1 & Pine AFGB1 & 2.47 & 2.467 & 2.469 & 2.32 & 2.322 & 2.321 \\
\hline 2016 & 1 & Pine AFG2 & 2.466 & 2.465 & 2.466 & 2.336 & 2.336 & 2.336 \\
\hline 2016 & 1 & Troxler 5850 & 2.476 & 2.475 & 2.476 & 2.338 & 2.333 & 2.336 \\
\hline 2016 & 6 & Troxler 5850 & 2.453 & 2.455 & 2.454 & 2.322 & 2.33 & 2.326 \\
\hline 2016 & 5 & IPC Servopac 2500 & 2.478 & 2.472 & 2.475 & 2.326 & 2.325 & 2.326 \\
\hline 2016 & 8 & Troxler 4141 & 2.459 & 2.458 & 2.459 & 2.324 & 2.326 & 2.325 \\
\hline 2016 & 5 & Pine AFGB1 & 2.458 & 2.458 & 2.458 & 2.329 & 2.33 & 2.33 \\
\hline 2016 & 5 & Troxler 5850 & 2.468 & 2.47 & 2.469 & 2.336 & 2.337 & 2.337 \\
\hline 2016 & 2 & Pine AFGB1 & 2.453 & 2.45 & 2.452 & 2.358 & 2.35 & 2.354 \\
\hline 2016 & 8 & Troxler 4140 & 2.456 & 2.461 & 2.459 & 2.33 & 2.333 & 2.332 \\
\hline 2016 & 6 & Troxler 4141 & 2.47 & 2.471 & 2.471 & 2.321 & 2.318 & 2.32 \\
\hline 2016 & 6 & Troxler 4140 & 2.461 & 2.465 & 2.463 & 2.348 & 2.347 & 2.348 \\
\hline 2016 & 6 & Troxler 4140 & 2.462 & 2.464 & 2.463 & 2.348 & 2.347 & 2.348 \\
\hline 2017 & 1 & Troxler 4141 & 2.488 & 2.491 & 2.49 & 2.333 & 2.343 & 2.338 \\
\hline 2017 & 9 & Pine AFG2 & 2.474 & 2.473 & 2.474 & 2.349 & 2.348 & 2.349 \\
\hline 2017 & 9 & Pine AFGB1 & 2.469 & 2.473 & 2.471 & 2.369 & 2.366 & 2.368 \\
\hline 2017 & & Troxler 4140 & 2.47 & 2.475 & 2.473 & 2.366 & 2.366 & 2.366 \\
\hline 2017 & & Pine AFG2 & 2.472 & 2.469 & 2.471 & 2.376 & 2.372 & 2.374 \\
\hline 2017 & 1 & Pine AFG2 & 2.483 & 2.478 & 2.481 & 2.327 & 2.337 & 2.332 \\
\hline 2017 & 1 & Pine AFG2 & 2.483 & 2.478 & 2.481 & 2.337 & 2.34 & 2.339 \\
\hline 2017 & 2 & Troxler 4140 & 2.484 & 2.482 & 2.483 & 2.348 & 2.343 & 2.346 \\
\hline 2017 & 2 & Troxler 4141 & 2.486 & 2.487 & 2.487 & 2.334 & 2.338 & 2.336 \\
\hline 2017 & 2 & Troxler 5850 & 2.489 & 2.489 & 2.489 & 2.347 & 2.348 & 2.348 \\
\hline 2017 & 5 & Troxler 4140 & 2.48 & 2.479 & 2.48 & 2.354 & 2.355 & 2.355 \\
\hline 2017 & 8 & Troxler 4141 & 2.477 & 2.476 & 2.477 & 2.33 & 2.329 & 2.33 \\
\hline 2017 & 6 & Troxler 5850 & 2.475 & 2.472 & 2.474 & 2.349 & 2.345 & 2.347 \\
\hline 2017 & 6 & Troxler 5850 & 2.484 & 2.488 & 2.486 & 2.336 & 2.337 & 2.337 \\
\hline 2017 & 8 & Pine AFG2 & 2.476 & 2.474 & 2.475 & 2.35 & 2.351 & 2.351 \\
\hline 2017 & 8 & Troxler 4140 & 2.476 & 2.474 & 2.475 & 2.347 & 2.358 & 2.353 \\
\hline 2017 & 8 & Troxler 4140 & 2.476 & 2.474 & 2.475 & 2.345 & 2.357 & 2.351 \\
\hline 2017 & 9 & Pine AFG2 & 2.476 & 2.472 & 2.474 & 2.354 & 2.352 & 2.353 \\
\hline 2017 & 1 & Troxler 4141 & 2.475 & 2.48 & 2.478 & 2.391 & 2.388 & 2.39 \\
\hline 2017 & 1 & Pine AFG2 & 2.476 & 2.476 & 2.476 & 2.332 & 2.33 & 2.331 \\
\hline 2017 & 1 & Pine AFGB1 & 2.484 & 2.483 & 2.484 & 2.33 & 2.338 & 2.334 \\
\hline
\end{tabular}




\begin{tabular}{|c|c|c|c|c|c|c|c|c|}
\hline Year & $\begin{array}{l}\text { District/ } \\
\text { CBM }\end{array}$ & $\begin{array}{c}\text { Gyratory Compactor } \\
\text { Type }\end{array}$ & $\mathrm{G}_{\mathrm{mm}} \# 1$ & $\mathrm{G}_{\mathrm{mm}} \# 2$ & Gmm Avg. & $\begin{array}{c}\text { Gmb } \\
\text { Gyro \#1 }\end{array}$ & Gmb Gyro\#2 & $\begin{array}{l}\text { Gmb } \\
\text { Avg. }\end{array}$ \\
\hline 2017 & 1 & Pine AFG2 & 2.488 & 2.487 & 2.488 & 2.33 & 2.332 & 2.331 \\
\hline 2017 & 1 & Pine AFG1 & 2.483 & 2.482 & 2.483 & 2.35 & 2.349 & 2.35 \\
\hline 2017 & 5 & IPC Servopac 2500 & 2.489 & 2.486 & 2.488 & 2.344 & 2.346 & 2.345 \\
\hline 2017 & 2 & Pine AFG1 & 2.472 & 2.475 & 2.474 & 2.341 & 2.347 & 2.344 \\
\hline 2017 & 5 & Pine AFGB1 & 2.477 & 2.478 & 2.478 & 2.343 & 2.346 & 2.345 \\
\hline 2017 & 2 & Troxler 5850 & 2.47 & 2.478 & 2.474 & 2.342 & 2.342 & 2.342 \\
\hline 2017 & 5 & Troxler 5850 & 2.476 & 2.476 & 2.476 & 2.35 & 2.353 & 2.352 \\
\hline 2017 & 2 & Pine AFG2 & 2.475 & 2.478 & 2.477 & 2.36 & 2.359 & 2.36 \\
\hline 2017 & 8 & Troxler 5850 & 2.476 & 2.479 & 2.478 & 2.34 & 2.344 & 2.342 \\
\hline 2017 & 6 & Troxler 4141 & 2.472 & 2.473 & 2.473 & 2.361 & 2.361 & 2.361 \\
\hline 2017 & 6 & Troxler 4140 & 2.481 & 2.483 & 2.482 & 2.355 & 2.36 & 2.358 \\
\hline 2017 & 6 & Troxler 4140 & 2.483 & 2.484 & 2.484 & 2.36 & 2.357 & 2.359 \\
\hline 2018 & 1 & Pine AFG2 & 2.438 & 2.439 & 2.439 & 2.327 & 2.325 & 2.326 \\
\hline 2018 & 9 & Pine AFG1 & 2.43 & 2.434 & 2.432 & 2.339 & 2.333 & 2.336 \\
\hline 2018 & & Troxler 4140 & 2.447 & 2.448 & 2.448 & 2.333 & 2.34 & 2.337 \\
\hline 2018 & & Pine AFG2 & 2.444 & 2.445 & 2.445 & 2.331 & 2.337 & 2.334 \\
\hline 2018 & 1 & Pine AFG2 & 2.455 & 2.458 & 2.457 & 2.309 & 2.317 & 2.313 \\
\hline 2018 & 2 & Troxler 4140 & 2.446 & 2.444 & 2.445 & 2.327 & 2.323 & 2.325 \\
\hline 2018 & 2 & Troxler 4141 & 2.449 & 2.446 & 2.448 & 2.332 & 2.323 & 2.328 \\
\hline 2018 & 2 & Troxler 5850 & 2.444 & 2.441 & 2.443 & 2.327 & 2.32 & 2.324 \\
\hline 2018 & 5 & Troxler 4140 & 2.446 & 2.448 & 2.447 & 2.333 & 2.323 & 2.328 \\
\hline 2018 & 6 & Troxler 4140 & 2.433 & 2.432 & 2.433 & 2.332 & 2.336 & 2.334 \\
\hline 2018 & 6 & Troxler 5850 & 2.433 & 2.432 & 2.433 & 2.33 & 2.327 & 2.329 \\
\hline 2018 & 6 & Troxler 5850 & 2.427 & 2.434 & 2.431 & 2.314 & 2.317 & 2.316 \\
\hline 2018 & 8 & Pine AFG2 & 2.455 & 2.453 & 2.454 & 2.315 & 2.309 & 2.312 \\
\hline 2018 & 8 & Pine AFG2 & 2.455 & 2.453 & 2.454 & 2.314 & 2.315 & 2.315 \\
\hline 2018 & 9 & Pine AFG2 & 2.433 & 2.432 & 2.433 & 2.329 & 2.327 & 2.328 \\
\hline 2018 & 6 & Troxler 4141 & 2.434 & 2.442 & 2.438 & 2.319 & 2.315 & 2.317 \\
\hline 2018 & 1 & Troxler 4141 & 2.455 & 2.452 & 2.454 & 2.29 & 2.289 & 2.29 \\
\hline 2018 & 1 & Pine AFG2 & 2.455 & 2.454 & 2.455 & 2.3 & 2.31 & 2.305 \\
\hline 2018 & 1 & Pine AFGB1 & 2.448 & 2.444 & 2.446 & 2.305 & 2.302 & 2.304 \\
\hline 2018 & 1 & Pine AFG2 & 2.446 & 2.444 & 2.445 & 2.313 & 2.311 & 2.312 \\
\hline 2018 & 1 & Troxler 5850 & 2.447 & 2.446 & 2.447 & 2.323 & 2.327 & 2.325 \\
\hline 2018 & 5 & IPC Servopac 2500 & & & & & & \\
\hline 2018 & 5 & IPC Servopac 2500 & 2.45 & 2.448 & 2.449 & 2.27 & 2.28 & 2.275 \\
\hline 2018 & 8 & Troxler 4141 & 2.44 & 2.436 & 2.438 & 2.322 & 2.317 & 2.32 \\
\hline 2018 & 5 & Troxler 4140 & 2.448 & 2.448 & 2.448 & 2.319 & 2.32 & 2.32 \\
\hline 2018 & 1 & Pine AFG2 & 2.442 & 2.437 & 2.44 & 2.298 & 2.291 & 2.295 \\
\hline 2018 & 5 & Troxler 5850 & 2.43 & 2.437 & 2.434 & 2.329 & 2.331 & 2.33 \\
\hline 2018 & 2 & Troxler 4141 & 2.438 & 2.446 & 2.442 & 2.307 & 2.313 & 2.31 \\
\hline 2018 & 2 & Pine AFG1 & 2.438 & 2.449 & 2.444 & 2.314 & 2.315 & 2.315 \\
\hline 2018 & 8 & Troxler 4141 & 2.456 & 2.45 & 2.453 & 2.323 & 2.323 & 2.323 \\
\hline 2018 & 6 & Troxler 4140 & 2.438 & 2.444 & 2.441 & 2.322 & 2.32 & 2.321 \\
\hline 2019 & 8 & Pine AFG2 & 2.434 & 2.438 & 2.436 & 2.329 & 2.336 & 2.333 \\
\hline 2019 & 5 & IPC Servopac 2500 & 2.447 & 2.445 & 2.446 & 2.304 & 2.312 & 2.308 \\
\hline 2019 & 1 & Pine AFGB1 & 2.445 & 2.449 & 2.447 & 2.337 & 2.334 & 2.336 \\
\hline
\end{tabular}




\begin{tabular}{|c|c|c|c|c|c|c|c|c|}
\hline Year & $\begin{array}{l}\text { District/ } \\
\text { CBM }\end{array}$ & $\begin{array}{c}\text { Gyratory Compactor } \\
\text { Type }\end{array}$ & $\mathrm{G}_{\mathrm{mm}} \# 1$ & $\mathrm{G}_{\mathrm{mm}} \# 2$ & Gmm Avg. & $\begin{array}{c}\text { Gmb } \\
\text { Gyro \#1 }\end{array}$ & $\mathrm{G}_{\mathrm{mb}}$ Gyro\#2 & $\begin{array}{l}\mathrm{G}_{\mathrm{mb}} \\
\text { Avg. }\end{array}$ \\
\hline 2019 & 2 & Pine AFGB1 & 2.442 & 2.447 & 2.445 & 2.345 & 2.344 & 2.345 \\
\hline 2019 & 5 & Pine AFGB1 & 2.44 & 2.44 & 2.44 & 2.33 & 2.338 & 2.334 \\
\hline 2019 & 2 & Troxler 5850 & 2.428 & 2.436 & 2.432 & 2.331 & 2.329 & 2.33 \\
\hline 2019 & 9 & Pine AFG2 & 2.436 & 2.438 & 2.437 & 2.348 & 2.343 & 2.346 \\
\hline 2019 & 6 & Troxler 4140 & 2.439 & 2.434 & 2.437 & 2.356 & 2.355 & 2.356 \\
\hline 2019 & 5 & Troxler 4140 & 2.444 & 2.439 & 2.442 & 2.338 & 2.342 & 2.34 \\
\hline 2019 & 8 & Pine AFG2 & 2.434 & 2.438 & 2.436 & 2.344 & 2.341 & 2.343 \\
\hline 2019 & 2 & Troxler 4140 & 2.438 & 2.442 & 2.44 & 2.347 & 2.347 & 2.347 \\
\hline 2019 & 5 & Troxler 4140 & 2.433 & 2.435 & 2.434 & 2.338 & 2.346 & 2.342 \\
\hline 2019 & 6 & Troxler 5850 & 2.439 & 2.434 & 2.437 & 2.337 & 2.335 & 2.336 \\
\hline 2019 & 2 & Troxler 5850 & 2.431 & 2.432 & 2.432 & 2.329 & 2.33 & 2.33 \\
\hline 2019 & 6 & Troxler 4140 & 2.436 & 2.436 & 2.436 & 2.344 & 2.344 & 2.344 \\
\hline 2019 & 5 & Troxler 5850 & 2.446 & 2.443 & 2.445 & 2.341 & 2.339 & 2.34 \\
\hline 2019 & 1 & Pine AFG2 & 2.442 & 2.448 & 2.445 & 2.34 & 2.336 & 2.338 \\
\hline 2019 & 1 & Troxler 5850 & 2.454 & 2.455 & 2.455 & 2.314 & 2.321 & 2.318 \\
\hline 2019 & 5 & Troxler 4140 & 2.428 & 2.436 & 2.432 & 2.353 & 2.351 & 2.352 \\
\hline 2019 & 6 & Troxler 5850 & 2.431 & 2.438 & 2.435 & 2.343 & 2.342 & 2.343 \\
\hline 2019 & 1 & Pine AFG2 & 2.44 & 2.439 & 2.44 & 2.346 & 2.341 & 2.344 \\
\hline 2019 & 6 & Troxler 4140 & 2.428 & 2.43 & 2.429 & 2.341 & 2.337 & 2.339 \\
\hline 2019 & 1 & Troxler 5850 & 2.448 & 2.442 & 2.445 & 2.346 & 2.352 & 2.349 \\
\hline 2019 & 8 & Pine AFG2 & 2.443 & 2.444 & 2.444 & 2.343 & 2.349 & 2.346 \\
\hline 2019 & 8 & Pine AFG2 & 2.436 & 2.44 & 2.438 & 2.332 & 2.334 & 2.333 \\
\hline 2019 & 1 & Pine AFG2 & 2.445 & 2.447 & 2.446 & 2.33 & 2.33 & 2.33 \\
\hline 2019 & 9 & Pine AFG2 & 2.426 & 2.431 & 2.429 & 2.365 & 2.35 & 2.358 \\
\hline 2019 & 9 & Pine AFG1 & 2.432 & 2.431 & 2.432 & 2.344 & 2.345 & 2.345 \\
\hline 2019 & 1 & Pine AFG2 & 2.449 & 2.449 & 2.449 & 2.335 & 2.329 & 2.332 \\
\hline 2019 & 1 & Pine AFGB1 & 2.451 & 2.449 & 2.45 & 2.316 & 2.312 & 2.314 \\
\hline 2019 & 2 & Troxler 5850 & 2.439 & 2.438 & 2.439 & 2.34 & 2.334 & 2.337 \\
\hline 2019 & & Troxler 4140 & 2.444 & 2.448 & 2.446 & 2.338 & 2.345 & 2.342 \\
\hline 2019 & & Pine AFG2 & 2.446 & 2.443 & 2.445 & 2.35 & 2.351 & 2.351 \\
\hline
\end{tabular}




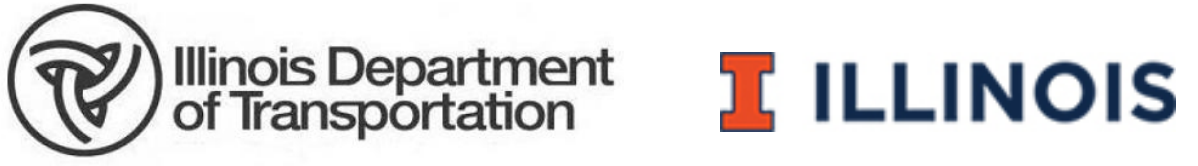

